\title{
Estimation of Energy Intensity in Wood Processing Sawmills based on Analysis of Product, Process and System parameters
}

Dayakar Devaru

Follow this and additional works at: https://researchrepository.wvu.edu/etd

\section{Recommended Citation}

Devaru, Dayakar, "Estimation of Energy Intensity in Wood Processing Sawmills based on Analysis of Product, Process and System parameters" (2015). Graduate Theses, Dissertations, and Problem Reports. 5482.

https://researchrepository.wvu.edu/etd/5482

This Dissertation is protected by copyright and/or related rights. It has been brought to you by the The Research Repository @ WVU with permission from the rights-holder(s). You are free to use this Dissertation in any way that is permitted by the copyright and related rights legislation that applies to your use. For other uses you must obtain permission from the rights-holder(s) directly, unless additional rights are indicated by a Creative Commons license in the record and/ or on the work itself. This Dissertation has been accepted for inclusion in WVU Graduate Theses, Dissertations, and Problem Reports collection by an authorized administrator of The Research Repository @ WVU.

For more information, please contact researchrepository@mail.wvu.edu. 


\title{
Estimation of Energy Intensity in Wood Processing Sawmills based on Analysis of Product, Process and System parameters
}

\author{
Dayakar Devaru
}

\author{
Dissertation \\ Submitted to the \\ Benjamin M. Statler \\ College of Engineering and Mineral Resources \\ at West Virginia University
}

in partial fulfillment of the requirements for the degree of

\author{
Doctor of Philosophy \\ in \\ Industrial Engineering
}

\author{
Bhaskaran Gopalakrishnan, Ph.D., P.E., Chair \\ Robert C. Creese, Ph.D., P.E. \\ Feng Yang, Ph.D. \\ Shawn T Grushecky, Ph.D. \\ Jingxin Wang, Ph.D.
}
Department of Industrial and Management Systems Engineering Morgantown, West Virginia

2015

Keywords: Sawmills Energy Profiling, Lumber Sawing, Energy Consumption Estimation, Wood Processing, Multiple Linear Regression, Lumber Surface Area, Sawmill Motors 


\title{
ABSTRACT \\ Estimation of Energy Intensity in Wood Processing Sawmills based on Analysis of Product, Process and System parameters
}

\author{
Dayakar Devaru
}

Energy costs have risen immensely in the recent past and have strained US industrial sectors. The forest products sector is considered as an energy intensive industry group and energy use has an important impact on sawmill's financial integrity. Energy intensity or specific energy consumption (SEC) is an important aspect to wood products producing sawmills since it also represents production efficiency to some extent. This research focuses on developing SEC profiles for the manufacture of hardwood lumber in sawmills and estimating energy intensity based on product, process and system parameters. Energy benchmarking will help the sawmill industry to know their level of performance and opportunities to improve their energy efficiency and productivity. Process, production and energy data were gathered by visiting three sawmills with single sawing lines and two sawmills with double sawing lines in West Virginia.

Initially SEC was calculated in the traditional way as total energy consumption by total board feet sawn and the average SEC for all the sawmills was around $100 \mathrm{kWh}$ per thousand board feet of lumber sawn. Effect of lumber sizes sawn on energy consumption was analyzed and a method to calculate SEC based on surface area sawn was developed. Sawmills' SEC developed based on surface area sawn yielded better results than traditionally calculated SEC since it exposed production bottle necks.

Data from four sawmills was used to develop three estimation models to estimate SEC of the fifth sawmill based on product, process and system parameters. The parameters that were included in the model were: species and lumber sizes for product, sawing time and maintenance schedule for process, and motor horse power, availability of resaw and production line configuration for system. The model which had 'motor horse power x minutes' as one of the estimator variables was better than the other two models in terms of both $\mathrm{R}^{2}$ and ability to estimate SEC of the fifth sawmill. One estimation model was developed to predict total energy consumption and although this model had the highest $\mathrm{R}^{2}$, it didn't estimate the fifth sawmill that well. Sensitivity analysis was conducted to find the effect of different widths of lumber sawn on energy consumption and also the parameters used in the estimation model were analyzed for their sensitivity towards the energy consumption. Energy consumption of Sawmill 3 was highly sensitive to estimator variables 'motor horse power' and 'grade lumber sizes'. Energy consumption of sawmill motors were compared and the highest energy consumer of sawmill 2 and 4 motors was main saw and carriage feed, since there was no resaw or a gang saw in them. The energy consumption of sawmill 1 motors was similar to sawmill 3 and energy consumption of sawmill 2 motors was similar to sawmill 4.

The 'Sawmill Energy Estimation Program' that takes the inputs from the user and estimates sawmill's energy intensity based on sawmill parameters and analyzes sawmill's efficiency and gives recommendations with estimated savings to improve sawmill's energy efficiency and productivity was also developed to help sawmill owners to analyze their sawmill. 


\section{Dedication}

This research work is dedicated to the universal consciousness also called as God with different names by different religions and is the thing which is responsible for the creation of this Universe and also manifests itself in every living being. Without that consciousness this work wouldn't have occurred since I am just a channel through which it is operating. 


\section{Acknowledgement}

I would like to wholeheartedly thank my advisor, Dr. B. Gopalakrishnan, for his continued support, guidance, and encouragement during my graduate studies at WVU and during this research work. I would also like to thank my research committee members, Dr. Shawn Grushecky, Dr. Robert Creese, Dr. Feng Yang, and Dr. Jingxin Wang for their constant advice and support and for providing me a scientific perspective to the analytical approach used in this research.

I would like to extend my special thanks to Mr. Bill Glasscock, Mr. Ed Dallison, Mr. John DiLorenzo, Mr. Mark Caroll, Mr. Mark Wilson, Mr. Mark Jones, Mr. David Shields and Mr. Tyler King, and the staff at sawmill facilities who made it possible to collect the invaluable data required for this research. I would like to extend my special thanks to Mr. Ramakrishna Maddula , Mr. Amir Abolhassani and my brother-in-law Mr. Vinod Kumar for their invaluable help and support for the success of this project.

Above all, I would like to thank my loving parents Mr. Gurupada Devaru and Mrs. Sundaramma for their moral support and blessings and my wife Shwetha for her constant support and my daughter Tanya for her inspiration and enabling my success and happiness in all my pursuits and endeavors in life. 


\section{Table of Contents}

Nomenclature

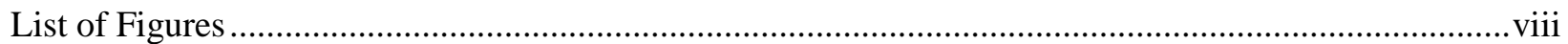

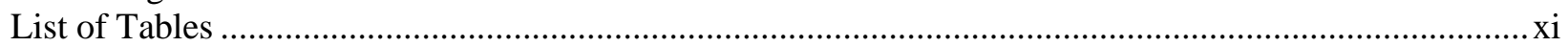

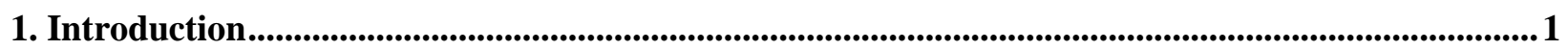

1.1 Lumber Production in US and Global Market ..................................................................... 2

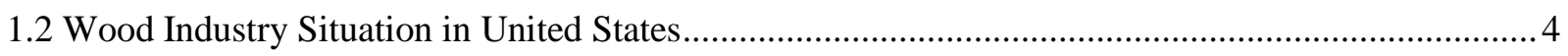

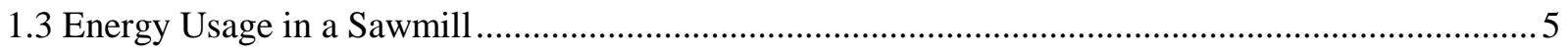

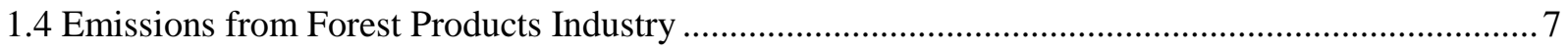

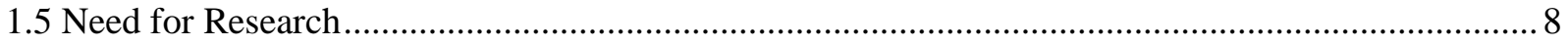

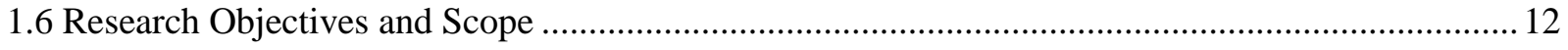

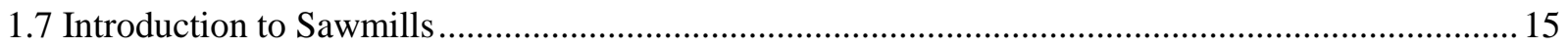

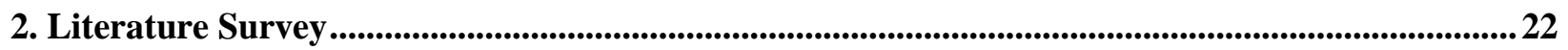

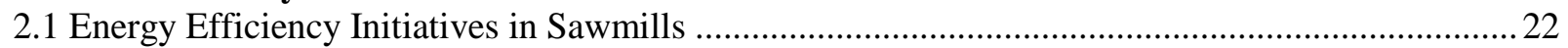

2.2 Energy Efficiency Initiatives in Specific Energy Systems .....................................................2 24

2.3 Study on Sawmill Energy Consumption and Energy Initiatives through Surveys ........................26

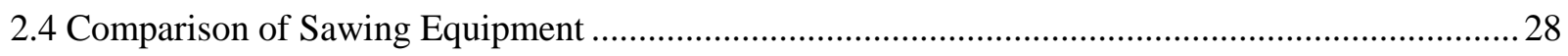

2.5 Research done to Predict Sawing Cutting Forces under various Cutting Conditions ......................29

2.6 Energy Profiling, Data Logging and Energy Measurement Activities in Other Industries ..............36

2.7 Developing Energy Profiles through Data Logging in Sawmills.................................................38

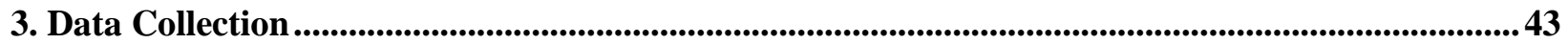

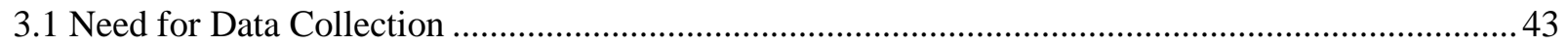

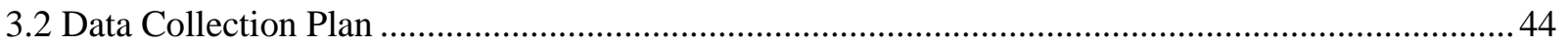

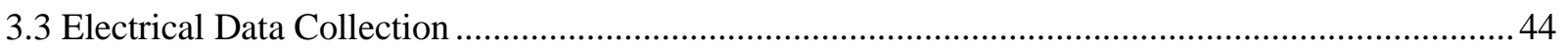

3.4 Real Time Data Monitoring using Data Loggers ....................................................................50

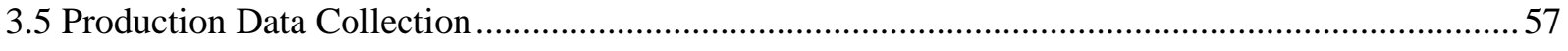

3.6 Data Collection of Saw Blade Material and Maintenance ............................................................... 61

4. Data Analysis ..............................................................................................................................................64

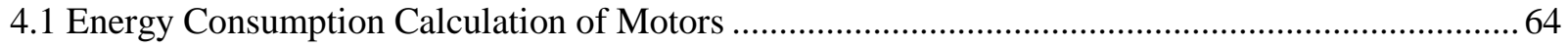

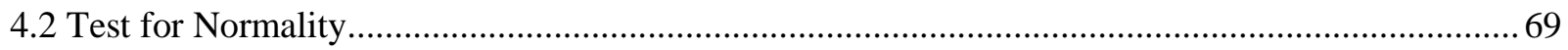

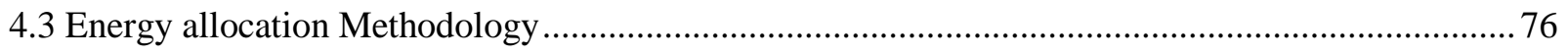

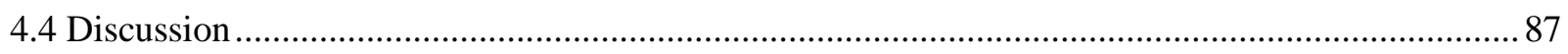

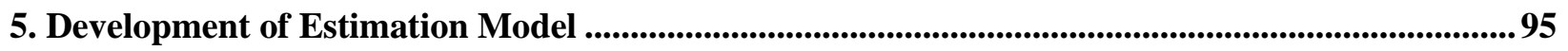

5.1 Selection of Product, Process and System Parameters.............................................................. 95

5.2 Estimation Model Development …..................................................................................... 99 


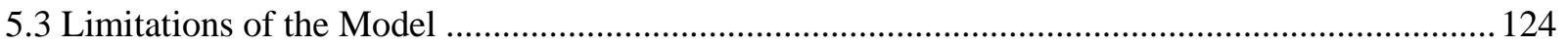

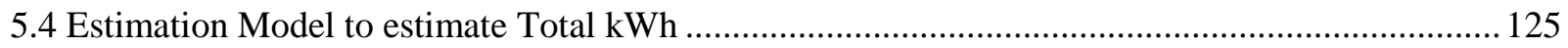

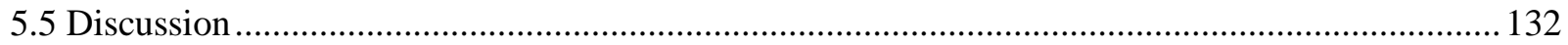

5.6 Sawmill Energy Estimation Program (SMEEP) Development ................................................... 139

6. Sensitivity Analysis and Comparison of Sawmill Motors .................................................................. 148

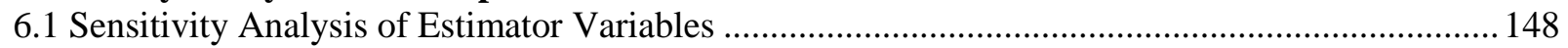

6.2 Sensitivity Analysis of different Lumber Widths produced on SEC …...................................... 154

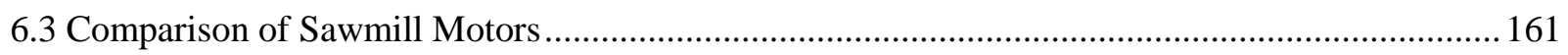

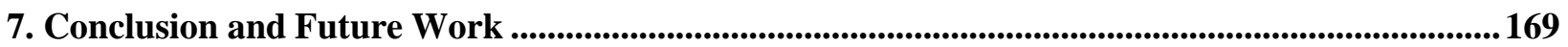

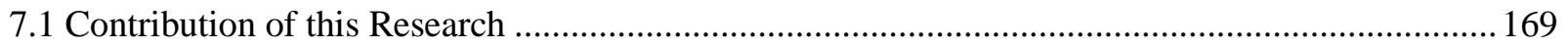

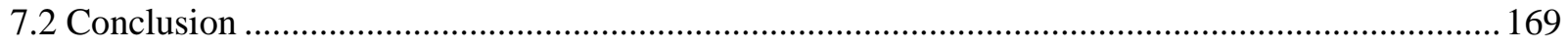

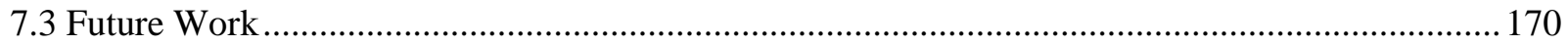

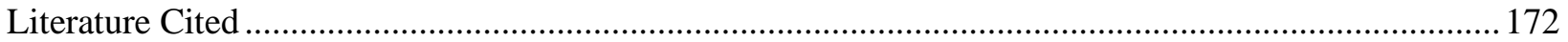

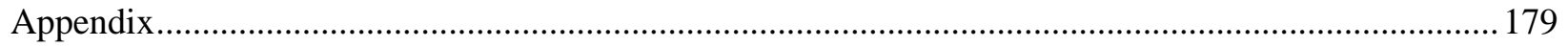




\section{Nomenclature}

\begin{tabular}{|c|l|}
\hline BF & Board Feet \\
\hline MBF & 1000 Board Feet \\
\hline kWh & Kilowatt Hour (Energy Usage) \\
\hline kW & Kilowatt (Power) \\
\hline MMBtu & Million British Thermal Units $=293 \mathrm{kWh}$ \\
\hline SEC & Specific Energy Consumption (kWh/MBF) \\
\hline SMEEP & Sawmill Energy Estimation Program \\
\hline SCFM & Standard Cubic Feet per Minute (Volumetric Air Flow Rate) \\
\hline hp & Horsepower of the motor \\
\hline MJ & Mega Joule \\
\hline PF & Power Factor \\
\hline HVAC & Heating, Ventilation, and Air Conditioning \\
\hline ITTO & International Tropical Timber Organization \\
\hline Tim & Timber \\
\hline Mins & Minutes \\
\hline Temp & Temperature \\
\hline GDP & Gross Domestic Product \\
\hline FPI & Forest Products Industry \\
\hline AFPA & American Forest and Paper Association \\
\hline IMF & International Monetary Fund \\
\hline USDA & U.S. Department of Agriculture \\
\hline FPIP & Forest Products Industry Profile \\
\hline EERE & Energy Efficiency \& Renewable Energy \\
\hline EPA & Environmental Protection Agency \\
\hline FSP & Fiber Saturation Point \\
\hline & \\
\hline & \\
\hline & \\
\hline & \\
\hline & \\
\hline &
\end{tabular}




\section{List of Figures}

Figure 1.1: Energy Consumption by Wood Products Industry in 2010 in Million MMBtu .........................2

Figure 1.2: US Softwood Lumber Production in 2010 (USCB 2010) .......................................................2

Figure 1.3: US Hardwood Lumber Production in 2010 (USCB 2010) ................................................... 3

Figure 1.4: ITTO Producers and Consumers Real GDP Growth, 2000-2017 (ITTO 2012)...................... 3

Figure 1.5: Major Tropical Sawnwood Exporters (left) and Importers (right) ........................................ 4

Figure 1.6: Total Number of Employees and Establishments in Wood Products Sector (BLS 2013)..........5

Figure 1.7: Breakdown of Sawmill Operating Costs (FPIP 1979).......................................................... 6

Figure 1.8: Breakdown of Sawmill's Energy Use (UN 1983) …............................................................ 6

Figure 1.9: Comparison between Prices of Electricity, Natural Gas and Lumber (EIA2013) ..................... 7

Figure 1.10: 'Criteria Air Pollutants' Emissions from Wood Industry for Year 2002 (EPA 2007) ............. 8

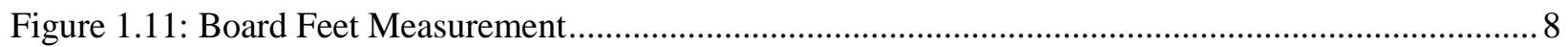

Figure 1.12: Overall Specific Energy Consumption of Sawmills ........................................................ 9

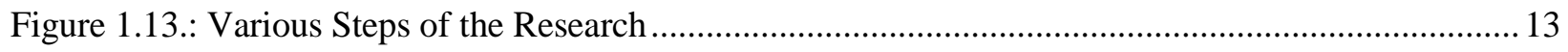

Figure 1.14: System Diagram of Sawmill Energy Estimation Program (SMEEP) .................................. 14

Figure 1.15: Typical Process Flow Diagram for a Hardwood Sawmill sawing operation........................ 15

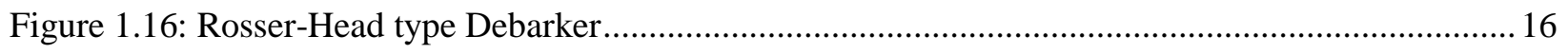

Figure 1.17: Band Saw (on the left) and Circular Saw (on the right) …............................................... 17

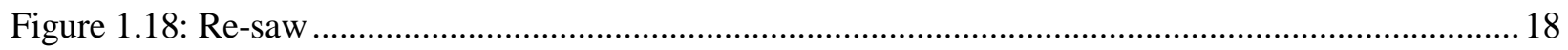

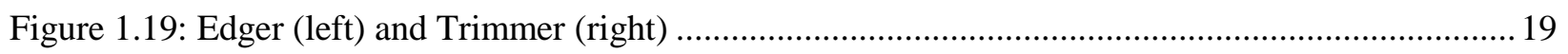

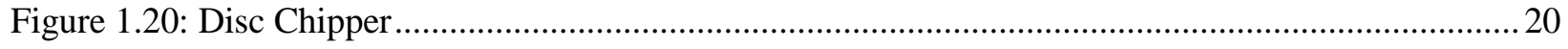

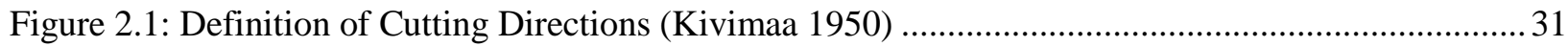

Figure 2.2: Cutting Force Components for Wood Band Sawing (Dalois 1990) ..........................................

Figure 2.3: Mismatch Zone and Overlap between Saw Blades: (a) Sawmill A, (b) Sawmill B ................. 35

Figure 3.1: Sample Amperage Data of Main Saw collected in Sawmill 1...............................................46

Figure 3.2: Histogram of Sample Amperage Data of Main Saw collected in Sawmill 1 .........................4 47

Figure 3.3: Normal Probability Test Results for Group Averages......................................................... 48

Figure 3.4: Standard Normal Distribution and Critical Area .................................................................49

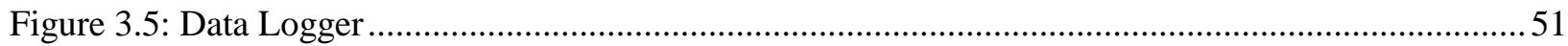

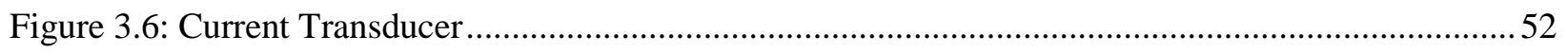

Figure 3.7: Data Logger launching screen for Data Logging (Onset 2013) .........................................53 
Figure 3.8: Graphical Representation of Amperage Consumption (Onset 2013) ....................................53

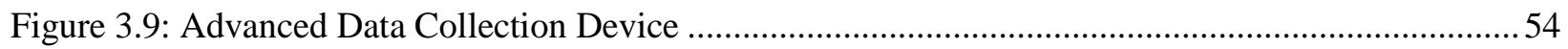

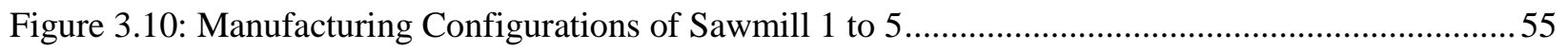

Figure 3.11: Data Logger and Current Transducer Setup ...................................................................57

Figure 4.1: Ryan-Joiner (similar to Shapiro-Wilk) Normality Test for all the Sawmills ..........................69

Figure 4.2: Ryan-Joiner (similar to Shapiro-Wilk) Normality Test for Sawmill 1 .................................. 70

Figure 4.3: Ryan-Joiner (similar to Shapiro-Wilk) Normality Test for Sawmill 2 2............................... 70

Figure 4.4: Ryan-Joiner (similar to Shapiro-Wilk) Normality Test for Sawmill 3 ................................71

Figure 4.5: Ryan-Joiner (similar to Shapiro-Wilk) Normality Test for Sawmill 4 ................................ 71

Figure 4.6: Ryan-Joiner (similar to Shapiro-Wilk) Normality Test for Sawmill 5 .................................. 72

Figure 4.7: Comparison between a Cant and Lumber of equal Board Feet ............................................. 76

Figure 4.8: Surface Area Cut for 1,000 Board Feet of each Size Lumber ............................................. 78

Figure 4.9: SEC of Sawmill 1 to 5 Calculated as per Surface Area Cut ...................................................82

Figure 4.10: Box Plot of 4/4 Size Lumber SEC's of all the 5 Sawmills .................................................. 83

Figure 4.11: Kruskal-Wallis Test Results for 4/4 Lumber SEC's of all the 5 Sawmills........................... 84

Figure 4.12: SEC of 4/4 Red Oak Lumber for Sawmill 1 to 5 Calculated as per Surface Area Cut .......... 86

Figure 4.13: Sample of Line 1 Head saw Production of Sawmill 3 ........................................................... 89

Figure 4.14: Sample of Line 2 Head Saw's Carriage Feed Production of Sawmill 3 ............................... 89

Figure 4.15: Sample of Gang Saw Production of Sawmill 3 .............................................................. 90

Figure 4.16: 250 hp Head Saw Amperage Consumption in Sawmill 5 …..............................................92

Figure 4.17: 150 hp Re-saw Amperage Consumption in Sawmill 5 ......................................................92

Figure 4.18: 100 hp Gang Saw Amperage Consumption in Sawmill 5 .................................................93

Figure 4.19: Motor Part -Load Efficiency (as a function of \% Full-Load Efficiency)............................. 93

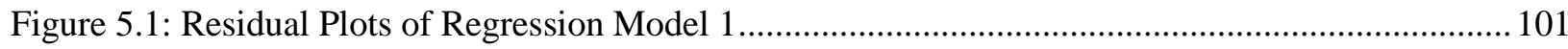

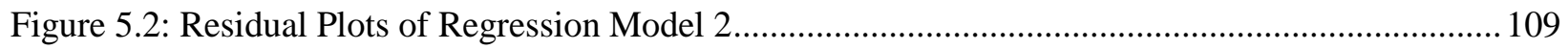

Figure 5.3: Model 2 Estimated Values converted to 'Total kWh' with Actual Values ........................... 115

Figure 5.4: Residual Plots of Regression Model 3 ................................................................................ 118

Figure 5.5: Estimated SEC values from Model 1, 2 and 3 plotted with Actual SEC Values................... 123

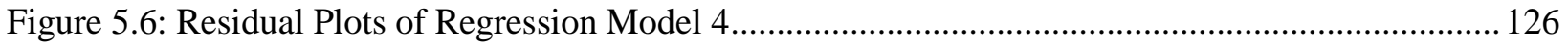

Figure 5.7: Estimated SEC Values from Model 2 and 4 plotted with Actual SEC Values...................... 133

Figure 5.8: Normality Test for Total kWh of Sawmill 1, 2, 3, 4, and 5............................................. 133 


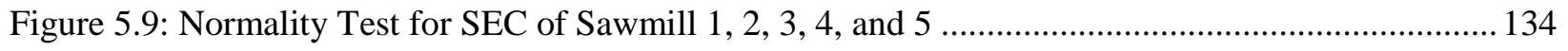

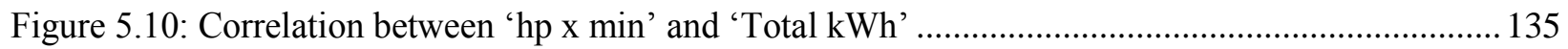

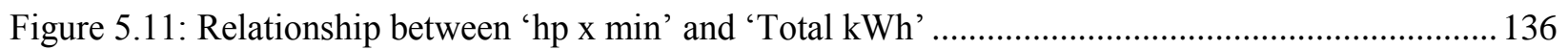

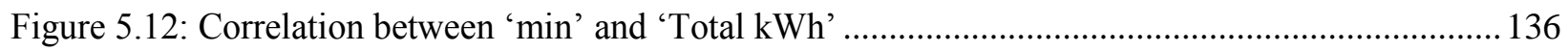

Figure 5.13: Correlation between 'Board Feet' and 'Total kWh' .......................................................... 137

Figure 5.14: Relationship between 'Board Feet' and 'Total kWh' ........................................................ 138

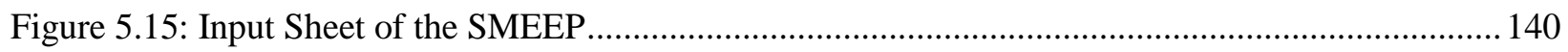

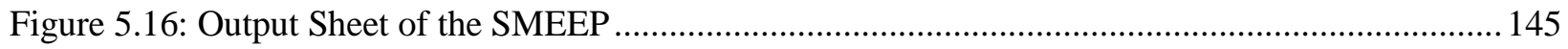

Figure 6.1: Sensitivity Analysis Results for Variable ‘Density' ........................................................... 149

Figure 6.2: Sensitivity Analysis Results for Variable 'Minutes' ............................................................ 149

Figure 6.3: Sensitivity Analysis Results for Variable 'Horse Power' .................................................... 150

Figure 6.4: Sensitivity Analysis Results for Variable '4/4 to 8/4 + Pallet' .............................................. 151

Figure 6.5: Sensitivity Analysis Results for Variable 'Cant + Timber' ............................................... 152

Figure 6.6: Sensitivity Analysis Results for Variable 'Level of Maintenance' ...................................... 153

Figure 6.7: Sensitivity Analysis of different widths of Red Oak sawn for Resaw Energy Consumption

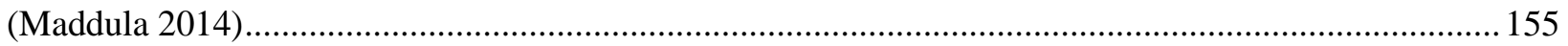

Figure 6.8: SEC's of 4/4 Size Red Oak Lumber for different widths ................................................. 161

Figure 6.9: Energy Consumption of Sawmill 1 Motors per 1,000 Square Feet of Surface Area sawn .... 165

Figure 6.10: Energy Consumption of Sawmill 2 Motors per 1,000 Square Feet of Surface Area sawn... 165

Figure 6.11: Energy Consumption of Sawmill 3 Motors per 1,000 Square Feet of Surface Area sawn... 166

Figure 6.12: Energy Consumption of Sawmill 4 Motors per 1,000 Square Feet of Surface Area sawn... 167

Figure 6.13: Energy Consumption of Sawmill 5 Motors per 1,000 Square Feet of Surface Area sawn... 167 


\section{List of Tables}

Table 1.1: Specific Cutting Energy for Hardwoods and Softwoods (Williston 1988 Chap. 25) ................ 10

Table 3.1: Calculated Averages of Groups taken from Sample Data .................................................... 47

Table 3.2: Characteristics of Major Motors in each Sawmill ...............................................................56

Table 3.3: Data Points for Hardwood Species sawn, Species grouped assigned (HHW: Hard-hardwood SHW: Soft-hardwood) and Total Board Feet sawn. ............................................................................58

Table 3.4: Lumber Thickness Characteristics measured in Board Feet at 5 Sawmills .............................59

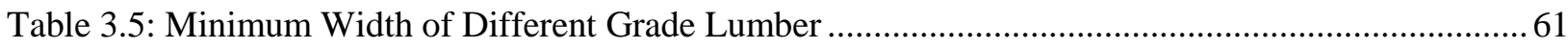

Table 3.6: National Hardwood Lumber Association Graded Lumber produced in Board Feet at 5

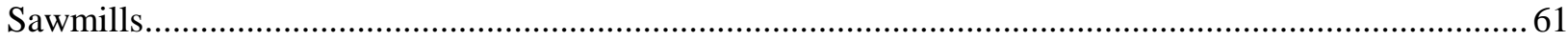

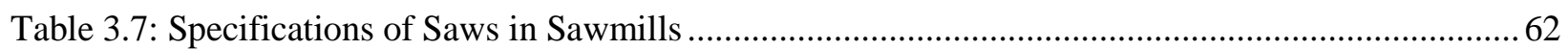

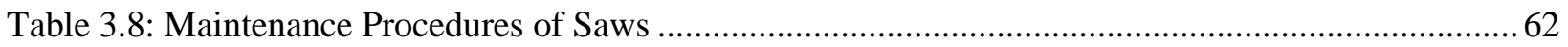

Table 4.1: Logged, Unlogged and Total Motor Horse Power of Sawmills .............................................64

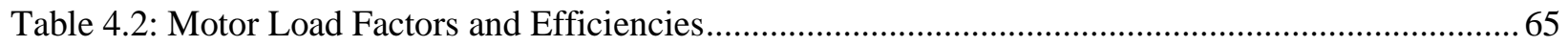

Table 4.3: Example of Energy Consumption in kWh recorded for Motors used during the Sawing of

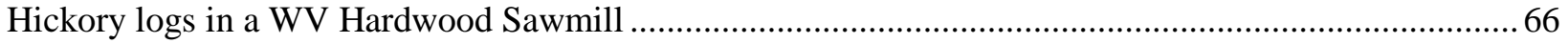

Table 4.4: Total Energy Consumption of Motors, Lighting, and HVAC in each Sawmill along with

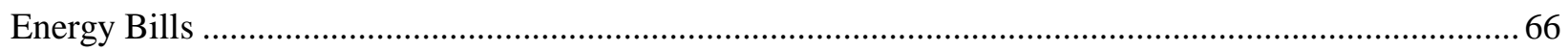

Table 4.5: Calculated SEC Values of 5 Sawmills for Various Shifts ......................................................6 68

Table 4.6: Lumber Production and Energy Consumption Information of Sawmills ................................69

Table 4.7: Means and Standard Deviations of Sawmill SEC ....................................................................... 72

Table 4.8: Results of Comparing Sawmill SEC Means using ANOVA …............................................... 73

Table 4.9: Pearson Correlation Coefficients for SEC and Total kWh vs. Lumber Sizes........................... 74

Table 4.10: Pearson Correlation Coefficients for Equipment Usage in Minutes vs. Lumber Sizes ........... 75

Table 4.11: Surface Area Cut and Factors allocation in Sawmill 2 ..................................................... 79

Table 4.12: Energy Consumption in kWh by various Motors for Sawing Hickory .................................. 79

Table 4.13: Energy Consumed for Sawing Different Size Lumber of Hickory …..................................... 79

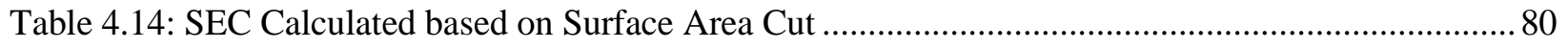

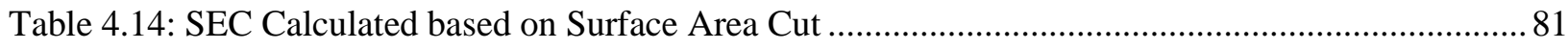

Table 4.15: Calculated SEC Values for 4/4 Lumber of 5 Sawmills for various Shifts*..........................83

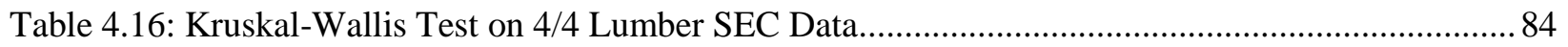

Table 4.17: Calculated SEC Values for 4/4 Red Oak Lumber of 5 Sawmills for various Shifts................ 85 


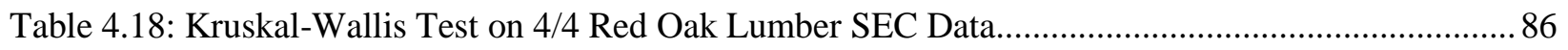

Table 4.19: Production and Energy Consumption of Day and Night Shifts of Sawmill 5 .......................91

Table 5.1: Densities of different Wood Species sawn in Sawmill 1 to 5 ....................................................96

Table 5.2: Qualitative (Categorical) and Quantitative Discrete Variables for Sawmill 1 to 5...................98

Table 5.3: Estimated SEC values from Regression Model 1 ................................................................. 103

Table 5.4: Data of Sawmill 3 and estimated SEC using Model 1 .......................................................... 107

Table 5.5: Estimated SEC values from Regression Model 2 ............................................................. 110

Table 5.6: Comparison of Model 2 Regression Coefficients with and without Outliers ......................... 115

Table 5.7: Data of Sawmill 3 and estimated SEC using Model 2 ....................................................... 116

Table 5.8: Estimated SEC values from Regression Model 3 ................................................................ 119

Table 5.9: Data of Sawmill 3 and estimated SEC using Model 3 ........................................................ 122

Table 5.10: Estimated SEC values from Regression Model 4 …...................................................... 127

Table 5.11: Data of Sawmill 3 and estimated SEC using Model 4 ..................................................... 131

Table 5.12 : Summary of ‘hp x min' Model to estimate 'Total kWh' ................................................... 134

Table 5.13: Surface Area Cut and Factors allocation for the SMEEP Test Data.................................... 142

Table 5.14: Energy consumed for Sawing different Size Lumber of SMEEP Test Data ........................ 143

Table 5.15: Estimated, Actual and Best Achieved SEC values for the SMEEP Test Data ..................... 143

Table 5.16: Best Achieved SEC values from Sawmill 1 for different Lumber Sizes .............................. 144

Table 5.17: Best Achieved SEC values from Sawmill 1 for different Cant Sizes .................................. 144

Table 5.18: Energy Savings and Energy Cost Savings for the SMEEP Test Data ................................. 145

Table 5.19: Productivity Savings and Productivity Cost Savings for the SMEEP Test Data ................... 146

Table 6.1: Data used for Sensitivity Analysis in Model 1 ................................................................... 148

Table 6.2: Data used for Sensitivity Analysis in Model 2 ................................................................ 152

Table 6.3: Resaw electricity consumption for different widths of Red Oak (Maddula 2014) ................. 154

Table 6.4: SEC of 4/4 size Lumber for different Widths and Species sawn in Sawmill 1 ..................... 155

Table 6.5: SEC for different Widths and Species sawn in Sawmill 1.................................................. 156

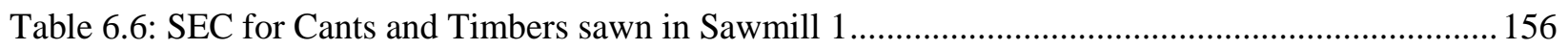

Table 6.7: SEC of 4/4 Lumber for different Widths and Species sawn in Sawmill 2 ............................ 157

Table 6.8: SEC for different Widths and Species sawn in Sawmill 2.................................................. 157

Table 6.9: SEC for different Cants and Timbers sawn in Sawmill 2 ................................................... 157

Table 6.10: SEC of 4/4 Lumber for different Widths and Species sawn in Sawmill 3........................... 158 
Table 6.11: SEC for different Widths of Poplar Species sawn in Sawmill 3......................................... 158

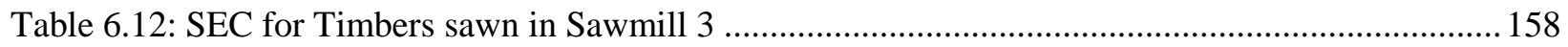

Table 6.13: SEC of 4/4 Lumber for different Widths and Species sawn in Sawmill 4............................ 159

Table 6.14: SEC for different Widths and Species sawn in Sawmill 4 ................................................... 159

Table 6.15: SEC for Cants and Timbers sawn in Sawmill 4 ................................................................. 159

Table 6.16: SEC of 4/4 Lumber for different Widths and Species sawn in Sawmill 5........................... 160

Table 6.17: SEC for different Widths and Species sawn in Sawmill 5 .................................................. 160

Table 6.18: SEC for Cants and Timbers sawn in Sawmill 5 ............................................................... 160

Table A.1: Format for Production Data Collection \& Sample Filled by one of the Sawmill .................. 179

Table A.2: Main Saw Amperage Data of Sawmill 1 used for Calculating Duration of Data Logging..... 180

Table A.3: Production Data Collected used for Analysis ................................................................... 181

Table A.4: Lumber Production Data Collected in Board Feet used for Analysis ................................... 186

Table A.5: Machines Run Time Data Collected in Minutes used for Correlation Analysis.................... 190

Table A.6. Amperage Consumption in amps of Individual Motors and Load Factor of Unlogged Motors in

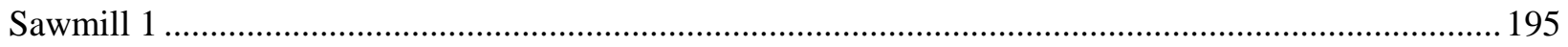

Table A.7. Amperage Consumption in amps of Individual Motors and Load Factor of Unlogged Motors in

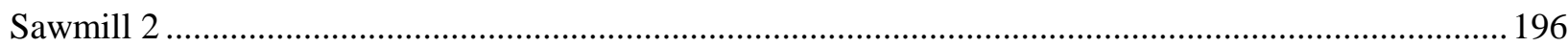

Table A.8. Amperage Consumption in amps of Individual Motors and Load Factor of Unlogged Motors in Sawmill 3 197

Table A.9. Amperage Consumption in amps of Individual Motors and Load Factor of Unlogged Motors in

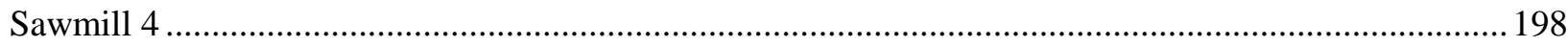

Table A.10. Amperage Consumption in amps of Individual Motors and Load Factor of Unlogged Motors in Sawmill 5 ......

Table A.11. Run Time in Minutes of Individual Motors in Sawmill 1 _................................................200

Table A.12. Run Time in Minutes of Individual Motors in Sawmill 2 ................................................201

Table A.13. Run Time in Minutes of Individual Motors in Sawmill 3 …..............................................2202

Table A.14. Run Time in Minutes of Individual Motors in Sawmill 4 .................................................203

Table A.15. Run Time in Minutes of Individual Motors in Sawmill 5..................................................204

Table A.16. Energy Consumption in kWh of Individual Motors in Sawmill 1 ......................................205

Table A.17. Energy Consumption in kWh of Individual Motors in Sawmill 2 .....................................206

Table A.18. Energy Consumption in kWh of Individual Motors in Sawmill 3 .....................................207

Table A.19. Energy Consumption in kWh of Individual Motors in Sawmill 4 ......................................208

Table A.20. Energy Consumption in kWh of Individual Motors in Sawmill 5 .....................................209 


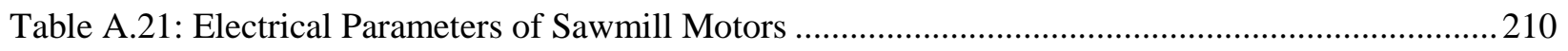

Table A.21: Electrical Parameters of Sawmill Motors .............................................................................211

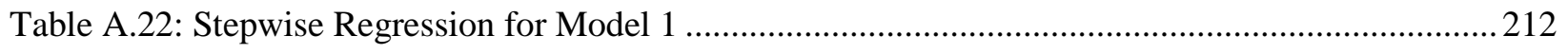

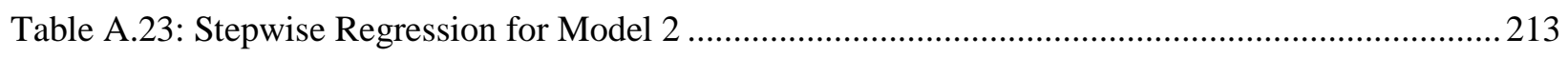

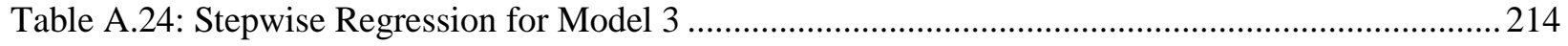

Table A.25: Stepwise Regression for Model 4 ............................................................................... 215

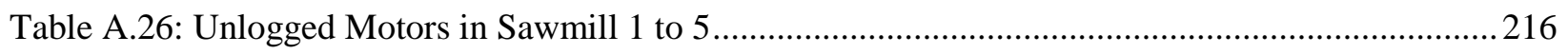

Table A.27: Operation Cost Report of Sawmill 4 for Sawing Poplar during Data Logging Period .........217

Table A.28: Sample Format used for Collecting Saw Blade Material and Maintenance Data Filled by

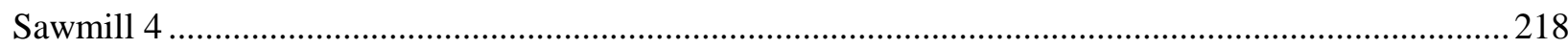




\section{Introduction}

The global forest-based industry is an important component of society in many nations. Its total economic value was US $\$ 468$ billion in 2006, employing 13.7 million people, according to the United Nations (FPI roadmap 2010). The world's forest-based industry covers six continents, with North America, Europe, and Asia having the largest portions.

The United States forest products industry accounted for approximately 4.5 percent of the total U.S. manufacturing gross domestic product (GDP) in 2012, placing it on par with the automotive and plastics industries (AFPA 2012). The industry generated $\$ 240$ billion in 2012 in sales and employs approximately 900,000 people earning $\$ 50$ billion in annual payroll and $\$ 4.6$ billion in state and local taxes. The industry is among the top 10 manufacturing employers in 47 states. This geographic diversity results in a widespread employment base that is concentrated in the nation's rural communities.

In 2012, the total value of shipments for sawmills and the engineered wood and panel products combined was $\$ 67.4$ billion, which is approximately 28 percent of the total shipment of $\$ 238.8$ billion for the forest products industry (AFPA 2012). In 2010, the U.S. forest products industry consumed 2.6 quadrillion Btu (quad), accounting for 13 percent of total manufacturing energy demand. Pulp and paper manufacturing industry used 2.1 quads, wood products industry used 0.27 quads and sawmills used 0.23 quads of energy (US EIA 2010). Figure 1.1 shows the energy consumption by wood products industry in 2010. In 2010, the sawmill industry consumed 4.5 billion $\mathrm{kWh}$ (15.4 million MMBtu) in electricity or $\$ 390$ million in electricity costs, 5 billion cubic feet (5 million MMBtu) of natural gas or $\$ 27.5$ million in gas costs and 195 million MMBtu of other fuels (US EIA 2010). 


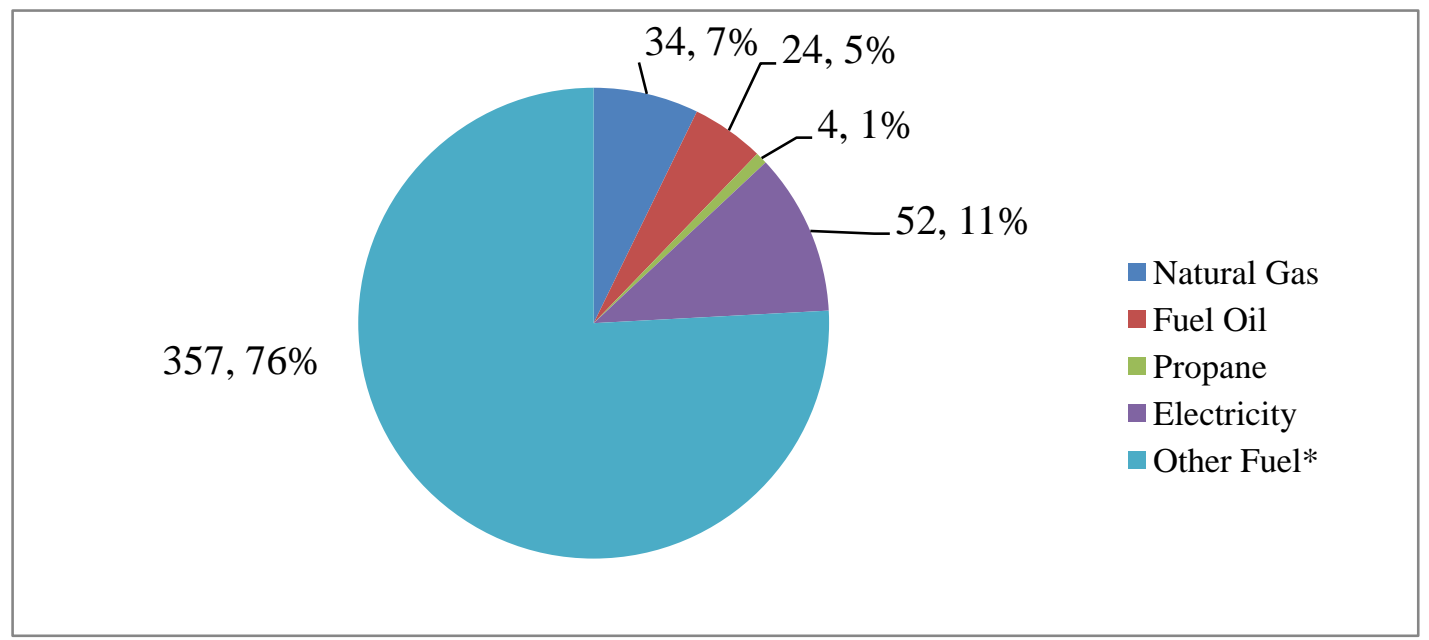

*Asphalt and road oil, lubricants, naphtha, waxes, and miscellaneous nonfuel products like biomass etc.,

\section{Figure 1.1: Energy Consumption by Wood Products Industry in 2010 in Million MMBtu}

\subsection{Lumber Production in US and Global Market}

The total lumber production in United States in 2010 was 68.5 million cubic meters (29,057 Million Board Feet). The total lumber exports was 5.6 million cubic meters and imports was 22.3 million cubic meters. The softwoods production was 56 million cubic meters $(23,718$ Million Board Feet) and hardwoods production was 12.5 million cubic meters (5,339 Million Board Feet) (USCB 2010). Figure 1.2 and 1.3 shows the volume of different species of softwood and hardwood lumber produced in United States during 2010.

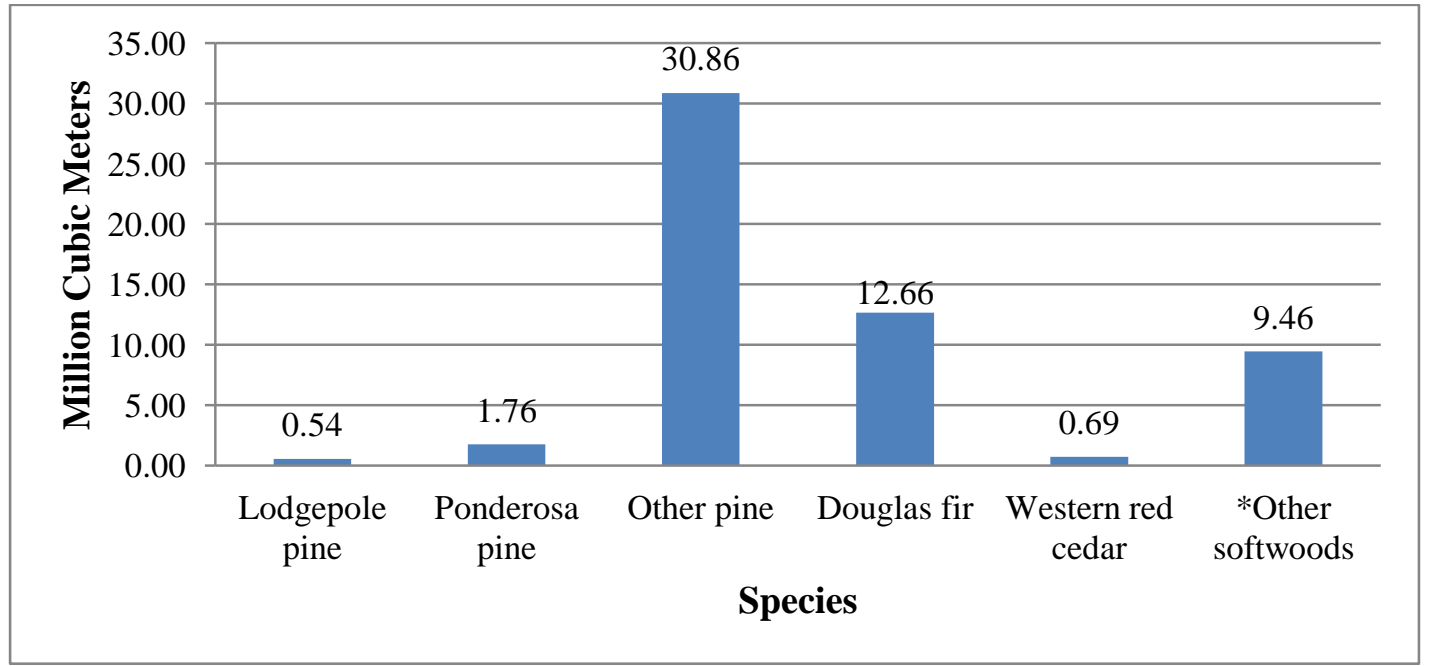

*Other softwoods: hemlock, spruce, fir, cedar, and mixed softwoods

Figure 1.2: US Softwood Lumber Production in 2010 (USCB 2010) 


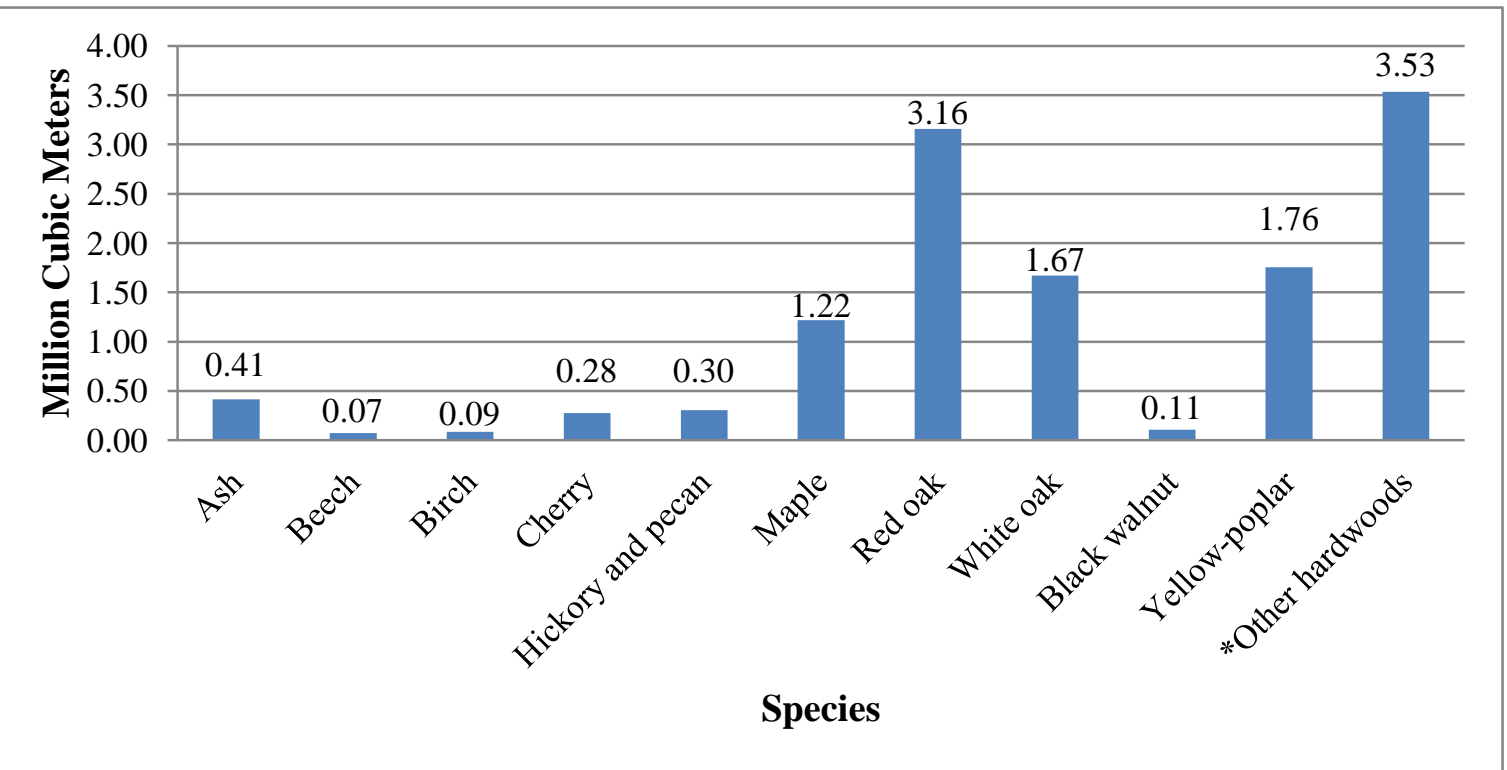

*Other hardwoods: cottonwood, aspen, gum, and mixed hardwoods

\section{Figure 1.3: US Hardwood Lumber Production in 2010 (USCB 2010)}

The total world lumber production in 2011 was 346.2 million cubic meters as per ITTO (International Tropical Timber Organization) annual review of 2012 (ITTO 2012). The total world exports of sawnwood was 101.4 million cubic meters worth of US \$27 billion and imports was 104.7 million cubic meters worth of US \$28 billion in 2011. Figure 1.4 shows the trends in GDP growth for ITTO producers and consumers over the last 12 years and International Monetary Fund (IMF) forecasts for 2013 to 2017. The GDP growth profile clearly shows the economic downturn of the years 2008 and 2009.

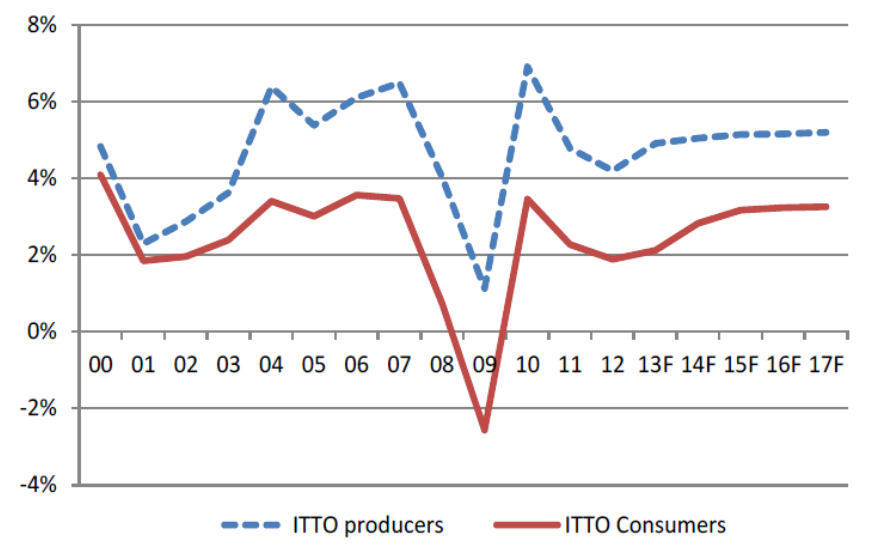

Figure 1.4: ITTO Producers and Consumers Real GDP Growth, 2000-2017 (ITTO 2012) 
Figure 1.5 shows the major trade flows of tropical sawnwood from 2010 to 2012. China and Thailand are the major importers of the sawnwood and Malaysia and Thailand are the major exporters. Increase in sawnwood imports by China and Thailand can be seen from 2010 to 2012.

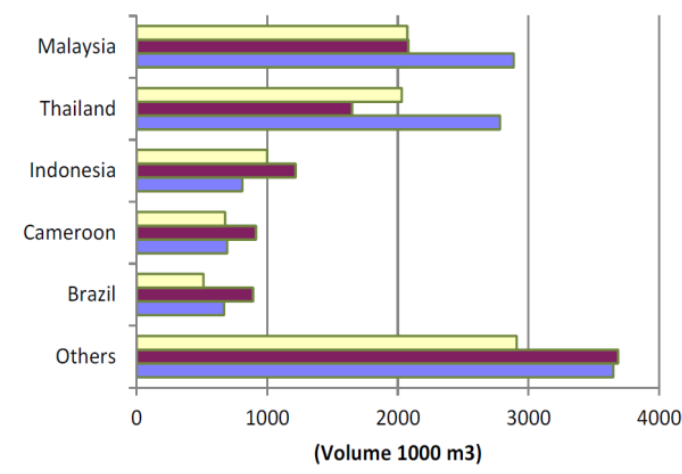

(ITTO 2012)

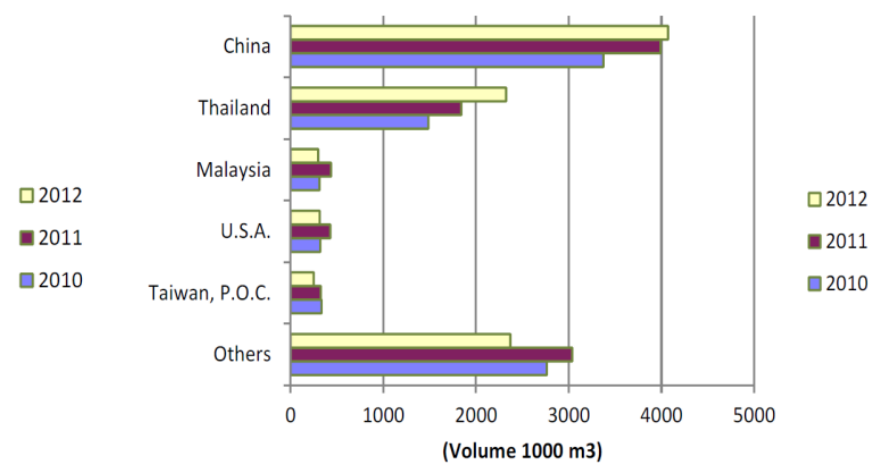

(ITTO 2012)

Figure 1.5: Major Tropical Sawnwood Exporters (left) and Importers (right)

\subsection{Wood Industry Situation in United States}

The United States wood industry was severely affected in the last economic downturn of 2008. The total number of wood products manufacturing establishments closed between 2006 and 2012 was 2,716 (BLS 2013). In 2006 the total number of wood products manufacturing establishments was 17,431 where as in 2012 it was 14,715 a reduction of $15.6 \%$ in last 6 years. The number of jobs lost was an alarming reduction rate of 38.9\%. In 2006 the total number of employees in wood products manufacturing sector was 555,237 where as in 2012 it was 338,977. Sawmills sector was also affected similarly from the economic downturn. The number of sawmills in 2006 was 3,870 and in 2012 was 3,228 a reduction of $16.6 \%$. The number of employees in sawmill sector in 2006 was 105,608 and in 2012 was 75,361 a reduction of $28.6 \%$. Figure 1.6 shows the number of employees and establishments in wood industry and sawmills from year 2006 to 2012 (BLS 2013). The operators that have remained in business over the last economic downturn have been investigating ways to lower the costs associated with the 
production of hardwood lumber. One potential way to lower costs is to focus on reducing their energy consumption.
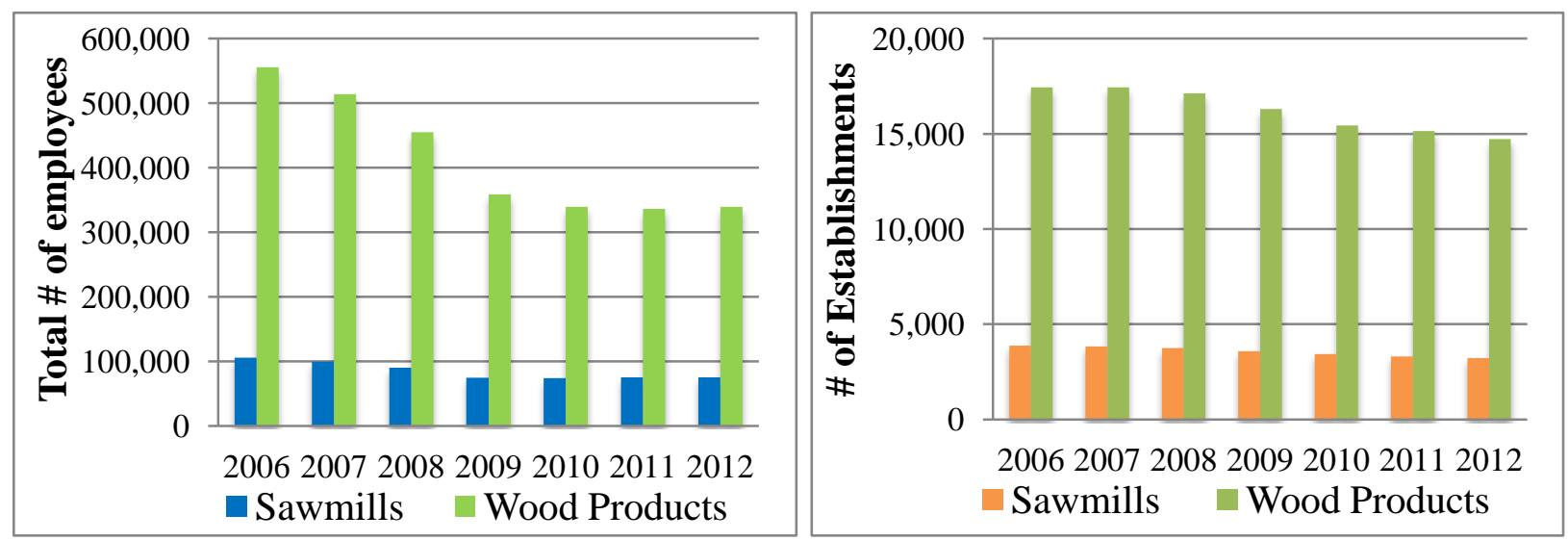

\section{Figure 1.6: Total Number of Employees and Establishments in Wood Products Sector (BLS 2013).}

In West Virginia, sawmills represent the largest component of the primary processing sector in both number of establishments and employees. West Virginia currently has approximately 85 sawmills that produce lumber of various grades from different hardwood species. The wood industry of West Virginia generates $\$ 3.2$ billion annually to the state's economy and employs more than 30,000 workers (WVDOF 2013).

\subsection{Energy Usage in a Sawmill}

If a sawmill produces only rough green lumber and has no kiln-drying facility, electricity will be the primary energy form consumed, otherwise the fuel used to produce heat for lumber drying will be the most important component of energy usage. Energy costs can be a significant component of operating costs in a lumber manufacturing industry (Gopalakrishnan et al. 2003) and can vary between 1 and 10 percent of the total operating costs (Mardikar 2007). With the addition of kilns at primary-processing facilities, energy use can be much higher, potentially using 6 to 9 times more energy than the sawmilling operation itself (Wengert and Meyer 1992). 
Figure 1.7 shows the breakdown of sawmill operating costs. Raw materials account for 60 percent of the total operating costs, whereas labor and overhead costs are 15 percent each, and the energy costs are 10 percent of the total sawmills operating costs (FPIP 1979).

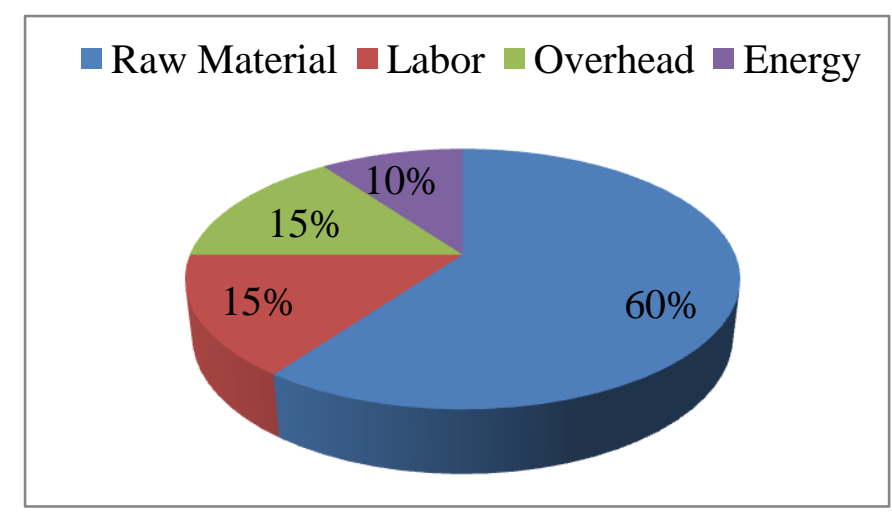

\section{Figure 1.7: Breakdown of Sawmill Operating Costs (FPIP 1979)}

The amount of energy required by each process in a sawmill varies widely but, as per the United Nations study the energy consumption in a typical Sawmill with kiln drying is shown in Figure 1.8 (UN 1983). Electrical energy usage is divided mainly among six processing categories, as shown in the Figure 1.8. For a sawmill with kiln-drying operations, thermal energy is by far the largest part of the energy consumption. However, $63 \%-80 \%$ of the thermal BTU's will be generated from wood residues (Bond 2008).

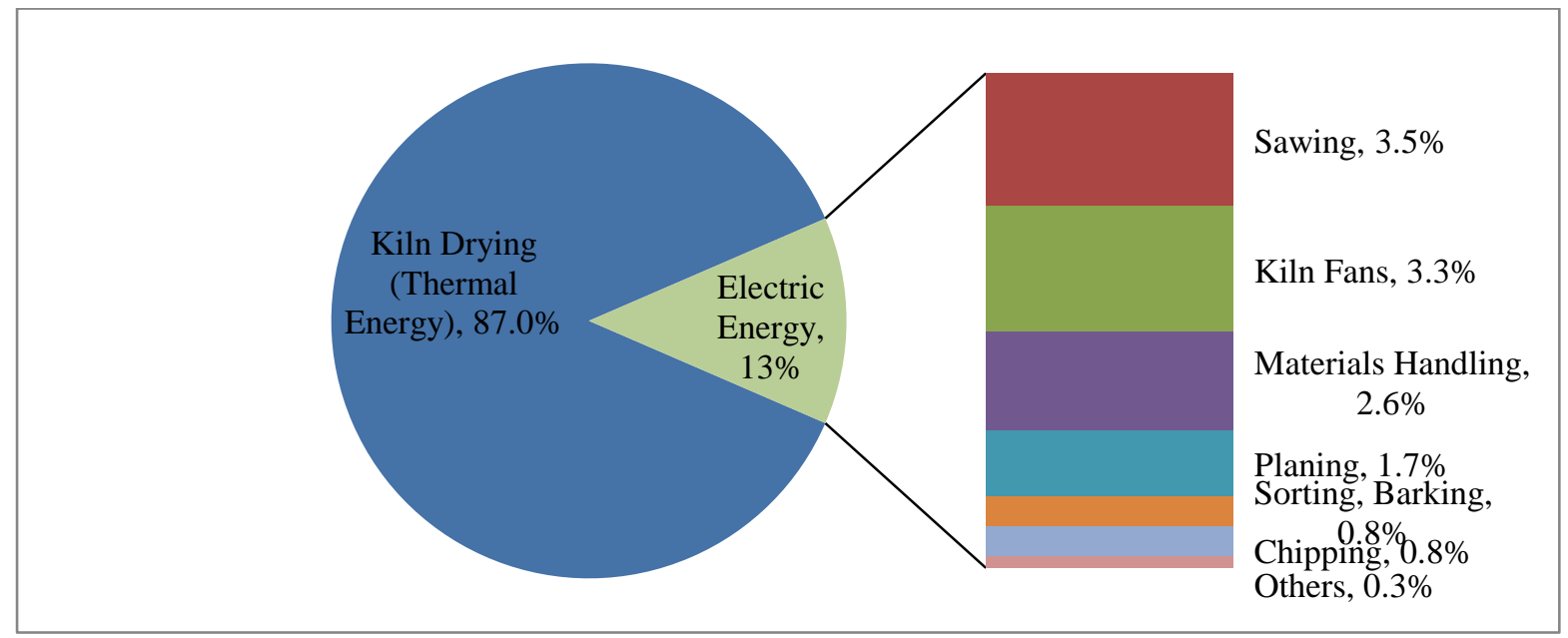

Figure 1.8: Breakdown of Sawmill's Energy Use (UN 1983) 
Increasing energy costs has a significant impact on the profit margin of lumber production, especially since it can represent a large percentage of the total costs of production. Although it has recently stabilized, the price of electricity for industrial sector has risen by more than 40 percent from 2000 to 2012, and natural gas prices increased and again decreased during the same period as shown in Figure 1.9 (US EIA 2013). Therefore, more attention is being given to energy consumption due to increasing energy prices (Mate 2002). The hardwood lumber prices have gone down from 2004 as shown in Figure 1.9 (USDA 2011). Hence, the sawmills must become more productive to compensate for the reduction in lumber prices and increase in energy costs.

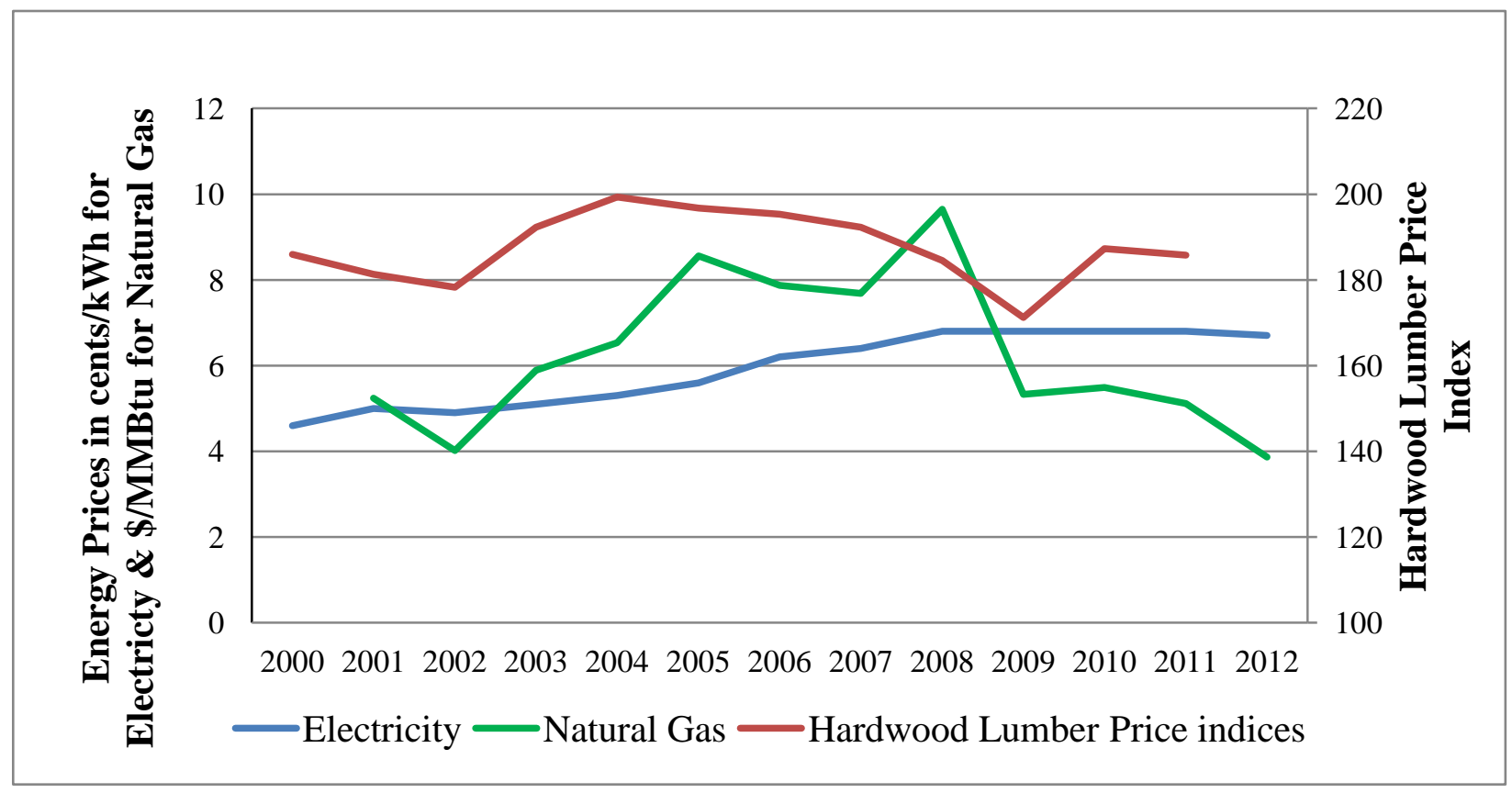

Figure 1.9: Comparison between Prices of Electricity, Natural Gas and Lumber (EIA2013)

\subsection{Emissions from Forest Products Industry}

The total carbon-dioxide emissions from the forest products industry was 68 million metric tons for year 2006 (AMO 2012). Air pollutants emitted to the environment from Wood 
Products industry in year 2002 is shown in Figure 1.10 (EPA 2007). The total energy related 'Criteria Air Pollutants' emission was 408,000 tons out of total emissions of 515,000 tons.
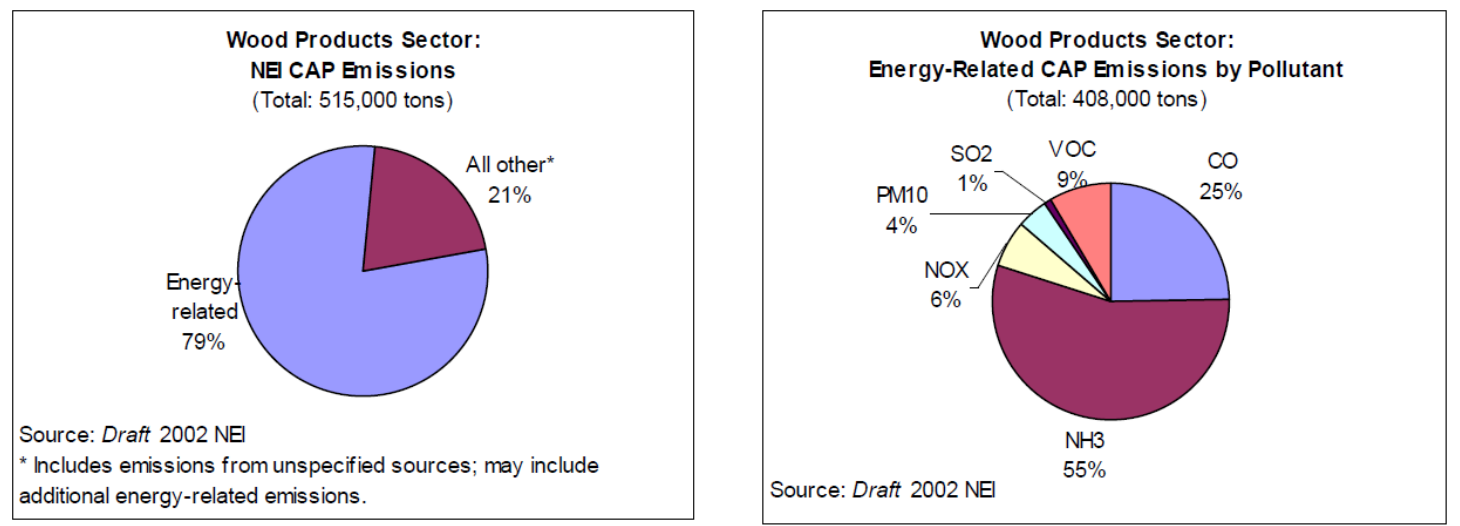

Figure 1.10: 'Criteria Air Pollutants' Emissions from Wood Industry for Year 2002 (EPA 2007)

\subsection{Need for Research}

Energy Intensity also can be called as specific energy consumption (SEC) is measured by the quantity of energy required per unit output or activity, so that using less energy to produce a product reduces the intensity (EERE 2012). In case of lumber manufacturing, SEC will be kilowatt hour consumed to produce one thousand board feet of lumber. One board feet of lumber is defined as a board of size 1 feet wide by 1 feet long by 1 inch thick (Figure 1.11).

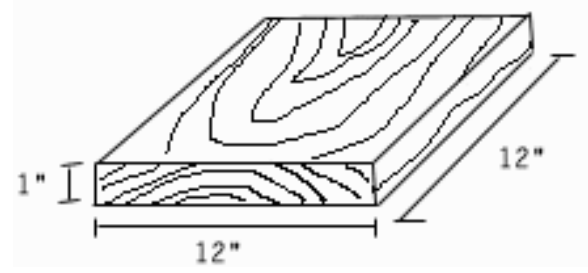

\section{Figure 1.11: Board Feet Measurement}

SEC for a particular type of manufacturing industry helps the industry to benchmark itself against standard energy consumption or industry bests and know its level of performance and the opportunities available to improve. Benchmarking is the process of comparing one's manufacturing processes and performance metrics to industry bests or best practices from other 
companies. The industry best practices can keep on improving due to inventions and continuous improvements happening every day. Research done has calculated the SEC of a sawmill by dividing total energy consumption by total board feet sawn (Gopalakrishnan et al. 2005, Lin et al. 2012). This overall SEC gives a rough estimate of the energy efficiency of a sawmill. Overall SEC calculated from data of 10 West Virginia hardwood sawmills collected during energy audits conducted by Industrial Assessment Center at West Virginia University between 2001 and 2010 are shown in Figure 1.12.

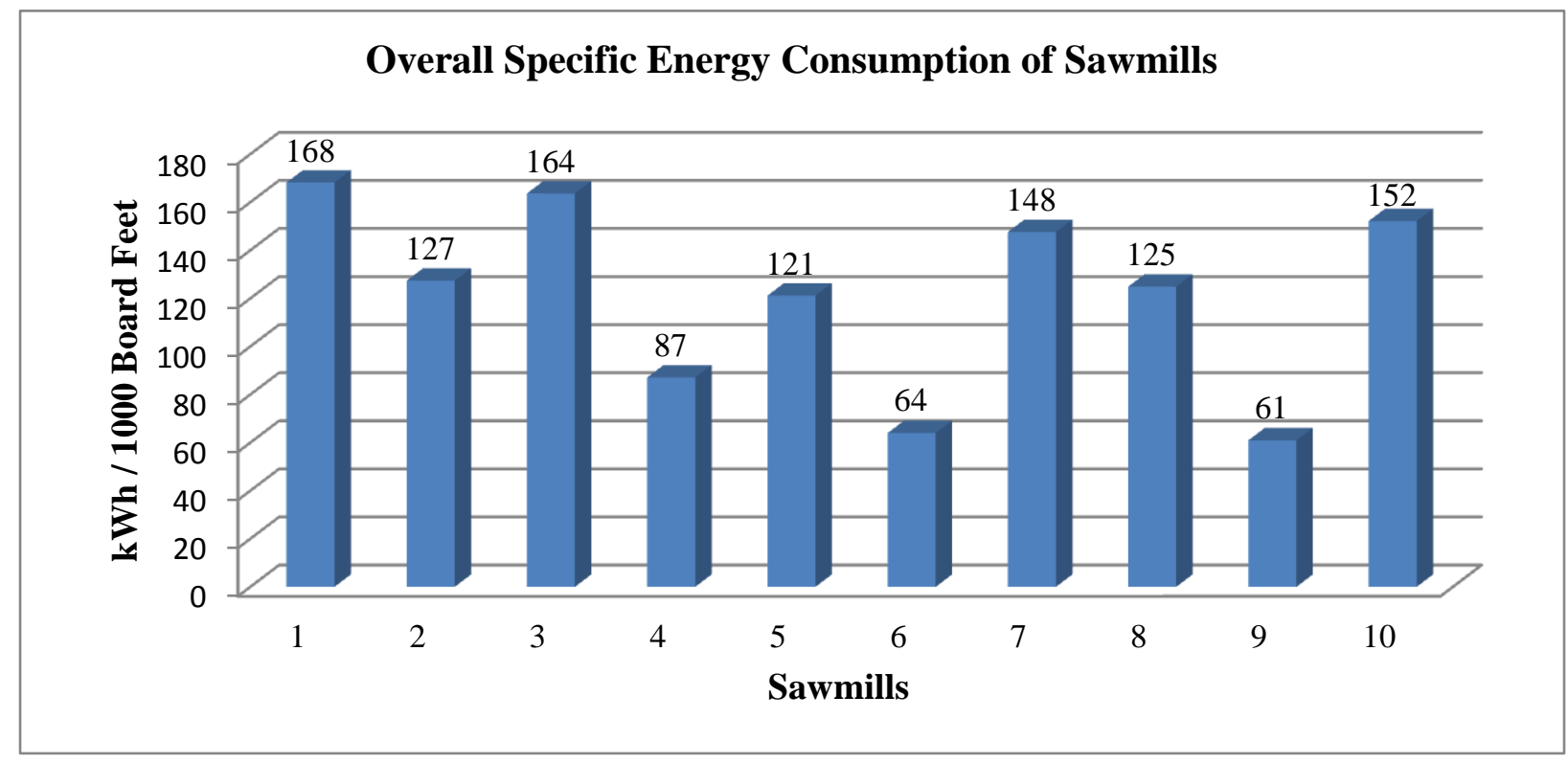

Figure 1.12: Overall Specific Energy Consumption of Sawmills

From the Figure 1.12, it can be seen that overall SEC of sawmills vary considerably. Comparing overall SEC is not an accurate method since each sawmill produces different species and sizes of lumber in varying quantities. If one sawmill is sawing more denser species compared to another sawmill, then it will consume more energy for sawing same volume of lumber since specific cutting energy for denser wood species is higher than less denser species as shown in Table 1.1 (Williston 1988 Chapter 25). Specific cutting energy is defined as the horsepower required to remove one cubic foot of wood per minute. 
Table 1.1: Specific Cutting Energy for Hardwoods and Softwoods (Williston 1988 Chap. 25)

\begin{tabular}{|c|c|c|c|}
\hline Wood Type & Species Name & $\begin{array}{c}\text { Specific Cutting } \\
\text { Energy* }\end{array}$ & $\begin{array}{c}\text { Specific Gravity } \\
\text { (no units) }\end{array}$ \\
\hline \multirow{3}{*}{ Hardwoods } & Hickory or Pecan & 32.6 & 0.61 \\
\cline { 2 - 4 } & White Oak & 29.1 & 0.59 \\
\cline { 2 - 4 } & Cottonwood & 14.6 & 0.33 \\
\hline \multirow{2}{*}{ Softwoods } & Southern Pine & 24.7 & 0.43 \\
\cline { 2 - 4 } & Hemlock & 18.3 & 0.41 \\
\hline
\end{tabular}

*C = Specific cutting energy $(\mathrm{hp} / \mathrm{ft} 3 / \mathrm{min})$

Lumber is sawn in different sizes based on its end use. Typically lumber is sawn in three different size ranges; board, dimension or cant and timbers. Lumber in board size are less than 2 inches thick, dimension size are between 2 and 5 inches thick and timbers size are greater than 5 inches thick. As the size indicates, less board feet will be present in a board size lumber than a dimension lumber or a timber for a piece of same width and length, but the amount of work involved to saw a board lumber is almost equal to the work for sawing a dimension lumber or timber. Hence if a sawmill is producing more of board size lumber, then it will consume more energy for sawing same volume of lumber than a sawmill producing more of dimension lumber or timbers. Hence, a method is required to calculate the SEC for sawing a particular size lumber of a particular species since more than one lumber size is sawn in the same shift. Once the method is developed, best achievable SEC can be calculated for different species and sizes sawn.

Also, it is important to know why the SEC of one sawmill is higher than the best achievable SEC since knowing this will help the sawmill to improve its energy efficiency. This can be known by studying a sawmill from the view point of productivity since energy efficiency also represents production efficiency to some extent. Also, SEC of a particular species and size sawn will help the sawmill industry to price its product based on the energy costs associated with sawing that particular type of product. 
Production and energy consumption data must be collected to develop SEC for sawing of different species and sizes of lumber and calculating best achievable energy consumption from it. Data cannot be collected from every sawmill to calculate SEC and hence there should be a way to estimate the SEC for the sawmills where data cannot be collected. An estimation model based on product, process and system parameters of the sawmill must be developed to estimate SEC using the knowledge obtained from collected data.

\section{Product, Process and System Parameters}

The main product parameters will be the type of wood species sawn and the board feet of different size lumber sawn. There were 10 different species that were sawn during the study and the density of these species can be considered as one of the variable to estimate the energy consumption. There are around 7 lumber sizes that were sawn in the sawmills during this study and the board feet sawn of each size can be considered as a variable.

The main process parameter will be the sawing time since it drives the production rate and hence it affects the sawing energy consumption. Other process parameters that can be considered are temperature and moisture content of the wooden logs and literature must be studied to find out the effect of these parameters on the sawing energy consumption and also collected data must be analyzed to find out the effect of these parameters.

The main system parameter will be the motor horsepower of the equipment used for sawing process. Each sawmill has different total motor horsepower and produce different production quantities and hence there is a direct relationship between the energy consumed for sawing and motor horsepower used for it. Also, type of equipment used for sawing and the line configuration employed can affect the energy consumption. The effect of type of equipment must be studied from the literature and also from the collected data. Other relevant product, process and system parameters must be considered after analyzing the data of the five sawmills. 
Sawmill Energy Estimation Program (SMEEP) that can estimate the SEC, total energy consumption and SEC of individual sizes of the species sawn based on the product, process and system parameters must be developed. The developed SEC must be compared and analyzed with the best achievable SEC. Reasons for the higher or lower value of SEC of particular sawmill must be found using the knowledge learnt from the data collected sawmills. Methods that can be used to improve productivity and efficiency of the new sawmill with estimated savings must be suggested to make more sense for the analysis. The SMEEP will help the sawmill owners to know their level of performance and the opportunities to improve.

\subsection{Research Objectives and Scope}

The objectives of this research are:

1. Develop a method to allocate energy consumption based on effect of lumber sizes sawn on energy consumption and calculate SEC for sawing different species and sizes of 5 sawmills and compare them.

2. Develop and validate a model that can estimate sawing energy consumption based on product, process and system parameters and conduct sensitivity analysis.

3. Develop SMEEP that takes sawmill's product, process and system parameters and calculates the sawing energy consumption and SEC of individual sizes, compares the calculated SEC with the best achievable SEC and analyzes the results.

Various steps of the research (Figure 1.13) are to collect data from the sawmills, analyze it to find the relation between lumber sizes sawn and energy consumption, develop a method to allocate energy based on lumber sizes sawn, calculate SEC for different sizes and species of lumber sawn and find the best achievable SEC, develop and validate a model to estimate energy consumption based on product, process and system parameters, and develop SMEEP (Figure 1.14) to calculate energy consumption and SEC for different sizes sawn and analyze the results. 
Calculation for number of data points to be collected for Electrical Data Collection

Production and Electrical Data Collection

$\checkmark$

Energy consumption calculation for Logged Motors

Energy consumption calculation for Unlogged Motors

Total energy consumption calculation and matching with energy bills

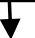

Specific Energy Consumption (SEC) Calculation

Normality Tests for SEC data

$\checkmark$

Comparison of SEC of different sawmills using ANOVA

$\checkmark$

Calculation of Pearson Correlation Coefficients

Calculation of SEC based on Surface Area Cut

$\checkmark$

Comparison of SEC calculated based on surface area cut using Kruskal-Wallis Test and discussion of results

Selection of Product, Process and System

Parameters for Estimation Model

Estimation Models Development and Validation

Sawmill Energy Estimation Program Development

Sensitivity Analysis of Estimator Variables \& Width of lumber sawn

Comparison of Sawmill Motors

Figure 1.13.: Various Steps of the Research 


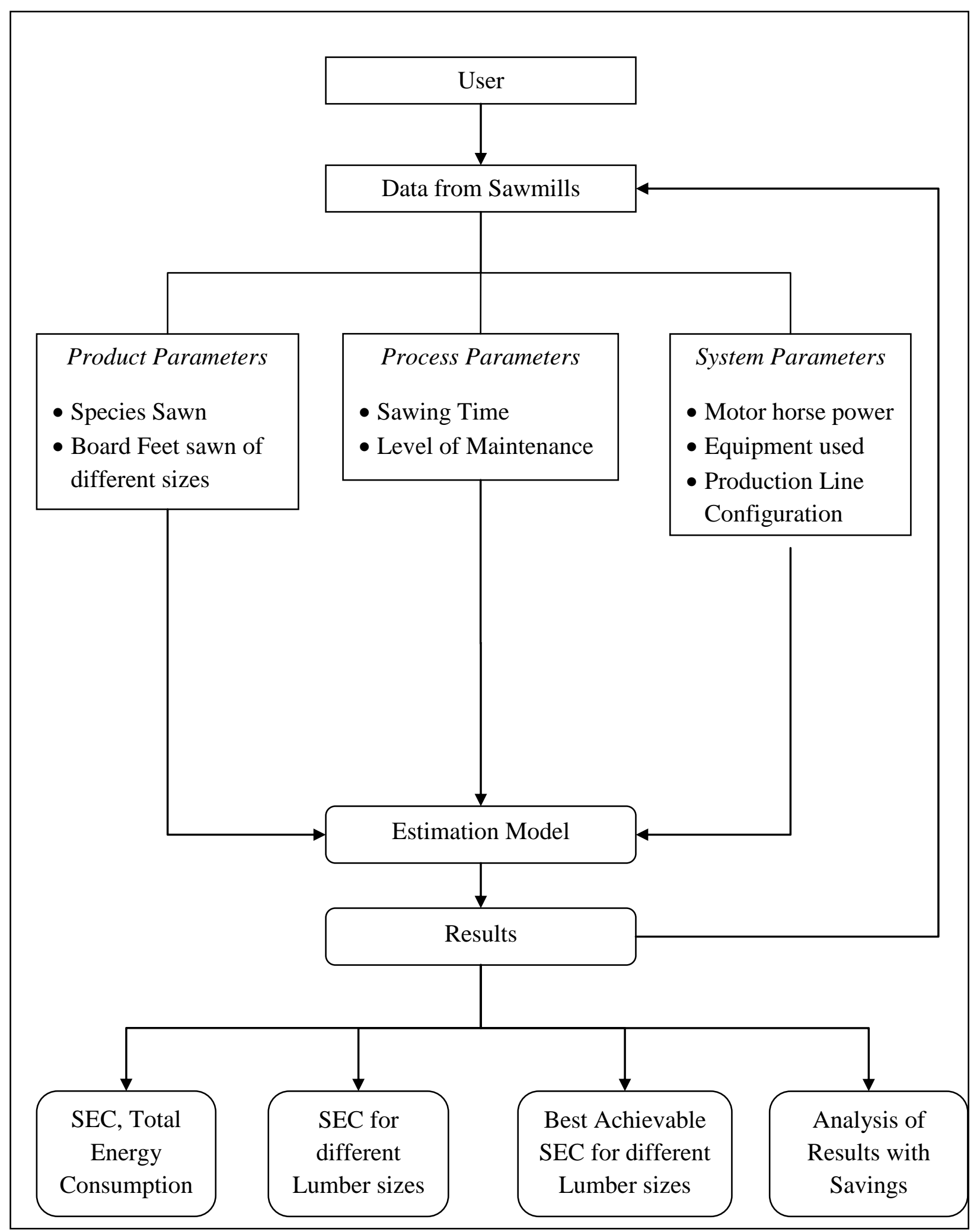

Figure 1.14: System Diagram of Sawmill Energy Estimation Program (SMEEP) 


\subsection{Introduction to Sawmills}

A typical hardwood sawmill combines five main operations including log debarking, log sawing, flitch edging and trimming, and waste chipping (Figure 1.15). Most hardwood sawmills have similar designs in that they have multiple pieces of equipment that are being run by several large electric motors. The motor size of the de-barker, head saw, head saw carriage, re-saw, edger, trimmer, and chipper would typically be 100, 400, 200, 300, 100, 50, and 300 horsepower respectively. In addition each sawmill will have an air compressor that operates additional equipment throughout the facility and it would typically have power ranging from 100-300 horsepower. Smaller sawmills will usually have similar equipment but the power of the individual motors are typically smaller. Close to 90 percent of the electrical energy used in a typical sawmill will be consumed by motors alone (Lin et al. 2012).

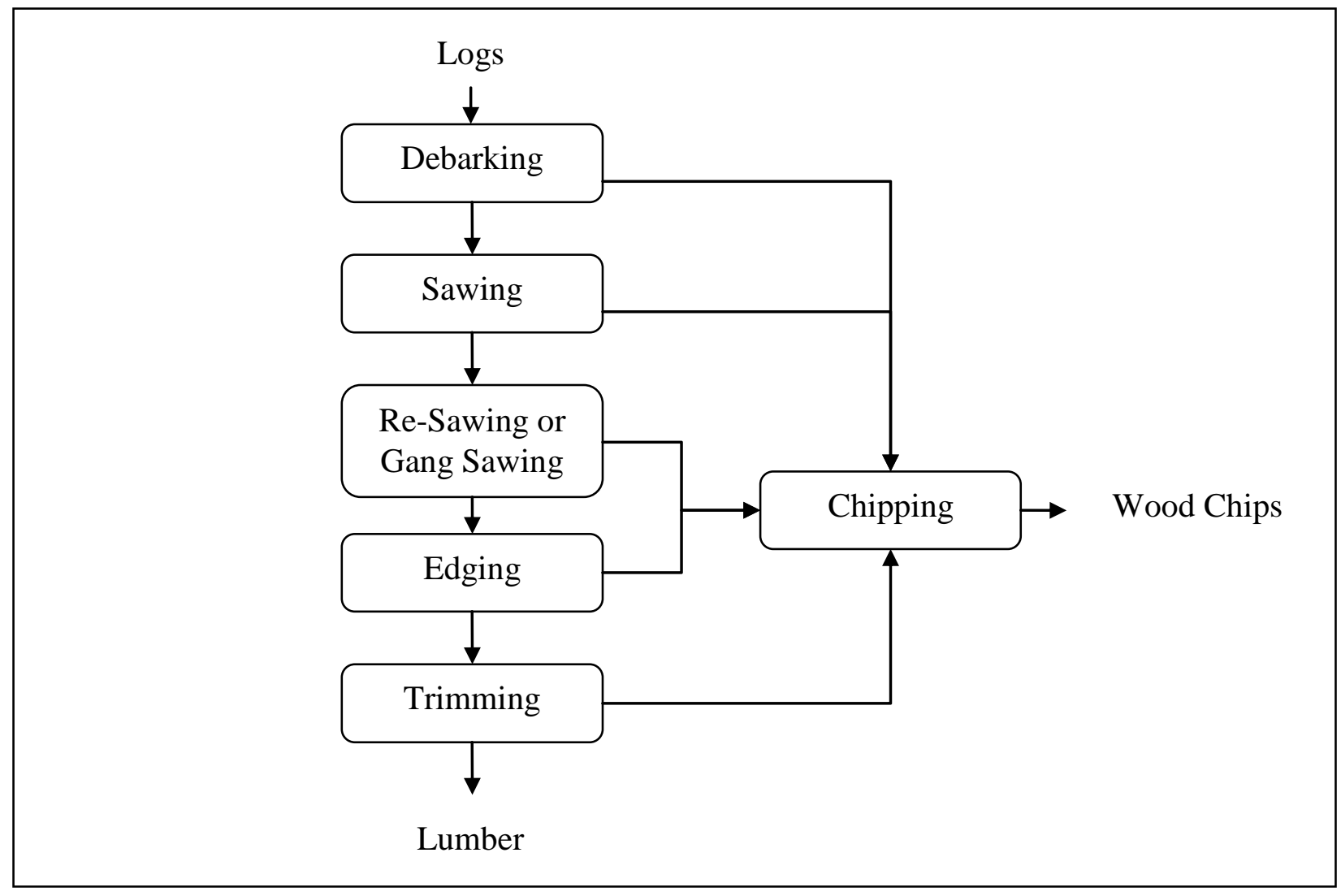

Figure 1.15: Typical Process Flow Diagram for a Hardwood Sawmill sawing operation 
The principal product of sawmills is air or kiln dried lumber, which is mainly used by the construction and furniture industries.

\section{Debarking}

Debarking is the process of removing the bark from wooden logs. Extra care is taken to minimize the removal of wood from the logs while removing the bark (Denig 1993). The bark removed from the logs is used in pulp products industry for different applications. Bark is also chipped into small pieces to produce low-grade fuel. The main purpose of debarking operation is to reduce the damage from the logs to various sawmill cutting tools employed for sawing logs. Debarking is an essential step and is done at the initial phase of wood processing irrespective of the type of end-product being made from the wooden logs. The logs can be better inspected for their grade and inherent defects after debarking. The equipment used for the debarking operation is called as debarker. Different types of debarkers are cambio, ring, rosser-head, hydraulic oscillating, ring type and drum type (Williston 1988 Chapter 6). Figure 1.16 shows a rosser-head type debarker.

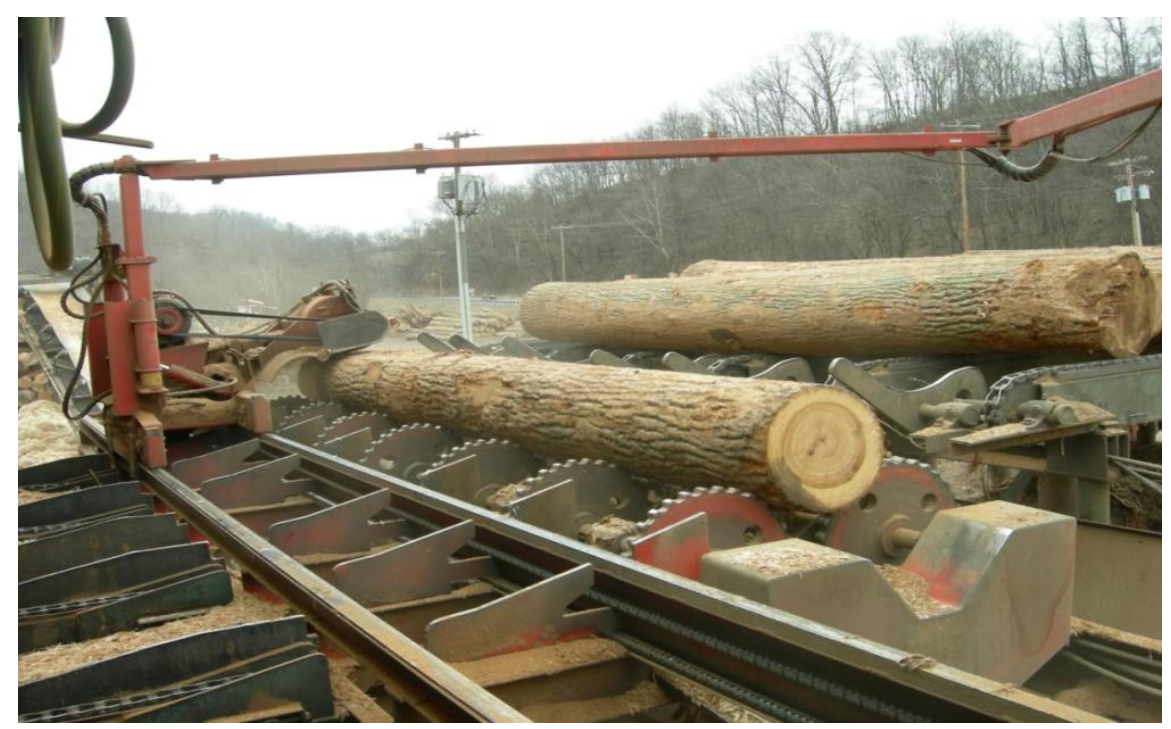

Figure 1.16: Rosser-Head type Debarker 


\section{Sawing}

Sawing is the process of cutting wooden logs into lumber and circular and band saws are the most commonly used sawing equipment. Debarked logs from the debarker are first sawn using a band saw or a circular saw into cants. A cant is a wooden log with rectangular cross section formed after removing the circular sides of the log. The equipment used for converting logs into cants is called as a head saw. At the head saw during sawing, the log is moved in a horizontal direction by a carriage and fed to the moving vertical saw blade (in the case of band saw). A circular saw or a band saw can be used for cutting the logs into cants and also cants into lumber (wooden boards). Circular saw blade has a limitation in its diameter to process logs larger than 60 inches in diameter (Williston 1988 Chapter 9). Another circular saw is added on the top instead of using a single saw of larger diameter for logs larger than 60 inches in diameter.
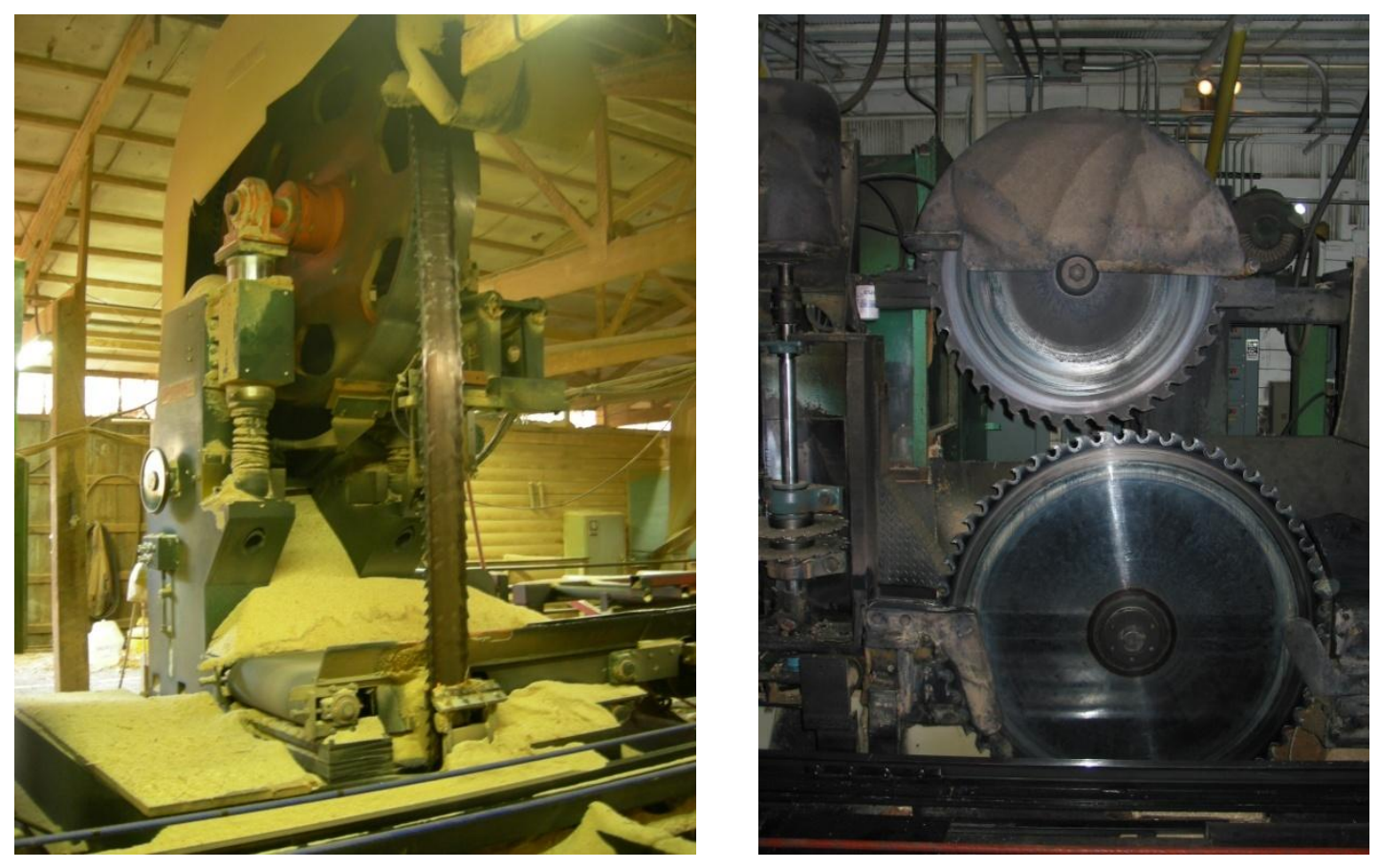

Figure 1.17: Band Saw (on the left) and Circular Saw (on the right)

Band saws can accommodate large-diameter logs very easily. The saw kerf (effective thickness of the blade) for a circular saw is more than the band saw. Therefore, less wood waste 
will be generated as saw dust by using a band saw instead of circular saw. Because of these advantages, band saws are preferred over circular saws irrespective of higher capital costs. Figure 1.17 shows a band saw and a circular saw.

\section{Re-sawing / Gang Sawing}

The cants are further sawn into boards using another band saw or a circular saw down the line. The saw used here is termed as re-saw. In re-saw, the cant is fed to the saw on a guided conveyor or a chain mechanism. Figure 1.18 shows a re-saw. Gang saw is similar to a re-saw in which the entire cant is sawn at once into many boards instead of one board every time as in a resaw.

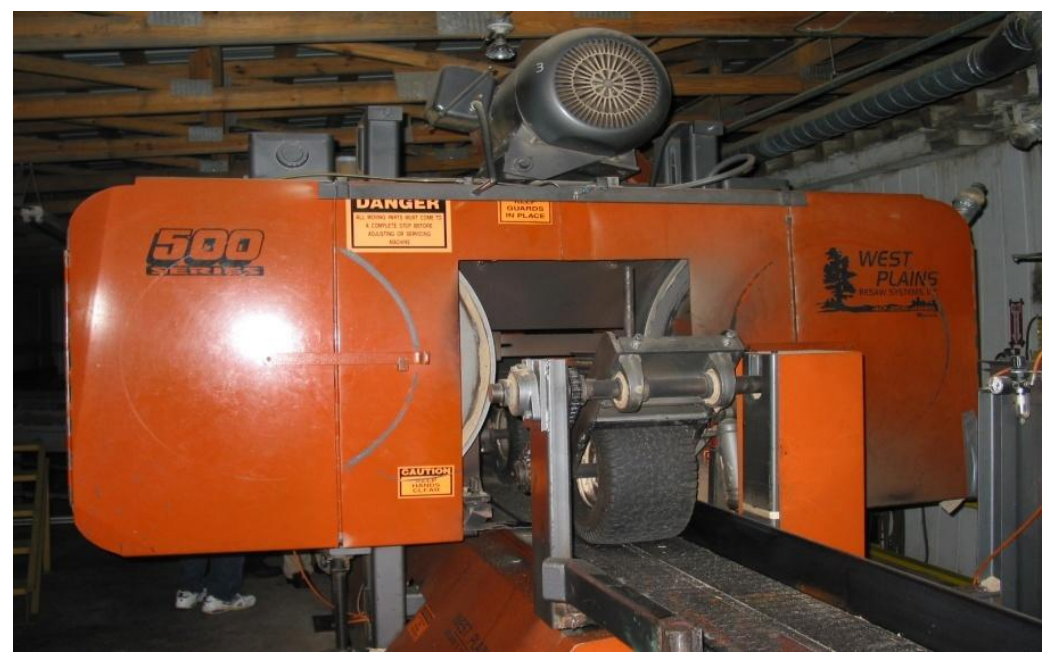

Figure 1.18: Re-saw

\section{Edging}

Edging is the process of cutting the rough edged wood pieces lengthwise into smooth edged pieces. The wooden boards with rough edges from the re-saw or head-saw are fed into the edger. The edger system will have 2 saws and a guiding mechanism. Circular saws are most commonly used for edging but band saws can also be used with comparatively thinner kerf. Wooden board is held by the guiding system and fed to the rotating saw. It is a best practice in 
sawmills to run the saw in the opposite direction to the material feed. This feeding direction minimizes any possibility of wood pieces and chips being propelled from the point of cut (Williston 1988 Chapter 11). Figure 1.19 shows an edger used in sawmills.

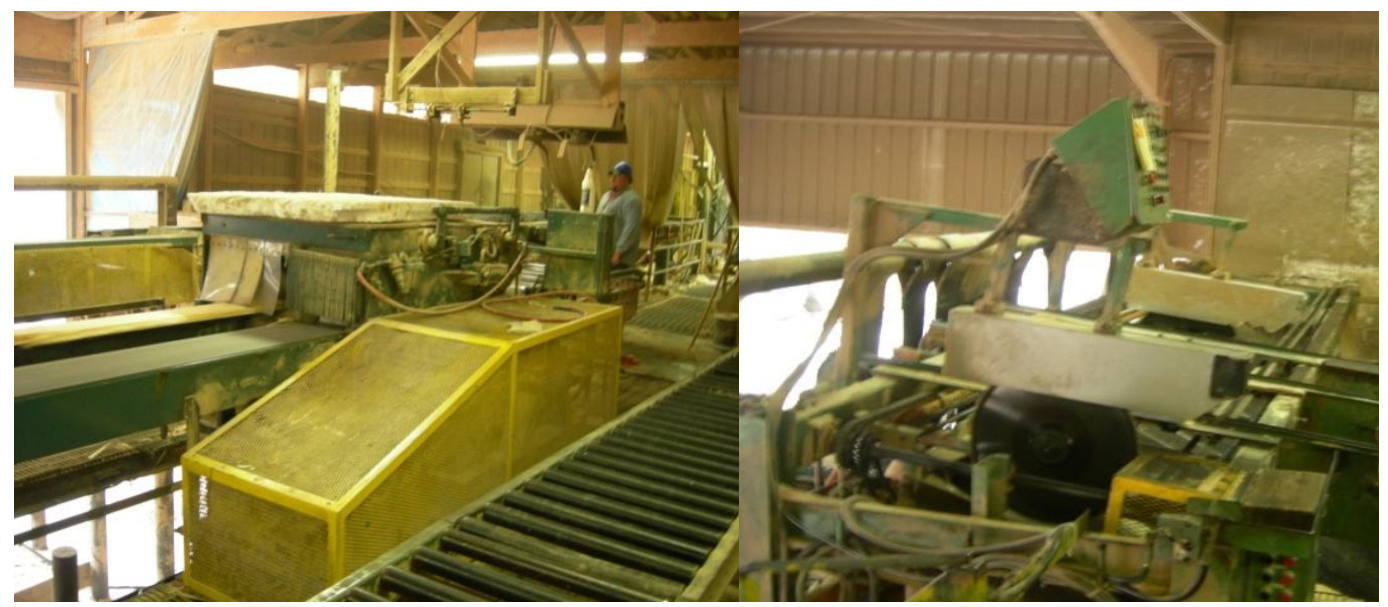

Figure 1.19: Edger (left) and Trimmer (right)

\section{Trimming}

The process of cutting the lumber across the width to form flat ends is known as trimming. The boards are fed from the edger to the trimmer. Trimmer will also have a saw, and a guiding mechanism like edger. Trimmers will be of single or double saw type. In the case of a single saw type trimmer, the wooden board will be fed again to the trim saw in order to trim the other end, which is not the case in a double trim saw where the board is fed only once and both the ends will be trimmed together (Williston 1988 Chapter 12). Figure 1.19 shows a typical trimmer used in sawmills.

\section{Chipping}

Sawmills also produce a valuable byproduct in the form of wood chips along with lumber. Wood chips will be usually made from the wood waste obtained from different woodworking processes and occasionally made from wood logs that are not of adequate quality 
to be processed into lumber. Bark from the debarking process, edges and end pieces from the edging and trimming processes, and wood slabs from the head saws and re-saws are used as a raw material for making chips. Various wood chip sizes are made based on the end use. Chipper is the name of the equipment used to produce chips. Drum and disc type are the two common types of chippers. Wood waste from different sawmill processes, is fed to the chipper using a vibrating conveyor. The chips produced are usually used as a fuel in the plant boiler for generating steam used in lumber drying process or sold in the market. In the case of disc chippers, wood pieces are cut into the desired chip size using knives mounted on the rotating disc of the chipper (Williston 1988 Chapter 20). Figure 1.20 shows a disc chipper used in sawmills.

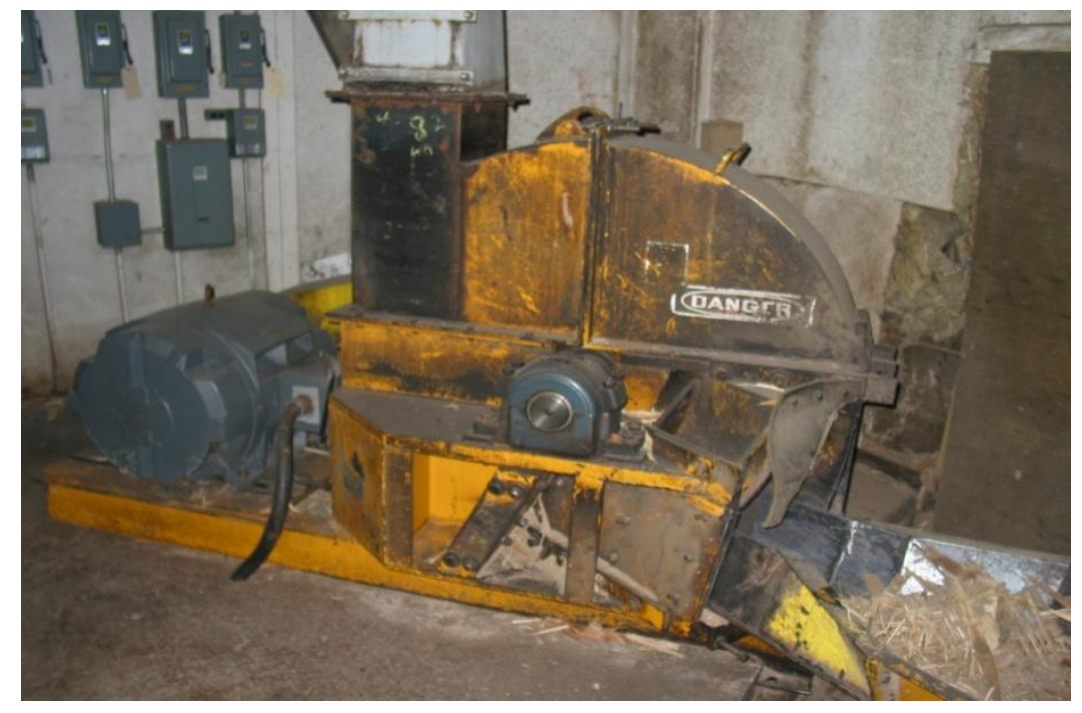

Figure 1.20: Disc Chipper

\section{Conclusion}

Increase in energy costs and reduction in lumber prices are affecting sawmills and sawmill owners are looking for ways to become more productive to compensate for these costs. Sawmill owners can become more productive by benchmarking themselves with better sawmills and there is a need for developing a tool to do benchmarking. Comparing sawmills overall SEC will not give clear picture of sawmill's performance since the variability of density and size can 
affect this comparison to a great extent. Hence a method is required to calculate the SEC for sawing a particular size lumber of a particular species and then that can be used for comparison. Also, for a sawmill where electrical data cannot be monitored, an estimation model is required to estimate energy consumption. Along with comparing SEC's between sawmills, manufacturing processes must be compared from the view point of productivity to know about the reasons for inefficiencies in productivity and energy efficiency. Once the sawmill owners know the inefficiencies of their processes, it can help them to make changes to save energy and improve productivity. 


\section{Literature Survey}

\subsection{Energy Efficiency Initiatives in Sawmills}

Several energy efficiency initiatives have been taken by the U.S. Department of Energy (USDOE BP) as best practices, which were developed through funded research for different industrial sectors. Research is conducted by several other organizations to help the sawmill industry to save energy. The discussion of such few initiatives is given here.

Wengert and Meyer have reported more than 75 economical ways to reduce energy consumption and electric bills to save money without affecting production (Wengert 1992). They have highlighted the importance of understanding the electric utility billing system and its components to help reduce energy costs. The author advices sawmill to get benefit from the free energy audits provided by the utility companies. The article provides a detailed list of recommendations on ways to save energy on all the major energy-consuming areas like lighting, electrical motors, compressors, sawing, boilers, kilns, and HVAC systems. The article mainly stresses that energy audit is the first step for saving energy in sawmills. Some of the important recommendations provided in the article are proper sizing of the electrical motors, using capacitors on motors, reducing electrical demand, shutting off idling motors, using cogeneration to generate in-house electricity, using efficient lighting systems, maintaining teeth of saw blades, boiler burners, monitoring air to fuel ratio of burners, using thinner kerf on saw blades, defrost frozen logs, using air drying before using kiln drying to dry lumber, insulating kiln surfaces, and the use of radiant heaters instead of convection heaters for comfort heating.

Lin conducted a survey to study the profile of Appalachian Sawmills in 2010 (Lin et. al. 2012). Survey was mailed to 776 hardwood sawmills in the Appalachian region that were selected as the sample population. Out of 238 responses received, 58 surveys were usable. 
Electricity was the main energy resource used in the surveyed sawmills and very few used natural gas. Average electricity consumption per month per mill was $107,007 \mathrm{kWh}$, and the average electric bill was $\$ 9,278 /$ month. The average electric cost rate was $\$ 0.0867 / \mathrm{kWh}$. The electricity consumption ranged from $31 \mathrm{kWh}$ per thousand board feet (MBF) to $588 \mathrm{kWh} / \mathrm{MBF}$ and averaged $220 \mathrm{kWh} / \mathrm{MBF}$ based on lumber production volume. The electricity cost ranged from $\$ 2$ to $\$ 41.67$ per MBF with an average of $\$ 17.78 / \mathrm{MBF}$.

Also, Lin summarized the sawmill audits done between 2001 and 2010 by Industrial Assessment Center of West Virginia University in the state of West Virginia (Lin et. al. 2012). The author has information of 17 sawmills and has compared their overall costs of production as well as the ways they could use to increase efficiency. Annual lumber production averaged at 55,444 MBF per sawmill and average energy use was 2,782,659 $\mathrm{kWh}$ per mill. Recommendations given by audit team can save approximately $275,110 \mathrm{kWh}$ of electricity/year (14 percent of the annual energy used calculated from \% savings of each sawmill) per mill or $4,676,873 \mathrm{kWh}$ for all the mills and total cost savings of $\$ 464,995$ per year for all the mills. Likewise, the conservation procedures recommended could save the audited mills an average of 587,045 pounds of carbon dioxide emissions per year. The energy saving recommendations given was mainly for lighting, compressor and motor systems.

Bond discusses the increase of natural gas and electrical energy prices and increase of stumpage prices and mentions that sawmill owners are looking for ways to reduce costs (Bond 2008). He further discusses that for a sawmill with kiln-drying operation, thermal energy is the largest part of the energy consumption and one way to dramatically reduce energy in drying is to practice air-drying. Also the author discusses about importance that sawing accuracy has on energy usage during the drying process and variable speed fans can save up to $50 \%$ in electric 
energy use with a $20 \%$ reduction in fan speed once moisture content drops below $30 \%$. The author also discusses about importance of free energy assessments by DOE that can save 10 to $15 \%$ of energy.

\subsection{Energy Efficiency Initiatives in Specific Energy Systems}

Northwest Energy Efficiency Alliance has reported a case study on using motor management program by Crown Pacific Lumber to make decisions about the maintenance of the electrical motors (CPL 2001). Crown Pacific Lumber acquired Gilchrist Mill which was an old sawmill facility with over 300 working motors on the process line. The facility's electrical superintendent with the help of a consulting engineer used a motor management program to build inventory of the electrical motors in the plant in 2001. The required information was obtained from the motor nameplate and maintenance history of the motors. The developed inventory was used to make decisions for replacing or rewinding a failed motor, replace a existing motor with an energy efficient motor etc., Replacing an existing 89\%-efficient motor with a new 96\%efficient motor, saved on average $\$ 3,400$ annually per motor with a simple payback of 1.8 years. The company also used data loggers to measure the amperage drawn by the motors over a period of time. Load profiles were developed from the logged data and were used to make decisions regarding proper sizing of the motors. The study revealed that the motors were oversized in most cases and were designed as per the production requirements at the starting of the old mill when the production requirements were different. The facility was able to replace its old, oversized, inefficient motors with new, energy-efficient motors with a payback of less than two years.

Frequency variable drives are common in industrial fans and pumps where the load on the motor varies over time. Research has been done to find out the advantages and disadvantages of a frequency variable drive for the electric motor of a bandsaw (Fenart 2000). This study was 
carried out in France with beech and oak logs to investigate the effects on productivity, sawing precision, sawing time, and electricity use. Sawing precision and sawing time were not affected, while electricity consumption of the bandsaw with a frequency variable drive decreased by $65 \%$. Payback period for the investment cost of the frequency variable drive was estimated to be within 3 years.

Compressed air systems are found throughout sawmill industry and account for a significant amount of electricity consumed. Applying a system-level strategy to optimize a compressed air system can improve system performance, production and save energy. A case study done by US DOE discusses the use of AIRMaster+ to optimize the compressor performance in a sawmill (DOE 2004). Compressed air was used for air-operated cylinders and various pneumatic tools, and it was particularly critical for proper operation of the quad that saws the logs. The quad uses compressed air to precisely place the logs, and if the compressor pressure goes down, logs get stuck in the quad. To clear the jam, mill personnel had to shut off the quad and cut the logs with chainsaws to remove them. This resulted in production downtime and higher labor costs. It also caused product waste because the jammed logs were unusable. Location of the compressors coupled with the manual control scheme and convoluted piping led to severe pressure fluctuations of $30 \mathrm{psi}$, (from 65 to $95 \mathrm{psig}$ ) that hindered production. To maintain the needed pressure, the mill had tried operating all compressors simultaneously, but that only generated excess air and wasted energy. AIRMaster+ best practice tool was used to analyze the compressed air system. As per the analysis, the sawmill upgraded the compressor controls, stabilized the pressure level, repaired leaks and installed pressure/flow controller with 2,500 gallons of additional storage capacity with the air treatment equipment. The performance of the compressed air system improved substantially after the mill implemented this system-level 
project. Once these devices were in place, the baseline measurements were retaken and the system pressure was lowered from 95 to 85 psig and a reduction of the flow rate from 2,0002,300 scfm to $1,750 \mathrm{scfm}$. The mill was able to satisfy its compressed air demand by just baseloading the 300-hp compressor and operating the 200-hp unit in load/unload mode and keeping the 150-hp unit as a backup compressor. The project yielded annual compressed air energy cost savings of $\$ 55,000$, with a simple payback of 1 year. In addition, the project served as a blueprint for successful projects at six other company facilities. The aggregate energy savings and energy cost savings resulted from these six facilities' projects were 6.8 million $\mathrm{kWh}$ and $\$ 250,000$.

\subsection{Study on Sawmill Energy Consumption and Energy Initiatives through Surveys}

A survey (Milota et al. 2005) on life cycle inventory of softwood lumber production in the four western mills and four southern mills was conducted during 1999 and 2000. For western production, the survey was for dimension lumber produced in the states of Oregon, Washington and west of the Cascade Mountains. For southern production, the survey region was the states of Georgia, Alabama, Mississippi, and Louisiana. The primary data in the western survey indicated that $78.1 \%$ of the planed, dry lumber produced was Western Hemlock and $21.9 \%$ was Douglasfir. The primary data in the southern survey indicated that planed dry southern pine accounts for nearly all dimension lumber production. This research mainly discusses about the energy used for production of planed dry lumber and $\mathrm{CO}_{2}$ emissions. Research estimated the SEC for sawing softwood lumber as $67.9 \mathrm{kWh}$ per MBF for 4 sawmills of the southern region and $86.8 \mathrm{kWh}$ per MBF for 4 sawmills of the western region. The conclusion of the research was that even though the electrical energy accounts for major share in sawing, maximum amount of energy consumption and $\mathrm{CO}_{2}$ emissions was from drying process. 
Another study (Bergman \& Bowe 2008) was done through survey of 20 sawmills across 20 states in the northeastern region of the United States. The survey indicated that the thermal energy required to produce lumber was generated onsite whereas electrical energy was from both onsite and offsite sources. Based on the results presented in this paper, $274 \mathrm{kWh}\left(608 \mathrm{MJ} / \mathrm{m}^{3}, 1\right.$ $\mathrm{kWh}=3.6 \mathrm{MJ} \& 1$ nominal $\left.\mathrm{MBF}=1.623 \mathrm{~m}^{3}\right)$ of electrical energy and 5.5 MMBtu $(5,800 \mathrm{MJ} /$ $\mathrm{m}^{3}, 1 \mathrm{MMBtu}=1,054 \mathrm{MJ}$ ) of thermal energy were spent to produce one MBF of planed dry lumber in these mills. The unit processes (sawing, drying, energy generation (boiler operation), and planing) consumed 50,25, 5, and $20 \%$ of the total electrical energy respectively. Based on these percentages, the four unit processes used 137, 68.5, 14, and $54.5 \mathrm{kWh}$ of electrical energy to produce one MBF of planed dry lumber. For hardwood species, $269 \mathrm{kWh}$ and for softwood species $151 \mathrm{kWh}$ of electrical energy were spent to produce one MBF of planed dry lumber in these mills. This research also found that the energy spent widely varies with type of wood species sawn, age of equipment, and drying methods.

A survey was conducted on 188 sawmills in eastern US primary hardwood products manufacturers in 2010 (Espinoza 2011) to find out the impact of high energy costs on wood products manufacturer's profitability and the actions taken by them to respond to energy related challenges. Results show that overall, the share of energy expenses on total production costs of respondents was $7.9 \%$. A majority of respondents $(61.8 \%)$ agreed that their energy expenses have increased by an average of $18.7 \%$ during the last five years. Half of the respondents reported a 5\% or higher negative impact of higher energy prices on their profits over the same period. Most companies (63 percent) indicated that they are focusing on improving energy efficiency and/or improving productivity (41.3 and 41.9\% respectively) to cope up with the rising energy prices. Around $8.6 \%$ of the companies indicated that they have established energy 
usage baselines and energy performance indicators which helps them to monitor their progress. $67 \%$ of the companies indicated that they are training employees on energy saving issues. The most common efficiency measures that were undertaken by the companies were using more efficient lighting, upgrading equipment with energy efficient equipment, and taking measures to minimize wastage of energy.

\subsection{Comparison of Sawing Equipment}

A bandsaw and a circular saw were compared in a small sawmill in Sweden (Uppgård 1995). The advantages of the bandsaw were that it had higher yield due to small kerf width, could easily handle larger logs, had a short changeover time and consumed less power. The advantages of the circular saw were that it was rugged and was able to saw dense woods easily, had easier blade alignment and needed less frequent manual handling since saw blade didn't required dismantling of the saw for maintenance.

Spinelli conducted a comparison study on two commercial chipper models, a disc and a drum chipper (Spinelli 2013). The effect of chipper type on productivity, power demand, fuel consumption and product quality were studied. Both the chippers had the same diameter capacity, same energy source (farm tractor of $100 \mathrm{~kW}$ output) and fed with the same feedstock types. Fifteen replications were conducted per machine for each of the four different feedstock types, resulting in a total of 120 tests. The disc chipper had a higher energy efficiency than the drum chipper and used $19 \%$ less fuel per unit product, The reason for this is possibly due to the simpler design of the disc chipper integrating comminuting and discharge system in one synergic device. Drum chipper was $8 \%$ more productive (difference was not statistically significant at $5 \%$ level), since it cut with the same energy all along the length of its knives. The drum chipper produced smaller chips, with a higher incidence of fines. 


\subsection{Research done to Predict Sawing Cutting Forces under various Cutting Conditions}

A research (Iris et. al. 2006) was conducted to find the cutting forces for tension, normal and frozen wood of maple in band sawing. This research measured cutting forces for frozen green wood, green and dry normal wood, and green and dry tension wood of sugar maple and red maple. An ice block was cut to compare the magnitude of its cutting forces with those obtained from frozen wood. Tension wood was obtained from leaning trees. Cutting force measures energy to sever a single chip. Three tooth designs of Stellite tips with different rake angles were tested. Saw teeth with larger rake angles required less energy to cut green and dry wood. The tooth with the largest rake angle required the least energy to cut dry and frozen wood, and also performed well when cutting green wood. Specific cutting force for frozen wood was nearly as great as for dry wood; specific cutting force was least for green wood. Increased cutting forces for frozen wood were due to cutting frozen cell walls, because ice alone requires little force to machine. Specific cutting force was less for tension wood than for normal wood. The results for tension wood are apparently due to thinner fiber cell walls and the amount and type of lignin present in tension wood fibers. As expected, green wood registered the lowest principal cutting force, followed by frozen wood. Dry wood generated the greatest value of cutting force but the differences between frozen and dry wood were not significant for sugar maple while for red maple they were significant.

A research (Mihai 2008) was performed in order to establish if the properties of frozen Spruce and Oak wood (in winter) are different from those of unfrozen timber with regard to its processing. Spruce timber specimens, cut from the same log, half of them frozen at $-30^{\circ} \mathrm{C}$ and half left unfrozen, were sawn under absolutely identical conditions (same machine, same tool, same devices and same cutting conditions), in order to determine comparatively the energy 
consumptions involved in the two cases. Only free water freezes in wood if the temperature does not drop below $-30^{\circ} \mathrm{C}$. The results revealed that freezing results in a significant decrease of the necessary power for cutting due to lowering of the mechanical strengths of wood. The explanation given was the transformation of liquid water into ice inside the cell lumen develops a certain pressure upon the cell walls; it can be assumed that the generated mechanical energy is capable of breaking some bonds between the bound water molecules and the wooden substance, "squeezing" out a certain amount of water from the cell walls and re-locating it into the cell lumen; due to this compressive stress exerted by the expansion of liquid water into the lumen, it is most likely that certain micro-fissures occur within the cell wall structure, thus diminishing the mechanical properties of wood. Other interesting fact from this paper was about the benefits of freezing for drying lumber. Freezing is a successful pre-treatment method for the drying of both hardwoods and softwoods from temperate and tropical regions, with a view to reducing shrinkage, collapse and warp, simultaneously with decreasing the drying time. Repeated cycles of freezing followed-up by thawing makes it possible to remove free water from wood with minimum energy supply.

The author of above paper mentions that the different results obtained in their study compared to the previous studies might be due to the different cutting conditions, especially the much smaller cutting height and the use of different tool. To this end, an important element noticed and emphasized by all previous authors refers to the high quantity of sawdust generated during the cutting of frozen logs, which gets stuck on the lateral kerf walls thus increasing the friction forces between the blade and the kerf walls. As a consequence, the active power consumption increases. On the other hand, the present research was performed with circular blades, and more important, at much lower cutting height, so that the chip and sawdust 
evacuation was easily achieved and constituted no significant influence factor upon the active power consumption.

Payam conducted research to investigate the effect of wood moisture content (MC) and cutting directions on the cutting forces in bandsaw processing of oak and beech wood (Payam 2013). Cutting forces in bandsaw processing of oak and beech wood were measured at two levels (about $12 \%$ and Fiber saturation point, $\mathrm{MC}=30 \%$ ) of wood moisture content for four cutting directions $\left(90^{\circ}-90^{\circ}, 90^{\circ}-0^{\circ}, 0^{\circ}-90^{\circ}\right.$ and $\left.90^{\circ}-45^{\circ}\right)($ Figure 2.1).

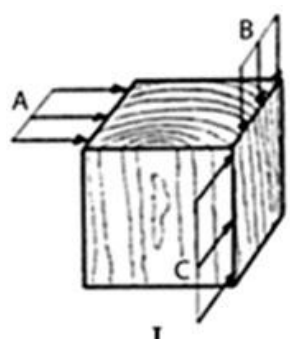

I

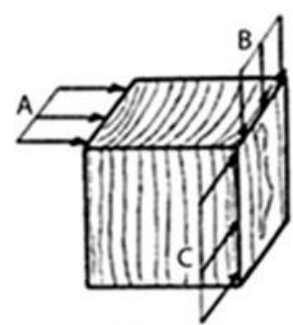

II

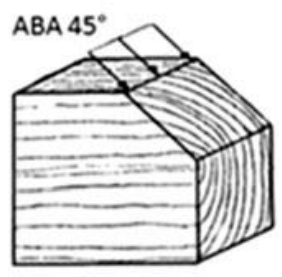

Mode $\mathrm{A}=$ cutting direction $90^{\circ}-90^{\circ}$, mode $\mathrm{B}=$ cutting direction $90^{\circ}-0^{\circ}$, mode $\mathrm{C}=$ cutting direction $0^{\circ}-90^{\circ}$, mode $\mathrm{ABA} 45^{\circ}=$ cutting direction $90^{\circ}-45^{\circ}$.

\section{Figure 2.1: Definition of Cutting Directions (Kivimaa 1950)}

A constant cutting speed of $40 \mathrm{~m} / \mathrm{s}$ and a feed rate of $20 \mathrm{~m} / \mathrm{min}$ were applied. A piezoelectric dynamometer (KISTLER type 9257A) mounted on the carriage of the vertical bandsaw machine (ESTERER model EB 1400) was used to measure the parallel (main), normal and lateral cutting forces (Figure 2.2).
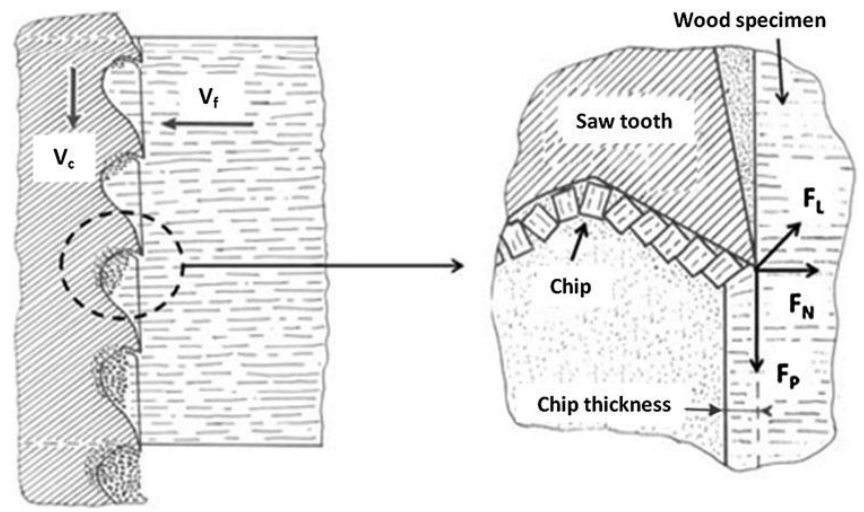

$\mathrm{V}_{\mathrm{c}}=$ Cutting speed, $\mathrm{V}_{\mathrm{f}}=$ Feed rate, $\mathrm{F}_{\mathrm{P}}=$ Parallel Force, $\mathrm{F}_{\mathrm{N}}=$ Normal Force, $\mathrm{F}_{\mathrm{L}}=$ Lateral Force Figure 2.2: Cutting Force Components for Wood Band Sawing (Dalois 1990) 
Overall, the cutting forces were found to be moisture and cutting direction dependent. All cutting forces decreased by increasing the wood moisture content from about $12 \%$ to Fiber Saturation Point (FSP). The greatest parallel force was observed for oak wood at $12 \% \mathrm{MC}$ for $90^{\circ}-90^{\circ}$ cutting direction $(44 \mathrm{~N} / \mathrm{mm})$ whereas the lowest one was for beech wood at $30 \% \mathrm{MC}$ for $0^{\circ}-90^{\circ}$ cutting direction $(20 \mathrm{~N} / \mathrm{mm})$. In contrast to the little change of lateral force at various cutting directions, the change in parallel force was significant. For both wood species, the normal force was less for green wood compared to dry wood except in $0^{\circ}-90^{\circ}$ cutting direction. Sawing dry wood needs more cutting force than green wood since the dried wood fiber will be hard compared to moist wood fiber. Also, addition or removal of water below the FSP has a pronounced effect on practically all wood properties but addition or removal of water above the FSP has no effect on any wood properties (Matan 2003). Moisture content of the wood sawn in the sawmills will be above FSP.

In Canada, as well as in any northern country producing paper and lumber, debarking of wood logs during the winter months is a source of concern. The colder the logs, the greater the debarking problems are due to stronger bark cohesion and higher wood adhesion. This leads to log volume losses, left-out bark on logs after debarking, and bark content in wood chips. This in turn results in accelerated wear of tool tips, increase in loss of wood chips and reduction in yield of lumber. More importantly, high bark particle content in the chips may lead to rejection of the chips by the pulp mill. It is, therefore, beneficial to raise the temperature of the log prior to debarking. In the past, sawmills used to thaw logs by soaking them in water of $8^{\circ} \mathrm{C}$ temperature for 20 minutes, but most have stopped this practice due to new environmental regulations that increase water treatment costs. The goal of the project described in this paper (Normand 2009) was to demonstrate, on a semi-industrial prototype, the applicability of using infrared radiation to 
preheat black spruce logs. The main objectives were to evaluate specific energy consumption and the profitability of the technology. Heating logs before debarking to reach cambium temperature of $-10^{\circ} \mathrm{C}$ to $-5^{\circ} \mathrm{C}$ in the winter could generate an estimated savings of up to half a million Canadian dollars for a sawmill processing half a million cubic meters of wood annually. If all of the economic considerations of bark content in woodchips for the pulp and papermill are considered, the return on investment of an infrared system to preheat frozen logs is believed to be less than one year.

In wood machining, there are three different approaches used to model the main cutting force (Cristóvão 2013). The first approach is based on specific cutting resistance, second approach is based on modern fracture mechanics and third one is based on predictive models using multivariate methods such as multiple linear regression and partial least squares regression. Here, cutting force prediction based on multivariate methods are discussed since the current research is also related to developing of a multivariate estimation model.

Knowledge of the effect of wood cutting parameters on power consumption could increase energy efficiency, reduce operating costs and increase profitability. Measuring power consumption also provides information about other variables, such as tool edge wear, occurrence of catastrophic failures, and other parameters that affect the quality of the sawn boards. In this work, (Cristóvão 2013) power consumption during sawing of Scots Pine using a double arbor circular saw was investigated. The tests were performed in the second saw for resawing (resaw). Both climb-sawing and counter-sawing were considered. Climb-sawing is sawing in the direction of the feed and counter-sawing is sawing in the direction opposite to feeding. The experiments were carried out under normal production conditions in two Swedish sawmills. Theoretical and actual power consumptions were compared. The relationship between cutting parameters and 
theoretical power consumption was developed according to the general laws $($ Power $=$ force $\mathrm{x}$ velocity) with an additional term describing the energy needed for the chip acceleration as described by Koch (1964) and Orlowski et al. (2013).

$$
P_{i}=F_{p i} * v_{i}+\frac{H * k * S * d * v_{i}^{2}}{2}
$$

Where,

$$
\begin{array}{lll}
\mathrm{F}_{\mathrm{pi}} & = & \text { main cutting force }(\mathrm{N}) \\
\mathrm{V}_{\mathrm{i}} & = & \text { is the cutting speed }(\mathrm{m} / \mathrm{s}) \\
\mathrm{H} & = & \text { depth of the cut }(\mathrm{mm}) \\
\mathrm{k} & = & \text { saw kerf width }(\mathrm{mm}) \\
\mathrm{S} & = & \text { feed speed }(\mathrm{m} / \mathrm{min}) \\
\mathrm{d} & = & \text { wood density }(\mathrm{kg} / \mathrm{m} 3) \\
\mathrm{v}_{\mathrm{i}} & = & \text { is the cutting speed }(\mathrm{m} / \mathrm{s})
\end{array}
$$

$\mathrm{F}_{\mathrm{pi}}$ was investigated using the model proposed by Axelsson et al. (1993) as shown below.

$$
F_{p i}=-7.37+\delta_{m} *(0.38 * d 8-224.5 * \alpha)+15.61 * K H-2.6 * K H^{3}+1.31 * r+0.2 * v_{i}+U *(0.3 * K H-0.01 * T)
$$

Where,

$$
\begin{array}{rll}
\delta_{m} & = & \text { average chip thickness }(\mathrm{mm}) \\
\mathrm{d} 8 & = & \text { average density at } 8 \% \text { of moisture content }(\mathrm{kg} / \mathrm{m} 3), \\
\alpha & = & \text { rake angle }(\text { radian }) \\
\mathrm{KH} & = & \text { angle between the cutting speed vector and the wood grain (radian) } \\
\mathrm{r} & = & \text { edge radius }(\mu \mathrm{m}) \\
\mathrm{v}_{\mathrm{i}} & = & \text { is the cutting speed }(\mathrm{m} / \mathrm{s}) \\
\mathrm{U} & = & \text { moisture content }(\%) \\
\mathrm{T} & = & \text { temperature }\left({ }^{\circ} \mathrm{C}\right)
\end{array}
$$

The experimental power consumption increased by 11 to $35 \%$ during an 8 -hour shift, mainly due to an increase in the tooth radius of the cutter. Based on experience, the tooth edge radius was estimated to be $5 \mu \mathrm{m}$ at the beginning and $50 \mu \mathrm{m}$ at the end of the test. The predicted model showed lower power consumption than the experimental. The differences between the predicted and experimental results might be due to the presence of wiper slots on circular saws, back sawing, motor efficiency, and other losses between the interaction of the cutting tool and work piece, which were not considered in the theoretical model. Additionally, 
this study showed that climb-sawing consumed more power than counter-sawing. The difference between climb-sawing and counter-sawing was more pronounced in sawmill B. Surprisingly, the theoretical and experimental power consumption data converged with an increase of cutting tool edge radius. The power consumption was higher in sawmill B than in sawmill A due to a high saw kerf width, cant height, high mismatch, and low overlap between saw blades (Figure 2.3).

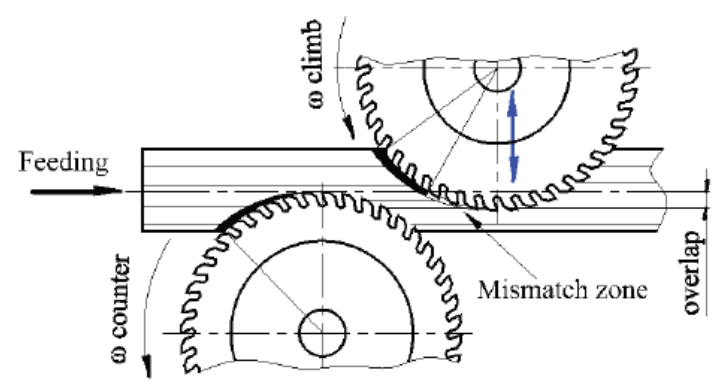

(a) (Cristóvão 2013)

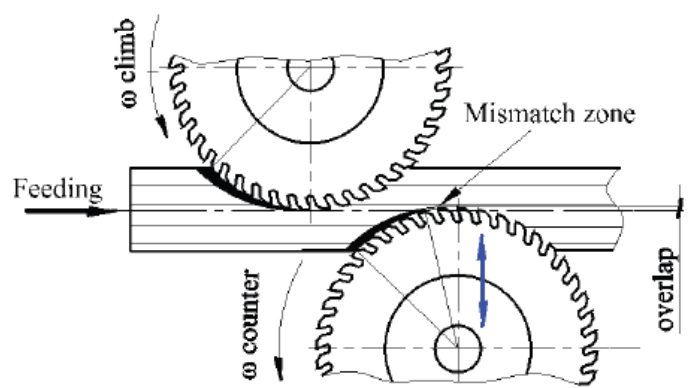

(b) (Cristóvão 2013)

Figure 2.3: Mismatch Zone and Overlap between Saw Blades: (a) Sawmill A, (b) Sawmill B

Determination of cutting parameters is required to optimize cutting processes, machines and tools in the cutting operations. This determination would enable the forestry and wood sector to achieve higher productivity and efficiency. Samples of a lesser-known wood species 'ntholo' and a well-known wood species 'ironwood' were machined in a test apparatus (Cristovao 2012). The wood species selected were hard to cut. A standard single saw tooth mounted on a piezoelectric load cell was used to evaluate the main cutting force. Three levels of chip thickness, rake angle, edge radius, moisture content, and cutting directions were used for the experiment. The experimental set-up used response surface methodology for developing predictive models. The experiment clearly determined the relationship $\left(\mathrm{R}^{2}=0.89\right)$ between the main (parallel) cutting force and edge radius, wood density, rake angle, chip thickness, moisture content and cutting direction as shown.

$$
\begin{aligned}
& F_{\text {PNtholo }}=1.94-0.04 * \alpha+0.21 * r+0.24 * D+0.66 * t+0.09 * M C-0.35 * C D \mathrm{Nmm}^{-1} \\
& F_{\text {PIron wood }}=2.23-0.1 * \alpha+0.21 * r+0.07 * D+0.77 * t-0.09 * M C-0.39 * C D \mathrm{Nmm}^{-1}
\end{aligned}
$$


Where,

$\begin{array}{lll}\alpha & = & \text { rake angle, degrees } \\ \mathrm{r} & = & \text { edge radius, } \mu \mathrm{m} \\ \mathrm{D} & = & \text { wood density, } \mathrm{kg} / \mathrm{m}^{3} \\ \mathrm{t} & = & \text { chip thickness, } \mathrm{mm} \\ \mathrm{MC} & = & \text { moisture content, } \% \\ \mathrm{CD} & = & \text { cutting direction, radian }\end{array}$

Among the studied variables, chip thickness, edge radius and cutting direction had the highest effect on the main cutting force level while wood density, moisture content and rake angle had the lowest effect. The conclusion was wood density alone is not a good estimator of main cutting force for the tested wood species, lower rake angle generates higher main cutting force for both species, main cutting force increases when the edge radius increases and when processing hard-to-cut woods it is necessary to use small chip thickness and use sharp edge radius to achieve low cutting force.

\subsection{Energy Profiling, Data Logging and Energy Measurement Activities in Other Industries}

Pawlik et al. in their article, 'Analyzing Facility Energy Use: A Balancing Act' discuss that while doing energy audit, it is important to know the energy usage of the main equipment in a particular facility. To focus on the equipment with most energy consumption, he says it is also important to know the proportion of the energy usage of particular equipment in a facility to the total energy consumption of that facility. He further says, developing energy profiles of all the equipment in a facility requires extensive data collection over a period of time which in not practical in all the cases and hence he provides a different approach to determine the energy usage of any equipment by using a system energy balance (Pawlik, et.al 2001).

Carole et al. in their article on 'Energy efficiency and use in the chemical industry' says chemical industry is very energy intensive and in some processes, energy for heat, power, and 
feedstocks can account for up to $85 \%$ of production costs and hence says energy efficiency is an important issue in chemical industry (Carole et.al 2001). The paper presents a summary of the energy profile in chemical industry and also refers to a study performed by the Office of Industrial Technologies (OIT) examining the energy and environmental profiling of the chemical industry. Six most energy-intensive chemical product chains, which account for more than 50 percent of the total chemical industry's process energy, are considered in the analysis. The article provides data on process flows, feedstock, energy usage for different processes, air emissions and hazardous waste streams. The article also provides a comparison of the theoretical minimum energy usage with the actual energy consumption based on previous studies. The article also discusses about utilizing DOE BestPractice Software tools like MotorMaster+, Pump System Assessment Tool, Adjustable Speed Drive Master, Steam System Scoping Tool, AirMaster+ and 3Eplus.

Ramırez has developed a methodology to measure the energy efficiency in the Dutch food industry (Ramírez, C., 2006). The method involves a comparison between the actual energy usage for the annual production based on the energy bills and a baseline energy level. Author defines baseline energy as the energy usage when no energy efficiency improvements are made. Energy consumption per unit of product is calculated to make better comparison of energy efficiency. Author also mentions that energy policies are developed based on modeling incorporating the real-time indicators, such as the specific energy consumption. He concludes that energy efficiency indicators should be used to determine the trend of energy efficiency and says they should be based on the physical output.

Mozzo discusses about the importance of correctly setting the baseline for the energy projects in performance contracting business (Mozzo 2000). Performance contracting involves 
conducting energy audits and finding opportunities to save energy in a facility and also verifying the savings that will be generated from the implementation of those opportunities. The energy cost savings from the implementation of an opportunity serves as a source of funding for the suggested improvements. Hence, it is very important to set the existing energy usage level accurately for the particular system under study. After implementation the new energy consumption is measured and will be expected to be lower than the original consumption. The difference in these two levels of energy usage will be the energy savings and will depend on how accurate the baseline is set. Further, the author presents four types of methodologies to set a baseline: stipulation, standardization, manufacturer specifications, and actual measurements. Each of the methods has its own advantages and disadvantages. Author concludes saying setting a baseline from actual measurements requires extensive and accurate data collection with the help of reliable data monitoring equipment such as data loggers.

\subsection{Developing Energy Profiles through Data Logging in Sawmills}

There has been very little empirical work completed on the impacts of motor size, product characteristics and equipment configuration on production economics in hardwood sawmills.

A study (Li 2006) called 'energy demand in wood processing plants' was done in a sawmill in New Zealand. Energy consumption and production data were collected for a period of one year. Three electrical meters were used to record the energy consumption for every 30 minutes. Log dimensions and timber volume details were collected from the sawmill on a daily basis. From the results of this study, it was observed that the lumber production increased as the smaller thickness lumber processed was increased since drying thinner lumber boards was faster in the kiln. An empirical model of energy demand was developed based on data collected from 
one commercial operation. With lumber production and board thickness as input parameters, the model predicted that unit thermal energy demand to produce dried lumber is constant at 422 $\mathrm{kWh} / \mathrm{m}^{3}$ regardless of lumber thickness. The unit electricity demand varied with the lumber thickness, increasing from $26 \mathrm{kWh} / \mathrm{m} 3$ for producing $20 \mathrm{~mm}$ lumber to $41 \mathrm{kWh} / \mathrm{m}^{3}$ for producing $50 \mathrm{~mm}$ lumber. The corresponding lumber production decreased from 357 to 202 tons/day. The ratio of electricity to thermal energy increased from 0.062 to 0.098 since the electricity consumption was not going down at the same ratio as the heat consumption. With $50 \%$ of the logs converted to dry timber, wood residues generated in the sawmill was more than enough to meet the energy demand in the forms of both heat and electricity.

Adams discusses about the usefulness of data logging equipment like power meters, to measure the power consumed by different equipment at sawmills (Adams 1982) and says, that research conducted with the help of wattmeter measurements can answer important questions like:

- Can the use of one type of equipment over another type of equipment reduce the energy consumption?

- What should be the typical energy usage of a mill designed for a specific operation?

- Will savings from the installation of capacitor banks for improving the power factor justify their implementation costs?

- What will be the difference in energy consumption for using a thin kerf saw versus a standard kerf saw in sawing logs?

Adams observed that wattmeter can be used to monitor most of the sawmill equipment that used three-wire and three-phase circuits. Adams states that power monitoring studies had no importance in the past due to low energy costs, but increase in energy costs has now made such 
studies inevitable and beneficial to energy users and concludes saying that knowing the energy usage for the different equipment used in sawmills will provide a better picture of the overall energy costs.

Poole in his article discusses about developing energy-load profiles for sawmills in the Amazon region (Poole and Pinheiro 2003). Author says development of equipment-load profiles can help to estimate the power and energy requirements of sawmills in the region, and hence can be used to identify any opportunities for onsite power generation using wood waste. The authors also felt that developing load profiles can help to identify a baseline for energy use by sawmills. Two sawmills were selected for their first visit. The instrumentation used was electrical sensors, data loggers, amperage meters, and necessary software. Five data loggers for measuring the AC current were used on major equipment motors with time interval set at 3 seconds for monitoring data. Amperage meters were used as a backup and also to validate measurement accuracy of loggers. Load profiles were generated for saws, chippers, and planers. The main findings were that sawing hardwoods influenced peak demand more than softwoods. The authors also thought that most of the electrical motors being used were inefficient and could be replaced with new energy efficient motors. The authors felt that there was an opportunity to use 'disconnect controls' on idling motors to reduce their energy consumption.

Garner discusses about the energy profiling and energy conservation for pulp, paper, and wood products industry in his article (Garner 2002). The article differentiates the pulp and paper industry from the wood products industry in terms of specific energy consumption. SEC for thermal processes, such as boilers and kilns used in sawmill is provided in the paper. Garner discusses about responsibility of the energy managers for energy conservation programs in some large facilities in the past. Garner believes that with proper instrumentation and control and 
energy monitoring, conservation practices are possible. In the end, the article lists tools like energy auditing, energy measurement and monitoring, and development of an energy balance for the system for achieving effective energy conservation and management.

Gopalakrishnan et al. in their article on energy efficiency measures in the wood manufacturing industry present an energy utilization profile for nine wood facilities (Gopalakrishnan 2005). The SEC of nine wood facilities was calculated by dividing the total $\mathrm{kWh}$ consumed by total board feet of lumber produced. Two of the facilities had kiln operation in addition to sawmill operation. The SEC of facilities that had only sawmills varied over a broad range of 93 to $404 \mathrm{kWh} / \mathrm{MBF}$ and in-depth analysis was not made to compare the SEC's of different sawmills. The possibility of the actual implementation of six prominent energy efficiency measures was discussed. The article also provides an electricity bill analysis for the nine facilities visited. Gopalakrishnan et al. discusses about the importance of the development and implementation of the EEMs to help reduce the energy costs in the wood industry.

Mardikar developed a model called "Baseline Electrical Energy Consumption in Wood Processing Sawmills". His work mainly involved calculating theoretical energy consumption for different sawmill equipment and calculating savings achievable for the motors of those equipment from implementation of standard motor 'energy conservation measures' (ECM's). Also the actual amperage consumption data for few hours (less than a day) was collected for these equipment from different sawmills and the actual energy consumption was calculated. Base line energy consumption was developed by subtracting savings achievable from ECM's from actual energy consumption for each equipment. Theoretical, baseline and actual energy consumptions were compared. Theoretical consumption was too low compared to actual 
consumption. Also, the actual consumption was calculated for only 3 species namely, red oak, white oak and maple and was not calculated for individual lumber sizes sawn. (Mardikar 2007).

Most of the work mentioned above provides gross estimates of energy use in hardwood sawmills and recommendations to save energy for a particular energy system. The prediction models developed were mainly for predicting the cutting forces for sawing under various cutting conditions and they don't deal with the energy consumption of a sawmill as a whole. There are no comparisons done between sawmills to find out which sawmill is more efficient and what are the reasons for that particular sawmill to be more efficient than other sawmills. No one has tried to find out the energy efficiency of a sawmill by looking at individual motor configuration, process and product characteristics and their relationships to energy usage. Hence, a through research is needed to find out the efficiency of the sawmill based on motor, process and product characteristics and finding ways to improve it.

\section{Conclusion}

Studies mentioned above have not dealt in detail to develop specific energy consumption profiles for each species and sizes sawn and also looked at sawmill from view point of productivity and hence, a thorough research is needed to address these things. This research will help the industry for bench marking and also the model that can estimate the energy consumption based on product, process and system parameters will greatly help the sawmill industry to known its level of performance and the opportunities to improve. Studying sawmill from productivity view point will identify opportunities to improve in terms of both productivity and energy efficiency. SMEEP that can estimate the energy consumption, compare it with the best achievable energy consumption and come up with methods to save energy and improve productivity with estimated savings can greatly help sawmill industry. 


\section{Data Collection}

\subsection{Need for Data Collection}

As seen in the literature review, research done so far has used the total energy consumption directly from the energy bills to calculate specific energy consumption. Total energy bills will have energy consumption of sawmill motors along with energy consumption of other things like HVAC, lighting, kiln motors if they have kilns and any other equipment that is not directly used for sawing logs. Hence, using energy bills is not an accurate way to calculate SEC. Also, energy bills give energy consumption for entire month and this consumption cannot be used to calculate SEC of individual species and sizes that will be sawn in different production shifts throughout the month.

Hence electrical energy consumption data of major equipment that are used for sawing logs along with the production data must be collected during the production of a particular species of lumber to find out the SEC of that particular species more accurately. Once the data is collected, further processing can be done to calculate SEC for particular sizes sawn and then to find out the best achievable SEC. Data collection of species sawn, sawing time, quantity of lumber sawn of different sizes, horse power of motors used for sawing and electrical energy consumption is required to develop the model that can estimate energy consumption of sawing process. This model can be used to estimate energy consumption of a new sawmill.

Three sawmills with single sawing line and two sawmills with double sawing lines were selected in state of West Virginia to do data collection. Three medium sized sawmills (weekly production between 40 to $200 \mathrm{MBF}$, Lin et al. 2012) and two large sized sawmills (weekly production > $200 \mathrm{MBF}$ ) were selected to get a good mix of different production sizes. 


\subsection{Data Collection Plan}

Visits to five sawmill facilities with varying production capacities were made on two days. First day activity in each sawmill began with discussions with the plant manager about the facilities manufacturing process and energy usage. After listing the types of products being made at the facility, a brief outline of the manufacturing process was developed. Information was gathered about the types of wood species processed at the facility. Further discussions focused upon the major energy consuming equipment used at the facility. Data collection questionnaire prepared prior to the visits was given to the plant manager to collect production data. The plant manager then gave a detailed tour of the facility. A detailed equipment list was generated and necessary digital images and videos of the process were taken. Major energy consuming equipment was then short-listed based on its rated capacity. The second half of the day was used for data collection activities using an advanced electrical data collection device and installing data loggers on major energy consuming equipment. One month after deploying the loggers, one more visit was made to each sawmill to collect the data loggers. Data collected from the loggers was downloaded and the production data was obtained and discussed with the plant manager.

\subsection{Electrical Data Collection}

Electric panels in each sawmills were accessed with the help of plant electrician to monitor electrical energy consumption. During the original visit to each mill, Energy, Current, Voltage and Power factor data were collected using an advanced electrical data collection device (AMPROBE) for approximately 20 minutes on each motor. This was done to measure the power factor for each of the motors and to have baseline data so that the results could be compared with those from the continuous monitoring equipment. Power factor measures the ratio of real power to the apparent power and is critical for calculating power consumption of the induction motor. 


\section{Data Sample Size}

Before staring the discussion on how to use the data loggers for electrical data collection, it is important to know how many motors should be logged and the duration of data collection for a particular motor.

\section{Number of Motors to be Logged}

Any sawmill facility has the basic set of main equipment that uses electrical motors, such as the debarker, head saw, re-saw, edger, trimmer, and chipper. In addition to these motors, there will be equipment for material handling and compressed air production. The electrical motors on the main equipment in the sawmill facilities contribute to approximately 70 to 80 percent of the total electrical energy usage. The remaining 20 to 30 percent energy is used by the additional equipment in the process and by the HVAC and lighting. Therefore, collecting electrical data on the main equipment is necessary to know the sawing energy consumption.

\section{Duration of Data Logging}

Data loggers were used to collect amperage data of motors in each sawmill for duration of one month. Data collection frequency was selected based on the storage capacity of the data loggers. The maximum storage capacity of data loggers was 43,000 data points and the best frequency of data collection that can be achieved by utilizing the complete storage capacity of the data loggers was one minute since total number of data points that will be collected in 30 days with one minute frequency is 43,200 . Since amperage data was collected for every minute and not every second, there were chances that the logged data did not represent the real amperage consumption of that minute. Motor used for lumber sawing will be either loaded or unloaded depending on whether the saw blade is cutting the wood or not. Usually, a saw blade makes few cuts in a minute and the data loggers may or may not record the cutting amperage and 
hence may not represent the average amperage used during that minute. So, a sample data (Figure 3.1) was collected on the main saw of sawmill 1 for duration of nine hours (data in Appendix Table A.2) to find out how many one minute frequency amperage data points must be collected to estimate the real average. The average of nine hours data was 84.6 amps and is assumed as real average. Also data was collected for every second using another device for 20 minutes and the average of that data was around 82 amps.

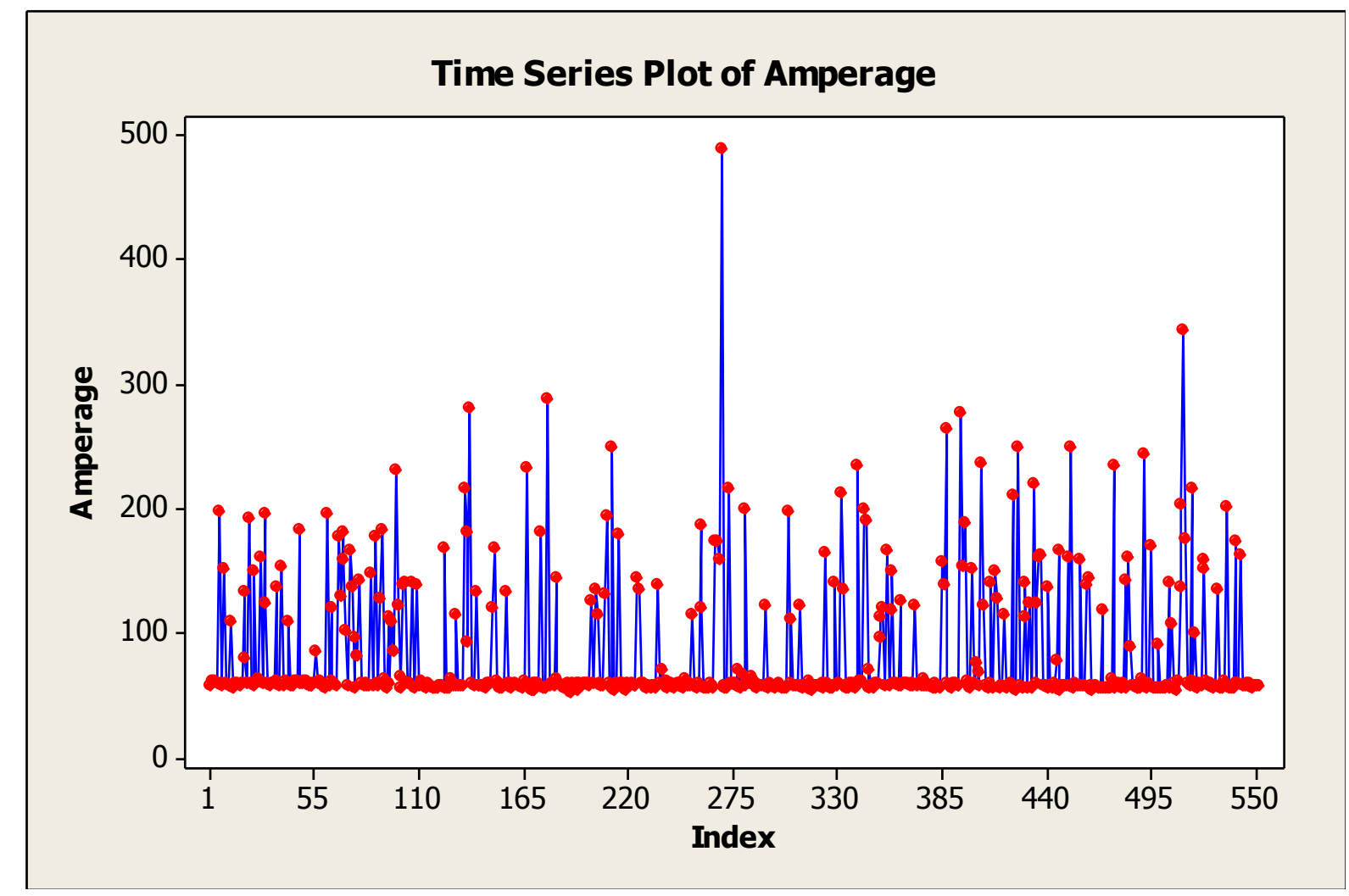

Figure 3.1: Sample Amperage Data of Main Saw collected in Sawmill 1

The frequency plot of the sample data is shown in Figure 3.2 and it didn't follow any particular probability distribution. Most of the values were located near 60 amps or motor unloaded condition and others were spread out between 80 and 240 amps. Since the sample data didn't follow any distribution, no formula was available to calculate number of data points to be collected to estimate the real mean. 


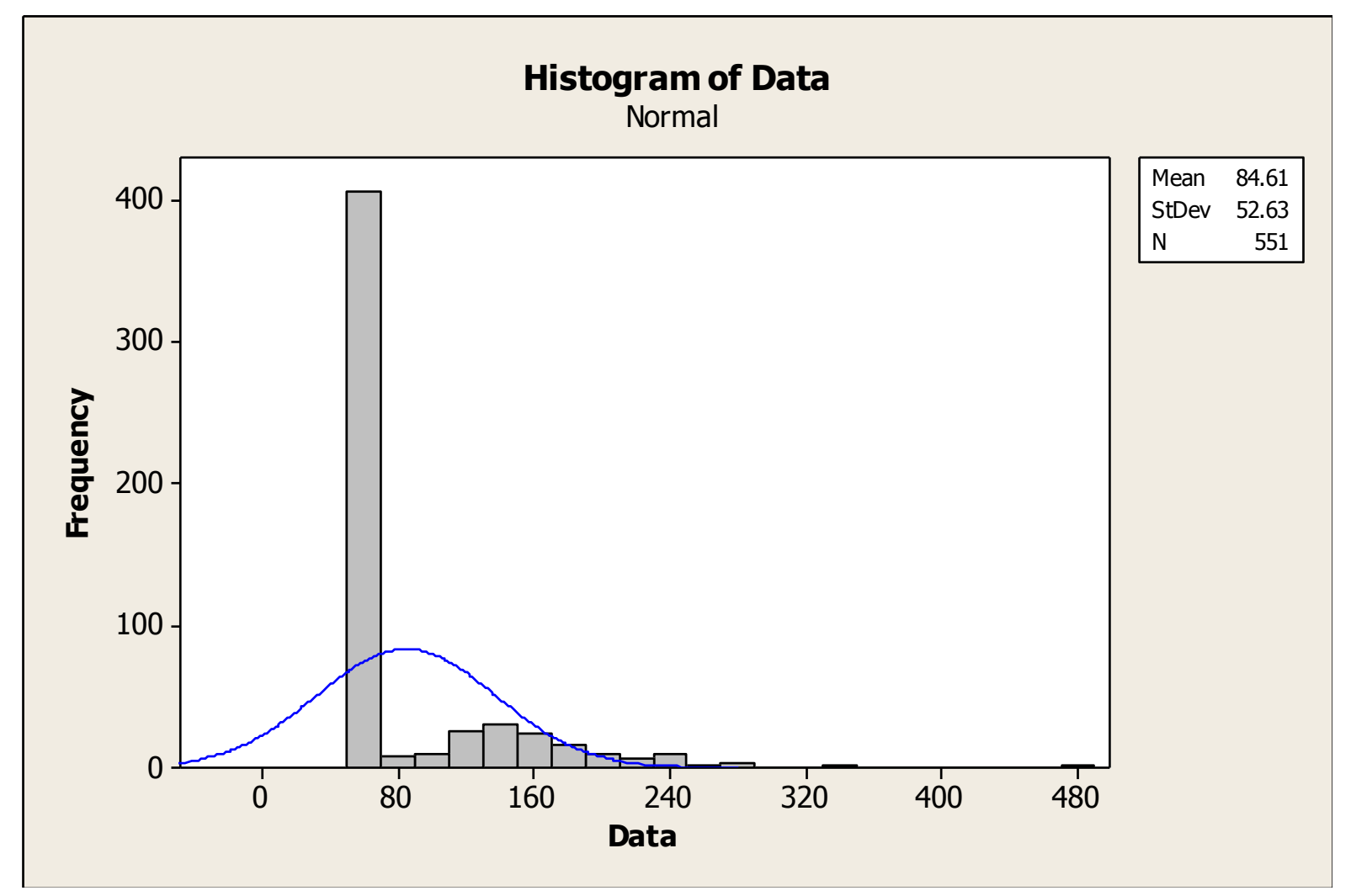

Figure 3.2: Histogram of Sample Amperage Data of Main Saw collected in Sawmill 1

Since there were no formula to calculate the number of data points to be collected to estimate the real mean, sample data was split into groups of 30 data points each and average for each group was calculated. The calculated averages are shown in Table 3.1.

Table 3.1: Calculated Averages of Groups taken from Sample Data

\begin{tabular}{|c|c|c|c|c|c|}
\hline 89.06 & 71.76 & 100.36 & 85.72 & 89.79 & 77.90 \\
\hline 74.57 & 76.63 & 91.25 & 70.79 & 72.07 & 94.98 \\
\hline 75.37 & 94.74 & 96.91 & 84.19 & 82.79 & 100.39 \\
\hline
\end{tabular}

From the sample data, totally 18 groups of 30 data points each was formed. Out of the 18 group averages calculated, 11 averages were outside $\pm 10 \%$ of the average amps range (76.5 93.5). The grand average of these group averages was 84.96 amps. The averages of these 18 groups were tested for normality (Figure 3.3) and they followed a normal distribution as per the 'Central Limit Theorem'. 


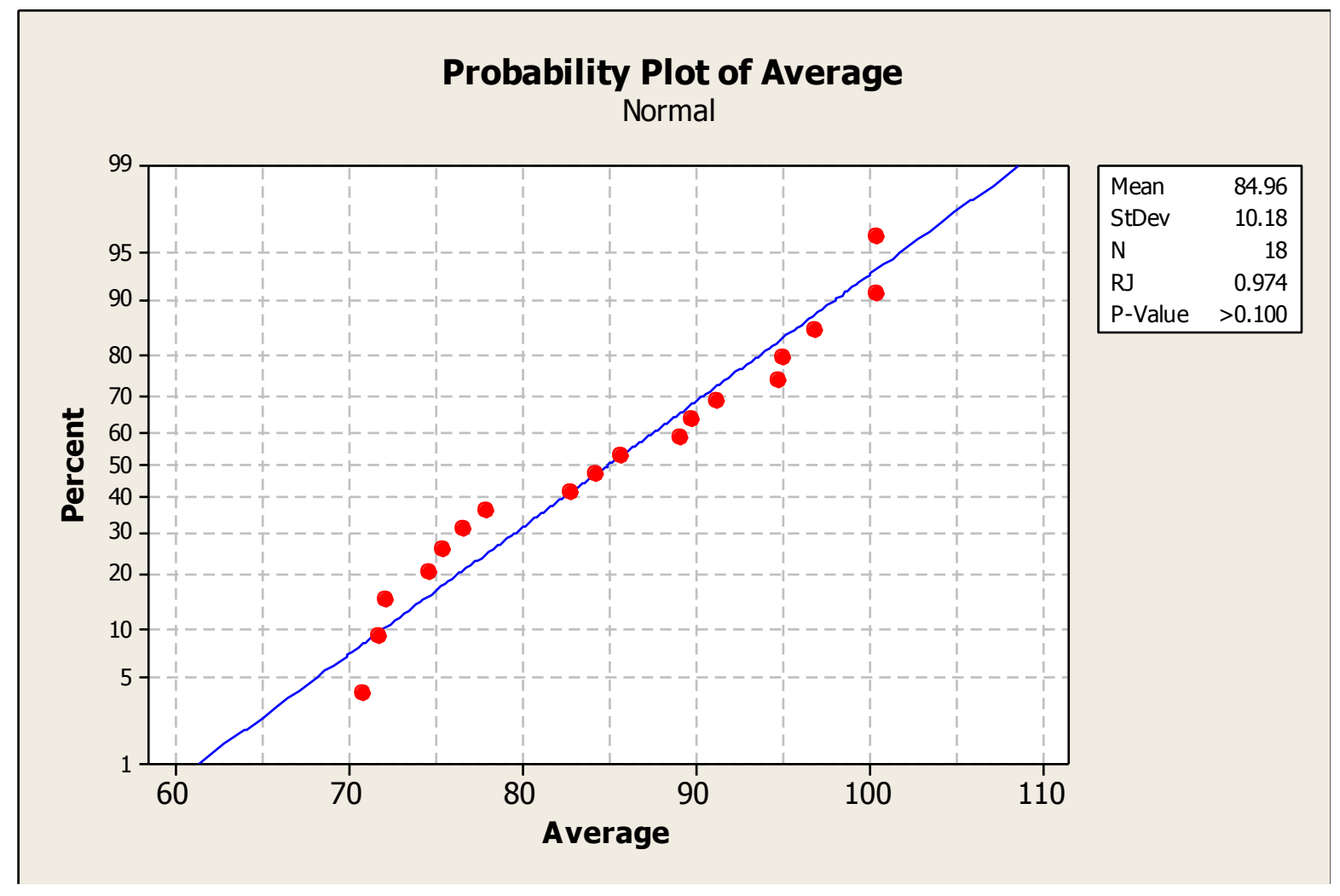

Figure 3.3: Normal Probability Test Results for Group Averages

Since the group averages followed a normal distribution, these averages were used to calculate number of group averages required to estimate the true mean or number of data points (groups $\mathrm{x} 30$ ) required to estimate the true mean.

The following strategy was used to determine the actual number of group averages to be collected to estimate the true mean. Let the sampling outcome include the following:

$\mathrm{N}_{\mathrm{i}}=$ Total number of group averages obtained when the equipment is actually cutting the wood during pilot study

$\mathrm{X}_{\mathrm{i}}=$ Value of each group average amperage when the equipment is cutting the wood during pilot study

$\mathrm{N}_{1}=$ Total number of group averages to be collected for each data set to estimate mean within a particular range from the true mean 
The sample variance $\left(s^{2}\right)$ for the pilot study when the equipment is actually cutting the wood is given by Equation 3.1 (Montgomery 2003 Chapter 6):

$$
s^{2}=\frac{\sum_{i=1}^{N_{1}} X_{i}^{2}-\frac{\left[\sum_{i=1}^{N_{1}} X_{i}\right]^{2}}{N_{i}}}{N_{i}-1}
$$

Knowing the sample variance from the pilot study, the total number of group averages $\mathrm{N}_{1}$ to be collected during the actual data collection can be determined. $\mathrm{N}_{1}$ can be determined by using Equation 3.2 (Montgomery 2003 Chapter 8):

$$
N_{1}=\left[\frac{Z_{\alpha / 2} * s}{e}\right]^{2}
$$

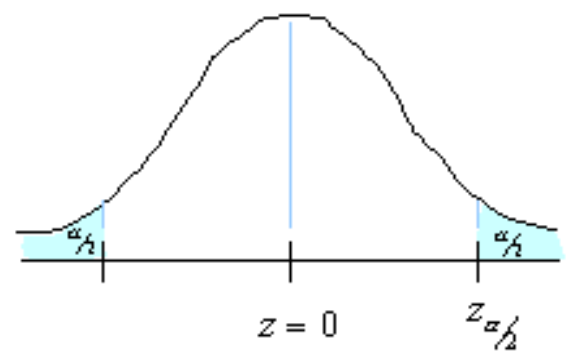

Figure 3.4: Standard Normal Distribution and Critical Area

Where,

$\mathrm{N}_{1}=$ Sample size for the data collection set

$\mathrm{Z}_{\alpha / 2}=$ Critical value, for the area of $\alpha / 2$ in the right tail of the standard normal distribution. (Figure 3.4)

$\mathrm{s}=$ Sample standard deviation from the pilot study, (Amps)

$\mathrm{e}=$ expected margin of error, $(\%$ of sample mean in Amps $)$

For the group averages calculated the sample standard deviation was determined to be 10.18 amps. For a confidence level of 95 percent; i.e. $\alpha=0.05$, and $\alpha / 2=0.025, Z_{\alpha / 2}=1.96$ 
(from standard $\mathrm{Z}$ tables). If the expected margin of error is taken as $\pm 10 \%$ of the true mean amps 84.6 (assuming pilot study mean is an approximate estimator of true mean), then the sample size $\mathrm{N}_{1}$ required for the data collection is given by Equation 3.2 as follows;

$$
\begin{aligned}
& N_{1}=\left[\frac{1.96 * 10.18}{84.6 * 0.1}\right]^{2} \\
& \mathrm{~N}_{1}=5.56 \text { group averages } \\
& \text { Or } \\
& \mathrm{N}_{1}=5.56 \times 30=167 \text { data points }
\end{aligned}
$$

Thus a sample of at least 167 data points or 2.75 hours data (since 60 data points are collected every hour) will be needed for each data set to estimate mean with in $\pm 10 \%$ error with 95 percent confidence level. Each sawmill produces one species or more than one species of lumber every day and each species is treated as a data set. Also, if the same species is sawn for more than one day, each day is considered as a data set since the operating parameters will vary every day. On days when more than one species were sawn on the same day and if the sawing time of any of these species is less than 2.75 hours, then there is a possibility that, the data collected for that species can have higher rate of error than $\pm 10 \%$ and may not represent the true mean. Also, when a sawmill switches from one species to another, there will be mix up of two species and the electrical data collected during that time will not represent either of the species and it may take around 2 hours to completely clear the previous species from the line.

\subsection{Real Time Data Monitoring using Data Loggers}

Data loggers (HOBO) with current transducers (Onset) were used to collect electrical energy consumption data in the sawmills. The loggers were installed on each motor and were set to collect amperage data every minute for one month. Data loggers have different options of setting the time interval between each recording to be made. A data logger can collect maximum 
of 43,000 data points in different frequency intervals. Hence, the duration for which the electrical data on a motor can be collected will depend on the time interval set between two successive readings.

Data Logger: A data logger (Figure 3.5) is an electronic device that records data over time either with a built in instrument or sensor or via external instruments and sensors. Increasingly, but not entirely, they are based on a digital processor (or computer). They generally are small, battery powered, portable, and equipped with a microprocessor, internal memory for data storage, and sensors. Some data loggers interface with a personal computer and utilize software to activate the data logger and view and analyze the collected data, while others have a local interface device (keypad, LCD) and can be used as a stand-alone device. The data logger selected for data collection uses a 12-bit resolution with a memory of $64 \mathrm{k}$ bytes and can record up to 43,000 measurements.

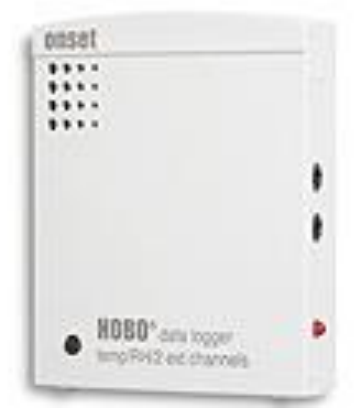

\section{Figure 3.5: Data Logger}

Current Transducer: A current transducer is a device that detects electrical current in a phase (legs) and generates a signal proportional to it. The current transducer used is a split core type as shown in Figure 3.6 and this transducer can measure AC current up to $600 \mathrm{amps}$ for power supplies with voltage less than 600 Volts AC. This current transducer is connected to one of the phases (legs) in the electrical motor's control cabinet to monitor the current consumed by the motor. 


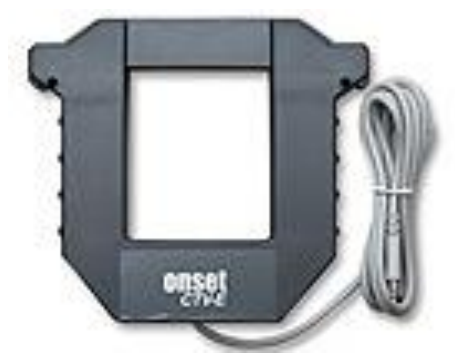

\section{Figure 3.6: Current Transducer}

The data logger is provided with software required to initialize the unit before starting the actual data logging. It is also required when the data logging is complete and data is ready for downloading to a computer. The initialization step is called as device launching and is shown in Figure 3.7. In the software screenshot shown in Figure 3.7, the user can enter equipment information to be monitored, the logger channel to be used for monitoring the data, the type of transducer to be used, the time interval between consecutive data measurements, and the start time or push button option for starting data logging. The set up will show the duration of data collection depending on the specified frequency for data collection. The device can then be used along with the particular transducer for monitoring the data. The recorded data can be downloaded to a personal computer using a USB (universal serial bus) cable. The software provides data in tabular as well as graphical formats as shown in Figure 3.8. It also provides some descriptive statistics on the data. The software can also be used to export the data to a Microsoft Excel ${ }^{\mathrm{TM}}$ spreadsheet for further analysis. The amperage data collected (Figure 3.8) for each motors was split into individual shifts and average amperage was calculated for each shift after removing the machine down time periods during break, lunch or machine break down.

The Advanced Data Collection Device: This is an electrical unit that measures and records current and voltage from 3 phases simultaneously. It can also measure power factor, reactive, real and apparent power. Figure 3.9 shows the device used for measuring power factor, voltage, current, and $\mathrm{kW}$. 


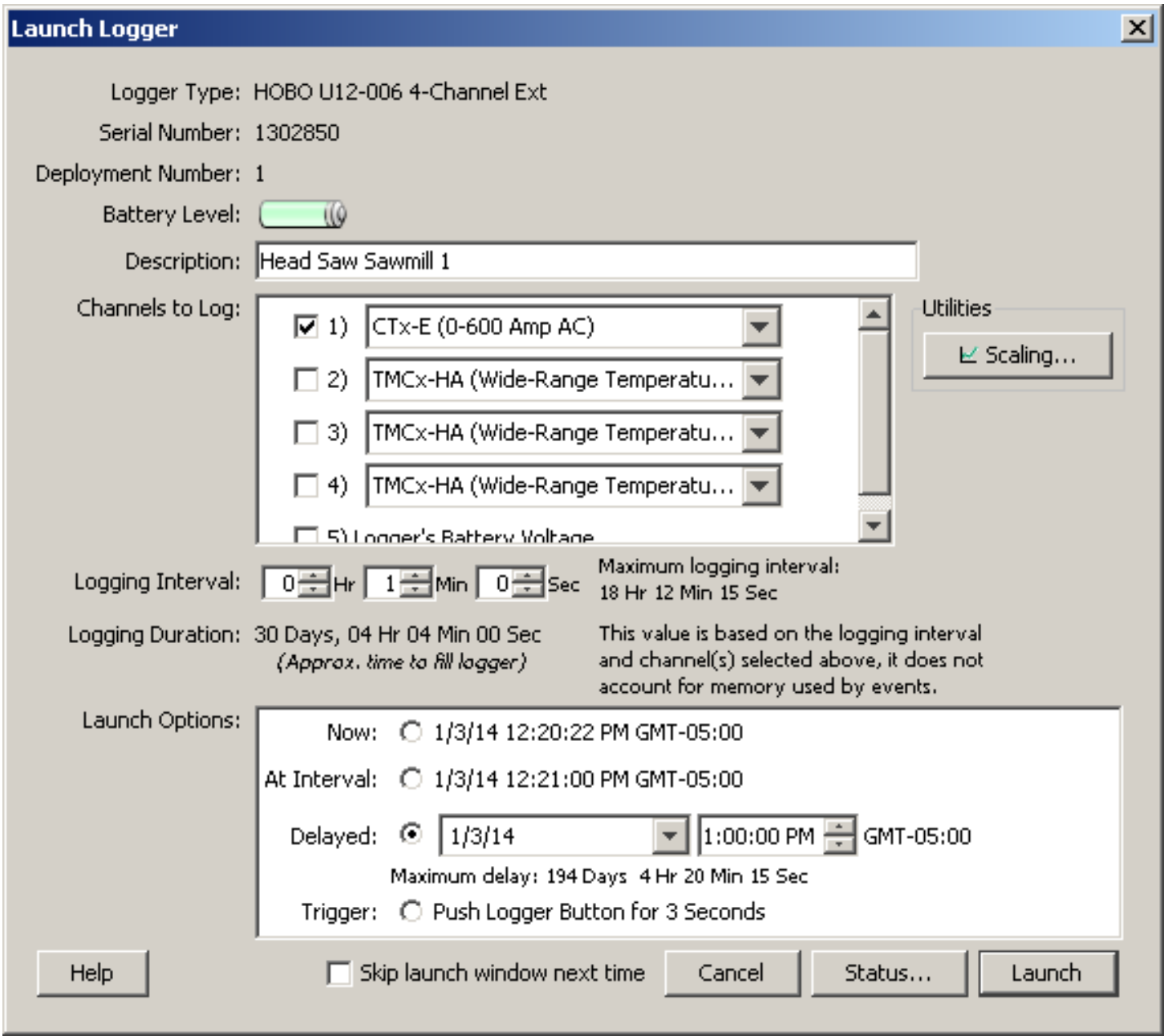

Figure 3.7: Data Logger launching screen for Data Logging (Onset 2013)

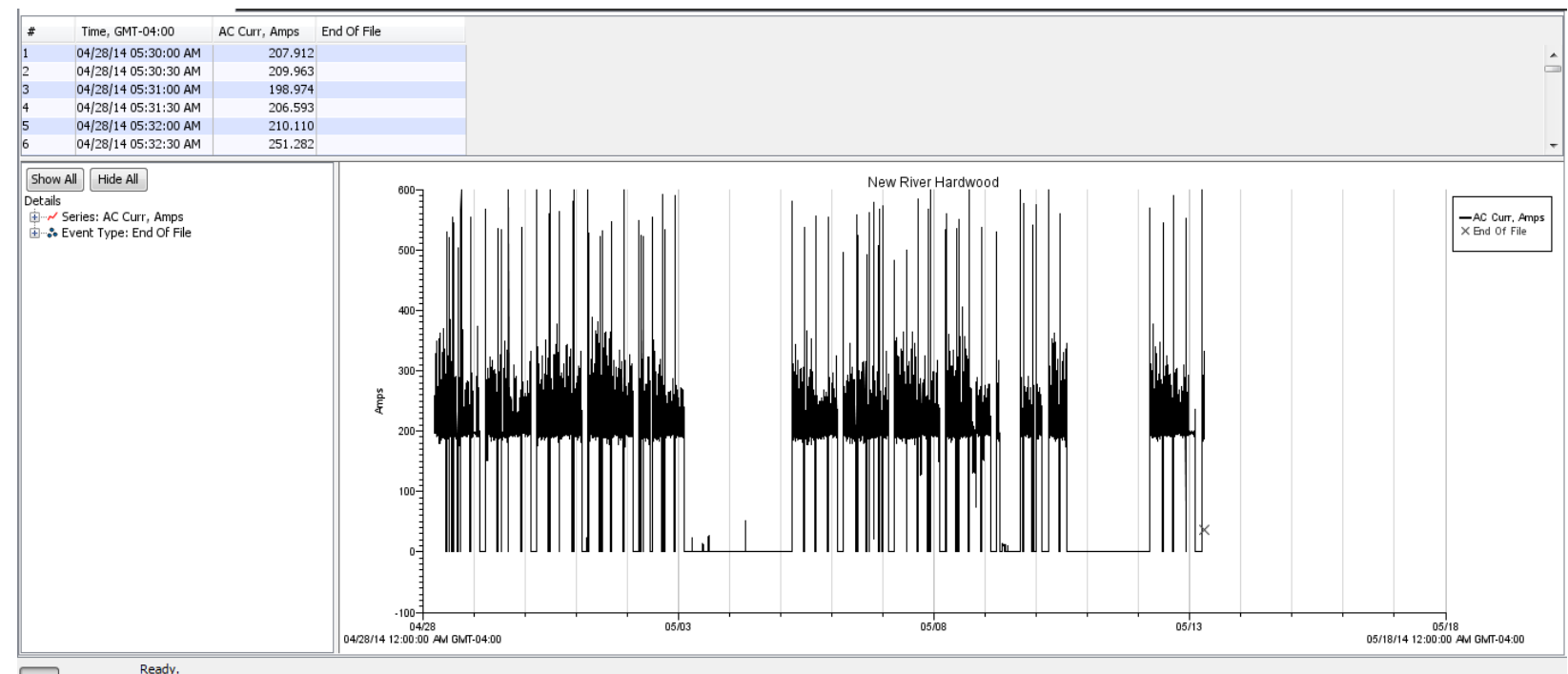

Figure 3.8: Graphical Representation of Amperage Consumption (Onset 2013) 


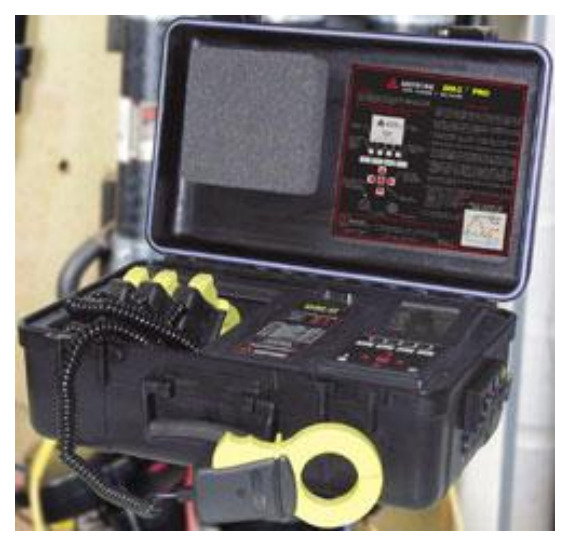

Figure 3.9: Advanced Data Collection Device

Electrical data collection was not easy due to the possibility of electric arching due to the flammable environment of sawmill with sawdust flying everywhere. Hence, lot of safety precautions like wearing electrical safety gloves and shoes was done along with staying away from the terminals while opening control panels and taking electrical measurements. Electrical data monitoring was done during winter months in some sawmills and since sawmills are open facilities, there were lot of chances of data loggers getting moisture condensation and hence, data loggers were kept inside a plastic sealable bag for the duration of data logging. Lot of waiting was done to open some of the control panels since their doors were connected to switches and to open them, the equipment had to be switched off and that was possible only during lunch or break times. Ambient temperature data for different sawmill locations for the data logging period was obtained from website weatherunderground.com and is shown in Appendix (Table A.3).

Of the 5 mills sampled, the sawmill 2 and 4 had a different production flow in that they were lacking a re-saw. In sawmills 1 and 3 the head saw converted logs into cants and then a resaw or a gang-saw was used to saw the cants into lumber. In sawmill 5 there were both resaw and gang saw for sawing the cants coming from the head saw. In sawmill 2 and 4 the head saw performed all of the log breakdown. Sawmill 3 and 4 had two sawing lines. Manufacturing configurations of all the five sawmills are shown in Figure 3.10. 


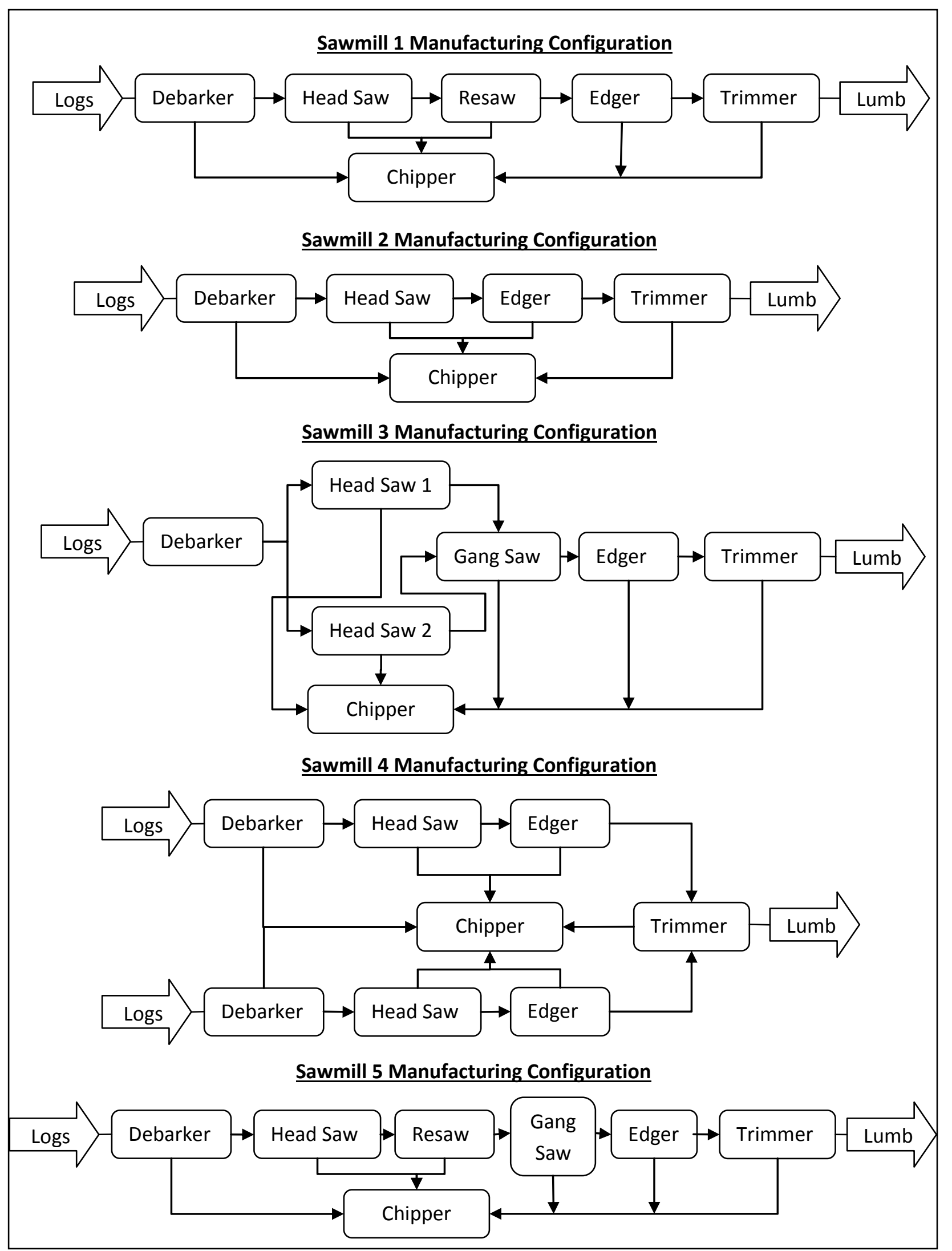

Figure 3.10: Manufacturing Configurations of Sawmill 1 to 5 
Eight main motors were selected for monitoring in all the five sawmills (Table 3.2). These motors were selected for data logging because they were the main energy consumers at each facility. Other motors were also selected based on their sizes. Several other motors were sampled using advanced data collection device (Unlogged motors list in Appendix Table A.26) along with the motors that were selected for monitoring in all the 5 sawmills.

Table 3.2: Characteristics of Major Motors in each Sawmill

\begin{tabular}{|c|l|c|l|c|l|c|}
\hline & \multicolumn{2}{|c}{ Sawmill 1 } & \multicolumn{2}{c|}{ Sawmill 2 } & \multicolumn{2}{c|}{ Sawmill 5 } \\
\hline No. & \multicolumn{1}{|c|}{ Motor Name } & $\begin{array}{c}\text { Motor } \\
\text { Size (hp) }\end{array}$ & \multicolumn{1}{|c|}{ Motor Name } & $\begin{array}{c}\text { Motor } \\
\text { Size (hp) }\end{array}$ & \multicolumn{1}{c|}{ Motor Name } & $\begin{array}{c}\text { Motor } \\
\text { Size (hp) }\end{array}$ \\
\hline 1 & Head saw & 200 & Head Saw & 200 & Head Saw & 150 \\
\hline 2 & Carriage feed motor & 100 & Carriage feed Motor & 150 & Carriage feed motor & 100 \\
\hline 3 & Chipper & 150 & Chipper & 150 & Chipper & 300 \\
\hline 4 & Debarker & 50 & Debarker & 85 & Debarker & 130 \\
\hline 5 & Edger & 50 & Edger & 50 & Edger & 50 \\
\hline 6 & Air compressor & 60 & Air Compressor & 40 & Air Compressor & 300 \\
\hline 7 & Re-saw & 60 & & - & Re-saw & 150 \\
\hline 8 & Trimmer & 10 & Trimmer & 25 & Trimmer & 100 \\
\hline 9 & Dust collector & 15 & Dust Collector & 37 & Gang Saw & 100 \\
\hline 10 & Chip blower & 30 & Chip Blower & 30 & Log Deck & 20 \\
\hline 11 & Log turner & 40 & Conveyor Motor & 15 & Log Turner & 20 \\
\hline 12 & Top saw & 40 & Barn Sweep Motor & 5 & Line Bar Hyd & 10 \\
\hline 13 & Unlogged Motors & 163 & Unlogged Motors & 30 & Unlogged Motors & 256 \\
\hline \multicolumn{2}{|c|}{ Total } & $\mathbf{9 6 8}$ & Total & $\mathbf{8 1 7}$ & & $\mathbf{1 , 6 8 6}$ \\
\hline
\end{tabular}

\begin{tabular}{|c|c|c|c|c|c|c|}
\hline & \multicolumn{3}{|c|}{ Sawmill 3} & \multicolumn{3}{|c|}{ Sawmill 4} \\
\hline No. & Motor Name & $\begin{array}{c}\text { Line } 1 \\
\text { Motor } \\
\text { Size (hp) }\end{array}$ & $\begin{array}{c}\text { Line } 2 \\
\text { Motor } \\
\text { Size (hp) }\end{array}$ & Motor Name & $\begin{array}{c}\text { Line } 1 \\
\text { Motor } \\
\text { Size (hp) }\end{array}$ & $\begin{array}{c}\text { Line } 2 \\
\text { Motor } \\
\text { Size (hp) }\end{array}$ \\
\hline 1 & Head saw & 172.5 & 172.5 & Head Saw & 200 & 150 \\
\hline 2 & Carriage feed motor & 150 & 150 & Carriage feed Motor & 150 & 100 \\
\hline 3 & Chipper & 200 & - & Chipper & 200 & - \\
\hline 4 & Debarker & 210 & - & Debarker & 40 & 40 \\
\hline 5 & Edger & 200 & - & Edger & 100 & 75 \\
\hline 6 & Air compressor & 150 & - & Air Compressor & 100 & - \\
\hline 7 & Gang Saw & 418 & - & - & & - \\
\hline 8 & Trimmer & 180 & - & Trimmer & 57.5 & - \\
\hline 9 & Sorter Chain & 50 & - & Log Turner & 20 & - \\
\hline 10 & Hydraulic Pump & 60 & - & Unlogged Motors & 301.5 & - \\
\hline \multirow[t]{2}{*}{11} & Unlogged Motors & 517.5 & - & & & - \\
\hline & Total & \multicolumn{2}{|c|}{$2,630.5$} & Total & \multicolumn{2}{|c|}{$\mathbf{1 , 5 3 4}$} \\
\hline
\end{tabular}


The voltage and power factor data collected using advanced data collection device is shown in Appendix (Table A.21). The subpanel used to supply power to each of the sample motors was located and the data logger and transducer were installed in each panel (Figure 3.11). The current transducer was secured around one of the demand side legs in the motor control panel of each motor and the transducer's output was connected to the data logger. The data logger was set to record current data every minute during the duration of data collection. The transducers and loggers were installed for a period of 30 days at each mill except for sawmill 5.

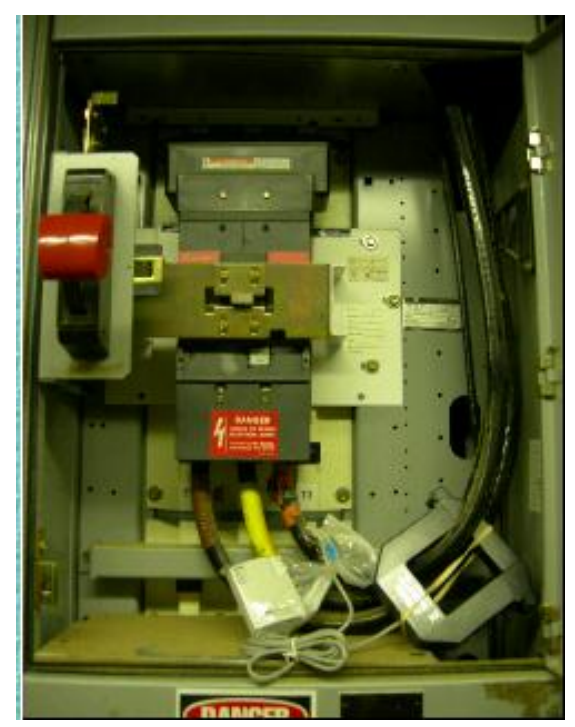

Figure 3.11: Data Logger and Current Transducer Setup

\subsection{Production Data Collection}

Data sheets that were provided to the sawmills and asked them to record production data during the time-period of energy usage sampling is shown in appendix (Table A.1). Each mill provided their production schedule that included species sawn as well as the different size and grade of the lumber produced during data collection. Data were provided at the shift level for each mill, which included new runs each morning as well as when the mill changed to a different species or production line. After the data collection period at each mill, data were downloaded from the loggers and associated production data were recorded. 
A total of 133 separate shifts, where both production data and electrical consumption data corresponded, were collected at the three sawmills with single sawing lines and two sawmills with double sawing lines during the study period. Around 4 million board feet of lumber were sawn during the data logging period in these 5 sawmills. The board-foot is a specialized unit of measure for the volume of lumber in the United States and Canada. It is the volume of a one-foot length of a board with one foot width and one inch thickness. The data sets typically corresponded to a particular species that was sawn during a particular period $(\mathrm{am} / \mathrm{pm})$ and represented multiple hours of data collection. Typically one or two species were sawn during an eight to ten hour work period. A total of 15, 23, 18, 18 and 11 days of production and energy consumption data were collected from sawmill 1, 2, 3, 4 and 5 respectively (Appendix Table A.3, A.4). Sawmill 5 worked 2 shifts during the data collection period and hence only 11 days data was collected from it. Red oak was the most common species sawed during the study period, followed by Yellow Poplar (Table 3.3).

Table 3.3: Data Points for Hardwood Species sawn, Species grouped assigned (HHW: Hard-hardwood SHW: Soft-hardwood) and Total Board Feet sawn.

\begin{tabular}{|l|c|c|c|c|}
\hline \multicolumn{1}{|c|}{ Species } & Species Group & No. Data Points & Board Feet & Percentage \\
\hline White Ash & HHW & 5 & 124,822 & 3.18 \\
\hline Black Birch & SHW & 1 & 43,716 & 1.11 \\
\hline Black Cherry & SHW & 4 & 122,655 & 3.13 \\
\hline Hickory & HHW & 7 & 114,901 & 2.93 \\
\hline Hard Maple & HHW & 18 & 412,634 & 10.52 \\
\hline Red Oak & HHW & 41 & $1,157,489$ & 29.51 \\
\hline Soft Maple & SHW & 16 & 589,886 & 15.04 \\
\hline Sycamore & SHW & 3 & 34,240 & 0.87 \\
\hline White Oak & HHW & 20 & 481,275 & 12.27 \\
\hline Yellow-poplar & SHW & 18 & 840,978 & 21.44 \\
\hline Total & & $\mathbf{1 3 3}$ & $\mathbf{3 , 9 2 2 , 5 9 6}$ & $\mathbf{1 0 0}$ \\
\hline
\end{tabular}

Logs were combined based on their density into hard-hardwoods and soft-hardwoods.

The hard-hardwood group included White Ash, Hickory, Hard Maple, Red Oak, and White Oak. The soft-hardwood group included Black Birch, Black Cherry, Soft Maple, Sycamore and 
Yellow-poplar. A total of 2,296,736 board feet of hard-hardwoods and 1,603,671 board feet of soft-hardwoods were sawn at the five mills during this study.

Each mill sawed various lumber thicknesses during each shift. Lumber thicknesses are specified in quarter of an inch size for board lumber. For example 4/4 lumber thickness means that there are 4 quarter inches in the thickness of that lumber or it is 1 inch thick. Similarly 5/4 inch thick lumber will be 1.25 inch thick and so on. The width of these lumber pieces varied between 3" to 12". Pallet size lumber will be usually 1 inch thick and the width varied between 6 to 8 inches. Cants and timber are bigger lumber sizes and cants will be of sizes 3" thick x 8 " width, 5" thick x 6" width, or 4" thick x 14" width and timber is usually 7" thick x 9" width. The length of these lumber pieces varied between 8 feet to 16 feet. By far, 4/4 lumber was the most common thickness representing 61 percent of the total lumber sawn (Table 3.4). Pallet parts, industrial cants, and railroad ties and timbers were also sawn by each of the mills during the study period. Overall, 75.5 percent of the lumber produced was of $4 / 4,5 / 4,6 / 4$ and $8 / 4$ (board size lumber) size and the remaining 24.5 percent was in pallet, cant and timber sizes.

Table 3.4: Lumber Thickness Characteristics measured in Board Feet at 5 Sawmills

\begin{tabular}{|c|c|c|c|c|c|c|c|c|}
\hline SAWMILL & $\begin{array}{c}\text { Total } \\
\text { Lumber }\end{array}$ & $\begin{array}{c}\text { Four } \\
\text { Quarter }\end{array}$ & $\begin{array}{c}\text { Five } \\
\text { Quarter }\end{array}$ & $\begin{array}{c}\text { Six } \\
\text { Quarter }\end{array}$ & $\begin{array}{c}\text { Eight } \\
\text { Quarter }\end{array}$ & Pallet & Cant & Timber \\
\hline Sawmill 1 & 460,994 & $\begin{array}{c}327,363 \\
(71 \%)\end{array}$ & $\begin{array}{c}23,905 \\
(5 \%)\end{array}$ & $\begin{array}{c}7,618 \\
(2 \%)\end{array}$ & $\begin{array}{c}9,820 \\
(2 \%)\end{array}$ & $\begin{array}{c}64,850 \\
(14 \%)\end{array}$ & $\begin{array}{c}17,403 \\
(4 \%)\end{array}$ & $\begin{array}{c}10,035 \\
(2 \%)\end{array}$ \\
\hline Sawmill 2 & 420,687 & $\begin{array}{c}158,100 \\
(38 \%)\end{array}$ & $\begin{array}{c}25,866 \\
(6 \%)\end{array}$ & $\begin{array}{c}12,284 \\
(3 \%)\end{array}$ & $\begin{array}{c}14,262 \\
(3 \%)\end{array}$ & $\begin{array}{c}14,666 \\
(3 \%)\end{array}$ & $\begin{array}{c}86,499 \\
(21 \%)\end{array}$ & $\begin{array}{c}109,010 \\
(26 \%)\end{array}$ \\
\hline Sawmill 3 & $1,431,387$ & $\begin{array}{c}1,031,633 \\
(72.5 \%)\end{array}$ & $\begin{array}{c}0 \\
(0 \%)\end{array}$ & $\begin{array}{c}31,020 \\
(2 \%)\end{array}$ & $\begin{array}{c}382 \\
(0 \%)\end{array}$ & $\begin{array}{c}246,408 \\
(17 \%)\end{array}$ & $\begin{array}{c}0 \\
(0 \%)\end{array}$ & $\begin{array}{c}121,944 \\
(8.5 \%)\end{array}$ \\
\hline Sawmill 4 & 660,379 & $\begin{array}{c}296,280 \\
(45 \%)\end{array}$ & $\begin{array}{c}0 \\
(0 \%)\end{array}$ & $\begin{array}{c}31,070 \\
(5 \%)\end{array}$ & $\begin{array}{c}182,383 \\
(28 \%)\end{array}$ & $\begin{array}{c}6,974 \\
(1 \%)\end{array}$ & $\begin{array}{c}106,688 \\
(16 \%)\end{array}$ & $\begin{array}{c}36,984 \\
(6 \%)\end{array}$ \\
\hline Sawmill 5 & 949,149 & $\begin{array}{c}594,681 \\
(62.5 \%)\end{array}$ & $\begin{array}{c}173,337 \\
(18.5 \%)\end{array}$ & $\begin{array}{c}0 \\
(0 \%)\end{array}$ & $\begin{array}{c}34,029 \\
(3.5 \%)\end{array}$ & $\begin{array}{c}57,221 \\
(6 \%)\end{array}$ & $\begin{array}{c}67,872 \\
(7 \%)\end{array}$ & $\begin{array}{c}22,009 \\
(2.5 \%)\end{array}$ \\
\hline Total & $\mathbf{3 , 9 2 2 , 5 9 6}$ & $\begin{array}{c}\mathbf{2 , 4 0 8 , 0 5 7} \\
(61 \%)\end{array}$ & $\begin{array}{c}\mathbf{2 2 3 , 1 0 8} \\
(6 \%)\end{array}$ & $\begin{array}{c}\mathbf{8 1 , 9 9 2} \\
(2 \%)\end{array}$ & $\begin{array}{c}\mathbf{2 4 0 , 8 7 6} \\
(6.5 \%)\end{array}$ & $\begin{array}{c}\mathbf{3 9 0 , 1 1 9} \\
(10 \%)\end{array}$ & $\begin{array}{c}\mathbf{2 7 8 , 4 6 2} \\
(7 \%)\end{array}$ & $\begin{array}{c}\mathbf{2 9 9}, \mathbf{9 8 2} \\
(7.5 \%)\end{array}$ \\
\hline
\end{tabular}


From the Table 3.4, it can be seen that sawmill 2 had the highest percentage of cants and timbers where as sawmill 1 had the lowest. Also, sawmill 2 had the lowest percentage to 4/4 lumber where as sawmill 3 had the highest.

Each of the hardwood mills sampled focused on grade lumber production. The commercial lumber is graded by some specific rules established by manufacturer's association that make purchasing uniform throughout the nation. In 1898, the National Hardwood Lumber Association was formed to standardize the grading of hardwood lumber (McDonald 1898). Grades are established based on the size and number of individual pieces that can be obtained during cutting process from a board of lumber. There are eight commonly used lumber grades in today's market. FAS is the highest grade whereas No.3B common is the lowest grade out of them. Here is a brief description of the common lumber grades.

FAS: The term FAS stands for "First and Seconds" and is considered as the highest grade of lumber and its width will be at least 6 inches with a length of 8-16 feet.

$F 1 F$ : It is also called as FAS 1-Face and the minimum width is 6 inches.

Selects: The minimum width is 4 inches and the price of this grade lumber is almost the same as FAS.

No. 1 Common: The minimum width is 3 inches and is suitable for making furniture.

No. 2A, 2B, 3A, 3B Common: The letter A represents clear cuttings and letter B represents that cuttings are required to free from rot, pith, shake, and wane (Cassens 2001). 2A and $2 \mathrm{~B}$ are the standard grades for making cabinets. $3 \mathrm{~A}$ and $3 \mathrm{~B}$ are suitable for flooring and pallets [Sawmill Magazine 2010]. The minimum width of these grades is 3 inches. As explained above, there are no standard widths specified for each grade and only minimum width is specified as shown in Table 3.5. 
Table 3.5: Minimum Width of Different Grade Lumber

\begin{tabular}{|c|c|}
\hline Grade & Minimum Width (Inches) \\
\hline FAS & 6 \\
\hline F1F & 6 \\
\hline Selects & 4 \\
\hline No.1,2A, 2B, 3A, 3B Common & 3 \\
\hline
\end{tabular}

All thicknesses were combined with respect to their grade while reporting total lumber produced in board feet for that grade since thickness is not considered in grading lumber. During the study period, sawmill number 5 produced the largest amount of common and better lumber, about five times that of sawmill 2 (Table 3.6). The upper NHLA grades (FAS-1COM) accounted for 50 percent of the grade lumber sawn.

Table 3.6: National Hardwood Lumber Association Graded Lumber produced in Board Feet at 5 Sawmills

\begin{tabular}{|c|c|c|c|c|c|c|}
\hline SAWMILL & FAS & FAS 1-Face & 1 Common & 2 Common & 3 Common & COMBET* \\
\hline Sawmill 1 & 0 & 135,953 & 65,532 & 95,442 & 71,779 & 201,485 \\
\hline Sawmill 2 & 26,371 & 16,279 & 61,769 & 75,870 & 30,223 & 104,419 \\
\hline Sawmill 3 & 237,059 & 94,171 & 37,282 & 332,736 & 343,219 & 368,512 \\
\hline Sawmill 4 & 90,245 & 55,616 & 161,071 & 185,104 & 17,697 & 306,932 \\
\hline Sawmill 5 & 177,249 & 96,370 & 237,314 & 248,211 & 42,903 & 510,933 \\
\hline
\end{tabular}

*COMBET $=$ FAS + FAS 1-Face + 1 Common

\subsection{Data Collection of Saw Blade Material and Maintenance}

As discussed earlier, in a sawmill head saw and re-saw are the main equipment involved in sawing operation. The material details and maintenance procedures of these saws were collected from all the 5 sawmills (Sample in Appendix Table A.28). Maintenance of saw blades is critical to reduce energy consumption during lumber sawing (Cristóvão 2013) and also to improve quality of lumber produced. In the study conducted, the experimental power consumption increased by 11 to $35 \%$ during an 8 -hour shift, mainly due to an increase in the tooth radius of the cutter due to lack of maintenance of saw blades. The material details and dimensions of the saws and maintenance procedures are shown in Table 3.7 and Table 3.8. 
Table 3.7: Specifications of Saws in Sawmills

\begin{tabular}{|c|c|c|c|c|c|c|}
\hline & \multicolumn{3}{|c|}{ Main saw } & \multicolumn{3}{|c|}{ Re-saw } \\
\hline & Type of Saw & Material & Dimensions & Type of Saw & Material & Dimensions \\
\hline Sawmill 1 & Circular Saw & $\begin{array}{c}\text { Carbon Steel } \\
\text { (Carbide Tips) }\end{array}$ & $\begin{array}{l}\text { Diameter: } 58 \text { inch } \\
\text { Thickness: } 0.176 \text { inch } \\
\text { Tooth Angle: } 35^{\circ} \text { to } 37^{\circ} \\
\text { Hook Angle: } 45^{\circ}\end{array}$ & Band Saw & $\begin{array}{c}\text { Carbon } \\
\text { Steel }\end{array}$ & $\begin{array}{l}\text { Length: } 21 \text { feet } \\
\text { Width: } 4.75 \text { inch } \\
\text { Thickness:0.048 inches } \\
\text { Hook Angle: } 30^{\circ}\end{array}$ \\
\hline Sawmill 2 & Band Saw & Carbon Steel & $\begin{array}{l}\text { Length: } 45 \text { feet } \\
\text { Width: } 12 \text { inch } \\
\text { Thickness: } 0.071 \text { inches }\end{array}$ & - & - & - \\
\hline Sawmill 3 & Band Saw & $\begin{array}{l}\text { Carbon Steel } \\
\text { (Udelholm) }\end{array}$ & $\begin{array}{l}\text { Length: } 42.5 \text { feet, } 38 \text { feet } \\
\text { Width: } 11 \text { inch } \\
\text { Thickness: } 0.078 \text { inches } \\
\text { Tooth Angle: } 44^{\circ} \\
\text { Hook Angle: } 30^{\circ}\end{array}$ & Circular - Gang & $\begin{array}{c}\text { Carbon } \\
\text { Steel } \\
\text { (Peerless) }\end{array}$ & $\begin{array}{l}\text { Diameter: } 30 \text { inch } \\
\text { Thickness: } 0.12 \text { inch } \\
\text { Tooth Angle: } 50^{\circ} \\
\text { Hook Angle: } 30^{\circ}\end{array}$ \\
\hline Sawmill 4 & Band Saw & $\begin{array}{c}\text { Carbon Steel } \\
\text { (Swedish) }\end{array}$ & $\begin{array}{l}\text { Length: } 40 \text { feet } \\
\text { Width: } 10 \text { inch } \\
\text { Thickness: } 0.078 \text { inches } \\
\text { Hook Angle: } 30^{\circ}\end{array}$ & - & - & - \\
\hline Sawmill 5 & Band Saw & Carbon Steel & $\begin{array}{l}\text { Length: } 47 \text { feet } \\
\text { Width: } 12 \text { inch } \\
\text { Thickness: } 0.078 \text { inches } \\
\text { Hook Angle: } 30^{\circ}\end{array}$ & Band Saw & $\begin{array}{c}\text { Carbon } \\
\text { Steel }\end{array}$ & $\begin{array}{l}\text { Length: } 40 \text { feet } \\
\text { Width: } 11 \text { inch } \\
\text { Thickness:0.078 inches } \\
\text { Hook Angle: } 30^{\circ}\end{array}$ \\
\hline
\end{tabular}

Table 3.8: Maintenance Procedures of Saws

\begin{tabular}{|c|c|c|c|c|c|c|c|c|}
\hline & \multicolumn{3}{|c|}{ Main Saw } & \multicolumn{3}{|c|}{ Re-saw } & \multirow{2}{*}{$\begin{array}{l}\text { Average } \\
\text { Runtime }\end{array}$} & \multirow{2}{*}{$\begin{array}{l}\text { Maintenance } \\
\text { Index }\end{array}$} \\
\hline & Runtime & Grinding Time ${ }^{*}$ & Saw Changing Time & Runtime & Grinding Time ${ }^{*}$ & Saw Changing Time & & \\
\hline Sawmill 1 & 3.5 Hours & 10 Minutes & 10 Minutes & 3.5 hours & 1 hour & 15 Minutes & 3.5 & 4 \\
\hline Sawmill 2 & 4 Hours & 2 Hours & 15 Minutes & - & - & - & 4 & 3 \\
\hline Sawmill 3 & 4 hours & 2 Hours & 8 Minutes & 6 hours & 10 Minutes & 30 Minutes & 5 & 2 \\
\hline Sawmill 4 & 5 hours & 1.75 Hours & 18 Minutes & - & - & - & 5 & 2 \\
\hline Sawmill 5 & 5 hours & 3 hours & 5 Minutes & 5 Hours & 3 Hours & 5 Minutes & 5 & 2 \\
\hline
\end{tabular}

${ }^{*}$ Grinding of saws is done off line, ${ }^{\#}$ Changing of Saws is done during lunch or break times. 
A maintenance index was assigned to each sawmill based on the average saw blade life of main saw and re-saw (Table 3.8). Since the power consumption goes up as the saw blade is used for longer time, higher maintenance index was assigned to sawmills using saw blades for shorter time. For average saw blade life (main saw and re-saw) between 3 to 3.9 hours, maintenance index value given was 4 , for average between 4 to 4.9 hours, index value was 3 , for average between 5 to 5.9 hours, index value was 2 and the typical range for maintenance index will be 1 to 5 .

\section{Conclusion}

Three sawmills with single sawing line and two sawmills with double sawing lines were selected to monitor their electrical energy consumption. Energy, Current, Voltage and Power factor data was collected using an advanced electrical data collection device for duration close to 20 minutes. The data loggers were set on all major motors to record current data every minute for the duration of 1 month. Manufacturing configurations along with the type of equipment used for sawing were studied. Data of the saw blade material used in different machines were collected along with the maintenance schedules of the saws.

Overall, production and electrical consumption data of 133 separate shifts, was collected from the five sawmills during the study period. From the collected data, sawmill 3 had the highest production and sawmill 2 the lowest. 


\section{Data Analysis}

\subsection{Energy Consumption Calculation of Motors}

The electrical and production data collected were used to calculate energy consumption for the lumber produced during a particular shift. Data were matched to production records based on the timestamps recorded by the data loggers. Total energy consumption in $\mathrm{kWh}$ for each motor was calculated for a particular time period using the logged data as follows:

Where,

$$
\mathrm{EC}_{\operatorname{logged}}=\sqrt{3} * \mathrm{~V} * \mathrm{I} * \cos \Phi * \text { No. of hours } /(1000)
$$

$$
\begin{array}{ll}
\mathrm{EC}_{\text {logged }} & =\text { Energy Consumption } \\
\mathrm{V} & =\text { Voltage } \\
\mathrm{I} & =\text { Amperage } \\
\cos \Phi & =\text { Power Factor measured using Amprobe }
\end{array}
$$

For example, the energy consumed by the main saw for sawing Hickory on $23^{\text {rd }}$ shift of data collection (Appendix Tables A.3 production data, A.7 amperage data, A.12 run time data, A.21 voltage and power factor data, A.17 energy consumption data) in sawmill 2 is calculated as,

$$
\begin{aligned}
\mathrm{EC}_{\text {logged }} & =\sqrt{3} * 487 * 142.34 * 0.41 *(278 / 60) / 1000 \\
& =228.08 \mathrm{kWh}
\end{aligned}
$$

The number of hours used to calculate $\mathrm{EC}_{\text {logged }}$ were those recorded by the data loggers and not those provided by the mill. While they were similar, the data loggers captured the true operating time without any introduction of human error. Similarly, the energy consumption was calculated for all other motors logged. The logged and unlogged motor horsepower of sawmills along with percentage logged and unlogged is shown in Table 4.1.

Table 4.1: Logged, Unlogged and Total Motor Horse Power of Sawmills

\begin{tabular}{|c|c|c|c|c|c|}
\hline Sawmill \# & Logged hp & Unlogged hp & Total hp & \% Logged & \% Unlogged \\
\hline 1 & 805 & 163 & 968 & 83 & 17 \\
\hline 2 & 787 & 30 & 817 & 96 & 4 \\
\hline 3 & 2,113 & 517.5 & $2,630.5$ & 80 & 20 \\
\hline 4 & $1,232.5$ & 301.5 & 1,534 & 80 & 20 \\
\hline 5 & 1,430 & 256 & 1,686 & 85 & 15 \\
\hline
\end{tabular}


The total energy consumption of the logged motors was $866.06 \mathrm{kWh}$ and the average load factor for the logged motors is calculated as,

$$
\begin{aligned}
& \text { Load Factor }=\frac{\text { Total } \mathrm{kWh} \times \text { Motor Efficiency }}{\text { Motor hp } \times \text { Hours } \times 0.746} \\
& \text { Load Factor }=\frac{866.06 \times 0.866}{787 \times(270 / 60) \times 0.746}=0.2839
\end{aligned}
$$

The electrical energy consumption of motors that were not logged was estimated based on average load factor of the logged motors and the total operating hours using the following relationship:

$$
\text { EC(Unlogged Motors })=\frac{\text { Horsepower x Load Factor x Operating Hours x 0.746 }\left(\frac{\mathrm{kW}}{\mathrm{hp}}\right)}{\text { Average Motor Efficiency }}
$$

For example, the energy consumed by the motors that were not logged for sawing hickory on $23^{\text {rd }}$ shift of data collection (Appendix Table A.3 production data, A.7 load factor data, A.12 run time data, A.17 energy consumption data) in sawmill 2 is calculated as,

$$
\begin{gathered}
\mathrm{EC}(\text { Unlogged Motors })=\frac{30 \times 0.2839 \times(270 / 60) \times 0.746(\mathrm{~kW} / \mathrm{hp})}{0.757} \\
\mathrm{EC}_{(\text {Not Logged Motors })}=37.77 \mathrm{kWh}
\end{gathered}
$$

Table 4.2 lists the average motor load factor, efficiency of logged motors, efficiency of unlogged motors with average motor sizes used for calculating efficiency in parenthesis.

Table 4.2: Motor Load Factors and Efficiencies

\begin{tabular}{|c|c|c|c|}
\hline Sawmill & $\begin{array}{c}\text { Average motor } \\
\text { Load factor }\end{array}$ & $\begin{array}{c}\text { Efficiency for } \\
\text { logged motors }\end{array}$ & $\begin{array}{c}\text { Efficiency for } \\
\text { unlogged motors }\end{array}$ \\
\hline 1 & 0.307 & $87.4(200 \mathrm{hp})$ & $78.6(7.5 \mathrm{hp})$ \\
\hline 2 & 0.265 & $86.6(150 \mathrm{hp})$ & $75.7(15 \mathrm{hp})$ \\
\hline 3 & 0.485 & $91.2(200 \mathrm{hp})$ & $87.7^{*}(20 \mathrm{hp})$ \\
\hline 4 & 0.358 & $88.5(200 \mathrm{hp})$ & $79.2(15 \mathrm{hp})$ \\
\hline 5 & 0.362 & $88.6(150 \mathrm{hp})$ & $85.6^{*}(20 \mathrm{hp})$ \\
\hline
\end{tabular}

*Have more large sized unlogged motors, ${ }^{\#}$ Obtained from MotorMaster+ International (USDOE 2015) 
The energy consumption calculated for various motors were tallied and combined with the corresponding shift production (Table 4.3, Appendix Table A.17). Total energy consumption $(\mathrm{kWh})$ was calculated by adding consumption from both logged and unlogged motors.

Table 4.3: Example of Energy Consumption in $\mathrm{kWh}$ recorded for Motors used during the Sawing of Hickory logs in a WV Hardwood Sawmill

\begin{tabular}{|c|c|c|c|c|c|c|c|c|c|c|}
\hline $\begin{array}{c}\text { Head } \\
\text { Saw }\end{array}$ & $\begin{array}{c}\text { Carriage } \\
\text { feed } \\
\text { motor }\end{array}$ & Edger & Trimmer & $\begin{array}{c}\text { Compre } \\
\text {-ssor }\end{array}$ & Chipper & Debarker & $\begin{array}{c}\text { Other } \\
\text { logged } \\
\text { motors }\end{array}$ & $\begin{array}{c}\text { Unlogged } \\
\text { motors }\end{array}$ & $\begin{array}{c}\text { Total } \\
\text { kWh }\end{array}$ & MBF $^{\mathbf{a}}$ \\
\hline 228.07 & 94.79 & 33.03 & 33.38 & 121.18 & 133.98 & 191.22 & 30.41 & 37.77 & 903.83 & 10.141 \\
\hline
\end{tabular}

Thousand board feet sawn during a given sampling period

Energy consumption for lighting and HVAC was calculated based on the collected data from sawmills. The total energy consumption of motors, lighting and HVAC was closely matching with the actual electricity bills except for sawmill 5 since it was working for 2 shifts and some equipment like compressor was running even in the $3^{\text {rd }}$ shift. (Table 4.4)

Table 4.4: Total Energy Consumption of Motors, Lighting, and HVAC in each Sawmill along with Energy Bills

\begin{tabular}{|c|c|c|c|c|c|}
\hline Sawmill & $\begin{array}{c}\text { Motors } \\
\text { (kWh) }\end{array}$ & $\begin{array}{c}\text { HVAC } \\
\text { (kWh) }\end{array}$ & $\begin{array}{c}\text { Lighting } \\
\mathbf{( k W h )}\end{array}$ & $\begin{array}{c}\text { Calculated } \\
\text { Total } \\
\mathbf{( k W h )}\end{array}$ & $\begin{array}{c}\text { Energy Bill } \\
\mathbf{( k W h )}\end{array}$ \\
\hline Sawmill 1 & 39,767 & - & 1,650 & 41,417 & 42,988 \\
\hline Sawmill 2 & 35,154 & - & 1,150 & 36,304 & 36,524 \\
\hline Sawmill 3 & 148,553 & 14,784 & 29,260 & 192,597 & 196,423 \\
\hline Sawmill 4 & 80,904 & - & 12,426 & 93,330 & 96,682 \\
\hline Sawmill 5 & 106,418 & 10,733 & 16,099 & 133,250 & 146,052 \\
\hline Total & $\mathbf{4 1 0 , 7 9 6}$ & & & & \\
\hline
\end{tabular}

Once consumption data were developed, it was then used to create a standardized metric for each shift based on the total lumber production for the shift (specific energy consumption in kWh per thousand board feet - SEC). The specific energy consumption (SEC) or total kWh consumed per thousand board feet $(\mathrm{MBF})$ was determined by dividing the total energy consumption during a set time period by the total lumber production for the same period. 


$$
\text { SEC }=\frac{\text { Total Energy Consumption }}{\mathrm{MBF}}
$$

For example, SEC for sawing Hickory on $23^{\text {rd }}$ shift of data collection (Appendix Table A.3) in sawmill 2 is calculated as,

$$
\begin{aligned}
\mathrm{SEC} & =\frac{903.83}{10.141} \\
& =89.13 \mathrm{kWh} / \mathrm{MBF}
\end{aligned}
$$

Board feet sawn per hour was calculated to know the production rate of each sawmill. For example, board feet sawn per hour for sawmill 2 is calculated as,

$$
\frac{\text { Board Feet }}{\text { Hour }}=\frac{420,687}{191}=2,203
$$

The highest board feet rate per hour was for sawmill 3 and the lowest was for sawmill 2 .

Board feet sawn per kWh was calculated to see how much quantity of board feet is produced from each sawmill per kWh of energy consumed. Board feet sawn per $\mathrm{kWh}$ is calculated as,

$$
\frac{\text { Board Feet }}{\mathrm{kWh}}=\frac{420,687}{35,154}=11.97
$$

The highest board feet produced per kWh was for sawmill 2 and the lowest was for sawmill 4.

Data from all the shifts for all the 5 sawmills (Table 4.5 ) were processed similarly and the results are summarized (Table 4.6). From the summarized results, SEC of sawmill 2 looks better than the other sawmills and SEC of sawmill 4 the worst. Sawmill 3 has the highest production rate and sawmill 2 the lowest. Load factor of sawmill 1 and 2 are lower than the other sawmills. SEC of each mill is calculated both as total energy consumed by total board feet and average SEC's of each shift. There is some difference between these two SEC's due to round off error. 
Table 4.5: Calculated SEC Values of 5 Sawmills for Various Shifts

\begin{tabular}{|c|c|c|c|c|c|}
\hline SI. No. & Sawmill 1 & Sawmill 2 & Sawmill 3 & Sawmill 4 & Sawmill 5 \\
\hline 1 & 70.05 & 89.13 & 105.28 & 115.22 & 106.13 \\
\hline 2 & 57.49 & 73.99 & 124.48 & 108.23 & 113.76 \\
\hline 3 & 79.48 & 91.16 & 104.00 & 99.65 & 153.86 \\
\hline 4 & 86.37 & 79.47 & 111.63 & 103.05 & 137.55 \\
\hline 5 & 79.31 & 76.00 & 11.68 & 109.70 & 67.71 \\
\hline 6 & 77.59 & 57.54 & 85.78 & 100.94 & 84.87 \\
\hline 7 & 79.62 & 61.25 & 104.21 & 116.97 & 67.73 \\
\hline 8 & 85.66 & 60.79 & 103.86 & 98.44 & 129.64 \\
\hline 9 & 90.42 & 70.04 & 111.65 & 137.93 & 98.24 \\
\hline 10 & 95.95 & 94.01 & 105.06 & 147.41 & 139.94 \\
\hline 11 & 94.75 & 85.15 & 108.29 & 169.34 & 113.82 \\
\hline 12 & 83.83 & 80.82 & 86.33 & 154.92 & 137.99 \\
\hline 13 & 88.84 & 94.05 & 89.69 & 78.61 & 113.90 \\
\hline 14 & 81.51 & 87.07 & 81.33 & 105.08 & 102.01 \\
\hline 15 & 116.38 & 76.63 & 84.82 & 90.29 & 117.99 \\
\hline 16 & 77.42 & 88.53 & 108.37 & 140.53 & 96.29 \\
\hline 17 & 119.23 & 84.54 & 124.17 & 144.54 & 112.49 \\
\hline 18 & 98.66 & 91.35 & 82.45 & 156.76 & 115.82 \\
\hline 19 & 95.50 & 68.88 & 140.73 & 111.76 & 138.43 \\
\hline 20 & 94.74 & 69.25 & 105.32 & 120.46 & 119.39 \\
\hline 21 & 90.76 & 107.59 & 110.70 & 120.26 & 151.36 \\
\hline 22 & 86.94 & 85.95 & 108.55 & 117.52 & 115.25 \\
\hline 23 & & 101.26 & 103.72 & 159.87 & 126.86 \\
\hline 24 & & 81.96 & 130.79 & 129.35 & 128.95 \\
\hline 25 & & 87.31 & 107.44 & 146.91 & 171.11 \\
\hline 26 & & 80.49 & & 138.38 & \\
\hline 27 & & 86.72 & & & \\
\hline 28 & & 81.71 & & & \\
\hline 29 & & 88.09 & & & \\
\hline 30 & & 88.15 & & & \\
\hline 31 & & 100.14 & & & \\
\hline 32 & & 79.64 & & & \\
\hline 33 & & 125.07 & & & \\
\hline 34 & & 89.72 & & & \\
\hline 35 & & 80.51 & & & \\
\hline Average & $\mathbf{8 7 . 7 5}$ & $\mathbf{8 4 . 1 1}$ & $\mathbf{1 0 5 . 6 1}$ & $\mathbf{1 2 3 . 9 3}$ & $\mathbf{1 1 8 . 4 4}$ \\
\hline & & & & & \\
\hline
\end{tabular}


Table 4.6: Lumber Production and Energy Consumption Information of Sawmills

\begin{tabular}{|c|c|c|c|c|c|c|c|c|c|c|}
\hline $\begin{array}{c}\text { Mill } \\
\#\end{array}$ & $\begin{array}{c}\text { Total } \\
\text { motor } \\
\text { hp }\end{array}$ & $\begin{array}{c}\text { \# of } \\
\text { hours }\end{array}$ & $\begin{array}{l}\text { \# of } \\
\text { days }\end{array}$ & $\begin{array}{c}\text { Board } \\
\text { Feet }\end{array}$ & $\begin{array}{c}\text { Board } \\
\text { feet/ } \\
\text { hour }\end{array}$ & $\begin{array}{l}\text { Total } \\
\text { kWh }\end{array}$ & $\begin{array}{c}\text { SEC } \\
(\mathbf{k W h} / \\
\text { MBF) }\end{array}$ & $\begin{array}{l}\text { Average } \\
\text { of Shift } \\
\text { SEC's }\end{array}$ & $\begin{array}{c}\text { Motor } \\
\text { Load } \\
\text { Factor }\end{array}$ & $\begin{array}{l}\text { Board } \\
\text { Feet/ } \\
\text { kWh }\end{array}$ \\
\hline 1 & 968 & 156.5 & 15 & 460,994 & 2,946 & 39,767 & 86.26 & 87.75 & 0.307 & 11.59 \\
\hline 2 & 817 & 191 & 23 & 420,687 & 2,203 & 35,154 & 83.56 & 84.11 & 0.265 & 11.97 \\
\hline 3 & $2,630.5$ & 143.5 & 18 & $1,431,387$ & 9,975 & 148,553 & 103.78 & 105.61 & 0.485 & 9.64 \\
\hline 4 & 1,534 & 169.75 & 18 & 660,379 & 3,890 & 80,904 & 122.51 & 123.93 & 0.358 & 8.16 \\
\hline 5 & 1,686 & 205.6 & 11 & 949,149 & 4,616 & 106,418 & 112.12 & 118.44 & 0.362 & 8.92 \\
\hline \multicolumn{4}{|c|}{ Total } & $3,922,596$ & 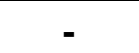 & 410,796 & 101.65 & 103.97 & - & - \\
\hline
\end{tabular}

\subsection{Test for Normality}

As per the requirement for comparing sawmill means, data was tested for normality. Ryan-Joiner (similar to Shapiro-Wilk) normality test was conducted for calculated SEC using Minitab software for each sawmill and the normality assumptions were met (p-value $>0.05)$ for all the five sawmills (Figure 4.2, 4.3, 4.4, $4.5 \&$ 4.6). The calculated SEC followed normality distribution at the sawmill level since it was coming from the same population. The normality test was conducted on data from all the 5 sawmills, but it failed at p-value $<0.01$ (Figure 4.1).

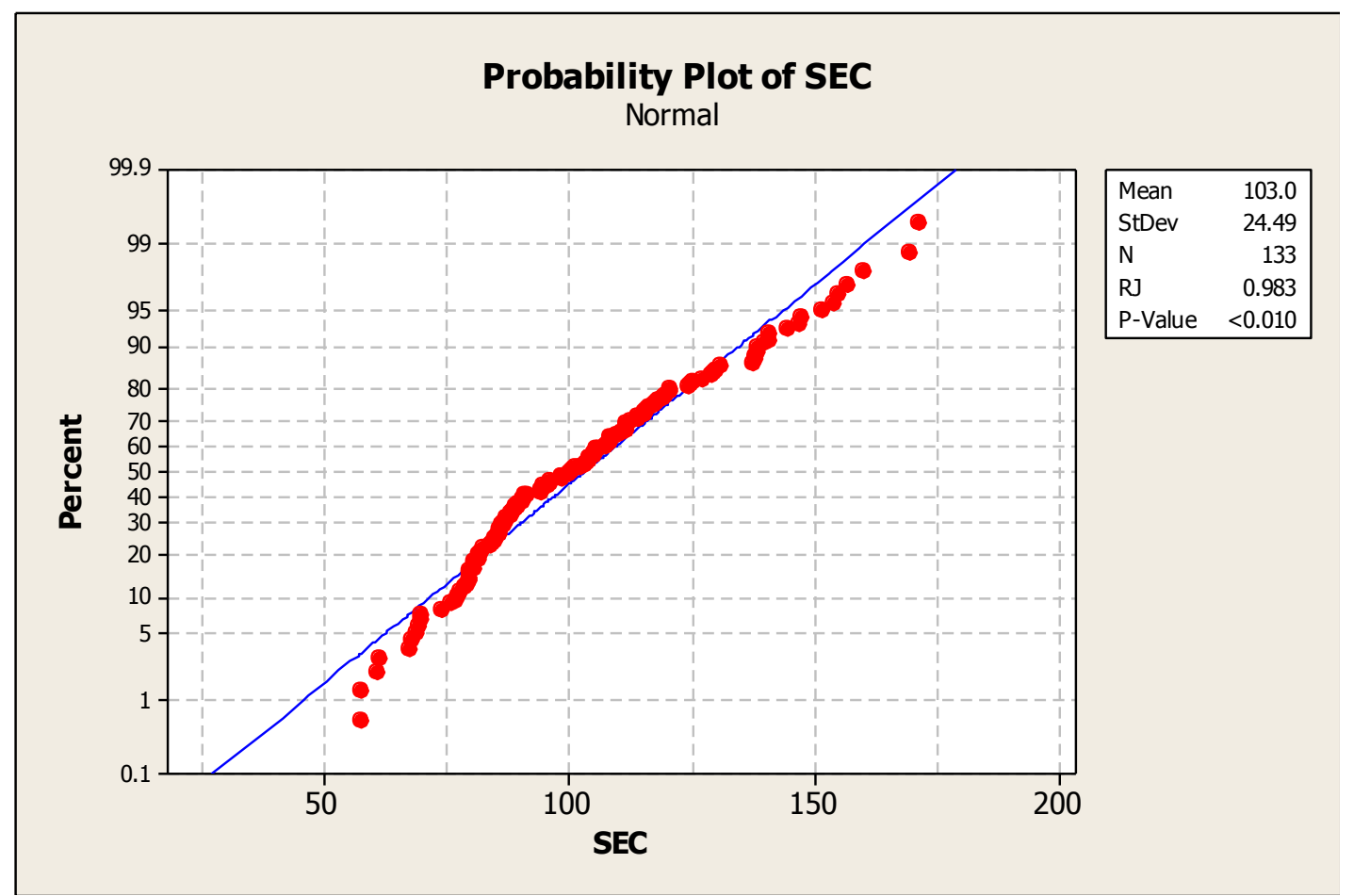

Figure 4.1: Ryan-Joiner (similar to Shapiro-Wilk) Normality Test for all the Sawmills 


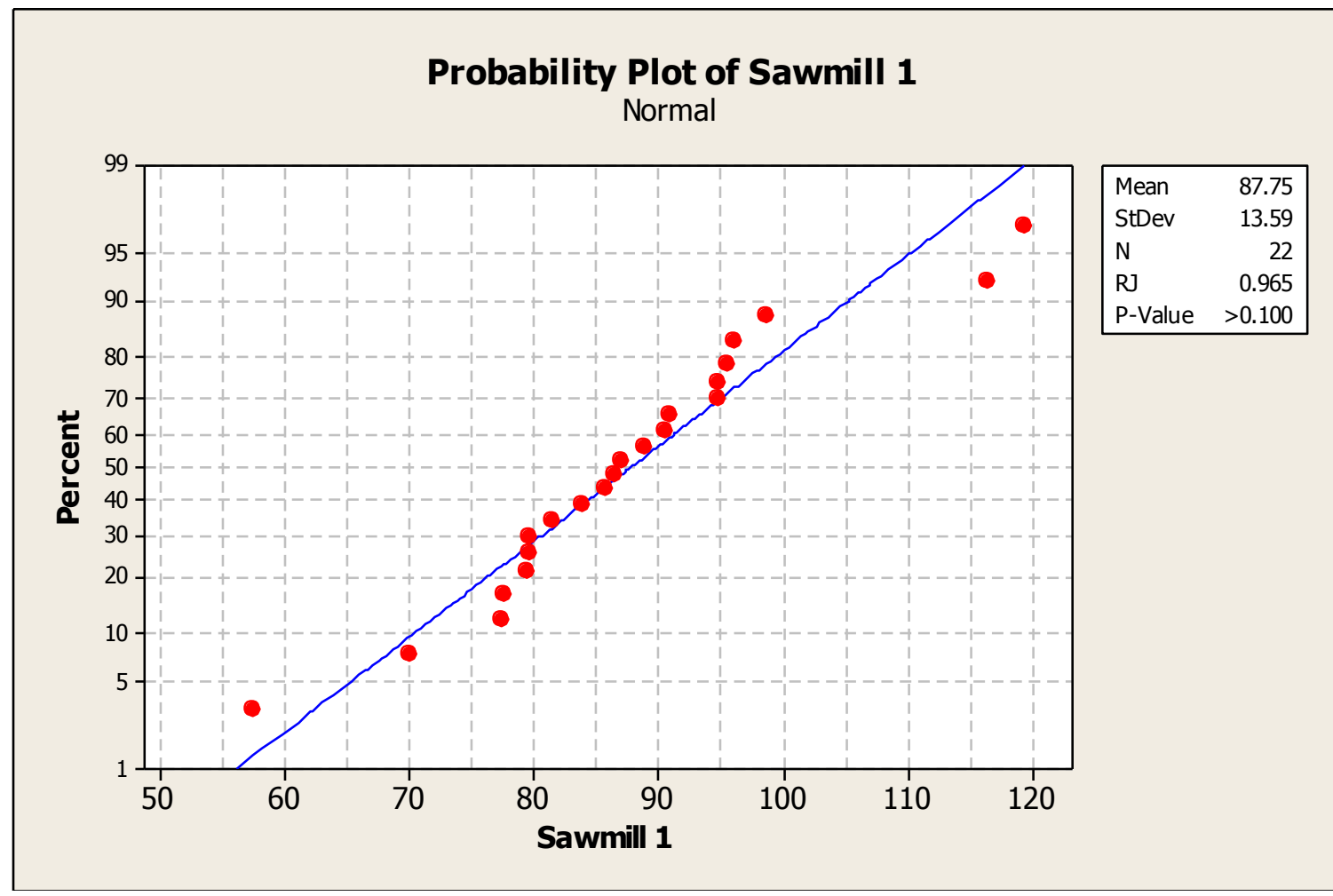

Figure 4.2: Ryan-Joiner (similar to Shapiro-Wilk) Normality Test for Sawmill 1

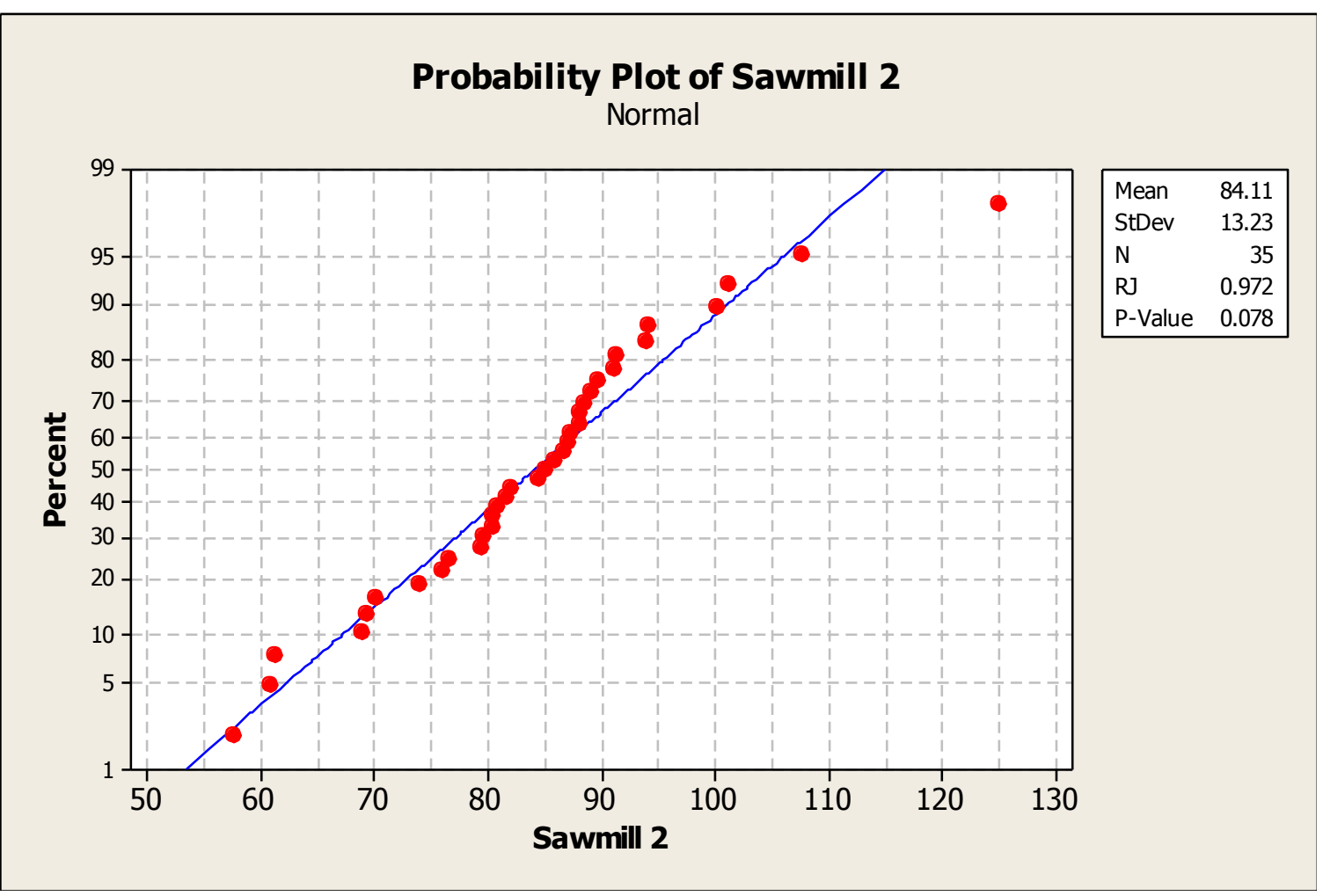

Figure 4.3: Ryan-Joiner (similar to Shapiro-Wilk) Normality Test for Sawmill 2 


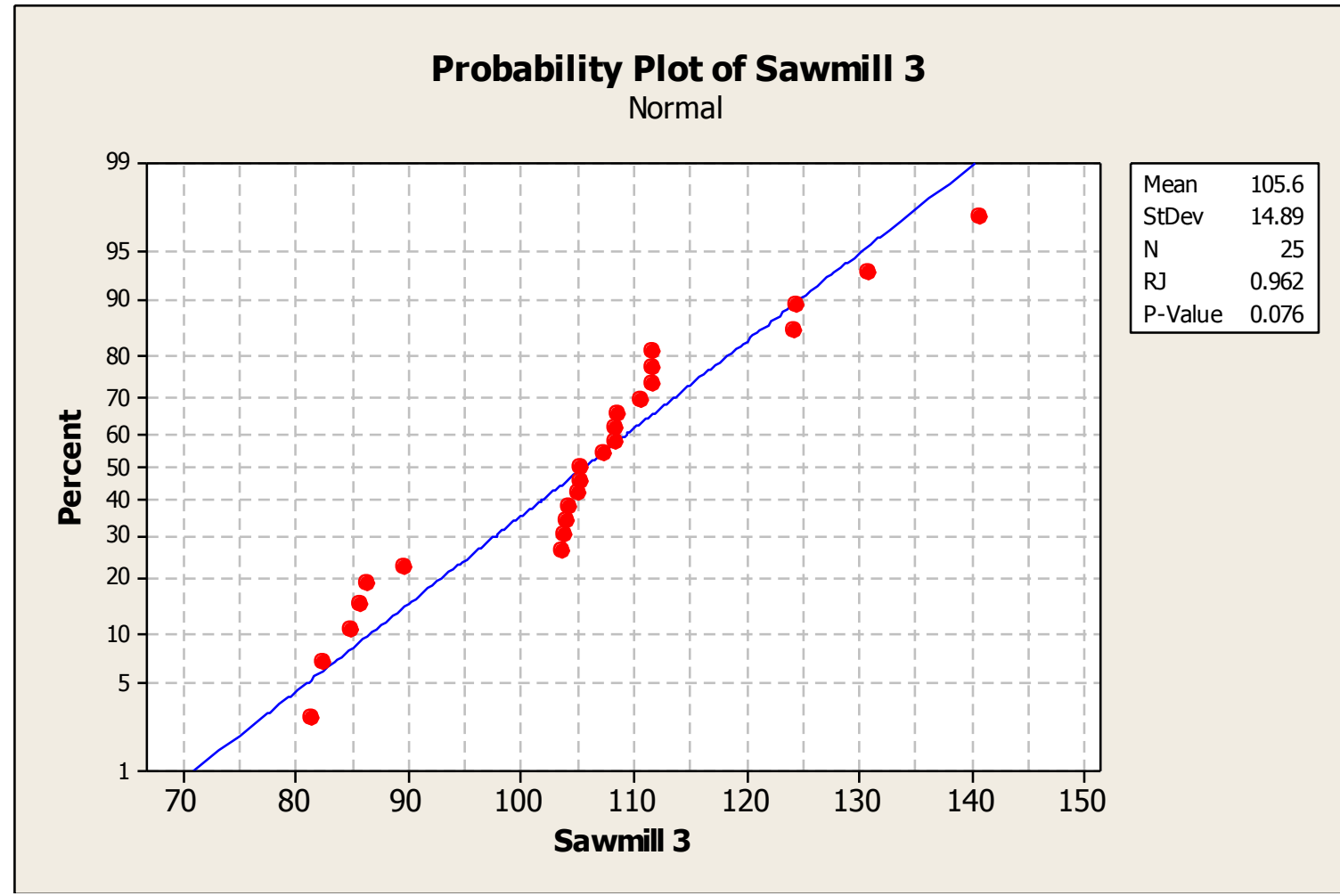

Figure 4.4: Ryan-Joiner (similar to Shapiro-Wilk) Normality Test for Sawmill 3

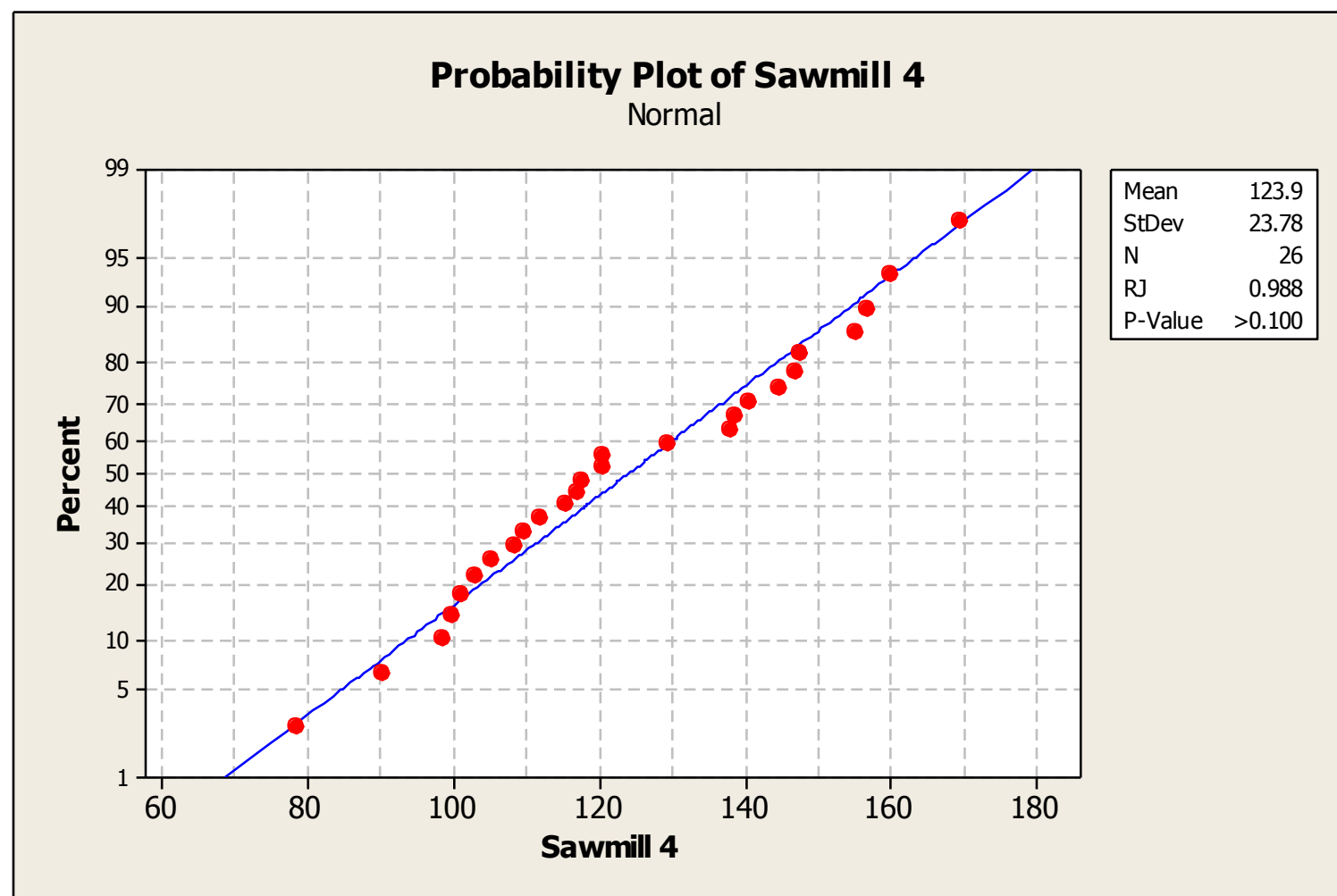

Figure 4.5: Ryan-Joiner (similar to Shapiro-Wilk) Normality Test for Sawmill 4 


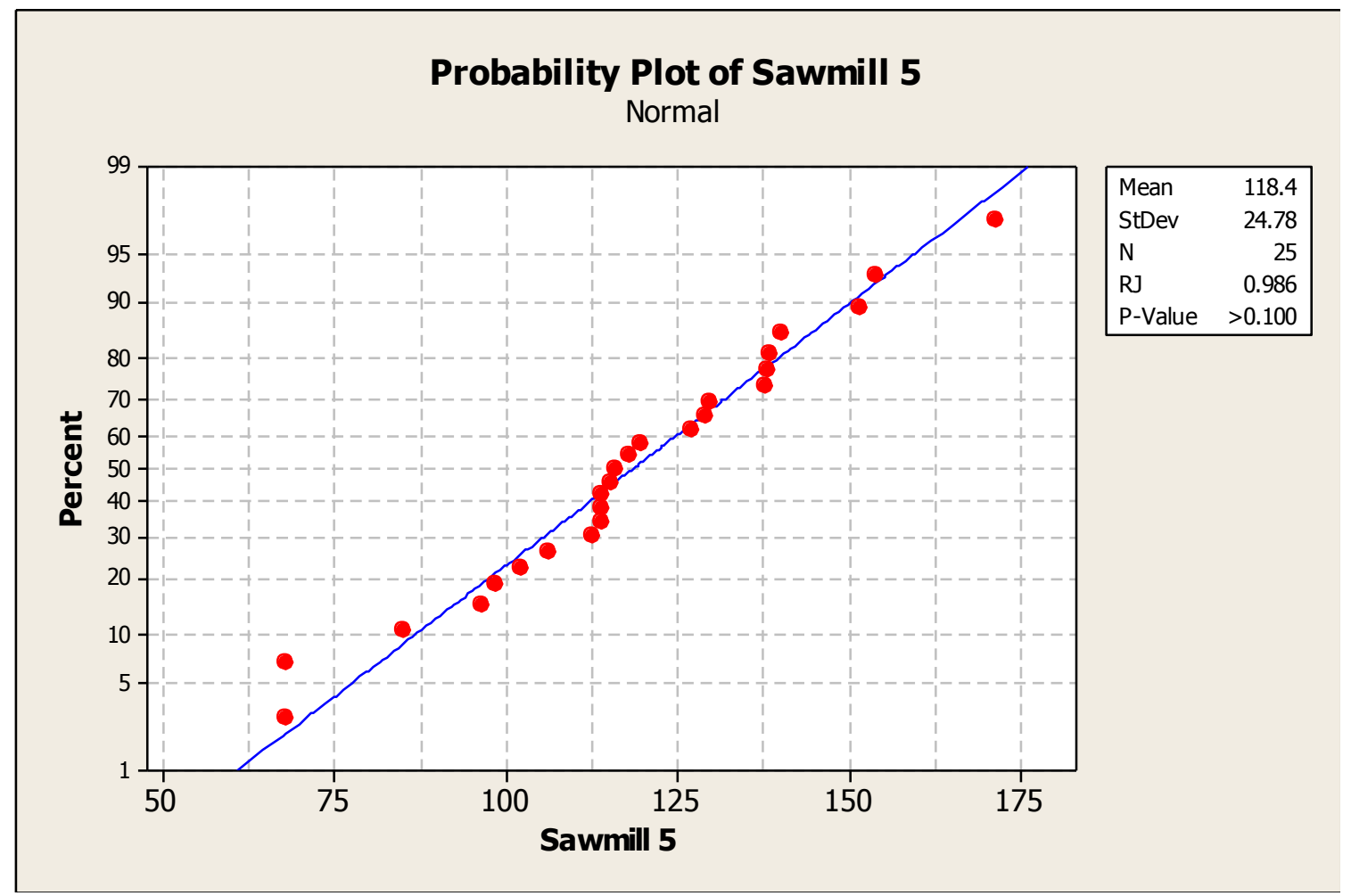

Figure 4.6: Ryan-Joiner (similar to Shapiro-Wilk) Normality Test for Sawmill 5

Since the data of all the five sawmills passed normality tests individually and the largest standard deviation from the 5 samples is less than twice the smallest standard deviation of the 5 samples, one way ANOVA (F-test) was conducted (data from Table 4.5) to find whether the SEC means of each sawmill are from the same population or not. The ANOVA results obtained $(\mathrm{F}=25.53$ and $\mathrm{P}=0.000)$ are in Table 4.7 and 4.8. The null and alternative hypotheses are;

$\mathrm{H}_{0}: \mu_{\mathrm{i}}=\mu_{\mathrm{j}}$ for all $\mathrm{i}, \mathrm{j} \quad \mathrm{H}_{0}: \mu_{\mathrm{i}} \neq \mu_{\mathrm{j}}$ for at least one $\mathrm{i}, \mathrm{j}$

Table 4.7: Means and Standard Deviations of Sawmill SEC

\begin{tabular}{|c|c|c|c|}
\hline Sawmill & N & Mean & $\begin{array}{c}\text { Standard } \\
\text { Deviation }\end{array}$ \\
\hline 1 & 22 & 87.75 & 13.59 \\
\hline 2 & 35 & 84.11 & 13.23 \\
\hline 3 & 25 & 105.61 & 14.89 \\
\hline 4 & 26 & 123.93 & 23.78 \\
\hline 5 & 25 & 118.44 & 24.78 \\
\hline \multicolumn{4}{|r|}{ Pooled Standard Deviation } \\
\hline
\end{tabular}




\section{Table 4.8: Results of Comparing Sawmill SEC Means using ANOVA}

\begin{tabular}{|c|c|c|cr|}
\hline Sawmill & N & Mean & \multicolumn{2}{|c|}{ Grouping } \\
\hline 4 & 26 & 123.93 & A & \\
\hline 5 & 25 & 118.44 & A & \\
\hline 3 & 25 & 105.61 & & B \\
\hline 1 & 22 & 87.75 & & C \\
\hline 2 & 35 & 84.11 & & C \\
\hline
\end{tabular}

P.S.: 1. Grouping information using Fisher Method

2. Means that do not share a letter are significantly different.

3. All Pairwise Comparisons, Simultaneous confidence level $=71.77 \%$

SEC means of sawmill 1 and 2 were concluded to be from the same population. SEC means of sawmill 4 and 5 were concluded to be from the same population. SEC mean of sawmill 3 was concluded to be different from the other 4 sawmills. Another point to be noted is higher the SEC value, higher is the standard deviation (sawmill 4 and 5).

The above F-test result gives an overall picture and is not accurate since the data has lot of variability due to different species and sizes that were sawn in each sawmill. Better way of comparing sawmills energy consumption will be to compare a particular size of a particular species lumber from each sawmill. This method of comparison will eliminate the variability due to wood species and lumber sizes. To calculate the energy consumption of a particular species, we have particular data points or shifts during which a particular species was sawn. But for calculating the energy consumption of a particular size lumber, we don't have any data points during which only a particular size lumber was sawn. More than one size lumber was sawn during each shift and each sawmill has sawn different proportion of lumber sizes during the data collection period (Table 3.4). To find out the relation between the percentage of different sizes of lumber sawn and energy consumption, Pearson correlation coefficients were calculated (Data in Appendix Table A.5). All the board size lumber (four-quarter to eight-quarter) were grouped together and also cants and timbers were grouped together to calculate the correlation coefficient. 
Even though Pallet was of four quarter size, it was kept separately to see its effect on energy consumption since its percentage was closer to the percentage of cants and timber. SEC and total $\mathrm{kWh}$ were positively correlated to the percentage of four to eight quarter lumber and negatively correlated to percentage of cants and timber being sawn (Table 4.9). Percentage of pallet was negatively correlated to the SEC but was positively correlated to total $\mathrm{kWh}$, but the negative correlation with SEC was not significant. Thus, as the mills sawed more grade lumber, as opposed to industrial type products like cants and timbers, the energy consumption and SEC increased. Conversely, as the production percentage of cants and timbers increased, the total kWh and SEC decreased (Table 4.9).

Table 4.9: Pearson Correlation Coefficients for SEC and Total kWh vs. Lumber Sizes

\begin{tabular}{|c|c|c|c|}
\hline & $\begin{array}{c}\text { Percent Four to } \\
\text { Eight Quarter }\end{array}$ & $\begin{array}{c}\text { Percent } \\
\text { Pallet }\end{array}$ & $\begin{array}{c}\text { Percent } \\
\text { Cant + Timber }\end{array}$ \\
\hline SEC & 0.363 & -0.006 & -0.31 \\
\hline P Value & $<0.0001$ & 0.947 & $<0.0001$ \\
\hline Total kWh & 0.442 & 0.315 & -0.503 \\
\hline P Value & $<0.0001$ & $<0.0001$ & $<0.0001$ \\
\hline
\end{tabular}

These findings follow the common view held by those in the industry. Most operators feel that their energy consumption was greater when sawing standard grade lumber versus sawing industrial products because of the increased number of lumber pieces. When the correlations were further investigated by comparing individual motor relationships (Data in Appendix Table A.5), a cause for the consumption difference becomes apparent.

The percentage of timbers and cants sawn was negatively correlated to the head saw, resaw, edger, trimmer, chipper, and compressor usage in minutes (Table 4.10). As the percentage of industrial products sawn increased in a shift, less work was performed by the head saw, resaw, edger, trimmer, chipper and compressor. Debarker usage also reduced when cants and timbers were sawn, but the correlation was not significant, this indicates that debarker has to be 
used irrespective of the lumber size sawn which is a valid statement. Percentage of pallets had positive correlation with re-saw, edger, trimmer, chipper, and debarker usage, but the correlation was not significant except for resaw. Percentage of pallets was negatively correlated to head saw and compressor usage, but the correlation was not significant.

Table 4.10: Pearson Correlation Coefficients for Equipment Usage in Minutes vs. Lumber Sizes

\begin{tabular}{|c|c|c|c|c|}
\hline $\begin{array}{c}\text { Equipment } \\
\text { Usage }\end{array}$ & Values & $\begin{array}{c}\text { Percent Four to } \\
\text { Eight Quarter }\end{array}$ & $\begin{array}{c}\text { Percent } \\
\text { Pallet }\end{array}$ & $\begin{array}{c}\text { Percent } \\
\text { Cant + Timber }\end{array}$ \\
\hline \multirow{2}{*}{ Head Saw } & Coefficient & 0.348 & -0.029 & -0.288 \\
\cline { 2 - 5 } & P - Value & $<0.0001$ & 0.739 & 0.001 \\
\hline \multirow{2}{*}{ Re-saw } & Coefficient & 0.532 & 0.439 & -0.627 \\
\cline { 2 - 5 } & P - Value & $<0.0001$ & $<0.0001$ & $<0.0001$ \\
\hline \multirow{2}{*}{ Edger } & Coefficient & 0.403 & 0.018 & -0.354 \\
\cline { 2 - 5 } & P - Value & $<0.0001$ & 0.834 & $<0.0001$ \\
\hline \multirow{2}{*}{ Trimmer } & Coefficient & 0.374 & 0.085 & -0.354 \\
\cline { 2 - 5 } & P - Value & $<0.0001$ & 0.332 & $<0.0001$ \\
\hline \multirow{2}{*}{ Chipper } & Coefficient & 0.378 & 0.030 & -0.337 \\
\cline { 2 - 5 } & P - Value & $<0.0001$ & 0.730 & $<0.0001$ \\
\hline \multirow{2}{*}{ Debarker } & Coefficient & 0.075 & 0.066 & -0.090 \\
\cline { 2 - 5 } & P - Value & 0.390 & 0.452 & 0.303 \\
\hline \multirow{2}{*}{ Compressor } & Coefficient & 0.350 & -0.104 & -0.261 \\
\cline { 2 - 5 } & P - Value & $<0.0001$ & 0.235 & 0.002 \\
\hline
\end{tabular}

Also, it is important to note that the percentage four to eight quarter lumber processed is positively correlated to head saw, re-saw, edger, trimmer, chipper, debarker and compressor usage in minutes. Again debarker usage is not significantly correlated to percentage four to eight quarter lumber similar to pallet percentage and cant + timber percentage. This indicates that irrespective of the lumber size sawn, debarker has to work. This helps to validate the data that were collected; as more four to eight quarter lumber was processed in a shift, all the equipment did more work or those shifts were longer than the shifts that had more percentage of cant and timber and hence has resulted in higher energy consumption. Hence, this will result in an increase in overall SEC for board size lumber. 


\subsection{Energy allocation Methodology}

As seen from Pearson correlation coefficients, board size lumber consumes more energy than other sizes or energy consumption for sawing is inversely proportional to the size of the lumber sawn. Hence, energy consumed for sawing must be allocated to a particular size lumber based on the work done to produce that size lumber. Work done for sawing depends on the surface area to be cut to make that lumber. Consider sawing the cant and the boards shown in Figure 4.7 having same board feet. It is obvious from the figure that for sawing boards, more time and energy is required than for sawing cant. The energy required to saw the boards is approximately 3 times of the energy required for sawing cant.
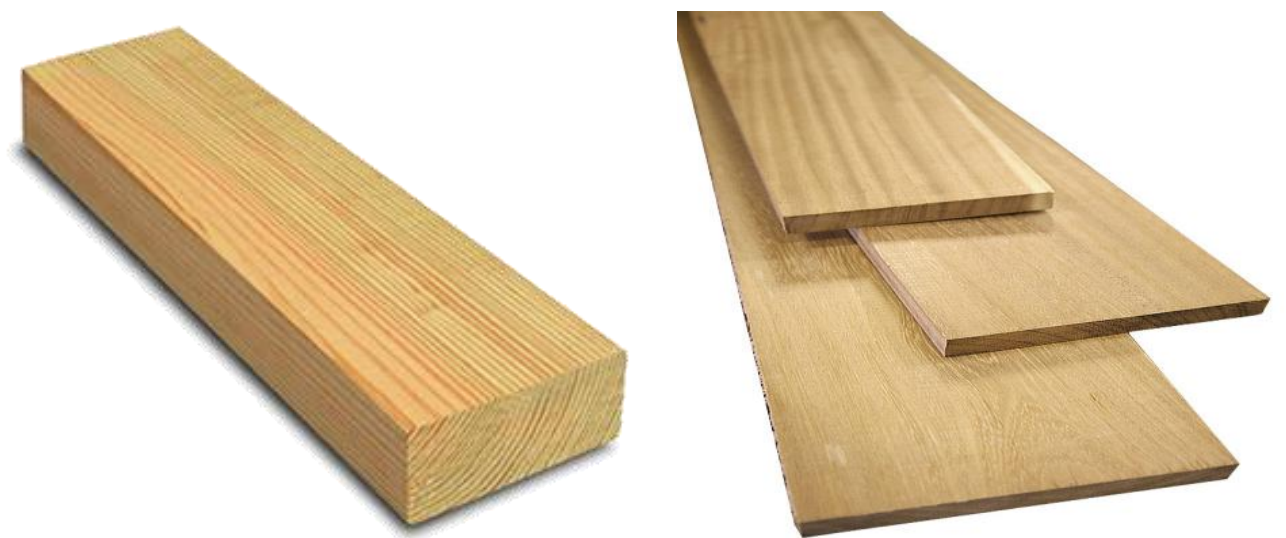

\section{Figure 4.7: Comparison between a Cant and Lumber of equal Board Feet}

Hence energy allocation must be done based on the surface area cut for that particular size of lumber in that particular equipment. Even though the percentage of different size lumber has strong correlation with the energy consumption, their effect cannot be eliminated by using statistical method like 'Analysis of Covariance' (ANCOVA) since the actual effect is produced not just by the percentage of different size lumber, but by the surface area cut for different size lumber. Surface area cut was calculated for head saw/resaw/gang saw, edger and trimmer as shown in the example. Surface area cut for the rest of the motors was taken as the sum of the surface areas cut by head saw/resaw/gang saw, edger and trimmer since they are not directly 
involved in sawing particular size lumber. Widths of grade lumber sawn varied and had minimum widths based on the grade sawn (Table 3.5), but for the energy allocation purpose, an average width of 6" is assumed. Later, sensitivity analysis based on different widths produced is done to calculate SEC.

Example for Sawmill 2:

Hickory $4 / 4$ size (1" thick x 6" wide x 10' long) sawn in $1^{\text {st }}$ shift (Appendix Table A.4 no 23)

Total board feet of $4 / 4$ cut $\quad=4,652 \mathrm{Bft}$

Total length cut

$=$ Total board feet cut $/$ (Width $\mathrm{x}$ Thickness)

$=4,652 \mathrm{Bft} /(0.5$ feet $\times 1$ inch $) \quad(1 \mathrm{bft}=1 \mathrm{ft} \times 1 \mathrm{ft} \times 1 \mathrm{inch})$

$=9,304 \mathrm{ft}$

Surface area cut by Head saw $=$ Total length cut $\mathrm{x}$ Width

$=9,304 \mathrm{ft} \times 0.5 \mathrm{ft}$

$=4,652$ sq. $\mathrm{ft}$

Surface area cut by Edger $\quad=$ Total length cut $\mathrm{x}$ Thickness

$=9,304 \mathrm{ft} \times(1 / 12) \mathrm{ft}$

$=775$ sq. $\mathrm{ft}$

No. of pieces cut

$=($ Total length cut/Average piece length $)$

$=9,304 \mathrm{ft} / 10 \mathrm{ft}$

$=930$ pieces

Surface area cut by Trimmer $=$ Width $\mathrm{x}$ thickness $\mathrm{x}$ No. of pieces cut

$=0.5 \mathrm{ft} \times(1 / 12) \mathrm{ft} \times 930$ pieces

$=39$ sq. $\mathrm{ft}$

SA for Rest of the Motors = Surface area cut by $($ Head saw + Edger + Trimmer $)$

$=4,652+775+39$

$=5,466$ sq. ft.

Even though the edger and trimmer will have two saws and will cut twice the surface area calculated above, only one side surface area cut is considered since it is enough for calculation. Also, generally cants and timbers doesn't go to edger and trimmer for sawing since they are 
usually made at the end of sawing a log or left over part of a log and hence the edger and trimmer surface area is not used for allocating energy to them and they will not have the share of energy consumed by edger and trimmer. Similarly, surface areas cut for other lumber sizes were calculated using the above method. The total surface area cut from head saw/resaw/gang saw, edger and trimmer for 1,000 board feet of each size lumber is shown in Figure 4.8.

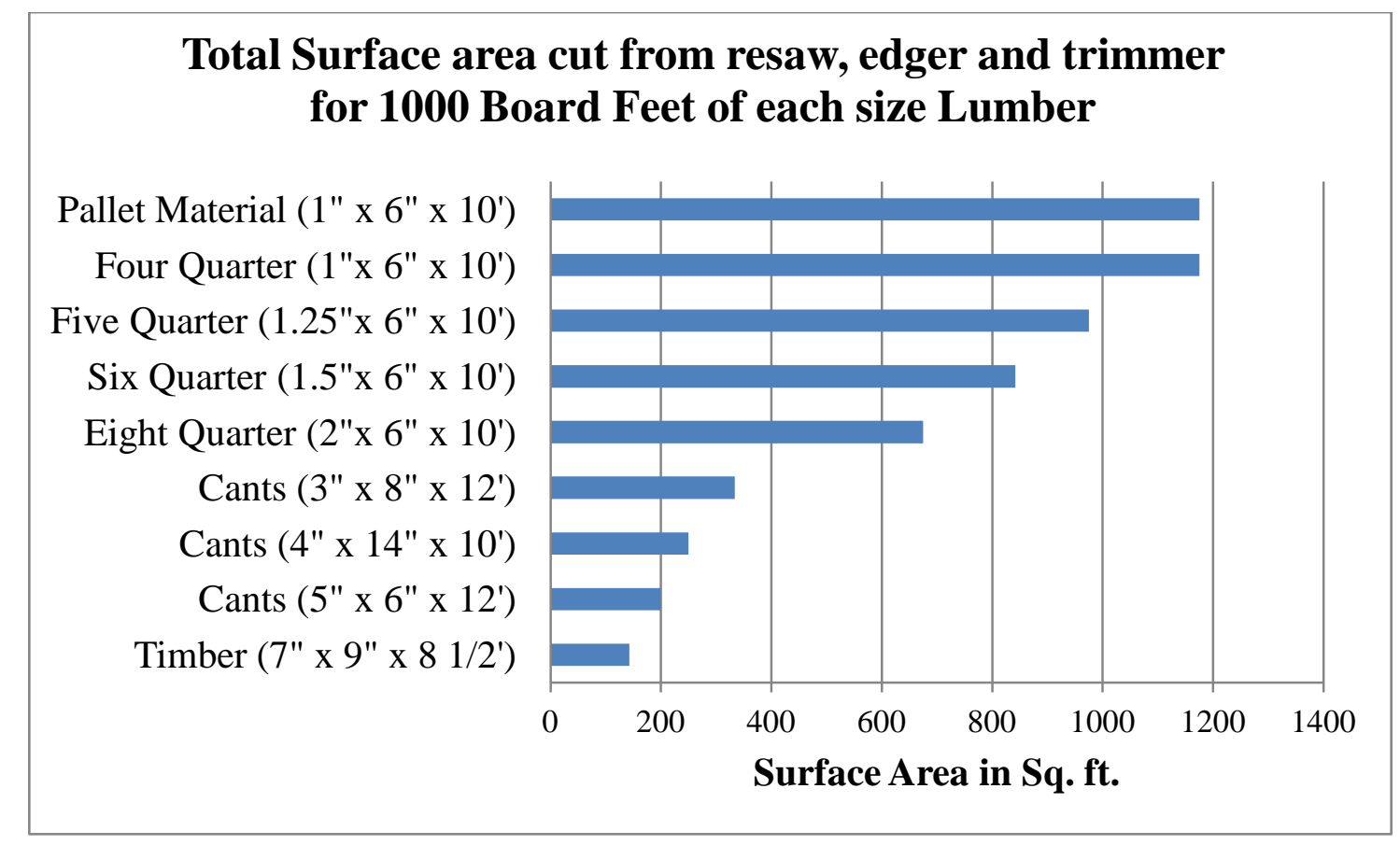

Figure 4.8: Surface Area Cut for 1,000 Board Feet of each Size Lumber

Energy was allocated to individual size of lumber by a factor that was calculated as the ratio of the surface area cut for that particular size in each machine to the total surface area cut by that machine during that period. For example for the same Hickory sawn in $1^{\text {st }}$ shift (Appendix Table A.4 shift no. 23), the factors are allocated as follows:

Factor for head saw for $4 / 4=$ Surface area cut for $4 / 4$ size $/$ Total Surface area cut by head saw

$$
\begin{aligned}
& =4,652 / 5,793 \\
& =0.8030
\end{aligned}
$$


Similarly, other factors are calculated and are shown in Table 4.11. Table 4.12 shows the total energy consumption of different motors for sawing Hickory (Appendix Table A.17 shift no 23).

Table 4.11: Surface Area Cut and Factors allocation in Sawmill 2

\begin{tabular}{|c|c|c|c|c|c|c|c|c|c|}
\hline Size & $\begin{array}{c}\text { Board } \\
\text { Feet }\end{array}$ & $\begin{array}{c}\text { Surface } \\
\text { Area } \\
\text { Head Saw }\end{array}$ & $\begin{array}{c}\text { Surface } \\
\text { Area } \\
\text { Edger }\end{array}$ & $\begin{array}{c}\text { Surface } \\
\text { Area } \\
\text { Trimmer }\end{array}$ & $\begin{array}{c}\text { Surface } \\
\text { Area } \\
\text { Rest }\end{array}$ & $\begin{array}{c}\text { Factor } \\
\text { Head } \\
\text { Saw }\end{array}$ & $\begin{array}{c}\text { Factor } \\
\text { Edger }\end{array}$ & $\begin{array}{c}\text { Factor } \\
\text { Trimmer }\end{array}$ & $\begin{array}{c}\text { Factor } \\
\text { Rest }\end{array}$ \\
\hline 4/4 & 4,652 & 4,652 & 775 & 39 & 5,466 & 0.8030 & 0.9486 & 0.9512 & 0.8218 \\
\hline 1"x 6"x10' & 252 & 252 & 42 & 2 & 296 & 0.0435 & 0.0514 & 0.0488 & 0.0445 \\
\hline 5"x 6"x 12' & 2,470 & 494 & 0 & 0 & 494 & 0.0853 & 0.0000 & 0.0000 & 0.0743 \\
\hline 7"x 9"x10" & 2,767 & 395 & 0 & 0 & 395 & 0.0682 & 0.0000 & 0.0000 & 0.0594 \\
\hline Total & $\mathbf{1 0 , 1 4 1}$ & $\mathbf{5 , 7 9 3}$ & $\mathbf{8 1 7}$ & $\mathbf{4 1}$ & $\mathbf{6 , 6 5 1}$ & $\mathbf{1}$ & $\mathbf{1}$ & $\mathbf{1}$ & $\mathbf{1}$ \\
\hline
\end{tabular}

Table 4.12: Energy Consumption in $\mathrm{kWh}$ by various Motors for Sawing Hickory

\begin{tabular}{|c|c|c|c|c|}
\hline $\begin{array}{c}\text { Mainsaw }+ \\
\text { Carriage Feed }\end{array}$ & Edger & Trimmer & Rest of the Motors & Total \\
\hline 322.86 & 33.03 & 33.38 & 514.56 & 903.83 \\
\hline
\end{tabular}

Energy consumed by particular size lumber was allocated based on the factors calculated before i.e., by multiplying the total energy consumption by that motor with the factor for that particular size. Total energy consumption was calculated by adding consumption from all the motors for that particular size. SEC was calculated by dividing the total energy allocated for that size by the MBF sawn for that particular size. Table 4.13 shows the energy consumed on various motors for sawing different size lumber and the total $\mathrm{kWh}$ consumed per thousand board feet of lumber.

Table 4.13: Energy Consumed for Sawing Different Size Lumber of Hickory

\begin{tabular}{|c|c|c|c|c|c|c|c|}
\hline Size & $\begin{array}{c}\text { Board } \\
\text { Feet }\end{array}$ & $\begin{array}{c}\text { Main saw } \\
\text { Motor } \\
\text { kWh }\end{array}$ & $\begin{array}{c}\text { Edger } \\
\text { Motor } \\
\mathbf{k W h}\end{array}$ & $\begin{array}{c}\text { Trimmer } \\
\text { Motor } \\
\text { kWh }\end{array}$ & $\begin{array}{c}\text { Rest of the } \\
\text { Motors } \\
\text { kWh }\end{array}$ & $\begin{array}{c}\text { Total kWh } \\
\text { Consumed }\end{array}$ & $\begin{array}{c}\text { kWh/ } \\
\text { thousand } \\
\text { Board Feet }\end{array}$ \\
\hline 4/4 & 4,652 & 259.26 & 31.33 & 31.67 & 422.86 & 745.11 & 160.17 \\
\hline 1"x 6"x10' & 252 & 14.04 & 1.70 & 1.71 & 22.91 & 40.36 & 160.16 \\
\hline 5"x 6" x 12' & 2,470 & 27.53 & 0 & 0 & 38.21 & 65.75 & 26.62 \\
\hline 7"x 9"x10" & 2,767 & 22.03 & 0 & 0 & 30.58 & 52.61 & 19.01 \\
\hline Total & $\mathbf{1 0 , 1 4 1}$ & $\mathbf{3 2 2 . 8 6}$ & $\mathbf{3 3 . 0 3}$ & $\mathbf{3 3 . 3 8}$ & $\mathbf{5 1 4 . 5 6}$ & $\mathbf{9 0 3 . 8 3}$ & - \\
\hline
\end{tabular}


Similarly, SEC was calculated for hickory sawn at different times during the one month logging period and the average was determined. Similarly, SEC for other species with different size lumber was calculated for all the 5 sawmills. Calculated average SEC based on surface area cut for all the species and sizes of entire sawmill production is summarized in Table 4.14. It can be noted that calculated SEC is lowest for sawmill 1 and highest for sawmill 4 (Figure 4.9).

Table 4.14: SEC Calculated based on Surface Area Cut

\begin{tabular}{|c|c|c|c|c|}
\hline \multicolumn{5}{|c|}{ Sawmill 1: Overall SEC: 86.26 kWh/MBF, 87.75 kWh/MBF } \\
\hline Size & Board Feet & kWh/Board Feet & kWh/MBF & Total kWh \\
\hline $1 " x 6 " x 10$ ' & 327,363 & 0.095 & 94.46 & $30,123.86$ \\
\hline $1.25 ” \times 6 " \times 10^{\prime}$ & 23,905 & 0.076 & 77.21 & $1,852.14$ \\
\hline $1.5 " \times 6 " \times 10$ ' & 7,618 & 0.073 & 73.89 & 562.77 \\
\hline $2 " \times 6 " \times 10^{\prime}$ & 9,820 & 0.046 & 47.34 & 508.40 \\
\hline Pallet & 64,850 & 0.095 & 95.39 & $6,160.40$ \\
\hline Cants & 17,403 & 0.027 & 25.32 & 441.73 \\
\hline \multirow[t]{2}{*}{ Timber } & 10,035 & 0.012 & 10.86 & 117.97 \\
\hline & 460,994 & & & 39,767.27 \\
\hline \multicolumn{5}{|c|}{ Sawmill 2: Overall SEC: 83.56 kWh/MBF, 84.11 kWh/MBF } \\
\hline Size & Board Feet & kWh/Board Feet & kWh/MBF & Total kWh \\
\hline $1 " x 6 " x 10$ ' & 158,100 & 0.153 & 153.42 & $22,292.49$ \\
\hline $1.25 ” \times 6 " \times 10$ & 25,866 & 0.144 & 144.17 & $3,892.90$ \\
\hline $1.5 ” \times 6 " \times 10$ & 12,284 & 0.095 & 94.85 & $1,151.85$ \\
\hline $2 " \times 6 " \times 10$ & 14,262 & 0.085 & 85.32 & $1,254.12$ \\
\hline Pallet & 14,666 & 0.157 & 157.12 & $2,188.07$ \\
\hline Cants & 86,499 & 0.029 & 29.20 & $2,141.13$ \\
\hline \multirow[t]{2}{*}{ Timber } & 109,010 & 0.019 & 18.51 & $2,233.10$ \\
\hline & 420,687 & & & $35,153.66$ \\
\hline \multicolumn{5}{|c|}{ 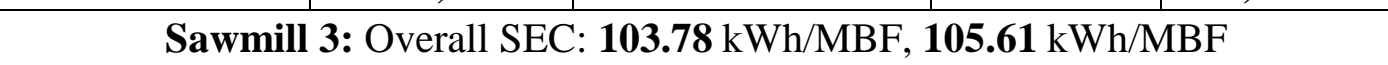 } \\
\hline Size & Board Feet & kWh/Board Feet & kWh/MBF & Total kWh \\
\hline $1 " x 6 " \times 10^{\prime}$ & $1,031,633$ & 0.118 & 118.31 & $116,260.99$ \\
\hline $1.5 " \times 6 " \times 10^{\prime}$ & 31,020 & 0.067 & 66.73 & $2,069.07$ \\
\hline $2 " \times 6 " \times 10$ ' & 382 & 0.054 & 53.72 & 20.521671 \\
\hline Pallet & 246,408 & 0.119 & 119.46 & $28,344.08$ \\
\hline \multirow[t]{2}{*}{ Timber } & 121,944 & 0.015 & 14.55 & $1,882.64$ \\
\hline & $1,431,387$ & & & $148,577.30 *$ \\
\hline
\end{tabular}


Table 4.14: SEC Calculated based on Surface Area Cut

\begin{tabular}{|c|c|c|c|c|}
\hline \multicolumn{5}{|c|}{ Sawmill 4: Overall SEC: $122.51 \mathrm{kWh} / \mathrm{MBF}, 121.95 \mathrm{kWh} / \mathrm{MBF}$} \\
\hline Size & Board Feet & kWh/Board Feet & kWh/MBF & Total kWh \\
\hline $1 " \times 6 " x 10$ ' & 296,280 & 0.173 & 172.98 & $50,012.52$ \\
\hline $1.5 " \times 6 " \times 10 "$ & 31,070 & 0.128 & 127.72 & $3,480.64$ \\
\hline $2 " \times 6 " \times 10 "$ & 182,383 & 0.119 & 118.69 & $20,884.13$ \\
\hline Pallet & 6,974 & 0.184 & 183.78 & $1,281.73$ \\
\hline Cants & 106,688 & 0.039 & 38.80 & $3,818.25$ \\
\hline Timber & 36,984 & 0.031 & 31.12 & $1,330.11$ \\
\hline & 660,379 & & & 80,807.38* \\
\hline \multicolumn{5}{|c|}{ Sawmill 5: Overall SEC: $112.12 \mathrm{kWh} / \mathrm{MBF} 118.44 \mathrm{kWh} / \mathrm{MBF}$} \\
\hline Size & Board Feet & kWh/Board Feet & $\mathbf{k W h} / \mathbf{M B F}$ & Total kWh \\
\hline $1 " \times 6 " x 10$ ' & 594,681 & 0.124 & 124.29 & 71464.68 \\
\hline $1.25 " \times 6 " \times 10 "$ & 173,337 & 0.118 & 118.33 & $23,624.78$ \\
\hline $2 " \times 6 " \times 10 ”$ & 34,029 & 0.057 & 56.71 & $1,844.05$ \\
\hline Pallet & 57,221 & 0.133 & 133.31 & $7,234.80$ \\
\hline Cants & 67,872 & 0.032 & 31.84 & 1796.89 \\
\hline \multirow[t]{2}{*}{ Timber } & 22,009 & 0.019 & 19.44 & 452.54 \\
\hline & 949,149 & & & $106,417.74$ \\
\hline
\end{tabular}

${ }^{*}$ Calculated total $\mathrm{kWh}$ is little different from the values in Table 4.6 due to round off error

The result obtained by energy allocation based on surface area cut is completely different from the result obtained by just calculating overall SEC in which sawmill 2 had the lowest (Table 4.6) and it became $2^{\text {nd }}$ highest now. The main reason for the change in the result for sawmill 2 can be attributed to higher percentage (47\%) of larger lumber sizes like cants and timbers that were sawn in it (Table 3.4). Also, it can be noted that the SEC of the lumber sawn in sawmill 4 went up very high after energy allocation based on surface area was done since they produced lower board feet per kWh compared to other sawmills and also produced higher percentage (22\%) of larger lumber sizes like cants and timbers compared to sawmill 1, 3 and 5 . The other thing to be noted is both sawmill 2 and 4 does not have resaw or gangsaw and hence their production rate in terms of grade lumber was lower compared to other sawmills. 


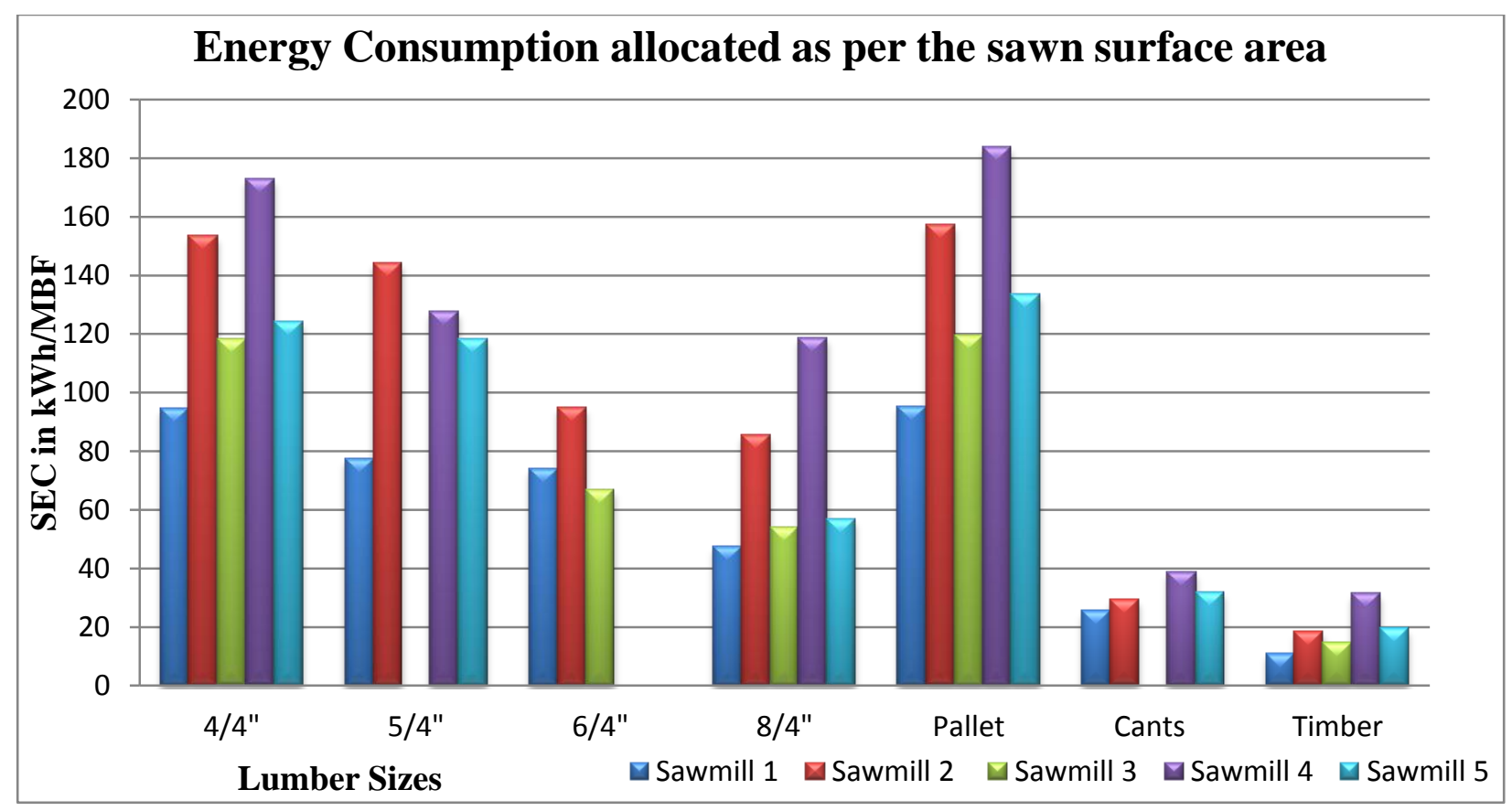

Figure 4.9: SEC of Sawmill 1 to 5 Calculated as per Surface Area Cut

Calculated SEC based on surface area cut for $4 / 4$ size lumber for each shift of all the 5 sawmills are shown in Table 4.15. SEC of 4/4 size lumber for sawmill 1 and 2 didn't pass normality test where as the other 3 sawmills passed the normality test. In order to verify whether the SEC of 4/4 lumber of each sawmill are from the same population or not, non parametric Kruskal-Wallis Test (Table 4.16) was used since all the sawmills data didn't follow normal distribution. Box plots were plotted to verify whether the data follows symmetric distribution and although the data had some outliers, more or less all the sawmill's data followed symmetric distribution (Figure 4.10). 
Table 4.15: Calculated SEC Values for 4/4 Lumber of 5 Sawmills for various Shifts*

\begin{tabular}{|c|c|c|c|c|c|}
\hline Sl. No. & $\begin{array}{c}\text { Sawmill } 1 \\
4 / 4\end{array}$ & $\begin{array}{c}\text { Sawmill } 2 \\
4 / 4\end{array}$ & $\begin{array}{c}\text { Sawmill } 3 \\
4 / 4\end{array}$ & $\begin{array}{c}\text { Sawmill } 4 \\
4 / 4\end{array}$ & $\begin{array}{c}\text { Sawmill } 5 \\
4 / 4\end{array}$ \\
\hline 1 & 74.88 & 160.17 & 117.76 & 158.76 & 109.78 \\
\hline 2 & 66.55 & 122.02 & 143.46 & 150.46 & 113.76 \\
\hline 3 & 91.05 & 142.30 & 122.40 & 134.54 & 153.86 \\
\hline 4 & 91.75 & 129.22 & 127.36 & 144.55 & 137.55 \\
\hline 5 & 87.10 & 131.74 & 111.68 & 149.60 & 85.73 \\
\hline 6 & 81.72 & 124.43 & 89.52 & 132.36 & 102.60 \\
\hline 7 & 83.36 & 108.52 & 116.53 & 181.82 & 82.54 \\
\hline 8 & 90.47 & 169.40 & 116.05 & 194.26 & 130.99 \\
\hline 9 & 92.21 & 139.54 & 168.35 & 200.56 & 101.93 \\
\hline 10 & 100.66 & 132.28 & 105.06 & 185.85 & 143.04 \\
\hline 11 & 100.28 & 196.87 & 112.18 & 167.70 & 116.56 \\
\hline 12 & 88.37 & 168.44 & 86.33 & 171.91 & 139.44 \\
\hline 13 & 94.80 & 143.16 & 89.69 & 187.75 & 116.97 \\
\hline 14 & 83.53 & 158.54 & 81.33 & 141.75 & 107.32 \\
\hline 15 & 118.31 & 147.90 & 90.74 & 156.37 & 143.75 \\
\hline 16 & 91.45 & 139.09 & 112.59 & 159.81 & 114.33 \\
\hline 17 & 132.13 & 144.44 & 179.73 & 190.27 & 136.45 \\
\hline 18 & 126.46 & 142.70 & 90.85 & 242.60 & 120.85 \\
\hline 19 & 101.12 & 209.77 & 140.73 & 202.21 & 128.56 \\
\hline 20 & 99.40 & 125.41 & 120.16 & 194.17 & 128.95 \\
\hline 21 & 92.65 & 128.03 & 127.79 & 185.28 & 195.04 \\
\hline 22 & 89.76 & 139.19 & 126.51 & & \\
\hline 23 & & 113.13 & 130.41 & & \\
\hline 24 & & 132.57 & 135.91 & & \\
\hline 25 & & 189.55 & 114.65 & & \\
\hline 26 & & 373.35 & & & \\
\hline 27 & & 160.03 & & & \\
\hline 28 & & 123.92 & & & \\
\hline Average & 94.46 & 153.42 & 118.31 & 172.98 & 124.29 \\
\hline
\end{tabular}

* Some of the shifts didn't saw 4/4 and hence those shifts SEC are not shown (Refer Appendix Table A.4)

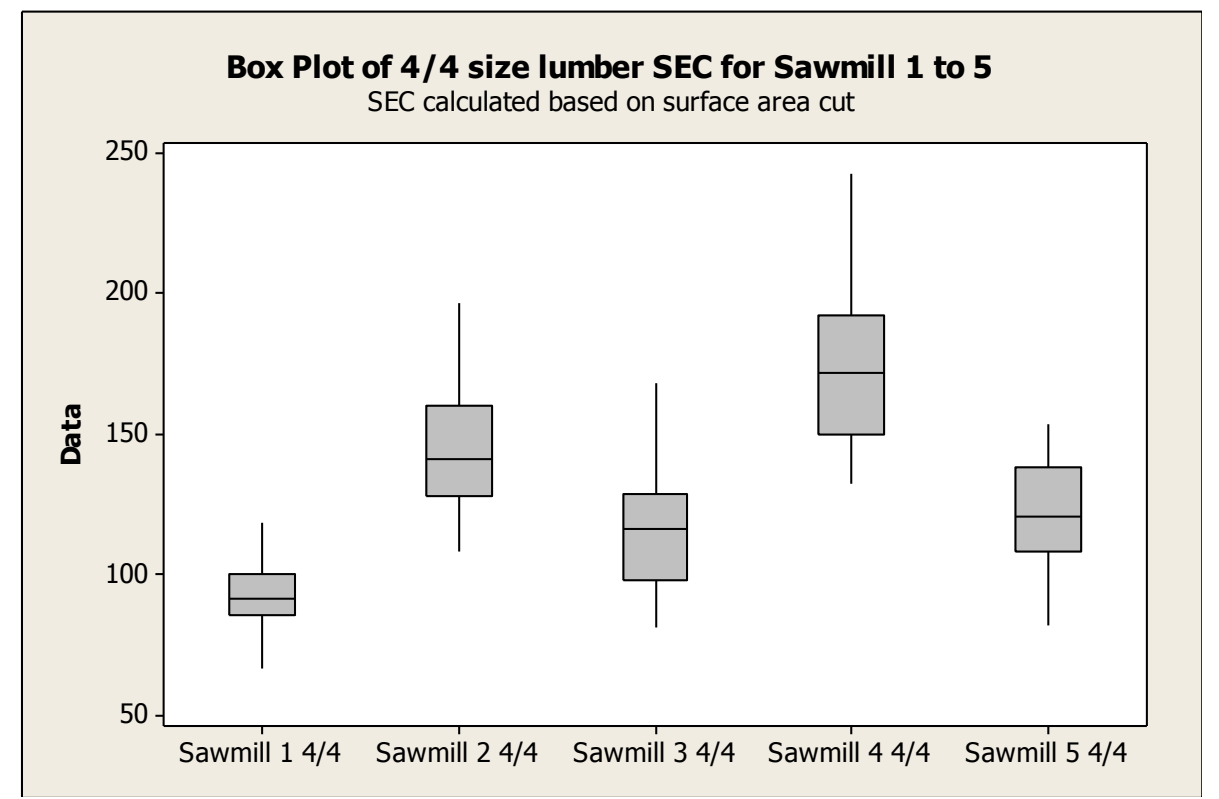

Figure 4.10: Box Plot of 4/4 Size Lumber SEC's of all the 5 Sawmills 
Table 4.16: Kruskal-Wallis Test on 4/4 Lumber SEC Data

\begin{tabular}{|c|c|c|c|c|}
\hline \multicolumn{5}{|c|}{ Multiple Comparisons } \\
\hline Sawmill & $\mathrm{N}$ & Median & Ave Rank & $\mathrm{Z}$ \\
\hline 1 & 22 & 91.60 & 20.9 & -5.85 \\
\hline 2 & 28 & 140.92 & 77.1 & 3.25 \\
\hline 3 & 25 & 116.53 & 45.2 & -2.29 \\
\hline 4 & 21 & 171.91 & 97.2 & 5.70 \\
\hline 5 & 21 & 120.85 & 53.0 & -0.90 \\
\hline Overall & 117 & - & 59.0 & - \\
\hline \multicolumn{5}{|c|}{$\mathrm{H}=67.18 \quad \mathrm{DF}=4 \mathrm{P}=0.000$} \\
\hline \multicolumn{5}{|c|}{ Pairwise Comparison Results of the Groups that showed Significant Differences } \\
\hline \multicolumn{2}{|c|}{ Groups } & \multicolumn{2}{|c|}{\begin{tabular}{l|l} 
Z vs. Critical value & \\
\end{tabular}} & P-value \\
\hline \multicolumn{2}{|c|}{1 vs. 4} & \multicolumn{2}{|l|}{$7.37160>=2.326$} & 0.0000 \\
\hline \multicolumn{2}{|c|}{1 vs. 2} & \multicolumn{2}{|l|}{$5.81915>=2.326$} & 0.0000 \\
\hline \multicolumn{2}{|c|}{3 vs. 4} & \multicolumn{2}{|l|}{$5.17823>=2.326$} & 0.0000 \\
\hline \multicolumn{2}{|c|}{4 vs. 5} & \multicolumn{2}{|l|}{$4.22618>=2.326$} & 0.0000 \\
\hline \multicolumn{2}{|c|}{2 vs. 3} & \multicolumn{2}{|l|}{$3.42248>=2.326$} & 0.0006 \\
\hline \multicolumn{2}{|c|}{1 vs. 5} & \multicolumn{2}{|l|}{$3.09657>=2.326$} & 0.0020 \\
\hline \multicolumn{2}{|c|}{2 vs. 5} & \multicolumn{2}{|l|}{$2.47054>=2.326$} & 0.0135 \\
\hline \multicolumn{2}{|c|}{1 vs. 3} & \multicolumn{2}{|l|}{$2.44981>=2.326$} & 0.0143 \\
\hline
\end{tabular}

\section{Multiple Comparisons Chart}

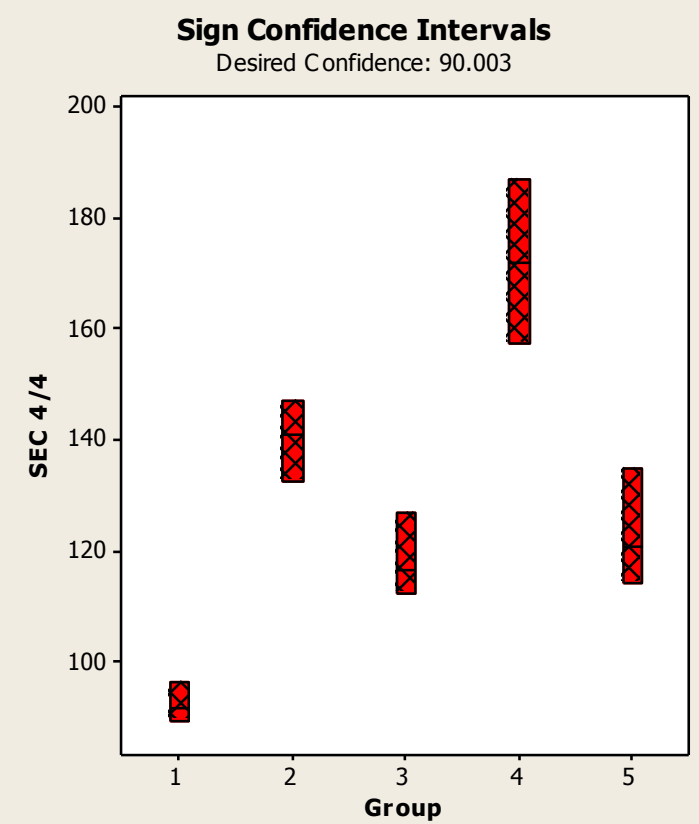

Family Alpha: 0.2

Bonferroni Indiv idual A lpha: 0.02

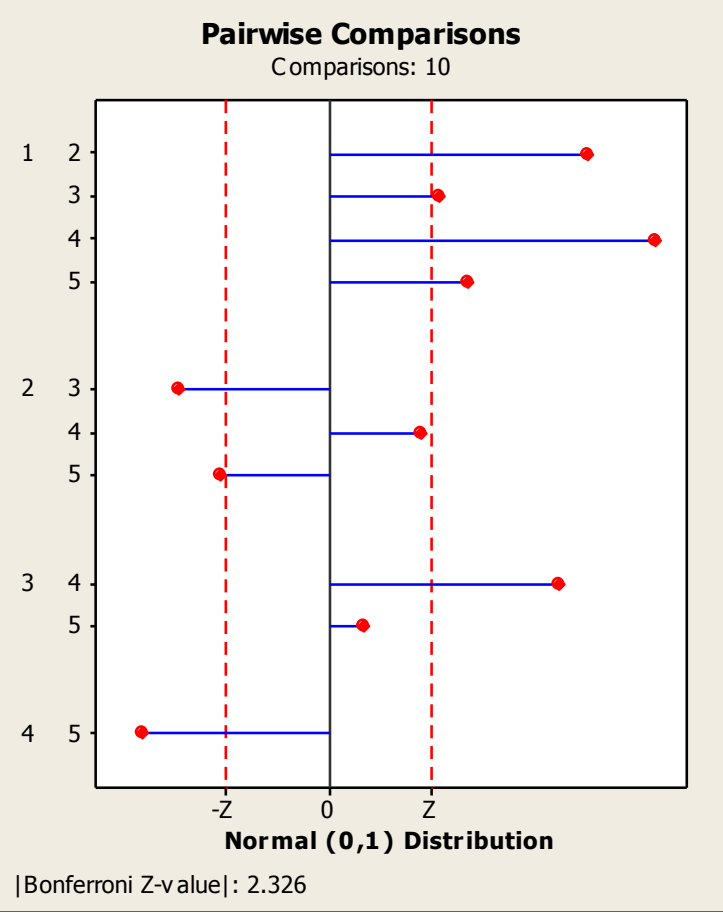

Figure 4.11: Kruskal-Wallis Test Results for 4/4 Lumber SEC's of all the 5 Sawmills 
From the Kruskal-Wallis Comparison test (Figure 4.11) it was evident that sawmill 4 had the highest energy consumption followed by sawmill 2. There was no difference between the median's of Sawmill 3 and 5 and they stayed below sawmill 4 and 2. Sawmill 1 had the lowest energy consumption compared to all the other sawmills.

The calculation of 4/4 lumber size SEC based on surface area cut has still the variability of species. So, SEC for only the species of red oak of size $4 / 4$ was calculated (Table 4.17) as an example for all the 5 sawmills and is shown in Figure 4.12.

Table 4.17: Calculated SEC Values for 4/4 Red Oak Lumber of 5 Sawmills for various Shifts

\begin{tabular}{|c|c|c|c|c|c|}
\hline Sl. No. & $\begin{array}{c}\text { Sawmill 1 } \\
\text { 4/4 RO }\end{array}$ & $\begin{array}{c}\text { Sawmill 2 } \\
\text { 4/4 RO }\end{array}$ & $\begin{array}{c}\text { Sawmill 3 } \\
\text { 4/4 RO }\end{array}$ & $\begin{array}{c}\text { Sawmill 4 } \\
\text { 4/4 RO }\end{array}$ & $\begin{array}{c}\text { Sawmill 5 } \\
\text { 4/4 RO }\end{array}$ \\
\hline 1 & 66.55 & 108.52 & 117.76 & 158.76 & 109.78 \\
\hline 2 & 91.05 & 169.40 & 143.46 & 167.70 & 130.99 \\
\hline 3 & 91.75 & 139.54 & 112.18 & 171.91 & 101.93 \\
\hline 4 & 87.10 & 132.28 & 112.59 & 187.75 & 143.04 \\
\hline 5 & 90.47 & 143.16 & 135.91 & 200.98 & 116.56 \\
\hline 6 & 99.40 & 158.54 & 114.65 & & 139.44 \\
\hline 7 & 92.65 & 147.90 & & & 116.97 \\
\hline 8 & 89.76 & 139.09 & & & 120.85 \\
\hline 9 & & 125.41 & & & 128.56 \\
\hline 10 & & 128.03 & & & 128.95 \\
\hline 11 & & 139.19 & & & 195.04 \\
\hline 12 & & 373.35 & & & \\
\hline 13 & & 160.03 & & & \\
\hline 14 & & 123.92 & & & $\mathbf{1 3 0 . 1 9}$ \\
\hline Average & $\mathbf{8 8 . 5 9}$ & $\mathbf{1 5 6 . 3 1}$ & $\mathbf{1 2 2 . 7 6}$ & $\mathbf{1 7 7 . 4 2}$ & \\
\hline
\end{tabular}

Again a Kruskal-Wallis Comparison test was conducted on the calculated values and the test results (Table 4.18) followed the similar pattern as 4/4 lumber test results. 


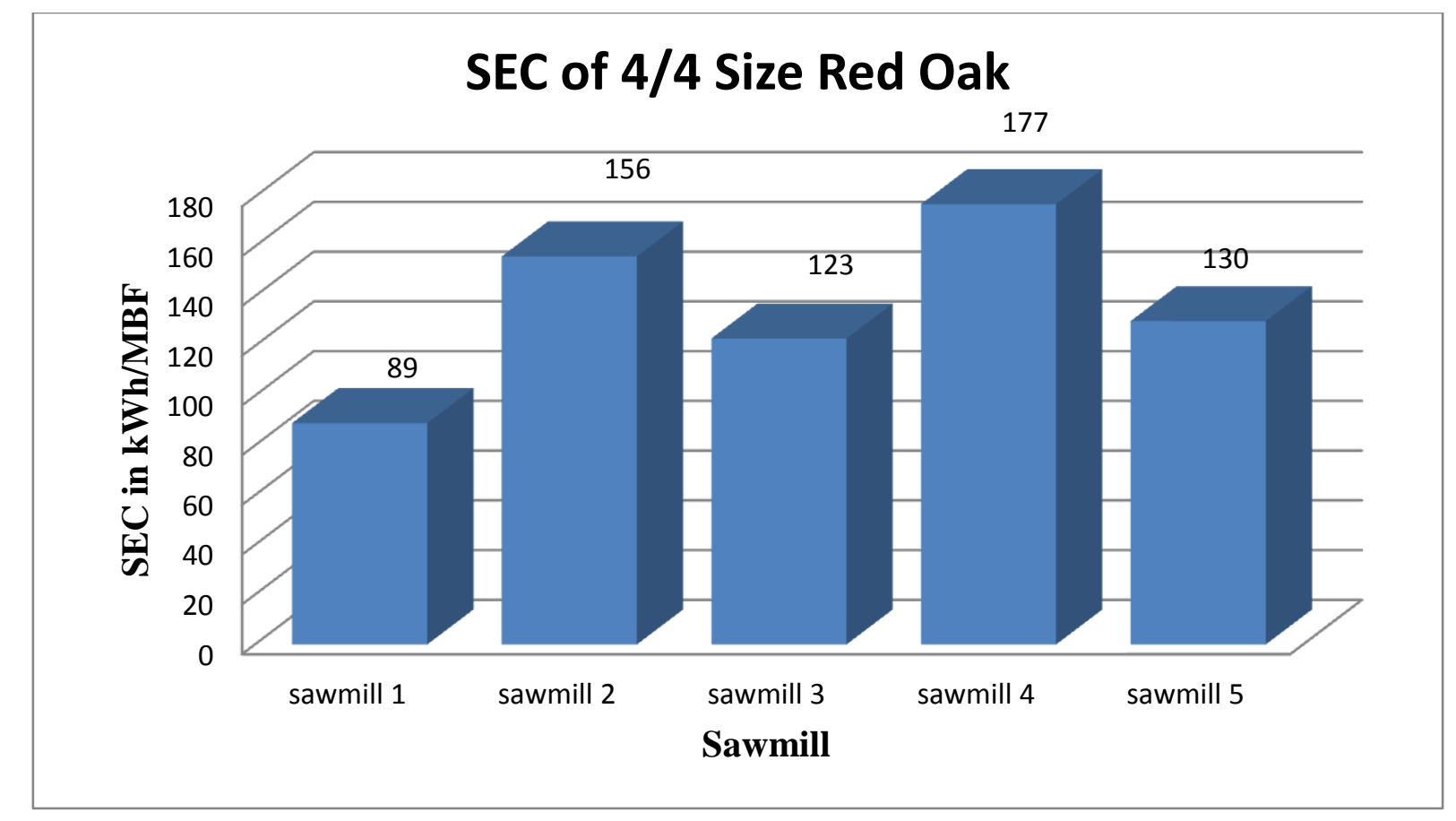

Figure 4.12: SEC of 4/4 Red Oak Lumber for Sawmill 1 to 5 Calculated as per Surface Area Cut

Table 4.18: Kruskal-Wallis Test on 4/4 Red Oak Lumber SEC Data

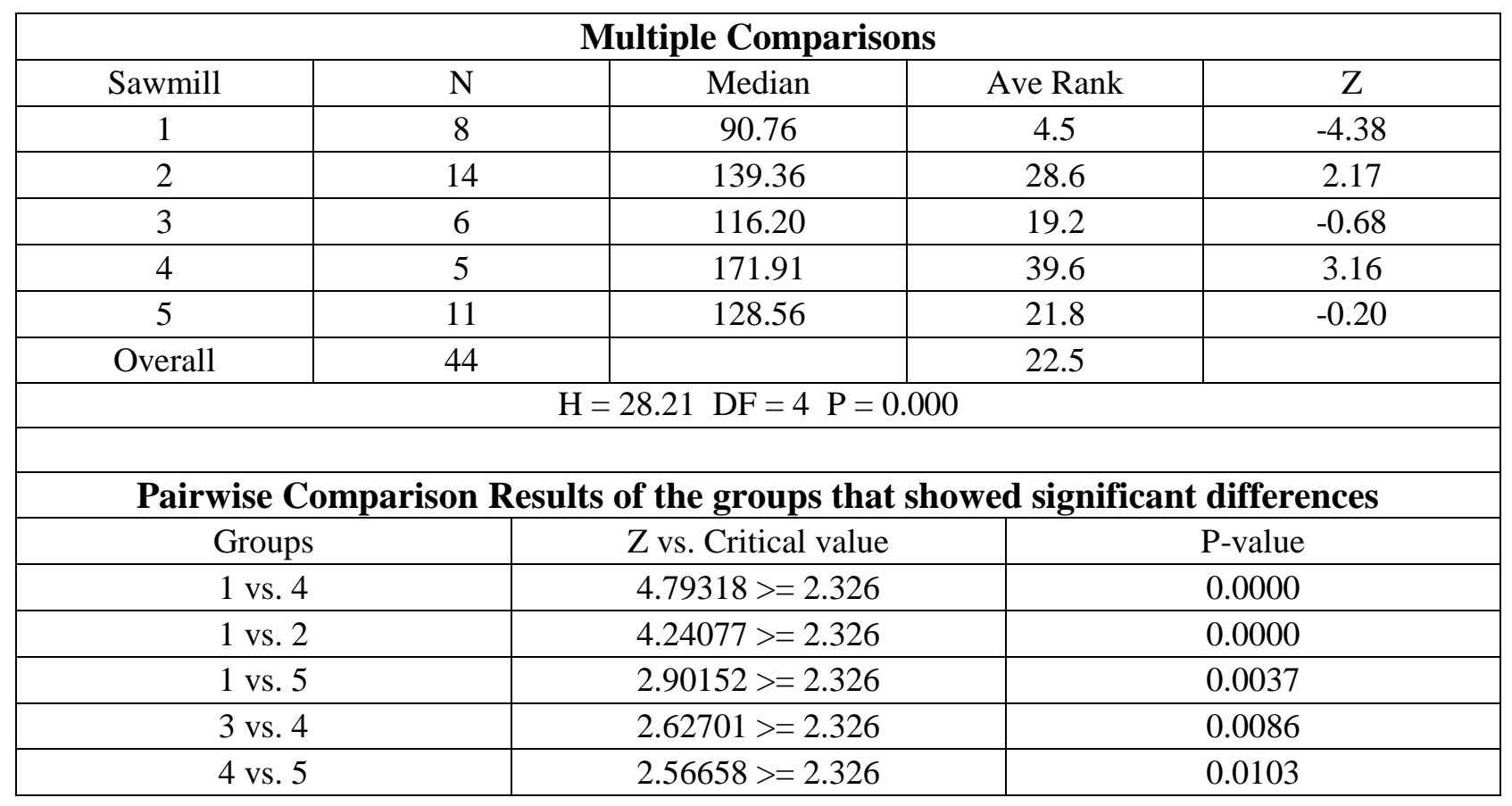




\subsection{Discussion}

From Figures 4.9 and 4.12, SEC of sawmill 2 and 4 are way more higher than the other sawmills and SEC of sawmill 1 is the lowest of all the sawmills. SEC of sawmill 3 and 5 are somewhere in the middle of all the sawmills.

Higher SEC of sawmills 2 and 4 can be attributed to the lack of re-saw (Figure 3.10). Although Sawmill 2 had the highest board feet produced per $\mathrm{kWh}$ spent (11.97 in Table 4.6), it is producing more of larger size lumber like cants and timbers (47\% in Table 3.4$)$ and hence ended up in consuming more SEC per board feet after energy allocation based on surface area was done. Sawmill 4 has the least board feet produced per kWh (8.16 in Table 4.6) due to lack of resaw and also produced higher percentage (22\% in Table 3.4) of larger lumber sizes like cants and timbers compared to sawmill 1,3 and 5 and hence its SEC went up really high after energy allocation based on surface area was done. Without a resaw or a gangsaw, only one machine i.e., head saw will be sawing all the lumber and hence slows down the production rate. Once the head saw production slows up, other machines will be idling due to this. In sawmills 1,3 and 5 there is either a resaw or a gangsaw in addition to headsaw to increase the production rate.

Sawmill 2 is no longer in business, it would have improved its productivity and energy efficiency by adding a resaw to its production line. Sawmill 4 has reported operating cost loss in some of the shifts during data collection period (Appendix Table A.27) due to working extra hours (overrun) than planned. That data is not discussed in detail since similar data from other sawmills is not available for comparison. Sawmill 4 can increase its production by adding a resaw or a gang saw. Also the board lumber price is higher than dimension lumber and timber and hence will increase the profitability of sawmill if it produces more of board lumber. If a 
sawmill can produce more of board lumber than dimension lumber and timber, then it has both productivity and profit compared to other sawmill that produces less of board lumber.

Even though sawmill 3 had the highest production rate in terms of board feet per hour $(9,975$ in Table 4.6$)$, its board feet production per kWh was moderate (9.64 in Table 4.6) and also it ended up in the lower middle position after energy allocation based on surface area cut was done. There are two production lines in sawmill 3 with only one gangsaw for both the lines (Figure 3.10). From the sample amperage data taken from sawmill 3, it can be seen that Line 1 was working more (Figure 4.13) than line 2 (Figure 4.14) during data logging period. It looks like gang saw was unable to handle the production (Figure 4.15) from both the lines and forced one line to slow down and hence ended up in higher energy consumption than it could have achieved if the capacities were matched. Figure 4.13, 4.14 and 4.15 shows the production/energy consumption of line 1 head saw, line 2 head saw carriage feed and gang saw. Saw will be sawing the $\log$ at the point where there is a peak in the energy consumption in the plotted graphs. It is clear that Line 1 is more busy than Line 2 and gang saw is the busiest of all the three saws. Gang saw of sawmill 3 is of very high horse power $418 \mathrm{hp}$ and the motor is loaded only to around $60 \%$ of its maximum capacity (Figure 4.15). The motor load factor (LF) is given by,

$$
\mathrm{LF}=(\sqrt{3} * \mathrm{~V} * \mathrm{I} * \cos \Phi /(1000)) /(\text { Motor hp } \mathrm{x} 0.746)
$$

Where,

$$
\begin{array}{ll}
\mathrm{V} & =470 \\
\mathrm{I} & =250(\text { Approximate Average of maximums in Figure 4.15) } \\
\cos \Phi & =0.88 \\
\text { Motor hp } & =418 \\
\mathrm{LF} \quad= & (\sqrt{3} * 470 * 250 * 0.88 /(1000)) /(418 \times 0.746) \\
= & 0.57
\end{array}
$$

If they had two gang saws of say $200 \mathrm{hp}$ each, definitely their production would have increased and also would have reduced energy consumption. 


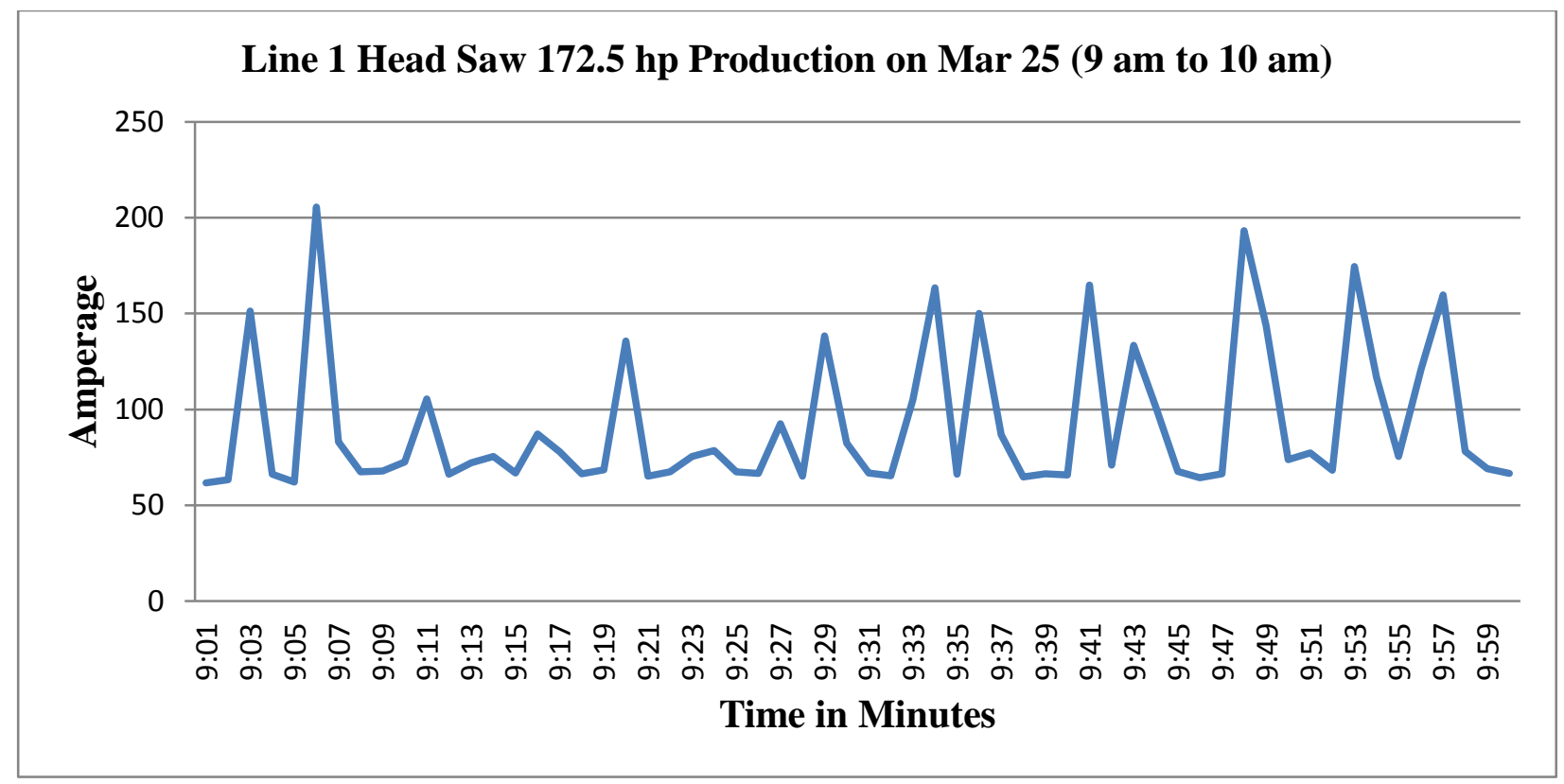

Figure 4.13: Sample of Line 1 Head saw Production of Sawmill 3

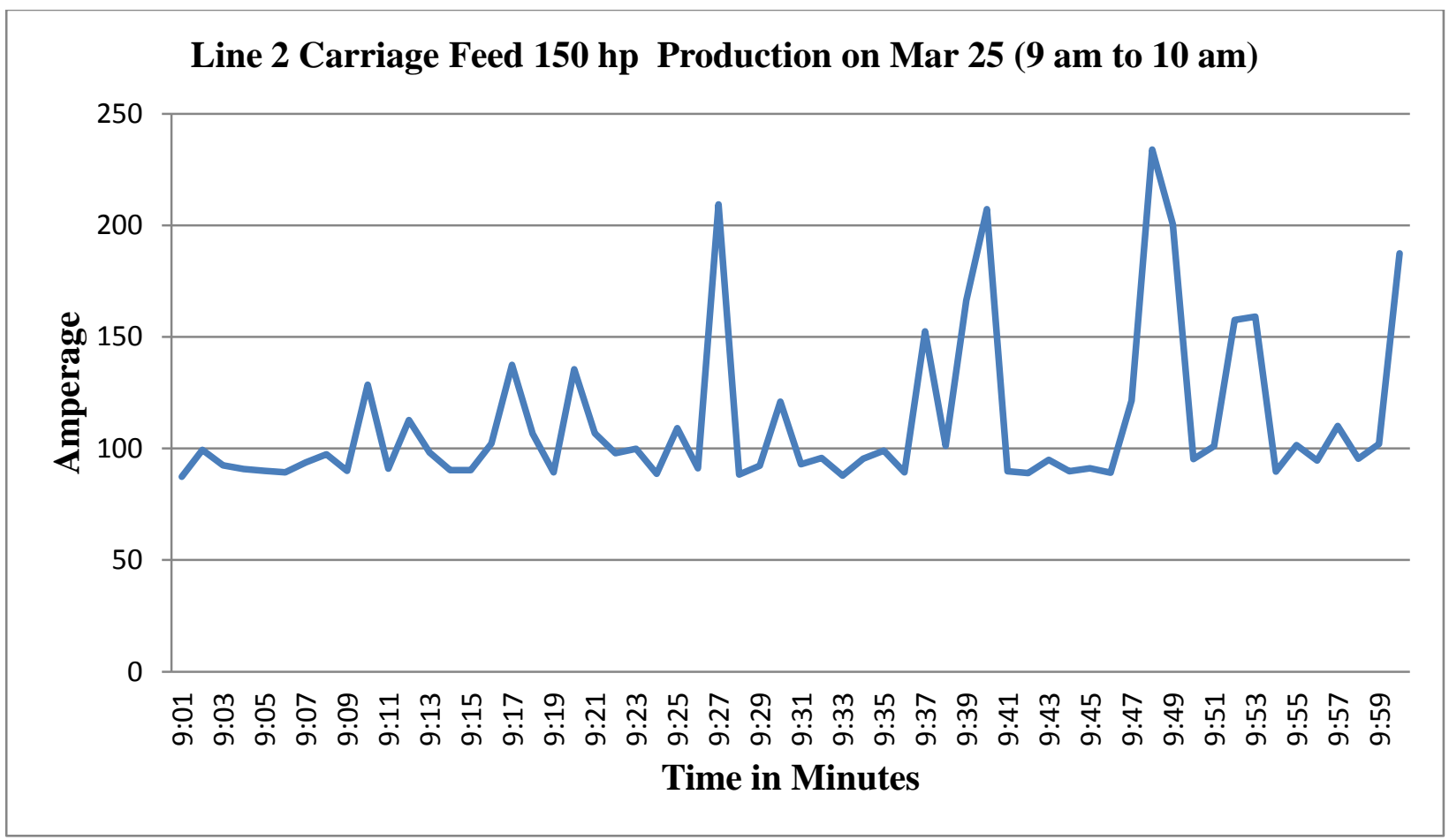

Figure 4.14: Sample of Line 2 Head Saw's Carriage Feed Production of Sawmill 3 


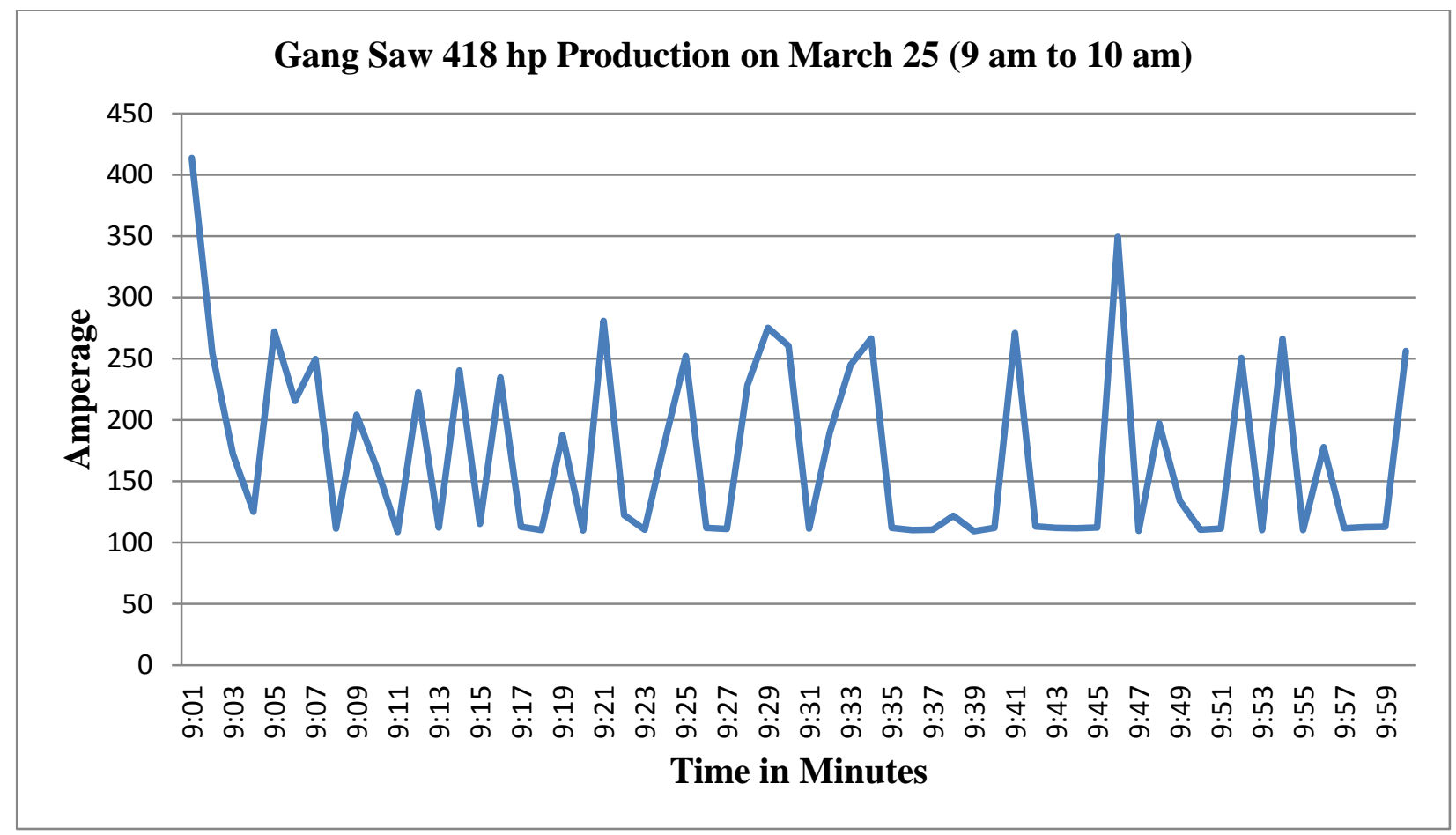

Figure 4.15: Sample of Gang Saw Production of Sawmill 3

SEC of sawmill 5 was in the middle and it stayed there even after energy allocation was done. SEC before energy allocation was 118.44 and after was 124.29 for 4/4 size lumber and hence didn't change much. Actually sawmill 5 worked two shifts during data collection period and there was clear difference between the energy consumption from day shift to night shift. Night shift consumed more energy per board feet by sawing less lumber in the same time compared to day shift (Table 4.19). If only the day shift's energy consumption is considered, then average SEC will be 108.23 and for night shift it will be 133.77. After energy allocation as per surface area cut is done, for $4 / 4$ size lumber, it will be 112.68 for day shift and 143.14 for night shift. Day shift SEC of 112.68 is lower than SEC of sawmill 3 (118.31) obtained after energy allocation.

Another interesting thing to notice from Table 4.19 data is row number 4 which has a higher SEC in shift 1. This happened since the data collection duration was only 1.5 hours and 
data of smaller data points will not represent the true mean as discussed in the data collection plan.

Table 4.19: Production and Energy Consumption of Day and Night Shifts of Sawmill 5

\begin{tabular}{|c|c|c|c|c|c|c|c|}
\hline Sl. No. & Date & $\begin{array}{l}\text { Start } \\
\text { Time }\end{array}$ & $\begin{array}{l}\text { End } \\
\text { Time }\end{array}$ & Species & $\begin{array}{c}\text { 4/4 to 8/4 } \\
\text { (Board Feet) }\end{array}$ & $\begin{array}{l}\text { Cant + Tim } \\
\text { (Board Feet) }\end{array}$ & $\begin{array}{c}\text { Sawmill } 5 \\
\text { SEC }\end{array}$ \\
\hline 1 & $4 / 28 / 2014$ & 6:00 AM & 10:00 AM & RO & 21,909 & - & 106.13 \\
\hline 2 & $4 / 28 / 2014$ & 10:00 AM & 4:00 PM & $\mathrm{HM}$ & 26,052 & - & 113.76 \\
\hline 3 & $4 / 28 / 2014$ & 5:00 PM & 2:30 AM & HM & 32,150 & - & 153.86 \\
\hline 4 & $4 / 29 / 2014$ & 6:00 AM & $7: 30 \mathrm{AM}$ & HM & 8,160 & - & 137.55 \\
\hline 5 & $4 / 29 / 2014$ & $7: 30 \mathrm{AM}$ & 4:00 PM & YP & 50,813 & 9,975 & 67.71 \\
\hline 6 & $4 / 29 / 2014$ & 5:00 PM & 2:30 AM & YP & 50,448 & 10,698 & 84.87 \\
\hline 7 & $4 / 30 / 2014$ & 6:00 AM & $3: 30 \mathrm{PM}$ & YP & 63,128 & 11,645 & 67.73 \\
\hline 8 & $4 / 30 / 2014$ & 3:30 PM & 2:30 AM & RO & 43,450 & - & 129.64 \\
\hline 9 & $5 / 1 / 2014$ & $6: 00 \mathrm{AM}$ & 4:00 PM & RO & 55,938 & - & 98.24 \\
\hline 10 & $5 / 1 / 2014$ & 5:00 PM & 2:30 AM & RO & 37,107 & - & 139.94 \\
\hline 11 & $5 / 2 / 2014$ & 6:00 AM & 4:00 PM & RO & 46,659 & - & 113.82 \\
\hline 12 & $5 / 2 / 2014$ & 5:00 PM & 2:30 AM & RO & 36,535 & - & 137.99 \\
\hline 13 & $5 / 5 / 2014$ & $6: 00 \mathrm{AM}$ & $7: 15 \mathrm{AM}$ & RO & 8,813 & - & 113.90 \\
\hline 14 & $5 / 5 / 2014$ & $7: 15 \mathrm{AM}$ & $2: 45 \mathrm{PM}$ & AS & 36,489 & - & 102.01 \\
\hline 15 & $5 / 5 / 2014$ & 5:00 PM & 2:30 AM & SM & 33,653 & 10,096 & 117.99 \\
\hline 16 & $5 / 6 / 2014$ & 6:00 AM & 4:00 PM & SM & 43,846 & 11,156 & 96.29 \\
\hline 17 & $5 / 6 / 2014$ & 4:30 PM & 12:00 PM & SM & 24,196 & 7,068 & 112.49 \\
\hline 18 & $5 / 7 / 2014$ & $6: 00 \mathrm{AM}$ & 4:00 PM & WO & 39,585 & 6,796 & 115.82 \\
\hline 19 & $5 / 7 / 2014$ & 5:00 PM & 2:30 AM & WO & 32,131 & 4,912 & 138.43 \\
\hline 20 & $5 / 8 / 2014$ & 6:00 AM & $4: 00 \mathrm{PM}$ & WO & 40,343 & 4,147 & 119.39 \\
\hline 21 & $5 / 8 / 2014$ & 5:00 PM & 2:30 AM & WO & 23,758 & 7,228 & 151.36 \\
\hline 22 & $5 / 10 / 2014$ & 6:00 AM & $2: 30 \mathrm{PM}$ & RO & 38,448 & 1,834 & 115.25 \\
\hline 23 & $5 / 12 / 2014$ & 6:00 AM & $6: 45 \mathrm{AM}$ & RO & 6,000 & - & 126.86 \\
\hline 24 & $5 / 12 / 2014$ & $6: 45 \mathrm{AM}$ & 4:00 PM & $\mathrm{HM}$ & 36,454 & - & 128.95 \\
\hline 25 & $5 / 12 / 2014$ & 5:00 PM & 2:30 AM & HM & 23,203 & 4,326 & 171.11 \\
\hline Average & & & & & & & 118.44 \\
\hline
\end{tabular}

Sawmill 5 has an additional gang saw along with resaw (Figure 3.10) to boost up the production and hence was better than sawmill 3 for day shift production. But the head saw cannot produce (Figure 4.16) enough cants to keep both resaw (Figure 4.17) and gang saw (Figure 4.18) busy and hence gang saw stays idle sometimes and consumes energy without 
producing anything and results in higher energy consumption than sawmill 1 . Sawmill 5 can improve both its productivity and energy efficiency by installing an additional head saw.

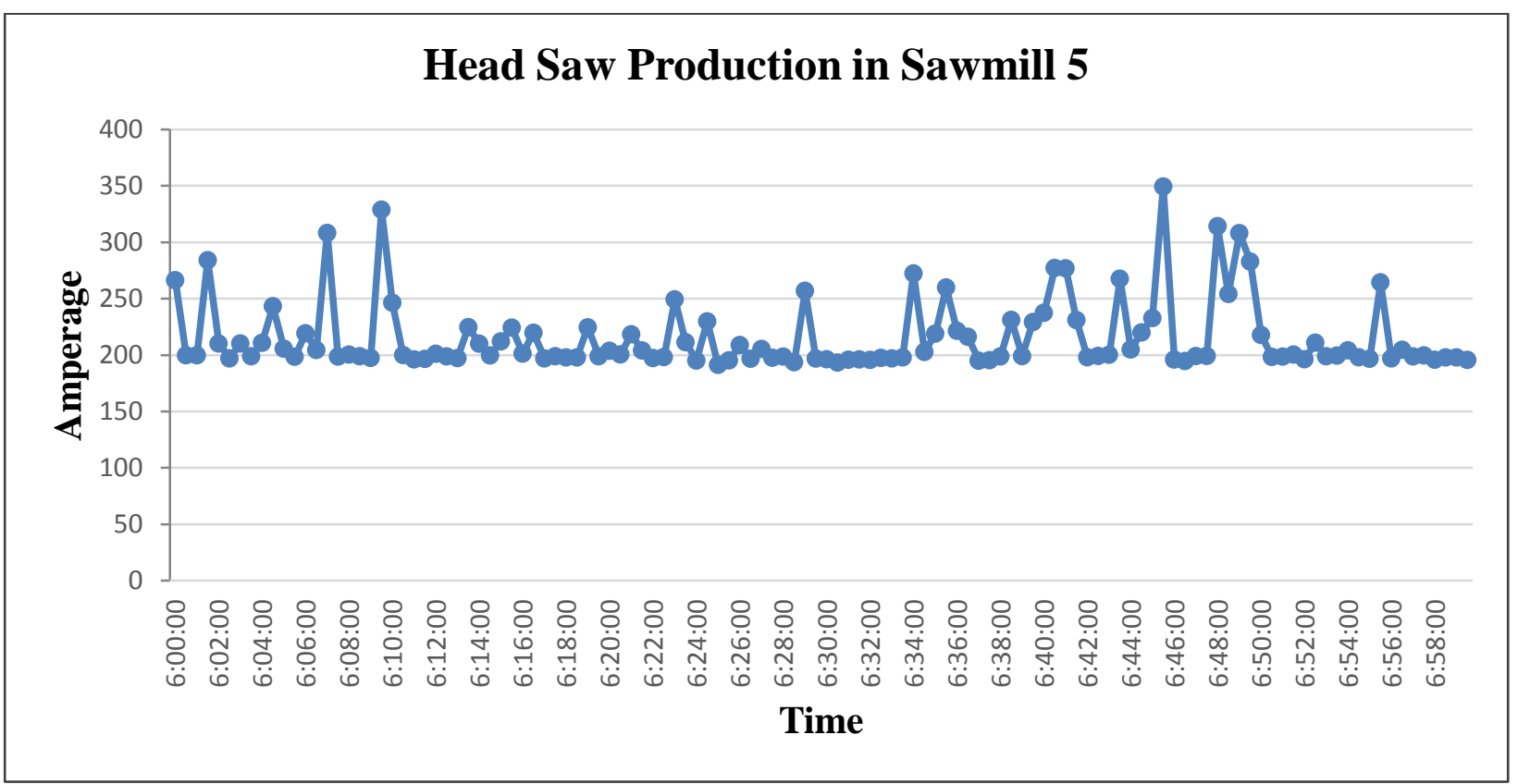

Figure 4.16: 250 hp Head Saw Amperage Consumption in Sawmill 5

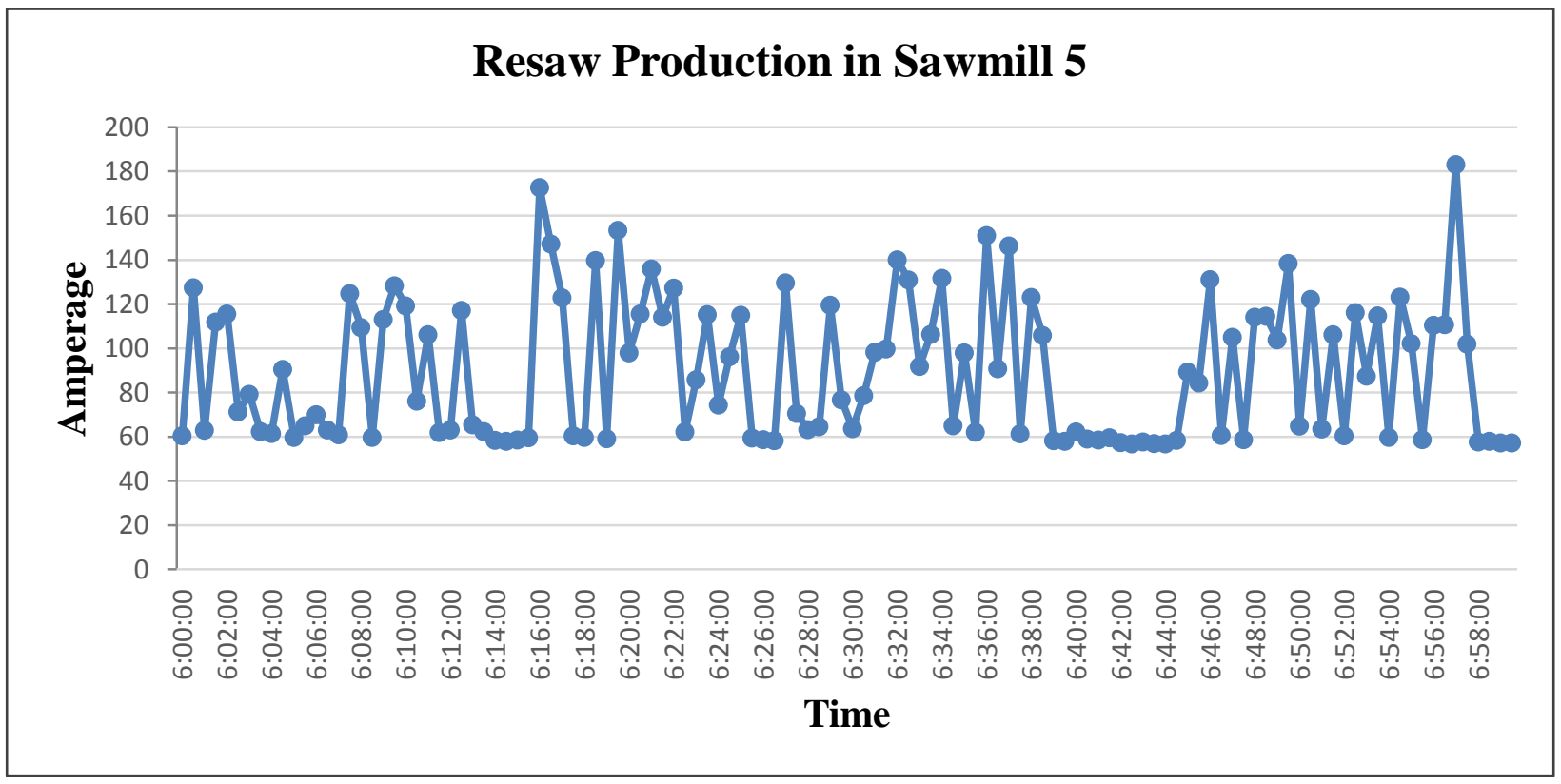

Figure 4.17: 150 hp Re-saw Amperage Consumption in Sawmill 5

Out of the five sawmills, sawmill 1 had the lowest energy consumption after energy allocation based on surface area was done. It looks like the manufacturing configuration of 
sawmill 1 is perfectly balanced to produce lumber at minimal energy consumption. Other thing to be noted about sawmill 1 is most of its motors capacity is small compared to other sawmills.

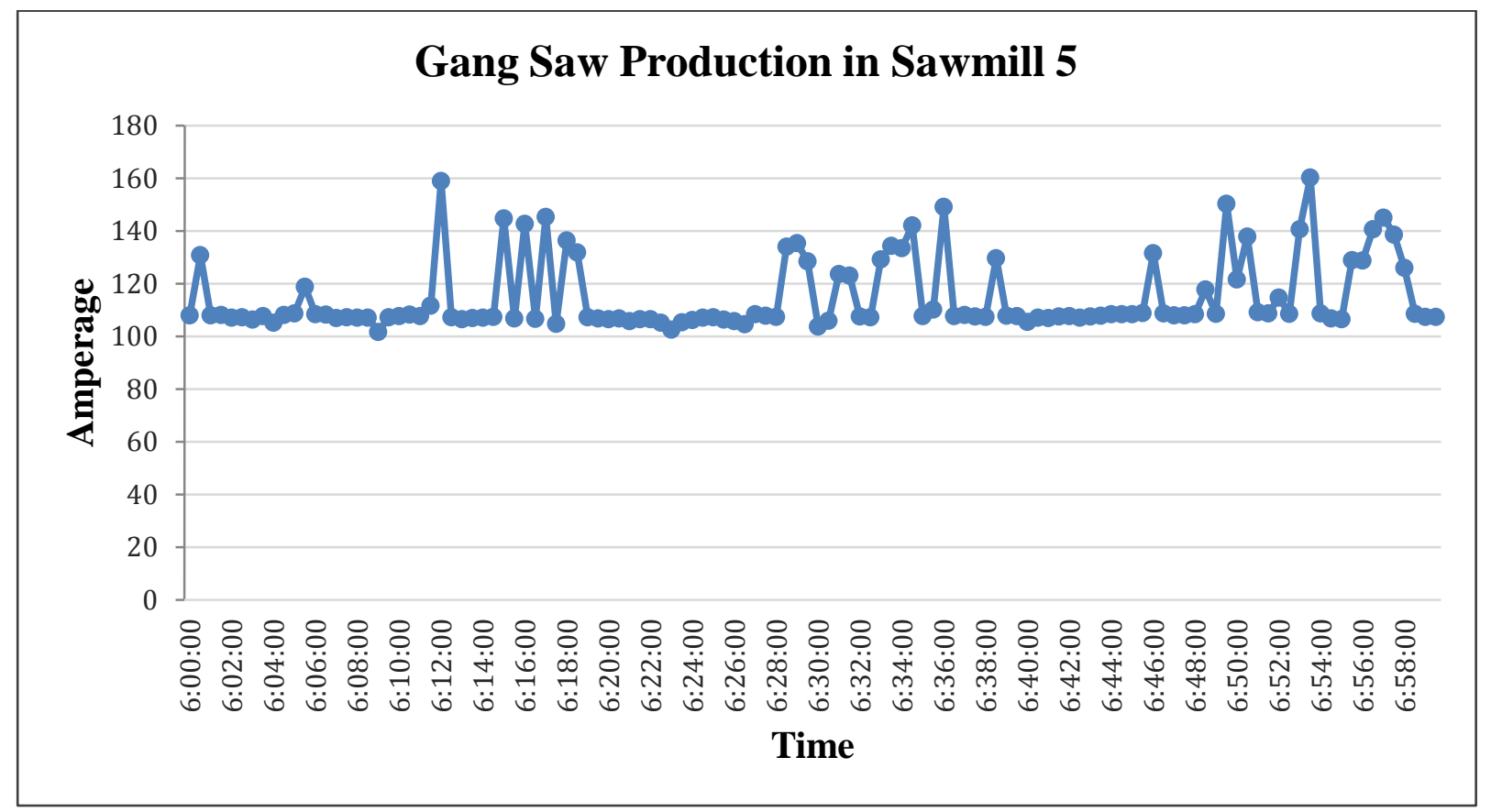

Figure 4.18: 100 hp Gang Saw Amperage Consumption in Sawmill 5

Average motor load factors of all the five sawmills are shown in Table 4.6. Except sawmill 5, all the other sawmills have load factor of less than $40 \%$. Load factor is the percentage of motor capacity used on average for doing the particular mechanical work.
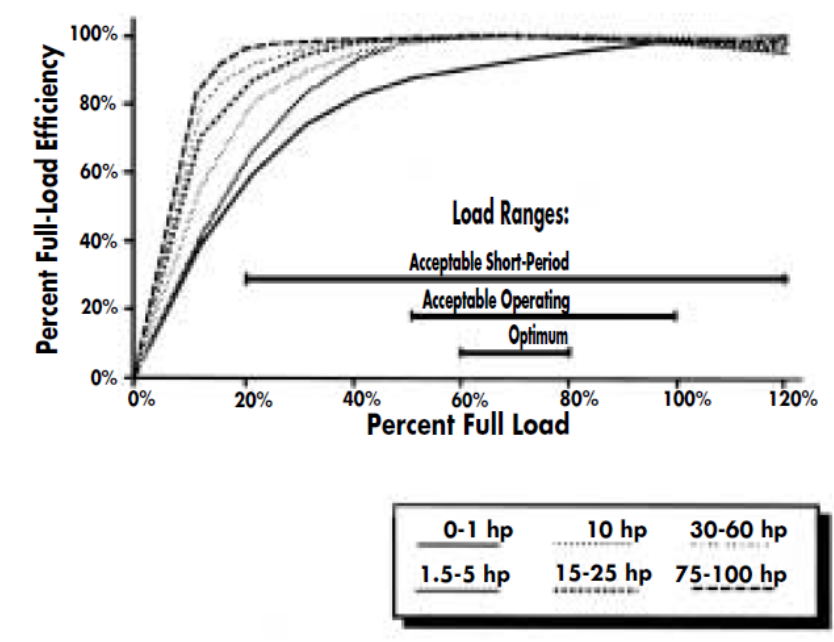

Figure 4.19: Motor Part -Load Efficiency (as a function of \% Full-Load Efficiency) 
Using of larger capacity motor to do small tasks compared to using smaller motors to do the same task will result in higher energy consumption for larger motor since motor efficiency goes down at loads lower than 40\% (Figure 4.19, Rutgers 2015). Sawmill 1, 2, 4 and 5 can save energy by re-sizing its motors. Other energy efficiency measures similar to re-sizing of motors that were discussed in the literature review like improving the efficiency of compressor, using VFD on motors etc., will help sawmills to reduce their energy consumption. These energy efficiency measures were not mentioned here since they are standardized and were recommended during the energy assessments conducted by Industrial Assessment Center of West Virginia University at these facilities and are also available in the literature.

\section{Conclusion}

Looking at gross energy consumption and calculating overall energy consumption per board feet and using it to estimate the energy efficiency of a sawmill or using it for benchmarking like the authors did in the literature review will lead to wrong conclusions. Sawmills energy efficiency must be analyzed at a deeper level by taking the sizes and species of lumber sawn into account and allocating the energy consumption based on surface area cut for that particular size. The energy allocation method developed in this research will give a better picture of the sawmill performance in terms of both energy efficiency and productivity.

From the comparison of sawmills, it was evident that having a resaw or a gang saw in sawmill will improve productivity and energy efficiency to a great extent. Both sawmills 2 and 4 didn't had either a resaw or a gang saw and hence ended up with high SEC compared to other sawmills. Also, it was clear that matching of machine capacities plays a major role to improve the productivity of a sawmill and sawmills 3 and 5 can improve their productivity and energy efficiency from matching their machine capacities. 


\section{Development of Estimation Model}

\subsection{Selection of Product, Process and System Parameters}

A model that can estimate the energy consumption of a sawmill without data logging was developed by using the information collected from 4 sawmills on which this study was done.

Data from Sawmill 1, 2, 4 and 5 was used to develop the model and the energy consumption of Sawmill 3 was estimated using the developed model. Production data that was collected from the 5 sawmills had information of the following sawmill parameters.

Product Parameters

- Species Sawn

- Board Feet sawn of different sizes

Process Parameters

- Sawing Time

- Ambient Temperature

- Level of Maintenance

System Parameters

- Motor horse power

- Equipment used

- Production Line Configuration

\section{Product Parameters}

The type of wood species sawn and the board feet of different size lumber sawn was considered as product parameters and they are quantitative (numerical) estimator variables. As discussed in the need for research, species is an important factor which affects the sawing energy consumption. There are 10 different species that were sawn during the study and the wood density of these species in $\mathrm{lb} / \mathrm{ft}^{3}$ (Engineering ToolBox 2015) was considered as one of the variable to estimate the energy consumption. Table 5.1 shows the range of density values for different species sawn during the research and also the values used in developing the model. 
Table 5.1: Densities of different Wood Species sawn in Sawmill 1 to 5

\begin{tabular}{|c|c|c|c|}
\hline Sl. No. & Species & $\begin{array}{c}\text { Density Range } \\
\left(\mathbf{l b} / \mathbf{f t}^{3}\right)\end{array}$ & $\begin{array}{c}\text { Selected Value } \\
\left(\mathbf{l b} / \mathbf{f t}^{\mathbf{3}}\right)^{-}\end{array}$ \\
\hline 1 & Soft Maple & $33 \sim 50$ & 35 \\
\hline 2 & Red Oak & $37 \sim 56$ & 44 \\
\hline 3 & White Oak & $40 \sim 59$ & 47 \\
\hline 4 & Ash & $34 \sim 52$ & 40 \\
\hline 5 & Hard Maple & $42 \sim 59$ & 47 \\
\hline 6 & Hickory & $48 \sim 64$ & 64 \\
\hline 7 & Cherry & $43 \sim 56$ & 56 \\
\hline 8 & Yellow Poplar & $22 \sim 31$ & 24 \\
\hline 9 & Birch & $42 \sim 57$ & 44 \\
\hline 10 & Sycamore & $24 \sim 37$ & 26 \\
\hline
\end{tabular}

The values of the density that was selected from the density range are the ones that minimized the estimation error. Also, the developed model is able to estimate the sawing energy consumption of a new species other than the 10 species considered in this study if the density of the new species is known.

From the data analysis, it was clear that lumber sizes were significantly affecting the sawing energy consumption. There are around 7 lumber sizes that were sawn in the sawmills during this study. These lumber sizes were broadly classified into three types as board, dimension or cant and timber sizes. All the 7 lumber sizes were not sawn in all the shifts in all the 5 sawmills. So, grouping of variables with common characteristics was done. All the board size lumber (4/4 to $8 / 4$ and pallet size, pallet will be usually of size $4 / 4)$ was grouped together since they are smaller thickness lumber. Point to be noted is 5/4,6/4 and 8/4 lumber sizes are in very low quantity when compared to $4 / 4$ size lumber (Table 3.4). Cants and timbers were grouped together since they are larger thickness lumber.

\section{Process Parameters}

The process efficiency of a manufacturing process can be basically evaluated by looking at the production rate or how much lumber is produced in a unit time for a sawmill. The variable 
that drives the production rate is sawing time and hence it will be one of the significant variable to estimate sawing energy consumption and was included as a quantitative estimator variable.

As discussed in literature review, maintenance of saw blades is critical to reduce energy consumption during sawing (Cristóvão 2013) and also to improve quality of lumber produced. In the article discussed, sawing energy consumption increased by 11 to $35 \%$ during an 8-hour shift, mainly due to an increase in the tooth radius and hence the level of maintenance of saw blades is considered as a process predictor variable for predicting energy consumption. Table 3.8 shows the collected data about maintenance procedure in different sawmills and the maintenance index assigned to each sawmill based on it. The maintenance index will be quantitative (numerical) discrete variable.

Sawmill data was collected in different periods of the year and the temperature of the logs sawn was different in different sawmills. Within each sawmill, temperature varied significantly from beginning to the end of the data collection period. Temperature or effect of seasonal variation was found to have some effect on the cutting force of sawing in one of the literature reviews and hence was included in the model and was tested for its significance.

The other process parameter, moisture content was discussed in the literature review and was found that it doesn't affect the sawing energy consumption significantly since the moisture content of the logs sawn in sawmills will be above fiber saturation point. Hence, atmospheric humidity which affects the moisture content of the wood was not considered as a parameter for developing estimation model.

\section{System Parameters}

The main system parameter identified is the motor horsepower of the equipment used for sawing process and it is a quantitative variable. Each sawmill has different total motor horsepower and produce different production quantities and hence there is a direct relationship 
between the energy consumed for sawing and motor horse power used for it. If a sawmill has higher motor horsepower then it must produce higher quantity of lumber proportionate to its motor horsepower to be energy efficient, else it will lose its efficiency.

The other system parameters considered are lack of resaw vs. having resaw, single production line vs. double production lines and ring debarker vs. rosser-head debarker. All these variables were considered as qualitative (categorical) variables. Since sawmill 3 and 5 had ring debarker and also gang saw, gang saw was not considered as a variable due to the problem of collinearity. Since sawmill 3 does not have resaw, gangsaw was considered as resaw for the lack of resaw vs having resaw variable. Table 5.2 lists the qualitative and quantitative discrete variables considered in all the five sawmills.

Table 5.2: Qualitative (Categorical) and Quantitative Discrete Variables for Sawmill 1 to 5

\begin{tabular}{|c|c|c|c|c|}
\hline Mill \# & Ring Debarker & Resaw & Double Line & Maintenance Index \\
\hline 1 & 0 & 1 & 0 & 4 \\
\hline 2 & 0 & 0 & 0 & 3 \\
\hline 3 & 1 & 1 & 1 & 2 \\
\hline 4 & 0 & 0 & 1 & 2 \\
\hline 5 & 1 & 1 & 0 & 2 \\
\hline
\end{tabular}

The other system parameters like type of equipment used for ex: Bandsaw vs Circular Saw, and disc chipper vs. drum chipper were not considered since only sawmill 1 had circular saw and none of the sawmills had drum chippers. Also, type of saw blade material was not considered as an estimator variable since, all the sawmills were using same saw blade material for their saws (Table 3.7). Totally ten estimator variables were considered for developing the estimation model. 


\subsection{Estimation Model Development}

Estimation model can be developed using many techniques. The basic technique used is ordinary least square regression model for independent variables that doesn't have substantial uncertainties. The ordinary least-squares model minimizes the sum of squared residuals, a residual being the difference between an observed value and the fitted value provided by a model. Least squares models can be linear or non-linear, depending on the relationship of the independent variable with the dependent variable. A multiple linear regression model with interaction effect will be of the form,

Where,

$$
y_{i}=\beta_{0}+\beta_{1} x_{i 1}+\beta_{2} x_{i 2}+\beta_{3} x_{i 2} x_{i 3}+\ldots \beta_{p} x_{i p}+\varepsilon_{i,} \quad i=1, \ldots, n .
$$

$$
\begin{aligned}
& \text { y } \quad=\text { dependent variable } \\
& x_{1}, x_{2}, x_{3}, x_{p}=\text { independent variables } \\
& x_{2} x_{3}=\text { interaction effect } \\
& \beta_{0} \quad=Y \text { intercept } \\
& \beta_{1}, \beta_{2}, \beta_{3}, \beta_{p}=\text { regression parameters } \\
& i \quad=\text { represents the } i^{\text {th }} \text { observation or data point } \\
& n=\text { total number of observations } \\
& p \quad=\text { total number of regression parameters } \\
& \varepsilon \quad=\text { residual }
\end{aligned}
$$

The assumption of the above model is residuals are normally distributed with mean 0 and variance $\sigma^{2}$ and variance is estimated by $\mathrm{s}^{2}$ and the formula to estimate $\mathrm{s}^{2}$ is shown below. $\mathrm{s}^{2}$ is also known as mean squared error or MSE.

$$
s^{2}=\frac{\sum e_{i}^{2}}{n-p-1}
$$

Estimation model development was tried using the variables from product, process and system parameters using multiple linear regression technique to estimate SEC (Table 4.5). Bidirectional elimination stepwise regression was used to select the significant variables from the 10 estimator variables. Alpha value used for both adding and removing the variable from the 
model was 0.15. Data from sawmill 1,2, 4 and 5 (Appendix Table A.3) was used to select the estimator variables using stepwise regression in Minitab. Totally there were 108 data points from sawmill 1, 2, 4 and 5 to develop estimation model. Traditionally, $70 \%$ of the data is used for model development and $30 \%$ will be used for validation. But due to the necessity of developing a robust estimation model, it was decided to use data from 4 sawmills to develop the model and use data from $5^{\text {th }}$ sawmill for validation.

The results of stepwise regression are shown in Appendix Table A.22. From the stepwise regression, 6 variables out of 10 were selected. Some estimators are highly correlated with each other and hence, Mallows' $\mathrm{Cp}$ is not displayed in the stepwise regression output. Mallows' Cp for the model with only the selected variables in stepwise regression is 7 which tell that the model fits the data well. The selected variables are Density, Lumber sizes (4 to 8 Qtr + Pallet, Cant + Tim), Minutes, Motor horsepower, and Resaw. Density was selected as expected since it was affecting energy consumption as discussed in the literature review. Motor horsepower and minutes were selected since they are the key variables that are used to calculate energy consumption of a motor. Lumber sizes were selected in stepwise regression since they affect the energy consumption as discussed in energy allocation methodology. As discussed in data analysis while comparing different sawmills, resaw was significantly affecting energy consumption and hence was selected in the stepwise regression. The other variables Debarker, Temperature, Double Line, and Level of Maintenance were rejected and hence can be considered as not significant. A multiple linear regression model (Model 1) was developed using the above 6 estimator variables in Minitab and the results are shown below. Residual plots (Figure 5.1) show that there are some outliers in the data and residuals follow a normal distribution and are distributed within $\pm 15 \mathrm{kwh} / \mathrm{MBF}$. 


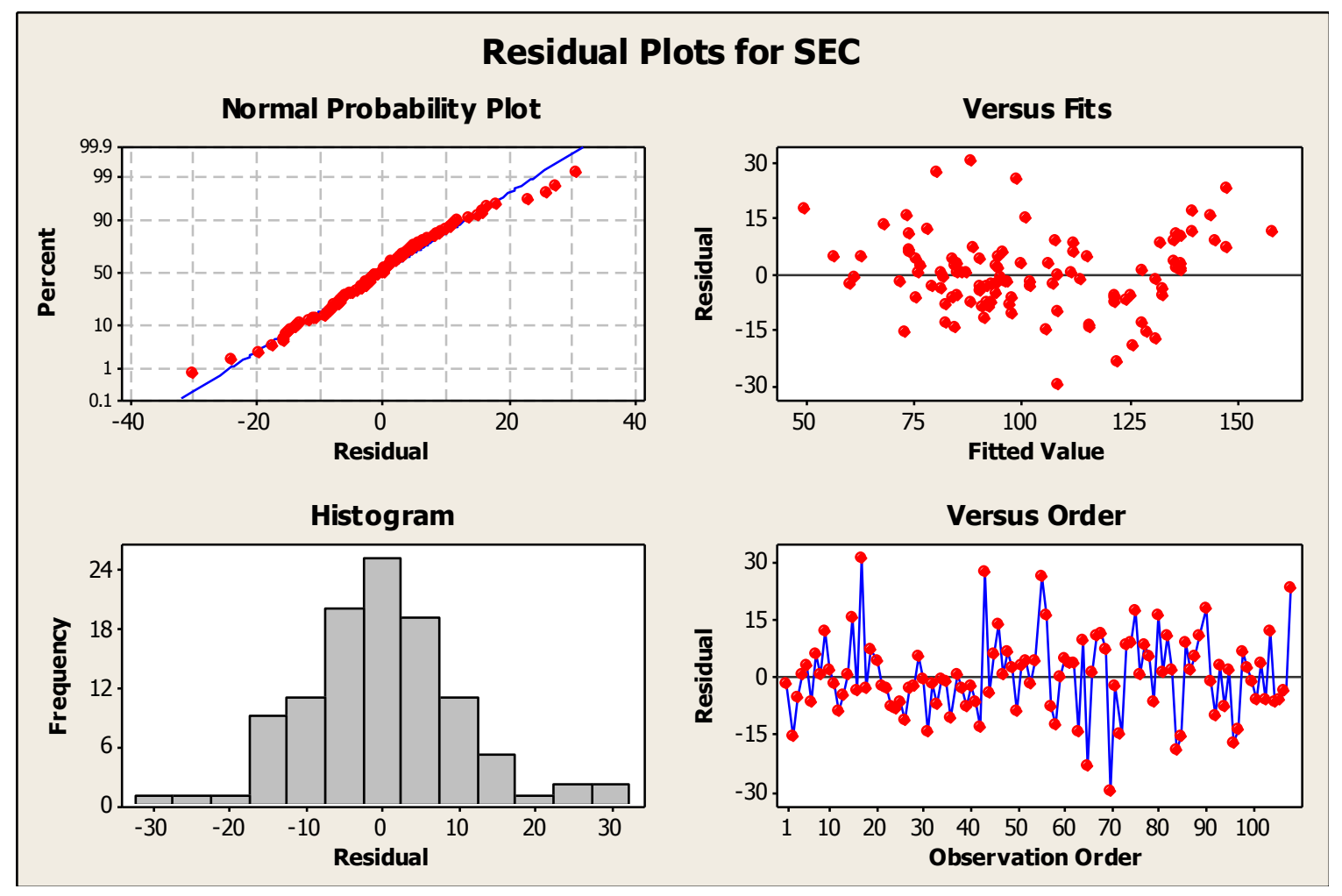

Figure 5.1: Residual Plots of Regression Model 1

Regression Equation

\begin{tabular}{|c|c|c|c|c|c|}
\hline $\begin{aligned} \mathrm{SEC}= & -28.1881+ \\
& 0.00163478\end{aligned}$ & $\begin{array}{l}0.0817785 \\
4 \text { to } 8 \text { etr }\end{array}$ & $\begin{array}{l}\text { Motor hp } \\
+ \text { Pallet }\end{array}$ & $\begin{array}{r}+0.106858 \\
-0.00231\end{array}$ & $\begin{array}{l}\text { Min }+ \\
198 \text { Can }\end{array}$ & $\begin{array}{l}0.780301 \\
t+\text { Tim }\end{array}$ \\
\hline \multicolumn{6}{|l|}{ Coefficients } \\
\hline Term & Coef & SE Coef & $\mathrm{T}$ & $\mathrm{P}$ & VIF \\
\hline Constant & -28.1881 & 7.45123 & -3.7830 & 0.000 & \\
\hline Motor hp & 0.0818 & 0.00397 & 20.5983 & 0.000 & 2.12048 \\
\hline Min & 0.1069 & 0.01096 & 9.7542 & 0.000 & 3.94462 \\
\hline Density & 0.7803 & 0.12891 & 6.0533 & 0.000 & 1.47212 \\
\hline 4 to 8 Qtr + Pallet & -0.0016 & 0.00019 & -8.6071 & 0.000 & 6.97387 \\
\hline Cant + Tim & -0.0023 & 0.00038 & -6.0118 & 0.000 & 1.76591 \\
\hline Resaw & -10.9730 & 2.99182 & -3.6677 & 0.000 & 2.12070 \\
\hline
\end{tabular}

Summary of Model

$\begin{array}{lll}S=10.5852 & R-S q=84.63 \% & R-S q(\text { adj })=83.72 \% \\ \operatorname{PRESS}=13304.6 & R-S q(\text { pred })=81.93 \% & \end{array}$

Analysis of Variance

Source

Regression

Motor hp

Min

Density

4 to 8 etr + Pallet

Cant + Tim

Resaw

Error

Total

\begin{tabular}{rrrrrr} 
DF & Seq SS & Adj SS & \multicolumn{1}{c}{ Adj MS } & $F$ & $P$ \\
6 & 62303.9 & 62303.9 & 10384.0 & 92.676 & 0.0000000 \\
1 & 32676.2 & 47540.1 & 47540.1 & 424.292 & 0.0000000 \\
1 & 119.0 & 10660.6 & 10660.6 & 95.145 & 0.0000000 \\
1 & 13314.0 & 4105.6 & 4105.6 & 36.642 & 0.0000000 \\
1 & 11917.7 & 8300.6 & 8300.6 & 74.082 & 0.0000000 \\
1 & 2769.8 & 4049.5 & 4049.5 & 36.141 & 0.0000000 \\
1 & 1507.2 & 1507.2 & 1507.2 & 13.452 & 0.0003927 \\
101 & 11316.6 & 11316.6 & 112.0 & & \\
107 & 73620.5 & & & &
\end{tabular}


$\mathrm{R}^{2}$ adjusted of the developed model 1 was $83.72 \%$, the $\mathrm{R}^{2}$ predicted was $81.93 \%$ and MSE was 112. The interesting thing to notice is the signs of the regression coefficients. Motor hp, minutes and density have positive signs since they are directly proportional to energy consumption. Lumber size 4 to 8 Qtr + Pallet, Cant + Tim have negative signs, which means that if more lumber is sawn in a given time, lesser will be the energy consumption per board feet. Also, another interesting thing to notice is the value of regression coefficient. The value of ' 4 to 8 Qtr + Pallet' regression coefficient is higher than 'Cant + Tim' coefficient by $41.4 \%$, which means that $41.4 \%$ more energy is consumed when board size lumber is sawn compared to cants and timbers. This percentage will be higher if only four quarter lumber is compared to timbers, since here all the board lumber sizes are grouped together and also cants and timbers are grouped together. The sign of the resaw is negative which tells that if a resaw is used in a sawmill, lesser will be the energy consumption per board feet. SE (standard error) coefficient measures the precision of the estimate of the coefficient and hence tells which variable can estimate better than the other variables. From the results it can be seen that ' 4 to 8 Qtr + Pallet' variable is the best estimator followed by 'Cant + Tim' and 'Motor hp'. The least precise estimator is the variable 'Resaw'. From the ANOVA (Analysis of Variance), and T test, it can be seen that all the estimator variables are significant with $\mathrm{P}$ value less than 0.01 and variance inflation factor of less than 10 and hence estimator variables are not correlated. The variable that is explaining the maximum variance is 'Motor hp' and then 'Minutes' and the variable that is explaining the least variance is 'Resaw'. Estimator variable 'Resaw' is significant in both $\mathrm{T}$ test and $\mathrm{F}$ test and has the least $\mathrm{P}$ value. The SEC values estimated from the fitted model 1 are shown in Table 5.3. 
Table 5.3: Estimated SEC values from Regression Model 1

\begin{tabular}{|c|c|c|c|c|c|c|c|c|c|c|}
\hline No. & $\begin{array}{c}\text { Mill } \\
\#\end{array}$ & $\begin{array}{l}\text { Motor } \\
\text { hp }\end{array}$ & $\begin{array}{l}\text { Run time } \\
\text { (Minutes) }\end{array}$ & $\begin{array}{c}\text { Density } \\
\left(\mathrm{lb} / \mathrm{ft}^{3}\right)\end{array}$ & $\begin{array}{c}/ 4 \text { to } 8 / 4 \\
\text { + Pallet } \\
\text { (Board ft.) }\end{array}$ & $\begin{array}{c}\text { Cant }+ \\
\text { Tim } \\
\text { (Board ft.) }\end{array}$ & Resaw & SEC & $\begin{array}{c}\text { Estimated } \\
\text { SEC }\end{array}$ & Error \\
\hline 1 & 1 & 968 & 555 & 35 & 29,726 & 2,648 & 1 & 70.05 & 71.90 & -1.85 \\
\hline 2 & 1 & 968 & 75 & 44 & 5,656 & 0 & 1 & 57.49 & 73.10 & -15.61 \\
\hline 3 & 1 & 968 & 630 & 44 & 33,160 & 984 & 1 & 79.48 & 85.17 & -5.69 \\
\hline 4 & 1 & 968 & 630 & 44 & 32,004 & 1,416 & 1 & 86.37 & 86.06 & 0.30 \\
\hline 5 & 1 & 968 & 235 & 44 & 12,188 & 1,187 & 1 & 79.31 & 76.78 & 2.53 \\
\hline 6 & 1 & 968 & 395 & 47 & 19,329 & 1,294 & 1 & 77.59 & 84.29 & -6.70 \\
\hline 7 & 1 & 968 & 240 & 40 & 12,954 & 832 & 1 & 79.62 & 73.76 & 5.87 \\
\hline 8 & 1 & 968 & 390 & 44 & 17,708 & 816 & 1 & 85.66 & 85.17 & 0.49 \\
\hline 9 & 1 & 968 & 120 & 47 & 6,765 & 0 & 1 & 90.42 & 78.44 & 11.98 \\
\hline 10 & 1 & 968 & 510 & 47 & 22,100 & 240 & 1 & 95.95 & 94.49 & 1.46 \\
\hline 11 & 1 & 968 & 570 & 47 & 24,663 & 312 & 1 & 94.75 & 96.54 & -1.79 \\
\hline 12 & 1 & 968 & 630 & 47 & 29,521 & 1,320 & 1 & 83.83 & 92.68 & -8.86 \\
\hline 13 & 1 & 968 & 630 & 47 & 28,348 & 1,640 & 1 & 88.84 & 93.86 & -5.02 \\
\hline 14 & 1 & 968 & 630 & 35 & 31,129 & 1,056 & 1 & 81.51 & 81.30 & 0.21 \\
\hline 15 & 1 & 968 & 240 & 64 & 8,489 & 192 & 1 & 116.38 & 101.26 & 15.12 \\
\hline 16 & 1 & 968 & 285 & 47 & 12,093 & 2,613 & 1 & 77.42 & 81.32 & -3.90 \\
\hline 17 & 1 & 968 & 105 & 56 & 3,337 & 435 & 1 & 119.23 & 88.46 & 30.77 \\
\hline 18 & 1 & 968 & 630 & 56 & 19,746 & 7,241 & 1 & 98.66 & 102.00 & -3.34 \\
\hline 19 & 1 & 968 & 195 & 56 & 8,815 & 676 & 1 & 95.50 & 88.56 & 6.94 \\
\hline 20 & 1 & 968 & 435 & 44 & 17,670 & 552 & 1 & 94.74 & 90.65 & 4.09 \\
\hline 21 & 1 & 968 & 630 & 44 & 28,526 & 744 & 1 & 90.76 & 93.30 & -2.54 \\
\hline 22 & 1 & 968 & 630 & 44 & 29,629 & 1,240 & 1 & 86.94 & 90.35 & -3.41 \\
\hline 23 & 2 & 817 & 270 & 64 & 4,904 & 5,237 & 0 & 89.13 & 97.29 & -8.16 \\
\hline 24 & 2 & 817 & 240 & 47 & 5,863 & 3,925 & 0 & 73.99 & 82.29 & -8.29 \\
\hline 25 & 2 & 817 & 510 & 47 & 10,301 & 6,540 & 0 & 91.16 & 97.84 & -6.68 \\
\hline 26 & 2 & 817 & 510 & 47 & 11,034 & 8,891 & 0 & 79.47 & 91.20 & -11.73 \\
\hline 27 & 2 & 817 & 180 & 47 & 3,975 & 3,867 & 0 & 76.00 & 79.09 & -3.09 \\
\hline 28 & 2 & 817 & 270 & 24 & 5,858 & 7,166 & 0 & 57.54 & 60.06 & -2.52 \\
\hline 29 & 2 & 817 & 120 & 24 & 2,598 & 4,194 & 0 & 61.25 & 56.23 & 5.01 \\
\hline 30 & 2 & 817 & 390 & 24 & 7,967 & 10,652 & 0 & 60.79 & 61.38 & -0.58 \\
\hline 31 & 2 & 817 & 510 & 44 & 13,481 & 8,950 & 0 & 70.04 & 84.73 & -14.68 \\
\hline 32 & 2 & 817 & 510 & 44 & 8,162 & 7,840 & 0 & 94.01 & 95.99 & -1.98 \\
\hline 33 & 2 & 817 & 510 & 44 & 10,465 & 7,593 & 0 & 85.15 & 92.79 & -7.64 \\
\hline 34 & 2 & 817 & 300 & 44 & 7,211 & 4,914 & 0 & 80.82 & 81.87 & -1.05 \\
\hline 35 & 2 & 817 & 150 & 64 & 1,852 & 2,775 & 0 & 94.05 & 95.15 & -1.10 \\
\hline 36 & 2 & 817 & 330 & 64 & 5,706 & 7,104 & 0 & 87.07 & 98.07 & -11.00 \\
\hline 37 & 2 & 817 & 150 & 44 & 3,231 & 3,307 & 0 & 76.63 & 76.06 & 0.58 \\
\hline 38 & 2 & 817 & 510 & 44 & 9,196 & 8,931 & 0 & 88.53 & 91.77 & -3.25 \\
\hline 39 & 2 & 817 & 510 & 44 & 9,802 & 8,309 & 0 & 84.54 & 92.22 & -7.68 \\
\hline 40 & 2 & 817 & 480 & 44 & 9,765 & 6,199 & 0 & 91.35 & 93.95 & -2.60 \\
\hline 41 & 2 & 817 & 30 & 47 & 613 & 862 & 0 & 68.88 & 75.51 & -6.63 \\
\hline
\end{tabular}




\begin{tabular}{|c|c|c|c|c|c|c|c|c|c|c|}
\hline No. & $\begin{array}{c}\text { Mill } \\
\#\end{array}$ & $\begin{array}{c}\text { Motor } \\
\text { hp }\end{array}$ & $\begin{array}{l}\text { Run time } \\
\text { (Minutes) }\end{array}$ & $\begin{array}{c}\text { Density } \\
\left(\mathrm{lb} / \mathrm{ft}^{3}\right)\end{array}$ & $\begin{array}{c}\text { 4/4 to } 8 / 4 \\
\text { + Pallet } \\
\text { (Board ft.) }\end{array}$ & $\begin{array}{c}\text { Cant }+ \\
\text { Tim } \\
\text { (Board ft.) }\end{array}$ & Resaw & SEC & $\begin{array}{l}\text { Estimated } \\
\text { SEC }\end{array}$ & Error \\
\hline 42 & 2 & 817 & 450 & 47 & 8,613 & 11,556 & 0 & 69.25 & 82.59 & -13.33 \\
\hline 43 & 2 & 817 & 105 & 47 & 1,682 & 1,600 & 0 & 107.59 & 80.07 & 27.52 \\
\hline 44 & 2 & 817 & 405 & 47 & 6,595 & 7,461 & 0 & 85.95 & 90.55 & -4.60 \\
\hline 45 & 2 & 817 & 450 & 47 & 6,872 & 7,177 & 0 & 101.26 & 95.56 & 5.70 \\
\hline 46 & 2 & 817 & 60 & 35 & 1,236 & 891 & 0 & 81.96 & 68.27 & 13.69 \\
\hline 47 & 2 & 817 & 510 & 35 & 10,589 & 6,930 & 0 & 87.31 & 87.10 & 0.21 \\
\hline 48 & 2 & 817 & 255 & 35 & 6,155 & 3,888 & 0 & 80.49 & 74.13 & 6.36 \\
\hline 49 & 2 & 817 & 255 & 44 & 5,320 & 2,990 & 0 & 86.72 & 84.60 & 2.13 \\
\hline 50 & 2 & 817 & 450 & 44 & 9,135 & 6,592 & 0 & 81.71 & 90.87 & -9.16 \\
\hline 51 & 2 & 817 & 330 & 44 & 6,847 & 5,067 & 0 & 88.09 & 85.31 & 2.78 \\
\hline 52 & 2 & 817 & 180 & 47 & 4,361 & 1,520 & 0 & 88.15 & 83.89 & 4.26 \\
\hline 53 & 2 & 817 & 510 & 47 & 10,900 & 4,348 & 0 & 100.14 & 101.93 & -1.79 \\
\hline 54 & 2 & 817 & 45 & 47 & 735 & 1,430 & 0 & 79.64 & 75.60 & 4.04 \\
\hline 55 & 2 & 817 & 465 & 44 & 2,584 & 8,378 & 0 & 125.07 & 99.05 & 26.02 \\
\hline 56 & 2 & 817 & 60 & 44 & 1,451 & 1,459 & 0 & 89.72 & 73.62 & 16.09 \\
\hline 57 & 2 & 817 & 450 & 44 & 10,119 & 6,966 & 0 & 80.51 & 88.40 & -7.89 \\
\hline 58 & 4 & 1,534 & 195 & 44 & 8,791 & 4,264 & 0 & 115.22 & 128.20 & -12.98 \\
\hline 59 & 4 & 1,534 & 405 & 24 & 25,259 & 4,138 & 0 & 108.23 & 108.40 & -0.17 \\
\hline 60 & 4 & 1,534 & 600 & 24 & 43,156 & 6,370 & 0 & 99.65 & 94.82 & 4.83 \\
\hline 61 & 4 & 1,534 & 600 & 24 & 38,884 & 7,182 & 0 & 103.05 & 99.93 & 3.12 \\
\hline 62 & 4 & 1,534 & 555 & 24 & 34,213 & 5,548 & 0 & 109.70 & 106.54 & 3.17 \\
\hline 63 & 4 & 1,534 & 45 & 26 & 1,678 & 1,744 & 0 & 100.94 & 115.58 & -14.64 \\
\hline 64 & 4 & 1,534 & 300 & 26 & 6,296 & 13,659 & 0 & 116.97 & 107.73 & 9.23 \\
\hline 65 & 4 & 1,534 & 300 & 47 & 19,689 & 5,040 & 0 & 98.44 & 122.15 & -23.72 \\
\hline 66 & 4 & 1,534 & 600 & 47 & 27,905 & 6,674 & 0 & 137.93 & 137.00 & 0.93 \\
\hline 67 & 4 & 1,534 & 180 & 47 & 7,188 & 1,852 & 0 & 147.41 & 137.14 & 10.27 \\
\hline 68 & 4 & 1,534 & 420 & 64 & 15,478 & 3,748 & 0 & 169.34 & 158.11 & 11.23 \\
\hline 69 & 4 & 1,534 & 330 & 64 & 15,437 & 4,070 & 0 & 154.92 & 147.82 & 7.10 \\
\hline 70 & 4 & 1,534 & 120 & 26 & 4,915 & 5,948 & 0 & 78.61 & 108.58 & -29.98 \\
\hline 71 & 4 & 1,534 & 465 & 35 & 23,908 & 11,956 & 0 & 105.08 & 107.53 & -2.45 \\
\hline 72 & 4 & 1,534 & 330 & 35 & 15,917 & 12,216 & 0 & 90.29 & 105.57 & -15.28 \\
\hline 73 & 4 & 1,534 & 270 & 44 & 12,724 & 3,244 & 0 & 140.53 & 132.14 & 8.39 \\
\hline 74 & 4 & 1,534 & 600 & 44 & 27,184 & 6,783 & 0 & 144.54 & 135.59 & 8.95 \\
\hline 75 & 4 & 1,534 & 525 & 44 & 21,340 & 5,565 & 0 & 156.76 & 139.94 & 16.82 \\
\hline 76 & 4 & 1,534 & 355.2 & 24 & 21,700 & 3,052 & 0 & 111.76 & 111.41 & 0.35 \\
\hline 77 & 4 & 1,534 & 600 & 24 & 33,112 & 5,922 & 0 & 120.46 & 112.28 & 8.18 \\
\hline 78 & 4 & 1,534 & 195 & 24 & 10,144 & 2,149 & 0 & 120.26 & 115.27 & 4.99 \\
\hline 79 & 4 & 1,534 & 394.8 & 40 & 21,944 & 4,512 & 0 & 117.52 & 124.35 & -6.84 \\
\hline 80 & 4 & 1,534 & 600 & 40 & 23,151 & 4,739 & 0 & 159.87 & 143.78 & 16.09 \\
\hline 81 & 4 & 1,534 & 330 & 40 & 16,449 & 3,752 & 0 & 129.35 & 128.17 & 1.18 \\
\hline 82 & 4 & 1,534 & 270 & 47 & 12,199 & 2,902 & 0 & 146.91 & 136.13 & 10.78 \\
\hline 83 & 4 & 1,534 & 600 & 47 & 28,046 & 6,643 & 0 & 138.38 & 136.84 & 1.54 \\
\hline
\end{tabular}




\begin{tabular}{|c|c|c|c|c|c|c|c|c|c|c|}
\hline No. & $\begin{array}{c}\text { Mill } \\
\#\end{array}$ & $\begin{array}{c}\text { Motor } \\
\text { hp }\end{array}$ & $\begin{array}{c}\text { Run time } \\
\text { (Minutes) }\end{array}$ & $\begin{array}{c}\text { Density } \\
\left(\text { lb/ft }{ }^{3}\right)\end{array}$ & $\begin{array}{c}\text { 4/4 to 8/4 } \\
\text { + Pallet } \\
(\text { Board ft.) }\end{array}$ & $\begin{array}{c}\text { Cant + } \\
\text { Tim } \\
\text { (Board ft.) }\end{array}$ & Resaw & SEC & $\begin{array}{c}\text { Estimated } \\
\text { SEC }\end{array}$ & Error \\
\hline 84 & $5,1 \#$ & 1,686 & 266 & 44 & 21,909 & - & 1 & 106.13 & 125.66 & $\mathbf{- 1 9 . 5 3}$ \\
\hline 85 & 5,1 & 1,686 & 342 & 47 & 26,052 & - & 1 & 113.76 & 129.35 & $\mathbf{- 1 5 . 5 9}$ \\
\hline 86 & 5,2 & 1,686 & 582 & 47 & 32,150 & - & 1 & 153.86 & 145.02 & 8.83 \\
\hline 87 & 5,1 & 1,686 & 130 & 47 & 8,160 & - & 1 & 137.55 & 135.94 & 1.60 \\
\hline 88 & 5,1 & 1,686 & 482 & 24 & 50,813 & 9,975 & 1 & 67.71 & 62.82 & 4.89 \\
\hline 89 & 5,2 & 1,686 & 598 & 24 & 50,448 & 10,698 & 1 & 84.87 & 74.14 & 10.73 \\
\hline 90 & 5,1 & 1,686 & 584 & 24 & 63,128 & 11,645 & 1 & $67.73 *$ & 49.73 & $\mathbf{1 8 . 0 0}$ \\
\hline 91 & 5,2 & 1,686 & 647 & 44 & 43,450 & - & 1 & 129.64 & 131.16 & -1.52 \\
\hline 92 & 5,1 & 1,686 & 627 & 44 & 55,938 & - & 1 & 98.24 & 108.60 & -10.37 \\
\hline 93 & 5,2 & 1,686 & 604 & 44 & 37,107 & - & 1 & 139.94 & 136.93 & 3.01 \\
\hline 94 & 5,1 & 1,686 & 608 & 44 & 46,659 & - & 1 & 113.82 & 121.74 & -7.92 \\
\hline 95 & 5,2 & 1,686 & 592 & 44 & 36,535 & - & 1 & 137.99 & 136.58 & 1.40 \\
\hline 96 & 5,1 & 1,686 & $\mathbf{1 1 7}$ & 44 & 8,813 & - & 1 & 113.90 & 131.15 & $\mathbf{- 1 7 . 2 5}$ \\
\hline 97 & 5,1 & 1,686 & 427 & 40 & 36,489 & - & 1 & 102.01 & 115.91 & -13.90 \\
\hline 98 & 5,2 & 1,686 & 601 & 35 & 33,653 & 10,096 & 1 & 117.99 & 111.89 & 6.10 \\
\hline 99 & 5,1 & 1,686 & 611 & 35 & 43,846 & 11,156 & 1 & 96.29 & 93.85 & 2.44 \\
\hline 100 & 5,2 & 1,686 & 410 & 35 & 24,196 & 7,068 & 1 & 112.49 & 113.94 & -1.45 \\
\hline 101 & 5,1 & 1,686 & 625 & 47 & 39,585 & 6,796 & 1 & 115.82 & 121.75 & -5.93 \\
\hline 102 & 5,2 & 1,686 & 596 & 47 & 32,131 & 4,912 & 1 & 138.43 & 135.20 & 3.24 \\
\hline 103 & 5,1 & 1,686 & 614 & 47 & 40,343 & 4,147 & 1 & 119.39 & 125.46 & -6.07 \\
\hline 104 & 5,2 & 1,686 & 562 & 47 & 23,758 & 7,228 & 1 & 151.36 & 139.90 & 11.47 \\
\hline 105 & 5,1 & 1,686 & 523 & 44 & 38,448 & 1,834 & 1 & 115.25 & 121.84 & -6.59 \\
\hline 106 & 5,1 & 1,686 & 90 & 44 & 6,000 & - & 1 & 126.86 & 132.86 & -6.00 \\
\hline 107 & 5,1 & 1,686 & 534 & 47 & 36,454 & - & 1 & 128.95 & 132.86 & -3.91 \\
\hline 108 & 5,2 & 1,686 & 565 & 47 & 23,203 & 4,326 & 1 & 171.11 & 147.83 & $\mathbf{2 3 . 2 8}$ \\
\hline & & & & Average of Absolute Error Value & & & & $\mathbf{7 . 7 1}$ \\
\hline
\end{tabular}

* denotes an observation whose $\mathrm{X}$ value gives it large leverage

\#Sawmill 5 data is shown with both $1^{\text {st }}$ and $2^{\text {nd }}$ shifts.

There are totally 16 data points out of 108 with error of greater than $\pm 15 \mathrm{kwh} / \mathrm{MBF}$ and the average of absolute error value was $7.71 \mathrm{kWh} / \mathrm{MBF}$ from the estimation results of Model 1 for sawmill 1, 2, 4 and 5. Error of $\pm 15 \mathrm{kwh} / \mathrm{MBF}$ was considered since the average SEC for all the sawmills was around $100 \mathrm{kWh} / \mathrm{MBF}$ and the $\mathrm{R}^{2}$ was around $85 \%$. The data points $2,17,43$, 56, 70, and 96 have shift run times less than 2.75 hours and hence have resulted in higher error levels. As discussed in data collection plan, to keep the error rate at $\pm 10 \%$, at least 2.75 hours data is required for each data set. 
Data point 55 seems to have an error in the reported data or the sawmill 2 has poor yield in that shift. Compare data points 50 and 55 from the same sawmill sawing same species as is Table 5.3. Data point 50 had production time of 450 minutes and produced $15,727(9,135$ of 4/4 to $8 / 4+$ Pallet, 6,592 Cant + Tim) board feet, where as data point 55 had production time of 465 minutes and produced $10,962(2,584$ of $4 / 4$ to $8 / 4+$ Pallet, 8,378 Cant + Tim) board feet resulting in 30\% lower yield and hence its SEC has gone up compared to other SEC's from sawmill 2 and hence cannot be estimated accurately.

Sawmill 5 had 2 shifts working during the data collection period and there was clear difference in the SEC between $1^{\text {st }}$ and $2^{\text {nd }}$ shift. $2^{\text {nd }}$ shift SEC was always higher than $1^{\text {st }}$ shift since it was sawing lumber during night and productivity of the workers was low. Data point 90 seems to have an error in the reported data as per Minitab analysis, or the sawmill 5 had very high yield in that shift. Compare data points 89 and 90 from the same sawmill sawing same species as is Table 5.3. Data point 89 had production time of 598 minutes and produced 61,146 $(50,448$ of $4 / 4$ to $8 / 4+$ Pallet, 10,698 Cant + Tim) board feet, where as data point 90 had production time of 584 minutes and produced 74,773 (63,128 of 4/4 to 8/4 + Pallet, 11,645 Cant + Tim) board feet resulting in 22\% higher yield and hence its SEC has gone down compared to data point 89's SEC and hence cannot be estimated accurately.

Still there are 7 data points $(15,65,72,75,80,84,85,108)$ with error of more than \pm 15 $\mathrm{kwh} / \mathrm{MBF}$ and must be reduced by improving the model 1 .

Table 5.4 shows the data from sawmill 3 and the estimated SEC values using the developed regression model 1 . The developed model 1 has failed to estimate the SEC of sawmill 3. There are only 2 data points out of 25 that have error value less than $\pm 15 \mathrm{kwh} / \mathrm{MBF}$ and the average of absolute error value is $41.24 \mathrm{kWh} / \mathrm{MBF}$. 
Table 5.4: Data of Sawmill 3 and estimated SEC using Model 1

\begin{tabular}{|c|c|c|c|c|c|c|c|c|c|c|}
\hline No. & $\begin{array}{c}\text { Mill } \\
\#\end{array}$ & $\begin{array}{c}\text { Motor } \\
\text { hp }\end{array}$ & $\begin{array}{c}\text { Run time } \\
(\text { Minutes })\end{array}$ & $\begin{array}{c}\text { Density } \\
\left(\mathbf{l b} / \mathrm{ft}^{3}\right)\end{array}$ & $\begin{array}{c}\mathbf{4} / \mathbf{4} \text { to 8/4 } \\
\text { + Pallet } \\
(\text { Board }\end{array}$ & $\begin{array}{c}\text { Cant }+ \\
\text { Tim } \\
(\text { Board }\end{array}$ & Resaw & SEC & $\begin{array}{c}\text { Estimated } \\
\text { SEC }\end{array}$ & Error \\
\hline 1 & 3 & 2630.5 & 480 & 44 & 70,762 & 9,645 & 1 & 105.28 & 123.60 & -18.33 \\
\hline 2 & 3 & 2630.5 & 120 & 44 & 15,476 & 2,717 & 1 & 124.48 & 191.53 & -67.06 \\
\hline 3 & 3 & 2630.5 & 360 & 47 & 52,297 & 10,694 & 1 & 104.00 & 140.88 & -36.88 \\
\hline 4 & 3 & 2630.5 & 390 & 47 & 53,822 & 8,726 & 1 & 111.63 & 146.14 & -34.52 \\
\hline 5 & 3 & 2630.5 & 90 & 47 & 14,251 & - & 1 & 111.68 & 198.95 & -87.27 \\
\hline 6 & 3 & 2630.5 & 120 & 47 & 25,722 & 1,272 & 1 & 85.78 & 180.46 & -94.69 \\
\hline 7 & 3 & 2630.5 & 360 & 35 & 54,330 & 7,372 & 1 & 104.21 & 135.88 & -31.66 \\
\hline 8 & 3 & 2630.5 & 240 & 35 & 36,481 & 4,917 & 1 & 103.86 & 157.91 & -54.05 \\
\hline 9 & 3 & 2630.5 & 210 & 64 & 24,743 & 15,166 & 1 & 111.65 & 172.82 & -61.18 \\
\hline 10 & 3 & 2630.5 & 480 & 56 & 82,405 & - & 1 & 105.06 & 136.23 & -31.17 \\
\hline 11 & 3 & 2630.5 & 480 & 44 & 77,793 & 3,172 & 1 & 108.29 & 127.07 & -18.78 \\
\hline 12 & 3 & 2630.5 & 480 & 24 & 84,341 & - & 1 & 86.33 & 108.10 & -21.77 \\
\hline 13 & 3 & 2630.5 & 480 & 24 & 80,230 & - & 1 & 89.69 & 114.82 & -25.13 \\
\hline 14 & 3 & 2630.5 & 480 & 24 & 82,402 & - & 1 & 81.33 & 111.27 & -29.94 \\
\hline 15 & 3 & 2630.5 & 480 & 24 & 83,415 & - & 1 & 84.82 & 109.61 & -24.79 \\
\hline 16 & 3 & 2630.5 & 480 & 44 & 76,564 & 3,388 & 1 & 108.37 & 128.58 & -20.21 \\
\hline 17 & 3 & 2630.5 & 315 & 44 & 28,493 & 15,223 & 1 & 124.17 & 162.18 & -38.01 \\
\hline 18 & 3 & 2630.5 & 165 & 24 & 34,619 & - & 1 & 82.45 & 155.72 & -73.27 \\
\hline 19 & 3 & 2630.5 & 300 & 47 & 38,783 & - & 1 & 140.73 & 181.29 & -40.56 \\
\hline 20 & 3 & 2630.5 & 180 & 35 & 25,114 & 4,076 & 1 & 105.32 & 172.02 & -66.71 \\
\hline 21 & 3 & 2630.5 & 480 & 35 & 63,695 & 11,321 & 1 & 110.70 & 124.26 & -13.56 \\
\hline 22 & 3 & 2630.5 & 480 & 35 & 65,815 & 12,566 & 1 & 108.55 & 117.91 & -9.36 \\
\hline 23 & 3 & 2630.5 & 90 & 35 & 12,258 & 3,681 & 1 & 103.72 & 184.34 & -80.62 \\
\hline 24 & 3 & 2630.5 & 390 & 44 & 49,854 & 2,217 & 1 & 130.79 & 165.34 & -34.55 \\
\hline 25 & 3 & 2630.5 & 480 & 44 & 75,778 & 5,791 & 1 & 107.44 & 124.31 & -16.87 \\
\hline & & & & Average of Absolute Error Value & & & & $\mathbf{4 1 . 2 4}$ \\
\hline
\end{tabular}

Estimation model 1 can be improved by adding the left over variables or considering interactions between the variables. Simply adding the left over variables will not improve the estimation model since those variables are not significant in the current model. Hence different combinations were tried and a multiple linear regression model (Model 2) with variable 'horsepower x minutes' along with 'level of maintenance' and 'Double line' variables was developed. Maintenance is a key for the performance of any machine and 'Double line' represents the line configuration and also some machines are shared in both the sawmills with double line. 
The results of the stepwise regression with are shown in Appendix Table A.23. 7 variables were selected out of 9 in the stepwise regression. The variables which were added to the model are 'Level of Maintenance' and 'Double Line' along with the variable 'hp x Min' and the ones left out are Debarker and Temperature. Again, Mallows' $\mathrm{Cp}$ is not displayed in the stepwise regression output since some estimators were highly correlated with each other. Mallows' $\mathrm{Cp}$ for the model with only the selected variables in stepwise regression is 8 which tell that the model fits the data well. The results of the developed model (Model 2) are shown below. Residual plots (Figure 5.2) show that there are some outliers in the data and the histogram in Figure 5.2 is better than 5.1 since most of the residuals are distributed within $\pm 10 \mathrm{kwh} / \mathrm{MBF}$.

$\mathrm{R}^{2}$ adjusted of the developed model 2 was $87.95 \%$, the $\mathrm{R}^{2}$ predicted was $85.88 \%$ and MSE was 82.9. Model 2 is totally different from Model 1 and signs of the regression coefficients no longer make much sense. The most precise variable and the variable that is explaining maximum variance is the variable ' $\mathrm{hp} \mathrm{x} \mathrm{min'.} \mathrm{All} \mathrm{the} \mathrm{variables} \mathrm{are} \mathrm{significant} \mathrm{in} \mathrm{both} \mathrm{T}$ and $\mathrm{F}$ Tests and have variance inflation factor less than 10. The SEC values estimated from the fitted model 2 are shown in Table 5.5. 


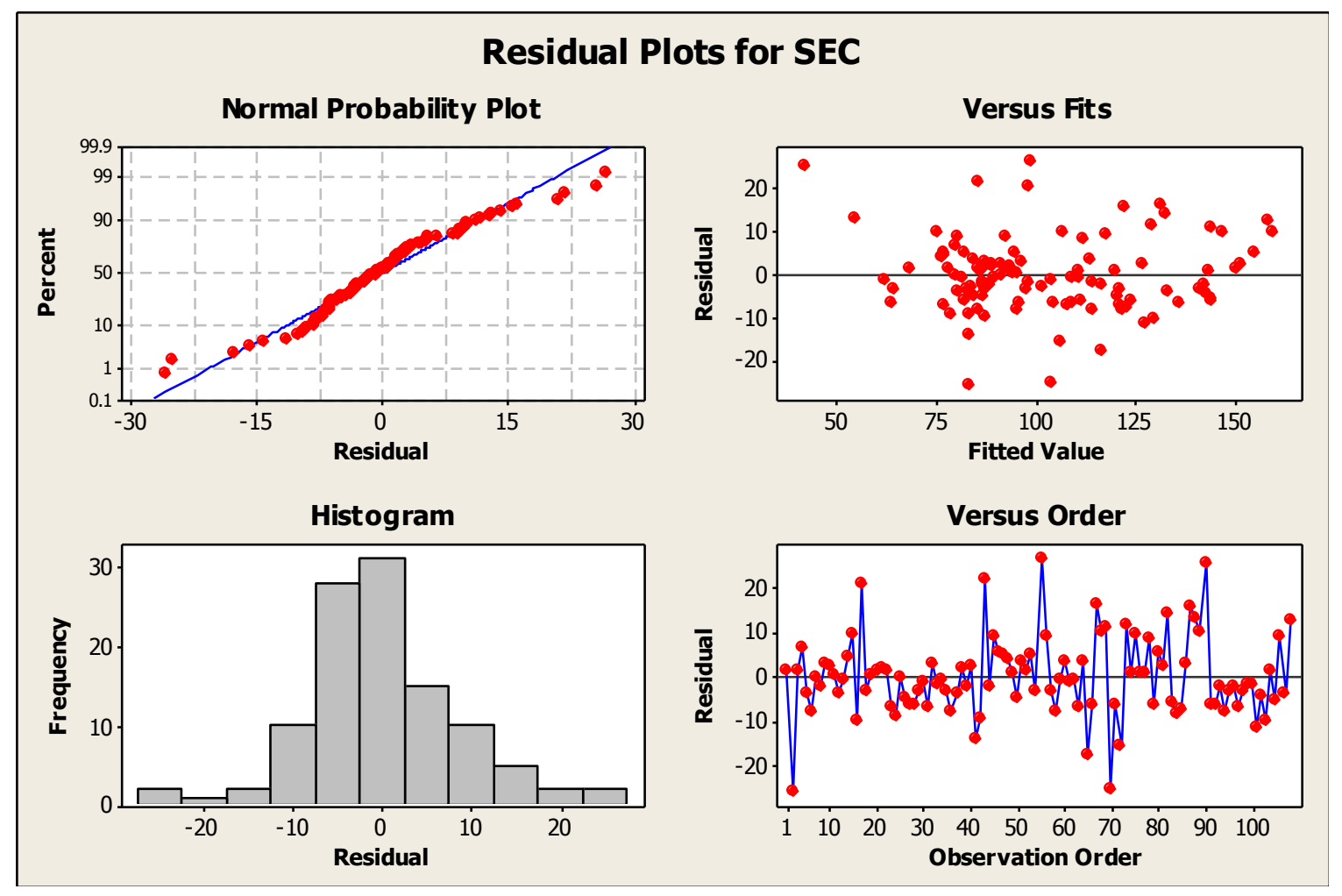

Figure 5.2: Residual Plots of Regression Model 2

Regression Equation

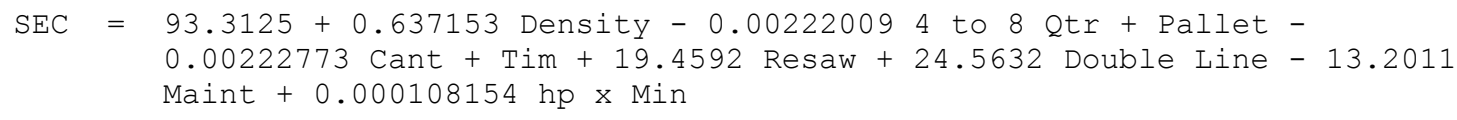

\begin{tabular}{rrr} 
DF & Seq SS & \multicolumn{1}{c}{ Adj SS } \\
7 & 65330.5 & 65330.5 \\
1 & 4137.4 & 2539.3 \\
1 & 6249.8 & 11187.3 \\
1 & 170.9 & 3679.3 \\
1 & 4170.8 & 3036.8 \\
1 & 21878.8 & 6030.5 \\
1 & 15609.2 & 5656.6 \\
1 & 13113.6 & 13113.6 \\
100 & 8290.0 & 8290.0 \\
107 & 73620.5 &
\end{tabular}

Adj MS

9332.9

2539.3

11187.3

3679.3

3036.8

6030.5

5656.6

13113.6

82.9

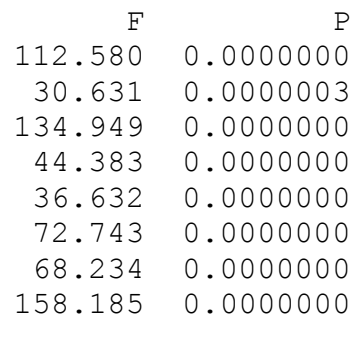


Table 5.5: Estimated SEC values from Regression Model 2

\begin{tabular}{|c|c|c|c|c|c|c|c|c|c|c|c|c|c|}
\hline No. & $\underset{\#}{\text { Mill }}$ & $\begin{array}{l}\text { Runtime } \\
\text { (Mins) }\end{array}$ & hp $x$ mins & $\begin{array}{c}\text { Density } \\
\left(\mathrm{lb} / \mathrm{ft}^{3}\right)\end{array}$ & $\begin{array}{c}4 / 4 \text { to } 8 / 4+ \\
\text { Pallet } \\
\text { (Board } \mathrm{ft} . \text { ) }\end{array}$ & $\begin{array}{c}\text { Cant }+ \\
\text { Tim } \\
\text { (Board ft.) } \\
\end{array}$ & Resaw & $\begin{array}{l}\text { Double } \\
\text { Line }\end{array}$ & $\begin{array}{l}\text { Maint } \\
\text { Level }\end{array}$ & SEC & $\begin{array}{c}\text { Estimated } \\
\text { SEC }\end{array}$ & Error & $\begin{array}{c}\% \\
\text { Error }\end{array}$ \\
\hline 1 & 1 & 555 & 537,240 & 35 & 29,726 & 2,648 & 1 & 0 & 4 & 70.05 & 68.48 & 1.57 & 2.25 \\
\hline 2 & 1 & 75 & 72,600 & 44 & 5,656 & 0 & 1 & 0 & 4 & 57.49 & 83.30 & -25.80 & -44.88 \\
\hline 3 & 1 & 630 & 609,840 & 44 & 33,160 & 984 & 1 & 0 & 4 & 79.48 & 78.15 & 1.33 & 1.68 \\
\hline 4 & 1 & 630 & 609,840 & 44 & 32,004 & 1,416 & 1 & 0 & 4 & 86.37 & 79.75 & 6.61 & 7.66 \\
\hline 5 & 1 & 235 & 227,480 & 44 & 12,188 & 1,187 & 1 & 0 & 4 & 79.31 & 82.90 & -3.60 & -4.53 \\
\hline 6 & 1 & 395 & 382,360 & 47 & 19,329 & 1,294 & 1 & 0 & 4 & 77.59 & 85.47 & -7.88 & -10.16 \\
\hline 7 & 1 & 240 & 232,320 & 40 & 12,954 & 832 & 1 & 0 & 4 & 79.62 & 79.97 & -0.34 & -0.43 \\
\hline 8 & 1 & 390 & 377,520 & 44 & 17,708 & 816 & 1 & 0 & 4 & 85.66 & 87.70 & -2.04 & -2.38 \\
\hline 9 & 1 & 120 & 116,160 & 47 & 6,765 & 0 & 1 & 0 & 4 & 90.42 & 87.46 & 2.96 & 3.28 \\
\hline 10 & 1 & 510 & 493,680 & 47 & 22,100 & 240 & 1 & 0 & 4 & 95.95 & 93.71 & 2.24 & 2.33 \\
\hline 11 & 1 & 570 & 551,760 & 47 & 24,663 & 312 & 1 & 0 & 4 & 94.75 & 94.14 & 0.61 & 0.65 \\
\hline 12 & 1 & 630 & 609,840 & 47 & 29,521 & 1,320 & 1 & 0 & 4 & 83.83 & 87.39 & -3.56 & -4.25 \\
\hline 13 & 1 & 630 & 609,840 & 47 & 28,348 & 1,640 & 1 & 0 & 4 & 88.84 & 89.28 & -0.45 & -0.50 \\
\hline 14 & 1 & 630 & 609,840 & 35 & 31,129 & 1,056 & 1 & 0 & 4 & 81.51 & 76.76 & 4.75 & 5.83 \\
\hline 15 & 1 & 240 & 232,320 & 64 & 8,489 & 192 & 1 & 0 & 4 & 116.38 & 106.60 & 9.79 & 8.41 \\
\hline 16 & 1 & 285 & 275,880 & 47 & 12,093 & 2,613 & 1 & 0 & 4 & 77.42 & 87.08 & -9.66 & -12.48 \\
\hline 17 & 1 & 105 & 101,640 & 56 & 3,337 & 435 & 1 & 0 & 4 & 119.23 & 98.26 & 20.97 & 17.59 \\
\hline 18 & 1 & 630 & 609,840 & 56 & 19,746 & 7,241 & 1 & 0 & 4 & 98.66 & 101.64 & -2.98 & -3.02 \\
\hline 19 & 1 & 195 & 188,760 & 56 & 8,815 & 676 & 1 & 0 & 4 & 95.50 & 94.99 & 0.51 & 0.54 \\
\hline 20 & 1 & 435 & 421,080 & 44 & 17,670 & 552 & 1 & 0 & 4 & 94.74 & 93.08 & 1.66 & 1.75 \\
\hline 21 & 1 & 630 & 609,840 & 44 & 28,526 & 744 & 1 & 0 & 4 & 90.76 & 88.97 & 1.79 & 1.97 \\
\hline 22 & 1 & 630 & 609,840 & 44 & 29,629 & 1,240 & 1 & 0 & 4 & 86.94 & 85.42 & 1.52 & 1.75 \\
\hline 23 & 2 & 270 & 220,590 & 64 & 4,904 & 5,237 & 0 & 0 & 3 & 89.13 & 95.79 & -6.66 & -7.48 \\
\hline 24 & 2 & 240 & 196,080 & 47 & 5,863 & 3,925 & 0 & 0 & 3 & 73.99 & 83.10 & -9.11 & -12.31 \\
\hline 25 & 2 & 510 & 416,670 & 47 & 10,301 & 6,540 & 0 & 0 & 3 & 91.16 & 91.28 & -0.13 & -0.14 \\
\hline 26 & 2 & 510 & 416,670 & 47 & 11,034 & 8,891 & 0 & 0 & 3 & 79.47 & 84.42 & -4.95 & -6.22 \\
\hline 27 & 2 & 180 & 147,060 & 47 & 3,975 & 3,867 & 0 & 0 & 3 & 76.00 & 82.12 & -6.12 & -8.05 \\
\hline 28 & 2 & 270 & 220,590 & 24 & 5,858 & 7,166 & 0 & 0 & 3 & 57.54 & 63.89 & -6.35 & -11.03 \\
\hline
\end{tabular}




\begin{tabular}{|c|c|c|c|c|c|c|c|c|c|c|c|c|c|}
\hline No. & $\begin{array}{c}\text { Mill } \\
\#\end{array}$ & $\begin{array}{l}\text { Runtime } \\
\text { (Mins) }\end{array}$ & hp $x$ mins & $\begin{array}{c}\text { Density } \\
\left(\mathrm{lb} / \mathrm{ft}^{3}\right)\end{array}$ & $\begin{array}{c}4 / 4 \text { to } 8 / 4+ \\
\text { Pallet } \\
\text { (Board } \mathrm{ft} \text { ) }\end{array}$ & $\begin{array}{c}\text { Cant }+ \\
\text { Tim } \\
\text { (Board ft.) }\end{array}$ & Resaw & $\begin{array}{l}\text { Double } \\
\text { Line }\end{array}$ & $\begin{array}{c}\text { Maint } \\
\text { Level }\end{array}$ & SEC & $\begin{array}{c}\text { Estimated } \\
\text { SEC }\end{array}$ & Error & $\begin{array}{c}\% \\
\text { Error }\end{array}$ \\
\hline 29 & 2 & 120 & 98,040 & 24 & 2,598 & 4,194 & 0 & 0 & 3 & 61.25 & 64.49 & -3.25 & -5.30 \\
\hline 30 & 2 & 390 & 318,630 & 24 & 7,967 & 10,652 & 0 & 0 & 3 & 60.79 & 62.04 & -1.25 & -2.06 \\
\hline 31 & 2 & 510 & 416,670 & 44 & 13,481 & 8,950 & 0 & 0 & 3 & 70.04 & 76.94 & -6.90 & -9.85 \\
\hline 32 & 2 & 510 & 416,670 & 44 & 8,162 & 7,840 & 0 & 0 & 3 & 94.01 & 91.22 & 2.79 & 2.96 \\
\hline 33 & 2 & 510 & 416,670 & 44 & 10,465 & 7,593 & 0 & 0 & 3 & 85.15 & 86.66 & -1.51 & -1.77 \\
\hline 34 & 2 & 300 & 245,100 & 44 & 7,211 & 4,914 & 0 & 0 & 3 & 80.82 & 81.30 & -0.48 & -0.59 \\
\hline 35 & 2 & 150 & 122,550 & 64 & 1,852 & 2,775 & 0 & 0 & 3 & 94.05 & 97.45 & -3.40 & -3.61 \\
\hline 36 & 2 & 330 & 269,610 & 64 & 5,706 & 7,104 & 0 & 0 & 3 & 87.07 & 95.15 & -8.08 & -9.28 \\
\hline 37 & 2 & 150 & 122,550 & 44 & 3,231 & 3,307 & 0 & 0 & 3 & 76.63 & 80.46 & -3.82 & -4.99 \\
\hline 38 & 2 & 510 & 416,670 & 44 & 9,196 & 8,931 & 0 & 0 & 3 & 88.53 & 86.50 & 2.03 & 2.29 \\
\hline 39 & 2 & 510 & 416,670 & 44 & 9,802 & 8,309 & 0 & 0 & 3 & 84.54 & 86.54 & -2.00 & -2.37 \\
\hline 40 & 2 & 480 & 392,160 & 44 & 9,765 & 6,199 & 0 & 0 & 3 & 91.35 & 88.67 & 2.68 & 2.93 \\
\hline 41 & 2 & 30 & 24,510 & 47 & 613 & 862 & 0 & 0 & 3 & 68.88 & 83.03 & -14.15 & -20.54 \\
\hline 42 & 2 & 450 & 367,650 & 47 & 8,613 & 11,556 & 0 & 0 & 3 & 69.25 & 78.55 & -9.30 & -13.43 \\
\hline 43 & 2 & 105 & 85,785 & 47 & 1,682 & 1,600 & 0 & 0 & 3 & 107.59 & 85.63 & 21.95 & 20.40 \\
\hline 44 & 2 & 405 & 330,885 & 47 & 6,595 & 7,461 & 0 & 0 & 3 & 85.95 & 88.18 & -2.23 & -2.60 \\
\hline 45 & 2 & 450 & 367,650 & 47 & 6,872 & 7,177 & 0 & 0 & 3 & 101.26 & 92.17 & 9.09 & 8.97 \\
\hline 46 & 2 & 60 & 49,020 & 35 & 1,236 & 891 & 0 & 0 & 3 & 81.96 & 76.58 & 5.38 & 6.56 \\
\hline 47 & 2 & 510 & 416,670 & 35 & 10,589 & 6,930 & 0 & 0 & 3 & 87.31 & 82.13 & 5.18 & 5.93 \\
\hline 48 & 2 & 255 & 208,335 & 35 & 6,155 & 3,888 & 0 & 0 & 3 & 80.49 & 76.22 & 4.28 & 5.31 \\
\hline 49 & 2 & 255 & 208,335 & 44 & 5,320 & 2,990 & 0 & 0 & 3 & 86.72 & 85.80 & 0.92 & 1.06 \\
\hline 50 & 2 & 450 & 367,650 & 44 & 9,135 & 6,592 & 0 & 0 & 3 & 81.71 & 86.54 & -4.83 & -5.91 \\
\hline 51 & 2 & 330 & 269,610 & 44 & 6,847 & 5,067 & 0 & 0 & 3 & 88.09 & 84.41 & 3.67 & 4.17 \\
\hline 52 & 2 & 180 & 147,060 & 47 & 4,361 & 1,520 & 0 & 0 & 3 & 88.15 & 86.49 & 1.65 & 1.88 \\
\hline 53 & 2 & 510 & 416,670 & 47 & 10,900 & 4,348 & 0 & 0 & 3 & 100.14 & 94.83 & 5.30 & 5.30 \\
\hline 54 & 2 & 45 & 36,765 & 47 & 735 & 1,430 & 0 & 0 & 3 & 79.64 & 82.81 & -3.18 & -3.99 \\
\hline 55 & 2 & 465 & 379,905 & 44 & 2,584 & 8,378 & 0 & 0 & 3 & 125.07 & 98.43 & 26.64 & 21.30 \\
\hline 56 & 2 & 60 & 49,020 & 44 & 1,451 & 1,459 & 0 & 0 & 3 & 89.72 & 80.57 & 9.14 & 10.19 \\
\hline 57 & 2 & 450 & 367,650 & 44 & 10,119 & 6,966 & 0 & 0 & 3 & 80.51 & 83.52 & -3.01 & -3.74 \\
\hline 58 & 4 & 195 & 299,130 & 44 & 8,791 & 4,264 & 0 & 1 & 2 & 115.22 & 122.84 & -7.62 & -6.61 \\
\hline
\end{tabular}




\begin{tabular}{|c|c|c|c|c|c|c|c|c|c|c|c|c|c|}
\hline No. & $\begin{array}{c}\text { Mill } \\
\#\end{array}$ & $\begin{array}{l}\text { Runtime } \\
\text { (Mins) }\end{array}$ & hp $x$ mins & $\begin{array}{c}\text { Density } \\
\left(\mathrm{lb} / \mathrm{ft}^{3}\right)\end{array}$ & $\begin{array}{c}4 / 4 \text { to } 8 / 4+ \\
\text { Pallet } \\
\text { (Board ft.) }\end{array}$ & $\begin{array}{c}\text { Cant }+ \\
\text { Tim } \\
\text { (Board ft.) }\end{array}$ & Resaw & $\begin{array}{c}\text { Double } \\
\text { Line }\end{array}$ & $\begin{array}{l}\text { Maint } \\
\text { Level }\end{array}$ & SEC & $\begin{array}{c}\text { Estimated } \\
\text { SEC }\end{array}$ & Error & $\begin{array}{c}\% \\
\text { Error }\end{array}$ \\
\hline 59 & 4 & 405 & 621,270 & 24 & 25,259 & 4,138 & 0 & 1 & 2 & 108.23 & 108.66 & -0.43 & -0.40 \\
\hline 60 & 4 & 600 & 920,400 & 24 & 43,156 & 6,370 & 0 & 1 & 2 & 99.65 & 96.31 & 3.34 & 3.35 \\
\hline 61 & 4 & 600 & 920,400 & 24 & 38,884 & 7,182 & 0 & 1 & 2 & 103.05 & 103.98 & -0.93 & -0.91 \\
\hline 62 & 4 & 555 & 851,370 & 24 & 34,213 & 5,548 & 0 & 1 & 2 & 109.70 & 110.53 & -0.83 & -0.75 \\
\hline 63 & 4 & 45 & 69,030 & 26 & 1,678 & 1,744 & 0 & 1 & 2 & 100.94 & 107.89 & -6.96 & -6.89 \\
\hline 64 & 4 & 300 & 460,200 & 26 & 6,296 & 13,659 & 0 & 1 & 2 & 116.97 & 113.41 & 3.56 & 3.05 \\
\hline 65 & 4 & 300 & 460,200 & 47 & 19,689 & 5,040 & 0 & 1 & 2 & 98.44 & 116.25 & -17.82 & -18.10 \\
\hline 66 & 4 & 600 & 920,400 & 47 & 27,905 & 6,674 & 0 & 1 & 2 & 137.93 & 144.15 & -6.21 & -4.50 \\
\hline 67 & 4 & 180 & 276,120 & 47 & 7,188 & 1,852 & 0 & 1 & 2 & 147.41 & 131.20 & 16.21 & 11.00 \\
\hline 68 & 4 & 420 & 644,280 & 64 & 15,478 & 3,748 & 0 & 1 & 2 & 169.34 & 159.22 & 10.12 & 5.98 \\
\hline 69 & 4 & 330 & 506,220 & 64 & 15,437 & 4,070 & 0 & 1 & 2 & 154.92 & 143.66 & 11.26 & 7.27 \\
\hline 70 & 4 & 120 & 184,080 & 26 & 4,915 & 5,948 & 0 & 1 & 2 & 78.61 & 103.79 & -25.18 & -32.03 \\
\hline 71 & 4 & 465 & 713,310 & 35 & 23,908 & 11,956 & 0 & 1 & 2 & 105.08 & 111.21 & -6.13 & -5.83 \\
\hline 72 & 4 & 330 & 506,220 & 35 & 15,917 & 12,216 & 0 & 1 & 2 & 90.29 & 105.97 & -15.68 & -17.37 \\
\hline 73 & 4 & 270 & 414,180 & 44 & 12,724 & 3,244 & 0 & 1 & 2 & 140.53 & 128.83 & 11.70 & 8.33 \\
\hline 74 & 4 & 600 & 920,400 & 44 & 27,184 & 6,783 & 0 & 1 & 2 & 144.54 & 143.59 & 0.95 & 0.65 \\
\hline 75 & 4 & 525 & 805,350 & 44 & 21,340 & 5,565 & 0 & 1 & 2 & 156.76 & 146.84 & 9.93 & 6.33 \\
\hline 76 & 4 & 355.2 & $544,876.8$ & 24 & 21,700 & 3,052 & 0 & 1 & 2 & 111.76 & 110.72 & 1.04 & 0.93 \\
\hline 77 & 4 & 600 & 920,400 & 24 & 33,112 & 5,922 & 0 & 1 & 2 & 120.46 & 119.61 & 0.86 & 0.71 \\
\hline 78 & 4 & 195 & 299,130 & 24 & 10,144 & 2,149 & 0 & 1 & 2 & 120.26 & 111.81 & 8.45 & 7.03 \\
\hline 79 & 4 & 394.8 & $605,623.2$ & 40 & 21,944 & 4,512 & 0 & 1 & 2 & 117.52 & 123.69 & -6.17 & -5.25 \\
\hline 80 & 4 & 600 & 920,400 & 40 & 23,151 & 4,739 & 0 & 1 & 2 & 159.87 & 154.55 & 5.32 & 3.33 \\
\hline 81 & 4 & 330 & 506,220 & 40 & 16,449 & 3,752 & 0 & 1 & 2 & 129.35 & 126.83 & 2.51 & 1.94 \\
\hline 82 & 4 & 270 & 414,180 & 47 & 12,199 & 2,902 & 0 & 1 & 2 & 146.91 & 132.67 & 14.25 & 9.70 \\
\hline 83 & 4 & 600 & 920,400 & 47 & 28,046 & 6,643 & 0 & 1 & 2 & 138.38 & 143.90 & -5.52 & -3.99 \\
\hline 84 & $5,1 \#$ & 266 & 448,476 & 44 & 21,909 & - & 1 & 0 & 2 & 106.13 & 114.27 & -8.14 & -7.67 \\
\hline 85 & 5,1 & 342 & 576,612 & 47 & 26,052 & - & 1 & 0 & 2 & 113.76 & 120.84 & -7.08 & -6.23 \\
\hline 86 & 5,2 & 582 & 981,252 & 47 & 32,150 & - & 1 & 0 & 2 & 153.86 & 151.07 & 2.79 & 1.81 \\
\hline 87 & 5,1 & 130 & 219,180 & 47 & 8,160 & - & 1 & 0 & 2 & 137.55 & 121.90 & 15.64 & 11.37 \\
\hline 88 & 5,1 & 482 & 812,652 & 24 & 50,813 & 9,975 & 1 & 0 & 2 & 67.71 & 54.52 & 13.18 & 19.47 \\
\hline
\end{tabular}




\begin{tabular}{|c|c|c|c|c|c|c|c|c|c|c|c|c|c|}
\hline No. & $\underset{\#}{\text { Mill }}$ & $\begin{array}{l}\text { Runtime } \\
\text { (Mins) }\end{array}$ & hp $x$ mins & $\begin{array}{c}\text { Density } \\
\left(\mathrm{lb} / \mathrm{ft}^{3}\right)\end{array}$ & $\begin{array}{c}4 / 4 \text { to } 8 / 4+ \\
\text { Pallet } \\
\text { (Board } \mathrm{ft} .)\end{array}$ & $\begin{array}{c}\text { Cant }+ \\
\text { Tim } \\
\text { (Board ft.) }\end{array}$ & Resaw & $\begin{array}{c}\text { Double } \\
\text { Line }\end{array}$ & $\begin{array}{l}\text { Maint } \\
\text { Level }\end{array}$ & SEC & $\begin{array}{c}\text { Estimated } \\
\text { SEC }\end{array}$ & Error & $\begin{array}{c}\% \\
\text { Error }\end{array}$ \\
\hline 89 & 5,2 & 598 & $1,008,228$ & 24 & 50,448 & 10,698 & 1 & 0 & 2 & 84.87 & 74.87 & 10.00 & 11.78 \\
\hline 90 & 5,1 & 584 & 984,624 & 24 & 63,128 & 11,645 & 1 & 0 & 2 & $67.73 *$ & 42.06 & 25.67 & 37.90 \\
\hline 91 & 5,2 & 647 & $1,090,842$ & 44 & 43,450 & - & 1 & 0 & 2 & 129.64 & 135.92 & -6.28 & -4.84 \\
\hline 92 & 5,1 & 627 & $1,057,122$ & 44 & 55,938 & - & 1 & 0 & 2 & 98.24 & 104.55 & -6.31 & -6.43 \\
\hline 93 & 5,2 & 604 & $1,018,344$ & 44 & 37,107 & - & 1 & 0 & 2 & 139.94 & 142.16 & -2.22 & -1.58 \\
\hline 94 & 5,1 & 608 & $1,025,088$ & 44 & 46,659 & - & 1 & 0 & 2 & 113.82 & 121.68 & -7.86 & -6.91 \\
\hline 95 & 5,2 & 592 & 998,112 & 44 & 36,535 & - & 1 & 0 & 2 & 137.99 & 141.24 & -3.26 & -2.36 \\
\hline 96 & 5,1 & 117 & 197,262 & 44 & 8,813 & - & 1 & 0 & 2 & 113.90 & 116.17 & -2.28 & -2.00 \\
\hline 97 & 5,1 & 427 & 719,922 & 40 & 36,489 & - & 1 & 0 & 2 & 102.01 & 108.71 & -6.70 & -6.57 \\
\hline 98 & 5,2 & 601 & $1,013,286$ & 35 & 33,653 & 10,096 & 1 & 0 & 2 & 117.99 & 121.06 & -3.06 & -2.60 \\
\hline 99 & 5,1 & 611 & $1,030,146$ & 35 & 43,846 & 11,156 & 1 & 0 & 2 & 96.29 & 97.89 & -1.60 & -1.66 \\
\hline 100 & 5,2 & 410 & 691,260 & 35 & 24,196 & 7,068 & 1 & 0 & 2 & 112.49 & 113.97 & -1.47 & -1.31 \\
\hline 101 & 5,1 & 625 & $1,053,750$ & 47 & 39,585 & 6,796 & 1 & 0 & 2 & 115.82 & 127.26 & -11.44 & -9.88 \\
\hline 102 & 5,2 & 596 & $1,004,856$ & 47 & 32,131 & 4,912 & 1 & 0 & 2 & 138.43 & 142.72 & -4.29 & -3.10 \\
\hline 103 & 5,1 & 614 & $1,035,204$ & 47 & 40,343 & 4,147 & 1 & 0 & 2 & 119.39 & 129.47 & -10.08 & -8.44 \\
\hline 104 & 5,2 & 562 & 947,532 & 47 & 23,758 & 7,228 & 1 & 0 & 2 & 151.36 & 149.95 & 1.41 & 0.93 \\
\hline 105 & 5,1 & 523 & 881,778 & 44 & 38,448 & 1,834 & 1 & 0 & 2 & 115.25 & 120.33 & -5.08 & -4.41 \\
\hline 106 & 5,1 & 90 & 151,740 & 44 & 6,000 & - & 1 & 0 & 2 & 126.86 & 117.49 & 9.37 & 7.38 \\
\hline 107 & 5,1 & 534 & 900,324 & 47 & 36,454 & - & 1 & 0 & 2 & 128.95 & 132.76 & -3.81 & -2.96 \\
\hline 108 & 5,2 & 565 & 952,590 & 47 & 23,203 & 4,326 & 1 & 0 & 2 & 171.11 & 158.19 & 12.92 & 7.55 \\
\hline \multicolumn{12}{|c|}{ Average of Absolute Error Value } & 6.44 & 6.69 \\
\hline
\end{tabular}

* denotes an observation whose $\mathrm{X}$ value gives it large leverage, \#Sawmill 5 data is shown with both $1^{\text {st }}$ and $2^{\text {nd }}$ shifts.

There are totally 10 data points out of 108 with error of greater than $\pm 15 \mathrm{kwh} / \mathrm{MBF}$ and the average of absolute error value was $6.44 \mathrm{kWh} / \mathrm{MBF}$ and the average of absolute percentage error value was $6.69 \mathrm{kWh} / \mathrm{MBF}$ from the estimation results of Model 2 for sawmill 1, 2, 4 and 5. The data points 2, 17, 43, 70, and 87 have shift run times less than 2.75 hours and hence have resulted in higher error levels. 
Data points 56 and 96 which had higher error values in Model 1 due to shorter run times have been estimated accurately by Model 2. Data points 55 and 90 still has higher error value and the explanation given before still applies here. Data points $15,75,80,84,85$, and 108 which had higher error values in Model 1 have been estimated accurately by Model 2. There are still 3 data points $(65,67,72)$ with error of more than $\pm 15 \mathrm{kwh} / \mathrm{MBF}$ in sawmill 4 . The point to be noted is whenever there is a change in the species, there are chances of two species getting mixed up in the same shift.

Data points 65, 67 and 72 have change in species and there are chances of mixing up of species and resulting in higher error in estimated value. Also, data points 15, 16, 24, 36, 68, 69, $73,75,78$ and 82 have higher error but within $\pm 15 \mathrm{kwh} / \mathrm{MBF}$ due to change in species. Error due to change is species is not mentioned for sawmill 5 since sawmill 5 has error from change in shift also. Also, error due to change in species is not happening every time.

Data points 2, 17, 43, 55, 65, 70, and 90 are identified as outliers from Minitab. After removing these points from the data, $\mathrm{R}^{2}$ adjusted and $\mathrm{R}^{2}$ predicted of model 2 becomes $93.69 \%$ and $92.51 \%$ respectively. After removing these 7 data points, data point 88 and 89 are identified as outliers from Minitab. If all the 9 data points were removed for developing the model, then the $\mathrm{R}^{2}$ adjusted and $\mathrm{R}^{2}$ predicted of model 2 becomes $95.06 \%$ and $94.40 \%$ respectively with error of all the data points remaining within $\pm 15 \mathrm{kwh} / \mathrm{MBF}$. Another point to be noted is the data points $(67,72)$ which had error of more than $\pm 15 \mathrm{kwh} / \mathrm{MBF}$ due to change in species automatically gets reduced once these 9 data points were removed. The obtained regression model looks like,

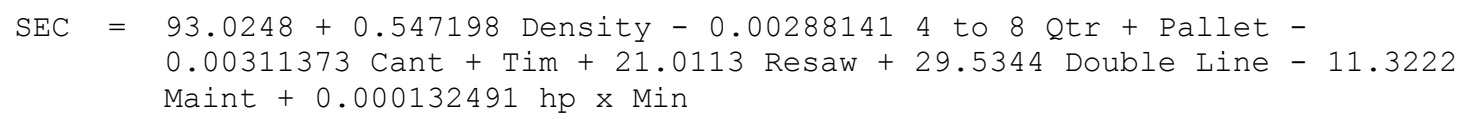

The regression coefficients of the model 2 with and without outliers are listed in Table 5.6. The main differences between the model with outliers and without outliers is increase in 
value of density variable coefficient by 0.09 , 'double line' variable coefficient by 4.97 , 'hp x min' variable coefficient by 0.000024 and decrease in value of ' 4 to $8 \mathrm{Qtr}+$ Pallet' variable coefficient by 0.0006 , and decrease in value of 'Cant + Tim' variable coefficient by 0.0009 . Even though the change in coefficients of variables 'hp x min', '4 to 8 Qtr + Pallet' and 'Cant + Tim' is small, its effect is significant since the magnitude of these variables is very high. Coefficients of other variables didn't change significantly.

Table 5.6: Comparison of Model 2 Regression Coefficients with and without Outliers

\begin{tabular}{|l|c|c|}
\hline \multicolumn{1}{|c|}{ Variable } & $\begin{array}{c}\text { Regression coefficient } \\
\text { value with outliers }\end{array}$ & $\begin{array}{c}\text { Regression coefficient } \\
\text { value without outliers }\end{array}$ \\
\hline Constant & 93.3125 & 93.0248 \\
\hline Density & 0.637153 & 0.547198 \\
\hline 4 to 8 Qtr + Pallet & -0.00222009 & -0.00288141 \\
\hline Cant + Tim & -0.00222773 & -0.00311373 \\
\hline Resaw & 19.4592 & 21.0113 \\
\hline Double Line & 24.5632 & 29.5344 \\
\hline Maint & -13.2011 & -11.3222 \\
\hline hp x Min & 0.000108154 & 0.000132491 \\
\hline
\end{tabular}

Estimated values of Model 2 were converted into 'Total $\mathrm{kWh}$ ' and are plotted with the actual 'Total kWh' values (Figure 5.3). Estimated values follow actual values very closely.

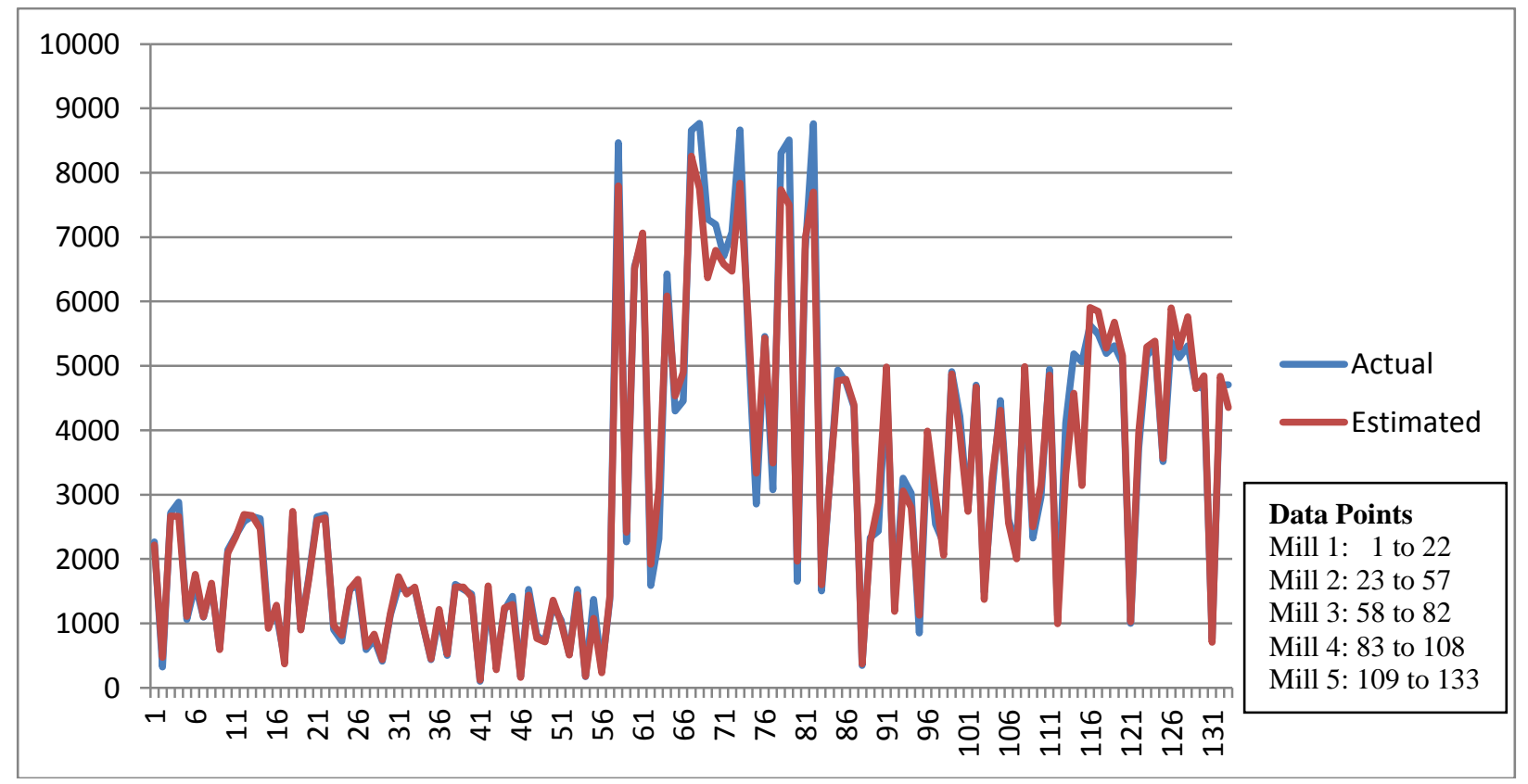

Figure 5.3: Model 2 Estimated Values converted to 'Total kWh' with Actual Values 
Table 5.7 shows the data from sawmill 3 and the estimated SEC values using the developed regression model 2.

Table 5.7: Data of Sawmill 3 and estimated SEC using Model 2

\begin{tabular}{|c|c|c|c|c|c|c|c|c|c|c|c|c|}
\hline No. & $\begin{array}{c}\text { Run } \\
\text { time } \\
\text { (Mins) }\end{array}$ & hp $x$ mins & $\begin{array}{c}\text { Density } \\
\left(\mathrm{lb} / \mathrm{ft}^{3}\right)\end{array}$ & $\begin{array}{c}4 / 4 \text { to } 8 / 4+ \\
\text { Pallet } \\
\text { (Board ft.) }\end{array}$ & $\begin{array}{c}\text { Cant }+ \\
\text { Tim } \\
\text { (Board ft.) }\end{array}$ & Resaw & $\begin{array}{l}\text { Double } \\
\text { Line }\end{array}$ & $\begin{array}{l}\text { Maint } \\
\text { Level }\end{array}$ & SEC & $\begin{array}{c}\text { Estimated } \\
\text { SEC }\end{array}$ & $\begin{array}{c}\text { Error } \\
\text { by } \\
\text { Model } 2\end{array}$ & $\begin{array}{c}\text { Error } \\
\text { by } \\
\text { Model } 1\end{array}$ \\
\hline 1 & 480 & $1,262,640$ & 44 & 70,762 & 9,645 & 1 & 1 & 2 & 105.28 & 96.94 & 8.33 & -18.33 \\
\hline 2 & 120 & 315,660 & 44 & 15,476 & 2,717 & 1 & 1 & 2 & 124.48 & 132.70 & -8.22 & -67.06 \\
\hline 3 & 360 & 946,980 & 47 & 52,297 & 10,694 & 1 & 1 & 2 & 104.00 & 103.37 & 0.63 & -36.88 \\
\hline 4 & 390 & $1,025,895$ & 47 & 53,822 & 8,726 & 1 & 1 & 2 & 111.63 & 112.90 & -1.28 & -34.52 \\
\hline 5 & 90 & 236,745 & 47 & 14,251 & - & 1 & 1 & 2 & 111.68 & 134.85 & -23.17 & -87.27 \\
\hline 6 & 120 & 315,660 & 47 & 25,722 & 1,272 & 1 & 1 & 2 & 85.78 & 115.08 & -29.30 & -94.69 \\
\hline 7 & 360 & 946,980 & 35 & 54,330 & 7,372 & 1 & 1 & 2 & 104.21 & 98.61 & 5.60 & -31.66 \\
\hline 8 & 240 & 631,320 & 35 & 36,481 & 4,917 & 1 & 1 & 2 & 103.86 & 109.57 & -5.71 & -54.05 \\
\hline 9 & 210 & 552,405 & 64 & 24,743 & 15,166 & 1 & 1 & 2 & 111.65 & 122.74 & -11.09 & -61.18 \\
\hline 10 & 480 & $1,262,640$ & 56 & 82,405 & - & 1 & 1 & 2 & 105.06 & 100.23 & 4.84 & -31.17 \\
\hline 11 & 480 & $1,262,640$ & 44 & 77,793 & 3,172 & 1 & 1 & 2 & 108.29 & 95.75 & 12.54 & -18.78 \\
\hline 12 & 480 & $1,262,640$ & 24 & 84,341 & - & 1 & 1 & 2 & 86.33 & 75.54 & 10.79 & -21.77 \\
\hline 13 & 480 & $1,262,640$ & 24 & 80,230 & - & 1 & 1 & 2 & 89.69 & 84.67 & 5.02 & -25.13 \\
\hline 14 & 480 & $1,262,640$ & 24 & 82,402 & - & 1 & 1 & 2 & 81.33 & 79.84 & 1.49 & -29.94 \\
\hline 15 & 480 & $1,262,640$ & 24 & 83,415 & - & 1 & 1 & 2 & 84.82 & 77.60 & 7.22 & -24.79 \\
\hline 16 & 480 & $1,262,640$ & 44 & 76,564 & 3,388 & 1 & 1 & 2 & 108.37 & 98.00 & 10.37 & -20.21 \\
\hline 17 & 315 & $828,607.5$ & 44 & 28,493 & 15,223 & 1 & 1 & 2 & 124.17 & 131.41 & -7.25 & -38.01 \\
\hline 18 & 165 & $4,340,325$ & 24 & 34,619 & - & 1 & 1 & 2 & 82.45 & 96.31 & -13.86 & -73.27 \\
\hline 19 & 300 & 789,150 & 47 & 38,783 & - & 1 & 1 & 2 & 140.73 & 140.13 & 0.60 & -40.56 \\
\hline 20 & 180 & 473,490 & 35 & 25,114 & 4,076 & 1 & 1 & 2 & 105.32 & 119.61 & -14.29 & -66.71 \\
\hline 21 & 480 & $1,262,640$ & 35 & 63,695 & 11,321 & 1 & 1 & 2 & 110.70 & 103.16 & 7.54 & -13.56 \\
\hline 22 & 480 & $1,262,640$ & 35 & 65,815 & 12,566 & 1 & 1 & 2 & 108.55 & 95.68 & 12.87 & -9.36 \\
\hline 23 & 90 & 236,745 & 35 & 12,258 & 3,681 & 1 & 1 & 2 & 103.72 & 123.42 & -19.70 & -80.62 \\
\hline 24 & 390 & $1,025,895$ & 44 & 49,854 & 2,217 & 1 & 1 & 2 & 130.79 & 134.30 & -3.51 & -34.55 \\
\hline 25 & 480 & $1,262,640$ & 44 & 75,778 & 5,791 & 1 & 1 & 2 & 107.44 & 94.39 & 13.05 & -16.87 \\
\hline \multicolumn{11}{|c|}{ Average of Absolute Error Value } & 9.53 & 41.24 \\
\hline
\end{tabular}


Model 2 has estimated the SEC of sawmill 3 way better than Model 1. The average of absolute error value is $9.53 \mathrm{kWh} / \mathrm{MBF}$ where as the average of absolute error value of Model 1 was $41.24 \mathrm{kWh} / \mathrm{MBF}$. Error was very high for shift run times (data points 5, 6 and 23 in Table 5.7) of less than 2.75 hours similar to other sawmills used for developing the model. The other data points were estimated with error of $\pm 15 \mathrm{kwh} / \mathrm{MBF}$.

An estimation model without horse power was developed to check whether the energy consumption can be estimated without using horsepower as an estimator variable. Results of the stepwise regression done to select the variables are shown in Appendix Table A.24.

7 variables were selected out of 9 in the stepwise regression. The variables which were left out are Debarker and Temperature. Mallow's $\mathrm{Cp}$ for the model is 8.7 which is greater than 8 (7 variables +1 Constant) and hence the model fits the data well. Mallow's Cp with only the selected variables in stepwise regression is 8 which again tell that the model fits the data well. The results of the developed model (Model 3) are shown below. Residual plots (Figure 5.4) show that there are some outliers in the data and the histogram in Figure 5.4 is similar to the one in Figure 5.1 since most of the residuals are distributed within $\pm 15 \mathrm{kwh} / \mathrm{MBF} . \mathrm{R}^{2}$ adjusted of the developed model 3 was $83.66 \%$, the $\mathrm{R}^{2}$ predicted was $81.64 \%$ and MSE was 112.4 . Model 2 was better than model 3 since its $\mathrm{R}^{2}$ adjusted was $87.95 \%$ and Model 1 had slightly better $\mathrm{R}^{2}$ adjusted of $83.72 \%$ than Model 3. Model 3 is totally different from Model 1 since it has 'Level of Maintenance' and 'Double Line' estimator variables in place of 'Motor hp'.

The most precise variable and the variable that is explaining maximum variance are the '4 to 8 Qtr + Pallet' and 'Level of Maintenance' respectively. All the variables are significant in both $\mathrm{T}$ and $\mathrm{F}$ Tests and have variance inflation factor of less than 10. The SEC values estimated from the fitted model 3 are shown in Table 5.8. 


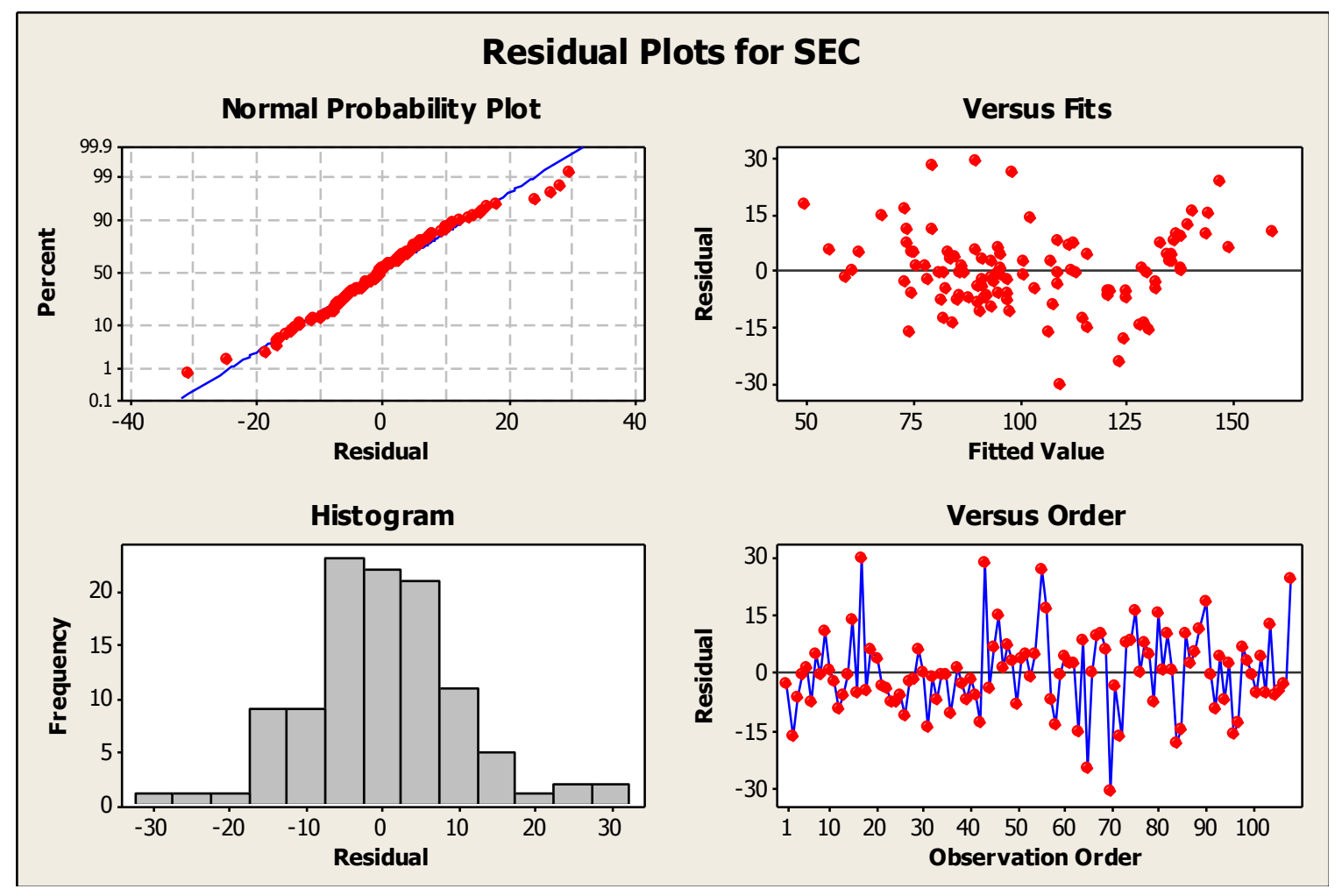

Figure 5.4: Residual Plots of Regression Model 3

Regression Equation

$\begin{aligned} \mathrm{SEC}= & 122.201+0.105517 \mathrm{Min}+0.795616 \text { Density }-0.001617544 \text { to } 8 \text { Qtr }+ \\ & \text { Pallet }-0.00223285 \text { Cant }+\mathrm{Tim}+31.4713 \text { Resaw }+31.6876 \text { Double } \\ & \text { Line }-28.3233 \text { Maint }\end{aligned}$

Coefficients

$\begin{array}{lrrrrr}\text { Term } & \text { Coef } & \text { SE Coef } & \text { T } & \text { P } & \text { VIF } \\ \text { Constant } & 122.201 & 9.00174 & 13.5753 & 0.000 & \\ \text { Min } & 0.106 & 0.01110 & 9.5055 & 0.000 & 4.03589 \\ \text { Density } & 0.796 & 0.13053 & 6.0952 & 0.000 & 1.50420 \\ 4 \text { to 8 Qtr + Pallet } & -0.002 & 0.00019 & -8.4478 & 0.000 & 7.06257 \\ \text { Cant + Tim } & -0.002 & 0.00040 & -5.6152 & 0.000 & 1.88133 \\ \text { Resaw } & 31.471 & 3.91284 & 8.0431 & 0.000 & 3.61464 \\ \text { Maint } & -28.323 & 1.92324 & -14.7269 & 0.000 & 2.14526 \\ \text { Double Line } & 31.688 & 3.32150 & 9.5402 & 0.000 & 1.93691\end{array}$

Summary of Model

\begin{tabular}{|c|c|c|c|c|c|c|}
\hline \multirow{2}{*}{$\begin{array}{ll}\mathrm{S}=10.6038 & \mathrm{R}-\mathrm{Sq} \\
\mathrm{PRESS}=13515.4 & \mathrm{R}-\mathrm{Sq} \\
\text { Analysis of Variance }\end{array}$} & $\begin{array}{l}84 . \\
\text { red) }\end{array}$ & $\begin{array}{l}73 \% \\
=81.64 \%\end{array}$ & \multicolumn{3}{|c|}{$R-S q(\operatorname{adj})=83.66 \%$} & \\
\hline & & & & & & \\
\hline Source & $\mathrm{DF}$ & Seq SS & Adj SS & Adj MS & $\mathrm{F}$ & $\mathrm{P}$ \\
\hline Regression & 7 & 62376.5 & 62376.5 & 8910.9 & 79.250 & 0.0000000 \\
\hline Min & 1 & 3198.6 & 10159.6 & 10159.6 & 90.355 & 0.0000000 \\
\hline Density & 1 & 4878.8 & 4177.3 & 4177.3 & 37.151 & 0.0000000 \\
\hline 4 to 8 Qtr + Pallet & 1 & 2324.5 & 8024.3 & 8024.3 & 71.365 & 0.0000000 \\
\hline Cant + Tim & 1 & 288.0 & 3545.3 & 3545.3 & 31.530 & 0.0000002 \\
\hline Resaw & 1 & 4073.9 & 7273.9 & 7273.9 & 64.691 & 0.0000000 \\
\hline Double Line & 1 & 23226.5 & 10233.7 & 10233.7 & 91.015 & 0.0000000 \\
\hline Maint & 1 & 24386.1 & 24386.1 & 24386.1 & 216.880 & 0.0000000 \\
\hline Error & 100 & 11244.0 & 11244.0 & 112.4 & & \\
\hline Total & 107 & 73620.5 & & & & \\
\hline
\end{tabular}


Table 5.8: Estimated SEC values from Regression Model 3

\begin{tabular}{|c|c|c|c|c|c|c|c|c|c|c|c|}
\hline No. & $\begin{array}{c}\text { Mill } \\
\#\end{array}$ & $\begin{array}{c}\text { Runtime } \\
\text { (Mins) }\end{array}$ & $\begin{array}{c}\text { Density } \\
\left(\mathrm{lb} / \mathrm{ft}^{3}\right)\end{array}$ & $\begin{array}{c}\text { 4/4 to } 8 / 4 \\
\text { + Pallet } \\
\text { (Board ft.) }\end{array}$ & $\begin{array}{c}\text { Cant + } \\
\text { Tim } \\
\text { (Board ft.) }\end{array}$ & Resaw & $\begin{array}{c}\text { Double } \\
\text { Line }\end{array}$ & $\begin{array}{l}\text { Maint } \\
\text { Level }\end{array}$ & SEC & $\begin{array}{l}\text { Estimated } \\
\text { SEC }\end{array}$ & Error \\
\hline 1 & 1 & 555 & 35 & 29,726 & 2,648 & 1 & 0 & 4 & 70.05 & 72.79 & -2.74 \\
\hline 2 & 1 & 75 & 44 & 5,656 & 0 & 1 & 0 & 4 & 57.49 & 74.15 & -16.66 \\
\hline 3 & 1 & 630 & 44 & 33,160 & 984 & 1 & 0 & 4 & 79.48 & 86.03 & -6.54 \\
\hline 4 & 1 & 630 & 44 & 32,004 & 1,416 & 1 & 0 & 4 & 86.37 & 86.93 & -0.57 \\
\hline 5 & 1 & 235 & 44 & 12,188 & 1,187 & 1 & 0 & 4 & 79.31 & 77.82 & 1.49 \\
\hline 6 & 1 & 395 & 47 & 19,329 & 1,294 & 1 & 0 & 4 & 77.59 & 85.30 & -7.71 \\
\hline 7 & 1 & 240 & 40 & 12,954 & 832 & 1 & 0 & 4 & 79.62 & 74.72 & 4.91 \\
\hline 8 & 1 & 390 & 44 & 17,708 & 816 & 1 & 0 & 4 & 85.66 & 86.07 & -0.41 \\
\hline 9 & 1 & 120 & 47 & 6,765 & 0 & 1 & 0 & 4 & 90.42 & 79.49 & 10.93 \\
\hline 10 & 1 & 510 & 47 & 22,100 & 240 & 1 & 0 & 4 & 95.95 & 95.30 & 0.64 \\
\hline 11 & 1 & 570 & 47 & 24,663 & 312 & 1 & 0 & 4 & 94.75 & 97.33 & -2.58 \\
\hline 12 & 1 & 630 & 47 & 29,521 & 1,320 & 1 & 0 & 4 & 83.83 & 93.55 & -9.72 \\
\hline 13 & 1 & 630 & 47 & 28,348 & 1,640 & 1 & 0 & 4 & 88.84 & 94.73 & -5.90 \\
\hline 14 & 1 & 630 & 35 & 31,129 & 1,056 & 1 & 0 & 4 & 81.51 & 81.99 & -0.48 \\
\hline 15 & 1 & 240 & 64 & 8,489 & 192 & 1 & 0 & 4 & 116.38 & 102.46 & 13.92 \\
\hline 16 & 1 & 285 & 47 & 12,093 & 2,613 & 1 & 0 & 4 & 77.42 & 82.45 & -5.03 \\
\hline 17 & 1 & 105 & 56 & 3,337 & 435 & 1 & 0 & 4 & 119.23 & 89.64 & 29.59 \\
\hline 18 & 1 & 630 & 56 & 19,746 & 7,241 & 1 & 0 & 4 & 98.66 & 103.30 & -4.64 \\
\hline 19 & 1 & 195 & 56 & 8,815 & 676 & 1 & 0 & 4 & 95.50 & 89.74 & 5.76 \\
\hline 20 & 1 & 435 & 44 & 17,670 & 552 & 1 & 0 & 4 & 94.74 & 91.47 & 3.27 \\
\hline 21 & 1 & 630 & 44 & 28,526 & 744 & 1 & 0 & 4 & 90.76 & 94.06 & -3.30 \\
\hline 22 & 1 & 630 & 44 & 29,629 & 1,240 & 1 & 0 & 4 & 86.94 & 91.17 & -4.23 \\
\hline 23 & 2 & 270 & 64 & 4,904 & 5,237 & 0 & 0 & 3 & 89.13 & 97.01 & $\begin{array}{l}-7.89 \\
\end{array}$ \\
\hline 24 & 2 & 240 & 47 & 5,863 & 3,925 & 0 & 0 & 3 & 73.99 & 81.70 & $\begin{array}{l}-7.71 \\
\end{array}$ \\
\hline 25 & 2 & 510 & 47 & 10,301 & 6,540 & 0 & 0 & 3 & 91.16 & 97.17 & -6.02 \\
\hline 26 & 2 & 510 & 47 & 11,034 & 8,891 & 0 & 0 & 3 & 79.47 & 90.74 & -11.27 \\
\hline 27 & 2 & 180 & 47 & 3,975 & 3,867 & 0 & 0 & 3 & 76.00 & 78.55 & -2.55 \\
\hline 28 & 2 & 270 & 24 & 5,858 & 7,166 & 0 & 0 & 3 & 57.54 & 59.34 & -1.80 \\
\hline 29 & 2 & 120 & 24 & 2,598 & 4,194 & 0 & 0 & 3 & 61.25 & 55.42 & 5.82 \\
\hline 30 & 2 & 390 & 24 & 7,967 & 10,652 & 0 & 0 & 3 & 60.79 & 60.81 & -0.02 \\
\hline 31 & 2 & 510 & 44 & 13,481 & 8,950 & 0 & 0 & 3 & 70.04 & 84.26 & -14.22 \\
\hline 32 & 2 & 510 & 44 & 8,162 & 7,840 & 0 & 0 & 3 & 94.01 & 95.34 & -1.33 \\
\hline 33 & 2 & 510 & 44 & 10,465 & 7,593 & 0 & 0 & 3 & 85.15 & 92.17 & -7.02 \\
\hline 34 & 2 & 300 & 44 & 7,211 & 4,914 & 0 & 0 & 3 & 80.82 & 81.26 & -0.44 \\
\hline 35 & 2 & 150 & 64 & 1,852 & 2,775 & 0 & 0 & 3 & 94.05 & 94.79 & -0.74 \\
\hline 36 & 2 & 330 & 64 & 5,706 & 7,104 & 0 & 0 & 3 & 87.07 & 97.88 & -10.81 \\
\hline 37 & 2 & 150 & 44 & 3,231 & 3,307 & 0 & 0 & 3 & 76.63 & 75.46 & 1.18 \\
\hline 38 & 2 & 510 & 44 & 9,196 & 8,931 & 0 & 0 & 3 & 88.53 & 91.24 & -2.71 \\
\hline 39 & 2 & 510 & 44 & 9,802 & 8,309 & 0 & 0 & 3 & 84.54 & 91.64 & -7.11 \\
\hline 40 & 2 & 480 & 44 & 9,765 & 6,199 & 0 & 0 & 3 & 91.35 & 93.25 & -1.90 \\
\hline 41 & 2 & 30 & 47 & 613 & 862 & 0 & 0 & 3 & 68.88 & 74.87 & -5.99 \\
\hline
\end{tabular}




\begin{tabular}{|c|c|c|c|c|c|c|c|c|c|c|c|}
\hline No. & $\begin{array}{c}\text { Mill } \\
\#\end{array}$ & $\begin{array}{l}\text { Runtime } \\
\text { (Mins) }\end{array}$ & $\begin{array}{c}\text { Density } \\
\left(\mathrm{lb} / \mathrm{ft}^{3}\right)\end{array}$ & $\begin{array}{c}\text { 4/4 to } 8 / 4 \\
\text { + Pallet } \\
\text { (Board ft.) }\end{array}$ & $\begin{array}{c}\text { Cant }+ \\
\text { Tim } \\
\text { (Board ft.) }\end{array}$ & Resaw & $\begin{array}{c}\text { Double } \\
\text { Line }\end{array}$ & $\begin{array}{c}\text { Maint } \\
\text { Level }\end{array}$ & SEC & $\begin{array}{c}\text { Estimated } \\
\text { SEC }\end{array}$ & Error \\
\hline 42 & 2 & 450 & 47 & 8,613 & 11,556 & 0 & 0 & 3 & 69.25 & 82.37 & -13.12 \\
\hline 43 & 2 & 105 & 47 & 1,682 & 1,600 & 0 & 0 & 3 & 107.59 & 79.41 & 28.18 \\
\hline 44 & 2 & 405 & 47 & 6,595 & 7,461 & 0 & 0 & 3 & 85.95 & 90.03 & -4.09 \\
\hline 45 & 2 & 450 & 47 & 6,872 & 7,177 & 0 & 0 & 3 & 101.26 & 94.97 & 6.29 \\
\hline 46 & 2 & 60 & 35 & 1,236 & 891 & 0 & 0 & 3 & 81.96 & 67.42 & 14.54 \\
\hline 47 & 2 & 510 & 35 & 10,589 & 6,930 & 0 & 0 & 3 & 87.31 & 86.29 & 1.02 \\
\hline 48 & 2 & 255 & 35 & 6,155 & 3,888 & 0 & 0 & 3 & 80.49 & 73.35 & 7.15 \\
\hline 49 & 2 & 255 & 44 & 5,320 & 2,990 & 0 & 0 & 3 & 86.72 & 83.86 & 2.86 \\
\hline 50 & 2 & 450 & 44 & 9,135 & 6,592 & 0 & 0 & 3 & 81.71 & 90.23 & -8.51 \\
\hline 51 & 2 & 330 & 44 & 6,847 & 5,067 & 0 & 0 & 3 & 88.09 & 84.67 & 3.42 \\
\hline 52 & 2 & 180 & 47 & 4,361 & 1,520 & 0 & 0 & 3 & 88.15 & 83.17 & 4.98 \\
\hline 53 & 2 & 510 & 47 & 10,900 & 4,348 & 0 & 0 & 3 & 100.14 & 101.10 & -0.96 \\
\hline 54 & 2 & 45 & 47 & 735 & 1,430 & 0 & 0 & 3 & 79.64 & 74.99 & 4.64 \\
\hline 55 & 2 & 465 & 44 & 2,584 & 8,378 & 0 & 0 & 3 & 125.07 & 98.42 & 26.66 \\
\hline 56 & 2 & 60 & 44 & 1,451 & 1,459 & 0 & 0 & 3 & 89.72 & 72.96 & 16.75 \\
\hline 57 & 2 & 450 & 44 & 10,119 & 6,966 & 0 & 0 & 3 & 80.51 & 87.80 & -7.29 \\
\hline 58 & 4 & 195 & 44 & 8,791 & 4,264 & 0 & 1 & 2 & 115.22 & 129.08 & -13.86 \\
\hline 59 & 4 & 405 & 24 & 25,259 & 4,138 & 0 & 1 & 2 & 108.23 & 108.97 & -0.74 \\
\hline 60 & 4 & 600 & 24 & 43,156 & 6,370 & 0 & 1 & 2 & 99.65 & 95.62 & 4.03 \\
\hline 61 & 4 & 600 & 24 & 38,884 & 7,182 & 0 & 1 & 2 & 103.05 & 100.71 & 2.34 \\
\hline 62 & 4 & 555 & 24 & 34,213 & 5,548 & 0 & 1 & 2 & 109.70 & 107.17 & 2.53 \\
\hline 63 & 4 & 45 & 26 & 1,678 & 1,744 & 0 & 1 & 2 & 100.94 & 116.07 & -15.13 \\
\hline 64 & 4 & 300 & 26 & 6,296 & 13,659 & 0 & 1 & 2 & 116.97 & 108.90 & 8.07 \\
\hline 65 & 4 & 300 & 47 & 19,689 & 5,040 & 0 & 1 & 2 & 98.44 & 123.19 & -24.75 \\
\hline 66 & 4 & 600 & 47 & 27,905 & 6,674 & 0 & 1 & 2 & 137.93 & 137.91 & 0.03 \\
\hline 67 & 4 & 180 & 47 & 7,188 & 1,852 & 0 & 1 & 2 & 147.41 & 137.87 & 9.54 \\
\hline 68 & 4 & 420 & 64 & 15,478 & 3,748 & 0 & 1 & 2 & 169.34 & 159.07 & 10.27 \\
\hline 69 & 4 & 330 & 64 & 15,437 & 4,070 & 0 & 1 & 2 & 154.92 & 148.92 & 6.00 \\
\hline 70 & 4 & 120 & 26 & 4,915 & 5,948 & 0 & 1 & 2 & 78.61 & 109.36 & -30.75 \\
\hline 71 & 4 & 465 & 35 & 23,908 & 11,956 & 0 & 1 & 2 & 105.08 & 108.79 & -3.71 \\
\hline 72 & 4 & 330 & 35 & 15,917 & 12,216 & 0 & 1 & 2 & 90.29 & 106.89 & -16.60 \\
\hline 73 & 4 & 270 & 44 & 12,724 & 3,244 & 0 & 1 & 2 & 140.53 & 132.91 & 7.62 \\
\hline 74 & 4 & 600 & 44 & 27,184 & 6,783 & 0 & 1 & 2 & 144.54 & 136.44 & 8.09 \\
\hline 75 & 4 & 525 & 44 & 21,340 & 5,565 & 0 & 1 & 2 & 156.76 & 140.70 & 16.06 \\
\hline 76 & 4 & 355.2 & 24 & 21,700 & 3,052 & 0 & 1 & 2 & 111.76 & 111.90 & -0.14 \\
\hline 77 & 4 & 600 & 24 & 33,112 & 5,922 & 0 & 1 & 2 & 120.46 & 112.86 & 7.60 \\
\hline 78 & 4 & 195 & 24 & 10,144 & 2,149 & 0 & 1 & 2 & 120.26 & 115.71 & 4.55 \\
\hline 79 & 4 & 394.8 & 40 & 21,944 & 4,512 & 0 & 1 & 2 & 117.52 & 125.15 & -7.64 \\
\hline 80 & 4 & 600 & 40 & 23,151 & 4,739 & 0 & 1 & 2 & 159.87 & 144.35 & 15.52 \\
\hline 81 & 4 & 330 & 40 & 16,449 & 3,752 & 0 & 1 & 2 & 129.35 & 128.90 & 0.44 \\
\hline 82 & 4 & 270 & 47 & 12,199 & 2,902 & 0 & 1 & 2 & 146.91 & 136.91 & 10.00 \\
\hline 83 & 4 & 600 & 47 & 28,046 & 6,643 & 0 & 1 & 2 & 138.38 & 137.75 & 0.63 \\
\hline
\end{tabular}




\begin{tabular}{|c|c|c|c|c|c|c|c|c|c|c|c|}
\hline No. & $\begin{array}{c}\text { Mill } \\
\#\end{array}$ & $\begin{array}{l}\text { Runtime } \\
\text { (Mins) }\end{array}$ & $\begin{array}{c}\text { Density } \\
\left(\mathrm{lb} / \mathrm{ft}^{3}\right)\end{array}$ & $\begin{array}{c}\text { 4/4 to } 8 / 4 \\
\text { + Pallet } \\
\text { (Board ft.) }\end{array}$ & $\begin{array}{c}\text { Cant }+ \\
\text { Tim } \\
\text { (Board ft.) }\end{array}$ & Resaw & $\begin{array}{c}\text { Double } \\
\text { Line }\end{array}$ & $\begin{array}{c}\text { Maint } \\
\text { Level }\end{array}$ & SEC & $\begin{array}{l}\text { Estimated } \\
\text { SEC }\end{array}$ & Error \\
\hline 84 & $5,1 \#$ & 266 & 44 & 21,909 & - & 1 & 0 & 2 & 106.13 & 124.66 & -18.53 \\
\hline 85 & 5,1 & 342 & 47 & 26,052 & - & 1 & 0 & 2 & 113.76 & 128.37 & -14.61 \\
\hline 86 & 5,2 & 582 & 47 & 32,150 & - & 1 & 0 & 2 & 153.86 & 143.83 & 10.03 \\
\hline 87 & 5,1 & 130 & 47 & 8,160 & - & 1 & 0 & 2 & 137.55 & 134.94 & 2.61 \\
\hline 88 & 5,1 & 482 & 24 & 50,813 & 9,975 & 1 & 0 & 2 & 67.71 & 62.51 & 5.19 \\
\hline 89 & 5,2 & 598 & 24 & 50,448 & 10,698 & 1 & 0 & 2 & 84.87 & 73.73 & 11.14 \\
\hline 90 & 5,1 & 584 & 24 & 63,128 & 11,645 & 1 & 0 & 2 & $67.73 *$ & 49.63 & 18.10 \\
\hline 91 & 5,2 & 647 & 44 & 43,450 & - & 1 & 0 & 2 & 129.64 & 130.02 & -0.38 \\
\hline 92 & 5,1 & 627 & 44 & 55,938 & - & 1 & 0 & 2 & 98.24 & 107.71 & -9.47 \\
\hline 93 & 5,2 & 604 & 44 & 37,107 & - & 1 & 0 & 2 & 139.94 & 135.74 & 4.20 \\
\hline 94 & 5,1 & 608 & 44 & 46,659 & - & 1 & 0 & 2 & 113.82 & 120.71 & -6.89 \\
\hline 95 & 5,2 & 592 & 44 & 36,535 & - & 1 & 0 & 2 & 137.99 & 135.40 & 2.59 \\
\hline 96 & 5,1 & 117 & 44 & 8,813 & - & 1 & 0 & 2 & 113.90 & 130.12 & -16.23 \\
\hline 97 & 5,1 & 427 & 40 & 36,489 & - & 1 & 0 & 2 & 102.01 & 114.88 & -12.88 \\
\hline 98 & 5,2 & 601 & 35 & 33,653 & 10,096 & 1 & 0 & 2 & 117.99 & 111.31 & 6.68 \\
\hline 99 & 5,1 & 611 & 35 & 43,846 & 11,156 & 1 & 0 & 2 & 96.29 & 93.51 & 2.78 \\
\hline 100 & 5,2 & 410 & 35 & 24,196 & 7,068 & 1 & 0 & 2 & 112.49 & 113.21 & -0.72 \\
\hline 101 & 5,1 & 625 & 47 & 39,585 & 6,796 & 1 & 0 & 2 & 115.82 & 121.16 & -5.34 \\
\hline 102 & 5,2 & 596 & 47 & 32,131 & 4,912 & 1 & 0 & 2 & 138.43 & 134.37 & 4.06 \\
\hline 103 & 5,1 & 614 & 47 & 40,343 & 4,147 & 1 & 0 & 2 & 119.39 & 124.69 & -5.30 \\
\hline 104 & 5,2 & 562 & 47 & 23,758 & 7,228 & 1 & 0 & 2 & 151.36 & 139.15 & 12.21 \\
\hline 105 & 5,1 & 523 & 44 & 38,448 & 1,834 & 1 & 0 & 2 & 115.25 & 120.93 & -5.68 \\
\hline 106 & 5,1 & 90 & 44 & 6,000 & - & 1 & 0 & 2 & 126.86 & 131.82 & -4.96 \\
\hline 107 & 5,1 & 534 & 47 & 36,454 & - & 1 & 0 & 2 & 128.95 & 131.80 & -2.85 \\
\hline 108 & 5,2 & 565 & 47 & 23,203 & 4,326 & 1 & 0 & 2 & 171.11 & 146.85 & 24.26 \\
\hline \multicolumn{11}{|c|}{ Average of Absolute Error Value } & 7.61 \\
\hline
\end{tabular}

* denotes an observation whose $\mathrm{X}$ value gives it large leverage, \#Sawmill 5 data is shown with both $1^{\text {st }} \& 2^{\text {nd }}$ shifts.

There are totally 15 data points out of 108 with error of $\pm 15 \mathrm{kwh} / \mathrm{MBF}$ or more and the average of absolute error value was $7.61 \mathrm{kWh} / \mathrm{MBF}$ from the estimation results of Model 3 for sawmill 1, 2, 4 and 5. Average of absolute error value of Model 3 is slightly lower than Model 1. The data points $2,17,43,56,63,70$, and 96 have shift run times less than 2.75 hours and hence have resulted in higher error levels. Data points 55 and 90 still has higher error value and the explanation given before still applies here. There are 3 data points $(65,72,75)$ with error of more than $\pm 15 \mathrm{kwh} / \mathrm{MBF}$ in sawmill 4 where change of species is happening resulting in higher error value. Inefficiency of Model 3 has resulted in higher error values for data points 80, 84 and 108. 
Table 5.9 shows the data from sawmill 3 and the estimated SEC values using the developed regression model 3.

Table 5.9: Data of Sawmill 3 and estimated SEC using Model 3

\begin{tabular}{|c|c|c|c|c|c|c|c|c|c|c|c|c|}
\hline No. & $\begin{array}{c}\text { Run } \\
\text { time } \\
\text { (Mins) }\end{array}$ & $\begin{array}{c}\text { Density } \\
\left(\mathrm{lb} / \mathrm{ft}^{3}\right)\end{array}$ & $\begin{array}{c}4 / 4 \text { to } 8 / 4+ \\
\text { Pallet } \\
\text { (Board } \mathrm{ft} .)\end{array}$ & $\begin{array}{c}\text { Cant }+ \\
\text { Tim } \\
\text { (Board ft.) }\end{array}$ & Resaw & $\begin{array}{c}\text { Double } \\
\text { Line }\end{array}$ & $\begin{array}{c}\text { Maint } \\
\text { Level }\end{array}$ & SEC & $\begin{array}{c}\text { Estimated } \\
\text { SEC }\end{array}$ & $\begin{array}{c}\text { Error } \\
\text { by } \\
\text { Model } 3\end{array}$ & $\begin{array}{c}\text { Error } \\
\text { by } \\
\text { Model } 2\end{array}$ & $\begin{array}{c}\text { Error } \\
\text { by } \\
\text { Model 1 }\end{array}$ \\
\hline 1 & 480 & 44 & 70,762 & 9,645 & 1 & 1 & 2 & 105.28 & 78.37 & 26.90 & 8.33 & -18.33 \\
\hline 2 & 120 & 44 & 15,476 & 2,717 & 1 & 1 & 2 & 124.48 & 145.28 & -20.81 & -8.22 & -67.06 \\
\hline 3 & 360 & 47 & 52,297 & 10,694 & 1 & 1 & 2 & 104.00 & 95.62 & 8.38 & 0.63 & -36.88 \\
\hline 4 & 390 & 47 & 53,822 & 8,726 & 1 & 1 & 2 & 111.63 & 100.72 & 10.91 & -1.28 & -34.52 \\
\hline 5 & 90 & 47 & 14,251 & - & 1 & 1 & 2 & 111.68 & 152.55 & -40.87 & -23.17 & -87.27 \\
\hline 6 & 120 & 47 & 25,722 & 1,272 & 1 & 1 & 2 & 85.78 & 134.32 & -48.54 & -29.30 & -94.69 \\
\hline 7 & 360 & 35 & 54,330 & 7,372 & 1 & 1 & 2 & 104.21 & 90.20 & 14.01 & 5.60 & -31.66 \\
\hline 8 & 240 & 35 & 36,481 & 4,917 & 1 & 1 & 2 & 103.86 & 111.90 & -8.04 & -5.71 & -54.05 \\
\hline 9 & 210 & 64 & 24,743 & 15,166 & 1 & 1 & 2 & 111.65 & 127.91 & -16.26 & -11.09 & -61.18 \\
\hline 10 & 480 & 56 & 82,405 & - & 1 & 1 & 2 & 105.06 & 90.62 & 14.44 & 4.84 & -31.17 \\
\hline 11 & 480 & 44 & 77,793 & 3,172 & 1 & 1 & 2 & 108.29 & 81.45 & 26.84 & 12.54 & -18.78 \\
\hline 12 & 480 & 24 & 84,341 & - & 1 & 1 & 2 & 86.33 & 62.03 & 24.30 & 10.79 & -21.77 \\
\hline 13 & 480 & 24 & 80,230 & - & 1 & 1 & 2 & 89.69 & 68.68 & 21.01 & 5.02 & -25.13 \\
\hline 14 & 480 & 24 & 82,402 & - & 1 & 1 & 2 & 81.33 & 65.17 & 16.16 & 1.49 & -29.94 \\
\hline 15 & 480 & 24 & 83,415 & - & 1 & 1 & 2 & 84.82 & 63.53 & 21.29 & 7.22 & -24.79 \\
\hline 16 & 480 & 44 & 76,564 & 3,388 & 1 & 1 & 2 & 108.37 & 82.96 & 25.41 & 10.37 & -20.21 \\
\hline 17 & 315 & 44 & 28,493 & 15,223 & 1 & 1 & 2 & 124.17 & 116.88 & 7.29 & -7.25 & -38.01 \\
\hline 18 & 165 & 24 & 34,619 & - & 1 & 1 & 2 & 82.45 & 109.22 & -26.77 & -13.86 & -73.27 \\
\hline 19 & 300 & 47 & 38,783 & - & 1 & 1 & 2 & 140.73 & 135.03 & 5.70 & 0.60 & -40.56 \\
\hline 20 & 180 & 35 & 25,114 & 4,076 & 1 & 1 & 2 & 105.32 & 125.83 & -20.51 & -14.29 & -66.71 \\
\hline 21 & 480 & 35 & 63,695 & 11,321 & 1 & 1 & 2 & 110.70 & 78.90 & 31.80 & 7.54 & -13.56 \\
\hline 22 & 480 & 35 & 65,815 & 12,566 & 1 & 1 & 2 & 108.55 & 72.69 & 35.86 & 12.87 & -9.36 \\
\hline 23 & 90 & 35 & 12,258 & 3,681 & 1 & 1 & 2 & 103.72 & 138.01 & -34.29 & -19.70 & -80.62 \\
\hline 24 & 390 & 44 & 49,854 & 2,217 & 1 & 1 & 2 & 130.79 & 119.28 & 11.51 & -3.51 & -34.55 \\
\hline 25 & 480 & 44 & 75,778 & 5,791 & 1 & 1 & 2 & 107.44 & 78.86 & 28.58 & 13.05 & -16.87 \\
\hline \multicolumn{10}{|c|}{ Average of Absolute Error Value } & 21.86 & 9.53 & 41.24 \\
\hline
\end{tabular}


Even without the horsepower estimator variable, Model 3 has estimated the SEC of sawmill 3 better than Model 1 . There are 8 data points out of 25 that have error value less than $\pm 15 \mathrm{kwh} / \mathrm{MBF}$. The average of absolute error value of Model 3 is $21.86 \mathrm{kWh} / \mathrm{MBF}$, where as the average of absolute error value of Model 1 was $41.24 \mathrm{kWh} / \mathrm{MBF}$. Error was very high for shift run times (data points 5, 6 and 23 in Table 5.9) of less than 2.75 hours similar to other sawmills used for developing the model. Overall, Model 2 is better than the other two models (Table 5.9).

Estimated SEC of sawmill 3 from models 1, 2 and 3 are plotted in Figure 5.5. From the figure it can be clearly seen that the estimated SEC values of model 1 are away from the actual SEC values. Estimated SEC values of model 2 are closely following the actual SEC values except for data point 5, 6 and 23. Estimated SEC values from model 3 are closer to the actual SEC values than model 1 but are not as close as the estimated SEC values from model 2.

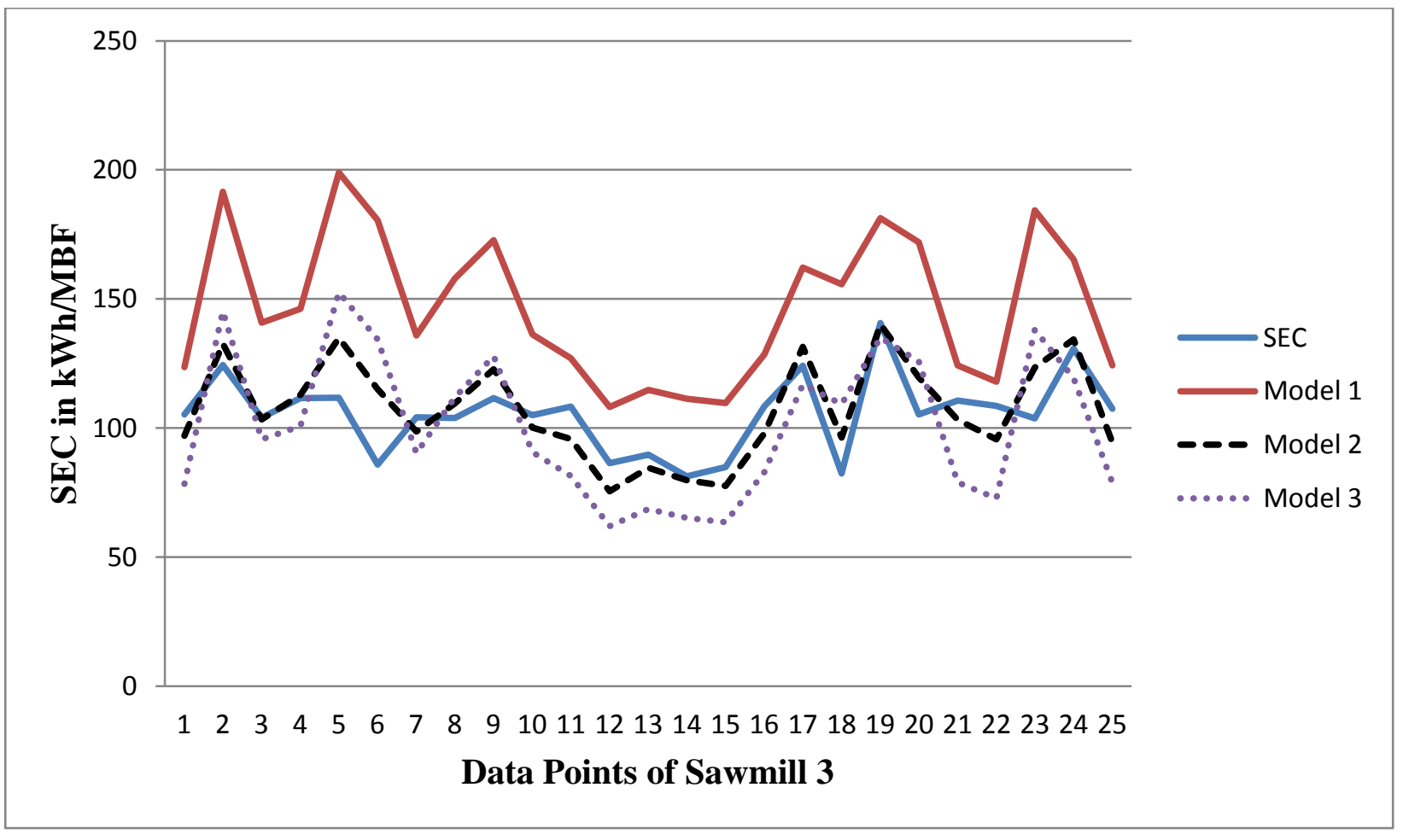

Figure 5.5: Estimated SEC values from Model 1, 2 and 3 plotted with Actual SEC Values 


\subsection{Limitations of the Model}

- Even though there are some data points with less than 2.75 hours that were estimated accurately, in general model cannot estimate energy consumption of a short production run of 2.75 hours or less accurately.

- Model cannot estimate accurately if there is a mix up of two or more species in the same production run.

- Model cannot estimate correctly if the data provided is not accurate or sawmill is performing differently from its normal operation.

- Model cannot estimate accurately if there is too much inconsistency (variance) in the maintenance schedule.

- Model has predicted $\mathrm{R}^{2}$ of 0.85 and hence can have error of around $15 \%$ in the estimated value. 


\subsection{Estimation Model to estimate Total $\mathrm{kWh}$}

Estimation Models developed so far were estimating SEC, total energy consumption in $\mathrm{kWh}$ per total board feet sawn in thousands. Estimation model can also be developed to estimate only total energy consumption in $\mathrm{kWh}$. The same 9 predictor variables were used for step-wise regression with one of the variable being interaction between 'motor horsepower and minutes'. The results of the step-wise regression are shown in Appendix Table A.25.

Interestingly, this time new variable temperature was selected and variable "Cant + Timber' was dropped compared to Model 2. Even though the data of sawmill 2 and 4 had high percentage of cants and timbers, it should be noted that variable 'Cant + Timber' was not selected in step-wise regression since it didn't had any significance in estimating total energy consumption and the correlation results obtained in data analysis chapter makes sense with this outcome. The Mallow's $\mathrm{Cp}$ was 8 when only the variables selected were used to run the stepwise regression and hence the model fits the data well.

The results of the developed model (Model 4) are shown below. Residual plots (Figure 5.6) show that there are some outliers in the data and the histogram in Figure 5.6 is different from other models since total $\mathrm{kWh}$ is estimated in this model. $\mathrm{R}^{2}$ adjusted of the developed model 4 was $99.38 \%$, the $\mathrm{R}^{2}$ predicted was $99.32 \%$ and MSE was 17,376 . Model 4 is better than other models developed so far since its $\mathrm{R}^{2}$ is the highest of all. The most precise variable and the variable that is explaining maximum variance is the variable ' $\mathrm{hp} \mathrm{x}$ min'. The variable that is explaining least variance is the temperature and the percentage of adjusted MS it represents is only $0.2 \%$. All the variables are significant in both $\mathrm{T}$ and $\mathrm{F}$ Tests and have variance inflation factor of less than 10 which indicates that they are not correlated. 


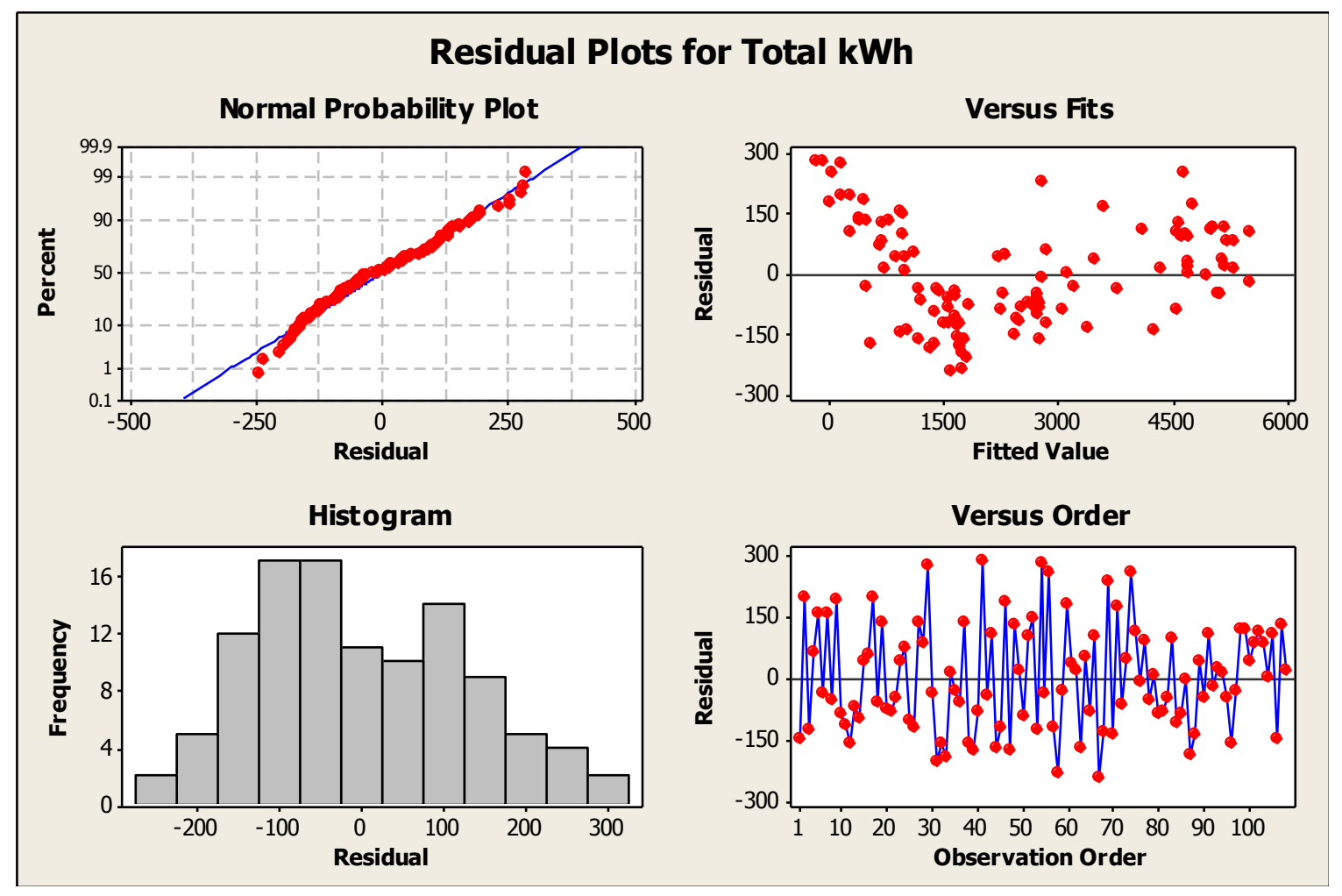

Figure 5.6: Residual Plots of Regression Model 4

\begin{tabular}{|c|c|c|c|c|c|c|}
\hline \multicolumn{7}{|l|}{ on } \\
\hline Total kWh & $\begin{array}{l}345.1 \\
+\quad \mathrm{Pal} \\
0.004\end{array}$ & $\begin{array}{r}-3.9785 \\
t+314.9 \\
982 \mathrm{hp} x\end{array}$ & $\begin{array}{l}7 \text { Temp + } \\
26 \text { Resaw } \\
\text { Min }\end{array}$ & $\begin{array}{l}5.59643 \mathrm{D} \\
+\quad 395.453\end{array}$ & $\begin{array}{l}\text { nsity } \\
\text { Doubl }\end{array}$ & $\begin{array}{l}0.0099 \\
\text { Line - }\end{array}$ \\
\hline \multicolumn{7}{|l|}{ Coefficients } \\
\hline Term & & Coef & SE Coef & $\mathrm{T}$ & $\mathrm{P}$ & VIF \\
\hline Constant & & 345.187 & 109.529 & 3.1516 & 0.002 & \\
\hline Temp & & -3.979 & 1.273 & -3.1252 & 0.002 & 2.48785 \\
\hline Density & & 5.596 & 1.578 & 3.5470 & 0.001 & 1.42215 \\
\hline 4 to 8 Qtr + & Pallet & 0.010 & 0.003 & 3.6538 & 0.000 & 9.28846 \\
\hline Resaw & & 314.926 & 49.841 & 6.3186 & 0.000 & 3.79517 \\
\hline Double Line & & 395.453 & 53.079 & 7.4503 & 0.000 & 3.20076 \\
\hline Maint & & -236.374 & 23.259 & -10.1628 & 0.000 & 2.03028 \\
\hline hp $x$ Min & & 0.004 & 0.000 & 38.6648 & 0.000 & 7.95604 \\
\hline
\end{tabular}

Summary of Model

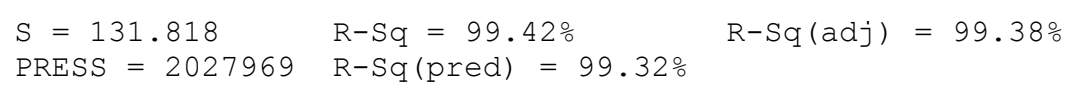

Analysis of Variance

$\begin{array}{lrr}\text { Source } & \text { DF } & \text { Seq SS } \\ \text { Regression } & 7 & 296751334 \\ \quad \text { Temp } & 1 & 73746050 \\ \text { Density } & 1 & 7433715 \\ \quad \text { to 8 Qtr + Pallet } & 1 & 167139625 \\ \quad \text { Resaw } & 1 & 10225313 \\ \quad \text { Double Line } & 1 & 1571979 \\ \text { Maint } & 1 & 10658000 \\ \quad \text { hp x Min } & 1 & 25976651 \\ \text { Error } & 100 & 1737605 \\ \text { Total } & 107 & 298488940\end{array}$

$\begin{array}{rrrr}\text { Adj SS } & \text { Adj MS } & F & P \\ 296751334 & 42393048 & 2439.74 & 0.0000000 \\ 169715 & 169715 & 9.77 & 0.0023255 \\ 218612 & 218612 & 12.58 & 0.0005949 \\ 231973 & 231973 & 13.35 & 0.0004137 \\ 693731 & 693731 & 39.92 & 0.0000000 \\ 964498 & 964498 & 55.51 & 0.0000000 \\ 1794647 & 1794647 & 103.28 & 0.0000000 \\ 25976651 & 25976651 & 1494.97 & 0.0000000 \\ 1737605 & 17376 & & \end{array}$


The total kWh and SEC values estimated from the fitted model 4 are shown in Table 5.10. SEC shown was calculated the same way as total energy consumed by total board feet sawn in thousands using equation 4.4 (page 67) for a particular shift.

Table 5.10: Estimated SEC values from Regression Model 4

\begin{tabular}{|c|c|c|c|c|c|c|c|c|c|c|c|c|c|c|c|}
\hline No. & $\begin{array}{c}\text { Mill } \\
\#\end{array}$ & $\begin{array}{c}\text { Runtime } \\
\text { (Mins) }\end{array}$ & $\begin{array}{c}\text { Density } \\
\left(\mathrm{lb} / \mathrm{ft}^{3}\right)\end{array}$ & $\begin{array}{c}\text { Temp } \\
\left({ }^{\circ} \mathrm{F}\right)\end{array}$ & $\begin{array}{l}\text { hp } x \\
\text { mins }\end{array}$ & $\begin{array}{l}4 / 4 \text { to } 8 / 4 \\
+ \text { Pallet }\end{array}$ & $\begin{array}{c}\text { Double } \\
\text { Line }\end{array}$ & Resaw & $\begin{array}{c}\text { Maint } \\
\text { Level }\end{array}$ & $\begin{array}{l}\text { Total } \\
\text { kWh }\end{array}$ & $\begin{array}{c}\text { Estimated } \\
\text { Total kWh }\end{array}$ & Error & $\begin{array}{c}\text { Estimated } \\
\text { SEC }\end{array}$ & SEC & Error \\
\hline 1 & 1 & 555 & 35 & 50 & 537,240 & 29,726 & 0 & 1 & 4 & $2,267.90$ & $2,420.15$ & -152.25 & 74.76 & 70.05 & -4.70 \\
\hline 2 & 1 & 75 & 44 & 54 & 72,600 & 5,656 & 0 & 1 & 4 & 325.19 & 128.39 & 196.80 & 22.70 & 57.49 & 34.79 \\
\hline 3 & 1 & 630 & 44 & 48 & 609,840 & 33,160 & 0 & 1 & 4 & $2,713.87$ & $2,838.69$ & -124.82 & 83.14 & 79.48 & -3.66 \\
\hline 4 & 1 & 630 & 44 & 48 & 609,840 & 32,004 & 0 & 1 & 4 & $2,886.32$ & $2,827.16$ & 59.16 & 84.59 & 86.37 & 1.77 \\
\hline 5 & 1 & 235 & 44 & 50 & 227,480 & 12,188 & 0 & 1 & 4 & $1,060.73$ & 904.84 & 155.89 & 67.65 & 79.31 & 11.66 \\
\hline 7 & 1 & 240 & 40 & 42 & 232,320 & 12,954 & 0 & 1 & 4 & $1,097.69$ & 943.65 & 154.04 & 68.45 & 79.62 & 11.17 \\
\hline 8 & 1 & 390 & 44 & 48 & 377,520 & 17,708 & 0 & 1 & 4 & $1,586.78$ & $1,641.50$ & -54.72 & 88.61 & 85.66 & -2.95 \\
\hline 9 & 1 & 120 & 47 & 36 & 116,160 & 6,765 & 0 & 1 & 4 & 611.69 & 423.43 & 188.26 & 62.59 & 90.42 & 27.83 \\
\hline 10 & 1 & 510 & 47 & 46 & 493,680 & 22,100 & 0 & 1 & 4 & $2,143.47$ & $2,231.59$ & -88.12 & 99.89 & 95.95 & -3.94 \\
\hline 11 & 1 & 570 & 47 & 55 & 551,760 & 24,663 & 0 & 1 & 4 & $2,366.43$ & $2,482.11$ & -115.68 & 99.38 & 94.75 & -4.63 \\
\hline 12 & 1 & 630 & 47 & 66 & 609,840 & 29,521 & 0 & 1 & 4 & $2,585.31$ & $2,747.57$ & -162.26 & 89.09 & 83.83 & -5.26 \\
\hline 14 & 1 & 630 & 35 & 60 & 609,840 & 31,129 & 0 & 1 & 4 & $2,623.49$ & $2,720.32$ & -96.83 & 84.52 & 81.51 & -3.01 \\
\hline 15 & 1 & 240 & 64 & 58 & 232,320 & 8,489 & 0 & 1 & 4 & $1,010.33$ & 969.77 & 40.56 & 111.71 & 116.38 & 4.67 \\
\hline 16 & 1 & 285 & 47 & 64 & 275,880 & 12,093 & 0 & 1 & 4 & $1,138.54$ & $1,082.28$ & 56.25 & 73.59 & 77.42 & 3.83 \\
\hline 17 & 1 & 105 & 56 & 66 & 101,640 & 3,337 & 0 & 1 & 4 & 449.74 & 255.06 & 194.68 & 67.62 & 119.23 & 51.61 \\
\hline 18 & 1 & 630 & 56 & 60 & 609,840 & 19,746 & 0 & 1 & 4 & $2,662.48$ & $2,724.32$ & -61.83 & 100.95 & 98.66 & -2.29 \\
\hline 19 & 1 & 195 & 56 & 48 & 188,760 & 8,815 & 0 & 1 & 4 & 906.37 & 772.46 & 133.91 & 81.39 & 95.50 & 14.11 \\
\hline 20 & 1 & 435 & 44 & 56 & 421,080 & 17,670 & 0 & 1 & 4 & $1,726.44$ & $1,804.87$ & -78.43 & 99.05 & 94.74 & -4.30 \\
\hline 21 & 1 & 630 & 44 & 61 & 609,840 & 28,526 & 0 & 1 & 4 & $2,656.64$ & $2,740.75$ & -84.11 & 93.64 & 90.76 & -2.87 \\
\hline 22 & 1 & 630 & 44 & 66 & 609,840 & 29,629 & 0 & 1 & 4 & $2,683.63$ & $2,731.86$ & -48.23 & 88.50 & 86.94 & -1.56 \\
\hline 23 & 2 & 270 & 64 & 43 & 220,590 & 4,904 & 0 & 0 & 3 & 903.83 & 862.48 & 41.35 & 85.05 & 89.13 & 4.08 \\
\hline 24 & 2 & 240 & 47 & 47 & 196,080 & 5,863 & 0 & 0 & 3 & 724.24 & 650.94 & 73.29 & 66.50 & 73.99 & 7.49 \\
\hline 25 & 2 & 510 & 47 & 58 & 416,670 & 10,301 & 0 & 0 & 3 & $1,535.14$ & $1,641.85$ & -106.71 & 97.49 & 91.16 & -6.34 \\
\hline
\end{tabular}




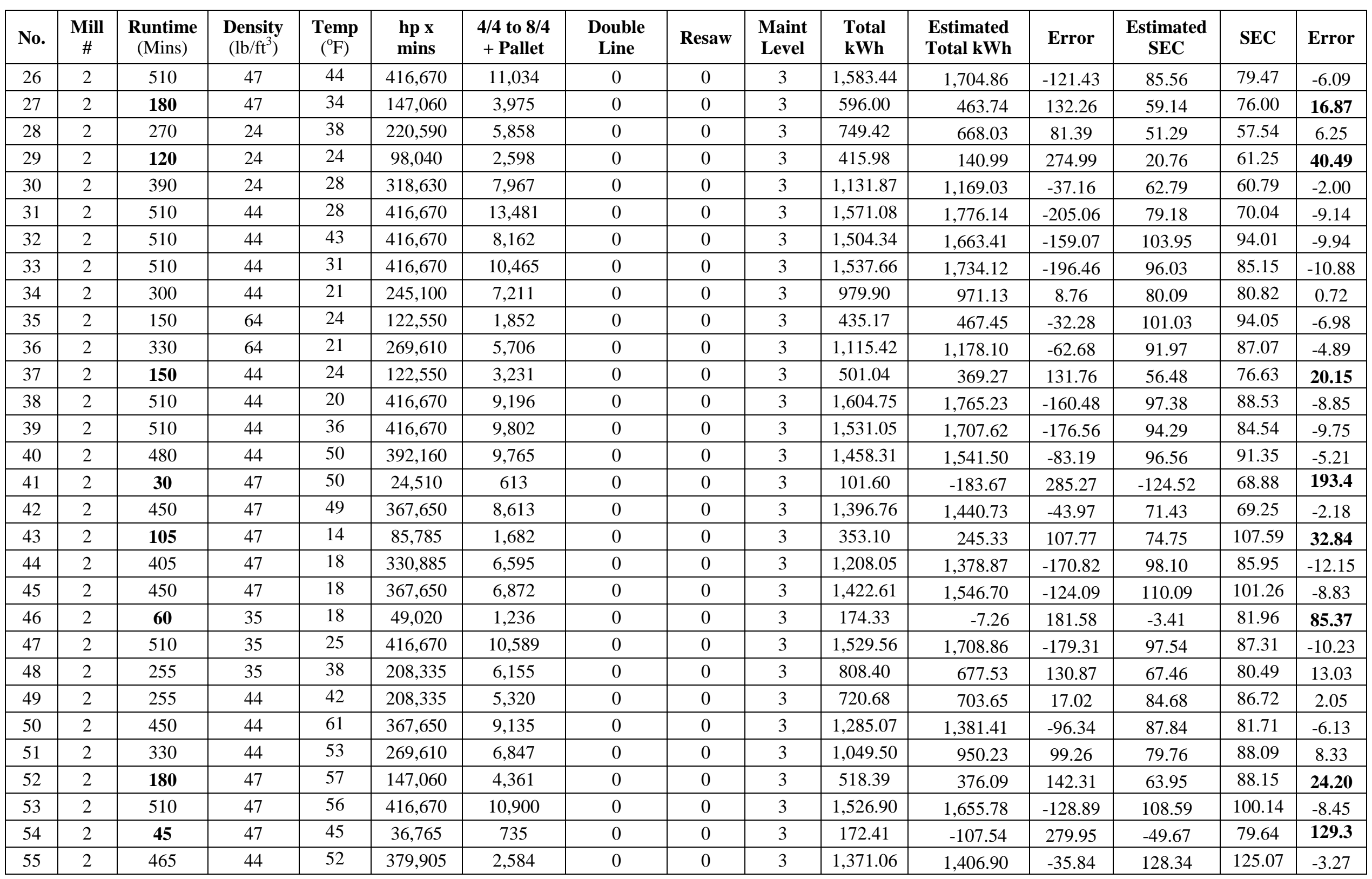




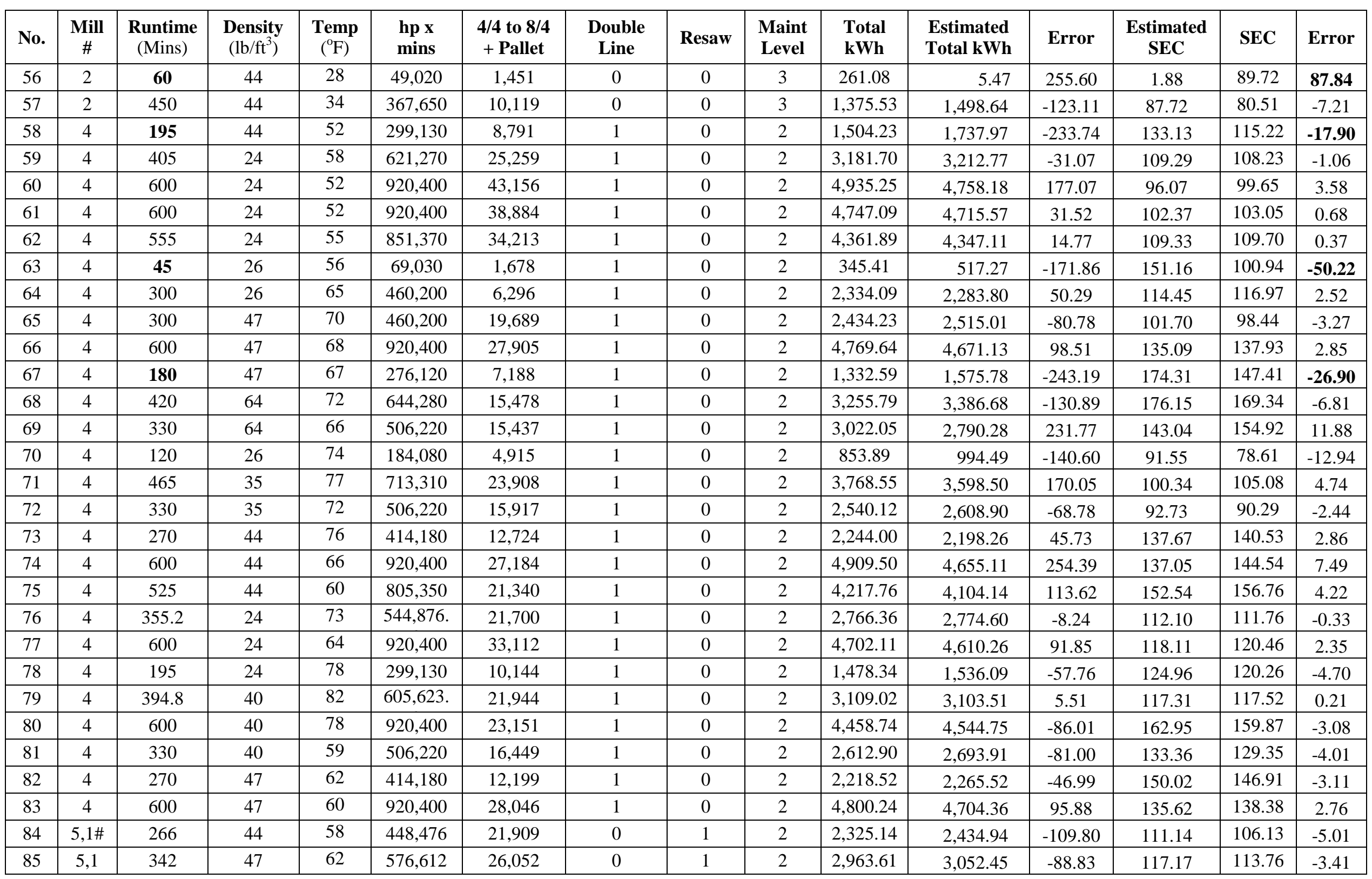




\begin{tabular}{|c|c|c|c|c|c|c|c|c|c|c|c|c|c|c|c|}
\hline No. & $\begin{array}{c}\text { Mill } \\
\#\end{array}$ & $\begin{array}{c}\text { Runtime } \\
\text { (Mins) }\end{array}$ & $\begin{array}{l}\text { Density } \\
\left(\mathrm{lb} / \mathrm{ft}^{3}\right)\end{array}$ & $\begin{array}{l}\text { Temp } \\
\left({ }^{\circ} \mathrm{F}\right)\end{array}$ & $\begin{array}{l}\text { hp } x \\
\text { mins }\end{array}$ & $\begin{array}{c}4 / 4 \text { to } 8 / 4 \\
+ \text { Pallet }\end{array}$ & $\begin{array}{l}\text { Double } \\
\text { Line }\end{array}$ & Resaw & $\begin{array}{l}\text { Maint } \\
\text { Level }\end{array}$ & $\begin{array}{l}\text { Total } \\
\text { kWh }\end{array}$ & $\begin{array}{l}\text { Estimated } \\
\text { Total kWh }\end{array}$ & Error & $\begin{array}{l}\text { Estimated } \\
\text { SEC }\end{array}$ & SEC & Error \\
\hline 86 & 5,2 & 582 & 47 & 57 & 981,252 & 32,150 & 0 & 1 & 2 & $4,946.48$ & $4,949.92$ & -3.44 & 153.96 & 153.86 & -0.11 \\
\hline 87 & 5,1 & 130 & 47 & 52 & 219,180 & 8,160 & 0 & 1 & 2 & $1,122.39$ & $1,308.98$ & -186.58 & 160.41 & 137.55 & -22.87 \\
\hline 88 & 5,1 & 482 & 24 & 56 & 812,652 & 50,813 & 0 & 1 & 2 & $4,115.69$ & $4,254.34$ & -138.65 & 69.99 & 67.71 & -2.28 \\
\hline 89 & 5,2 & 598 & 24 & 50 & $1,008,22$ & 50,448 & 0 & 1 & 2 & $5,189.42$ & $5,152.67$ & 36.75 & 84.27 & 84.87 & 0.60 \\
\hline 90 & 5,1 & 584 & 24 & 65 & 984,624 & 63,128 & 0 & 1 & 2 & $5,064.19$ & $5,113.48$ & -49.28 & 68.39 & 67.73 & -0.66 \\
\hline 91 & 5,2 & 647 & 44 & 60 & $1,090,84$ & 43,450 & 0 & 1 & 2 & $5,632.85$ & $5,525.94$ & 106.92 & 127.18 & 129.64 & 2.46 \\
\hline 92 & 5,1 & 627 & 44 & 56 & $1,057,12$ & 55,938 & 0 & 1 & 2 & $5,495.17$ & $5,515.01$ & -19.84 & 98.59 & 98.24 & -0.35 \\
\hline 93 & 5,2 & 604 & 44 & 51 & $1,018,34$ & 37,107 & 0 & 1 & 2 & $5,192.91$ & $5,172.98$ & 19.94 & 139.41 & 139.94 & 0.54 \\
\hline 94 & 5,1 & 608 & 44 & 51 & $1,025,08$ & 46,659 & 0 & 1 & 2 & $5,310.84$ & $5,298.53$ & 12.31 & 113.56 & 113.82 & 0.26 \\
\hline 95 & 5,2 & 592 & 44 & 48 & 998,112 & 36,535 & 0 & 1 & 2 & $5,041.39$ & $5,088.37$ & -46.98 & 139.27 & 137.99 & -1.29 \\
\hline 96 & 5,1 & 117 & 44 & 61 & 197,262 & 8,813 & 0 & 1 & 2 & $1,003.77$ & $1,164.48$ & -160.71 & 132.13 & 113.90 & -18.24 \\
\hline 97 & 5,1 & 427 & 40 & 63 & 719,922 & 36,489 & 0 & 1 & 2 & $3,722.08$ & $3,756.82$ & -34.75 & 102.96 & 102.01 & -0.95 \\
\hline 98 & 5,2 & 601 & 35 & 56 & $1,013,28$ & 33,653 & 0 & 1 & 2 & $5,162.08$ & $5,045.56$ & 116.53 & 115.33 & 117.99 & 2.66 \\
\hline 99 & 5,1 & 611 & 35 & 67 & $1,030,14$ & 43,846 & 0 & 1 & 2 & $5,296.20$ & $5,179.15$ & 117.05 & 94.16 & 96.29 & 2.13 \\
\hline 100 & 5,2 & 410 & 35 & 63 & 691,260 & 24,196 & 0 & 1 & 2 & $3,517.04$ & $3,477.55$ & 39.49 & 111.23 & 112.49 & 1.26 \\
\hline 101 & 5,1 & 625 & 47 & 72 & $1,053,75$ & 39,585 & 0 & 1 & 2 & $5,371.99$ & $5,289.90$ & 82.09 & 114.05 & 115.82 & 1.77 \\
\hline 102 & 5,2 & 596 & 47 & 67 & $1,004,85$ & 32,131 & 0 & 1 & 2 & $5,127.90$ & $5,015.92$ & 111.98 & 135.41 & 138.43 & 3.02 \\
\hline 103 & 5,1 & 614 & 47 & 69 & $1,035,20$ & 40,343 & 0 & 1 & 2 & $5,311.83$ & $5,226.13$ & 85.70 & 117.47 & 119.39 & 1.93 \\
\hline 104 & 5,2 & 562 & 47 & 64 & 947,532 & 23,758 & 0 & 1 & 2 & $4,690.13$ & $4,686.97$ & 3.15 & 151.26 & 151.36 & 0.10 \\
\hline 105 & 5,1 & 523 & 44 & 60 & 881,778 & 38,448 & 0 & 1 & 2 & $4,642.43$ & $4,537.39$ & 105.04 & 112.64 & 115.25 & 2.61 \\
\hline 106 & 5,1 & 90 & 44 & 67 & 151,740 & 6,000 & 0 & 1 & 2 & 761.18 & 908.17 & -147.00 & 151.36 & 126.86 & -24.50 \\
\hline 107 & 5,1 & 534 & 47 & 72 & 900,324 & 36,454 & 0 & 1 & 2 & $4,700.60$ & $4,569.82$ & 130.78 & 125.36 & 128.95 & 3.59 \\
\hline 108 & 5,2 & 565 & 47 & 67 & 952,590 & 23,203 & 0 & 1 & 2 & $4,710.43$ & $4,692.21$ & 18.22 & 170.45 & 171.11 & 0.66 \\
\hline \multicolumn{15}{|c|}{ Average of Absolute Error Value } & 12.06 \\
\hline
\end{tabular}

$*$ denotes an observation whose $\mathrm{X}$ value gives it large leverage, \#Sawmill 5 data is shown with both $1^{\text {st }}$ and $2^{\text {nd }}$ shifts.

There are totally 18 data points out of 108 with error of $\pm 15 \mathrm{kwh} / \mathrm{MBF}$ or more and the average of absolute error value was $12.06 \mathrm{kWh} / \mathrm{MBF}$ from the estimation results of Model 4 for sawmill 1, 2, 4 and 5. Average of absolute error value of Model 4 is greater than all the other Models developed so far. The data points with error of $\pm 15 \mathrm{kwh} / \mathrm{MBF}$ or more have shift run times less than 
3 hours except for one data point with shift run time of 3.25 hours. Also, the error value increased rapidly as the shift run time decreased.

Table 5.11: Data of Sawmill 3 and estimated SEC using Model 4

\begin{tabular}{|c|c|c|c|c|c|c|c|c|c|c|c|c|c|c|}
\hline No. & $\begin{array}{l}\text { Runtime } \\
\text { (Mins) }\end{array}$ & $\begin{array}{c}\text { Density } \\
\left(\mathrm{lb} / \mathrm{ft}^{3}\right)\end{array}$ & $\begin{array}{c}\text { Temp } \\
\left({ }^{\circ} \mathrm{F}\right)\end{array}$ & hp $x$ mins & $\begin{array}{l}4 / 4 \text { to } 8 / 4 \\
+ \text { Pallet }\end{array}$ & $\begin{array}{l}\text { Double } \\
\text { Line }\end{array}$ & Resaw & $\begin{array}{c}\text { Maint } \\
\text { Level }\end{array}$ & Total kWh & $\begin{array}{l}\text { Estimated } \\
\text { Total kWh }\end{array}$ & Error & $\begin{array}{l}\text { Estimated } \\
\text { SEC }\end{array}$ & SEC & Error \\
\hline 1 & 480 & 44 & 52 & $1,262,640$ & 70,762 & 1 & 1 & 2 & $8,464.90$ & $6,996.96$ & $1,467.94$ & 87.02 & 105.28 & 18.26 \\
\hline 2 & 120 & 44 & 32 & 315,660 & 15,476 & 1 & 1 & 2 & $2,264.58$ & $2,273.36$ & -8.78 & 124.96 & 124.48 & -0.48 \\
\hline 3 & 360 & 47 & 39 & 946,980 & 52,297 & 1 & 1 & 2 & $6,551.06$ & $5,464.05$ & $1,087.00$ & 86.74 & 104.00 & 17.26 \\
\hline 4 & 390 & 47 & 42 & $1,025,895$ & 53,822 & 1 & 1 & 2 & $6,981.93$ & $5,821.64$ & $1,160.29$ & 93.07 & 111.63 & 18.55 \\
\hline 5 & 90 & 47 & 44 & 236,745 & 14,251 & 1 & 1 & 2 & $1,591.53$ & $1,875.87$ & -284.35 & 131.63 & 111.68 & -19.95 \\
\hline 6 & 120 & 47 & 34 & 315,660 & 25,722 & 1 & 1 & 2 & $2,315.49$ & $2,384.38$ & -68.89 & 88.33 & 85.78 & -2.55 \\
\hline 7 & 360 & 35 & 39 & 946,980 & 54,330 & 1 & 1 & 2 & $6,430.15$ & $5,417.17$ & $1,012.98$ & 87.80 & 104.21 & 16.42 \\
\hline 8 & 240 & 35 & 45 & 631,320 & 36,481 & 1 & 1 & 2 & $4,299.55$ & $3,798.02$ & 501.52 & 91.74 & 103.86 & 12.11 \\
\hline 9 & 210 & 64 & 47 & 552,405 & 24,743 & 1 & 1 & 2 & $4,455.75$ & $3,480.98$ & 974.78 & 87.22 & 111.65 & 24.43 \\
\hline 10 & 480 & 56 & 62 & $1,262,640$ & 82,405 & 1 & 1 & 2 & $8,657.71$ & $7,140.46$ & $1,517.25$ & 86.65 & 105.06 & 18.41 \\
\hline 11 & 480 & 44 & 70 & $1,262,640$ & 77,793 & 1 & 1 & 2 & $8,767.84$ & $6,995.47$ & $1,772.36$ & 86.40 & 108.29 & 21.89 \\
\hline 12 & 480 & 24 & 61 & $1,262,640$ & 84,341 & 1 & 1 & 2 & $7,281.16$ & $6,984.66$ & 296.50 & 82.81 & 86.33 & 3.52 \\
\hline 13 & 480 & 24 & 66 & $1,262,640$ & 80,230 & 1 & 1 & 2 & $7,195.51$ & $6,923.77$ & 271.74 & 86.30 & 89.69 & 3.39 \\
\hline 14 & 480 & 24 & 71 & $1,262,640$ & 82,402 & 1 & 1 & 2 & $6,701.76$ & $6,925.54$ & -223.78 & 84.05 & 81.33 & -2.72 \\
\hline 15 & 480 & 24 & 61 & $1,262,640$ & 83,415 & 1 & 1 & 2 & $7,075.26$ & $6,975.43$ & 99.83 & 83.62 & 84.82 & 1.20 \\
\hline 16 & 480 & 44 & 34 & $1,262,640$ & 76,564 & 1 & 1 & 2 & $8,664.44$ & $7,126.45$ & $1,538.00$ & 89.13 & 108.37 & 19.24 \\
\hline 17 & 315 & 44 & 49 & $828,607.5$ & 28,493 & 1 & 1 & 2 & $5,428.20$ & $4,638.59$ & 789.61 & 106.11 & 124.17 & 18.06 \\
\hline 18 & 165 & 24 & 53 & $4,340,325$ & 34,619 & 1 & 1 & 2 & $2,854.32$ & $2,800.28$ & 54.04 & 80.89 & 82.45 & 1.56 \\
\hline 19 & 300 & 47 & 42 & 789,150 & 38,783 & 1 & 1 & 2 & $5,457.95$ & $4,608.70$ & 849.25 & 118.83 & 140.73 & 21.90 \\
\hline 20 & 180 & 35 & 44 & 473,490 & 25,114 & 1 & 1 & 2 & $3,074.22$ & $2,980.00$ & 94.22 & 102.09 & 105.32 & 3.23 \\
\hline 21 & 480 & 35 & 48 & $1,262,640$ & 63,695 & 1 & 1 & 2 & $8,304.22$ & $6,892.03$ & $1,412.20$ & 91.87 & 110.70 & 18.83 \\
\hline 22 & 480 & 35 & 50 & $1,262,640$ & 65,815 & 1 & 1 & 2 & $8,508.43$ & $6,905.21$ & $1,603.21$ & 88.10 & 108.55 & 20.45 \\
\hline 23 & 90 & 35 & 48 & 236,745 & 12,258 & 1 & 1 & 2 & $1,653.18$ & $1,772.92$ & -119.74 & 111.23 & 103.72 & -7.51 \\
\hline 24 & 390 & 44 & 54 & $1,025,895$ & 49,854 & 1 & 1 & 2 & $6,810.27$ & $5,717.53$ & $1,092.74$ & 109.80 & 130.79 & 20.99 \\
\hline 25 & 480 & 44 & 51 & $1,262,640$ & 75,778 & 1 & 1 & 2 & $8,764.15$ & $7,050.97$ & $1,713.18$ & 86.44 & 107.44 & 21.00 \\
\hline \multicolumn{14}{|c|}{ Average of Absolute Error Value } & 13.36 \\
\hline
\end{tabular}


Data points 55 and 90 which had higher error values in other models were estimated accurately from Model 4. But the Minitab still identifies data point 90 as the observation with large leverage from its $X$ value. Other 3 data points $(65,72,75)$ which had error of more than $\pm 15 \mathrm{kwh} / \mathrm{MBF}$ in the estimation results of Model 2 were estimated accurately from Model 4 . Table 5.11 shows the data from sawmill 3 and the estimated SEC values using the developed regression model 4.

Even though Model 4 had very high $\mathrm{R}^{2}$ predicted of $99.38 \%$ it has not estimated the SEC of sawmill 3 that well. There are only 10 data points that were estimated with error of less than $15 \mathrm{kWh} / \mathrm{MBF}$. Another thing to notice is that the shifts with shorter run times have less error compared to other shifts which is opposite to how Model 4 estimated shorter shift run times for sawmill 1, 2, 4 and 5. The average of absolute error value of Model 4 for sawmill 3 is 13.36 $\mathrm{kWh} / \mathrm{MBF}$, where as the average of absolute error value of Model 2 was $9.53 \mathrm{kWh} / \mathrm{MBF}$. Model 4 was good in estimating SEC of shift run times of more than 3 hours for sawmill 1, 2, 4 and 5 but was not good for sawmill 3. Model 4 was developed to illustrate, estimation of SEC can also be done by estimating total energy consumption of each shift. Same estimator variables used in Model 2 were used in Model 4, but still, it didn't estimate sawmill 3 as good as Model 2. Estimated SEC values from model 4 and model 2 are plotted along with the actual SEC values for comparison (Figure 5.7). From the figure, it can be seen that estimated values from Model 4 are not following the actual SEC values as good as Model 2.

\subsection{Discussion}

Even though the $\mathrm{R}^{2}$ predicted of Model 4 is $99.38 \%$, it didn't estimate the SEC values as good as Model 2. The reason is too much variability in the distribution of Total $\mathrm{kWh}$ (total $\mathrm{kWh}$ range is $100 \mathrm{kWh}$ to $8,700 \mathrm{kWh}, \mathrm{SD} 2,292$ ) as seen in normal probability plot (Figure 5.8) and 
hence the categorical variables cannot handle a large range of total $\mathrm{kWh}$ efficiently. Once the Total $\mathrm{kWh}$ values are converted into SEC, the variability gets reduced (SEC range is 60 to 170 , SD 24.49) as seen in normal probability plot (Figure 5.9) due to normalization. Hence Model 2 predicts SEC better than Model 4 since categorical variables can handle a small range efficiently.

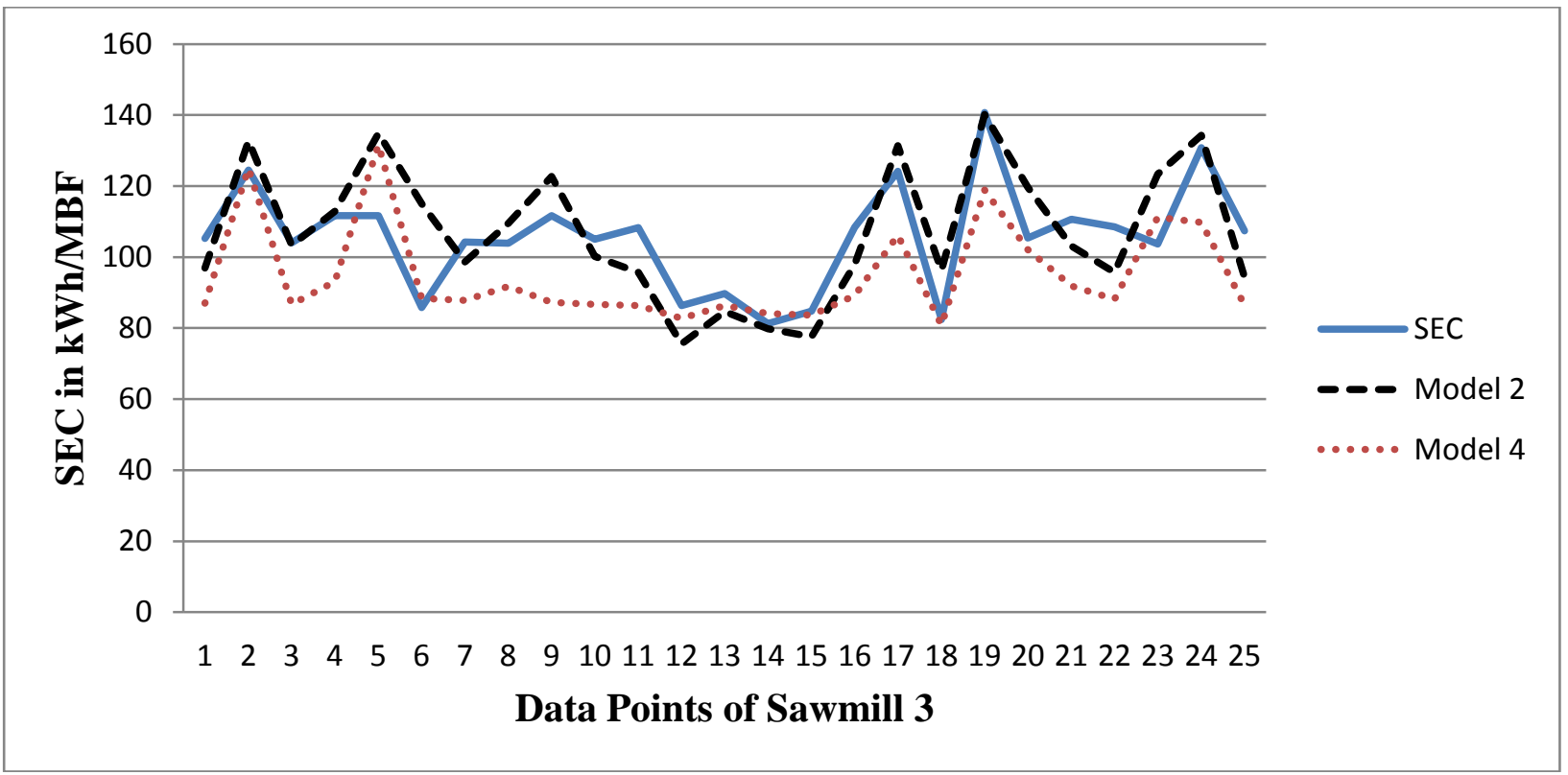

Figure 5.7: Estimated SEC Values from Model 2 and 4 plotted with Actual SEC Values

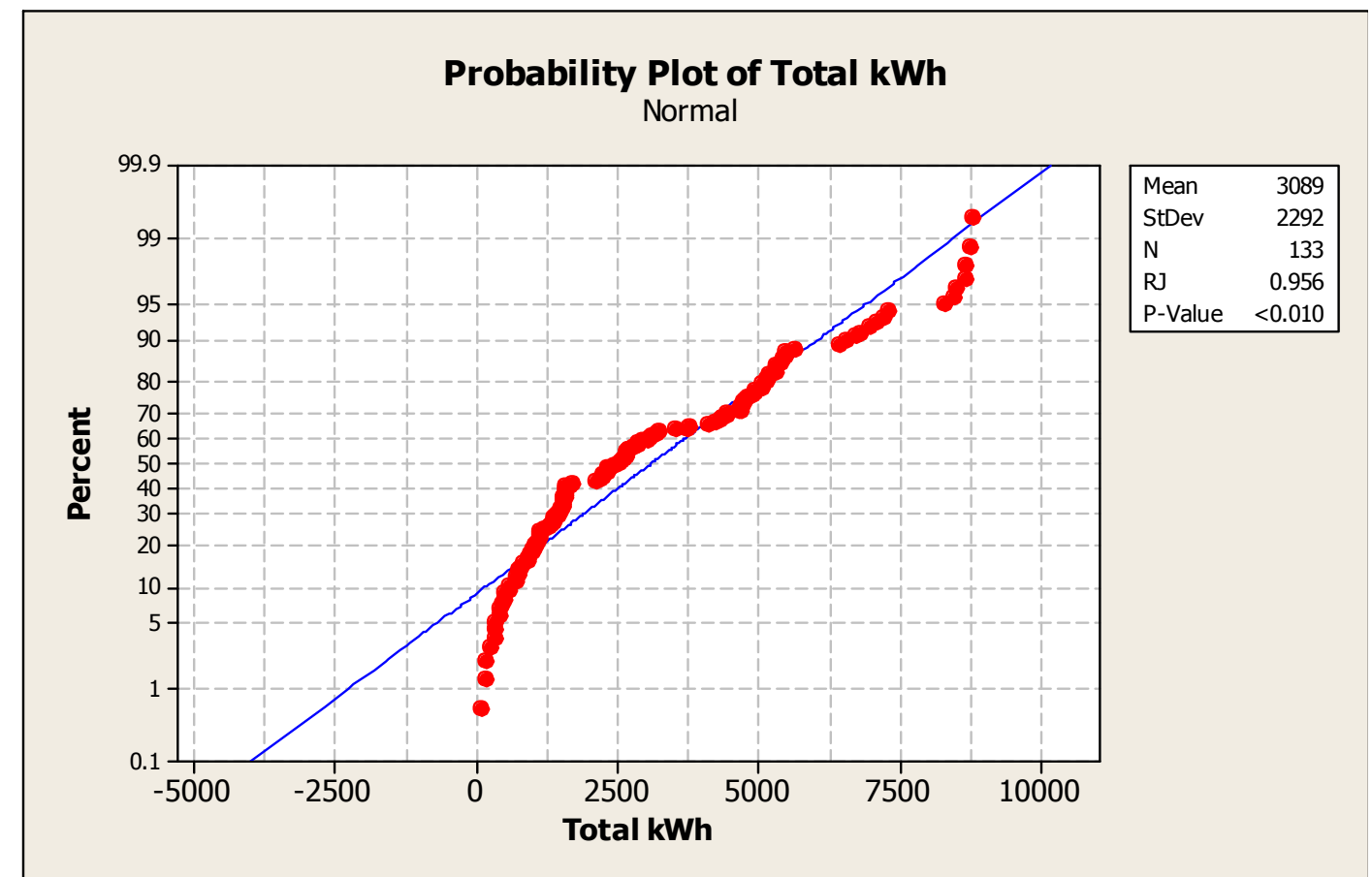

Figure 5.8: Normality Test for Total kWh of Sawmill 1, 2, 3, 4, and 5 


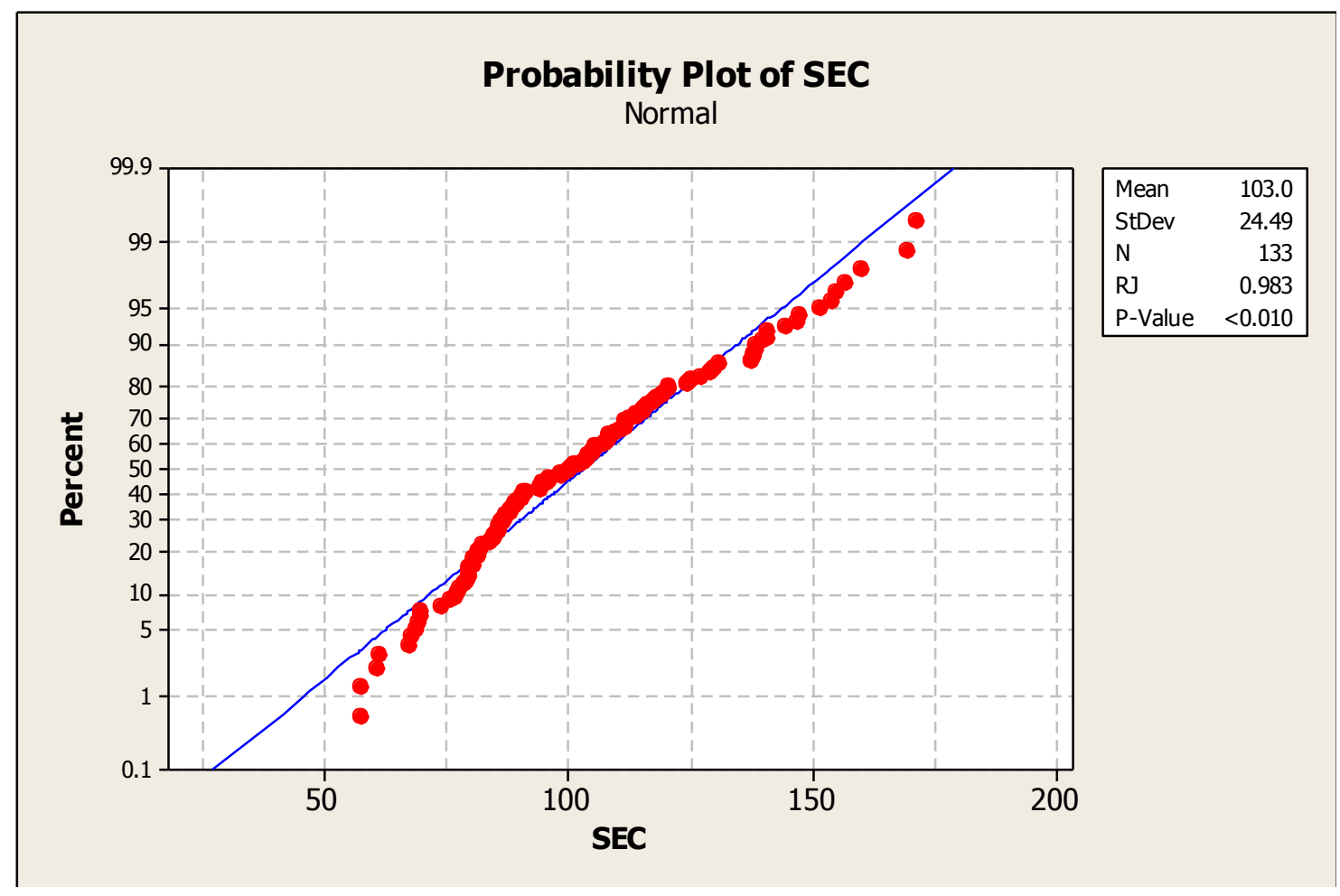

Figure 5.9: Normality Test for SEC of Sawmill 1, 2, 3, 4, and 5

Another interesting thing noticed from Model 4 is very high correlation of estimator variable ' $h p \mathrm{x}$ minutes' with predictor variable 'Total $\mathrm{kWh}$ ' (Figure 5.10). The $\mathrm{R}^{2}$ of the estimation models with only 'hp x min' variable was more than 0.99 (Table 5.12) for individual sawmills. Even though, the $\mathrm{R}^{2}$ was very high at individual sawmill levels, at more than one sawmill level the estimation model with only ' $\mathrm{hp} x \mathrm{~min}$ ' variable didn't perform well since the regression coefficients and constants were different in model of each sawmill due to different motor load factors of each sawmill (Table 5.12).

Table 5.12 : Summary of 'hp x min' Model to estimate 'Total kWh'

\begin{tabular}{|c|c|c|c|c|}
\hline $\begin{array}{c}\text { Model for } \\
\text { Sawmill }\end{array}$ & $\begin{array}{c}\text { Motor } \\
\text { Horse Power }\end{array}$ & Model & $\mathbf{R}^{\mathbf{2}}$ & $\begin{array}{c}\text { Motor } \\
\text { Load Factor }\end{array}$ \\
\hline 1 & 968 & $29.1406+0.00430452 \mathrm{hp} \mathrm{x} \mathrm{min}$ & 99.22 & 0.307 \\
\hline 2 & 817 & $34.2681+0.0036265 \mathrm{hp} \mathrm{x} \mathrm{Min}$ & 99.19 & 0.265 \\
\hline 4 & 1,534 & $-15.5785+0.00520418 \mathrm{hp} \mathrm{x} \mathrm{Min}$ & 99.18 & 0.358 \\
\hline 5 & 1,686 & $-0.101295+0.00511631 \mathrm{hp} \mathrm{x} \mathrm{Min}$ & 99.79 & 0.362 \\
\hline $1,2,4$ \& 5 & - & $-287.293+0.00534421 \mathrm{hp} \mathrm{x} \mathrm{min}$ & 98.10 & - \\
\hline
\end{tabular}


In equation 4.3 (page 65) which calculates total $\mathrm{kWh}$, only minutes is the variable and the rest are constants. Horse power and minutes are known, efficiency will be almost same for every sawmill (Table 4.2) and the thing that is different for each sawmill is load factor. Motor load factor is the percent of total motor capacity used to do a particular work. Lumber sawing takes place intermittently, what it means is either the motor will be sawing or it will be idling. When idling it may consume around $15 \%$ of motor capacity and while sawing it may consume around $60 \%$ of motor capacity or more depending on what species and size it is sawing. Also, the frequency of cutting matters a lot for getting a particular load factor. If one sawmill's cutting frequency is high then it will have more load factor and it is indicated in terms of board feet, not in terms of 'hp x min'. Sawmill will be fast if it has a resaw or a gang saw. Sawmill 3 has a high load factor compared to other sawmills since it has very high board feet production per hour per hp (Table 6.22).

Correlation between 'hp x min' and 'Total kWh' is shown in Figure 5.10. Variable ' $h p$ x min' was divided by 1,000 and 'Total kWh' was divided by 10 for comparison. Even though hp x min has similar pattern as the total $\mathrm{kWh}\left(\right.$ hence it has $\mathrm{R}^{2}>0.99$ ), there is a gap between hp $\mathrm{x}$ min and $\mathrm{kWh}$ and that gap is different for each sawmill (Figure 5.11).

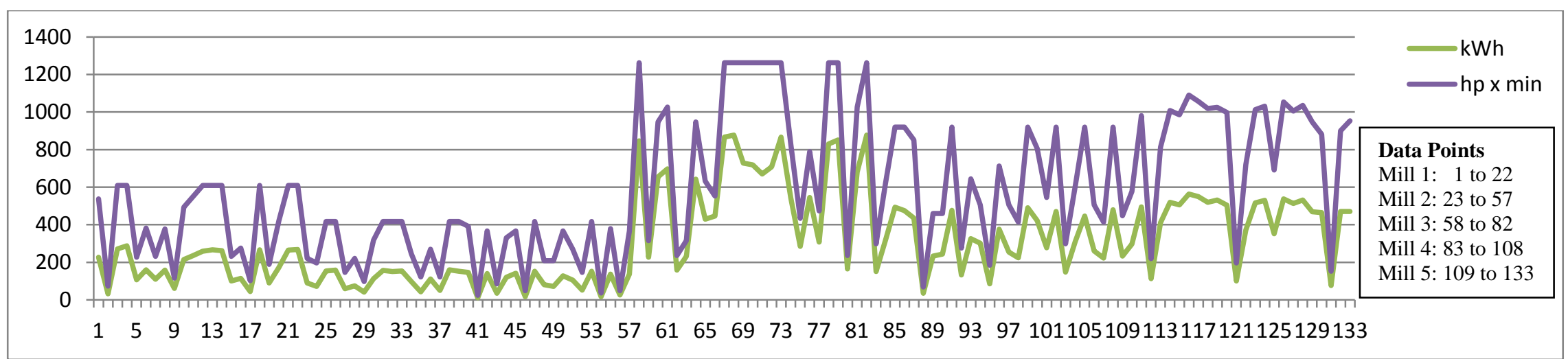

Figure 5.10: Correlation between 'hp x min' and 'Total kWh' 
Relationship between 'hp x min' and 'Total kWh' is plotted in Figure 5.11. From Figure 5.11, Sawmill 2 has least gap with the X-axis and then Sawmill 1. Sawmill 4 and 5 have same gap and Sawmill 3 has the biggest gap. This gap is nothing but the motor load factor. This gap cannot be estimated just by the constant in the regression equation keeping the same regression coefficient for the 'hp $\mathrm{x}$ min' variable in the regression model since both the constants and regression coefficients are different in the regression models of each sawmill. Hence additional variables that represent motor load factor are required along with 'hp x min' to estimate 'Total kWh'.

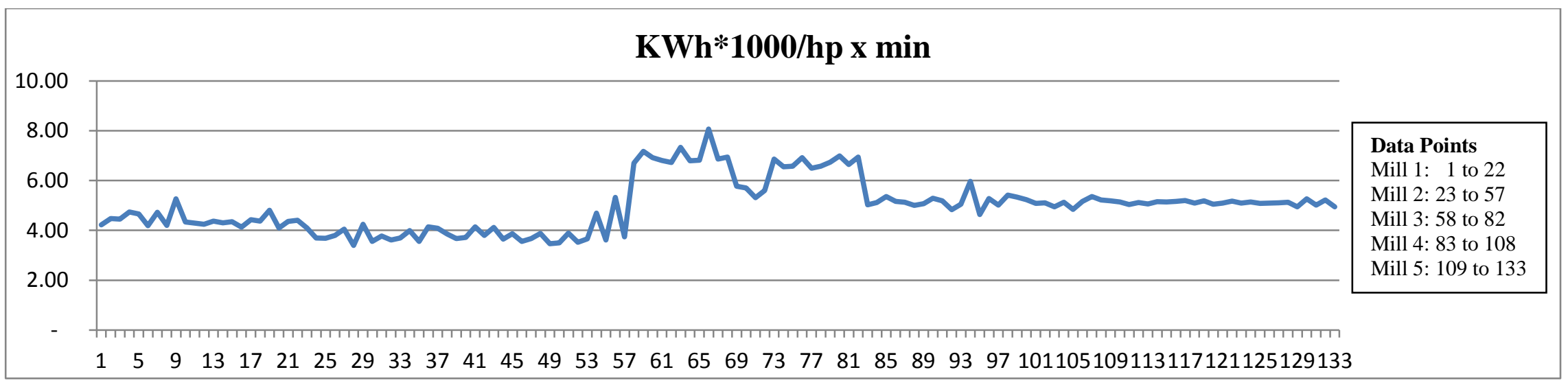

Figure 5.11: Relationship between 'hp $\mathrm{x}$ min' and 'Total $\mathrm{kWh}$ '

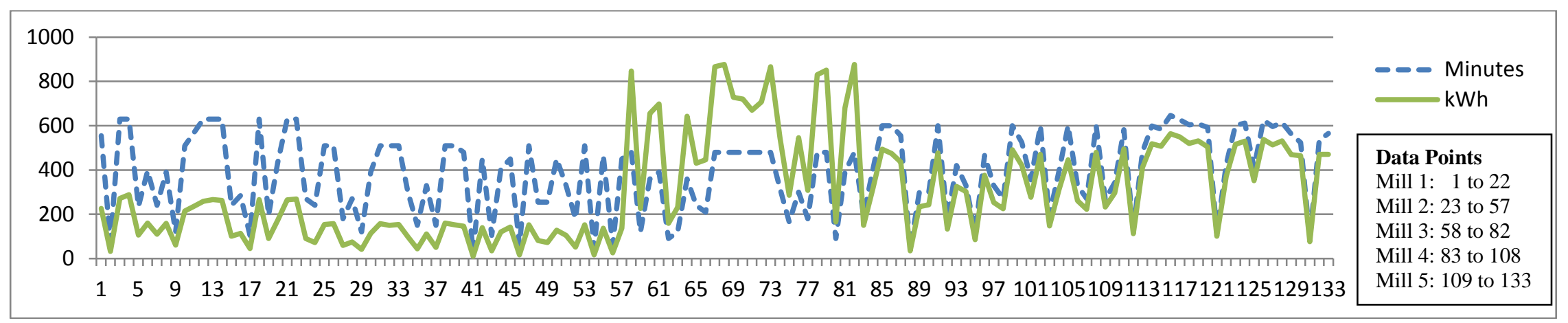

Figure 5.12: Correlation between 'min' and 'Total kWh' 
Since horse power was a constant, the actual correlation was between variable 'minutes' and 'Total kWh' (Figure 5.12). Variable 'Minutes' is in actual value and variable 'Total kWh' is divided by 10 for comparison. Again the gap between 'minutes' and 'Total $\mathrm{kWh}$ ' is totally different for different sawmills.

Also, total board feet sawn is correlated to 'Total kWh' (Pearson Correlation Coefficient $=0.949$ ) as shown in Figure 5.13. Total board feet is divided by 100 and 'Total kWh' by 10 for comparison. Interesting thing is the gap between Board Feet and kWh is really narrow. The reason is average $\mathrm{kWh} / \mathrm{MBF}$ is 100 for all the sawmills. Board feet is above $\mathrm{kWh}$ for sawmill 1 and 2 since the average SEC of sawmill 1 and 2 are 88 and $84 \mathrm{kWh} / \mathrm{MBF}$ (Table 4.6) respectively. For sawmill 3 the board feet is aligning with the $\mathrm{kWh}$ since the average SEC of sawmill 3 is $106 \mathrm{kWh} / \mathrm{MBF}$. For sawmill 4 and 5 the board feet is below kWh since the average SEC of sawmill 4 and 5 are 124 and $118 \mathrm{kWh} / \mathrm{MBF}$ respectively. Also there are places where board feet is off from the kWh due to sawing a very low or high density wood, for example: Poplar a very low density wood species is sawn in sawmill 3 between points 66 and 73.

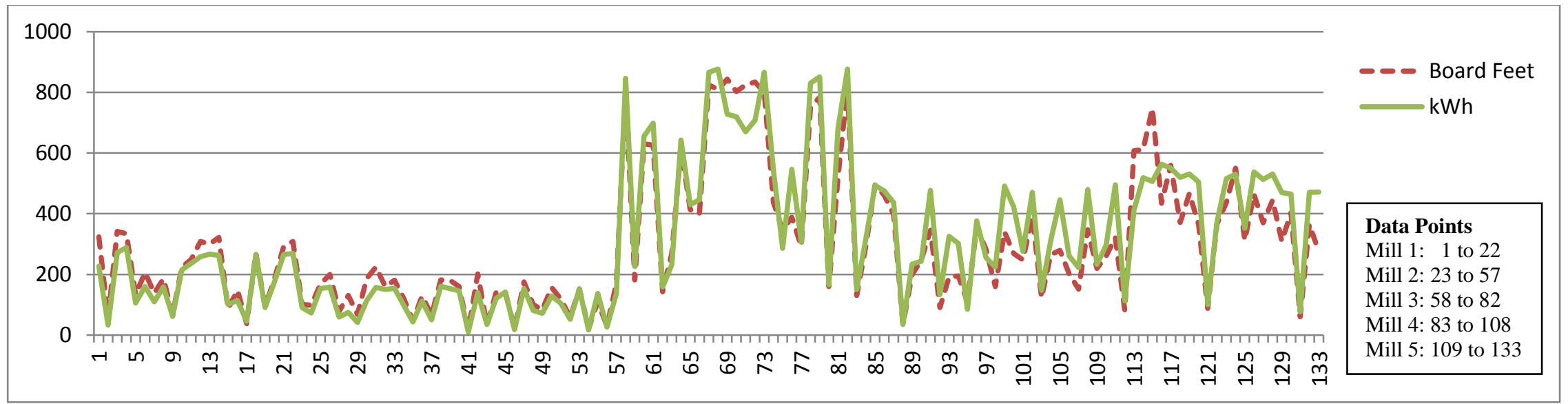

Figure 5.13: Correlation between 'Board Feet' and 'Total kWh' 
Another interesting thing to notice is the wider gap between board feet and $\mathrm{kWh}$ for sawmill 5. This is happening due to poor production during shift 2 and more production in shift 1 to compensate for that. So, without board feet, total kWh cannot be predicted properly. So, board feet, density and minutes dictate the energy consumption and all the other variables are constants.

The relationship between total board feet sawn and total kWh is shown in Figure 5.14. The value shown are nothing but SEC values. Model 1, 2 and 3 are estimating SEC. SEC is highest for sawmill 4 and 5 and lowest for sawmill 1and 2 and sawmill 3 is in the middle (Figure 5.14). Model 4 is estimating 'Total kWh' and the 'Total kWh' is highest for sawmill 3 , then sawmill 4 and 5 and lowest for sawmill 2 and then 1. So, the signs of the regression coefficients of the variables representing board feet are negative in SEC models (i.e., higher the board feet production, lower will be the SEC) and are positive in 'Total kWh' models (i.e., higher the board feet production, higher will be the Total $\mathrm{kWh}$ ).

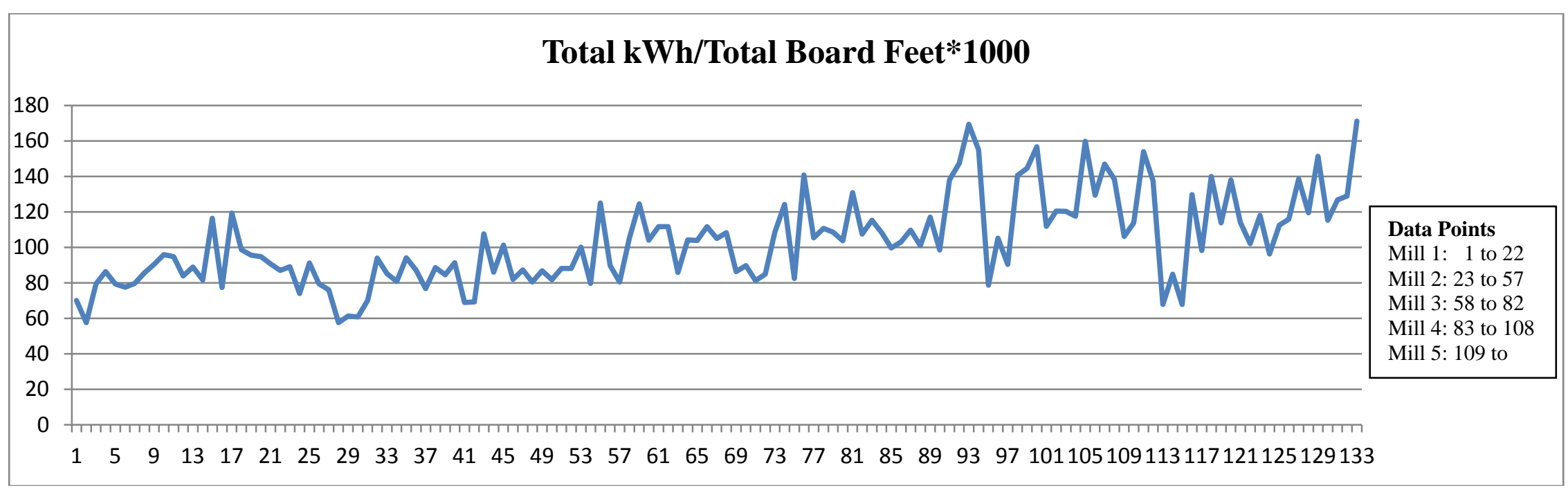

Figure 5.14: Relationship between 'Board Feet' and 'Total kWh' 


\subsection{Sawmill Energy Estimation Program (SMEEP) Development}

Sawmill energy estimation program was developed to make the estimation and analysis easy for a sawmill owner. 'VisualBasic $₫$ for Applications in Excel' was thought to be the right tool to develop the program since the program involves lot of calculations like estimation of energy consumption, allocation of energy consumption based on sizes sawn, analysis to find out the reasons for inefficiency of a sawmill and suggesting solutions with estimated savings to overcome those inefficiencies and robust Microsoft Excel@ can easily support these calculations.

The system diagram of SMEEP is shown in Figure 1.14. The inputs to the SMEEP are the wood species and board feet of different sizes lumber sawn as product parameters, sawing time and level of maintenance (saw blade usage time) as process parameters, and motor horsepower of equipment, usage of resaw or gangsaw and line configuration of single or double line as system parameters. Also, average electricity rate in $\$ / \mathrm{kWh}$ and sawing cost/MBF of grade lumber will be the inputs. The outputs from the SMEEP are estimated $\mathrm{kWh} / \mathrm{MBF}$, total energy consumption for the shift data entered, motor load factor, SEC for different lumber sizes, best achieved SEC for different lumber sizes, details of energy savings and productivity savings and suggestions to improve efficiency.

$1^{\text {st }}$ shift data of Hickory species from sawmill 2 used in data analysis chapter (Table 4.13) was used to test the developed SMEEP. Input sheet with inputs are shown in Figure 5.15. There is an option to either enter the horsepower or not to enter it to run the program. Estimation Model 2 will be used for calculation if horse power of the motors were entered; otherwise estimation Model 3 will be used for calculation. There are ten species in the pull down menu and if the program has to be tested for new species, there is an option to enter density value in $1 \mathrm{~b} / \mathrm{ft}^{3}$. For 
the new species whose density value is entered, best achieved SEC values of species closest to its density value is used for calculating savings and is also displayed in the output.

Figure 5.16 shows the output for the entered data. The estimated SEC (kWh/MBF) is the one obtained by Model 2. The estimated SEC, estimated total kWh (energy consumption), the calculated SEC for individual sizes, best achieved SEC values for individual sizes and motor load factor along with the species and its density value are shown in the output.

\section{Calculations of SMEEP Test Data}

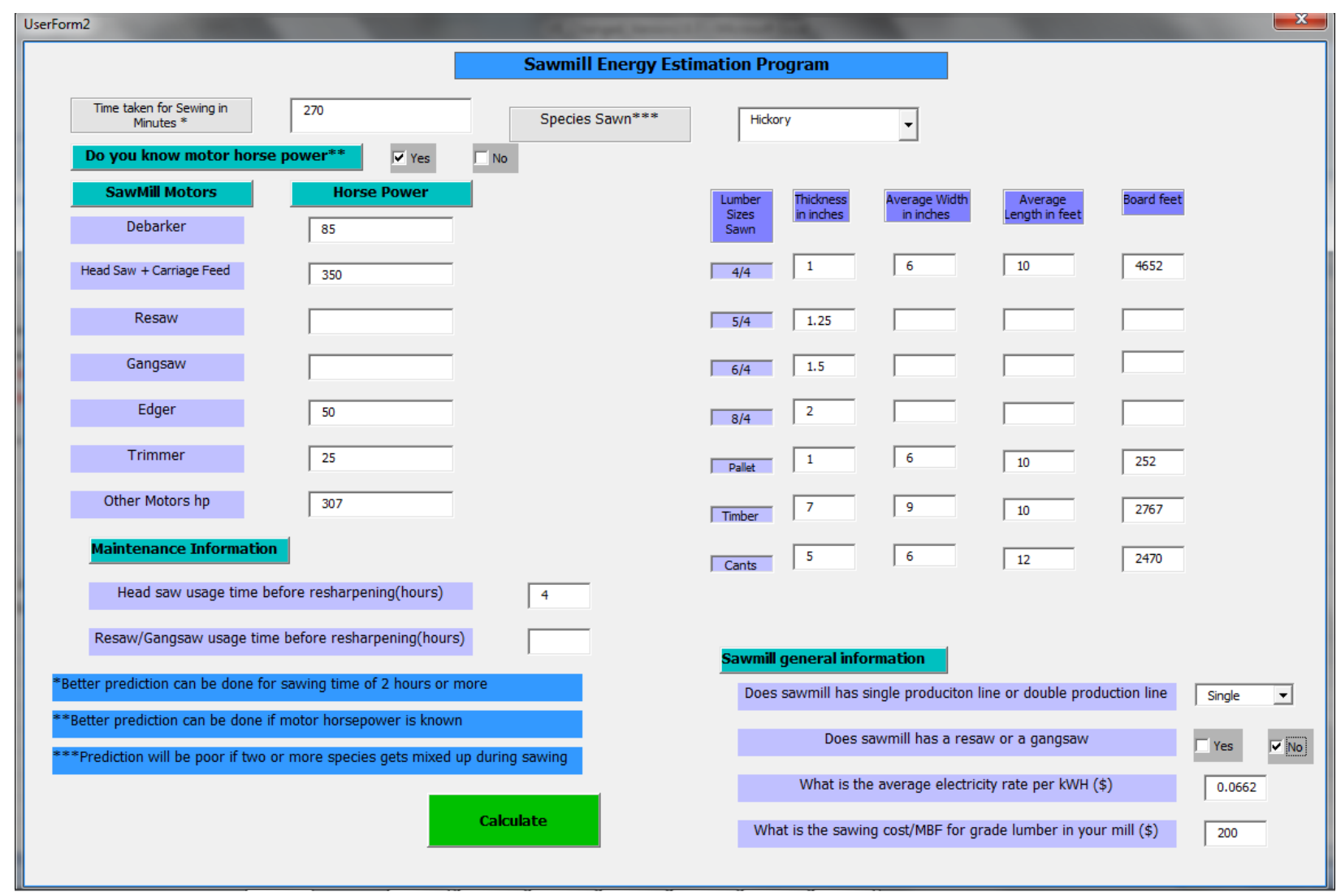

Figure 5.15: Input Sheet of the SMEEP

Some of the input values were converted or calculated into the following values before entering them into the regression model.

Species $=$ Hickory $\longrightarrow$ Density $=64 \mathrm{lb} / \mathrm{ft}^{3}$

Head saw usage time before resharpening $=4$ hours $\longrightarrow$ Maintenance Index: 3 


$$
\begin{aligned}
& \text { Total hp }=85+350+50+25+307=817 \\
& 4 \text { to } 8 \text { Qtr }+ \text { Pallet }=4,652+252=4,904 \text { Board Feet } \\
& \text { Cant }+ \text { Tim }=2,767+2,470=5,237 \text { Board Feet } \\
& \text { hp } \times \text { min }=817 \times 270=220,590
\end{aligned}
$$

The estimated SEC was calculated using the following regression equation of model 2.

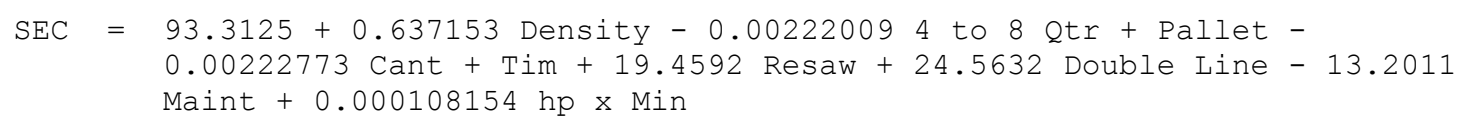

The regression equation with the input values looks like.

$\mathrm{SEC}=93.3125+0.637153 \times 64-0.00222009 \times 4,904-0.00222773 \times 5,237+19.4592 \times$ $0+24.5632 \times 0-13.2011 \times 3+0.000108154 \times 220,590$

$\mathrm{SEC}=95.79 \mathrm{kWh} / \mathrm{MBF}$

Estimated total $\mathrm{kWh}=\mathrm{SEC} \times$ Total Board Feet $/ 1,000$

$$
\begin{aligned}
& =95.79 \times(4,904+5,237) \\
& =971.41 \mathrm{kWh}
\end{aligned}
$$

Load Factor is calculated as,

$$
\begin{aligned}
& \text { Load Factor }=\frac{\text { Total } \mathrm{kWh} \times \text { Efficiency }}{\text { Motor } \mathrm{hp} \times \text { Hours } \times 0.746} \\
& \text { Load Factor }=\frac{971.41 \times 0.9}{817 \times(270 / 60) \times 0.746}=31.88 \%
\end{aligned}
$$

Calculation of SEC for individual sizes need calculation of surface area cut on Main saw, Edger and Trimmer for all the sizes sawn in the given shift. Calculation for $4 / 4$ size is shown as an example.

Total board feet of $4 / 4$ cut $=4,652 \mathrm{Bft}$ Total length cut

$=$ Total board feet cut / (Width $\mathrm{x}$ Thickness)

$$
\begin{aligned}
& =4,652 \mathrm{Bft} /(0.5 \text { feet } \times 1 \text { inch }) \quad(1 \mathrm{bft}=1 \mathrm{ft} \times 1 \mathrm{ft} \times 1 \text { inch }) \\
& =9,304 \mathrm{ft}
\end{aligned}
$$


Surface area cut by head saw $=$ Total length cut $\mathrm{x}$ Width

$$
\begin{aligned}
& =9,304 \mathrm{ft} \times 0.5 \mathrm{ft} \\
& =4,652 \mathrm{sq} . \mathrm{ft}
\end{aligned}
$$

Surface area cut by Edger $\quad=$ Total length cut $\mathrm{x}$ Thickness

$=9,304 \mathrm{ft} \times(1 / 12) \mathrm{ft}$

$=775$ sq. $\mathrm{ft}$

No. of pieces cut $\quad=($ Total length cut/Average piece length $)$

$=9,304 \mathrm{ft} / 10 \mathrm{ft}$

$=930$ pieces

Surface area cut by Trimmer $=$ Width $\mathrm{x}$ thickness $\mathrm{x}$ No. of pieces cut

$$
=0.5 \mathrm{ft} \times(1 / 12) \mathrm{ft} \times 930 \text { pieces }
$$$$
=39 \text { sq. } \mathrm{ft}
$$

Total surface area cut for $4 / 4=$ Surface area cut by (head saw + Edger + Trimmer)

$$
\begin{aligned}
& =4,652+775+39 \\
& =5,466 \text { sq. ft. }
\end{aligned}
$$

Energy was allocated to individual size of lumber by a factor that was calculated as the ratio of the total surface area cut for that particular size to the total surface area cut for all the sizes in that shift. For example for $4 / 4$ size, the factors are allocated as follows:

Factor for $4 / 4=$ Total Surface area cut for $4 / 4$ size / Total Surface area cut for all the sizes

$$
\begin{aligned}
& =5,466 / 6,651 \\
& =0.8218
\end{aligned}
$$

Similarly factors for other sizes are calculated and are shown in Table 5.13.

Table 5.13: Surface Area Cut and Factors allocation for the SMEEP Test Data

\begin{tabular}{|c|c|c|c|c|c|c|c|}
\hline $\begin{array}{c}\text { Size } \\
\text { Type }\end{array}$ & Size & $\begin{array}{c}\text { Board } \\
\text { Feet }\end{array}$ & $\begin{array}{c}\text { Surface } \\
\text { Area } \\
\text { Head saw }\end{array}$ & $\begin{array}{c}\text { Surface } \\
\text { Area } \\
\text { Edger }\end{array}$ & $\begin{array}{c}\text { Surface } \\
\text { Area } \\
\text { Trimmer }\end{array}$ & $\begin{array}{c}\text { Surface } \\
\text { Area } \\
\text { Total }\end{array}$ & Factor \\
\hline Four Quarter & $4 / 4$ & 4,652 & 4,652 & 775 & 39 & 5,466 & 0.8218 \\
\hline Pallet & 1"x 6"x10' & 252 & 252 & 42 & 2 & 296 & 0.0445 \\
\hline Timber & 7"x 9"x10" & 2,767 & 395 & 0 & 0 & 395 & 0.0594 \\
\hline Cant & 5"x 6" x 12' & 2,470 & 494 & 0 & 0 & 494 & 0.0743 \\
\hline & Total & $\mathbf{1 0 , 1 4 1}$ & $\mathbf{5 , 7 9 3}$ & $\mathbf{8 1 7}$ & $\mathbf{4 1}$ & $\mathbf{6 , 6 5 1}$ & $\mathbf{1}$ \\
\hline
\end{tabular}


Energy consumed by particular size lumber was allocated based on the factors calculated by multiplying the total energy consumption by the factor for that particular size. The energy consumed by main saw, edger and trimmer were not allocated individually like the way done in energy allocation methodology since the energy consumption of individual motors is not known here. SEC was calculated by dividing the total energy allocated for that size by the MBF sawn for that particular size. Table 5.14 shows the energy consumed for sawing different size lumber and the total $\mathrm{kWh}$ consumed per thousand board feet of lumber.

Table 5.14: Energy consumed for Sawing different Size Lumber of SMEEP Test Data

\begin{tabular}{|c|c|c|c|c|}
\hline $\begin{array}{c}\text { Size } \\
\text { Type }\end{array}$ & Size & $\begin{array}{c}\text { Board } \\
\text { Feet }\end{array}$ & $\begin{array}{c}\text { Total kWh } \\
\text { Consumed }\end{array}$ & $\begin{array}{c}\mathbf{k W h} \text { / } \\
\text { thousand } \\
\text { Board Feet }\end{array}$ \\
\hline Four Quarter & $4 / 4$ & 4,652 & 798.29 & 171.60 \\
\hline Pallet & 1"x 6"x10" & 252 & 43.24 & 171.60 \\
\hline Timber & 7"x 9"x10" & 2,767 & 57.73 & 20.86 \\
\hline Cant & 5"x 6"x 12' & 2,470 & 72.15 & 29.21 \\
\hline & Total & $\mathbf{1 0 , 1 4 1}$ & $\mathbf{9 7 1 . 4 1}$ & - \\
\hline
\end{tabular}

The estimated values by the SMEEP and the actual values from Table 4.5 and Table 4.13 for the $1^{\text {st }}$ shift data of Hickory species from sawmill 2 are shown in Table 5.15 for comparison. Since the estimated SEC is greater than actual SEC by $6.7 \mathrm{kWh} / \mathrm{MBF}$, the other values calculated from, it are also higher than actual values. Also, the best achieved values from sawmill 1 are shown in Table 5.15.

Table 5.15: Estimated, Actual and Best Achieved SEC values for the SMEEP Test Data

\begin{tabular}{|c|c|c|c|}
\hline $\begin{array}{c}\text { Sawmill 2 } \\
\mathbf{1}^{\text {st }} \text { Shift Data } \\
\text { Results }\end{array}$ & Estimated & Actual & Best Achieved \\
\hline SEC & 95.79 & 89.13 & Not Applicable \\
\hline Total kWh & 971.41 & 903.83 & Not Applicable \\
\hline $4 / 4$ SEC & 171.60 & 160.17 & 118.31 \\
\hline Pallet SEC & 171.60 & 160.16 & 118.31 \\
\hline Timber SEC & 20.86 & 19.01 & 13.82 \\
\hline Cant SEC & 29.21 & 26.62 & 24.73 \\
\hline
\end{tabular}


Table 5.16 and Table 5.17 shows the best achieved values from sawmill 1 used in the SMEEP for comparison purpose. Best achieved values for the species and sizes not sawn in sawmill 1 were estimated based on the values of species and sizes sawn in sawmill 1.

Table 5.16: Best Achieved SEC values from Sawmill 1 for different Lumber Sizes

\begin{tabular}{|c|c|c|c|c|c|c|}
\hline Species & $\begin{array}{c}\text { Four } \\
\text { Quarter }\end{array}$ & $\begin{array}{c}\text { Five } \\
\text { Quarter }\end{array}$ & $\begin{array}{c}\text { Six } \\
\text { Quarter }\end{array}$ & $\begin{array}{c}\text { Eight } \\
\text { Quarter }\end{array}$ & $\begin{array}{c}\text { Pallet } \\
\text { Material }\end{array}$ & Timber \\
\hline Yellow Poplar & 70.21 & 55.12 & 50.34 & 41.27 & 70.21 & 7.43 \\
\hline Sycamore & 70.81 & 56.31 & 51.78 & 41.57 & 70.81 & 7.69 \\
\hline Soft Maple & 79.00 & 64.55 & 60.12 & 45.64 & 79.00 & 8.46 \\
\hline Ash & 83.36 & 70.42 & 66.52 & 47.81 & 83.36 & 9.44 \\
\hline Birch & 91.21 & 77.10 & 73.30 & 51.77 & 91.21 & 9.89 \\
\hline Red Oak & 91.12 & 77.72 & 73.30 & 51.77 & 91.12 & 9.89 \\
\hline White Oak & 94.01 & 77.59 & 73.87 & 53.21 & 94.01 & 10.73 \\
\hline Hard Maple & 91.53 & 76.94 & 72.66 & 51.95 & 91.53 & 10.09 \\
\hline Cherry & 120.29 & 114.55 & 106.64 & 66.14 & 120.29 & 14.11 \\
\hline Hickory & 118.31 & 113.69 & 105.55 & 65.30 & 118.31 & 13.82 \\
\hline
\end{tabular}

Table 5.17: Best Achieved SEC values from Sawmill 1 for different Cant Sizes

\begin{tabular}{|c|c|c|c|c|c|}
\hline Species & $\begin{array}{c}\text { Cants } \\
\left(3^{\prime \prime} \times 8 \text { "x12') }\right.\end{array}$ & $\begin{array}{c}\text { Cants } \\
\text { (3.5"x6"x12') }\end{array}$ & $\begin{array}{c}\text { Cants } \\
\text { (14"x4"x12') }\end{array}$ & $\begin{array}{c}\text { Cants } \\
\text { (5"x6"x12') }\end{array}$ & $\begin{array}{c}\text { Cants } \\
\left(3^{\prime \prime} \times 4 " x 12 '\right)\end{array}$ \\
\hline Yellow Poplar & 17.43 & 20.43 & 22.06 & 13.07 & 21.79 \\
\hline Sycamore & 17.61 & 20.61 & 22.24 & 13.21 & 22.01 \\
\hline Soft Maple & 20.61 & 24.71 & 26.34 & 16.28 & 27.14 \\
\hline Ash & 22.02 & 26.15 & 27.78 & 17.36 & 28.94 \\
\hline Birch & 25.52 & 29.72 & 31.25 & 20.24 & 33.20 \\
\hline Red Oak & 24.26 & 28.52 & 30.15 & 19.14 & 31.90 \\
\hline White Oak & 23.82 & 28.11 & 29.74 & 18.83 & 31.39 \\
\hline Hard Maple & 23.85 & 28.19 & 29.82 & 18.89 & 31.49 \\
\hline Cherry & 32.36 & 37.15 & 38.78 & 25.61 & 42.69 \\
\hline Hickory & 31.39 & 35.97 & 37.6 & 24.73 & 41.21 \\
\hline
\end{tabular}

If the calculated SEC for individual sizes is greater than best achieved values by $20 \%$, then energy savings and productivity savings are calculated for reaching best achieved values along with suggestions to reach best achieved values. Difference of $20 \%$ is considered since the predicted $\mathrm{R}^{2}$ of Model 2 is $85.88 \%$ and predicted $\mathrm{R}^{2}$ of Model 3 is $81.64 \%$ and hence it is assumed that there can be a maximum error of $14 \%$ to $18.5 \%$ and $20 \%$ is more than these error values. 
For the data entered from sawmill 2, the suggestions given are shown in the output (Figure 5.16). The suggestions are to install a resaw or a gangsaw, increase saw blade resharpening frequency, and resizing of motors to improve motor load factor.

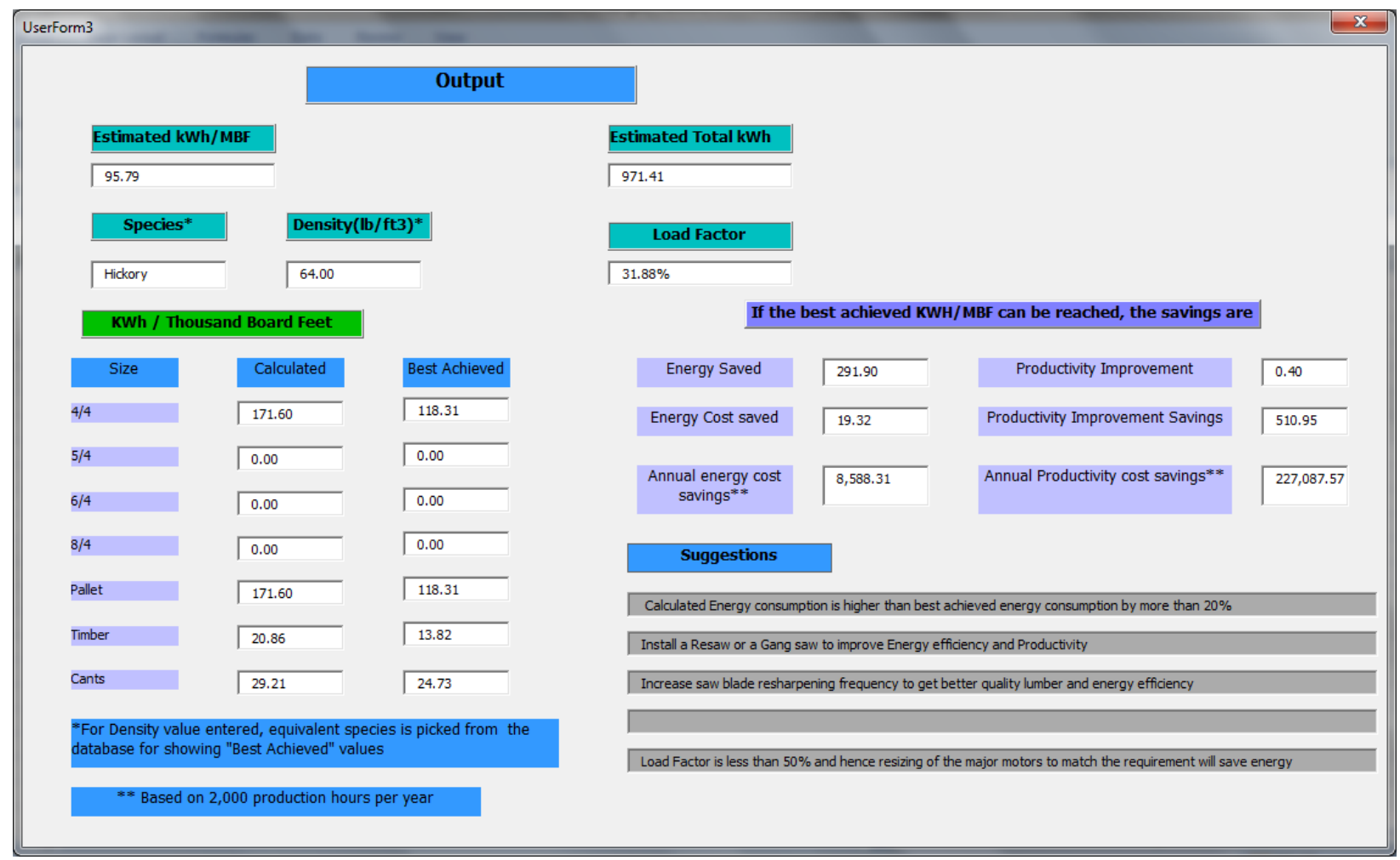

Figure 5.16: Output Sheet of the SMEEP

Table 5.18: Energy Savings and Energy Cost Savings for the SMEEP Test Data

\begin{tabular}{|c|c|c|c|c|c|c|c|}
\hline $\begin{array}{l}\text { Lumber } \\
\text { Size }\end{array}$ & $\begin{array}{c}\text { Calculated } \\
\text { SEC } \\
(\mathbf{a}) \\
\text { kWh/MBF } \\
\end{array}$ & $\begin{array}{c}\text { Best } \\
\text { Achieved } \\
\text { SEC (b) } \\
\text { kWh/MBF }\end{array}$ & $\begin{array}{c}\text { Energy } \\
\text { Savings } \\
\mathrm{c}=(\mathbf{a})-(\mathbf{b}) \\
\mathrm{kWh} / \mathrm{MBF} \\
\end{array}$ & $\begin{array}{l}\text { Board } \\
\text { Feet } \\
\text { Sawn } \\
\text { (d) MBF } \\
\end{array}$ & $\begin{array}{c}\text { Total Energy } \\
\text { Savings per } \\
\text { shift }(\mathrm{kWh}) \\
\mathrm{e}=(\mathrm{c}) \times(\mathrm{d}) \\
\end{array}$ & $\begin{array}{c}\text { Energy Cost } \\
\text { Savings per } \\
\text { shift }(\$) \\
\text { f= (e) } x \mathbf{0 . 0 6 6 2} \\
\end{array}$ & $\begin{array}{c}\text { Energy Cost } \\
\text { Savings per } \\
\text { year } \\
(\$) \\
\end{array}$ \\
\hline $4 / 4$ & 171.60 & 118.31 & 53.29 & 4.652 & 247.9 & 16.41 & $7,293.73$ \\
\hline Pallet & 171.60 & 118.31 & 53.29 & 0.252 & 13.4 & 0.89 & 394.26 \\
\hline Timber & 20.86 & 13.82 & 7.04 & 2.767 & 19.5 & 1.29 & 573.73 \\
\hline Cants & 29.21 & 24.73 & 4.48 & 2.470 & 11.1 & 0.73 & 326.59 \\
\hline Total & - & - & - & 10.141 & 291.90 & 19.32 & $8,588.31$ \\
\hline
\end{tabular}


The calculation involved in estimating the energy and energy cost savings are shown in Table 5.18. The energy savings is estimated to be the difference between calculated SEC and best achieved values.

The industrial electricity rate of Appalachian Power Co in West Virginia, the utility provider for sawmill 2 is $\$ 0.0662 / \mathrm{kWh}$ (US EIA 2013). Energy cost savings are calculated by multiplying average energy rate of $\$ 0.0662 / \mathrm{kWh}$ with the $\mathrm{kWh}$ energy savings. The Energy cost savings per year is calculated as shown below.

Energy Cost Savings per year $=\frac{\text { Energy Cost Savings per shift x } 2000 \text { production hours } / \text { year }}{\text { Test Data Shift time in Minutes } / 60}$

Energy Cost Savings per year $=\frac{19.32 \times 2000 \text { production hours } / \text { year }}{270 / 60}$

$$
=\$ 8,588.31
$$

Also, the estimated energy savings is $10,811 \mathrm{kWh} /$ month or $129,732 \mathrm{kWh} /$ year based on 2,000 production hours per year.

The calculation involved in estimating productivity improvement and productivity improvement cost savings are shown in Table 5.19. As per the discussion with the sawmill owners, the sawing cost per MBF for $4 / 4$ to $8 / 4$ lumber excluding energy cost is around $\$ 200$. For the cants and timbers, sawing cost per MBF was estimated to be $30 \%$ and $15 \%$ of $4 / 4$ to $8 / 4$ lumber production cost which becomes $\$ 60$ and $\$ 30$ respectively.

Table 5.19: Productivity Savings and Productivity Cost Savings for the SMEEP Test Data

\begin{tabular}{|c|c|c|c|c|c|c|c|}
\hline $\begin{array}{c}\text { Lumber } \\
\text { Size }\end{array}$ & $\begin{array}{c}\text { Calculated } \\
\text { SEC } \\
(\mathbf{a}) \\
\text { kWh/MBF } \\
\end{array}$ & $\begin{array}{c}\text { Best } \\
\text { Achieved } \\
\text { SEC (b) } \\
\text { kWh/MBF } \\
\end{array}$ & $\begin{array}{c}\text { Productivity } \\
\text { Savings } \\
(\mathbf{c})=(\mathbf{a} / \mathbf{b})-1 \\
\text { kWh/MBF } \\
\end{array}$ & $\begin{array}{c}\text { Board } \\
\text { Feet } \\
\text { Sawn } \\
\text { (d) MBF } \\
\end{array}$ & $\begin{array}{l}\text { Productivity } \\
\text { Savings per } \\
\text { shift (MBF) } \\
(\text { e) }=\text { (c) } x \text { (d) }\end{array}$ & $\begin{array}{c}\text { Production } \\
\text { Cost (\$) per } \\
\text { MBF } \\
\text { (f) } \\
\end{array}$ & $\begin{array}{l}\text { Productivity } \\
\text { Cost Savings } \\
\text { per shift (\$) } \\
(\mathrm{g})=(\mathrm{e}) \times(\mathrm{f})\end{array}$ \\
\hline $4 / 4$ & 171.60 & 118.31 & 0.45 & 4.652 & 2.095 & 200 & 419.10 \\
\hline Pallet & 171.60 & 118.31 & 0.45 & 0.252 & 0.114 & 200 & 22.70 \\
\hline Timber & 20.86 & 13.82 & 0.51 & 2.767 & 1.411 & 30 & 42.31 \\
\hline Cants & 29.21 & 24.73 & 0.181 & 2.470 & 0.447 & 60 & 26.84 \\
\hline Total & - & - & - & 10.141 & 4.067 & & $\mathbf{5 1 0 . 9 5}$ \\
\hline
\end{tabular}


The productivity savings will be (e)/(d) in the Table 5.19 which turns out to be 0.40 or $40 \%$. The productivity cost savings per year is calculated as shown below.

Productivity Cost Savings per year $=\frac{\text { Productivity Cost Savings per shift x } 2000 \text { production hours / year }}{\text { Test Data Shift time in Minutes } / 60}$

Productivity Cost Savings per year $=\frac{510.95 \times 2000 \text { production hours } / \text { year }}{270 / 60}=\$ 227,087.57$

\section{Conclusion:}

Ten Variables were selected from Product, Process, and System Parameters. Stepwise regression was used to select the variables. Three multiple linear regression models were developed to estimate energy consumption per thousand board feet. Model 1 had 6 estimator variables, Model 2 had 7 estimator variables with 'hp x min' variable and Model 3 had 7 estimator variables. The most important variables was 'Motor hp' and Minutes in Model 1, 'Motor hp x Min' in Model 2 and 'Level of Maintenance' in Model 3. Model 2 had the highest $\mathrm{R}^{2}$ value and estimated sawmill $3 \mathrm{SEC}$ better than the other two models. Although sawmill 5 had data from day and night shifts with significant difference in the SEC's between them, Model 2 predicted all the SEC values of sawmill 5 within acceptable error level except for one shift. Even though Model 3 didn't had 'Motor hp' variable, it estimated sawmill 3 better than Model 1. One multiple linear regression model was developed to estimate total energy consumption of each shift. It estimated all the data points with shift run times of greater than 3.25 hours in sawmill 1 , 2, 4 and 5 accurately, but it didn't accurately estimate sawmill 3. Overall, Model 2 was better than all the models. SMEEP was developed to help the end user to input sawmill data and estimate energy consumption of sawing and calculate SEC of different lumber sizes and compare it with the best achievable SEC to find out the efficiency of the sawmill. SMEEP also provided methods to improve sawmill efficiency with estimated savings. 


\section{Sensitivity Analysis and Comparison of Sawmill Motors}

\subsection{Sensitivity Analysis of Estimator Variables}

Sensitivity analysis was done to find out the effect of different variables on energy consumption. The following variables were used for sensitivity analysis.

1. Density

2. Minutes

3. Horsepower

4. $4 / 4$ to $8 / 4+$ Pallet

5. Cant + Timber

6. Level of Maintenance

7. Width of the Lumber Sawn

Model 1 was used to do the sensitivity analysis for the $1^{\text {st }}$ five variables and Model 2 was used for the $6^{\text {th }}$ variable since it was not present in Model 1 . The $1^{\text {st }}$ five variables were tested for their sensitivity to energy consumption by varying their values to $\pm 10 \%$ and $\pm 20 \%$. The $6^{\text {th }}$ variable was tested for its sensitivity to energy consumption by changing its value by \pm 1 . Estimator variables 'Resaw' and 'Double Line' were not considered for sensitivity analysis since they are binary variables. Width of the lumber sawn in sawmills was considered for sensitivity analysis since the width sawn affected the energy consumption of main saw, resaw and gangsaw.

Table 6.1 shows the sawmill data used for conducting sensitivity analysis. One shift data of 'Red Oak' Species was used from all the 5 sawmills for doing sensitivity analysis.

Table 6.1: Data used for Sensitivity Analysis in Model 1

\begin{tabular}{|c|c|c|c|c|c|c|c|c|c|}
\hline Mill \# & $\begin{array}{c}\text { Motor } \\
\text { hp }\end{array}$ & Minutes & Density & $\begin{array}{c}\text { 4/4 to 8/4 } \\
\text { + Pallet }\end{array}$ & $\begin{array}{c}\text { Cant + } \\
\text { Timber }\end{array}$ & Resaw & SEC & $\begin{array}{c}\text { Estimated } \\
\text { SEC }\end{array}$ & Error \\
\hline 1 & 968 & 630 & 44 & 29,629 & 1,240 & 1 & 86.94 & 90.35 & -3.41 \\
\hline 2 & 817 & 450 & 44 & 10,119 & 6,966 & 0 & 80.51 & 88.40 & -7.89 \\
\hline 3 & $2,630.5$ & 480 & 44 & 75,778 & 5,791 & 1 & 107.44 & 124.31 & -16.87 \\
\hline 4 & 1,534 & 600 & 44 & 27,184 & 6,783 & 0 & 144.54 & 139.68 & 8.95 \\
\hline 5 & 1,686 & 523 & 44 & 38,448 & 1,834 & 1 & 115.25 & 121.84 & -6.59 \\
\hline
\end{tabular}




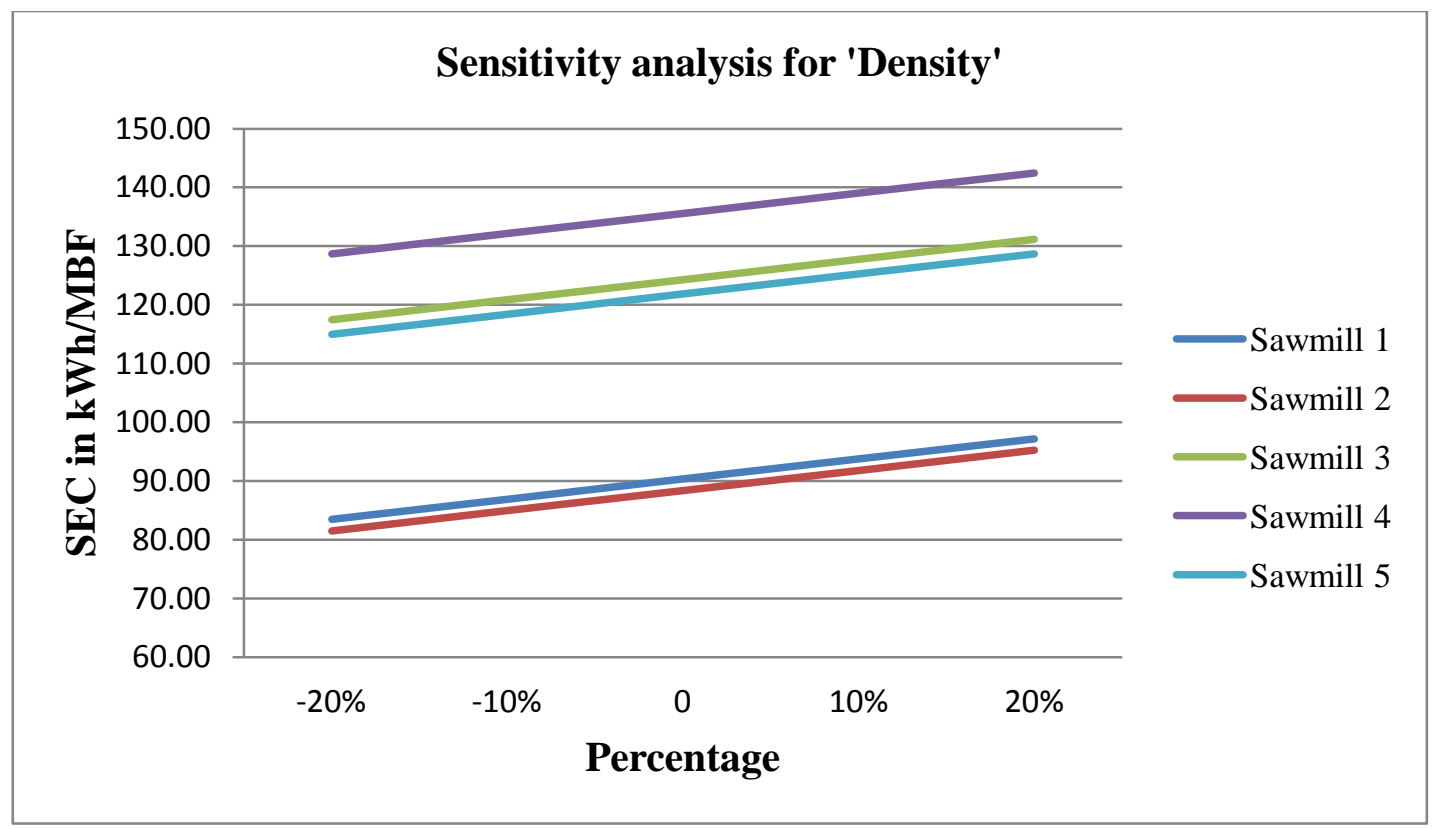

Figure 6.1: Sensitivity Analysis Results for Variable 'Density'

Figure 6.1 shows the sensitivity analysis results of variable 'density'. Since the density chosen for sensitivity analysis was same for all the 5 sawmills, the effect of changing it also remained same for all the five sawmills. As the value of density is increased, the energy consumption also increased.

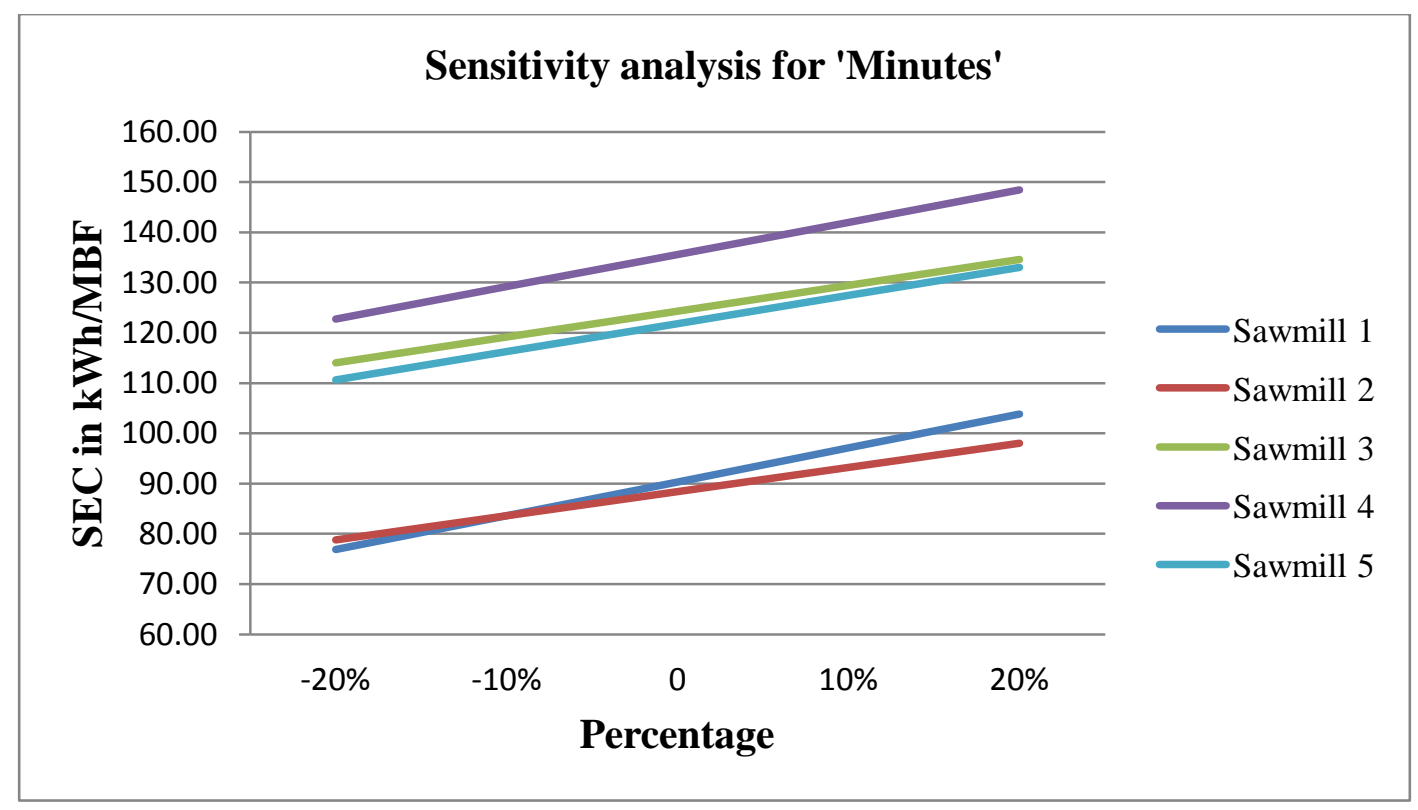

Figure 6.2: Sensitivity Analysis Results for Variable 'Minutes' 
Figure 6.2 shows the sensitivity analysis results of variable 'minutes'. The minutes chosen for sensitivity analysis was different for each sawmill, and hence the effect of changing it has resulted in some difference between the sawmills. As the value of minutes is increased, the energy consumption also increased. Change in minutes has shown more effect on the energy consumption of sawmill 1 and 4 since the shift data selected for them had more minutes than the other sawmills.

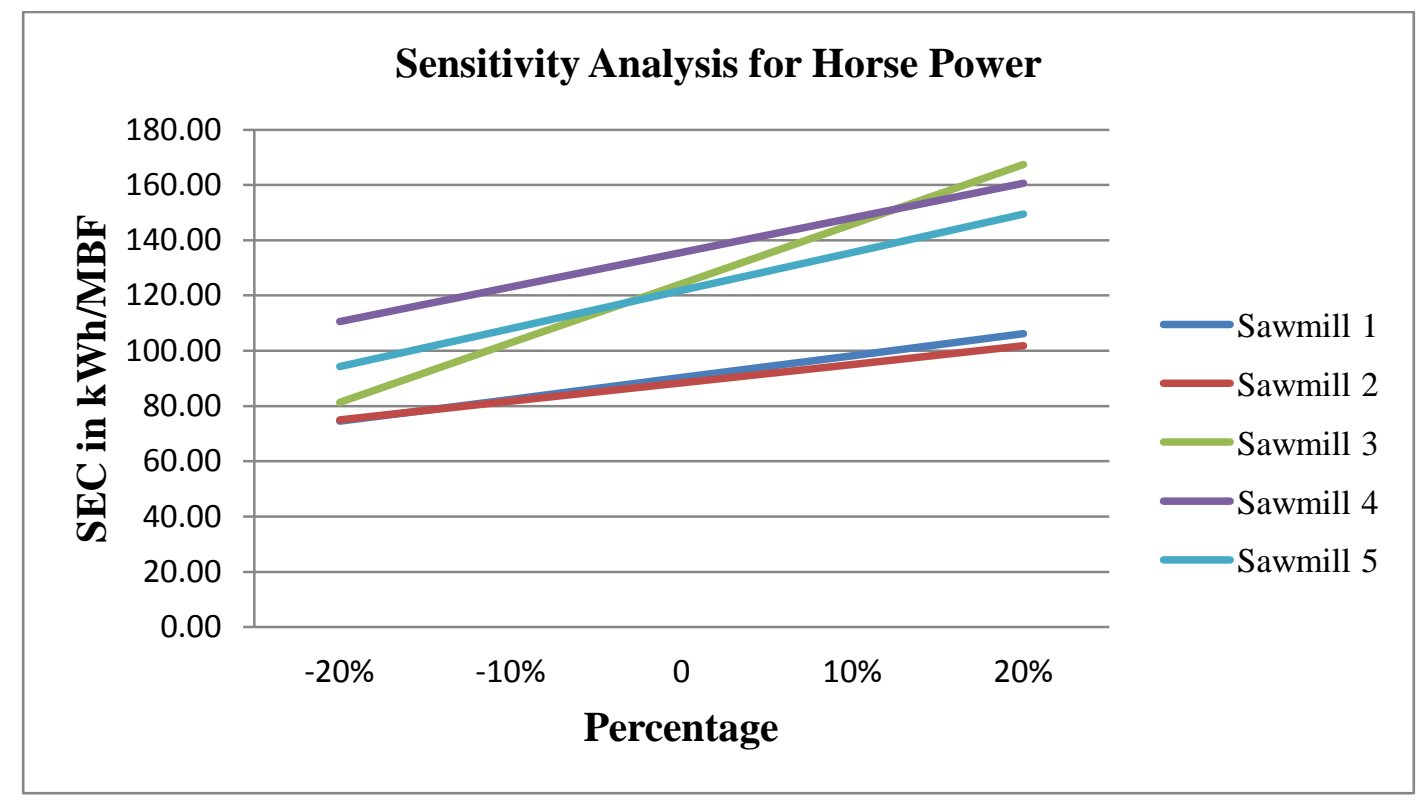

Figure 6.3: Sensitivity Analysis Results for Variable 'Horse Power'

Figure 6.3 shows the sensitivity analysis results of variable 'horsepower'. The horsepower was different for each sawmill, and hence the effect of changing it has resulted in significant difference among sawmills. As the value of horsepower is increased, the energy consumption also increased. Change in horsepower has shown more effect on the energy consumption of sawmill 3 and then sawmill 4 and 5 since the horsepower of sawmill 3 is the highest and then the horsepower of sawmill 5 and 4 comes in $2^{\text {nd }}$ and $3^{\text {rd }}$ highest position among sawmills. 


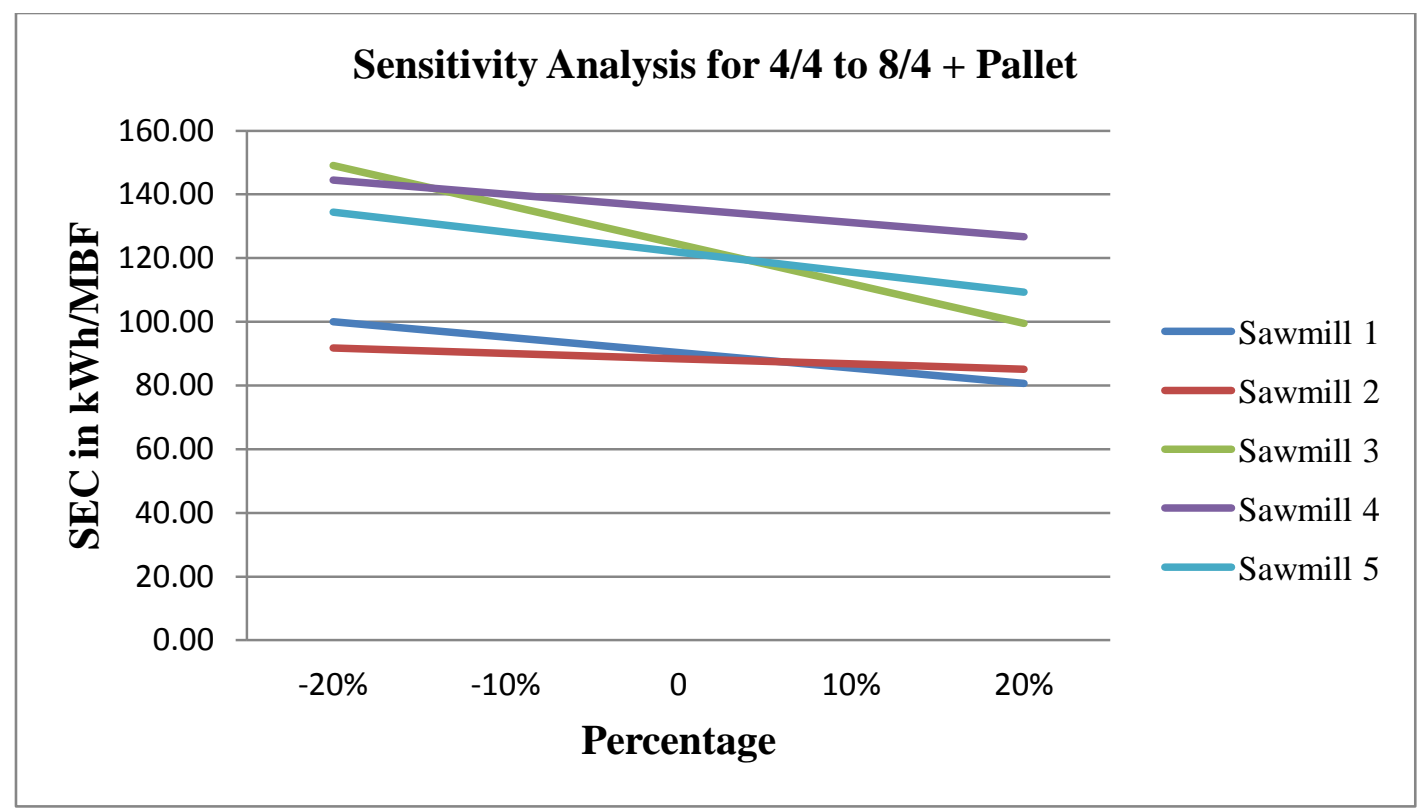

Figure 6.4: Sensitivity Analysis Results for Variable '4/4 to 8/4 + Pallet'

Figure 6.4 shows the sensitivity analysis results of variable ' $4 / 4$ to $8 / 4+$ Pallet'. The quantity of ' $4 / 4$ to $8 / 4$ + Pallet' produced in the shift selected from each sawmill was different except for sawmill 1 and 4 . The effect of changing it has resulted in significant difference among sawmills. As the value of ' $4 / 4$ to $8 / 4$ + Pallet' is increased, the energy consumption decreased which suggests that within the same shift if more production of ' $4 / 4$ to $8 / 4+$ Pallet' is done, it will result in lower energy consumption. Change in '4/4 to 8/4 + Pallet' has shown more effect on the energy consumption of sawmill 3 and then sawmill 5 and then sawmill 1 and 4 and least effect on sawmill 2 since the quantity of ' $4 / 4$ to 8/4 + Pallet' produced follows that order. 


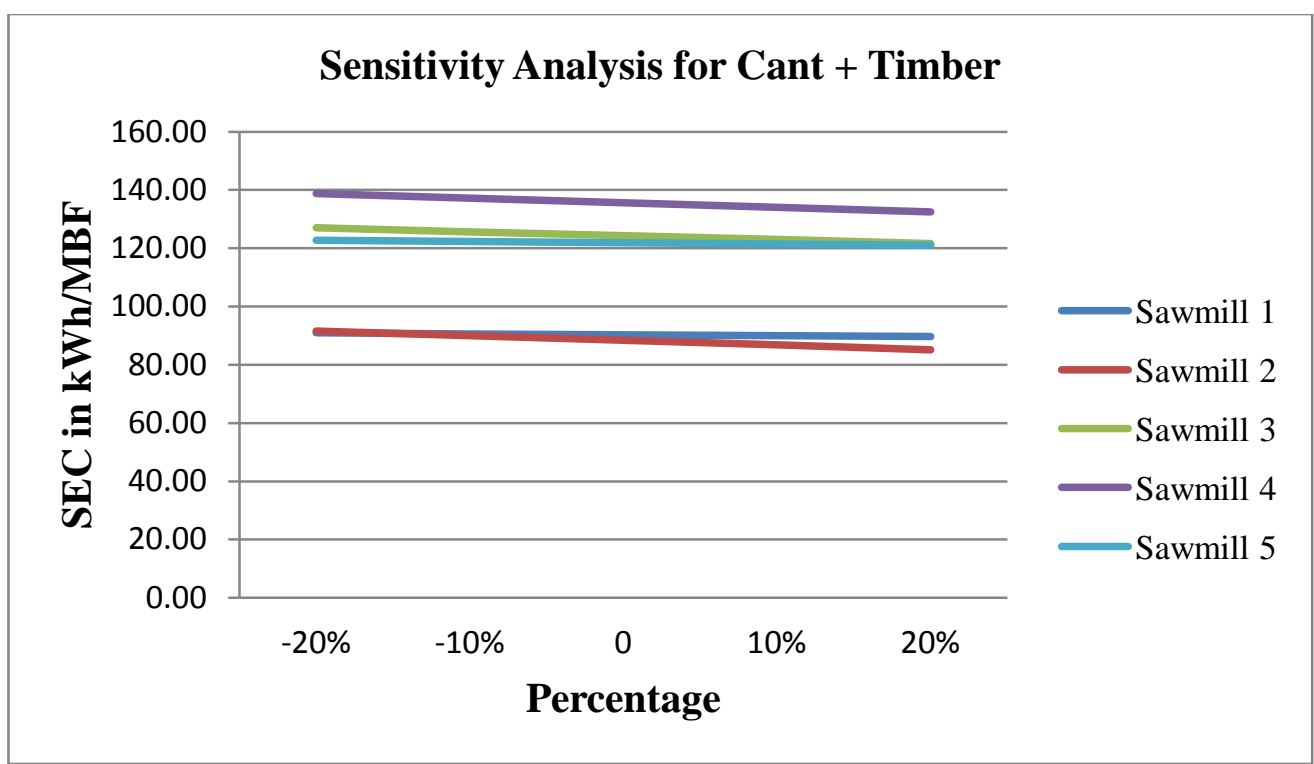

Figure 6.5: Sensitivity Analysis Results for Variable 'Cant + Timber'

Figure 6.5 shows the sensitivity analysis results of variable 'Cant + Timber'. The quantity of 'Cant + Timber' produced in the shift selected from each sawmill was different except for sawmill 2 and 4. The effect of changing it has resulted in some difference among sawmills. As the value of 'Cant + Timber' is increased, the energy consumption decreased which suggests that within the same shift if more production of 'Cant + Timber' is done, it will result in lower energy consumption. Change in 'Cant + Timber' has shown more effect on the energy consumption of sawmill 2 and 4 than sawmill 1, 3 and 5 since sawmill 2 and 4 were producing more percentage of 'Cant + Timber'. Another thing to notice is that effect of changing 'Cant + Timber' variable on energy consumption is way lower than the effect of changing ' $4 / 4$ to $8 / 4+$ Pallet' variable since for sawing ' $4 / 4$ to $8 / 4$ + Pallet' lumber more energy is required than 'Cant + Timber'.

Table 6.2: Data used for Sensitivity Analysis in Model 2

\begin{tabular}{|c|c|c|c|c|c|c|c|c|c|c|}
\hline $\begin{array}{c}\text { Mill } \\
\#\end{array}$ & $\begin{array}{c}\text { Hp x } \\
\text { Min }\end{array}$ & Density & $\begin{array}{c}\text { 4/4 to 8/4 } \\
\text { + Pallet }\end{array}$ & $\begin{array}{c}\text { Cant + } \\
\text { Timber }\end{array}$ & Resaw & $\begin{array}{c}\text { Double } \\
\text { Line }\end{array}$ & Maint & SEC & $\begin{array}{c}\text { Estimated } \\
\text { SEC }\end{array}$ & Error \\
\hline 1 & 609,840 & 44 & 29,629 & 1,240 & 1 & 0 & 4 & 86.94 & 85.42 & 1.52 \\
\hline 2 & 367,650 & 44 & 10,119 & 6,966 & 0 & 0 & 3 & 80.51 & 83.52 & -3.01 \\
\hline 3 & $1,262,640$ & 44 & 75,778 & 5,791 & 1 & 1 & 2 & 107.44 & 94.39 & 13.05 \\
\hline 4 & 920,400 & 44 & 27,184 & 6,783 & 0 & 1 & 2 & 144.54 & 143.59 & 0.95 \\
\hline 5 & 881,778 & 44 & 38,448 & 1,834 & 1 & 0 & 2 & 115.25 & 120.33 & -5.08 \\
\hline
\end{tabular}


Same data that was used in Model 1 was used for conducting sensitivity analysis using Model 2 (Table 6.2). The only variable that was tested for sensitivity using Model 2 was 'Level of Maintenance'.

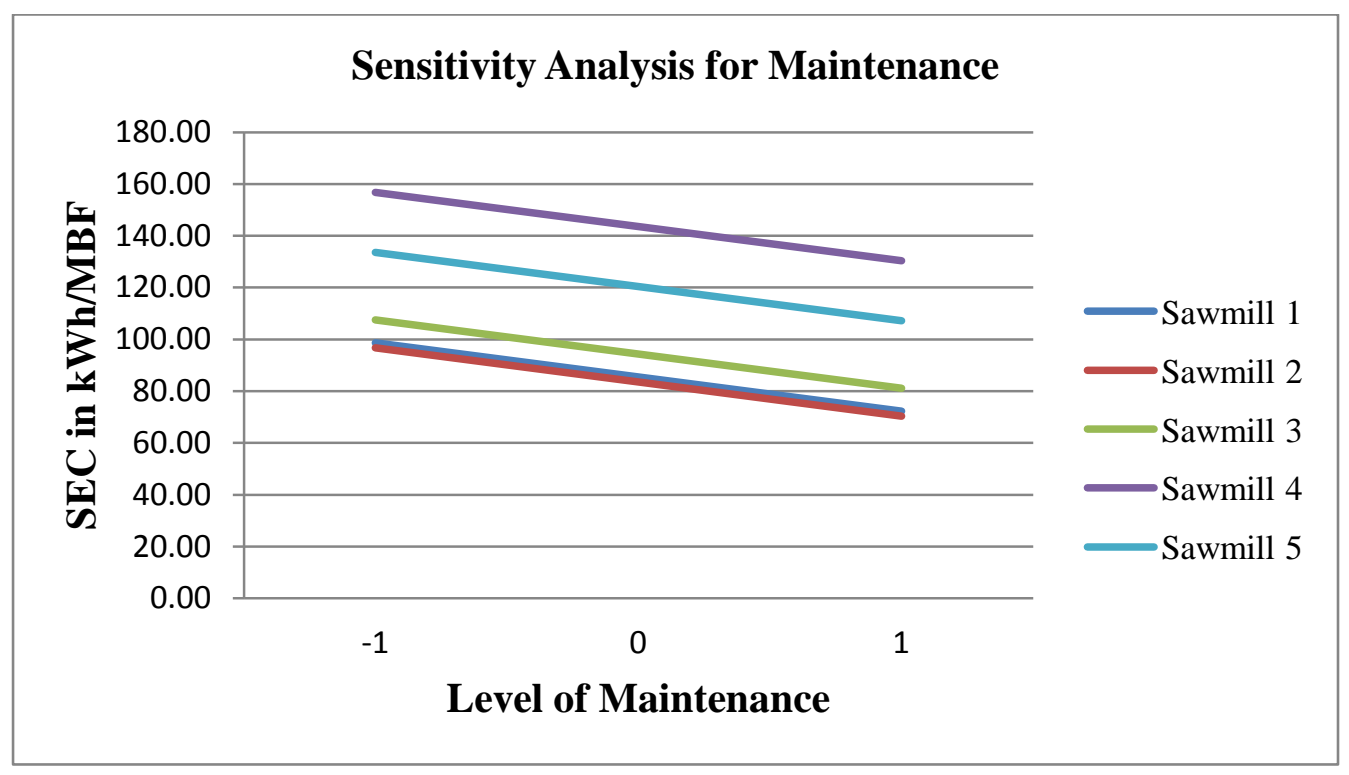

Figure 6.6: Sensitivity Analysis Results for Variable 'Level of Maintenance'

Figure 6.6 shows the sensitivity analysis results of variable 'level of maintenance'. The effect of changing maintenance level has remained same for all the five sawmills. As the level of maintenance went up, the energy consumption decreased. Maintenance level has been decreased and increased only by one level since the frequency of re-sharpening in sawmill 1 is already 3.5 hours and practically it cannot be decreased beyond 2.5 hours and also the SEC values achieved by sawmill 1 and sawmill 2 when the maintenance level is increased by 2 levels is not practically achievable. Increase in two levels of maintenance will result in decrease of SEC by 26.4 $\mathrm{kWh} / \mathrm{MBF}$. 


\subsection{Sensitivity Analysis of different Lumber Widths produced on SEC}

As seen, the main sawing operation in sawmills is performed by main saw, re-saw, and gang saw. The energy consumption of these motors were allocated to different size lumber based on surface area cut as length by average width (6") of lumber. Actually the width of the lumber sawn varies considerably. During the visits to the sawmill 5, it was found that the electricity consumption of these motors did not increase proportionately with the width of the lumber sawn. Data of red oak species was collected in Sawmill 5 to find the variation in electricity consumption of re-saw for different widths of $4 / 4$ size lumber of 10 feet length sawn. As shown in Table 6.3, the electricity consumption is not increasing at the same proportion of the widths.

Table 6.3: Resaw electricity consumption for different widths of Red Oak (Maddula 2014)

\begin{tabular}{|c|c|c|c|c|c|}
\hline $\begin{array}{c}\text { Width } \\
\text { (Inches) }\end{array}$ & $\begin{array}{c}\text { Electricity } \\
\text { Consumption } \\
(\text { Amps) ' } \mathrm{X} \text { ' }\end{array}$ & $\begin{array}{l}\text { Energy } \\
\text { Factor } \\
(\mathrm{X} / 105)\end{array}$ & $\begin{array}{c}\text { Board Feet } \\
\text { (Y) }\end{array}$ & $\begin{array}{c}\text { Productivity } \\
\text { Factor } \\
(5 / Y)\end{array}$ & $\begin{array}{c}\text { Combined } \\
\text { Factor } \\
(\mathrm{X} / \mathbf{1 0 5}) *(\mathbf{5} / \mathrm{Y})\end{array}$ \\
\hline 4 & 89 & 0.85 & 3.33 & 1.5 & 1.27 \\
\hline 5 & 95 & 0.90 & 4.17 & 1.2 & 1.09 \\
\hline 6 & 105 & 1.00 & 5.00 & 1 & 1.00 \\
\hline 8 & 117 & 1.11 & 6.67 & 0.75 & 0.84 \\
\hline 10 & 121 & 1.15 & 8.33 & 0.6 & 0.69 \\
\hline 12 & 130 & 1.24 & 10.00 & 0.5 & 0.62 \\
\hline
\end{tabular}

Main saw, Resaw and gang saw motors must operate more time when sawing 4 inch width boards to produce one MBF of lumber compared to 12 inch width boards because of less volume in them. As explained before, motors energy was allocated based on an average width of 6 inches for grade lumber. The electricity consumption and board feet calculated for 6 inch width lumber is considered as standard electricity consumption and standard board feet for calculating energy and productivity factors. Energy factors for other widths were calculated by dividing the electricity consumption for that width by the standard electricity consumption i.e. 105 amps. Productivity factors were obtained by dividing board feet of that particular size by the standard board feet i.e. 5 board feet. Combined factor was calculated by multiplying energy and 
productivity factors. Then the energy consumption of main saw, resaw and gang saw motors for other widths $(4,8,10,12)$ were calculated by multiplying the total energy consumption of these motors by the calculated combined factors. The calculated energy consumption of different widths was used to allocate energy to lumber produced during each shift as explained before. Figure 6.7 shows the combined factor obtained for different widths of lumber sawn. From the figure it can be seen that, for sawing unit board feet of 4 inch width lumber, twice the energy required for sawing unit board feet of 12 inch width lumber is needed on resaw.

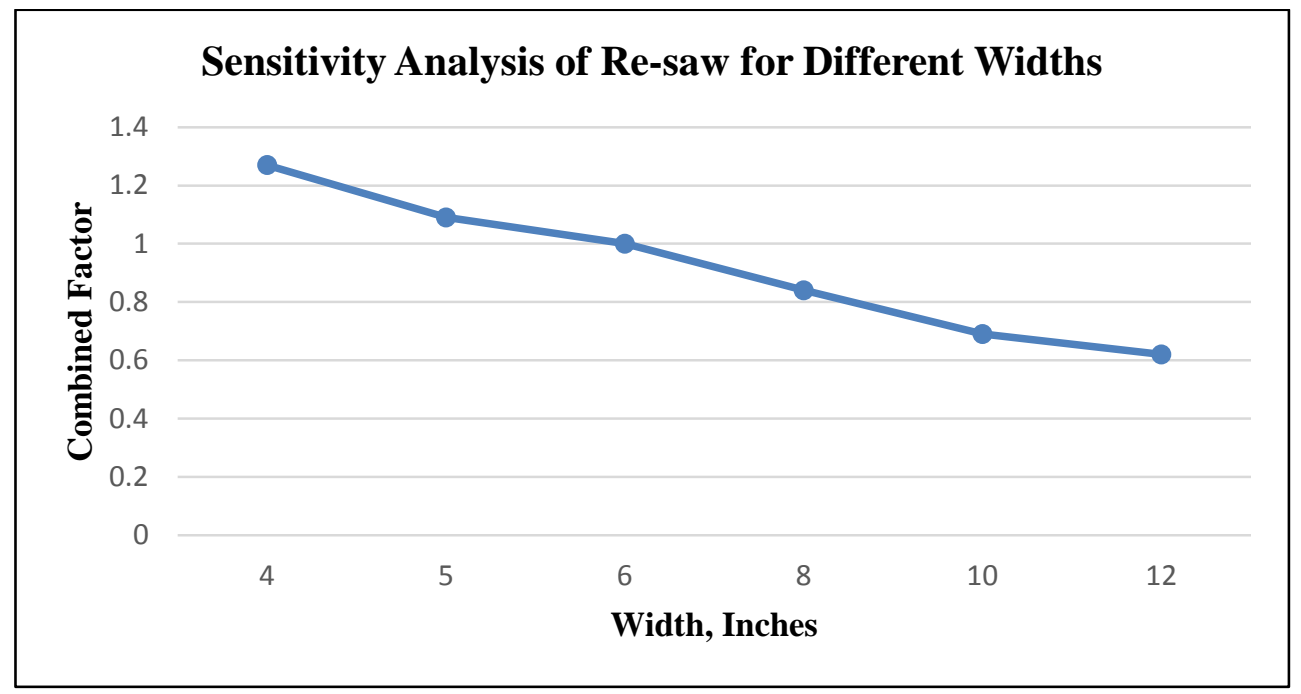

Figure 6.7: Sensitivity Analysis of different widths of Red Oak sawn for Resaw Energy Consumption (Maddula 2014)

Table 6.4 shows the SEC of $4 / 4$ lumber size for widths of 4" to 12 " for different species sawn in sawmill 1.

Table 6.4: SEC of 4/4 size Lumber for different Widths and Species sawn in Sawmill 1

\begin{tabular}{|c|c|c|c|c|c|}
\hline Species & 4" Width & 6" Width & 8" Width & 10" Width & 12" Width \\
\hline Hickory & 124.55 & 118.31 & 114.61 & 107.43 & 106.19 \\
\hline Hard Maple & 98.24 & 91.53 & 87.54 & 79.95 & 78.60 \\
\hline Cherry & 129.32 & 120.29 & 114.97 & 105.62 & 103.76 \\
\hline Red Oak & 97.52 & 91.12 & 87.31 & 80.10 & 78.80 \\
\hline Soft Maple & 84.75 & 79.00 & 75.60 & 69.46 & 68.28 \\
\hline White Oak & 100.85 & 94.01 & 89.95 & 82.52 & 81.10 \\
\hline ASH & 89.69 & 83.36 & 79.62 & 72.54 & 71.27 \\
\hline
\end{tabular}


Since the thickness of 4/4 lumber and pallet were same, SEC of 4/4 lumber can be considered as the SEC of pallet size also. SEC of Hickory and Cherry species are higher than other species since their densities are higher compared to other species and also more time is spent in sawing them so that less wastage is produced since they are expensive species. Table 6.5 shows the SEC of 5/4, 6/4 and 8/4 lumber sizes for widths of 4" to 12 " for different species sawn in sawmill 1.

Table 6.5: SEC for different Widths and Species sawn in Sawmill 1

\begin{tabular}{|c|c|c|c|c|c|c|}
\hline Species & Thickness & 4" Width & 6" Width & 8" Width & 10" Width & 12" Width \\
\hline Hard Maple & $5 / 4$ & 83.41 & 76.94 & 73.19 & 66.59 & 65.32 \\
\hline Red Oak & $5 / 4$ & 84.00 & 77.72 & 74.08 & 67.70 & 66.46 \\
\hline White Oak & $5 / 4$ & 83.55 & 77.59 & 74.13 & 68.25 & 67.06 \\
\hline White Oak & $6 / 4$ & 80.55 & 73.87 & 70.06 & 64.00 & 62.68 \\
\hline Red Oak & $8 / 4$ & 57.07 & 51.77 & 48.79 & 44.17 & 43.17 \\
\hline
\end{tabular}

Table 6.6 shows the SEC of cants and timbers for different species sawn in sawmill 1. The point to be noted is the SEC of these will remain the same since their width is fixed.

Table 6.6: SEC for Cants and Timbers sawn in Sawmill 1

\begin{tabular}{|c|c|c|}
\hline Species & $\begin{array}{c}\text { Cants } \\
\text { (3'x8"x12') }\end{array}$ & $\begin{array}{c}\text { Timbers } \\
\left(\mathbf{7}^{\prime \prime} \mathbf{x} \mathbf{\prime}^{\prime \mathbf{x 1 0}} \mathbf{)}\right.\end{array}$ \\
\hline Hickory & 31.39 & - \\
\hline Hard Maple & 23.85 & 10.09 \\
\hline Cherry & 32.36 & 14.11 \\
\hline Red Oak & 24.26 & 9.89 \\
\hline Soft Maple & 20.61 & 8.46 \\
\hline White Oak & 23.82 & 10.73 \\
\hline ASH & 22.02 & 9.44 \\
\hline
\end{tabular}

Table 6.7 shows the SEC of $4 / 4$ lumber size for widths of 4 " to 12 " for different species sawn in sawmill 2. 
Table 6.7: SEC of 4/4 Lumber for different Widths and Species sawn in Sawmill 2

\begin{tabular}{|c|c|c|c|c|c|}
\hline Species & 4" Width & 6" Width & 8" Width $^{\prime \prime}$ & 10" Width & 12" Width \\
\hline Hickory & 188.42 & 169.53 & 158.53 & 149.28 & 145.08 \\
\hline Hard Maple & 143.77 & 129.93 & 121.83 & 114.65 & 111.35 \\
\hline Poplar & 137.73 & 124.43 & 116.61 & 109.75 & 106.58 \\
\hline Red Oak & 157.96 & 142.25 & 133.09 & 125.17 & 121.57 \\
\hline Soft Maple* & 179.65 & 162.78 & 153.01 & 144.26 & 140.41 \\
\hline White Oak & 150.59 & 135.90 & 127.33 & 119.86 & 116.45 \\
\hline
\end{tabular}

*Produced in lesser volume and hence has high SEC

Table 6.8 shows the SEC of $5 / 4,6 / 4$ and $8 / 4$ lumber sizes for widths of 4 " to 12 " for different species sawn in sawmill 2.

Table 6.8: SEC for different Widths and Species sawn in Sawmill 2

\begin{tabular}{|c|c|c|c|c|c|c|}
\hline Species & Thickness & $\mathbf{4}^{\prime \prime}$ Width & 6" Width $^{\prime \prime}$ & 8" Width $^{\prime \prime}$ & 10" Width $^{\text {12" Width }}$ \\
\hline Soft Maple & $5 / 4$ & 151.57 & 137.35 & 129.02 & 121.61 & 118.23 \\
\hline White Oak & $5 / 4$ & 177.16 & 159.58 & 149.29 & 140.57 & 136.55 \\
\hline Poplar & $6 / 4$ & 102.11 & 93.15 & 87.70 & 82.63 & 80.09 \\
\hline White Oak & $6 / 4$ & 104.56 & 95.13 & 89.45 & 84.33 & 81.80 \\
\hline Poplar & $8 / 4$ & 80.51 & 72.95 & 68.31 & 64.23 & 62.10 \\
\hline Red Oak & $8 / 4$ & 91.58 & 82.84 & 77.51 & 72.82 & 70.41 \\
\hline Soft Maple & $8 / 4$ & 105.51 & 95.71 & 89.78 & 84.49 & 81.84 \\
\hline
\end{tabular}

Table 6.9 shows the SEC of cants and timbers for different species sawn in sawmill 2.

Table 6.9: SEC for different Cants and Timbers sawn in Sawmill 2

\begin{tabular}{|c|c|c|c|c|}
\hline Species & $\begin{array}{c}\text { Cants } \\
\left(5^{\prime \prime} \times 6 \text { 'x12') }\right.\end{array}$ & $\begin{array}{c}\text { Cants } \\
\left(3^{\prime \prime} \times 4^{\prime \prime} \times 12 '\right)\end{array}$ & $\begin{array}{c}\text { Cants } \\
\left(3.5^{\prime \prime} \times 6^{\prime \prime} \times 12 \text { ') }\right.\end{array}$ & $\begin{array}{c}\text { Timber } \\
\left(7^{\prime \prime x 9 " x 10 ')}\right.\end{array}$ \\
\hline Hickory & 27.89 & - & - & 20.35 \\
\hline Hard Maple & - & - & 30.77 & 16.87 \\
\hline Poplar & 20.64 & 36.25 & - & 14.80 \\
\hline Red Oak & 22.85 & - & 47.68 & 19.99 \\
\hline Soft Maple & 27.63 & - & - & 20.54 \\
\hline White Oak & 25.59 & - & - & 18.59 \\
\hline
\end{tabular}

Table 6.10 shows the SEC of 4/4 lumber size for widths of 4 " to 12 " for different species sawn in sawmill 3. 
Table 6.10: SEC of 4/4 Lumber for different Widths and Species sawn in Sawmill 3

\begin{tabular}{|c|c|c|c|c|c|}
\hline Species & 4" Width & 6" Width & 8" Width $^{\prime \prime}$ & 10" Width & 12" Width \\
\hline Hard Maple & 129.62 & 119.26 & 113.12 & 107.36 & 104.68 \\
\hline Poplar & 94.98 & 87.29 & 82.72 & 78.43 & 76.43 \\
\hline Red Oak & 128.84 & 118.37 & 112.17 & 106.37 & 103.66 \\
\hline Soft Maple & 133.19 & 122.74 & 116.56 & 110.78 & 108.07 \\
\hline White Oak & 135.61 & 124.92 & 118.58 & 112.66 & 109.89 \\
\hline Birch* & 193.38 & 179.73 & 171.65 & 164.16 & 160.62 \\
\hline Black Cherry & 114.09 & 105.06 & 99.71 & 94.70 & 92.36 \\
\hline Hickory* & 182.73 & 168.35 & 159.84 & 151.94 & 148.22 \\
\hline
\end{tabular}

*Produced in lesser volume in only half shift and hence have high SEC

Table 6.11 shows the SEC of $6 / 4$ and $8 / 4$ lumber sizes for widths of 4 " to 12 " for poplar species sawn in sawmill 3.

Table 6.11: SEC for different Widths of Poplar Species sawn in Sawmill 3

\begin{tabular}{|c|c|c|c|c|c|c|}
\hline Species & Thickness & 4" Width & 6" Width & 8" Width & 10" Width & 12" Width \\
\hline Poplar & $6 / 4$ & 73.31 & 66.70 & 62.89 & 59.53 & 57.89 \\
\hline Poplar & $8 / 4$ & 58.95 & 53.72 & 50.66 & 48.01 & 46.66 \\
\hline
\end{tabular}

Table 6.12 shows the SEC of timbers for different species sawn in sawmill 3.

Table 6.12: SEC for Timbers sawn in Sawmill 3

\begin{tabular}{|c|c|}
\hline Species & $\begin{array}{c}\text { Timber } \\
\left(\mathbf{7}^{\prime \prime} \mathbf{x} \mathbf{9}^{\mathbf{x} 10} \mathbf{)}\right)\end{array}$ \\
\hline Hard Maple & 10.21 \\
\hline Red Oak & 13.84 \\
\hline Soft Maple & 14.17 \\
\hline White Oak & 14.26 \\
\hline Birch* & 20.18 \\
\hline Hickory* & 19.15 \\
\hline
\end{tabular}

*Produced in lesser volume in only half shift and hence have high SEC

Table 6.13 shows the SEC of 4/4 lumber size for widths of 4" to 12 " for different species sawn in sawmill 4. 
Table 6.13: SEC of 4/4 Lumber for different Widths and Species sawn in Sawmill 4

\begin{tabular}{|c|c|c|c|c|c|}
\hline Species & 4" Width & 6" Width & 8" Width & 10" Width & 12" Width \\
\hline Hard Maple & 194.09 & 175.28 & 164.11 & 153.57 & 148.65 \\
\hline Poplar & 161.71 & 146.21 & 137.00 & 128.24 & 124.21 \\
\hline Red Oak & 193.31 & 174.38 & 163.14 & 152.67 & 147.68 \\
\hline Ash & 237.94 & 215.66 & 202.39 & 189.64 & 183.81 \\
\hline Hickory & 214.85 & 193.23 & 180.37 & 168.39 & 162.67 \\
\hline
\end{tabular}

Table 6.14 shows the SEC of $6 / 4$ and $8 / 4$ lumber sizes for widths of 4 " to 12 " for different species sawn in sawmill 4.

Table 6.14: SEC for different Widths and Species sawn in Sawmill 4

\begin{tabular}{|c|c|c|c|c|c|c|}
\hline Species & Thickness & 4" Width & 6" Width & 8" Width & 10" Width & 12" Width \\
\hline Poplar & $6 / 4$ & 123.77 & 111.20 & 103.86 & 97.24 & 94.06 \\
\hline Ash & $6 / 4$ & 194.71 & 175.90 & 164.79 & 154.59 & 149.70 \\
\hline Hard Maple & $8 / 4$ & 114.92 & 103.13 & 96.20 & 90.07 & 87.00 \\
\hline Poplar & $8 / 4$ & 93.65 & 84.06 & 78.41 & 73.37 & 70.88 \\
\hline Soft Maple & $8 / 4$ & 150.84 & 136.19 & 127.53 & 119.57 & 115.76 \\
\hline Ash & $8 / 4$ & 136.69 & 122.95 & 114.82 & 107.50 & 103.89 \\
\hline Sycamore & $8 / 4$ & 218.11 & 197.25 & 184.94 & 173.97 & 168.52 \\
\hline
\end{tabular}

Table 6.15 shows the SEC of cants and timbers for different species sawn in sawmill 4.

Table 6.15: SEC for Cants and Timbers sawn in Sawmill 4

\begin{tabular}{|c|c|c|}
\hline Species & $\begin{array}{c}\text { Cants } \\
\text { (14'x4"x12') }\end{array}$ & $\begin{array}{c}\text { Timber } \\
\text { (7"x9"x10') }\end{array}$ \\
\hline Hard Maple & 34.72 & \\
\hline Poplar & 29.46 & \\
\hline Red Oak & 34.40 & 18.20 \\
\hline Soft Maple & 47.97 & 28.43 \\
\hline Ash & 42.99 & \\
\hline Sycamore & 65.62 & 43.54 \\
\hline Hickory & 38.02 & \\
\hline
\end{tabular}

Table 6.16 shows the SEC of 4/4 lumber size for widths of 4" to 12 " for different species sawn in sawmill 5. Point to be noted is some species have higher SEC's than less denser species since they were produced in $2^{\text {nd }}$ shift which had higher overall SEC. 
Table 6.16: SEC of 4/4 Lumber for different Widths and Species sawn in Sawmill 5

\begin{tabular}{|c|c|c|c|c|c|}
\hline Species & 4" Width & 6" Width & 8" Width & 10" Width & 12" Width \\
\hline Hard Maple & 160.93 & 144.68 & 135.06 & 126.05 & 121.84 \\
\hline Poplar & 100.64 & 90.00 & 83.69 & 77.76 & 75.00 \\
\hline Red Oak & 137.81 & 123.27 & 114.65 & 106.56 & 102.78 \\
\hline Soft Maple & 143.86 & 128.95 & 120.12 & 111.89 & 108.03 \\
\hline Ash & 120.25 & 107.32 & 99.66 & 92.45 & 89.10 \\
\hline
\end{tabular}

Table 6.17 shows the SEC of $5 / 4$ and $8 / 4$ lumber sizes for widths of 4 " to 12 " for different species sawn in sawmill 5.

Table 6.17: SEC for different Widths and Species sawn in Sawmill 5

\begin{tabular}{|c|c|c|c|c|c|c|}
\hline Species & Thickness & 4" Width $^{\prime \prime}$ & 6" Width & 8" Width & 10" Width & 12" Width \\
\hline Red Oak & $5 / 4$ & 110.24 & 98.57 & 91.68 & 85.29 & 82.27 \\
\hline White Oak & $5 / 4$ & 163.75 & 146.85 & 136.83 & 127.47 & 123.09 \\
\hline Poplar & $8 / 4$ & 58.92 & 52.69 & 49.03 & 45.77 & 44.16 \\
\hline Ash & $8 / 4$ & 71.77 & 64.06 & 59.54 & 55.49 & 53.51 \\
\hline
\end{tabular}

Table 6.18 shows the SEC of cants and timbers for different species sawn in sawmill 5.

Table 6.18: SEC for Cants and Timbers sawn in Sawmill 5

\begin{tabular}{|c|c|c|}
\hline Species & $\begin{array}{c}\text { Cants } \\
\left(3.5^{\prime \prime} \times 6^{\prime \prime} \times 12^{\prime}\right)\end{array}$ & $\begin{array}{c}\text { Timber } \\
\left(7^{\prime \prime} 9^{\prime \prime} \times 10 '\right)\end{array}$ \\
\hline Hard Maple & 42.75 & - \\
\hline Poplar & 20.56 & - \\
\hline Red Oak & - & 13.78 \\
\hline Soft Maple & 29.06 & - \\
\hline White Oak & 42.83 & 21.18 \\
\hline
\end{tabular}

SEC of 4/4 size red oak lumber for widths of 4" to 12" is plotted in Figure 6.8. In Figure 6.8, Sawmill 4 and 2 have higher SEC's than the other sawmills. Other thing to notice is that sawmills $(4,2,5)$ with higher SEC's have more difference between the SEC's of different widths than sawmills $(3,1)$ with lower SEC's. 


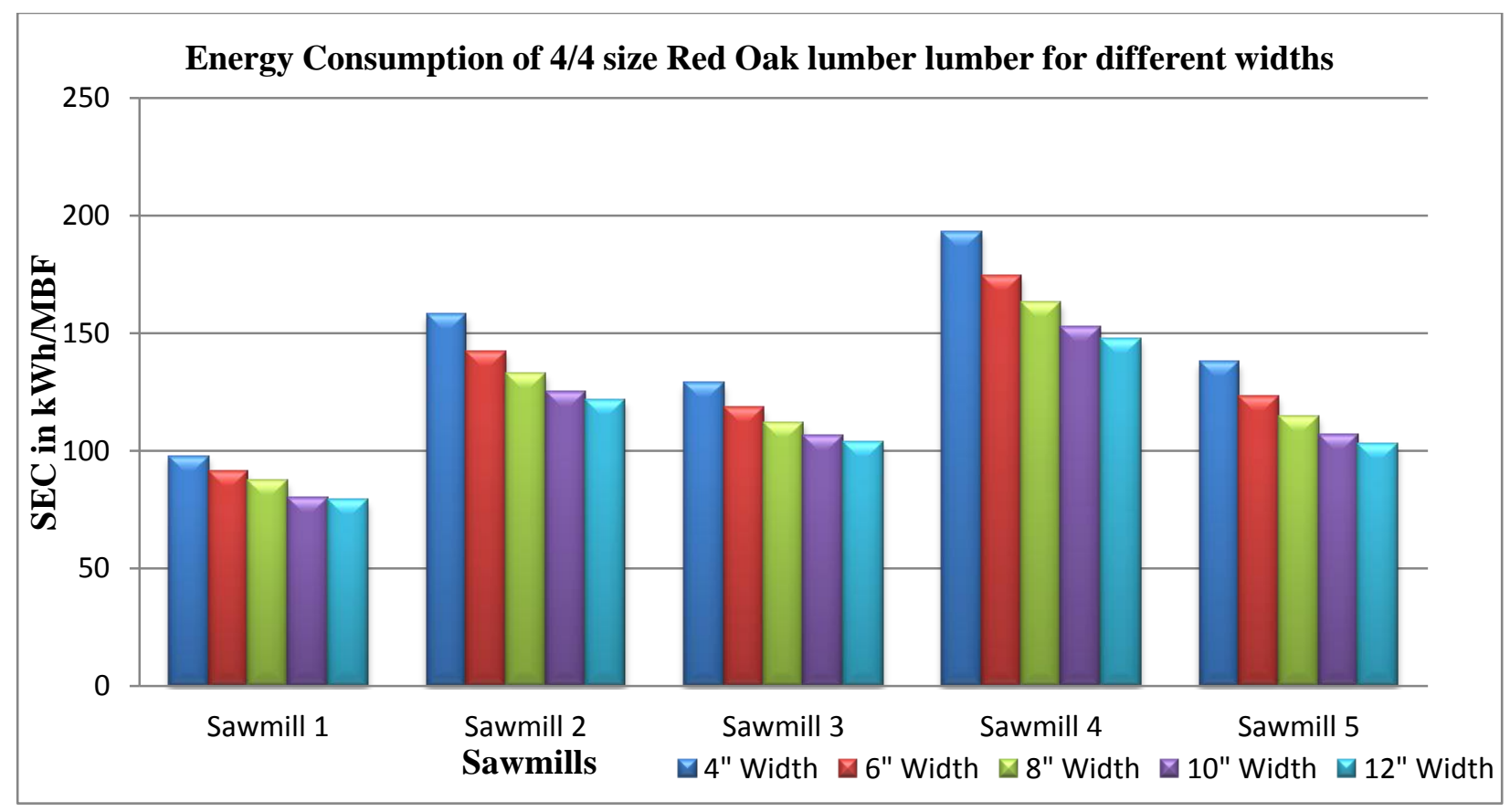

Figure 6.8: SEC's of 4/4 Size Red Oak Lumber for different widths

\subsection{Comparison of Sawmill Motors}

Sawmill motors energy consumption were compared with in the sawmill and also with other sawmills to see how much energy is consumed in different lumber manufacturing operations. Motor horsepower and Energy consumption of nine major sawmill motors of all the sawmills are shown in Table 6.19 and 6.20. Energy consumption of all the logged and unlogged motors of all the five sawmills is shown in Appendix Table A.16 to A.20.

Table 6.19: Motor Capacities in Horse Power of Major Sawmill Motors

\begin{tabular}{|c|c|c|c|c|c|c|c|c|c|c|}
\hline Sawmill & $\begin{array}{c}\text { Main } \\
\text { Saw + } \\
\text { Carriage } \\
\text { Feed }\end{array}$ & Resaw & $\begin{array}{c}\text { Gang } \\
\text { Saw }\end{array}$ & Edger & Trimmer & Debarker & Chipper & Compressor & $\begin{array}{c}\text { Other } \\
\text { Motors }\end{array}$ & $\begin{array}{c}\text { Total } \\
\text { kWh }\end{array}$ \\
\hline 1 & 300 & 60 & - & 50 & 10 & 50 & 150 & 60 & 288 & 968 \\
\hline 2 & 350 & - & - & 50 & 25 & 85 & 187 & 40 & 80 & 817 \\
\hline 3 & 645 & - & 418 & 200 & 180 & 210 & 200 & 150 & 627.5 & $2,630.5$ \\
\hline 4 & 600 & - & - & 175 & 57.5 & 80 & 200 & 100 & 321.5 & 1,534 \\
\hline 5 & 250 & 150 & 100 & 50 & 100 & 130 & 300 & 300 & 306 & 1,686 \\
\hline
\end{tabular}

Even though sawmill 3 and 4 had two lines, horse power capacities and energy consumptions were combined together from both the lines to make the comparison easier with 
other sawmills. Sawmill 3 had the highest motor capacity and energy consumption and sawmill 2 the lowest.

Table 6.20: Energy Consumption in kWh of Major Sawmill Motors

\begin{tabular}{|c|c|c|c|c|c|c|c|c|c|c|}
\hline Sawmill & $\begin{array}{c}\text { Main } \\
\text { Saw + } \\
\text { Carriage } \\
\text { Feed }\end{array}$ & Resaw & $\begin{array}{c}\text { Gang } \\
\text { Saw }\end{array}$ & Edger & Trimmer & Debarker & Chipper & Compressor & $\begin{array}{c}\text { Other } \\
\text { Motors }\end{array}$ & $\begin{array}{c}\text { Total } \\
\text { kWh }\end{array}$ \\
\hline 1 & 8,351 & 2,254 & - & 1,732 & 1,444 & 1,231 & 3,927 & 7,831 & 12,997 & 39,767 \\
\hline 2 & 12,489 & - & - & 1,338 & 1,369 & 5,927 & 5,856 & 5,319 & 2,856 & 35,154 \\
\hline 3 & 33,211 & - & 14,351 & 5,427 & 10,681 & 9,220 & 13,606 & 20,693 & 41,364 & 148,553 \\
\hline 4 & 31,903 & - & - & 5,694 & 3,538 & 3,106 & 7,358 & 11,041 & 18,264 & 80,904 \\
\hline 5 & 20,523 & 11,752 & 4,529 & 6,083 & 13,538 & 4,163 & 12,249 & 12,044 & 21,537 & 106,418 \\
\hline
\end{tabular}

Even though sawmill 4 produced less than half the quantity of lumber compared to sawmill 3 (Table 6.22) Energy consumption by main saw and carriage feed of sawmill 3 and 4 were almost same. Even though sawmill 2 produced less quantity of lumber compared to sawmill 1, energy consumption of main saw and carriage feed of sawmill 2 was higher than sawmill 1. The reason for higher energy consumption of main saw and carriage feed by sawmill 4 and 2 is that they lack a resaw or a gang saw. Percentage of energy consumed by each motor is shown in Table 6.21.

Table 6.21: Percentage Energy Consumption of Major Sawmill Motors

\begin{tabular}{|c|c|c|c|c|c|c|c|c|c|c|}
\hline Sawmill & $\begin{array}{c}\text { Main } \\
\text { Saw + } \\
\text { Carriage } \\
\text { Feed (a) }\end{array}$ & $\begin{array}{c}\text { Resaw } \\
\text { (b) }\end{array}$ & $\begin{array}{c}\text { Gang } \\
\text { Saw } \\
(\mathbf{c})\end{array}$ & a+b+c & Edger & Trimmer & Debarker & Chipper & Compressor & $\begin{array}{c}\text { Other } \\
\text { Motors }\end{array}$ \\
\hline 1 & 0.21 & 0.06 & - & 0.27 & 0.04 & 0.04 & 0.03 & 0.10 & 0.20 & 0.32 \\
\hline 2 & 0.36 & - & - & 0.36 & 0.04 & 0.04 & 0.17 & 0.17 & 0.15 & 0.07 \\
\hline 3 & 0.22 & - & 0.10 & 0.32 & 0.04 & 0.07 & 0.06 & 0.09 & 0.14 & 0.28 \\
\hline 4 & 0.39 & - & - & 0.39 & 0.07 & 0.04 & 0.04 & 0.09 & 0.14 & 0.23 \\
\hline 5 & 0.19 & 0.11 & 0.04 & 0.34 & 0.06 & 0.13 & 0.04 & 0.12 & 0.11 & 0.20 \\
\hline
\end{tabular}

Percentage of energy used by main saw and carriage feed of sawmill 1 is the lowest and sawmill 4 the highest. Energy consumption of main saw and carriage feed of sawmill 2 and 4 are the highest and also they are almost equal since they use main saw for sawing all the lumber. Energy consumption for the main sawing (breaking down of log into lumber before edging and 
trimming) was lowest for sawmill 1 and highest for sawmill 4. The reason for the lowest energy consumption by sawmill 1 can be contributed to better maintenance of saw blades and use of small size motor in resaw. Energy consumption of debarker in sawmill 1 is the lowest and in sawmill 2 the highest. This happened since the hydraulic pump used in debarker was not included with the debarker during data collection in sawmill 1 , where as it was included in sawmill 2. Another thing to notice in sawmill 2 is energy consumption by other motors is very low compared to other sawmills since those motors energy consumption was merged with the energy consumption of debarker and chipper since they were located in the control panels of debarker and chipper. Trimmer usage is high in sawmill 3 and 5 since they sawed more grade lumber than other sawmills (Table 3.6).

Board feet sawn and surface area sawn in square feet (surface feet) in each sawmill is shown in Table 6.22. Surface feet sawn was calculated using the method explained in energy allocation methodology of Chapter 4. Surface feet sawn of sawmill 2 went down drastically since it sawed more of cants and timbers. Also, board feet sawn per hour per horsepower and surface feet sawn per hour per horsepower were calculated to show how productive is each sawmill since just board feet per hour or surface feet per hour won't give the real picture of productivity of each sawmill. Sawmill 4 had the highest value for both board feet sawn per hour per horsepower and surface feet sawn per hour per horsepower and hence has the highest motor load factor. Sawmill 2 and 4 has very low surface feet sawn per hour per horsepower since they does not have a resaw or a gangsaw. Sawmill 1 has good surface feet sawn per hour per horsepower since it has a resaw and small size motors. Energy consumed by each motor per surface feet sawn was used to compare different motor's energy consumption among sawmills since energy consumed per board feet sawn won't give correct comparison results as discussed in Chapter 4. 
Table 6.22: Board Feet sawn and Surface Feet sawn in each Sawmill with Motor Load Factors

\begin{tabular}{|c|c|c|c|c|c|c|c|}
\hline Sawmill & Board Feet & $\begin{array}{c}\text { Surface } \\
\text { Area Sawn } \\
\text { in Sq. Ft. }\end{array}$ & $\begin{array}{c}\text { Board feet } \\
\text { Per hour }\end{array}$ & $\begin{array}{c}\text { Surface } \\
\text { Feet Per hr }\end{array}$ & $\begin{array}{c}\text { Board feet } \\
\text { per hour } \\
\text { per hp }\end{array}$ & $\begin{array}{c}\text { Surface } \\
\text { Feet Per hr } \\
\text { per hp }\end{array}$ & $\begin{array}{c}\text { Motor } \\
\text { Load } \\
\text { Factor }\end{array}$ \\
\hline 1 & 460,994 & 504,433 & 2,946 & 3,223 & 3.04 & 3.33 & 0.307 \\
\hline 2 & 420,687 & 282,329 & 2,203 & 1,478 & 2.70 & 1.81 & 0.265 \\
\hline 3 & $1,431,387$ & $1,545,485$ & 9,975 & 10,770 & 3.79 & 4.09 & 0.485 \\
\hline 4 & 660,379 & 537,538 & 3,890 & 3,167 & 2.54 & 2.06 & 0.358 \\
\hline 5 & 949,149 & 980,494 & 4,616 & 4,769 & 2.74 & 2.83 & 0.362 \\
\hline Total & $\mathbf{3 , 9 2 2 , 5 9 6}$ & $\mathbf{3 , 8 5 0 , 2 7 9}$ & & & & & \\
\hline
\end{tabular}

Energy consumption by different motors per 1,000 square feet of surface area sawn is shown in Table 6.23. The average energy consumed is for total lumber sawn in each sawmill and not for individual lumber sizes. Total Energy consumption per 1,000 square feet surface area sawn follows similar pattern as percentage energy consumption of motors.

Table 6.23: Energy Consumption in kWh per 1,000 Square Feet of Surface Area sawn by Major Sawmill Motors

\begin{tabular}{|c|c|c|c|c|c|c|c|c|c|c|}
\hline Sawmill & $\begin{array}{c}\text { Main } \\
\text { Saw + } \\
\text { Carriage } \\
\text { Feed }\end{array}$ & Resaw & $\begin{array}{c}\text { Gang } \\
\text { Saw }\end{array}$ & Edger & Trimmer & Debarker & Chipper & Compressor & $\begin{array}{c}\text { Other } \\
\text { Motors }\end{array}$ & $\begin{array}{c}\text { Total } \\
\text { kWh/ 1000 } \\
\text { Sq. Ft. }\end{array}$ \\
\hline 1 & 16.56 & 4.47 & - & 3.43 & 2.86 & 2.44 & 7.79 & 15.52 & 25.77 & 78.84 \\
\hline 2 & 44.23 & - & - & 4.74 & 4.85 & 20.99 & 20.74 & 18.84 & 10.12 & 124.51 \\
\hline 3 & 21.49 & - & 9.29 & 3.51 & 6.91 & 5.97 & 8.80 & 13.39 & 26.77 & 96.12 \\
\hline 4 & 59.35 & - & - & 10.59 & 6.58 & 5.78 & 13.69 & 20.54 & 33.98 & 150.51 \\
\hline 5 & 20.93 & 11.99 & 4.62 & 6.20 & 13.81 & 4.25 & 12.49 & 12.28 & 21.97 & 108.53 \\
\hline
\end{tabular}

Since the percentage energy consumption of motors had only percentage values of energy consumed with in the sawmill, it didn't give any information about the actual energy consumption values in $\mathrm{kWh}$. Energy consumption per 1,000 square feet of surface area sawn clearly shows how much energy is consumed by each motor. Sawmill 1 had the lowest energy consumed per 1,000 square feet of surface area sawn and sawmill 4 had the highest.

Energy consumption of individual motors per 1,000 square feet of surface area sawn of sawmill 1, 2, 3, 4 and 5 are shown in Figures 6.9 through 6.13. 


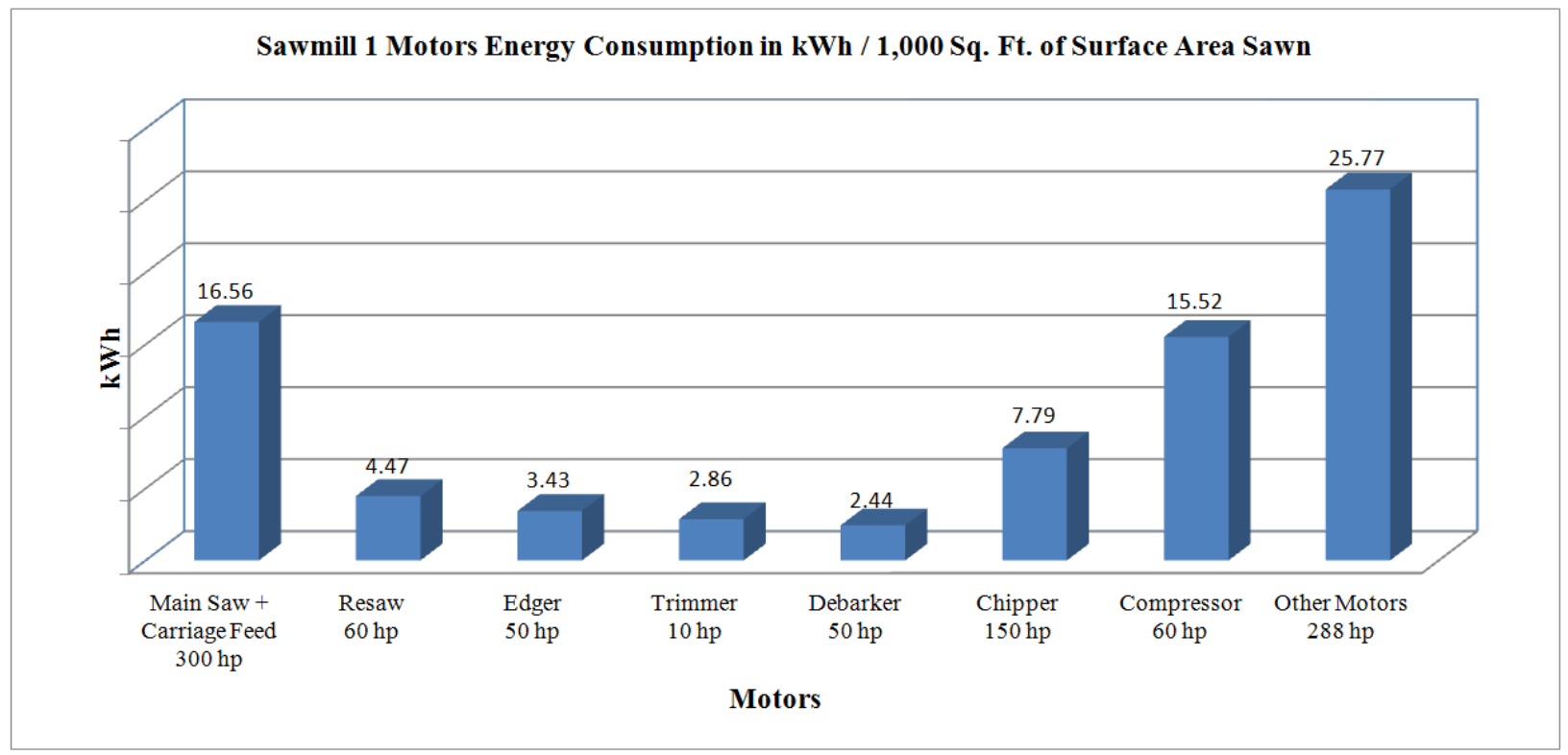

Figure 6.9: Energy Consumption of Sawmill 1 Motors per 1,000 Square Feet of Surface Area sawn

The main consumers of energy in sawmill 1 were main saw and carriage feed, chipper, compressor and other motors. Other motors had motors like dust collector, hydraulic pump of debarker, trim saws and chip blower which consumed considerable amount of energy.

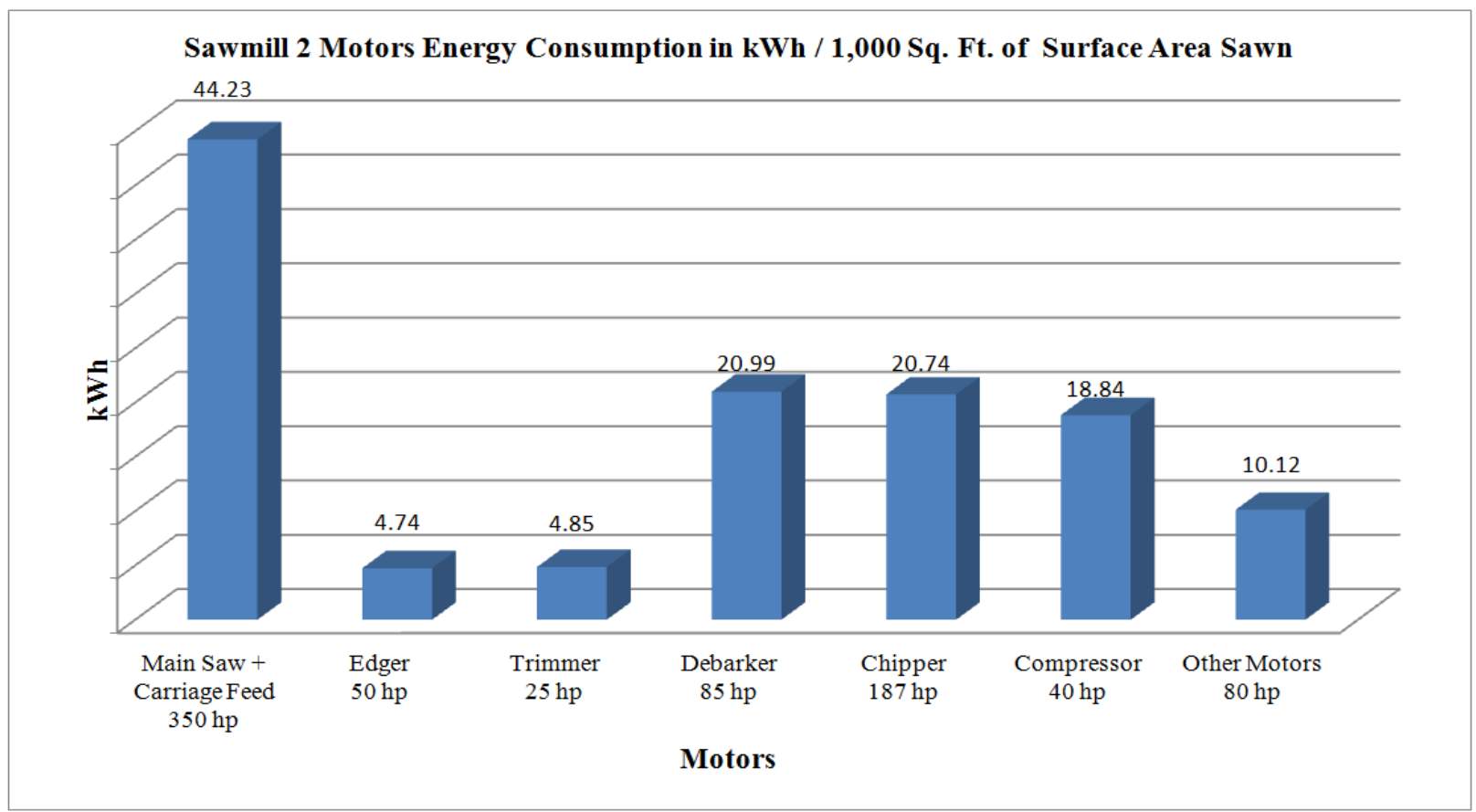

Figure 6.10: Energy Consumption of Sawmill 2 Motors per 1,000 Square Feet of Surface Area sawn 
The highest energy consumer of sawmill 2 motors was main saw and carriage feed, since there was no resaw or a gang saw in sawmill 2. Other main energy consumers were debarker, chipper and compressor. Debarker had hydraulic pump and chipper had chip blower and dust collector and hence have higher energy consumption than other sawmills.

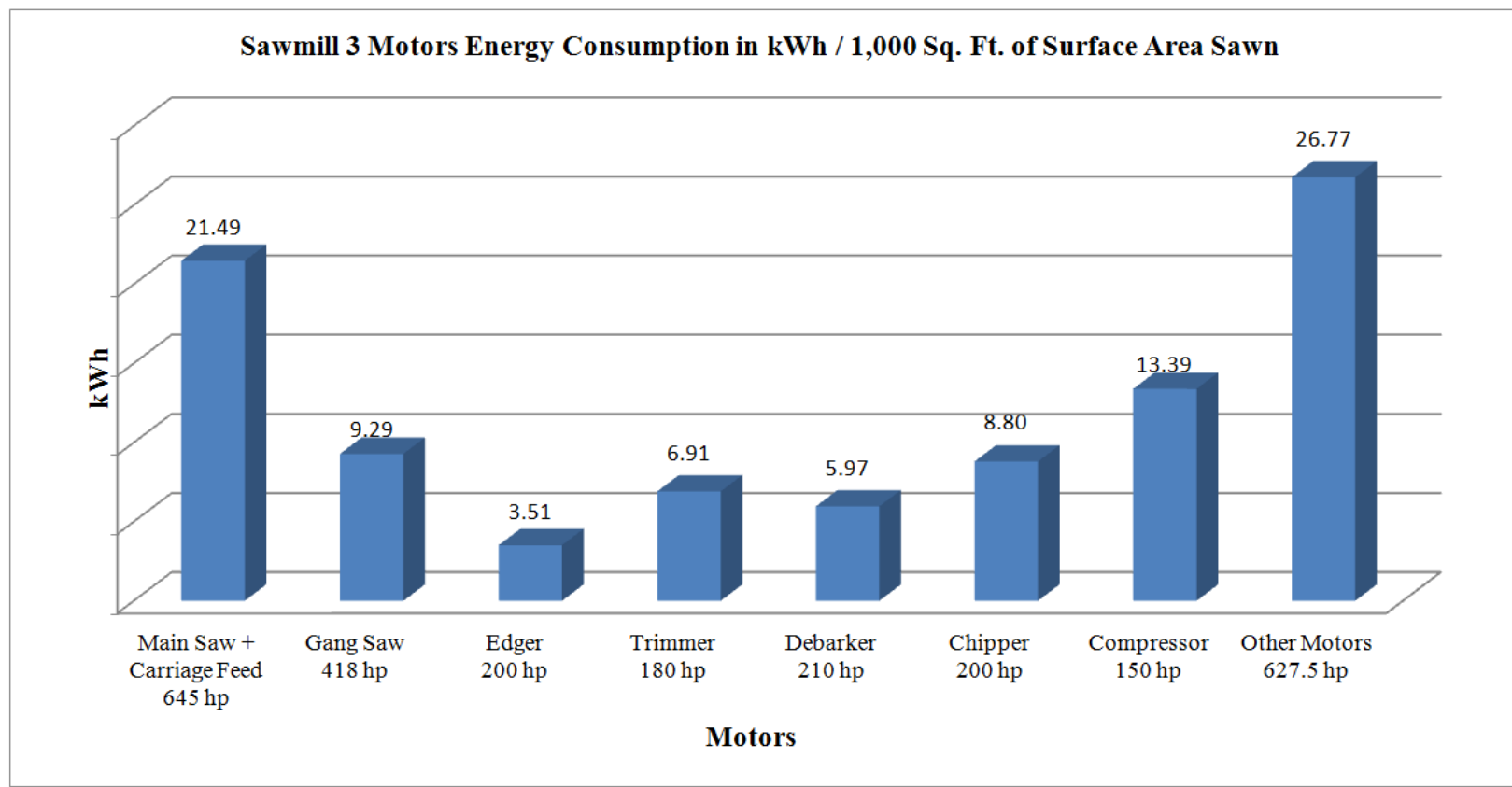

Figure 6.11: Energy Consumption of Sawmill 3 Motors per 1,000 Square Feet of Surface Area sawn

The energy consumption of sawmill 3 motors was similar to sawmill 1 . The main consumers of energy in sawmill 3 were main saw and carriage feed, gang saw, chipper, compressor and other motors. Edger consumed less energy than trimmer in sawmill 3 since sawmill 3 had gang saw which was sawing cants and there was not much need of edger to do edging of the lumber coming from gang saw. Since sawmill 3 produced lots of grade lumber and grade lumber needed trimming, trimmer consumed more energy than edger and debarker in sawmill 3. Since sawmill 3 was a large capacity sawmill, there were lot of motors under the other motors category (Appendix Table A.26). 


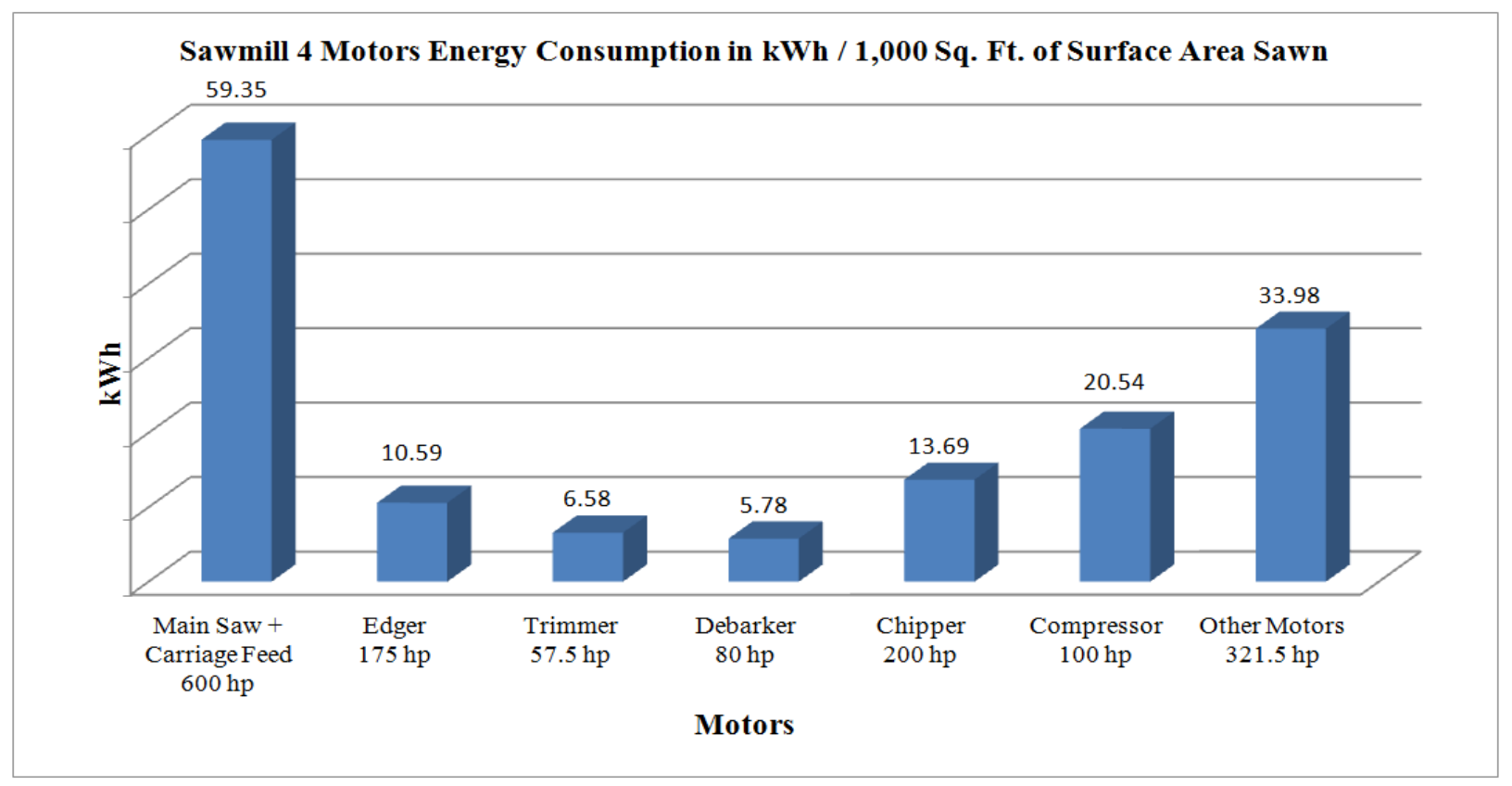

Figure 6.12: Energy Consumption of Sawmill 4 Motors per 1,000 Square Feet of Surface Area sawn

The energy consumption of sawmill 4 motors was similar to sawmill 2. The highest energy consumer of sawmill 4 motors was main saw and carriage feed, since there was no resaw or a gang saw in sawmill 4. Other main energy consumers were chipper, compressor and other motors.

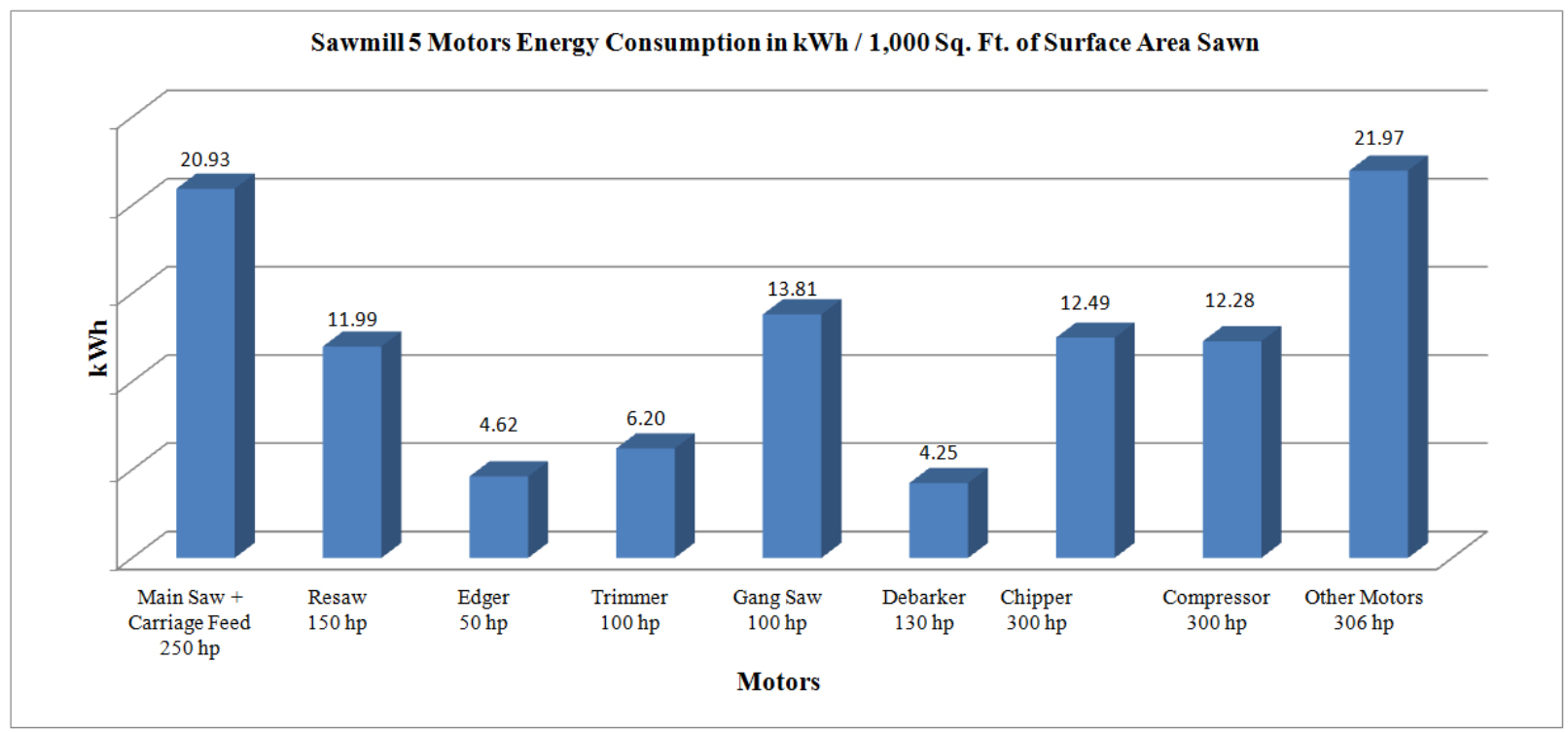

Figure 6.13: Energy Consumption of Sawmill 5 Motors per 1,000 Square Feet of Surface Area sawn 
The energy consumption of sawmill 5 was different from rest of the sawmills since it had both a resaw and a gang saw. The main consumers of energy in sawmill 5 were main saw and carriage feed, resaw, gang saw, chipper, compressor and other motors. Since sawmill 5 produced the highest quantity of grade lumber among all the sawmills, and grade lumber needed trimming, trimmer consumed more energy than edger and debarker in sawmill 5.

\section{Conclusion}

Estimator variables density, minutes and horsepower were positively correlated to energy consumption where as ' $4 / 4$ to $8 / 4+$ Pallet', 'Cant + Timber' and 'Level of Maintenance' were negatively correlated in SEC models. Sensitivity analysis conducted on the estimator variables showed that sawmill 3 had the highest effect on its energy consumption from estimator variables 'horsepower' and '4/4 to 8/4 + Pallet'. Sensitivity analysis conducted on width of lumber showed that for sawing one unit board feet of 4 inch width lumber, twice the energy required for sawing one unit board feet of 12 inch width lumber is needed on resaw. In overall SEC, energy consumed for sawing 4 inch width lumber of unit board feet was higher by $24 \%$ to $34 \%$ than energy required for sawing one unit board feet of 12 inch width lumber depending on the horsepower of the main saw, resaw and gang saw motors used in different sawmills. Sawmill 2 and 4 had higher SEC's as discussed earlier and also didn't follow the order of density correctly. In sawmill 5 also SEC didn't follow the order of density since the lower SEC of $1^{\text {st }}$ shift and higher SEC of $2^{\text {nd }}$ shift were mixed together resulting in higher SEC's for some species. The highest energy consumer of sawmill 2 and 4 motors was main saw and carriage feed, since there was no resaw or a gang saw in them. The energy consumption of sawmill 1 motors was similar to sawmill 3 and energy consumption of sawmill 2 motors was similar to sawmill 4 . 


\section{Conclusion and Future Work}

\subsection{Contribution of this Research}

1. The energy allocation methodology developed based on surface area cut.

2. Analysis of sawmills from productivity view point showing the production bottle necks.

3. Estimation models to estimate energy consumption and identification of important estimator variables.

4. Development of best achievable specific energy consumption values for different sizes and species of lumber.

5. Sawmill Energy Estimation Program that estimates SEC, analyzes the results and gives suggestions with estimated savings.

6. Identification of the correlation between lumber production variables minutes and board feet with total energy consumed.

7. Development of a new method to calculate data collection sample size for data of unknown probability distribution.

\subsection{Conclusion}

Benchmarking is the best way to know individual sawmill's level of performance in energy consumption and there was a need for developing best achievable energy consumption and a tool to do benchmarking. Previous studies did not consider sawmill manufacturing from the view point of both energy and productivity. Three sawmills with single sawing line and two sawmills with double sawing lines were selected to monitor their electrical energy consumption and production. 
Looking at gross energy consumption and calculating overall energy consumption per board feet and using it to estimate the energy efficiency of a sawmill or using it for benchmarking like the authors did in the literature review lead to wrong conclusions. This research analyzed sawmills energy efficiency by taking the sizes and species of lumber sawn into account and allocating the energy consumption based on surface area cut for that particular size which yielded better results. The energy allocation method developed in this research will give a better picture of the sawmill performance in terms of energy efficiency and productivity. Also, the results from the comparison of sawmills concluded that resaw/gangsaw and matching of machine capacities plays major role in achieving energy efficiency and productivity of sawmill.

Ten Variables were selected from Product, Process, and System Parameters. Three multiple linear regression models were developed to estimate energy consumption per thousand board feet. The estimation model with the 'Motor hp x Min' variable was the most promising model developed. As the common sense says, maintenance is the key for the performance of any machine, 'Level of Maintenance' also turned out to be an important estimator variable. SMEEP developed will help the end user to bench mark their sawmill along with knowing methods to improve their sawmill's efficiency with estimated savings.

\subsection{Future Work}

- Only amperage data was logged for duration of 1 month and voltage and power factor data was collected for only 20 minutes in this research. Better quality data and hence better model can be obtained if energy data can be logged using energy meters.

- There was mix up of species during the data collection of this research and hence some data collected was not accurate. Better data collection can happen if there is no mix up of 
species and best data collection can happen if real time tracking of logs using some tracking method can be done.

- Data collection was done for $80 \%$ of the motors capacity and remaining $20 \%$ was estimated. The estimation accuracy of the model can be improved if $100 \%$ of the motor capacity can be logged.

- Five sawmills were studied in this research. Studying more sawmills can help to understand the sawmill manufacturing process better and may help to improve the model by including more estimator variables. For Ex.: New saw blade material like Stellite.

- Estimation Model has not considered the difference in energy efficiency of equipment like using premium efficiency motor vs. standard efficiency motor or compressor with VFD vs. without VFD etc., since the sawmills studied does not have those type of equipment. So, variable for the difference in efficiency of the equipment can be included in the future model or difference in efficiency can be incorporated by multiplying the motor horse power with a factor that represents the motor or equipment efficiency.

- Estimation model grouped board lumber sizes between four quarter to eight quarter and cants and timbers. A future estimation model can split these sizes to obtain better results.

- Production capacities of sawing equipment like head saw, resaw and gang saw were compared by using the amperage data collected every minute. A better comparison of these machine capacities and balancing them can be done by conducting proper time study and assembly line balancing. 


\section{Literature Cited}

1. Adams, E., 1982 - Using a recording watt/varmeter to measure power consumption of sawmill equipment, Department of Agriculture, Forest Service, Northeastern Forest Experimental Station, Gen. Tech. Rep. NE-71, 1982

2. AFPA 2012 - American Forest and Paper Association Fact Sheet http://www.afandpa.org/our-industry/economic-impact (Accessed Dec 11, 2013)

3. Axelsson, B., Lundberg, A., and Grönlund, J. (1993). Studies of the main force at and near cutting edge Holz als Roh-und Werktoff 51(2), 43-48.

4. AMO 2012 - U.S. Department of Energy : Advanced Manufacturing Office https://www1.eere.energy.gov/manufacturing/pdfs/energy_use_and_loss_and_emissions_ forest.pdf (Accessed Dec 15, 2013)

5. Bergman, R., Bowe, S. 2008. Environmental impact of producing hardwood lumber using life-cycle inventory. Wood and Fiber Science, 40(3):448 - 458

6. BLS 2013 - United States Department of Labor - Bureau of Labor Statistics, Quarterly Census of Employment and Wages - for NAICS 321 Wood Product Manufacturing and 321113 Sawmills, http://data.bls.gov/cgi-bin/dsrv (Accessed Dec 30, 2013)

7. Bond, B. 2008. Sawmill and treating insights: Rein in escalating energy costs. Online: http://www.palletenterprise.com/articledatabase/view.asp?articleID=2648.

(Accessed Dec 30, 2013)

8. Carole, T., et.al 2001 - Energy Efficiency and Use in the Chemical Industry, Proceedings ACEEE Summer Study on Energy Efficiency in Industry, Vol. 1, pp 267275,2001

9. Cassens, D. L., 2001 "Quality Control in Lumber Purchasing: Hardwood Lumber Grades," Department of Forestry and Natural Resources, Purdue University.

10. CPL 2001 - Motor Management Success: Crown Pacific Lumber Saves Money with Motor Management Tools

http://www.motorsmatter.org/case_studies/Crown_Pacific.pdf (Accessed Dec 29, 2013)

11. Cristovao 2012 - Main cutting force models for two species of tropical wood, Wood Material Science \& Engineering, Volume 7, Issue 3, 2012, Special Issue: $20^{\text {th }}$ International Wood Machining Seminar 
12. Cristóvão 2013 - Luís Cristóvão, Mats Ekevad, and Anders Grönlund, Industrial Sawing of Pinus sylvestris L.: Power Consumption, BioResources 8(4), 6044-6053

13. Dalois C, 1990 - Manuel de sciage et d'affutage. Centre Technique Forestier Tropical, Department du CIRAD

14. Denig, J., 1993 — Small Sawmill Handbook - Doing it Right and Making Money, Chapter 3, Sawmill Equipment - Primary Breakdown, pp 39 - 72, Miller Freeman, Inc., San Francisco, 1993

15. DOE 2004 - US DOE Best Practices Case Study, Weyerhaeuser: Compressed Air System Improvement Saves Energy and Improves Production at a Sawmill https://www1.eere.energy.gov/manufacturing/tech_assistance/pdfs/bp_cs_weyerhaeuser.p df (Accessed on Dec 29, 2013)

16. DOE 2006, U.S. Department of Energy. Forest Products Technologies: Public Private Partnerships Produce R\&D Results. Online:

http://www1.eere.energy.gov/industry/forest/pdfs/forestsuccesses.pdf (Accessed April $25,2013)$

17. EERE 2012 - US Department of Energy : Office of Energy Efficiency \& Renewable Energy http://www1.eere.energy.gov/analysis/eii_efficiency_intensity.html (Accessed Dec 15, 2013)

18. Engineering Toolbox, Wood Densities (Accessed Mar 25, 2015) http://www.engineeringtoolbox.com/weigt-wood-d_821.html http://www.engineeringtoolbox.com/wood-density-d_40.html

19. EPA 2007 - U.S. Environmental Protection Agency : Energy Trends in Selected Manufacturing Sectors http://www.epa.gov/sectors/pdf/energy/report.pdf (Accessed Dec 15, 2013)

20. Espinoza O, Buehlmann U, and Bond B 2011 - Energy and the US hardwood industry Part II: Responses to increasing prices. BioResources 6(4):3899-3914.

21. Fenart 2000 - Fénart, P, Snieg, O. The frequency variables: a tool to increase the productivity and decrease the energy consumption in sawmills, CTBA Info 2000 No. 86 pp. 6-9 
22. FPI roadmap 2010 - Forest Products Industry Technology Roadmap http://www.twosides.info/Content/rsPDF_101.pdf (Accessed Dec 11, 2013)

23. FPIP 1979 - Forest Products Industry Profile, Website http://www.fpl.fs.fed.us/documnts/fplrp/fplrp310.pdf (Accessed Dec 11, 2013)

24. Garner, J., 2002 - Energy Conservation in the Pulp, Paper, and Wood Products Industry, Technical Paper, 2002, http://www.emt-india.net/process/pulp_paper/pdf/garner-paper2002.pdf (Accessed Jan 6, 2014)

25. Gopalakrishnan, B., R. W. Plummer, and W. H. Iskander. 2003. A comparative study on energy assessment data from manufacturing industry. ACEEE Summer Study on Energy Efficiency in Industry, July 29-August 1, 2003, Rye Brook, New York; American Council for an Energy-Efficient Economy, Washington, D.C. pp. 86-95.

26. Gopalakrishnan, 2005 - Energy Efficiency Measures in the Wood Manufacturing Industry, 2005 ACEEE Summer Study on Energy Efficiency in Industry

27. Iris 2006 - Iris Vazquez-Cooz, Robert W. Meyer. Cutting Forces for tension and normal wood of Maple. Forest Products Journal. Apr2006, Vol. 56 Issue 4, p26-34. 9p http://www.fao.org/docrep/ARTICLE/WFC/XII/0886-A2.HTM (Accessed on Dec 23, 2013)

28. ITTO 2012 - International Tropical Timber Organization, Annual Review and Assessment of the World Timber Situation 2012 http://www.itto.int/annual_review/ (Accessed Dec 30, 2013)

29. Koch, P. 1964. Wood Machining Processes, Ronald Press, New York, USA.

30. Kivimaa E 1950 - Cutting force in wood working. State Institute for Technical Research, Helsinki

31. Li 2006 - Li, Jingge, McCurdy, Murray, Pang, Shusheng. Energy demand in wood processing plants. New Zealand Journal of Forestry, 2006:51(2), pp. 13-18. http://ir.canterbury.ac.nz/bitstream/10092/167/1/12603292_Main.pdf (Accessed Jan 6, 2014)

32. Lin, W., J. Wang, S.T. Grushecky and D. Summerfield and B. Gopalakrishnan. 2012. Energy Consumption and Efficiency of Appalachian Hardwood Sawmills. Forest Products Journal, 62(1):32-38 
33. Maddula - Energy Intensity Determination in Wood Processing Sawmills, M.S. Thesis, West Virginia University, 2014

34. Mardikar, Y. 2007. Establishing baseline electrical energy consumption in wood processing sawmills: A model based on energy analysis and diagnostics. Ph.D dissertation. West Virginia University, Morgantown.

35. Matan 2003 - Matan, N. and Kyokong. B, Effect of moisture content on some physical and mechanical properties of juvenile rubberwood, Songklanakarin Journal of Science and Technology, 2003, 25(3) : 327-340

36. Mate, A. 2002. Energy analysis and diagnostics in wood manufacturing industry. Master's thesis. West Virginia University, Morgantown.

37. McDonald K. A., and Kretschmann, D. E., 1898 "The Encyclopedia of Wood," U.S. Department of Agriculture, pp. 1-2. Chap. 5.

38. Mihai 2008 - Research concerning the workability by sawing of frozen and unfrozen spruce wood - PRO LIGNO - Open Access Scientific Journal in the Field of Wood Engineering 2008 Volume 4.

39. Milota, M., West, C., Hartley, I. 2005. Gate to gate life cycle inventory of softwood lumber production. Wood and Fiber Science, 37:47-57.

40. Montgomery, D., Runger, G., 2003 - Applied Statistics and Probability for Engineers, Chapter 6, Random Sampling and Data Description, pp 189 - 219, Third Edition John Wiley and Sons, Inc., 2003

41. Montgomery, D., Runger, G., 2003 - Applied Statistics and Probability for Engineers, Chapter 8, Statistical Intervals for a Single Sample, pp 247 - 276, Third Edition John Wiley and Sons, Inc., 2003

42. Mozzo, M., 2000 - The Importance of Properly Setting the Baseline for Performance Contracts, Energy Engineering Journal, Vol. 98, \# 2, pp 73 - 80, 2000

43. Nadel, S., et.al; 2002 - Energy Efficient Motor Systems: A Handbook on Technology, Program, and Policy Opportunities, Chapter 2, Motor Technologies, pp 13 - 85, Second Edition, American Council for an Energy-Efficient Economy, 2002

44. Normand 2009 - Normand Be'dard, Beno1`t Laganie`re, Debarking enhancement of frozen logs, Part II: Infrared system for heating logs prior to debarking, Forest Products Journal, Jun2009, Vol. 59 Issue 6, p25-30. 6p 
45. Onset Data Loggers 2013 - http://www.onsetcomp.com (accessed on Jan $3^{\text {rd }} 2013$ )

46. Orlowski, 2013 - Orlowski K., Ochrymiuk, T., Atkins, A., and Chuchala, D. (2013). Application of fracture mechanics for energetic effects predictions while wood sawing, Wood Science and Technology 47(5), 949-963.

47. Pawlik, et.al 2001 - Analyzing Facility Energy Use: A Balancing Act, Journal of Strategic Planning for Energy and the Environment, Vol. 21, \# 2, pp 8 - 33, 2001

48. Payam 2013 - Payam Moradpour, Kazem Doosthoseini, Frieder Scholz, Asghar Tarmian Cutting forces in bandsaw processing of oak and beech wood as affected by wood moisture content and cutting directions, European Journal of Wood and Wood Products, November 2013, Volume 71, Issue 6, pp 747-754

49. Poole, A; Pinheiro, P. 2003. Developing Energy Profiles for Sawmills in the Amazon Region First Field Visit to Rondolândia and Ji-Paraná. The National Institute of Energy Efficiency, Brazil. Online:

http://www.inee.org.br/down_loads/biomassa/AmazonSawmill.pdf (Accessed April 25, 2013)

50. Ramírez, C., 2006 - Adding Apples and Oranges: The Monitoring of Energy Efficiency in the Dutch Food Industry Energy Policy Journal, Vol. 34, Issue 14, pp 1720-1735, 2006

51. Rutgers 2015, Motor Demonstration Lab, https://caes.rutgers.edu/labMotor

52. Sawmill and Woodlot Magazine, 2010, "Understanding Hardwood Lumber Grading,"

53. Spinelli R., Cavallo E., Eliasson L., Facello A. 2013. Comparing the efficiency of drum and disc chippers. Silva Fennica vol. 2013 no. 2 article id 930. 11 p.

54. Uppgård, R. 1995 - Small-scale sawing. Time studies on circular band saw technique, Swedish University of Agricultural Sciences, Faculty of Forestry, Department of Operational Efficiency, Sweden

55. UN 1983 - Food and agricultural Organization of United Nations, Energy Utilization in Sawmilling. http://www.fao.org/docrep/t0269e/t0269e04.htm (Accessed April 25, 2013)

56. USCB 2010 - United States Census Bureau - Annual Current Industrial Reports of Lumber Production and Mill Stocks.

http://www.census.gov/manufacturing/cir/historical_data/ma321t/index.html

(Accessed Dec 11, 2013) 
57. USDA 2011 - U.S. Department of Agriculture - Bulletin of Harwood Market Statistics http://www.nrs.fs.fed.us/pubs/rn/rn_nrs158.pdf

58. USDOE BP Best Practice Tools - US Department of Energy - Energy Efficiency and Renewable Energy, AMO Energy Resources Center https://ecenter.ee.doe.gov/Pages/default.aspx (Accessed on Dec 23, 2013)

59. USDOE 2015 - MotorMaster+ International - US Department of Energy http://www.energy.gov/eere/amo/articles/motormaster-international

60. US EIA 2010 - US Energy Information Administration Annual Energy Review http://www.eia.gov/consumption/manufacturing/data/2010/pdf/Table1_1.pdf (Accessed Dec 11, 2013)

61. US EIA 2013 - US Energy Information Administration U.S. Energy Prices http://www.eia.gov/electricity/sales_revenue_price/pdf/table8.pdf (Accessed May 23, 2015)

62. Wengert 1992 - Wengert, G. and D. Meyer. 1992. Energy at the sawmill: Conservation and cost reduction. Forestry Facts No. 61. Online: http://forest.wisc.edu/sites/default/files/pdfs/publications/61.PDF. (Accessed Dec 23, 2013)

63. Williston, E., 1988 - Lumber Manufacturing, Chapter 6, Debarking at the Long-Log Deck, pp 45 - 57, Revised Edition, Miller Freeman Publications, Inc., 1988

64. Williston, E., 1988 - Lumber Manufacturing, Chapter 9, Principles and Systems for Primary Log Breakdown, pp 72 - 103, Revised Edition, Miller Freeman Publications, Inc., 1988

65. Williston, E., 1988 - Lumber Manufacturing, Chapter 11, Edgers, pp 109 - 121, Revised Edition, Miller Freeman Publications, Inc., 1988

66. Williston, E., 1988 - Lumber Manufacturing, Chapter 12, Trimming Rough Lumber, pp 122 - 128, Revised Edition, Miller Freeman Publications, Inc., 1988

67. Williston, E., 1988 - Lumber Manufacturing, Chapter 20, Chipping and Chip Handling, pp 216 - 224, Revised Edition, Miller Freeman Publications, Inc., 1988

68. Williston, E., 1988 - Lumber Manufacturing, Chapter 25, Saw Design and Maintenance, pp 304 - 345, Revised Edition, Miller Freeman Publications, Inc., 1988 
69. WVDOF 2013 - West Virginia Division of Forestry

http://www.wvforestry.com/indassistance.cfm?menucall=industry (Accessed Dec 15, 2013) 


\section{Appendix}

Table A.1: Format for Production Data Collection \& Sample Filled by one of the Sawmill

Format for Production Schedule:

(Please provide us the production schedule details for the time loggers are hooked)

Date Starting time Ending time Species Grade Size Board Feet

\section{Required Format for Production Schedule:}

(Please provide us the production schedule details for the time loggers are hooked)

Date Starting time Ending time Species Grade Size Board Feet $\quad$ | $4-16-09 \quad 5: 30 \mathrm{Am}$ Red Opls. $\frac{\text { Reg }-1 F}{812^{\prime}}+4 / 4 \quad 3,991$ EAS - IF $-1 / 4$
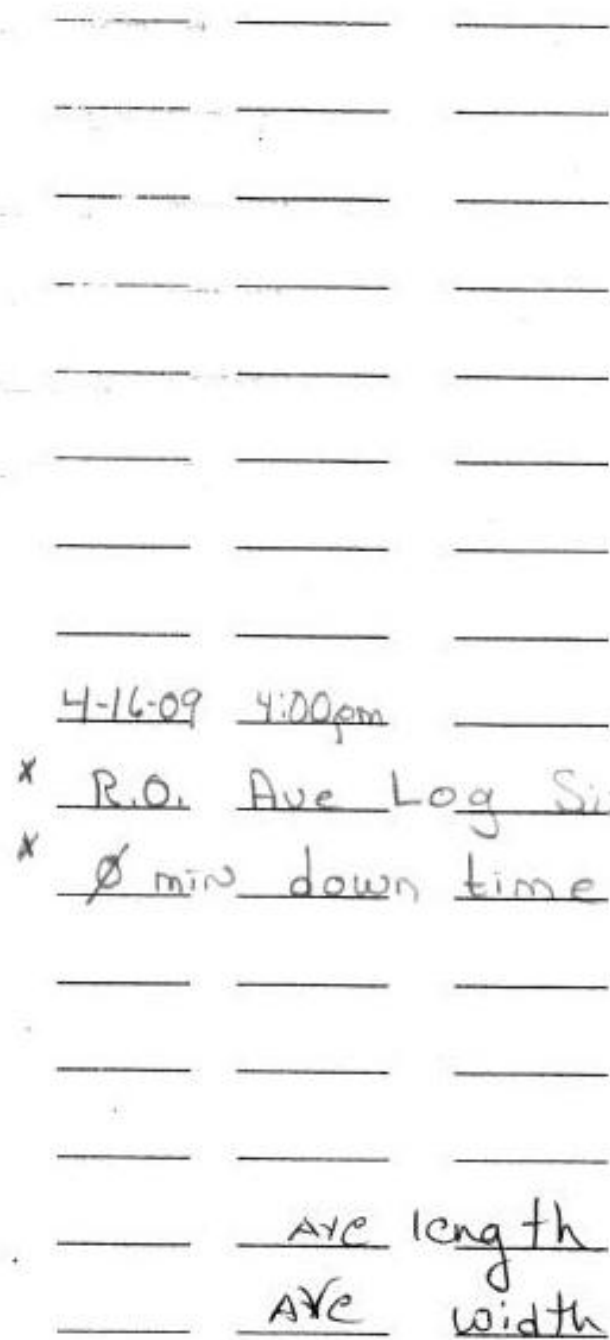
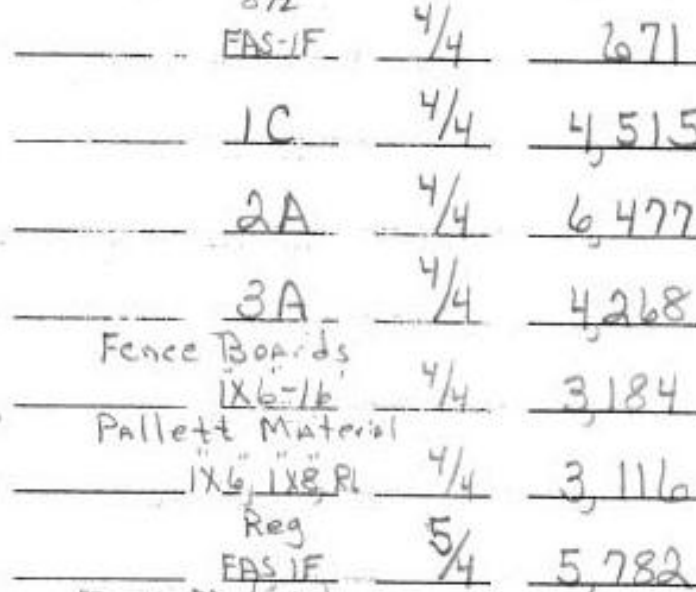

Thine Material
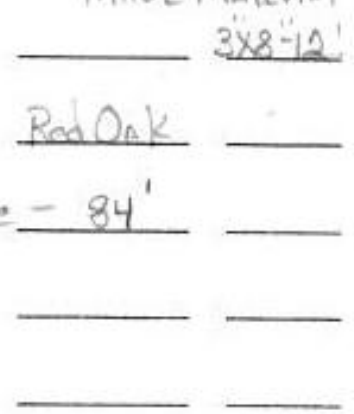

\section{-}
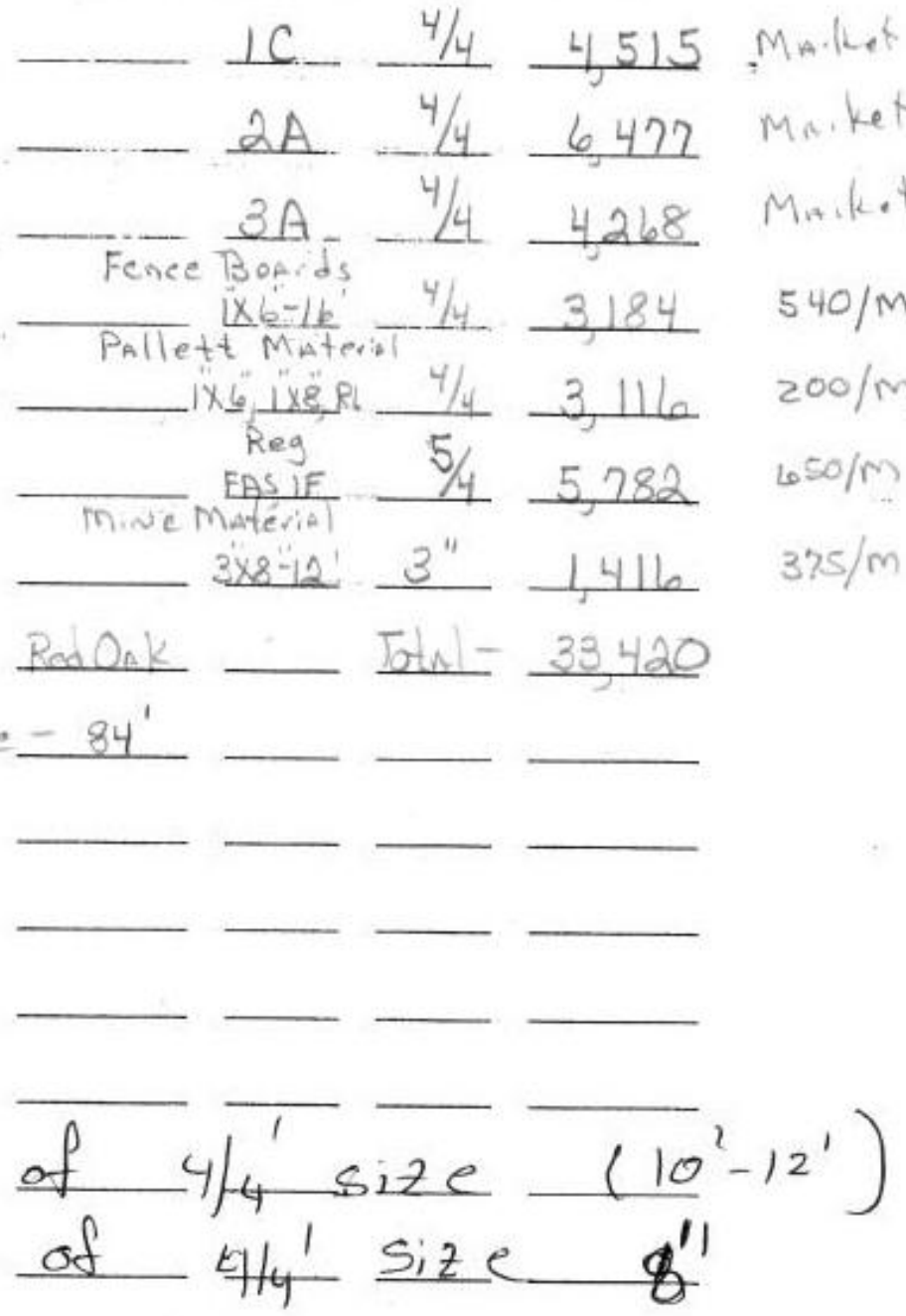
Table A.2: Main Saw Amperage Data of Sawmill 1 used for Calculating Duration of Data Logging

\begin{tabular}{|c|c|c|c|c|c|c|c|c|c|c|c|}
\hline 57.94 & 182.30 & 56.62 & 58.23 & 58.37 & 58.08 & 57.94 & 58.52 & 57.20 & 56.03 & 138.94 & 59.55 \\
\hline 60.43 & 60.28 & 113.31 & 133.52 & 55.74 & 56.03 & 69.95 & 164.72 & 58.52 & 58.37 & 144.21 & 54.13 \\
\hline 62.18 & 59.84 & 58.96 & 57.35 & 56.47 & 58.37 & 55.01 & 58.67 & 122.97 & 57.35 & 58.37 & 61.30 \\
\hline 59.11 & 61.16 & 109.94 & 56.91 & 56.91 & 56.47 & 66.43 & 56.32 & 57.94 & 114.04 & 54.42 & 136.89 \\
\hline 197.24 & 61.16 & 85.77 & 57.79 & 58.81 & 58.08 & 56.76 & 55.15 & 60.13 & 55.59 & 56.03 & 203.83 \\
\hline 57.20 & 58.37 & 231.67 & 58.08 & 51.78 & 138.21 & 199.44 & 57.50 & 56.91 & 56.76 & 57.06 & 342.41 \\
\hline 59.69 & 58.23 & 122.97 & 56.47 & 58.52 & 59.40 & 59.25 & 140.11 & 57.06 & 59.40 & 55.44 & 175.42 \\
\hline 152.12 & 57.79 & 56.62 & 58.96 & 55.30 & 69.65 & 58.81 & 56.76 & 63.35 & 210.13 & 56.47 & 58.81 \\
\hline 58.81 & 59.11 & 65.70 & 59.25 & 60.28 & 59.40 & 64.38 & 59.11 & 58.08 & 56.47 & 118.87 & 57.64 \\
\hline 57.64 & 85.03 & 139.23 & 58.81 & 54.13 & 60.72 & 58.81 & 213.21 & 57.06 & 53.54 & 56.62 & 215.26 \\
\hline 109.64 & 59.25 & 140.41 & 120.34 & 58.81 & 55.30 & 56.18 & 134.69 & 58.23 & 249.83 & 56.32 & 61.45 \\
\hline 57.06 & 61.45 & 58.81 & 168.97 & 58.37 & 57.35 & 60.13 & 58.08 & 56.32 & 56.91 & 56.32 & 99.39 \\
\hline 56.47 & 57.35 & 59.25 & 60.43 & 59.84 & 58.52 & 57.35 & 55.44 & 55.88 & 55.30 & 56.18 & 55.30 \\
\hline 59.55 & 59.84 & 59.55 & 58.52 & 59.99 & 56.62 & 58.08 & 55.74 & 58.67 & 111.99 & 63.94 & 58.81 \\
\hline 59.40 & 55.88 & 139.82 & 56.03 & 56.76 & 56.76 & 56.76 & 59.25 & 57.64 & 140.11 & 234.89 & 57.06 \\
\hline 57.64 & 195.04 & 56.03 & 56.47 & 58.81 & 56.91 & 122.97 & 59.25 & 55.44 & 55.88 & 56.62 & 159.74 \\
\hline 58.96 & 57.50 & 138.06 & 57.64 & 125.17 & 59.55 & 58.08 & 56.18 & 157.10 & 123.85 & 56.76 & 152.42 \\
\hline 133.81 & 120.63 & 57.35 & 133.81 & 59.55 & 58.81 & 56.03 & 57.20 & 138.65 & 56.03 & 59.25 & 60.86 \\
\hline 78.88 & 61.74 & 58.52 & 59.99 & 135.13 & 56.03 & 58.67 & 235.33 & 264.62 & 219.36 & 56.62 & 58.37 \\
\hline 59.11 & 59.11 & 62.18 & 54.86 & 114.48 & 62.62 & 58.37 & 61.16 & 59.25 & 58.67 & 58.81 & 58.81 \\
\hline 191.82 & 57.20 & 57.94 & 58.81 & 57.79 & 57.50 & 56.18 & 61.30 & 57.94 & 124.59 & 142.31 & 56.47 \\
\hline 58.52 & 176.88 & 56.47 & 57.35 & 60.28 & 58.96 & 57.06 & 200.02 & 56.47 & 160.33 & 56.32 & 56.91 \\
\hline 57.35 & 130.15 & 59.11 & 59.40 & $\begin{array}{l}58.37 \\
\end{array}$ & $\begin{array}{l}57.79 \\
\end{array}$ & 56.76 & 189.33 & 59.40 & 162.96 & 160.91 & 56.76 \\
\hline 150.37 & 180.25 & 57.06 & 58.23 & 131.03 & 114.77 & 59.84 & 56.62 & 58.81 & 58.37 & 88.40 & 134.99 \\
\hline 59.11 & 159.16 & 56.18 & 58.23 & 194.02 & 57.94 & 56.47 & 70.53 & 58.23 & 58.37 & 58.23 & 55.59 \\
\hline 62.33 & 101.59 & 55.88 & 56.76 & 59.40 & 54.86 & 56.32 & 57.06 & 57.50 & 56.62 & 57.64 & 55.44 \\
\hline 160.03 & 57.35 & 56.03 & 56.47 & 55.15 & 59.40 & 56.32 & 55.15 & 276.20 & 136.16 & 56.47 & 58.08 \\
\hline 58.96 & 166.48 & 56.32 & 60.57 & 249.54 & 187.28 & 197.53 & 60.13 & 153.88 & 57.06 & 56.18 & 61.30 \\
\hline 196.66 & 136.30 & 58.37 & 232.69 & 53.98 & 120.19 & 58.67 & 59.69 & 188.16 & 56.18 & 56.62 & 200.46 \\
\hline 123.71 & 56.62 & 58.08 & 56.91 & 58.52 & 55.74 & 110.38 & 95.44 & 60.57 & 58.96 & 63.50 & 55.15 \\
\hline 59.25 & 96.75 & 56.18 & 54.71 & 179.08 & 55.88 & 57.06 & 113.75 & 56.32 & 77.71 & 243.09 & 55.01 \\
\hline 57.79 & 81.08 & 168.24 & 59.25 & 58.96 & 55.88 & 57.20 & 119.46 & 57.94 & 165.45 & 58.37 & 55.74 \\
\hline 60.28 & 142.02 & 56.62 & 54.27 & 58.96 & 58.81 & 56.91 & 57.64 & 151.98 & 53.69 & 55.74 & 173.95 \\
\hline 59.55 & 58.67 & 56.32 & 59.25 & 57.06 & 55.30 & 122.68 & 165.60 & 59.11 & 57.94 & 58.81 & 60.28 \\
\hline 137.18 & 57.35 & 63.21 & 59.84 & 54.57 & 57.06 & 55.15 & 57.35 & 75.22 & 57.20 & 170.44 & 59.55 \\
\hline 60.57 & 59.11 & 57.35 & 181.27 & 59.55 & 173.51 & 57.06 & 118.14 & 57.94 & 58.37 & 55.59 & 162.96 \\
\hline 57.79 & 57.20 & 58.23 & 55.74 & 57.20 & 173.07 & 58.08 & 148.90 & 69.21 & 161.35 & 56.18 & 58.23 \\
\hline 153.59 & 57.79 & 114.04 & 56.47 & 58.67 & 158.72 & 56.32 & 58.52 & 235.47 & 57.50 & 56.32 & 57.50 \\
\hline 58.23 & 148.76 & 57.94 & 56.32 & 57.79 & 488.31 & 61.30 & 59.55 & 121.80 & 249.39 & 91.19 & 59.40 \\
\hline 60.43 & 57.64 & 57.06 & 288.50 & 56.76 & 58.08 & 53.98 & 58.23 & 57.35 & 56.32 & 55.74 & 56.91 \\
\hline 58.81 & 177.91 & 58.23 & 58.08 & 143.92 & 55.15 & 57.06 & 126.34 & 55.01 & 59.55 & 56.62 & 58.52 \\
\hline 109.20 & 56.91 & 216.43 & 59.99 & 134.25 & 56.62 & 56.47 & 57.35 & 59.84 & 57.50 & 56.47 & 55.88 \\
\hline 57.64 & 59.40 & 180.25 & 57.35 & 59.84 & 216.14 & 57.94 & 59.11 & 139.97 & 57.35 & 57.20 & 58.08 \\
\hline 57.35 & 128.25 & 92.36 & 144.36 & 58.52 & 58.52 & 57.50 & 58.81 & 56.03 & 159.60 & 141.14 & 57.64 \\
\hline 62.04 & 182.59 & 280.88 & 62.48 & 55.88 & 59.40 & 57.35 & 58.96 & 150.37 & 57.35 & 55.15 & 57.64 \\
\hline 61.89 & 63.35 & 59.11 & 58.81 & 56.32 & 58.67 & 56.47 & 57.20 & 127.66 & 57.64 & 107.15 & \\
\hline
\end{tabular}


Table A.3: Production Data Collected used for Analysis

\begin{tabular}{|c|c|c|c|c|c|c|c|c|c|c|c|c|c|c|c|}
\hline $\begin{array}{l}\text { Shift } \\
\text { No. }\end{array}$ & Mill \# & $\begin{array}{c}\text { Horse } \\
\text { power } \\
\text { (hp) }\end{array}$ & Species* & $\begin{array}{c}\text { Density } \\
\text { (lb/ft3) }\end{array}$ & $\begin{array}{c}4 / 4 \text { to } 8 / 4+ \\
\text { Pallet } \\
\text { (Board ft.) }\end{array}$ & $\begin{array}{c}\text { Cant }+ \\
\text { Tim } \\
\text { (Board ft.) }\end{array}$ & $\begin{array}{c}\text { Run } \\
\text { Time } \\
\text { (Mins) }\end{array}$ & $\begin{array}{c}\text { Temp } \\
\left({ }^{\mathbf{0}} \mathbf{F}\right)\end{array}$ & Resaw & Debarker & $\begin{array}{c}\text { Double } \\
\text { Line }\end{array}$ & $\begin{array}{c}\text { Maint. } \\
\text { Level }\end{array}$ & $\begin{array}{c}\text { Total } \\
\text { Board } \\
\text { Feet }\end{array}$ & $\begin{array}{l}\text { Total } \\
\text { kWh }\end{array}$ & SEC \\
\hline 1 & 1 & 968 & SM & 35 & 29,726 & 2,648 & 555 & 50 & 1 & 0 & 0 & 4 & 32,374 & $2,267.90$ & 70.05 \\
\hline 2 & 1 & 968 & $\mathrm{RO}$ & 44 & 5,656 & 0 & 75 & 54 & 1 & 0 & 0 & 4 & 5,656 & 325.19 & 57.49 \\
\hline 3 & 1 & 968 & $\mathrm{RO}$ & 44 & 33,160 & 984 & 630 & 48 & 1 & 0 & 0 & 4 & 34,144 & $2,713.87$ & 79.48 \\
\hline 4 & 1 & 968 & $\mathrm{RO}$ & 44 & 32,004 & 1,416 & 630 & 48 & 1 & 0 & 0 & 4 & 33,420 & $2,886.32$ & 86.37 \\
\hline 5 & 1 & 968 & $\mathrm{RO}$ & 44 & 12,188 & 1,187 & 235 & 50 & 1 & 0 & 0 & 4 & 13,375 & $1,060.73$ & 79.31 \\
\hline 6 & 1 & 968 & WO & 47 & 19,329 & 1,294 & 395 & 62 & 1 & 0 & 0 & 4 & 20,623 & $1,600.11$ & 77.59 \\
\hline 7 & 1 & 968 & AS & 40 & 12,954 & 832 & 240 & 42 & 1 & 0 & 0 & 4 & 13,786 & $1,097.69$ & 79.62 \\
\hline 8 & 1 & 968 & RO & 44 & 17,708 & 816 & 390 & 48 & 1 & 0 & 0 & 4 & 18,524 & $1,586.78$ & 85.66 \\
\hline 9 & 1 & 968 & WO & 47 & 6,765 & 0 & 120 & 36 & 1 & 0 & 0 & 4 & 6,765 & 611.69 & 90.42 \\
\hline 10 & 1 & 968 & $\mathrm{WO}$ & 47 & 22,100 & 240 & 510 & 46 & 1 & 0 & 0 & 4 & 22,340 & $2,143.47$ & 95.95 \\
\hline 11 & 1 & 968 & WO & 47 & 24,663 & 312 & 570 & 55 & 1 & 0 & 0 & 4 & 24,975 & $2,366.43$ & 94.75 \\
\hline 12 & 1 & 968 & $\mathrm{HM}$ & 47 & 29,521 & 1,320 & 630 & 66 & 1 & 0 & 0 & 4 & 30,841 & $2,585.31$ & 83.83 \\
\hline 13 & 1 & 968 & HM & 47 & 28,348 & 1,640 & 630 & 66 & 1 & 0 & 0 & 4 & 29,988 & $2,664.01$ & 88.84 \\
\hline 14 & 1 & 968 & SM & 35 & 31,129 & 1,056 & 630 & 60 & 1 & 0 & 0 & 4 & 32,185 & $2,623.49$ & 81.51 \\
\hline 15 & 1 & 968 & $\mathrm{HK}$ & 64 & 8,489 & 192 & 240 & 58 & 1 & 0 & 0 & 4 & 8,681 & $1,010.33$ & 116.38 \\
\hline 16 & 1 & 968 & WO & 47 & 12,093 & 2,613 & 285 & 64 & 1 & 0 & 0 & 4 & 14,706 & $1,138.54$ & 77.42 \\
\hline 17 & 1 & 968 & $\mathrm{CH}$ & 56 & 3,337 & 435 & 105 & 66 & 1 & 0 & 0 & 4 & 3,772 & 449.74 & 119.23 \\
\hline 18 & 1 & 968 & $\mathrm{CH}$ & 56 & 19,746 & 7,241 & 630 & 60 & 1 & 0 & 0 & 4 & 26,987 & $2,662.48$ & 98.66 \\
\hline 19 & 1 & 968 & $\mathrm{CH}$ & 56 & 8,815 & 676 & 195 & 48 & 1 & 0 & 0 & 4 & 9,491 & 906.37 & 95.50 \\
\hline 20 & 1 & 968 & $\mathrm{RO}$ & 44 & 17,670 & 552 & 435 & 56 & 1 & 0 & 0 & 4 & 18,222 & $1,726.44$ & 94.74 \\
\hline 21 & 1 & 968 & RO & 44 & 28,526 & 744 & 630 & 61 & 1 & 0 & 0 & 4 & 29,270 & $2,656.64$ & 90.76 \\
\hline 22 & 1 & 968 & $\mathrm{RO}$ & 44 & 29,629 & 1,240 & 630 & 66 & 1 & 0 & 0 & 4 & 30,869 & $2,683.63$ & 86.94 \\
\hline 23 & 2 & 817 & HK & 64 & 4,904 & 5,237 & 270 & 43 & 0 & 0 & 0 & 3 & 10,141 & 903.83 & 89.13 \\
\hline 24 & 2 & 817 & WO & 47 & 5,863 & 3,925 & 240 & 47 & 0 & 0 & 0 & 3 & 9,788 & 724.24 & 73.99 \\
\hline 25 & 2 & 817 & $\mathrm{WO}$ & 47 & 10,301 & 6,540 & 510 & 58 & 0 & 0 & 0 & 3 & 16,841 & $1,535.14$ & 91.16 \\
\hline 26 & 2 & 817 & WO & 47 & 11,034 & 8,891 & 510 & 44 & 0 & 0 & 0 & 3 & 19,925 & $1,583.44$ & 79.47 \\
\hline 27 & 2 & 817 & WO & 47 & 3,975 & 3,867 & 180 & 34 & 0 & 0 & 0 & 3 & 7,842 & 596.00 & 76.00 \\
\hline 28 & 2 & 817 & YP & 24 & 5,858 & 7,166 & 270 & 38 & 0 & 0 & 0 & 3 & 13,024 & 749.42 & 57.54 \\
\hline 29 & 2 & 817 & YP & 24 & 2,598 & 4,194 & 120 & 24 & 0 & 0 & 0 & 3 & 6,792 & 415.98 & 61.25 \\
\hline 30 & 2 & 817 & YP & 24 & 7,967 & 10,652 & 390 & 28 & 0 & 0 & 0 & 3 & 18,619 & $1,131.87$ & 60.79 \\
\hline 31 & 2 & 817 & RO & 44 & 13,481 & 8,950 & 510 & 28 & 0 & 0 & 0 & 3 & 22,431 & $1,571.08$ & 70.04 \\
\hline
\end{tabular}




\begin{tabular}{|c|c|c|c|c|c|c|c|c|c|c|c|c|c|c|c|}
\hline $\begin{array}{l}\text { Shift } \\
\text { No. }\end{array}$ & Mill \# & $\begin{array}{c}\text { Horse } \\
\text { power } \\
\text { (hp) } \\
\end{array}$ & Species* & $\begin{array}{r}\text { Density } \\
\text { (lb/ft3) }\end{array}$ & $\begin{array}{c}4 / 4 \text { to } 8 / 4+ \\
\text { Pallet } \\
\text { (Board ft.) }\end{array}$ & $\begin{array}{c}\text { Cant }+ \\
\text { Tim } \\
\text { (Board ft.) }\end{array}$ & $\begin{array}{c}\text { Run } \\
\text { Time } \\
\text { (Mins) }\end{array}$ & $\begin{array}{c}\text { Temp } \\
\left({ }^{\circ} \mathbf{F}\right)\end{array}$ & Resaw & Debarker & $\begin{array}{c}\text { Double } \\
\text { Line }\end{array}$ & $\begin{array}{c}\text { Maint. } \\
\text { Level }\end{array}$ & $\begin{array}{c}\text { Total } \\
\text { Board } \\
\text { Feet }\end{array}$ & $\begin{array}{l}\text { Total } \\
\text { kWh }\end{array}$ & SEC \\
\hline 32 & 2 & 817 & $\mathrm{RO}$ & 44 & 8,162 & 7,840 & 510 & 43 & 0 & 0 & 0 & 3 & 16,002 & $1,504.34$ & 94.01 \\
\hline 33 & 2 & 817 & RO & 44 & 10,465 & 7,593 & 510 & 31 & 0 & 0 & 0 & 3 & 18,058 & $1,537.66$ & 85.15 \\
\hline 34 & 2 & 817 & $\mathrm{RO}$ & 44 & 7,211 & 4,914 & 300 & 21 & 0 & 0 & 0 & 3 & 12,125 & 979.90 & 80.82 \\
\hline 35 & 2 & 817 & HK & 64 & 1,852 & 2,775 & 150 & 24 & 0 & 0 & 0 & 3 & 4,627 & 435.17 & 94.05 \\
\hline 36 & 2 & 817 & HK & 64 & 5,706 & 7,104 & 330 & 21 & 0 & 0 & 0 & 3 & 12,810 & $1,115.42$ & 87.07 \\
\hline 37 & 2 & 817 & $\mathrm{RO}$ & 44 & 3,231 & 3,307 & 150 & 24 & 0 & 0 & 0 & 3 & 6,538 & 501.04 & 76.63 \\
\hline 38 & 2 & 817 & RO & 44 & 9,196 & 8,931 & 510 & 20 & 0 & 0 & 0 & 3 & 18,127 & $1,604.75$ & 88.53 \\
\hline 39 & 2 & 817 & RO & 44 & 9,802 & 8,309 & 510 & 36 & 0 & 0 & 0 & 3 & 18,111 & $1,531.05$ & 84.54 \\
\hline 40 & 2 & 817 & RO & 44 & 9,765 & 6,199 & 480 & 50 & 0 & 0 & 0 & 3 & 15,964 & $1,458.31$ & 91.35 \\
\hline 41 & 2 & 817 & WO & 47 & 613 & 862 & 30 & 50 & 0 & 0 & 0 & 3 & 1,475 & 101.60 & 68.88 \\
\hline 42 & 2 & 817 & WO & 47 & 8,613 & 11,556 & 450 & 49 & 0 & 0 & 0 & 3 & 20,169 & $1,396.76$ & 69.25 \\
\hline 43 & 2 & 817 & WO & 47 & 1,682 & 1,600 & 105 & 14 & 0 & 0 & 0 & 3 & 3,282 & 353.10 & 107.59 \\
\hline 44 & 2 & 817 & WO & 47 & 6,595 & 7,461 & 405 & 18 & 0 & 0 & 0 & 3 & 14,056 & $1,208.05$ & 85.95 \\
\hline 45 & 2 & 817 & WO & 47 & 6,872 & 7,177 & 450 & 18 & 0 & 0 & 0 & 3 & 14,049 & $1,422.61$ & 101.26 \\
\hline 46 & 2 & 817 & SM & 35 & 1,236 & 891 & 60 & 18 & 0 & 0 & 0 & 3 & 2,127 & 174.33 & 81.96 \\
\hline 47 & 2 & 817 & SM & 35 & 10,589 & 6,930 & 510 & 25 & 0 & 0 & 0 & 3 & 17,519 & $1,529.56$ & 87.31 \\
\hline 48 & 2 & 817 & SM & 35 & 6,155 & 3,888 & 255 & 38 & 0 & 0 & 0 & 3 & 10,043 & 808.40 & 80.49 \\
\hline 49 & 2 & 817 & RO & 44 & 5,320 & 2,990 & 255 & 42 & 0 & 0 & 0 & 3 & 8,310 & 720.68 & 86.72 \\
\hline 50 & 2 & 817 & $\mathrm{RO}$ & 44 & 9,135 & 6,592 & 450 & 61 & 0 & 0 & 0 & 3 & 15,727 & $1,285.07$ & 81.71 \\
\hline 51 & 2 & 817 & RO & 44 & 6,847 & 5,067 & 330 & 53 & 0 & 0 & 0 & 3 & 11,914 & $1,049.50$ & 88.09 \\
\hline 52 & 2 & 817 & HM & 47 & 4,361 & 1,520 & 180 & 57 & 0 & 0 & 0 & 3 & 5,881 & 518.39 & 88.15 \\
\hline 53 & 2 & 817 & $\mathrm{HM}$ & 47 & 10,900 & 4,348 & 510 & 56 & 0 & 0 & 0 & 3 & 15,248 & $1,526.90$ & 100.14 \\
\hline 54 & 2 & 817 & HM & 47 & 735 & 1,430 & 45 & 45 & 0 & 0 & 0 & 3 & 2,165 & 172.41 & 79.64 \\
\hline 55 & 2 & 817 & RO & 44 & 2,584 & 8,378 & 465 & 52 & 0 & 0 & 0 & 3 & 10,962 & $1,371.06$ & 125.07 \\
\hline 56 & 2 & 817 & $\mathrm{RO}$ & 44 & 1,451 & 1,459 & 60 & 28 & 0 & 0 & 0 & 3 & 2,910 & 261.08 & 89.72 \\
\hline 57 & 2 & 817 & $\mathrm{RO}$ & 44 & 10,119 & 6,966 & 450 & 34 & 0 & 0 & 0 & 3 & 17,085 & $1,375.53$ & 80.51 \\
\hline 58 & 3 & $2,630.5$ & $\mathrm{RO}$ & 44 & 70,762 & 9,645 & 480 & 52 & 1 & 1 & 1 & 2 & 80,407 & $8,464.90$ & 105.28 \\
\hline 59 & 3 & $2,630.5$ & $\mathrm{RO}$ & 44 & 15,476 & 2,717 & 120 & 32 & 1 & 1 & 1 & 2 & 18,193 & $2,264.58$ & 124.48 \\
\hline 60 & 3 & $2,630.5$ & WO & 47 & 52,297 & 10,694 & 360 & 39 & 1 & 1 & 1 & 2 & 62,991 & $6,551.06$ & 104.00 \\
\hline 61 & 3 & $2,630.5$ & WO & 47 & 53,822 & 8,726 & 390 & 42 & 1 & 1 & 1 & 2 & 62,548 & $6,981.93$ & 111.63 \\
\hline 62 & 3 & $2,630.5$ & $\mathrm{HM}$ & 47 & 14,251 & - & 90 & 44 & 1 & 1 & 1 & 2 & 14,251 & $1,591.53$ & 111.68 \\
\hline 63 & 3 & $2,630.5$ & $\mathrm{HM}$ & 47 & 25,722 & 1,272 & 120 & 34 & 1 & 1 & 1 & 2 & 26,994 & $2,315.49$ & 85.78 \\
\hline 64 & 3 & $2,630.5$ & $\mathrm{SM}$ & 35 & 54,330 & 7,372 & 360 & 39 & 1 & 1 & 1 & 2 & 61,702 & $6,430.15$ & 104.21 \\
\hline
\end{tabular}




\begin{tabular}{|c|c|c|c|c|c|c|c|c|c|c|c|c|c|c|c|}
\hline $\begin{array}{l}\text { Shift } \\
\text { No. }\end{array}$ & Mill \# & $\begin{array}{c}\text { Horse } \\
\text { power } \\
\text { (hp) }\end{array}$ & Species* & $\begin{array}{r}\text { Density } \\
\text { (lb/ft3) }\end{array}$ & $\begin{array}{c}4 / 4 \text { to } 8 / 4+ \\
\text { Pallet } \\
\text { (Board ft.) }\end{array}$ & $\begin{array}{c}\text { Cant }+ \\
\text { Tim } \\
\text { (Board ft.) }\end{array}$ & $\begin{array}{c}\text { Run } \\
\text { Time } \\
\text { (Mins) }\end{array}$ & $\begin{array}{c}\text { Temp } \\
\left({ }^{\mathbf{0}} \mathbf{F}\right)\end{array}$ & Resaw & Debarker & $\begin{array}{c}\text { Double } \\
\text { Line }\end{array}$ & $\begin{array}{c}\text { Maint. } \\
\text { Level }\end{array}$ & $\begin{array}{c}\text { Total } \\
\text { Board } \\
\text { Feet }\end{array}$ & $\begin{array}{l}\text { Total } \\
\text { kWh }\end{array}$ & SEC \\
\hline 65 & 3 & $2,630.5$ & SM & 35 & 36,481 & 4,917 & 240 & 45 & 1 & 1 & 1 & 2 & 41,398 & $4,299.55$ & 103.86 \\
\hline 66 & 3 & $2,630.5$ & HK & 64 & 24,743 & 15,166 & 210 & 47 & 1 & 1 & 1 & 2 & 39,909 & $4,455.75$ & 111.65 \\
\hline 67 & 3 & $2,630.5$ & $\mathrm{CH}$ & 56 & 82,405 & - & 480 & 62 & 1 & 1 & 1 & 2 & 82,405 & $8,657.71$ & 105.06 \\
\hline 68 & 3 & $2,630.5$ & $\mathrm{RO}$ & 44 & 77,793 & 3,172 & 480 & 70 & 1 & 1 & 1 & 2 & 80,965 & $8,767.84$ & 108.29 \\
\hline 69 & 3 & $2,630.5$ & YP & 24 & 84,341 & - & 480 & 61 & 1 & 1 & 1 & 2 & 84,341 & $7,281.16$ & 86.33 \\
\hline 70 & 3 & $2,630.5$ & YP & 24 & 80,230 & - & 480 & 66 & 1 & 1 & 1 & 2 & 80,230 & $7,195.51$ & 89.69 \\
\hline 71 & 3 & $2,630.5$ & YP & 24 & 82,402 & - & 480 & 71 & 1 & 1 & 1 & 2 & 82,402 & $6,701.76$ & 81.33 \\
\hline 72 & 3 & $2,630.5$ & YP & 24 & 83,415 & - & 480 & 61 & 1 & 1 & 1 & 2 & 83,415 & $7,075.26$ & 84.82 \\
\hline 73 & 3 & $2,630.5$ & $\mathrm{RO}$ & 44 & 76,564 & 3,388 & 480 & 34 & 1 & 1 & 1 & 2 & 79,952 & $8,664.44$ & 108.37 \\
\hline 74 & 3 & $2,630.5$ & BR & 44 & 28,493 & 15,223 & 315 & 49 & 1 & 1 & 1 & 2 & 43,716 & $5,428.20$ & 124.17 \\
\hline 75 & 3 & $2,630.5$ & YP & 24 & 34,619 & - & 165 & 53 & 1 & 1 & 1 & 2 & 34,619 & $2,854.32$ & 82.45 \\
\hline 76 & 3 & $2,630.5$ & HM & 47 & 38,783 & - & 300 & 42 & 1 & 1 & 1 & 2 & 38,783 & $5,457.95$ & 140.73 \\
\hline 77 & 3 & $2,630.5$ & SM & 35 & 25,114 & 4,076 & 180 & 44 & 1 & 1 & 1 & 2 & 29,190 & $3,074.22$ & 105.32 \\
\hline 78 & 3 & $2,630.5$ & SM & 35 & 63,695 & 11,321 & 480 & 48 & 1 & 1 & 1 & 2 & 75,016 & $8,304.22$ & 110.70 \\
\hline 79 & 3 & $2,630.5$ & SM & 35 & 65,815 & 12,566 & 480 & 50 & 1 & 1 & 1 & 2 & 78,381 & $8,508.43$ & 108.55 \\
\hline 80 & 3 & $2,630.5$ & SM & 35 & 12,258 & 3,681 & 90 & 48 & 1 & 1 & 1 & 2 & 15,939 & $1,653.18$ & 103.72 \\
\hline 81 & 3 & $2,630.5$ & RO & 44 & 49,854 & 2,217 & 390 & 54 & 1 & 1 & 1 & 2 & 52,071 & $6,810.27$ & 130.79 \\
\hline 82 & 3 & $2,630.5$ & $\mathrm{RO}$ & 44 & 75,778 & 5,791 & 480 & 51 & 1 & 1 & 1 & 2 & 81,569 & $8,764.15$ & 107.44 \\
\hline 83 & 4 & 1,534 & $\mathrm{RO}$ & 44 & 8,791 & 4,264 & 195 & 52 & 0 & 0 & 1 & 2 & 13,055 & $1,504.23$ & 115.22 \\
\hline 84 & 4 & 1,534 & $\mathrm{YP}$ & 24 & 25,259 & 4,138 & 405 & 58 & 0 & 0 & 1 & 2 & 29,397 & $3,181.70$ & 108.23 \\
\hline 85 & 4 & 1,534 & YP & 24 & 43,156 & 6,370 & 600 & 52 & 0 & 0 & 1 & 2 & 49,526 & $4,935.25$ & 99.65 \\
\hline 86 & 4 & 1,534 & YP & 24 & 38,884 & 7,182 & 600 & 52 & 0 & 0 & 1 & 2 & 46,066 & $4,747.09$ & 103.05 \\
\hline 87 & 4 & 1,534 & YP & 24 & 34,213 & 5,548 & 555 & 55 & 0 & 0 & 1 & 2 & 39,761 & $4,361.89$ & 109.70 \\
\hline 88 & 4 & 1,534 & SY & 26 & 1,678 & 1,744 & 45 & 56 & 0 & 0 & 1 & 2 & 3,422 & 345.41 & 100.94 \\
\hline 89 & 4 & 1,534 & SY & 26 & 6,296 & 13,659 & 300 & 65 & 0 & 0 & 1 & 2 & 19,955 & $2,334.09$ & 116.97 \\
\hline 90 & 4 & 1,534 & $\mathrm{HM}$ & 47 & 19,689 & 5,040 & 300 & 70 & 0 & 0 & 1 & 2 & 24,729 & $2,434.23$ & 98.44 \\
\hline 91 & 4 & 1,534 & HM & 47 & 27,905 & 6,674 & 600 & 68 & 0 & 0 & 1 & 2 & 34,579 & $4,769.64$ & 137.93 \\
\hline 92 & 4 & 1,534 & HM & 47 & 7,188 & 1,852 & 180 & 67 & 0 & 0 & 1 & 2 & 9,040 & $1,332.59$ & 147.41 \\
\hline 93 & 4 & 1,534 & HK & 64 & 15,478 & 3,748 & 420 & 72 & 0 & 0 & 1 & 2 & 19,226 & $3,255.79$ & 169.34 \\
\hline 94 & 4 & 1,534 & $\mathrm{HK}$ & 64 & 15,437 & 4,070 & 330 & 66 & 0 & 0 & 1 & 2 & 19,507 & $3,022.05$ & 154.92 \\
\hline 95 & 4 & 1,534 & SY & 26 & 4,915 & 5,948 & 120 & 74 & 0 & 0 & 1 & 2 & 10,863 & 853.89 & 78.61 \\
\hline 96 & 4 & 1,534 & SM & 35 & 23,908 & 11,956 & 465 & 77 & 0 & 0 & 1 & 2 & 35,864 & $3,768.55$ & 105.08 \\
\hline 97 & 4 & 1,534 & SM & 35 & 15,917 & 12,216 & 330 & 72 & 0 & 0 & 1 & 2 & 28,133 & $2,540.12$ & 90.29 \\
\hline
\end{tabular}




\begin{tabular}{|c|c|c|c|c|c|c|c|c|c|c|c|c|c|c|c|}
\hline $\begin{array}{l}\text { Shift } \\
\text { No. }\end{array}$ & Mill \# & $\begin{array}{c}\text { Horse } \\
\text { power } \\
\text { (hp) }\end{array}$ & Species* & $\begin{array}{c}\text { Density } \\
\text { (lb/ft3) }\end{array}$ & $\begin{array}{c}4 / 4 \text { to } 8 / 4+ \\
\text { Pallet } \\
\text { (Board ft.) }\end{array}$ & $\begin{array}{c}\text { Cant }+ \\
\text { Tim } \\
\text { (Board ft.) }\end{array}$ & $\begin{array}{c}\text { Run } \\
\text { Time } \\
\text { (Mins) }\end{array}$ & $\begin{array}{c}\text { Temp } \\
\left({ }^{\circ} \mathbf{F}\right)\end{array}$ & Resaw & Debarker & $\begin{array}{c}\text { Double } \\
\text { Line }\end{array}$ & $\begin{array}{c}\text { Maint. } \\
\text { Level }\end{array}$ & $\begin{array}{c}\text { Total } \\
\text { Board } \\
\text { Feet } \\
\end{array}$ & $\begin{array}{l}\text { Total } \\
\text { kWh }\end{array}$ & SEC \\
\hline 98 & 4 & 1,534 & $\mathrm{RO}$ & 44 & 12,724 & 3,244 & 270 & 76 & 0 & 0 & 1 & 2 & 15,968 & $2,244.00$ & 140.53 \\
\hline 99 & 4 & 1,534 & RO & 44 & 27,184 & 6,783 & 600 & 66 & 0 & 0 & 1 & 2 & 33,967 & $4,909.50$ & 144.54 \\
\hline 100 & 4 & 1,534 & $\mathrm{RO}$ & 44 & 21,340 & 5,565 & 525 & 60 & 0 & 0 & 1 & 2 & 26,905 & $4,217.76$ & 156.76 \\
\hline 101 & 4 & 1,534 & YP & 24 & 21,700 & 3,052 & 355 & 73 & 0 & 0 & 1 & 2 & 24,752 & $2,766.36$ & 111.76 \\
\hline 102 & 4 & 1,534 & YP & 24 & 33,112 & 5,922 & 600 & 64 & 0 & 0 & 1 & 2 & 39,034 & $4,702.11$ & 120.46 \\
\hline 103 & 4 & 1,534 & YP & 24 & 10,144 & 2,149 & 195 & 78 & 0 & 0 & 1 & 2 & 12,293 & $1,478.34$ & 120.26 \\
\hline 104 & 4 & 1,534 & AS & 40 & 21,944 & 4,512 & 395 & 82 & 0 & 0 & 1 & 2 & 26,456 & $3,109.02$ & 117.52 \\
\hline 105 & 4 & 1,534 & AS & 40 & 23,151 & 4,739 & 600 & 78 & 0 & 0 & 1 & 2 & 27,890 & $4,458.74$ & 159.87 \\
\hline 106 & 4 & 1,534 & AS & 40 & 16,449 & 3,752 & 330 & 59 & 0 & 0 & 1 & 2 & 20,201 & $2,612.90$ & 129.35 \\
\hline 107 & 4 & 1,534 & $\mathrm{HM}$ & 47 & 12,199 & 2,902 & 270 & 62 & 0 & 0 & 1 & 2 & 15,101 & $2,218.52$ & 146.91 \\
\hline 108 & 4 & 1,534 & $\mathrm{HM}$ & 47 & 28,046 & 6,643 & 600 & 60 & 0 & 0 & 1 & 2 & 34,689 & $4,800.24$ & 138.38 \\
\hline 109 & $5,1 \#$ & 1,686 & $\mathrm{RO}$ & 44 & 21,909 & - & 266 & 58 & 1 & 1 & 0 & 2 & 21,909 & $2,325.14$ & 106.13 \\
\hline 110 & 5,1 & 1,686 & $\mathrm{HM}$ & 47 & 26,052 & - & 342 & 62 & 1 & 1 & 0 & 2 & 26,052 & $2,963.61$ & 113.76 \\
\hline 111 & 5,2 & 1,686 & $\mathrm{HM}$ & 47 & 32,150 & - & 582 & 57 & 1 & 1 & 0 & 2 & 32,150 & $4,946.48$ & 153.86 \\
\hline 112 & 5,1 & 1,686 & HM & 47 & 8,160 & - & 130 & 52 & 1 & 1 & 0 & 2 & 8,160 & $1,122.39$ & 137.55 \\
\hline 113 & 5,1 & 1,686 & YP & 24 & 50,813 & 9,975 & 482 & 56 & 1 & 1 & 0 & 2 & 60,788 & $4,115.69$ & 67.71 \\
\hline 114 & 5,2 & 1,686 & $\mathrm{YP}$ & 24 & 50,448 & 10,698 & 598 & 50 & 1 & 1 & 0 & 2 & 61,146 & $5,189.42$ & 84.87 \\
\hline 115 & 5,1 & 1,686 & YP & 24 & 63,128 & 11,645 & 584 & 65 & 1 & 1 & 0 & 2 & 74,773 & $5,064.19$ & 67.73 \\
\hline 116 & 5,2 & 1,686 & RO & 44 & 43,450 & - & 647 & 60 & 1 & 1 & 0 & 2 & 43,450 & $5,632.85$ & 129.64 \\
\hline 117 & 5,1 & 1,686 & $\mathrm{RO}$ & 44 & 55,938 & - & 627 & 56 & 1 & 1 & 0 & 2 & 55,938 & $5,495.17$ & 98.24 \\
\hline 118 & 5,2 & 1,686 & $\mathrm{RO}$ & 44 & 37,107 & - & 604 & 51 & 1 & 1 & 0 & 2 & 37,107 & $5,192.91$ & 139.94 \\
\hline 119 & 5,1 & 1,686 & $\mathrm{RO}$ & 44 & 46,659 & - & 608 & 51 & 1 & 1 & 0 & 2 & 46,659 & $5,310.84$ & 113.82 \\
\hline 120 & 5,2 & 1,686 & RO & 44 & 36,535 & - & 592 & 48 & 1 & 1 & 0 & 2 & 36,535 & $5,041.39$ & 137.99 \\
\hline 121 & 5,1 & 1,686 & RO & 44 & 8,813 & - & 117 & 61 & 1 & 1 & 0 & 2 & 8,813 & $1,003.77$ & 113.90 \\
\hline 122 & 5,1 & 1,686 & AS & 40 & 36,489 & - & 427 & 63 & 1 & 1 & 0 & 2 & 36,489 & $3,722.08$ & 102.01 \\
\hline 123 & 5,2 & 1,686 & SM & 35 & 33,653 & 10,096 & 601 & 56 & 1 & 1 & 0 & 2 & 43,749 & $5,162.08$ & 117.99 \\
\hline 124 & 5,1 & 1,686 & SM & 35 & 43,846 & 11,156 & 611 & 67 & 1 & 1 & 0 & 2 & 55,002 & $5,296.20$ & 96.29 \\
\hline 125 & 5,2 & 1,686 & SM & 35 & 24,196 & 7,068 & 410 & 63 & 1 & 1 & 0 & 2 & 31,264 & $3,517.04$ & 112.49 \\
\hline 126 & 5,1 & 1,686 & WO & 47 & 39,585 & 6,796 & 625 & 72 & 1 & 1 & 0 & 2 & 46,381 & $5,371.99$ & 115.82 \\
\hline 127 & 5,2 & 1,686 & WO & 47 & 32,131 & 4,912 & 596 & 67 & 1 & 1 & 0 & 2 & 37,043 & $5,127.90$ & 138.43 \\
\hline 128 & 5,1 & 1,686 & WO & 47 & 40,343 & 4,147 & 614 & 69 & 1 & 1 & 0 & 2 & 44,490 & $5,311.83$ & 119.39 \\
\hline 129 & 5,2 & 1,686 & WO & 47 & 23,758 & 7,228 & 562 & 64 & 1 & 1 & 0 & 2 & 30,986 & $4,690.13$ & 151.36 \\
\hline 130 & 5,1 & 1,686 & $\mathrm{RO}$ & 44 & 38,448 & 1,834 & 523 & 60 & 1 & 1 & 0 & 2 & 40,282 & $4,642.43$ & 115.25 \\
\hline
\end{tabular}




\begin{tabular}{|c|c|c|c|c|c|c|c|c|c|c|c|c|c|c|c|}
\hline $\begin{array}{c}\text { Shift } \\
\text { No. }\end{array}$ & Mill \# & $\begin{array}{c}\text { Horse } \\
\text { power } \\
\text { (hp) }\end{array}$ & Species* & $\begin{array}{r}\text { Density } \\
\text { (lb/ft3) }\end{array}$ & $\begin{array}{c}4 / 4 \text { to } 8 / 4+ \\
\text { Pallet } \\
\text { (Board ft.) }\end{array}$ & $\begin{array}{c}\text { Cant }+ \\
\text { Tim } \\
\text { (Board ft.) }\end{array}$ & $\begin{array}{c}\text { Run } \\
\text { Time } \\
\text { (Mins) }\end{array}$ & $\begin{array}{c}\text { Temp } \\
\left({ }^{0} \mathbf{F}\right)\end{array}$ & Resaw & Debarker & $\begin{array}{c}\text { Double } \\
\text { Line }\end{array}$ & $\begin{array}{c}\text { Maint. } \\
\text { Level }\end{array}$ & $\begin{array}{c}\text { Total } \\
\text { Board } \\
\text { Feet }\end{array}$ & $\begin{array}{l}\text { Total } \\
\text { kWh }\end{array}$ & SEC \\
\hline 131 & 5,1 & 1,686 & RO & 44 & 6,000 & - & 90 & 67 & 1 & 1 & 0 & 2 & 6,000 & 761.18 & 126.86 \\
\hline 132 & 5,1 & 1,686 & HM & 47 & 36,454 & - & 534 & 72 & 1 & 1 & 0 & 2 & 36,454 & $4,700.60$ & 128.95 \\
\hline 133 & 5,2 & 1,686 & HM & 47 & 23,203 & 4,326 & 565 & 67 & 1 & 1 & 0 & 2 & 27,529 & $4,710.43$ & 171.11 \\
\hline
\end{tabular}

* SM - Soft Maple, RO - Red Oak, WO - White Oak, AS - Ash, HM - Hard Maple, HK - Hickory, CH - Cherry, YP - Yellow Poplar, BR - Birch, SY - Sycamore 
Table A.4: Lumber Production Data Collected in Board Feet used for Analysis

\begin{tabular}{|c|c|c|c|c|c|c|c|c|c|c|c|c|c|c|c|}
\hline $\begin{array}{l}\text { Shift } \\
\text { No. }\end{array}$ & $\begin{array}{c}\text { Mill } \\
\#\end{array}$ & Date & Start time & End time & $4 / 4$ & $5 / 4$ & $6 / 4$ & $8 / 4$ & Pallet & $\begin{array}{c}\text { Cants } \\
\text { 3"x8"x12' } \\
\end{array}$ & $\begin{array}{c}\text { Cants } \\
5 \text { "x6"x12' } \\
\end{array}$ & $\begin{array}{c}\text { Cants } \\
\text { 3"x4"x12' } \\
\end{array}$ & $\begin{array}{c}\text { Cants } \\
3.5 " \times 6 " x 12 \text { " }\end{array}$ & $\begin{array}{c}\text { Cants } \\
\text { 14"x4"x12, }\end{array}$ & $\begin{array}{c}\text { Timber } \\
\text { 7"x9"x12, }\end{array}$ \\
\hline 1 & 1 & $4 / 14 / 09$ & 5:30 AM & $2: 45$ PM & 29,726 & 0 & 0 & 0 & 0 & 1,728 & 0 & 0 & 0 & 0 & 920 \\
\hline 2 & 1 & $4 / 14 / 09$ & 2:45 PM & 4:00 PM & 2,939 & 0 & 0 & 1,932 & 785 & 0 & 0 & 0 & 0 & 0 & 0 \\
\hline 4 & 1 & $4 / 16 / 09$ & 5:30 AM & 4:00 PM & 19,922 & 5,782 & 0 & 0 & 6,300 & 1,416 & 0 & 0 & 0 & 0 & 0 \\
\hline 5 & 1 & $4 / 20 / 09$ & $5: 30 \mathrm{AM}$ & $9: 25 \mathrm{AM}$ & 8,557 & 1,210 & 0 & 0 & 2,421 & 312 & 0 & 0 & 0 & 0 & 875 \\
\hline 6 & 1 & $4 / 20 / 09$ & 9:25 AM & 4:00 PM & 13,670 & 0 & 0 & 0 & 5,659 & 699 & 0 & 0 & 0 & 0 & 595 \\
\hline 8 & 1 & $4 / 21 / 09$ & 9:30 AM & 4:00 PM & 12,708 & 2,424 & 0 & 0 & 2,576 & 816 & 0 & 0 & 0 & 0 & 0 \\
\hline 9 & 1 & $4 / 22 / 09$ & 5:30 AM & $7: 30 \mathrm{AM}$ & 4,925 & 827 & 0 & 0 & 1,013 & 0 & 0 & 0 & 0 & 0 & 0 \\
\hline 10 & 1 & $4 / 22 / 09$ & $7: 30 \mathrm{AM}$ & 4:00 PM & 14,722 & 0 & 3,284 & 0 & 4,094 & 240 & 0 & 0 & 0 & 0 & 0 \\
\hline 11 & 1 & $4 / 23 / 09$ & 5:30 AM & 3:00 PM & 16,521 & 0 & 4,334 & 0 & 3,808 & 312 & 0 & 0 & 0 & 0 & 0 \\
\hline 12 & 1 & $4 / 27 / 09$ & $5: 30 \mathrm{AM}$ & 4:00 PM & 22,509 & 3,890 & 0 & 0 & 3,122 & 1,320 & 0 & 0 & 0 & 0 & 0 \\
\hline 13 & 1 & $4 / 28 / 09$ & 5:30 AM & 4:00 PM & 21,655 & 3,418 & 0 & 0 & 3,275 & 720 & 0 & 0 & 0 & 0 & 920 \\
\hline 14 & 1 & $4 / 29 / 09$ & $5: 30 \mathrm{AM}$ & $4: 00 \mathrm{PM}$ & 27,033 & 0 & 0 & 0 & 4,096 & 1,056 & 0 & 0 & 0 & 0 & 0 \\
\hline 16 & 1 & $4 / 30 / 09$ & 9:30 AM & 2:15 PM & 9,604 & 0 & 0 & 0 & 2,489 & 408 & 0 & 0 & 0 & 0 & 2,205 \\
\hline 17 & 1 & $4 / 30 / 09$ & $2: 15$ PM & 4:00 PM & 2,373 & 0 & 0 & 0 & 964 & 120 & 0 & 0 & 0 & 0 & 315 \\
\hline 18 & 1 & $5 / 4 / 09$ & $5: 30 \mathrm{AM}$ & 4:00 PM & 14,815 & 0 & 0 & 0 & 4,931 & 3,312 & 0 & 0 & 0 & 0 & 3,929 \\
\hline 19 & 1 & $5 / 5 / 09$ & $5: 30 \mathrm{AM}$ & $8: 45$ AM & 6,238 & 0 & 0 & 0 & 2,577 & 480 & 0 & 0 & 0 & 0 & 196 \\
\hline 20 & 1 & $5 / 5 / 09$ & $8: 45$ AM & 4:00 PM & 12,204 & 2,831 & 0 & 0 & 2,635 & 552 & 0 & 0 & 0 & 0 & 0 \\
\hline 21 & 1 & $5 / 6 / 09$ & $5: 30 \mathrm{AM}$ & 4:00 PM & 23,998 & 301 & 0 & 0 & 4,227 & 744 & 0 & 0 & 0 & 0 & 0 \\
\hline 22 & 1 & $5 / 7 / 09$ & 5:30 AM & 4:00 PM & 25,295 & 325 & 0 & 0 & 4,009 & 1,200 & 0 & 0 & 0 & 0 & 40 \\
\hline 23 & 2 & $2 / 10 / 2009$ & 6:00 AM & $10: 30 \mathrm{AM}$ & 4,652 & 0 & 0 & 0 & 252 & 0 & 2,470 & 0 & 0 & 0 & 2,767 \\
\hline 24 & 2 & $2 / 10 / 2009$ & $10: 30 \mathrm{AM}$ & 2:30 PM & 3,783 & 0 & 1,792 & 0 & 288 & 0 & 2,155 & 0 & 0 & 0 & 1,770 \\
\hline 25 & 2 & $2 / 11 / 2009$ & 6:00 AM & $2: 30 \mathrm{PM}$ & 7,819 & 0 & 1,748 & 0 & 734 & 0 & 4,070 & 0 & 0 & 0 & 2,470 \\
\hline 26 & 2 & $2 / 12 / 2009$ & 6:00 AM & $2: 30 \mathrm{PM}$ & 10,190 & 0 & 288 & 0 & 556 & 0 & 5,080 & 0 & 0 & 0 & 3,811 \\
\hline 27 & 2 & $2 / 13 / 2009$ & 6:00 AM & 9:00 AM & 3,479 & 0 & 0 & 0 & 496 & 0 & 1,885 & 0 & 0 & 0 & 1,982 \\
\hline 28 & 2 & $2 / 13 / 2009$ & 9:00 AM & $1: 30 \mathrm{PM}$ & 0 & 0 & 5,858 & 0 & 0 & 0 & 1,520 & 5,332 & 0 & 0 & 314 \\
\hline 29 & 2 & $2 / 16 / 2009$ & 6:00 AM & 8:00 AM & 0 & 0 & 2,598 & 0 & 0 & 0 & 0 & 3,994 & 0 & 0 & 200 \\
\hline 30 & 2 & $2 / 16 / 2009$ & 8:00 AM & 2:30 PM & 6,689 & 0 & 0 & 1,074 & 204 & 0 & 6,660 & 0 & 0 & 0 & 3,992 \\
\hline
\end{tabular}




\begin{tabular}{|c|c|c|c|c|c|c|c|c|c|c|c|c|c|c|c|}
\hline $\begin{array}{l}\text { Shift } \\
\text { No. }\end{array}$ & $\begin{array}{c}\text { Mill } \\
\#\end{array}$ & Date & Start time & End time & $4 / 4$ & $5 / 4$ & $6 / 4$ & $8 / 4$ & Pallet & $\begin{array}{c}\text { Cants } \\
\text { 3"x8"x12' } \\
\end{array}$ & $\begin{array}{c}\text { Cants } \\
5 \text { "x6"x12' }\end{array}$ & $\begin{array}{c}\text { Cants } \\
\text { 3"x4"x12' }\end{array}$ & $\begin{array}{c}\text { Cants } \\
3.5 " \times 6 " x 12 \text { ' }\end{array}$ & $\begin{array}{c}\text { Cants } \\
\text { 14"x4"x12, }\end{array}$ & $\begin{array}{c}\text { Timber } \\
\text { 7"x9"x12, }\end{array}$ \\
\hline 33 & 2 & $2 / 19 / 2009$ & 6:00 AM & 2:30 PM & 8,979 & 0 & 0 & 1,138 & 348 & 0 & 2,600 & 0 & 0 & 0 & 4,993 \\
\hline 34 & 2 & $2 / 20 / 2009$ & 6:00 AM & 11:00 AM & 5,783 & 0 & 0 & 1,144 & 284 & 0 & 1,840 & 0 & 0 & 0 & 3,074 \\
\hline 36 & 2 & $2 / 23 / 2009$ & 6:00 AM & 11:30 AM & 5,448 & 0 & 0 & 0 & 258 & 0 & 1,580 & 0 & 0 & 0 & 5,524 \\
\hline 37 & 2 & $2 / 23 / 2009$ & 12:00 PM & $2: 30 \mathrm{PM}$ & 2,731 & 0 & 0 & 392 & 108 & 0 & 825 & 0 & 0 & 0 & 2,482 \\
\hline 38 & 2 & $2 / 24 / 2009$ & 6:00 AM & $2: 30 \mathrm{PM}$ & 8,068 & 0 & 0 & 610 & 518 & 0 & 2,515 & 0 & 0 & 0 & 6,416 \\
\hline 40 & 2 & $2 / 26 / 2009$ & 6:00 AM & 2:00 PM & 8,821 & 0 & 0 & 380 & 564 & 0 & 2,945 & 0 & 0 & 0 & 3,254 \\
\hline 41 & 2 & $2 / 26 / 2009$ & 2:00 PM & $2: 30 \mathrm{PM}$ & 534 & 69 & 0 & 0 & 10 & 0 & 0 & 0 & 0 & 0 & 862 \\
\hline 42 & 2 & $2 / 27 / 2009$ & 6:00 AM & $1: 30 \mathrm{PM}$ & 6,795 & 1,488 & 0 & 0 & 330 & 0 & 1,140 & 0 & 0 & 0 & 10,416 \\
\hline 43 & 2 & $3 / 2 / 2009$ & 6:00 AM & 7:45 AM & 466 & 1,188 & 0 & 0 & 28 & 0 & 185 & 0 & 0 & 0 & 1,415 \\
\hline 44 & 2 & $3 / 2 / 2009$ & $7: 45$ AM & 2:30 PM & 0 & 6,251 & 0 & 0 & 344 & 0 & 2,510 & 0 & 0 & 0 & 4,951 \\
\hline 45 & 2 & $3 / 3 / 2009$ & 6:00 AM & 1:30 PM & 0 & 6,310 & 0 & 0 & 562 & 0 & 3,650 & 0 & 0 & 0 & 3,527 \\
\hline 46 & 2 & $3 / 3 / 2009$ & 1:30 PM & $2: 30 \mathrm{PM}$ & 0 & 692 & 0 & 540 & 4 & 0 & 240 & 0 & 0 & 0 & 651 \\
\hline 48 & 2 & $3 / 5 / 2009$ & 6:00 AM & $10: 15$ AM & 0 & 3,685 & 0 & 2,014 & 456 & 0 & 3,235 & 0 & 0 & 0 & 653 \\
\hline 49 & 2 & $3 / 5 / 2009$ & 10:15 AM & $2: 30 \mathrm{PM}$ & 5,142 & 0 & 0 & 0 & 178 & 0 & 1,515 & 0 & 0 & 0 & 1,475 \\
\hline 50 & 2 & $3 / 6 / 2009$ & $6: 00$ AM & 1:30 PM & 8,507 & 0 & 0 & 0 & 628 & 0 & 1,630 & 0 & 361 & 0 & 4,601 \\
\hline 51 & 2 & $3 / 9 / 2009$ & 6:00 AM & 11:30 AM & 6,395 & 0 & 0 & 0 & 452 & 0 & 0 & 0 & 764 & 0 & 4,303 \\
\hline 52 & 2 & $3 / 9 / 2009$ & 11:30 AM & 2:30 PM & 4,261 & 0 & 0 & 0 & 100 & 0 & 0 & 0 & 322 & 0 & 1,198 \\
\hline 53 & 2 & $3 / 10 / 2009$ & 6:00 AM & 2:30 PM & 10,666 & 0 & 0 & 0 & 234 & 0 & 0 & 0 & 854 & 0 & 3,494 \\
\hline 54 & 2 & $3 / 11 / 2009$ & 6:00 AM & $6: 45$ AM & 729 & 0 & 0 & 0 & 6 & 0 & 0 & 0 & 39 & 0 & 1,391 \\
\hline 55 & 2 & $3 / 11 / 2009$ & $6: 45$ AM & $2: 30 \mathrm{PM}$ & 1,786 & 0 & 0 & 0 & 798 & 0 & 0 & 0 & 1,100 & 0 & 7,278 \\
\hline 56 & 2 & $3 / 12 / 2009$ & 6:00 AM & 7:00 AM & 1,369 & 0 & 0 & 0 & 82 & 0 & 0 & 0 & 14 & 0 & 1,445 \\
\hline 57 & 2 & $3 / 12 / 2009$ & 7:00 AM & $2: 30 \mathrm{PM}$ & 9,513 & 0 & 0 & 0 & 606 & 0 & 0 & 0 & 1,327 & 0 & 5,639 \\
\hline 58 & 3 & $3 / 25 / 2010$ & 7:00 AM & 3:30 PM & 55,362 & 0 & 0 & 0 & 15,400 & 0 & 0 & 0 & 0 & 0 & 9,645 \\
\hline 59 & 3 & $3 / 26 / 2010$ & 7:00 AM & 9:00 AM & 12,559 & 0 & 0 & 0 & 2,917 & 0 & 0 & 0 & 0 & 0 & 2,717 \\
\hline 60 & 3 & $3 / 26 / 2010$ & 9:00 AM & 3:30 PM & 42,275 & 0 & 0 & 0 & 10,022 & 0 & 0 & 0 & 0 & 0 & 10,694 \\
\hline 61 & 3 & $3 / 29 / 2010$ & 7:00 AM & 2:00 PM & 43,531 & 0 & 0 & 0 & 10,291 & 0 & 0 & 0 & 0 & 0 & 8,726 \\
\hline 62 & 3 & $3 / 29 / 2010$ & 2:00 PM & $3: 30 \mathrm{PM}$ & 11,066 & 0 & 0 & 0 & 3,185 & 0 & 0 & 0 & 0 & 0 & 0 \\
\hline 65 & 3 & $3 / 31 / 2010$ & 7:00 AM & 11:00 AM & 29,375 & 0 & 0 & 0 & 7,106 & 0 & 0 & 0 & 0 & 0 & 4,917 \\
\hline 66 & 3 & $3 / 31 / 2010$ & 11:30 AM & 3:00 PM & 14,729 & 0 & 0 & 0 & 10,014 & 0 & 0 & 0 & 0 & 0 & 15,166 \\
\hline
\end{tabular}




\begin{tabular}{|c|c|c|c|c|c|c|c|c|c|c|c|c|c|c|c|}
\hline $\begin{array}{l}\text { Shift } \\
\text { No. }\end{array}$ & $\begin{array}{c}\text { Mill } \\
\#\end{array}$ & Date & Start time & End time & $4 / 4$ & $5 / 4$ & $6 / 4$ & $8 / 4$ & Pallet & $\begin{array}{c}\text { Cants } \\
\text { 3"x8"x12' } \\
\end{array}$ & $\begin{array}{c}\text { Cants } \\
5 \text { "x6"x12' }\end{array}$ & $\begin{array}{c}\text { Cants } \\
\text { 3"x4"x12' }\end{array}$ & $\begin{array}{c}\text { Cants } \\
3.5 " \times 6 " x 12 \text { ' }\end{array}$ & $\begin{array}{c}\text { Cants } \\
\text { 14"x4"x12, }\end{array}$ & $\begin{array}{c}\text { Timber } \\
\text { 7"x9"x12, }\end{array}$ \\
\hline 67 & 3 & $4 / 1 / 2010$ & 7:00 AM & 3:30 PM & 69,023 & 0 & 0 & 0 & 13,382 & 0 & 0 & 0 & 0 & 0 & 0 \\
\hline 68 & 3 & $4 / 2 / 2010$ & 7:00 AM & $3: 30 \mathrm{PM}$ & 62,390 & 0 & 0 & 0 & 15,403 & 0 & 0 & 0 & 0 & 0 & 3,172 \\
\hline 70 & 3 & $4 / 6 / 2010$ & 7:00 AM & $3: 30 \mathrm{PM}$ & 63,511 & 0 & 0 & 0 & 16,719 & 0 & 0 & 0 & 0 & 0 & 0 \\
\hline 71 & 3 & $4 / 7 / 2010$ & 7:00 AM & $3: 30 \mathrm{PM}$ & 62,532 & 0 & 0 & 0 & 19,870 & 0 & 0 & 0 & 0 & 0 & 0 \\
\hline 72 & 3 & $4 / 8 / 2010$ & 7:00 AM & 3:30 PM & 63,574 & 0 & 19,841 & 0 & 0 & 0 & 0 & 0 & 0 & 0 & 0 \\
\hline 74 & 3 & $4 / 12 / 2010$ & $7: 00 \mathrm{AM}$ & $12: 45 \mathrm{PM}$ & 22,325 & 0 & 0 & 0 & 6,168 & 0 & 0 & 0 & 0 & 0 & 15,223 \\
\hline 75 & 3 & $4 / 12 / 2010$ & $12: 45 \mathrm{PM}$ & 3:30 PM & 18,201 & 0 & 11,179 & 382 & 4,857 & 0 & 0 & 0 & 0 & 0 & 0 \\
\hline 76 & 3 & $4 / 19 / 2010$ & 7:00 AM & 12:30 PM & 32,383 & 0 & 0 & 0 & 6,400 & 0 & 0 & 0 & 0 & 0 & 0 \\
\hline 77 & 3 & $4 / 19 / 2010$ & 12:30 PM & 3:30 PM & 19,909 & 0 & 0 & 0 & 5,205 & 0 & 0 & 0 & 0 & 0 & 4,076 \\
\hline 78 & 3 & $4 / 20 / 2010$ & 7:00 AM & 3:30 PM & 50,814 & 0 & 0 & 0 & 12,881 & 0 & 0 & 0 & 0 & 0 & 11,321 \\
\hline 79 & 3 & $4 / 21 / 2010$ & 7:00 AM & 3:30 PM & 52,128 & 0 & 0 & 0 & 13,687 & 0 & 0 & 0 & 0 & 0 & 12,566 \\
\hline 80 & 3 & $4 / 22 / 2010$ & 7:00 AM & $8: 30$ AM & 9,583 & 0 & 0 & 0 & 2,675 & 0 & 0 & 0 & 0 & 0 & 3,681 \\
\hline 82 & 3 & $4 / 23 / 2010$ & 7:00 AM & 3:30 PM & 61,593 & 0 & 0 & 0 & 14,185 & 0 & 0 & 0 & 0 & 0 & 5,791 \\
\hline 83 & 4 & $5 / 16 / 2011$ & 6:00 AM & 9:15 AM & 8,449 & 0 & 0 & 0 & 342 & 0 & 0 & 0 & 0 & 2,264 & 2,000 \\
\hline 84 & 4 & $5 / 16 / 2011$ & 9:15 AM & $4: 30 \mathrm{PM}$ & 13,125 & 0 & 0 & 11,938 & 196 & 0 & 0 & 0 & 0 & 4,138 & 0 \\
\hline 85 & 4 & $5 / 17 / 2011$ & 6:00 AM & 4:30 PM & 24,247 & 0 & 0 & 18,708 & 201 & 0 & 0 & 0 & 0 & 6,370 & 0 \\
\hline 86 & 4 & $5 / 18 / 2011$ & 6:00 AM & $4: 30 \mathrm{PM}$ & 20,503 & 0 & 0 & 18,150 & 231 & 0 & 0 & 0 & 0 & 7,182 & 0 \\
\hline 87 & 4 & $5 / 19 / 2011$ & 6:00 AM & $3: 45$ PM & 19,177 & 0 & 0 & 14,962 & 74 & 0 & 0 & 0 & 0 & 5,548 & 0 \\
\hline 88 & 4 & $5 / 19 / 2011$ & 3:45 PM & 4:30 PM & 0 & 0 & 0 & 1,678 & 0 & 0 & 0 & 0 & 0 & 970 & 774 \\
\hline 89 & 4 & $5 / 23 / 2011$ & 6:00 AM & 11:00 AM & 0 & 0 & 0 & 6,216 & 80 & 0 & 0 & 0 & 0 & 546 & 13,113 \\
\hline 90 & 4 & $5 / 23 / 2011$ & 11:00 AM & 4:30 PM & 13,719 & 0 & 0 & 5,688 & 282 & 0 & 0 & 0 & 0 & 5,040 & 0 \\
\hline 91 & 4 & $5 / 24 / 2011$ & 6:00 AM & $4: 30 \mathrm{PM}$ & 20,158 & 0 & 0 & 7,430 & 317 & 0 & 0 & 0 & 0 & 6,674 & 0 \\
\hline 92 & 4 & $5 / 25 / 2011$ & 6:00 AM & 9:00 AM & 5,384 & 0 & 0 & 1,732 & 72 & 0 & 0 & 0 & 0 & 1,852 & 0 \\
\hline 93 & 4 & $5 / 25 / 2011$ & 9:00 AM & 4:30 PM & 14,911 & 0 & 0 & 0 & 567 & 0 & 0 & 0 & 0 & 3,748 & 0 \\
\hline 94 & 4 & $5 / 27 / 2011$ & 6:00 AM & 12:00 PM & 14,799 & 0 & 0 & 0 & 638 & 0 & 0 & 0 & 0 & 4,070 & 0 \\
\hline 95 & 4 & $5 / 31 / 2011$ & 6:00 AM & $8: 00$ AM & 0 & 0 & 0 & 4,785 & 130 & 0 & 0 & 0 & 0 & 42 & 5,906 \\
\hline 96 & 4 & $5 / 31 / 2011$ & $8: 15$ AM & $4: 30 \mathrm{PM}$ & 0 & 0 & 0 & 23,880 & 28 & 0 & 0 & 0 & 0 & 5,159 & 6,797 \\
\hline 99 & 4 & $6 / 2 / 2011$ & 6:00 AM & 4:30 PM & 26,153 & 0 & 0 & 0 & 1,031 & 0 & 0 & 0 & 0 & 6,783 & 0 \\
\hline 100 & 4 & $6 / 3 / 2011$ & 6:00 AM & $3: 15$ PM & 20,888 & 0 & 0 & 0 & 452 & 0 & 0 & 0 & 0 & 5,565 & 0 \\
\hline
\end{tabular}




\begin{tabular}{|c|c|c|c|c|c|c|c|c|c|c|c|c|c|c|c|}
\hline $\begin{array}{l}\text { Shift } \\
\text { No. }\end{array}$ & $\begin{array}{c}\text { Mill } \\
\#\end{array}$ & Date & Start time & End time & $4 / 4$ & $5 / 4$ & $6 / 4$ & $8 / 4$ & Pallet & $\begin{array}{c}\text { Cants } \\
\text { 3"x8"x12' }\end{array}$ & $\begin{array}{c}\text { Cants } \\
5 \text { "x6"x12' } \\
\end{array}$ & $\begin{array}{c}\text { Cants } \\
\text { 3"x4"x12' } \\
\end{array}$ & $\begin{array}{c}\text { Cants } \\
3.5 " \times 6 " x 12 \text { ' }\end{array}$ & $\begin{array}{c}\text { Cants } \\
\text { 14"x4"x12, }\end{array}$ & $\begin{array}{c}\text { Timber } \\
\text { 7"x9"x12, }\end{array}$ \\
\hline 101 & 4 & $6 / 6 / 2011$ & 10:05 AM & 4:30 PM & 11,378 & 0 & 10,258 & 2 & 62 & 0 & 0 & 0 & 0 & 3,052 & 0 \\
\hline 102 & 4 & $6 / 7 / 2011$ & 6:00 AM & 4:30 PM & 17,413 & 0 & 15,536 & 0 & 163 & 0 & 0 & 0 & 0 & 5,922 & 0 \\
\hline 104 & 4 & $6 / 8 / 2011$ & 9:25 AM & 4:30 PM & 6,120 & 0 & 0 & 15,568 & 256 & 0 & 0 & 0 & 0 & 4,512 & 0 \\
\hline 105 & 4 & $6 / 9 / 2011$ & 6:00 AM & $4: 30 \mathrm{PM}$ & 8,698 & 0 & 398 & 13,582 & 473 & 0 & 0 & 0 & 0 & 4,739 & 0 \\
\hline 106 & 4 & $6 / 13 / 2011$ & 6:00 AM & 11:30 AM & 5,865 & 0 & 0 & 10,294 & 290 & 0 & 0 & 0 & 0 & 3,752 & 0 \\
\hline 108 & 4 & $6 / 14 / 2011$ & 6:00 AM & $4: 30 \mathrm{PM}$ & 19,040 & 0 & 0 & 8,526 & 480 & 0 & 0 & 0 & 0 & 6,643 & 0 \\
\hline 109 & $5,1 \#$ & $4 / 28 / 2014$ & 6:00 AM & 10:00 AM & 15,602 & 4,529 & 0 & 0 & 1,778 & 0 & 0 & 0 & 0 & 0 & 0 \\
\hline 110 & 5,1 & $4 / 28 / 2014$ & 10:00 AM & 4:00 PM & 23,999 & 0 & 0 & 0 & 2,053 & 0 & 0 & 0 & 0 & 0 & 0 \\
\hline 111 & 5,2 & $4 / 28 / 2014$ & 5:00 PM & $2: 30 \mathrm{AM}$ & 28,479 & 0 & 0 & 0 & 3,671 & 0 & 0 & 0 & 0 & 0 & 0 \\
\hline 112 & 5,1 & $4 / 29 / 2014$ & 6:00 AM & $7: 30 \mathrm{AM}$ & 7,017 & 0 & 0 & 0 & 1,143 & 0 & 0 & 0 & 0 & 0 & 0 \\
\hline 113 & 5,1 & $4 / 29 / 2014$ & $7: 30$ AM & 4:00 PM & 37,240 & 0 & 0 & 12,636 & 937 & 0 & 0 & 0 & 9,975 & 0 & 0 \\
\hline 114 & 5,2 & $4 / 29 / 2014$ & 5:00 PM & 2:30 AM & 42,719 & 0 & 0 & 5,782 & 1,947 & 0 & 0 & 0 & 10,698 & 0 & 0 \\
\hline 116 & 5,2 & $4 / 30 / 2014$ & 3:30 PM & 2:30 AM & 36,660 & 2,807 & 0 & 0 & 3,983 & 0 & 0 & 0 & 0 & 0 & 0 \\
\hline 117 & 5,1 & $5 / 1 / 2014$ & 6:00 AM & 4:00 PM & 36,390 & 12,699 & 0 & 0 & 6,849 & 0 & 0 & 0 & 0 & 0 & 0 \\
\hline 118 & 5,2 & $5 / 1 / 2014$ & 5:00 PM & $2: 30 \mathrm{AM}$ & 27,376 & 5,048 & 0 & 0 & 4,683 & 0 & 0 & 0 & 0 & 0 & 0 \\
\hline 119 & 5,1 & $5 / 2 / 2014$ & 6:00 AM & 4:00 PM & 34,148 & 6,919 & 0 & 0 & 5,592 & 0 & 0 & 0 & 0 & 0 & 0 \\
\hline 120 & 5,2 & $5 / 2 / 2014$ & 5:00 PM & 2:30 AM & 30,093 & 2,398 & 0 & 0 & 4,044 & 0 & 0 & 0 & 0 & 0 & 0 \\
\hline 121 & 5,1 & $5 / 5 / 2014$ & 6:00 AM & 7:15 AM & 6,594 & 1,471 & 0 & 0 & 748 & 0 & 0 & 0 & 0 & 0 & 0 \\
\hline 122 & 5,1 & $5 / 5 / 2014$ & $7: 15$ AM & $2: 45 \mathrm{PM}$ & 29,710 & 0 & 0 & 4,486 & 2,293 & 0 & 0 & 0 & 0 & 0 & 0 \\
\hline 123 & 5,2 & $5 / 5 / 2014$ & 5:00 PM & $2: 30 \mathrm{AM}$ & 31,084 & 0 & 0 & 0 & 2,569 & 0 & 0 & 0 & 10,096 & 0 & 0 \\
\hline 124 & 5,1 & $5 / 6 / 2014$ & 6:00 AM & 4:00 PM & 42,391 & 0 & 0 & 0 & 1,455 & 0 & 0 & 0 & 11,156 & 0 & 0 \\
\hline 125 & 5,2 & $5 / 6 / 2014$ & $4: 30 \mathrm{PM}$ & 12:00 PM & 21,243 & 0 & 0 & 0 & 2,953 & 0 & 0 & 0 & 7,068 & 0 & 0 \\
\hline 126 & 5,1 & $5 / 7 / 2014$ & 6:00 AM & 4:00 PM & 0 & 39,281 & 0 & 0 & 304 & 0 & 0 & 0 & 0 & 0 & 6,796 \\
\hline 127 & 5,2 & $5 / 7 / 2014$ & 5:00 PM & $2: 30 \mathrm{AM}$ & 0 & 32,087 & 0 & 0 & 44 & 0 & 0 & 0 & 2,860 & 0 & 2,052 \\
\hline 128 & 5,1 & $5 / 8 / 2014$ & 6:00 AM & 4:00 PM & 0 & 40,325 & 0 & 0 & 18 & 0 & 0 & 0 & 0 & 0 & 4,147 \\
\hline 129 & 5,2 & $5 / 8 / 2014$ & 5:00 PM & $2: 30$ AM & 0 & 23,751 & 0 & 0 & 7 & 0 & 0 & 0 & 48 & 0 & 7,180 \\
\hline 130 & 5,1 & $5 / 10 / 2014$ & 6:00 AM & 2:30 PM & 33,057 & 1,516 & 0 & 0 & 3,875 & 0 & 0 & 0 & 0 & 0 & 1,834 \\
\hline 133 & 5,2 & $5 / 12 / 2014$ & 5:00 PM & $2: 30 \mathrm{AM}$ & 21,115 & 0 & 0 & 0 & 2,088 & 0 & 0 & 0 & 4,326 & 0 & 0 \\
\hline
\end{tabular}


Table A.5: Machines Run Time Data Collected in Minutes used for Correlation Analysis

\begin{tabular}{|c|c|c|c|c|c|c|c|c|c|c|c|c|c|}
\hline $\begin{array}{c}\text { Shift } \\
\text { No. }\end{array}$ & $\underset{\#}{\text { Mill }}$ & $\begin{array}{c}\text { Head Saw } \\
\text { Run } \\
\text { Time }\end{array}$ & $\begin{array}{c}\text { Resaw } \\
\text { Run } \\
\text { Time }\end{array}$ & $\begin{array}{c}\text { Edger } \\
\text { Run } \\
\text { Time }\end{array}$ & $\begin{array}{c}\text { Trimmer } \\
\text { Run } \\
\text { Time }\end{array}$ & $\begin{array}{c}\text { Chipper } \\
\text { Run } \\
\text { Time }\end{array}$ & $\begin{array}{c}\text { Debarker } \\
\text { Run } \\
\text { Time }\end{array}$ & $\begin{array}{c}\text { Compressor } \\
\text { Run } \\
\text { Time }\end{array}$ & $\begin{array}{c}\% \\
4 \text { to } 8 \\
\text { Qtr }\end{array}$ & $\begin{array}{c}\% \\
\text { Pallet }\end{array}$ & $\begin{array}{c}\% \text { Cant } \\
+ \text { Tim }\end{array}$ & $\begin{array}{l}\text { Total } \\
\text { kWh }\end{array}$ & SEC \\
\hline 1 & 1 & 488.0 & 487.0 & 491.0 & 505.0 & 556.0 & 217.0 & 555.5 & 0.9182 & 0.0000 & 0.0818 & $2,267.90$ & 70.05 \\
\hline 2 & 1 & 62.0 & 75.0 & 75.0 & 76.0 & 82.0 & 22.0 & 75.0 & 0.8612 & 0.1388 & 0.0000 & 325.19 & 57.50 \\
\hline 3 & 1 & 556.0 & 565.0 & 604.0 & 580.0 & 704.0 & 217.0 & 665.0 & 0.8556 & 0.1156 & 0.0288 & $2,713.87$ & 79.48 \\
\hline 4 & 1 & 567.0 & 553.0 & 593.0 & 580.0 & 708.0 & 648.0 & 667.5 & 0.7691 & 0.1885 & 0.0424 & $2,886.32$ & 86.37 \\
\hline 5 & 1 & 223.0 & 222.0 & 228.0 & 226.0 & 298.0 & 76.0 & 265.5 & 0.7302 & 0.1810 & 0.0887 & $1,060.73$ & 79.31 \\
\hline 6 & 1 & 347.0 & 351.0 & 360.0 & 356.0 & 423.0 & 142.0 & 370.0 & 0.6629 & 0.2744 & 0.0627 & $1,600.11$ & 77.59 \\
\hline 7 & 1 & 225.0 & 224.0 & 235.0 & 228.0 & 299.0 & 77.0 & 273.5 & 0.8743 & 0.0654 & 0.0604 & $1,097.69$ & 79.62 \\
\hline 8 & 1 & 338.0 & 342.0 & 359.0 & 349.0 & 394.0 & 124.0 & 390.0 & 0.8169 & 0.1391 & 0.0441 & $1,586.78$ & 85.66 \\
\hline 9 & 1 & 119.0 & 118.0 & 142.0 & 123.0 & 184.0 & 37.0 & 154.0 & 0.8503 & 0.1497 & 0.0000 & 611.69 & 90.42 \\
\hline 10 & 1 & 435.0 & 411.0 & 462.0 & 464.0 & 569.0 & 167.0 & 506.5 & 0.8060 & 0.1833 & 0.0107 & $2,143.47$ & 95.95 \\
\hline 11 & 1 & 501.0 & 442.0 & 514.0 & 512.0 & 643.0 & 166.0 & 549.0 & 0.8350 & 0.1525 & 0.0125 & $2,366.43$ & 94.75 \\
\hline 12 & 1 & 575.0 & 568.0 & 605.0 & 579.0 & 708.0 & 220.0 & 584.0 & 0.8560 & 0.1012 & 0.0428 & $2,585.31$ & 83.83 \\
\hline 13 & 1 & 540.0 & 558.0 & 579.0 & 571.0 & 730.0 & 231.0 & 659.0 & 0.8361 & 0.1092 & 0.0547 & $2,664.01$ & 88.84 \\
\hline 14 & 1 & 538.0 & 537.0 & 562.0 & 572.0 & 712.0 & 233.0 & 663.5 & 0.8399 & 0.1273 & 0.0328 & $2,623.49$ & 81.51 \\
\hline 15 & 1 & 145.0 & 163.0 & 185.0 & 216.0 & 311.0 & 66.0 & 276.5 & 0.8603 & 0.1176 & 0.0221 & $1,010.33$ & 116.39 \\
\hline 16 & 1 & 240.0 & 239.0 & 254.0 & 242.0 & 285.0 & 109.0 & 285.0 & 0.6531 & 0.1693 & 0.1777 & $1,138.54$ & 77.42 \\
\hline 17 & 1 & 105.0 & 105.0 & 105.0 & 105.0 & 114.0 & 27.0 & 105.0 & 0.6291 & 0.2556 & 0.1153 & 449.74 & 119.23 \\
\hline 18 & 1 & 576.0 & 554.0 & 599.0 & 578.0 & 716.0 & 183.0 & 662.5 & 0.5490 & 0.1827 & 0.2683 & $2,662.48$ & 98.66 \\
\hline 19 & 1 & 181.0 & 192.0 & 192.0 & 196.0 & 258.0 & 58.0 & 229.5 & 0.6573 & 0.2715 & 0.0712 & 906.37 & 95.50 \\
\hline 20 & 1 & 362.0 & 374.0 & 394.0 & 380.0 & 444.0 & 117.0 & 435.0 & 0.8251 & 0.1446 & 0.0303 & $1,726.44$ & 94.75 \\
\hline 21 & 1 & 558.0 & 504.0 & 587.0 & 574.0 & 710.0 & 213.0 & 662.5 & 0.8302 & 0.1444 & 0.0254 & $2,656.64$ & 90.76 \\
\hline 22 & 1 & 554.0 & 555.0 & 582.0 & 571.0 & 718.0 & 218.0 & 666.0 & 0.8300 & 0.1299 & 0.0402 & $2,683.63$ & 86.94 \\
\hline 23 & 2 & 278.0 & 0.0 & 251.0 & 255.0 & 267.0 & 284.0 & 286.0 & 0.4587 & 0.0249 & 0.5164 & 903.83 & 89.13 \\
\hline 24 & 2 & 204.0 & 0.0 & 199.0 & 210.0 & 241.0 & 219.0 & 236.0 & 0.5696 & 0.0294 & 0.4010 & 724.24 & 73.99 \\
\hline 25 & 2 & 451.0 & 0.0 & 439.0 & 465.0 & 510.0 & 450.0 & 560.0 & 0.5681 & 0.0436 & 0.3883 & $1,535.14$ & 91.16 \\
\hline 26 & 2 & 486.0 & 0.0 & 447.0 & 465.0 & 498.0 & 487.0 & 554.0 & 0.5259 & 0.0279 & 0.4462 & $1,583.44$ & 79.47 \\
\hline 27 & 2 & 199.0 & 0.0 & 174.0 & 180.0 & 181.0 & 198.0 & 232.0 & 0.4436 & 0.0632 & 0.4931 & 596.00 & 76.00 \\
\hline 28 & 2 & 228.0 & 0.0 & 211.0 & 225.0 & 271.0 & 209.0 & 274.0 & 0.4498 & 0.0000 & 0.5502 & 749.42 & 57.54 \\
\hline 29 & 2 & 144.0 & 0.0 & 118.0 & 120.0 & 135.0 & 142.0 & 148.0 & 0.3825 & 0.0000 & 0.6175 & 415.98 & 61.25 \\
\hline 30 & 2 & 346.0 & 0.0 & 327.0 & 345.0 & 393.0 & 353.0 & 388.0 & 0.4169 & 0.0110 & 0.5721 & $1,131.87$ & 60.79 \\
\hline
\end{tabular}




\begin{tabular}{|c|c|c|c|c|c|c|c|c|c|c|c|c|c|}
\hline $\begin{array}{c}\text { Shift } \\
\text { No. }\end{array}$ & $\underset{\#}{\text { Mill }}$ & $\begin{array}{c}\text { Head Saw } \\
\text { Run } \\
\text { Time }\end{array}$ & $\begin{array}{c}\text { Resaw } \\
\text { Run } \\
\text { Time }\end{array}$ & $\begin{array}{c}\text { Edger } \\
\text { Run } \\
\text { Time }\end{array}$ & $\begin{array}{c}\text { Trimmer } \\
\text { Run } \\
\text { Time }\end{array}$ & $\begin{array}{c}\text { Chipper } \\
\text { Run } \\
\text { Time }\end{array}$ & $\begin{array}{c}\text { Debarker } \\
\text { Run } \\
\text { Time }\end{array}$ & $\begin{array}{c}\text { Compressor } \\
\text { Run } \\
\text { Time }\end{array}$ & $\begin{array}{c}\% \\
4 \text { to } 8 \\
\text { Qtr }\end{array}$ & $\begin{array}{c}\% \\
\text { Pallet }\end{array}$ & $\begin{array}{l}\% \text { Cant } \\
+ \text { Tim }\end{array}$ & $\begin{array}{l}\text { Total } \\
\text { kWh }\end{array}$ & SEC \\
\hline 31 & 2 & 487.0 & 0.0 & 446.0 & 465.0 & 509.0 & 510.0 & 560.0 & 0.4245 & 0.1765 & 0.3990 & $1,571.08$ & 70.04 \\
\hline 32 & 2 & 467.0 & 0.0 & 424.0 & 465.0 & 493.0 & 433.0 & 560.0 & 0.4893 & 0.0207 & 0.4899 & $1,504.34$ & 94.01 \\
\hline 33 & 2 & 481.0 & 0.0 & 445.0 & 465.0 & 512.0 & 493.0 & 567.0 & 0.5603 & 0.0193 & 0.4205 & $1,537.66$ & 85.15 \\
\hline 34 & 2 & 312.0 & 0.0 & 278.0 & 285.0 & 293.0 & 300.0 & 347.0 & 0.5713 & 0.0234 & 0.4053 & 979.90 & 80.82 \\
\hline 35 & 2 & 105.0 & 0.0 & 102.0 & 120.0 & 157.0 & 153.0 & 158.0 & 0.3908 & 0.0095 & 0.5997 & 435.17 & 94.05 \\
\hline 36 & 2 & 346.0 & 0.0 & 309.0 & 315.0 & 319.0 & 341.0 & 375.0 & 0.4253 & 0.0201 & 0.5546 & $1,115.42$ & 87.07 \\
\hline 37 & 2 & 143.0 & 0.0 & 141.0 & 150.0 & 174.0 & 147.0 & 189.0 & 0.4777 & 0.0165 & 0.5058 & 501.04 & 76.64 \\
\hline 38 & 2 & 483.0 & 0.0 & 435.0 & 465.0 & 532.0 & 504.0 & 557.0 & 0.4787 & 0.0286 & 0.4927 & $1,604.75$ & 88.53 \\
\hline 39 & 2 & 483.0 & 0.0 & 446.0 & 465.0 & 508.0 & 434.0 & 559.0 & 0.5184 & 0.0229 & 0.4588 & $1,531.05$ & 84.54 \\
\hline 40 & 2 & 458.0 & 0.0 & 423.0 & 435.0 & 474.0 & 455.0 & 527.0 & 0.5764 & 0.0353 & 0.3883 & $1,458.31$ & 91.35 \\
\hline 41 & 2 & 27.0 & 0.0 & 26.0 & 30.0 & 37.0 & 30.0 & 36.0 & 0.4088 & 0.0068 & 0.5844 & 101.60 & 68.88 \\
\hline 42 & 2 & 430.0 & 0.0 & 388.0 & 405.0 & 447.0 & 359.0 & 504.0 & 0.4107 & 0.0164 & 0.5730 & $1,396.76$ & 69.25 \\
\hline 43 & 2 & 125.0 & 0.0 & 100.0 & 105.0 & 98.0 & 117.0 & 152.0 & 0.5040 & 0.0085 & 0.4875 & 353.10 & 107.59 \\
\hline 44 & 2 & 356.0 & 0.0 & 352.0 & 360.0 & 394.0 & 348.0 & 405.0 & 0.4447 & 0.0245 & 0.5308 & $1,208.05$ & 85.95 \\
\hline 45 & 2 & 421.0 & 0.0 & 391.0 & 405.0 & 460.0 & 435.0 & 476.0 & 0.4491 & 0.0400 & 0.5109 & $1,422.61$ & 101.26 \\
\hline 46 & 2 & 49.0 & 0.0 & 59.0 & 60.0 & 61.0 & 59.0 & 60.0 & 0.5792 & 0.0019 & 0.4189 & 174.33 & 81.96 \\
\hline 47 & 2 & 451.0 & 0.0 & 436.0 & 465.0 & 528.0 & 450.0 & 566.0 & 0.5766 & 0.0279 & 0.3956 & $1,529.56$ & 87.31 \\
\hline 48 & 2 & 263.0 & 0.0 & 233.0 & 240.0 & 272.0 & 255.0 & 305.0 & 0.5675 & 0.0454 & 0.3871 & 808.40 & 80.49 \\
\hline 49 & 2 & 219.0 & 0.0 & 216.0 & 225.0 & 255.0 & 224.0 & 246.0 & 0.6188 & 0.0214 & 0.3598 & 720.68 & 86.72 \\
\hline 50 & 2 & 386.0 & 0.0 & 363.0 & 405.0 & 467.0 & 363.0 & 505.0 & 0.5409 & 0.0399 & 0.4192 & $1,285.07$ & 81.71 \\
\hline 51 & 2 & 343.0 & 0.0 & 308.0 & 315.0 & 341.0 & 302.0 & 379.0 & 0.5368 & 0.0379 & 0.4253 & $1,049.50$ & 88.09 \\
\hline 52 & 2 & 142.0 & 0.0 & 142.0 & 150.0 & 176.0 & 146.0 & 184.0 & 0.7245 & 0.0170 & 0.2585 & 518.39 & 88.15 \\
\hline 53 & 2 & 454.0 & 0.0 & 455.0 & 465.0 & 528.0 & 472.0 & 571.0 & 0.6995 & 0.0153 & 0.2852 & $1,526.90$ & 100.14 \\
\hline 54 & 2 & 62.0 & 0.0 & 44.0 & 45.0 & 44.0 & 51.0 & 89.0 & 0.3367 & 0.0028 & 0.6605 & 172.41 & 79.64 \\
\hline 55 & 2 & 420.0 & 0.0 & 409.0 & 420.0 & 469.0 & 409.0 & 467.0 & 0.1629 & 0.0728 & 0.7643 & $1,371.06$ & 125.07 \\
\hline 56 & 2 & 83.0 & 0.0 & 57.0 & 60.0 & 71.0 & 69.0 & 115.0 & 0.4705 & 0.0282 & 0.5014 & 261.08 & 89.72 \\
\hline 57 & 2 & 401.0 & 0.0 & 405.0 & 405.0 & 435.0 & 435.0 & 456.0 & 0.5568 & 0.0355 & 0.4077 & $1,375.53$ & 80.51 \\
\hline 58 & 3 & 478.8 & 463.2 & 489.0 & 525.0 & 501.0 & 561.6 & 571.0 & 0.6885 & 0.1915 & 0.1200 & $8,464.90$ & 105.28 \\
\hline 59 & 3 & 115.5 & 115.2 & 129.0 & 151.8 & 157.8 & 226.8 & 120.0 & 0.6903 & 0.1603 & 0.1493 & $2,264.58$ & 124.48 \\
\hline 60 & 3 & 351.3 & 334.2 & 355.8 & 433.2 & 403.8 & 345.6 & 390.0 & 0.6711 & 0.1591 & 0.1698 & $6,551.06$ & 104.00 \\
\hline 61 & 3 & 396.6 & 246.0 & 406.8 & 430.8 & 447.0 & 394.8 & 420.6 & 0.6960 & 0.1645 & 0.1395 & $6,981.93$ & 111.63 \\
\hline 62 & 3 & 82.8 & 82.8 & 82.8 & 88.2 & 91.8 & 82.8 & 90.0 & 0.7765 & 0.2235 & 0.0000 & $1,591.53$ & 111.68 \\
\hline
\end{tabular}




\begin{tabular}{|c|c|c|c|c|c|c|c|c|c|c|c|c|c|}
\hline $\begin{array}{c}\text { Shift } \\
\text { No. }\end{array}$ & $\underset{\#}{\text { Mill }}$ & $\begin{array}{c}\text { Head Saw } \\
\text { Run } \\
\text { Time }\end{array}$ & $\begin{array}{c}\text { Resaw } \\
\text { Run } \\
\text { Time }\end{array}$ & $\begin{array}{c}\text { Edger } \\
\text { Run } \\
\text { Time }\end{array}$ & $\begin{array}{c}\text { Trimmer } \\
\text { Run } \\
\text { Time }\end{array}$ & $\begin{array}{c}\text { Chipper } \\
\text { Run } \\
\text { Time }\end{array}$ & $\begin{array}{c}\text { Debarker } \\
\text { Run } \\
\text { Time }\end{array}$ & $\begin{array}{c}\text { Compressor } \\
\text { Run } \\
\text { Time }\end{array}$ & $\begin{array}{c}\% \\
4 \text { to } 8 \\
\text { Qtr }\end{array}$ & $\begin{array}{c}\% \\
\text { Pallet }\end{array}$ & $\begin{array}{l}\% \text { Cant } \\
+ \text { Tim }\end{array}$ & $\begin{array}{l}\text { Total } \\
\text { kWh }\end{array}$ & SEC \\
\hline 63 & 3 & 126.0 & 109.8 & 129.0 & 157.8 & 162.6 & 115.8 & 120.6 & 0.7616 & 0.1913 & 0.0471 & $2,315.49$ & 85.78 \\
\hline 64 & 3 & 353.7 & 343.8 & 351.6 & 394.8 & 384.6 & 348.0 & 390.0 & 0.7271 & 0.1534 & 0.1195 & $6,430.15$ & 104.21 \\
\hline 65 & 3 & 243.3 & 214.2 & 247.2 & 256.2 & 280.8 & 247.8 & 240.0 & 0.7096 & 0.1717 & 0.1188 & $4,299.55$ & 103.86 \\
\hline 66 & 3 & 213.3 & 192.0 & 214.8 & 211.8 & 240.0 & 210.6 & 210.0 & 0.3691 & 0.2509 & 0.3800 & $4,455.75$ & 111.65 \\
\hline 67 & 3 & 469.8 & 447.0 & 486.0 & 529.2 & 537.0 & 472.8 & 504.6 & 0.8376 & 0.1624 & 0.0000 & $8,657.71$ & 105.06 \\
\hline 68 & 3 & 475.2 & 457.2 & 505.2 & 535.8 & 561.6 & 465.6 & 511.2 & 0.7706 & 0.1902 & 0.0392 & $8,767.84$ & 108.29 \\
\hline 69 & 3 & 477.9 & 456.0 & 511.8 & 550.2 & 538.8 & 423.0 & 510.0 & 0.8025 & 0.1975 & 0.0000 & $7,281.16$ & 86.33 \\
\hline 70 & 3 & 466.8 & 469.8 & 502.8 & 522.0 & 535.8 & 276.0 & 510.0 & 0.7916 & 0.2084 & 0.0000 & $7,195.51$ & 89.69 \\
\hline 71 & 3 & 494.4 & 456.0 & 511.2 & 547.8 & 540.0 & 463.8 & 510.0 & 0.7589 & 0.2411 & 0.0000 & $6,701.76$ & 81.33 \\
\hline 72 & 3 & 493.2 & 439.2 & 505.2 & 523.8 & 484.8 & 498.6 & 510.0 & 1.0000 & 0.0000 & 0.0000 & $7,075.26$ & 84.82 \\
\hline 73 & 3 & 478.5 & 448.2 & 502.2 & 517.8 & 522.0 & 465.6 & 510.0 & 0.7767 & 0.1809 & 0.0424 & $8,664.44$ & 108.37 \\
\hline 74 & 3 & 262.5 & 255.0 & 328.2 & 363.0 & 387.0 & 304.8 & 345.0 & 0.5107 & 0.1411 & 0.3482 & $5,428.20$ & 124.17 \\
\hline 75 & 3 & 159.0 & 151.2 & 160.8 & 163.2 & 160.8 & 154.8 & 165.0 & 0.8597 & 0.1403 & 0.0000 & $2,854.32$ & 82.45 \\
\hline 76 & 3 & 305.1 & 265.8 & 318.0 & 355.8 & 346.8 & 301.2 & 330.0 & 0.8350 & 0.1650 & 0.0000 & $5,457.95$ & 140.73 \\
\hline 77 & 3 & 174.6 & 171.0 & 175.2 & 177.0 & 177.6 & 175.2 & 180.0 & 0.6821 & 0.1783 & 0.1396 & $3,074.22$ & 105.32 \\
\hline 78 & 3 & 442.5 & 399.0 & 487.8 & 522.0 & 537.6 & 442.2 & 510.0 & 0.6774 & 0.1717 & 0.1509 & $8,304.22$ & 110.70 \\
\hline 79 & 3 & 476.4 & 436.8 & 499.2 & 510.0 & 540.0 & 475.2 & 510.0 & 0.6651 & 0.1746 & 0.1603 & $8,508.43$ & 108.55 \\
\hline 80 & 3 & 96.9 & 70.2 & 100.2 & 107.4 & 133.8 & 67.2 & 90.0 & 0.6012 & 0.1678 & 0.2309 & $1,653.18$ & 103.72 \\
\hline 81 & 3 & 382.2 & 373.2 & 387.0 & 417.6 & 412.8 & 235.2 & 420.0 & 0.7598 & 0.1977 & 0.0426 & $6,810.27$ & 130.79 \\
\hline 82 & 3 & 477.6 & 454.8 & 523.8 & 522.6 & 552.6 & 472.8 & 510.0 & 0.7551 & 0.1739 & 0.0710 & $8,764.15$ & 107.45 \\
\hline 83 & 4 & 174.0 & 0.0 & 181.5 & 155.1 & 195.0 & 53.5 & 196.0 & 0.6524 & 0.0258 & 0.3218 & $1,504.23$ & 113.53 \\
\hline 84 & 4 & 369.5 & 0.0 & 371.0 & 328.7 & 411.0 & 112.5 & 476.0 & 0.8546 & 0.0066 & 0.1389 & $3,181.70$ & 106.76 \\
\hline 85 & 4 & 574.0 & 0.0 & 571.5 & 514.2 & 661.0 & 218.5 & 724.0 & 0.8689 & 0.0040 & 0.1271 & $4,935.25$ & 98.46 \\
\hline 86 & 4 & 562.5 & 0.0 & 582.0 & 490.5 & 646.0 & 143.0 & 674.0 & 0.8412 & 0.0050 & 0.1539 & $4,747.09$ & 101.73 \\
\hline 87 & 4 & 504.5 & 0.0 & 530.5 & 448.5 & 605.0 & 130.5 & 616.0 & 0.8606 & 0.0018 & 0.1376 & $4,361.89$ & 108.19 \\
\hline 88 & 4 & 42.5 & 0.0 & 44.0 & 35.3 & 51.0 & 10.5 & 53.0 & 0.4970 & 0.0000 & 0.5030 & 345.41 & 99.63 \\
\hline 89 & 4 & 265.5 & 0.0 & 280.0 & 242.8 & 314.0 & 85.5 & 347.0 & 0.3217 & 0.0040 & 0.6744 & $2,334.09$ & 115.24 \\
\hline 90 & 4 & 276.0 & 0.0 & 287.5 & 254.8 & 337.0 & 71.0 & 420.0 & 0.7874 & 0.0113 & 0.2014 & $2,434.23$ & 97.26 \\
\hline 91 & 4 & 553.0 & 0.0 & 587.5 & 492.0 & 654.0 & 145.0 & 688.0 & 0.8013 & 0.0090 & 0.1897 & $4,769.64$ & 135.58 \\
\hline 92 & 4 & 146.0 & 0.0 & 149.5 & 133.9 & 192.0 & 46.0 & 201.0 & 0.7913 & 0.0078 & 0.2009 & $1,332.59$ & 144.53 \\
\hline 93 & 4 & 384.5 & 0.0 & 397.0 & 328.9 & 425.0 & 85.0 & 486.0 & 0.7804 & 0.0289 & 0.1908 & $3,255.79$ & 165.72 \\
\hline 94 & 4 & 365.0 & 0.0 & 381.5 & 315.2 & 421.0 & 65.0 & 554.0 & 0.7627 & 0.0322 & 0.2052 & $3,022.05$ & 152.34 \\
\hline
\end{tabular}




\begin{tabular}{|c|c|c|c|c|c|c|c|c|c|c|c|c|c|}
\hline $\begin{array}{c}\text { Shift } \\
\text { No. }\end{array}$ & $\underset{\#}{\text { Mill }}$ & $\begin{array}{c}\text { Head Saw } \\
\text { Run } \\
\text { Time }\end{array}$ & $\begin{array}{c}\text { Resaw } \\
\text { Run } \\
\text { Time }\end{array}$ & $\begin{array}{c}\text { Edger } \\
\text { Run } \\
\text { Time }\end{array}$ & $\begin{array}{c}\text { Trimmer } \\
\text { Run } \\
\text { Time }\end{array}$ & $\begin{array}{c}\text { Chipper } \\
\text { Run } \\
\text { Time }\end{array}$ & $\begin{array}{c}\text { Debarker } \\
\text { Run } \\
\text { Time }\end{array}$ & $\begin{array}{c}\text { Compressor } \\
\text { Run } \\
\text { Time }\end{array}$ & $\begin{array}{c}\% \\
4 \text { to } 8 \\
\text { Qtr }\end{array}$ & $\begin{array}{c}\% \\
\text { Pallet }\end{array}$ & $\begin{array}{l}\% \text { Cant } \\
+ \text { Tim }\end{array}$ & $\begin{array}{l}\text { Total } \\
\text { kWh }\end{array}$ & SEC \\
\hline 95 & 4 & 73.0 & 0.0 & 71.0 & 74.5 & 136.0 & 36.0 & 168.0 & 0.4466 & 0.0118 & 0.5416 & 853.89 & 77.75 \\
\hline 96 & 4 & 443.0 & 0.0 & 457.5 & 397.7 & 497.0 & 165.5 & 555.0 & 0.6701 & 0.0008 & 0.3291 & $3,768.55$ & 103.73 \\
\hline 97 & 4 & 296.0 & 0.0 & 311.0 & 259.3 & 325.0 & 88.5 & 348.0 & 0.5707 & 0.0001 & 0.4292 & $2,540.12$ & 89.24 \\
\hline 98 & 4 & 256.5 & 0.0 & 257.5 & 235.3 & 301.0 & 76.0 & 390.0 & 0.7765 & 0.0238 & 0.1998 & $2,244.00$ & 138.19 \\
\hline 99 & 4 & 572.5 & 0.0 & 575.0 & 508.6 & 650.0 & 156.0 & 758.0 & 0.7740 & 0.0298 & 0.1962 & $4,909.50$ & 142.03 \\
\hline 100 & 4 & 482.0 & 0.0 & 487.5 & 428.8 & 642.0 & 139.5 & 642.0 & 0.7806 & 0.0165 & 0.2029 & $4,217.76$ & 153.77 \\
\hline 101 & 4 & 329.5 & 0.0 & 333.0 & 290.3 & 370.0 & 56.0 & 465.0 & 0.8760 & 0.0025 & 0.1216 & $2,766.36$ & 110.18 \\
\hline 102 & 4 & 559.0 & 0.0 & 563.5 & 492.5 & 650.0 & 77.0 & 780.0 & 0.8465 & 0.0041 & 0.1494 & $4,702.11$ & 118.64 \\
\hline 103 & 4 & 168.5 & 0.0 & 174.5 & 148.9 & 212.0 & 32.5 & 228.0 & 0.8224 & 0.0055 & 0.1721 & $1,478.34$ & 118.38 \\
\hline 104 & 4 & 366.5 & 0.0 & 368.5 & 327.5 & 441.0 & 83.0 & 457.0 & 0.8224 & 0.0095 & 0.1680 & $3,109.02$ & 115.79 \\
\hline 105 & 4 & 503.0 & 0.0 & 529.0 & 442.5 & 639.0 & 112.0 & 701.0 & 0.8171 & 0.0166 & 0.1663 & $4,458.74$ & 156.50 \\
\hline 106 & 4 & 328.0 & 0.0 & 307.5 & 266.0 & 352.0 & 69.5 & 386.0 & 0.8031 & 0.0141 & 0.1827 & $2,612.90$ & 127.27 \\
\hline 107 & 4 & 255.5 & 0.0 & 263.0 & 230.9 & 306.0 & 74.5 & 331.0 & 0.8014 & 0.0098 & 0.1888 & $2,218.52$ & 144.33 \\
\hline 108 & 4 & 573.0 & 0.0 & 585.5 & 502.6 & 638.0 & 153.0 & 682.0 & 0.7982 & 0.0136 & 0.1882 & $4,800.24$ & 136.03 \\
\hline 109 & $5,1 \#$ & 270.0 & 270.0 & 233.0 & 266.0 & 270.0 & 268.0 & 271.0 & 0.9189 & 0.0812 & 0.0000 & $2,325.14$ & 106.13 \\
\hline 110 & 5,1 & 310.0 & 343.0 & 345.0 & 361.0 & 349.5 & 314.5 & 390.5 & 0.9212 & 0.0788 & 0.0000 & $2,963.61$ & 113.76 \\
\hline 111 & 5,2 & 580.0 & 583.0 & 587.0 & 528.0 & 576.5 & 591.0 & 629.5 & 0.8858 & 0.1142 & 0.0000 & $4,946.48$ & 153.86 \\
\hline 112 & 5,1 & 123.0 & 121.0 & 142.0 & 140.0 & 124.5 & 127.5 & 131.5 & 0.8599 & 0.1401 & 0.0000 & $1,122.39$ & 137.55 \\
\hline 113 & 5,1 & 477.0 & 488.0 & 454.0 & 454.0 & 462.0 & 423.0 & 540.5 & 0.8205 & 0.0154 & 0.1641 & $4,115.69$ & 67.71 \\
\hline 114 & 5,2 & 588.0 & 571.0 & 612.0 & 605.0 & 631.5 & 529.5 & 630.5 & 0.7932 & 0.0318 & 0.1750 & $5,189.42$ & 84.87 \\
\hline 115 & 5,1 & 567.0 & 566.0 & 572.0 & 611.0 & 597.0 & 551.0 & 616.0 & 0.8301 & 0.0142 & 0.1557 & $5,064.19$ & 67.73 \\
\hline 116 & 5,2 & 633.0 & 661.0 & 641.0 & 639.0 & 666.5 & 614.0 & 690.5 & 0.9083 & 0.0917 & 0.0000 & $5,632.85$ & 129.64 \\
\hline 117 & 5,1 & 585.0 & 601.0 & 631.0 & 674.0 & 631.0 & 586.0 & 676.0 & 0.8776 & 0.1224 & 0.0000 & $5,495.17$ & 98.24 \\
\hline 118 & 5,2 & 563.0 & 614.0 & 610.0 & 605.0 & 635.5 & 599.5 & 630.5 & 0.8738 & 0.1262 & 0.0000 & $5,192.91$ & 139.94 \\
\hline 119 & 5,1 & 559.0 & 576.0 & 589.0 & 663.0 & 637.5 & 524.5 & 675.5 & 0.8802 & 0.1198 & 0.0000 & $5,310.84$ & 113.82 \\
\hline 120 & 5,2 & 551.0 & 595.0 & 580.0 & 599.0 & 627.0 & 598.0 & 629.5 & 0.8893 & 0.1107 & 0.0000 & $5,041.39$ & 137.99 \\
\hline 121 & 5,1 & 105.5 & 100.0 & 111.0 & 133.0 & 109.5 & 105.5 & 120.5 & 0.9151 & 0.0849 & 0.0000 & $1,003.77$ & 113.90 \\
\hline 122 & 5,1 & 430.5 & 424.0 & 391.0 & 421.0 & 441.5 & 425.0 & 450.5 & 0.9372 & 0.0628 & 0.0000 & $3,722.08$ & 102.01 \\
\hline 123 & 5,2 & 587.0 & 576.0 & 619.5 & 594.0 & 616.0 & 582.5 & 629.5 & 0.7105 & 0.0587 & 0.2308 & $5,162.08$ & 117.99 \\
\hline 124 & 5,1 & 596.5 & 603.0 & 625.0 & 654.0 & 635.0 & 552.0 & 675.5 & 0.7707 & 0.0265 & 0.2028 & $5,296.20$ & 96.29 \\
\hline 125 & 5,2 & 366.0 & 393.0 & 317.0 & 445.0 & 450.5 & 439.5 & 450.5 & 0.6795 & 0.0945 & 0.2261 & $3,517.04$ & 112.50 \\
\hline 126 & 5,1 & 602.0 & 583.0 & 625.0 & 668.0 & 625.5 & 592.5 & 675.5 & 0.8469 & 0.0066 & 0.1465 & $5,371.99$ & 115.82 \\
\hline
\end{tabular}




\begin{tabular}{|c|c|c|c|c|c|c|c|c|c|c|c|c|c|}
\hline $\begin{array}{c}\text { Shift } \\
\text { No. }\end{array}$ & $\underset{\#}{\text { Mill }}$ & $\begin{array}{c}\text { Head Saw } \\
\text { Run } \\
\text { Time }\end{array}$ & $\begin{array}{c}\text { Resaw } \\
\text { Run } \\
\text { Time }\end{array}$ & $\begin{array}{c}\text { Edger } \\
\text { Run } \\
\text { Time }\end{array}$ & $\begin{array}{c}\text { Trimmer } \\
\text { Run } \\
\text { Time }\end{array}$ & $\begin{array}{c}\text { Chipper } \\
\text { Run } \\
\text { Time }\end{array}$ & $\begin{array}{c}\text { Debarker } \\
\text { Run } \\
\text { Time }\end{array}$ & $\begin{array}{c}\text { Compressor } \\
\text { Run } \\
\text { Time }\end{array}$ & $\begin{array}{c}\% \\
4 \text { to } 8 \\
\text { Qtr }\end{array}$ & $\begin{array}{c}\% \\
\text { Pallet }\end{array}$ & $\begin{array}{l}\% \text { Cant } \\
+ \text { Tim }\end{array}$ & $\begin{array}{l}\text { Total } \\
\text { kWh }\end{array}$ & SEC \\
\hline 127 & 5,2 & 569.0 & 584.0 & 582.0 & 601.0 & 630.5 & 602.5 & 630.5 & 0.8662 & 0.0012 & 0.1326 & $5,127.90$ & 138.43 \\
\hline 128 & 5,1 & 576.5 & 581.0 & 614.0 & 573.0 & 634.5 & 597.0 & 675.5 & 0.9064 & 0.0004 & 0.0932 & $5,311.83$ & 119.39 \\
\hline 129 & 5,2 & 584.5 & 585.0 & 616.0 & 566.0 & 532.0 & 583.0 & 630.5 & 0.7665 & 0.0002 & 0.2333 & $4,690.13$ & 151.36 \\
\hline 130 & 5,1 & 496.0 & 492.0 & 462.0 & 542.0 & 572.5 & 457.5 & 585.5 & 0.8583 & 0.0962 & 0.0455 & $4,642.43$ & 115.25 \\
\hline 131 & 5,1 & 79.0 & 75.0 & 97.0 & 99.0 & 79.0 & 83.0 & 90.5 & 0.9200 & 0.0800 & 0.0000 & 761.18 & 126.86 \\
\hline 132 & 5,1 & 526.5 & 541.0 & 532.0 & 566.0 & 557.5 & 477.0 & 585.5 & 0.9275 & 0.0725 & 0.0000 & $4,700.60$ & 128.95 \\
\hline 133 & 5,2 & 579.0 & 580.0 & 542.0 & 606.0 & 626.0 & 571.0 & 629.5 & 0.7670 & 0.0758 & 0.1571 & $4,710.43$ & 171.11 \\
\hline
\end{tabular}


Table A.6. Amperage Consumption in amps of Individual Motors and Load Factor of Unlogged Motors in Sawmill 1

\begin{tabular}{|c|c|c|c|c|c|c|c|c|c|c|c|c|c|}
\hline $\begin{array}{l}\text { Shift } \\
\text { No. }\end{array}$ & $\begin{array}{c}\text { Head } \\
\text { Saw } \\
(200 \text { hp })\end{array}$ & $\begin{array}{l}\text { Resaw } \\
\text { (60 hp) }\end{array}$ & $\begin{array}{c}\text { Edger } \\
(50 \text { hp) }\end{array}$ & $\begin{array}{c}\text { Trimmer } \\
(10 \text { hp })\end{array}$ & $\begin{array}{l}\text { Chipper } \\
\text { (150 hp) }\end{array}$ & $\begin{array}{c}\text { Debarker } \\
(50 \text { hp })\end{array}$ & $\begin{array}{c}\text { Compressor } \\
(60 \text { hp })\end{array}$ & $\begin{array}{l}\text { Carriage } \\
\text { Feed } \\
\text { Motor } \\
(100 \text { hp })\end{array}$ & $\begin{array}{c}\text { Top } \\
\text { Saw } \\
\text { (40 hp) }\end{array}$ & $\begin{array}{c}\text { Log } \\
\text { Turner } \\
\text { (40 hp) }\end{array}$ & $\begin{array}{c}\text { Dust } \\
\text { Collector } \\
\text { (15 hp) }\end{array}$ & $\begin{array}{c}\text { Chip } \\
\text { blower } \\
\text { (30 hp) }\end{array}$ & $\begin{array}{c}\text { Unlogged } \\
\text { Motors } \\
\text { Load } \\
\text { Factor }\end{array}$ \\
\hline 1 & 82.36 & 23.39 & 52.16 & 19.60 & 30.80 & 41.86 & 153.15 & 30.81 & 2.72 & 14.05 & 14.96 & 42.20 & 0.3204 \\
\hline 2 & 83.26 & 25.78 & 55.21 & 20.07 & 31.37 & 42.89 & 155.37 & 29.44 & 13.54 & 13.00 & 15.58 & 45.93 & 0.3091 \\
\hline 3 & 81.63 & 25.17 & 52.46 & 19.48 & 31.69 & 45.16 & 156.77 & 28.83 & 12.67 & 13.76 & 14.92 & 35.00 & 0.3080 \\
\hline 4 & 84.12 & 26.24 & 52.26 & 19.48 & 31.83 & 42.48 & 157.32 & 30.07 & 10.63 & 13.82 & 15.60 & 27.51 & 0.3222 \\
\hline 5 & 83.94 & 25.06 & 52.88 & 19.48 & 29.68 & 42.67 & 150.35 & 30.05 & 7.50 & 13.82 & 14.89 & 31.93 & 0.3207 \\
\hline 6 & 86.24 & 25.85 & 54.24 & 20.09 & 31.03 & 47.32 & 146.01 & 30.53 & 1.64 & 13.34 & 15.86 & 31.79 & 0.2881 \\
\hline 7 & 84.41 & 27.76 & 53.24 & 20.49 & 29.91 & 49.08 & 150.71 & 30.76 & 6.81 & 14.08 & 15.54 & 31.28 & 0.3258 \\
\hline 8 & 83.60 & 25.17 & 52.82 & 20.76 & 29.97 & 46.91 & 153.56 & 28.75 & 6.82 & 13.42 & 16.22 & 36.54 & 0.2901 \\
\hline 9 & 79.37 & 24.42 & 50.79 & 20.74 & 29.72 & 48.13 & 159.79 & 30.79 & 12.79 & 15.66 & 14.84 & 26.86 & 0.3668 \\
\hline 10 & 83.95 & 26.30 & 53.45 & 20.53 & 30.87 & 47.93 & 156.57 & 31.15 & 9.63 & 14.43 & 14.94 & 36.64 & 0.2989 \\
\hline 11 & 81.60 & 24.75 & 52.17 & 20.59 & 29.49 & 44.59 & 154.56 & 29.50 & 10.57 & 15.03 & 15.46 & 42.03 & 0.2984 \\
\hline 12 & 79.89 & 26.01 & 53.34 & 20.84 & 30.01 & 41.91 & 148.64 & 29.23 & 2.42 & 13.35 & 15.02 & 35.44 & 0.2969 \\
\hline 13 & 80.55 & 25.32 & 52.59 & 20.64 & 30.45 & 42.20 & 152.98 & 30.26 & 4.55 & 12.78 & 14.93 & 38.51 & 0.3004 \\
\hline 14 & 79.63 & 23.73 & 51.34 & 20.61 & 28.90 & 37.58 & 154.28 & 28.48 & 5.74 & 13.22 & 15.01 & 45.04 & 0.2957 \\
\hline 15 & 87.65 & 25.58 & 50.50 & 20.98 & 27.95 & 40.89 & 157.20 & 27.42 & 3.40 & 13.00 & 14.52 & 63.31 & 0.3002 \\
\hline 16 & 88.44 & 24.76 & 50.74 & 20.45 & 29.92 & 40.14 & 153.85 & 30.39 & 9.88 & 13.18 & 14.84 & 30.57 & 0.2858 \\
\hline 17 & 72.06 & 22.39 & 52.05 & 20.74 & 29.62 & 33.68 & 156.13 & 25.84 & 8.93 & 12.73 & 15.87 & 49.95 & 0.3059 \\
\hline 18 & 82.15 & 21.81 & 51.39 & 20.41 & 26.97 & 38.19 & 154.34 & 31.18 & 9.84 & 13.31 & 14.80 & 38.54 & 0.3049 \\
\hline 19 & 74.48 & 25.79 & 53.02 & 20.50 & 29.02 & 39.76 & 154.30 & 29.93 & 11.08 & 12.97 & 14.65 & 39.99 & 0.3342 \\
\hline 20 & 78.08 & 24.80 & 52.54 & 20.57 & 29.41 & 36.53 & 155.77 & 29.87 & 9.77 & 11.88 & 14.85 & 42.36 & 0.2846 \\
\hline 21 & 77.74 & 25.69 & 52.20 & 20.45 & 29.88 & 38.95 & 154.12 & 29.48 & 10.91 & 13.92 & 14.89 & 40.60 & 0.3018 \\
\hline 22 & 79.11 & 26.48 & 51.85 & 20.42 & 30.55 & 39.19 & 153.86 & 29.61 & 12.02 & 12.92 & 15.16 & 34.58 & 0.3090 \\
\hline
\end{tabular}


Table A.7. Amperage Consumption in amps of Individual Motors and Load Factor of Unlogged Motors in Sawmill 2

\begin{tabular}{|c|c|c|c|c|c|c|c|c|c|c|c|}
\hline $\begin{array}{l}\text { Shift } \\
\text { No. }\end{array}$ & $\begin{array}{c}\text { Main } \\
\text { Saw } \\
(200 \text { hp })\end{array}$ & $\begin{array}{c}\text { Carriage } \\
\text { Motor } \\
(150 \text { hp })\end{array}$ & $\begin{array}{c}\text { Edger } \\
(50 \text { hp) }\end{array}$ & $\begin{array}{l}\text { Trimmer } \\
(25 \text { hp) }\end{array}$ & $\begin{array}{c}\text { Compressor } \\
(40 \text { hp })\end{array}$ & $\begin{array}{l}\text { Chipper } \\
\text { (187 hp) }\end{array}$ & $\begin{array}{c}\text { Debarker } \\
\text { (85 hp) }\end{array}$ & $\begin{array}{l}\text { Chip } \\
\text { Blower } \\
\text { (30 hp) }\end{array}$ & $\begin{array}{c}\text { Barn } \\
\text { Sweep } \\
(5 \text { hp) }\end{array}$ & $\begin{array}{l}\text { Conveyor } \\
\text { (15 hp) }\end{array}$ & $\begin{array}{c}\text { Unlogged } \\
\text { Motors } \\
\text { Load Factor }\end{array}$ \\
\hline 23 & 142.34 & 59.16 & 22.33 & 25.11 & 47.29 & 84.99 & 68.42 & 7.33 & 2.76 & 7.04 & 0.2839 \\
\hline 24 & 142.22 & 66.40 & 22.88 & 25.12 & 47.04 & 86.99 & 66.10 & 8.14 & 3.38 & 8.27 & 0.2502 \\
\hline 25 & 141.18 & 66.50 & 22.56 & 25.12 & 46.84 & 83.67 & 60.37 & 7.16 & 3.45 & 7.84 & 0.2522 \\
\hline 26 & 137.95 & 61.71 & 21.26 & 25.12 & 46.22 & 87.79 & 60.40 & 9.87 & 2.99 & 7.33 & 0.2592 \\
\hline 27 & 135.91 & 58.33 & 21.26 & 25.11 & 45.37 & 85.60 & 50.13 & 7.19 & 2.43 & 6.35 & 0.2805 \\
\hline 28 & 134.73 & 63.65 & 22.63 & 25.12 & 45.43 & 87.55 & 55.57 & 9.67 & 3.68 & 8.32 & 0.2294 \\
\hline 29 & 133.24 & 53.75 & 23.69 & 25.12 & 48.47 & 85.96 & 46.13 & 7.23 & 2.42 & 6.47 & 0.2921 \\
\hline 30 & 138.25 & 64.31 & 22.16 & 25.12 & 47.81 & 84.79 & 51.70 & 9.68 & 3.31 & 7.87 & 0.2423 \\
\hline 31 & 138.08 & 61.58 & 22.72 & 25.12 & 47.78 & 85.55 & 53.73 & 7.49 & 2.98 & 7.59 & 0.2574 \\
\hline 32 & 137.86 & 64.22 & 22.51 & 25.12 & 47.57 & 82.34 & 55.57 & 9.79 & 3.59 & 7.98 & 0.2477 \\
\hline 33 & 139.18 & 62.35 & 22.21 & 25.12 & 46.99 & 84.93 & 50.08 & 7.10 & 3.14 & 7.66 & 0.2525 \\
\hline 34 & 135.71 & 58.92 & 22.73 & 25.12 & 47.85 & 88.93 & 60.73 & 7.34 & 2.89 & 6.98 & 0.2705 \\
\hline 35 & 138.98 & 73.71 & 23.56 & 25.12 & 46.89 & 86.56 & 62.61 & 7.26 & 3.09 & 9.94 & 0.2433 \\
\hline 36 & 140.63 & 58.72 & 23.10 & 25.12 & 47.53 & 89.18 & 66.11 & 8.51 & 2.79 & 6.88 & 0.2827 \\
\hline 37 & 138.20 & 67.65 & 22.27 & 25.12 & 47.44 & 84.93 & 54.41 & 12.20 & 3.82 & 8.84 & 0.2760 \\
\hline 38 & 136.79 & 62.09 & 23.38 & 25.12 & 47.92 & 87.85 & 56.96 & 9.03 & 3.12 & 8.08 & 0.2624 \\
\hline 39 & 138.80 & 62.09 & 22.85 & 25.12 & 47.81 & 84.40 & 55.45 & 7.39 & 3.49 & 7.53 & 0.2516 \\
\hline 40 & 138.19 & 61.26 & 22.42 & 25.12 & 47.26 & 83.45 & 54.63 & 8.44 & 3.17 & 7.51 & 0.2518 \\
\hline 41 & 139.05 & 71.65 & 22.65 & 25.13 & 46.53 & 82.21 & 68.32 & 6.49 & 3.90 & 9.80 & 0.2794 \\
\hline 42 & 140.98 & 60.74 & 23.79 & 25.12 & 47.21 & 89.64 & 65.03 & 7.40 & 3.93 & 7.92 & 0.2584 \\
\hline 43 & 134.49 & 54.17 & 22.66 & 25.12 & 47.44 & 86.32 & 42.78 & 7.77 & 2.58 & 6.85 & 0.2797 \\
\hline 44 & 136.87 & 65.22 & 23.54 & 25.12 & 48.28 & 88.66 & 61.18 & 11.72 & 3.42 & 7.53 & 0.2473 \\
\hline 45 & 136.92 & 62.04 & 23.25 & 25.12 & 48.47 & 91.77 & 60.64 & 10.03 & 2.97 & 7.41 & 0.2627 \\
\hline 46 & 133.31 & 78.96 & 22.03 & 25.10 & 46.39 & 89.29 & 45.09 & 11.03 & 3.11 & 6.81 & 0.2402 \\
\hline 47 & 135.26 & 66.50 & 23.50 & 25.12 & 48.54 & 85.64 & 53.68 & 10.23 & 3.41 & 7.84 & 0.2513 \\
\hline 48 & 137.90 & 58.86 & 22.64 & 25.12 & 46.13 & 86.92 & 47.30 & 7.39 & 2.87 & 7.06 & 0.2681 \\
\hline 49 & 142.08 & 66.26 & 22.71 & 25.12 & 46.32 & 84.54 & 47.75 & 10.33 & 3.49 & 8.02 & 0.2384 \\
\hline 50 & 138.02 & 67.67 & 22.12 & 25.12 & 45.86 & 84.52 & 50.73 & 7.04 & 3.83 & 8.41 & 0.2399 \\
\hline 51 & 135.46 & 59.23 & 22.00 & 25.12 & 45.95 & 85.43 & 58.19 & 7.55 & 3.30 & 7.13 & 0.2678 \\
\hline 52 & 175.93 & 68.13 & 23.07 & 25.12 & 46.66 & 83.28 & 48.00 & 11.29 & 3.96 & 8.89 & 0.2417 \\
\hline 53 & 137.46 & 66.06 & 22.59 & 25.12 & 45.86 & 84.12 & 54.51 & 7.44 & 3.26 & 7.46 & 0.2510 \\
\hline 54 & 136.67 & 46.82 & 23.72 & 25.11 & 44.79 & 81.26 & 51.47 & 7.11 & 2.62 & 6.77 & 0.3216 \\
\hline 55 & 139.64 & 64.50 & 22.98 & 25.12 & 46.96 & 82.45 & 56.90 & 8.03 & 3.53 & 7.67 & 0.2459 \\
\hline 56 & 142.87 & 93.25 & 23.08 & 25.10 & 45.65 & 83.20 & 47.89 & 7.28 & 2.51 & 6.81 & 0.3650 \\
\hline 57 & 138.58 & 65.14 & 22.85 & 25.12 & 47.78 & 86.23 & 63.63 & 7.49 & 3.10 & 7.30 & 0.2571 \\
\hline
\end{tabular}


Table A.8. Amperage Consumption in amps of Individual Motors and Load Factor of Unlogged Motors in Sawmill 3

\begin{tabular}{|c|c|c|c|c|c|c|c|c|c|c|c|}
\hline $\begin{array}{l}\text { Shift } \\
\text { No. }\end{array}$ & $\begin{array}{c}7 \text { Feet Saw } \\
(345 \text { hp) }\end{array}$ & $\begin{array}{c}\text { Edger } \\
(200 \mathrm{hp})\end{array}$ & $\begin{array}{l}\text { Trimmer } \\
(180 \text { hp })\end{array}$ & $\begin{array}{c}6 \text { feet } \\
\text { Carriage } \\
\text { Feed } \\
(300 \text { hp })\end{array}$ & $\begin{array}{c}\text { Gang } \\
\text { Saw } \\
(418 \text { hp) }\end{array}$ & $\begin{array}{l}\text { Chipper } \\
(200 \text { hp) }\end{array}$ & $\begin{array}{c}\text { Debarker } \\
(210 \text { hp })\end{array}$ & $\begin{array}{c}\text { Sorter } \\
\text { Chain } \\
(50 \text { hp })\end{array}$ & $\begin{array}{c}\text { Compressor } \\
\text { (150 hp) }\end{array}$ & $\begin{array}{c}\text { Hydraulic } \\
\text { Pump } \\
(60 \text { hp })\end{array}$ & $\begin{array}{c}\text { Unlogged } \\
\text { Motors } \\
\text { Load } \\
\text { Factor }\end{array}$ \\
\hline 58 & 190.95 & 52.80 & 97.86 & 207.62 & 156.29 & 119.28 & 97.18 & 11.61 & 164.28 & 88.18 & 0.4879 \\
\hline 59 & 231.34 & 60.59 & 108.45 & 203.45 & 153.28 & 103.16 & 76.91 & 11.42 & 171.06 & 64.18 & 0.5235 \\
\hline 60 & 201.10 & 61.15 & 107.82 & 214.53 & 164.88 & 125.15 & 118.74 & 9.89 & 171.06 & 105.73 & 0.5038 \\
\hline 61 & 200.88 & 61.56 & 107.05 & 210.41 & 170.27 & 132.64 & 114.64 & 11.58 & 170.75 & 110.89 & 0.4959 \\
\hline 62 & 223.93 & 63.05 & 107.54 & 221.19 & 185.72 & 135.61 & 116.22 & 10.68 & 170.73 & 103.86 & 0.4891 \\
\hline 63 & 209.41 & 62.29 & 109.81 & 207.59 & 171.69 & 102.01 & 122.87 & 13.11 & 170.01 & 141.48 & 0.5348 \\
\hline 64 & 181.27 & 61.98 & 107.71 & 224.30 & 155.72 & 133.34 & 115.29 & 12.29 & 171.10 & 103.72 & 0.4943 \\
\hline 65 & 187.39 & 60.40 & 107.20 & 213.79 & 157.33 & 128.29 & 110.96 & 12.19 & 171.76 & 110.18 & 0.4951 \\
\hline 66 & 221.25 & 85.71 & 128.76 & 242.38 & 171.87 & 178.66 & 142.18 & 11.54 & 189.32 & 132.27 & 0.5871 \\
\hline 67 & 185.64 & 60.63 & 108.85 & 224.70 & 153.53 & 130.36 & 115.69 & 9.68 & 172.14 & 116.92 & 0.4991 \\
\hline 68 & 191.32 & 62.26 & 108.01 & 219.02 & 163.36 & 115.66 & 117.96 & 9.36 & 174.44 & 117.11 & 0.5050 \\
\hline 69 & 159.92 & 43.04 & 91.29 & 178.33 & 144.31 & 100.69 & 99.85 & 10.27 & 142.70 & 109.48 & 0.4198 \\
\hline 70 & 156.53 & 41.88 & 89.00 & 193.87 & 140.90 & 119.31 & 85.44 & 9.58 & 142.70 & 185.48 & 0.4147 \\
\hline 71 & 132.47 & 42.59 & 81.65 & 171.13 & 133.26 & 74.36 & 87.15 & 10.47 & 142.70 & 92.30 & 0.3860 \\
\hline 72 & 141.91 & 41.41 & 79.16 & 184.86 & 118.81 & 147.43 & 80.79 & 10.35 & 135.54 & 92.08 & 0.4077 \\
\hline 73 & 199.89 & 62.30 & 109.57 & 207.71 & 156.42 & 130.95 & 109.67 & 11.21 & 171.35 & 116.71 & 0.4999 \\
\hline 74 & 171.82 & 60.43 & 107.39 & 228.65 & 147.25 & 134.38 & 114.45 & 9.00 & 171.35 & 119.64 & 0.4761 \\
\hline 75 & 174.27 & 63.41 & 109.27 & 215.35 & 155.26 & 149.75 & 121.34 & 11.33 & 171.35 & 116.90 & 0.4785 \\
\hline 76 & 184.98 & 61.83 & 108.57 & 206.82 & 158.53 & 123.50 & 108.95 & 10.09 & 171.35 & 114.98 & 0.5039 \\
\hline 77 & 179.60 & 62.30 & 108.27 & 208.74 & 148.22 & 146.95 & 114.08 & 10.97 & 171.35 & 102.94 & 0.4727 \\
\hline 78 & 186.50 & 63.61 & 109.28 & 209.26 & 155.26 & 135.85 & 114.61 & 9.81 & 171.35 & 117.72 & 0.4780 \\
\hline 79 & 177.56 & 61.47 & 108.68 & 212.35 & 149.67 & 132.75 & 113.39 & 10.20 & 171.35 & 112.90 & 0.4905 \\
\hline 80 & 197.72 & 61.34 & 107.59 & 202.86 & 163.33 & 107.61 & 112.81 & 10.49 & 171.35 & 182.58 & 0.5083 \\
\hline 81 & 191.89 & 63.06 & 108.78 & 209.51 & 163.42 & 139.72 & 115.52 & 11.16 & 171.35 & 169.70 & 0.4833 \\
\hline 82 & 205.47 & 61.22 & 107.86 & 206.20 & 162.41 & 120.76 & 113.94 & 10.43 & 171.35 & 116.28 & 0.5050 \\
\hline
\end{tabular}


Table A.9. Amperage Consumption in amps of Individual Motors and Load Factor of Unlogged Motors in Sawmill 4

\begin{tabular}{|c|c|c|c|c|c|c|c|c|c|}
\hline $\begin{array}{l}\text { Shift } \\
\text { No. }\end{array}$ & $\begin{array}{c}\text { Head } \\
\text { Saws } \\
(350 \text { hp })\end{array}$ & $\begin{array}{c}\text { Edger } \\
(175 \text { hp) }\end{array}$ & $\begin{array}{l}\text { Trimmer } \\
(57.5 \text { hp })\end{array}$ & $\begin{array}{c}\text { Carriage } \\
\text { feeds } \\
(250 \mathrm{hp})\end{array}$ & $\begin{array}{l}\text { Chipper } \\
(200 \text { hp) }\end{array}$ & $\begin{array}{l}\text { Debarker } \\
\text { (80 hp) }\end{array}$ & $\begin{array}{c}\text { Log } \\
\text { Turner } \\
(20 \text { hp) }\end{array}$ & $\begin{array}{c}\text { Compressor } \\
(100 \text { hp })\end{array}$ & $\begin{array}{c}\text { Unlogged } \\
\text { Motors } \\
\text { Load } \\
\text { Factor }\end{array}$ \\
\hline 83 & 225.91 & 60.87 & 45.18 & 139.28 & 74.30 & 134.22 & 41.49 & 79.24 & 0.3496 \\
\hline 84 & 221.80 & 59.57 & 44.28 & 144.02 & 71.88 & 114.42 & 37.30 & 77.58 & 0.3566 \\
\hline 85 & 227.65 & 60.27 & 41.94 & 142.19 & 70.95 & 88.71 & 27.93 & 77.07 & 0.3732 \\
\hline 86 & 223.63 & 60.67 & 43.96 & 138.73 & 71.27 & 118.66 & 42.55 & 77.52 & 0.3584 \\
\hline 87 & 227.59 & 60.28 & 44.48 & 143.60 & 69.64 & 125.74 & 42.57 & 77.43 & 0.3562 \\
\hline 88 & 205.98 & 60.93 & 45.81 & 102.90 & 85.35 & 136.53 & 35.05 & 76.69 & 0.3482 \\
\hline 89 & 217.25 & 61.84 & 44.41 & 142.15 & 73.82 & 120.82 & 36.70 & 78.04 & 0.3528 \\
\hline 90 & 218.14 & 61.62 & 42.31 & 142.79 & 71.44 & 102.86 & 44.06 & 76.81 & 0.3679 \\
\hline 91 & 226.69 & 61.75 & 43.83 & 139.69 & 71.46 & 115.10 & 42.43 & 77.62 & 0.3608 \\
\hline 92 & 222.75 & 62.29 & 48.31 & 139.90 & 71.40 & 153.06 & 37.49 & 77.10 & 0.3355 \\
\hline 93 & 228.18 & 60.88 & 45.89 & 134.45 & 69.18 & 146.47 & 40.58 & 76.55 & 0.3521 \\
\hline 94 & 233.60 & 61.69 & 37.63 & 127.22 & 70.92 & 65.04 & 53.05 & 68.45 & 0.4168 \\
\hline 95 & 259.14 & 61.53 & 57.89 & 140.16 & 73.23 & 166.42 & 11.86 & 78.33 & 0.3214 \\
\hline 96 & 213.43 & 62.03 & 42.02 & 136.67 & 75.11 & 90.51 & 29.41 & 81.17 & 0.3666 \\
\hline 97 & 220.80 & 61.89 & 45.74 & 138.47 & 76.03 & 127.41 & 36.99 & 79.87 & 0.3464 \\
\hline 98 & 219.55 & 61.13 & 41.24 & 142.70 & 72.10 & 84.82 & 38.34 & 77.36 & 0.3770 \\
\hline 99 & 227.31 & 61.03 & 42.40 & 140.38 & 70.55 & 92.27 & 41.39 & 78.42 & 0.3742 \\
\hline 100 & 226.92 & 60.84 & 44.00 & 135.03 & 69.97 & 113.59 & 34.26 & 78.80 & 0.3607 \\
\hline 101 & 211.80 & 60.94 & 43.98 & 135.48 & 69.09 & 142.94 & 71.54 & 77.83 & 0.3553 \\
\hline 102 & 212.51 & 60.39 & 43.79 & 139.52 & 70.36 & 154.28 & 83.93 & 77.46 & 0.3566 \\
\hline 103 & 226.13 & 60.81 & 47.07 & 135.82 & 69.32 & 176.98 & 53.31 & 78.45 & 0.3415 \\
\hline 104 & 217.63 & 61.79 & 43.33 & 144.82 & 68.82 & 118.87 & 52.86 & 77.91 & 0.3579 \\
\hline 105 & 228.73 & 61.20 & 48.73 & 128.11 & 68.71 & 174.01 & 41.38 & 77.68 & 0.3390 \\
\hline 106 & 224.03 & 62.27 & 44.59 & 119.26 & 69.65 & 122.49 & 44.88 & 77.75 & 0.3592 \\
\hline 107 & 229.56 & 61.47 & 42.02 & 148.92 & 70.78 & 88.50 & 36.74 & 76.10 & 0.3715 \\
\hline 108 & 223.89 & 61.56 & 42.91 & 139.10 & 72.58 & 102.12 & 42.45 & 75.94 & 0.3658 \\
\hline
\end{tabular}


Table A.10. Amperage Consumption in amps of Individual Motors and Load Factor of Unlogged Motors in Sawmill 5

\begin{tabular}{|c|c|c|c|c|c|c|c|c|c|c|c|c|}
\hline $\begin{array}{l}\text { Shift } \\
\text { No. }\end{array}$ & $\begin{array}{c}\text { Resaw } \\
(150 \text { hp })\end{array}$ & $\begin{array}{c}\text { Edger } \\
(50 \text { hp })\end{array}$ & $\begin{array}{c}\text { Trimmer } \\
(100 \text { hp) }\end{array}$ & $\begin{array}{c}\text { Main Saw + } \\
\text { Carriage } \\
\text { Feed } \\
(250 \text { hp })\end{array}$ & $\begin{array}{c}\text { Gang } \\
\text { Saw } \\
(100 \text { hp })\end{array}$ & $\begin{array}{c}\text { Debarker } \\
(130 \text { hp })\end{array}$ & $\begin{array}{l}\text { Chipper } \\
\text { (300 hp) }\end{array}$ & $\begin{array}{c}\text { Compressor } \\
(300 \mathrm{hp})\end{array}$ & $\begin{array}{c}\text { Log } \\
\text { Turner } \\
(20 \text { hp) }\end{array}$ & $\begin{array}{c}\text { Log } \\
\text { Deck } \\
(20 \text { hp) }\end{array}$ & $\begin{array}{c}\text { Line } \\
\text { Bar } \\
\text { Hdy. } \\
\text { (10 hp) }\end{array}$ & $\begin{array}{c}\text { Unlogged } \\
\text { Motors } \\
\text { Load } \\
\text { Factor }\end{array}$ \\
\hline 109 & 87.51 & 33.30 & 32.11 & 211.53 & 108.89 & 64.17 & 200.95 & 111.33 & 23.27 & 23.30 & 5.61 & 0.3674 \\
\hline 110 & 87.59 & 32.92 & 40.69 & 210.39 & 103.86 & 63.23 & 200.38 & 111.11 & 20.17 & 22.34 & 6.30 & 0.3646 \\
\hline 111 & 85.44 & 32.79 & 36.28 & 198.44 & 99.30 & 63.20 & 200.90 & 114.66 & 23.86 & 22.18 & 5.53 & 0.3527 \\
\hline 112 & 86.72 & 33.17 & 33.92 & 205.66 & 137.17 & 63.75 & 199.50 & 112.35 & 19.72 & 18.90 & 6.79 & 0.3644 \\
\hline 113 & 84.56 & 33.13 & 35.51 & 206.76 & 103.83 & 66.50 & 199.19 & 111.07 & 21.36 & 26.00 & 6.62 & 0.3566 \\
\hline 114 & 85.41 & 33.09 & 34.97 & 206.16 & 117.80 & 65.94 & 197.82 & 111.99 & 24.33 & 25.93 & 5.93 & 0.3639 \\
\hline 115 & 91.53 & 33.25 & 36.51 & 209.30 & 110.12 & 65.31 & 198.83 & 109.54 & 22.12 & 24.03 & 6.31 & 0.3601 \\
\hline 116 & 85.34 & 32.97 & 35.79 & 209.70 & 107.63 & 63.20 & 199.27 & 112.73 & 21.94 & 23.03 & 5.78 & 0.3612 \\
\hline 117 & 97.40 & 33.28 & 33.84 & 211.27 & 120.34 & 63.08 & 198.66 & 109.68 & 22.65 & 23.14 & 6.07 & 0.3696 \\
\hline 118 & 83.95 & 32.95 & 34.14 & 207.06 & 111.27 & 62.54 & 198.60 & 110.97 & 21.85 & 21.71 & 5.63 & 0.3612 \\
\hline 119 & 91.07 & 33.06 & 38.35 & 204.47 & 126.49 & 63.94 & 196.01 & 110.65 & 21.54 & 24.72 & 6.75 & 0.3676 \\
\hline 120 & 81.89 & 33.21 & 36.04 & 203.95 & 105.86 & 63.33 & 198.13 & 111.31 & 21.72 & 21.46 & 5.48 & 0.3595 \\
\hline 121 & 95.46 & 33.56 & 38.82 & 211.85 & 138.27 & 66.44 & 196.76 & 112.99 & 25.40 & 23.81 & 7.59 & 0.3609 \\
\hline 122 & 94.53 & 33.45 & 34.85 & 205.42 & 106.79 & 64.53 & 197.69 & 109.74 & 22.49 & 23.27 & 5.74 & 0.3607 \\
\hline 123 & 80.85 & 33.70 & 34.37 & 202.98 & 122.11 & 63.91 & 196.17 & 111.27 & 23.73 & 23.28 & 5.60 & 0.3619 \\
\hline 124 & 83.71 & 32.81 & 38.38 & 207.08 & 106.62 & 62.17 & 196.68 & 110.47 & 21.14 & 24.77 & 6.31 & 0.3655 \\
\hline 125 & 80.29 & 32.48 & 40.17 & 199.38 & 124.55 & 62.27 & 196.49 & 113.87 & 20.98 & 18.53 & 4.84 & 0.3624 \\
\hline 126 & 86.77 & 32.94 & 36.88 & 208.12 & 119.69 & 62.82 & 199.37 & 106.57 & 22.59 & 23.55 & 6.34 & 0.3604 \\
\hline 127 & 78.19 & 32.81 & 36.36 & 205.52 & 116.20 & 62.63 & 201.79 & 112.67 & 21.61 & 21.56 & 5.63 & 0.3610 \\
\hline 128 & 88.44 & 33.16 & 35.06 & 208.66 & 122.69 & 63.02 & 202.13 & 110.66 & 21.43 & 22.28 & 5.96 & 0.3623 \\
\hline 129 & 76.49 & 33.08 & 43.29 & 194.43 & 69.97 & 63.38 & 205.59 & 114.33 & 19.44 & 19.68 & 5.82 & 0.3518 \\
\hline 130 & 89.47 & 32.95 & 35.85 & 210.36 & 129.59 & 64.44 & 202.01 & 111.61 & 22.78 & 25.39 & 6.80 & 0.3748 \\
\hline 131 & 82.98 & 32.37 & 37.69 & 212.02 & 160.60 & 66.04 & 195.24 & 112.69 & 26.17 & 22.56 & 7.67 & 0.3567 \\
\hline 132 & 92.63 & 33.36 & 38.35 & 209.65 & 96.19 & 64.17 & 199.58 & 112.56 & 20.99 & 25.43 & 6.49 & 0.3700 \\
\hline 133 & 80.63 & 32.97 & 45.87 & 204.40 & 39.83 & 63.80 & 203.35 & 116.43 & 21.86 & 23.74 & 5.88 & 0.3521 \\
\hline
\end{tabular}


Table A.11. Run Time in Minutes of Individual Motors in Sawmill 1

\begin{tabular}{|c|c|c|c|c|c|c|c|c|c|c|c|c|c|}
\hline $\begin{array}{l}\text { Shift } \\
\text { No. }\end{array}$ & $\begin{array}{c}\text { Head } \\
\text { Saw } \\
(200 \text { hp })\end{array}$ & $\begin{array}{c}\text { Resaw } \\
(60 \text { hp })\end{array}$ & $\begin{array}{c}\text { Edger } \\
(50 \text { hp })\end{array}$ & $\begin{array}{c}\text { Trimmer } \\
(10 \text { hp })\end{array}$ & $\begin{array}{l}\text { Chipper } \\
\text { (150 hp) }\end{array}$ & $\begin{array}{l}\text { Debarker } \\
(50 \text { hp })\end{array}$ & $\begin{array}{c}\text { Compressor } \\
(60 \text { hp })\end{array}$ & $\begin{array}{l}\text { Carriage } \\
\text { Feed } \\
\text { Motor } \\
(\mathbf{1 0 0} \text { hp })\end{array}$ & $\begin{array}{c}\text { Top } \\
\text { Saw } \\
(40 \\
\text { hp) }\end{array}$ & $\begin{array}{c}\text { Log } \\
\text { Turner } \\
\text { (40 hp) }\end{array}$ & $\begin{array}{c}\text { Dust } \\
\text { Collector } \\
(15 \text { hp) }\end{array}$ & $\begin{array}{c}\text { Chip } \\
\text { blower } \\
\text { (30 hp) }\end{array}$ & $\begin{array}{c}\text { Unlogged } \\
\text { Motors } \\
\text { (163 hp) }\end{array}$ \\
\hline 1 & 488 & 487 & 491 & 505 & 556 & 217 & 555.5 & 488 & 488 & 487 & 556 & 556 & 505 \\
\hline 2 & 62 & 75 & 75 & 76 & 82 & 22 & 75 & 62 & 62 & 75 & 82 & 82 & 75 \\
\hline 3 & 556 & 565 & 604 & 580 & 704 & 217 & 665 & 556 & 556 & 565 & 704 & 704 & 630 \\
\hline 4 & 567 & 553 & 593 & 580 & 708 & 648 & 667.5 & 567 & 567 & 553 & 708 & 708 & 630 \\
\hline 5 & 223 & 222 & 228 & 226 & 298 & 76 & 265.5 & 223 & 223 & 222 & 298 & 298 & 235 \\
\hline 6 & 347 & 351 & 360 & 356 & 423 & 142 & 370 & 347 & 347 & 351 & 423 & 423 & 395 \\
\hline 7 & 225 & 224 & 235 & 228 & 299 & 77 & 273.5 & 225 & 225 & 224 & 299 & 299 & 240 \\
\hline 8 & 338 & 342 & 359 & 349 & 394 & 124 & 390 & 338 & 338 & 342 & 394 & 394 & 390 \\
\hline 9 & 119 & 118 & 142 & 123 & 184 & 37 & 154 & 119 & 119 & 118 & 184 & 184 & 120 \\
\hline 10 & 435 & 411 & 462 & 464 & 569 & 167 & 506.5 & 435 & 435 & 411 & 569 & 569 & 510 \\
\hline 11 & 501 & 442 & 514 & 512 & 643 & 166 & 549 & 501 & 501 & 442 & 643 & 643 & 570 \\
\hline 12 & 575 & 568 & 605 & 579 & 708 & 220 & 584 & 575 & 575 & 568 & 708 & 708 & 630 \\
\hline 13 & 540 & 558 & 579 & 571 & 730 & 231 & 659 & 540 & 540 & 558 & 730 & 730 & 630 \\
\hline 14 & 538 & 537 & 562 & 572 & 712 & 233 & 663.5 & 538 & 538 & 537 & 712 & 712 & 630 \\
\hline 15 & 145 & 163 & 185 & 216 & 311 & 66 & 276.5 & 145 & 145 & 163 & 311 & 311 & 240 \\
\hline 16 & 240 & 239 & 254 & 242 & 285 & 109 & 285 & 240 & 240 & 239 & 285 & 285 & 285 \\
\hline 17 & 105 & 105 & 105 & 105 & 114 & 27 & 105 & 105 & 105 & 105 & 114 & 114 & 105 \\
\hline 18 & 576 & 554 & 599 & 578 & 716 & 183 & 662.5 & 576 & 576 & 554 & 716 & 716 & 630 \\
\hline 19 & 181 & 192 & 192 & 196 & 258 & 58 & 229.5 & 181 & 181 & 192 & 258 & 258 & 195 \\
\hline 20 & 362 & 374 & 394 & 380 & 444 & 117 & 435 & 362 & 362 & 374 & 444 & 444 & 435 \\
\hline 21 & 558 & 504 & 587 & 574 & 710 & 213 & 662.5 & 558 & 558 & 504 & 710 & 710 & 630 \\
\hline 22 & 554 & 555 & 582 & 571 & 718 & 218 & 666 & 554 & 554 & 555 & 718 & 718 & 630 \\
\hline
\end{tabular}


Table A.12. Run Time in Minutes of Individual Motors in Sawmill 2

\begin{tabular}{|c|c|c|c|c|c|c|c|c|c|c|c|}
\hline $\begin{array}{l}\text { Shift } \\
\text { No. }\end{array}$ & $\begin{array}{c}\text { Main } \\
\text { Saw } \\
(200 \text { hp })\end{array}$ & $\begin{array}{c}\text { Carriage } \\
\text { Motor } \\
(\mathbf{1 5 0} \text { hp) }\end{array}$ & $\begin{array}{c}\text { Edger } \\
(50 \text { hp })\end{array}$ & $\begin{array}{c}\text { Trimmer } \\
\text { (25 hp) }\end{array}$ & $\begin{array}{c}\text { Compressor } \\
(40 \mathrm{hp})\end{array}$ & $\begin{array}{l}\text { Chipper } \\
\text { (187 hp) }\end{array}$ & $\begin{array}{c}\text { Debarker } \\
(85 \text { hp })\end{array}$ & $\begin{array}{c}\text { Chip } \\
\text { Blower } \\
\text { (30 hp) }\end{array}$ & $\begin{array}{c}\text { Barn } \\
\text { Sweep } \\
\text { (5 hp) }\end{array}$ & $\begin{array}{l}\text { Conveyor } \\
\text { (15 hp) }\end{array}$ & $\begin{array}{c}\text { Unlogged } \\
\text { Motors } \\
(\mathbf{3 0} \text { hp) }\end{array}$ \\
\hline 23 & 278 & 278 & 251 & 255 & 286 & 267 & 284 & 267 & 284 & 251 & 270 \\
\hline 24 & 204 & 204 & 199 & 210 & 236 & 241 & 219 & 241 & 219 & 199 & 240 \\
\hline 25 & 451 & 451 & 439 & 465 & 560 & 510 & 450 & 510 & 450 & 439 & 510 \\
\hline 26 & 486 & 486 & 447 & 465 & 554 & 498 & 487 & 498 & 487 & 447 & 510 \\
\hline 27 & 199 & 199 & 174 & 180 & 232 & 181 & 198 & 181 & 198 & 174 & 180 \\
\hline 28 & 228 & 228 & 211 & 225 & 274 & 271 & 209 & 271 & 209 & 211 & 270 \\
\hline 29 & 144 & 144 & 118 & 120 & 148 & 135 & 142 & 135 & 142 & 118 & 120 \\
\hline 30 & 346 & 346 & 327 & 345 & 388 & 393 & 353 & 393 & 353 & 327 & 390 \\
\hline 31 & 487 & 487 & 446 & 465 & 560 & 509 & 510 & 509 & 510 & 446 & 510 \\
\hline 32 & 467 & 467 & 424 & 465 & 560 & 493 & 433 & 493 & 433 & 424 & 510 \\
\hline 33 & 481 & 481 & 445 & 465 & 567 & 512 & 493 & 512 & 493 & 445 & 510 \\
\hline 34 & 312 & 312 & 278 & 285 & 347 & 293 & 300 & 293 & 300 & 278 & 300 \\
\hline 35 & 105 & 105 & 102 & 120 & 158 & 157 & 153 & 157 & 153 & 102 & 150 \\
\hline 36 & 346 & 346 & 309 & 315 & 375 & 319 & 341 & 319 & 341 & 309 & 330 \\
\hline 37 & 143 & 143 & 141 & 150 & 189 & 174 & 147 & 174 & 147 & 141 & 150 \\
\hline 38 & 483 & 483 & 435 & 465 & 557 & 532 & 504 & 532 & 504 & 435 & 510 \\
\hline 39 & 483 & 483 & 446 & 465 & 559 & 508 & 434 & 508 & 434 & 446 & 510 \\
\hline 40 & 458 & 458 & 423 & 435 & 527 & 474 & 455 & 474 & 455 & 423 & 480 \\
\hline 41 & 27 & 27 & 26 & 30 & 36 & 37 & 30 & 37 & 30 & 26 & 30 \\
\hline 42 & 430 & 430 & 388 & 405 & 504 & 447 & 359 & 447 & 359 & 388 & 450 \\
\hline 43 & 125 & 125 & 100 & 105 & 152 & 98 & 117 & 98 & 117 & 100 & 105 \\
\hline 44 & 356 & 356 & 352 & 360 & 405 & 394 & 348 & 394 & 348 & 352 & 405 \\
\hline 45 & 421 & 421 & 391 & 405 & 476 & 460 & 435 & 460 & 435 & 391 & 450 \\
\hline 46 & 49 & 49 & 59 & 60 & 60 & 61 & 59 & 61 & 59 & 59 & 60 \\
\hline 47 & 451 & 451 & 436 & 465 & 566 & 528 & 450 & 528 & 450 & 436 & 510 \\
\hline 48 & 263 & 263 & 233 & 240 & 305 & 272 & 255 & 272 & 255 & 233 & 255 \\
\hline 49 & 219 & 219 & 216 & 225 & 246 & 255 & 224 & 255 & 224 & 216 & 255 \\
\hline 50 & 386 & 386 & 363 & 405 & 505 & 467 & 363 & 467 & 363 & 363 & 450 \\
\hline 51 & 343 & 343 & 308 & 315 & 379 & 341 & 302 & 341 & 302 & 308 & 330 \\
\hline 52 & 142 & 142 & 142 & 150 & 184 & 176 & 146 & 176 & 146 & 142 & 180 \\
\hline 53 & 454 & 454 & 455 & 465 & 571 & 528 & 472 & 528 & 472 & 455 & 510 \\
\hline 54 & 62 & 62 & 44 & 45 & 89 & 44 & 51 & 44 & 51 & 44 & 45 \\
\hline 55 & 420 & 420 & 409 & 420 & 467 & 469 & 409 & 469 & 409 & 409 & 465 \\
\hline 56 & 83 & 83 & 57 & 60 & 115 & 71 & 69 & 71 & 69 & 57 & 60 \\
\hline 57 & 401 & 401 & 405 & 405 & 456 & 435 & 435 & 435 & 435 & 405 & 450 \\
\hline
\end{tabular}


Table A.13. Run Time in Minutes of Individual Motors in Sawmill 3

\begin{tabular}{|c|c|c|c|c|c|c|c|c|c|c|c|}
\hline $\begin{array}{l}\text { Shift } \\
\text { No. }\end{array}$ & $\begin{array}{c}7 \text { Feet Saw } \\
\text { (345 hp) }\end{array}$ & $\begin{array}{c}\text { Edger } \\
(200 \mathrm{hp})\end{array}$ & $\begin{array}{c}\text { Trimmer } \\
(180 \text { hp) }\end{array}$ & $\begin{array}{c}6 \text { feet } \\
\text { Carriage } \\
\text { Feed } \\
(\mathbf{3 0 0} \text { hp })\end{array}$ & $\begin{array}{c}\text { Gang } \\
\text { Saw } \\
(418 \text { hp })\end{array}$ & $\begin{array}{l}\text { Chipper } \\
(200 \text { hp) }\end{array}$ & $\begin{array}{c}\text { Debarker } \\
(210 \text { hp) }\end{array}$ & $\begin{array}{c}\text { Sorter } \\
\text { Chain } \\
(50 \text { hp) }\end{array}$ & $\begin{array}{c}\text { Compressor } \\
(150 \mathrm{hp})\end{array}$ & $\begin{array}{c}\text { Hydraulic } \\
\text { Pump } \\
\text { (60 hp) }\end{array}$ & $\begin{array}{c}\text { Unlogged } \\
\text { Motors } \\
(\mathbf{5 1 7 . 5} \text { hp })\end{array}$ \\
\hline 58 & 478.8 & 489 & 525 & 478.8 & 463.2 & 501 & 561.6 & 525 & 571 & 561.6 & 480 \\
\hline 59 & 115.5 & 129 & 151.8 & 115.5 & 115.2 & 157.8 & 226.8 & 151.8 & 120 & 226.8 & 120 \\
\hline 60 & 351.3 & 355.8 & 433.2 & 351.3 & 334.2 & 403.8 & 345.6 & 433.2 & 390 & 345.6 & 360 \\
\hline 61 & 396.6 & 406.8 & 430.8 & 396.6 & 246 & 447 & 394.8 & 430.8 & 420.6 & 394.8 & 390 \\
\hline 62 & 82.8 & 82.8 & 88.2 & 82.8 & 82.8 & 91.8 & 82.8 & 88.2 & 90 & 82.8 & 90 \\
\hline 63 & 126 & 129 & 157.8 & 126 & 109.8 & 162.6 & 115.8 & 157.8 & 120.6 & 115.8 & 120 \\
\hline 64 & 353.7 & 351.6 & 394.8 & 353.7 & 343.8 & 384.6 & 348 & 394.8 & 390 & 348 & 360 \\
\hline 65 & 243.3 & 247.2 & 256.2 & 243.3 & 214.2 & 280.8 & 247.8 & 256.2 & 240 & 247.8 & 240 \\
\hline 66 & 213.3 & 214.8 & 211.8 & 213.3 & 192 & 240 & 210.6 & 211.8 & 210 & 210.6 & 210 \\
\hline 67 & 469.8 & 486 & 529.2 & 469.8 & 447 & 537 & 472.8 & 529.2 & 504.6 & 472.8 & 480 \\
\hline 68 & 475.2 & 505.2 & 535.8 & 475.2 & 457.2 & 561.6 & 465.6 & 535.8 & 511.2 & 465.6 & 480 \\
\hline 69 & 477.9 & 511.8 & 550.2 & 477.9 & 456 & 538.8 & 423 & 550.2 & 510 & 423 & 480 \\
\hline 70 & 466.8 & 502.8 & 522 & 466.8 & 469.8 & 535.8 & 276 & 522 & 510 & 276 & 480 \\
\hline 71 & 494.4 & 511.2 & 547.8 & 494.4 & 456 & 540 & 463.8 & 547.8 & 510 & 463.8 & 480 \\
\hline 72 & 493.2 & 505.2 & 523.8 & 493.2 & 439.2 & 484.8 & 498.6 & 523.8 & 510 & 498.6 & 480 \\
\hline 73 & 478.5 & 502.2 & 517.8 & 478.5 & 448.2 & 522 & 465.6 & 517.8 & 510 & 465.6 & 480 \\
\hline 74 & 262.5 & 328.2 & 363 & 262.5 & 255 & 387 & 304.8 & 363 & 345 & 304.8 & 315 \\
\hline 75 & 159 & 160.8 & 163.2 & 159 & 151.2 & 160.8 & 154.8 & 163.2 & 165 & 154.8 & 165 \\
\hline 76 & 305.1 & 318 & 355.8 & 305.1 & 265.8 & 346.8 & 301.2 & 355.8 & 330 & 301.2 & 300 \\
\hline 77 & 174.6 & 175.2 & 177 & 174.6 & 171 & 177.6 & 175.2 & 177 & 180 & 175.2 & 180 \\
\hline 78 & 442.5 & 487.8 & 522 & 442.5 & 399 & 537.6 & 442.2 & 522 & 510 & 442.2 & 480 \\
\hline 79 & 476.4 & 499.2 & 510 & 476.4 & 436.8 & 540 & 475.2 & 510 & 510 & 475.2 & 480 \\
\hline 80 & 96.9 & 100.2 & 107.4 & 96.9 & 70.2 & 133.8 & 67.2 & 107.4 & 90 & 67.2 & 90 \\
\hline 81 & 382.2 & 387 & 417.6 & 382.2 & 373.2 & 412.8 & 235.2 & 417.6 & 420 & 235.2 & 390 \\
\hline 82 & 477.6 & 523.8 & 522.6 & 477.6 & 454.8 & 552.6 & 472.8 & 522.6 & 510 & 472.8 & 480 \\
\hline
\end{tabular}


Table A.14. Run Time in Minutes of Individual Motors in Sawmill 4

\begin{tabular}{|c|c|c|c|c|c|c|c|c|c|}
\hline $\begin{array}{l}\text { Shift } \\
\text { No. }\end{array}$ & $\begin{array}{c}\text { Head } \\
\text { Saws } \\
(\mathbf{3 5 0} \text { hp })\end{array}$ & $\begin{array}{c}\text { Edger } \\
\text { (175 hp) }\end{array}$ & $\begin{array}{l}\text { Trimmer } \\
(57.5 \text { hp) }\end{array}$ & $\begin{array}{c}\text { Carriage } \\
\text { feeds } \\
(250 \mathrm{hp})\end{array}$ & $\begin{array}{l}\text { Chipper } \\
\text { (200 hp) }\end{array}$ & $\begin{array}{l}\text { Debarker } \\
(80 \text { hp })\end{array}$ & $\begin{array}{c}\text { Log } \\
\text { Turner } \\
(20 \text { hp })\end{array}$ & $\begin{array}{c}\text { Compressor } \\
(100 \text { hp })\end{array}$ & $\begin{array}{c}\text { Unlogged } \\
\text { Motors } \\
(301.5 \text { hp) }\end{array}$ \\
\hline 83 & 174 & 181.5 & 155.1 & 174 & 195 & 53.5 & 53.5 & 196 & 195 \\
\hline 84 & 369.5 & 371 & 328.7 & 369.5 & 411 & 112.5 & 112.5 & 476 & 405 \\
\hline 85 & 574 & 571.5 & 514.2 & 574 & 661 & 218.5 & 218.5 & 724 & 600 \\
\hline 86 & 562.5 & 582 & 490.5 & 562.5 & 646 & 143 & 143 & 674 & 600 \\
\hline 87 & 504.5 & 530.5 & 448.5 & 504.5 & 605 & 130.5 & 130.5 & 616 & 555 \\
\hline 88 & 42.5 & 44 & 35.3 & 42.5 & 51 & 10.5 & 10.5 & 53 & 45 \\
\hline 89 & 265.5 & 280 & 242.8 & 265.5 & 314 & 85.5 & 85.5 & 347 & 300 \\
\hline 90 & 276 & 287.5 & 254.8 & 276 & 337 & 71 & 71 & 420 & 300 \\
\hline 91 & 553 & 587.5 & 492 & 553 & 654 & 145 & 145 & 688 & 600 \\
\hline 92 & 146 & 149.5 & 133.9 & 146 & 192 & 46 & 46 & 201 & 180 \\
\hline 93 & 384.5 & 397 & 328.9 & 384.5 & 425 & 85 & 85 & 486 & 420 \\
\hline 94 & 365 & 381.5 & 315.2 & 365 & 421 & 65 & 65 & 554 & 330 \\
\hline 95 & 73 & 71 & 74.5 & 73 & 136 & 36 & 36 & 168 & 120 \\
\hline 96 & 443 & 457.5 & 397.7 & 443 & 497 & 165.5 & 165.5 & 555 & 465 \\
\hline 97 & 296 & 311 & 259.3 & 296 & 325 & 88.5 & 88.5 & 348 & 330 \\
\hline 98 & 256.5 & 257.5 & 235.3 & 256.5 & 301 & 76 & 76 & 390 & 270 \\
\hline 99 & 572.5 & 575 & 508.6 & 572.5 & 650 & 156 & 156 & 758 & 600 \\
\hline 100 & 482 & 487.5 & 428.8 & 482 & 642 & 139.5 & 139.5 & 642 & 525 \\
\hline 101 & 329.5 & 333 & 290.3 & 329.5 & 370 & 56 & 56 & 465 & 355 \\
\hline 102 & 559 & 563.5 & 492.5 & 559 & 650 & 77 & 77 & 780 & 600 \\
\hline 103 & 168.5 & 174.5 & 148.9 & 168.5 & 212 & 32.5 & 32.5 & 228 & 195 \\
\hline 104 & 366.5 & 368.5 & 327.5 & 366.5 & 441 & 83 & 83 & 457 & 395 \\
\hline 105 & 503 & 529 & 442.5 & 503 & 639 & 112 & 112 & 701 & 600 \\
\hline 106 & 328 & 307.5 & 266 & 328 & 352 & 69.5 & 69.5 & 386 & 330 \\
\hline 107 & 255.5 & 263 & 230.9 & 255.5 & 306 & 74.5 & 74.5 & 331 & 270 \\
\hline 108 & 573 & 585.5 & 502.6 & 573 & 638 & 153 & 153 & 682 & 600 \\
\hline
\end{tabular}


Table A.15. Run Time in Minutes of Individual Motors in Sawmill 5

\begin{tabular}{|c|c|c|c|c|c|c|c|c|c|c|c|c|}
\hline $\begin{array}{l}\text { Shift } \\
\text { No. }\end{array}$ & $\begin{array}{c}\text { Resaw } \\
(150 \\
\text { hp) }\end{array}$ & $\begin{array}{c}\text { Edger } \\
(\mathbf{5 0} \\
\mathbf{h p})\end{array}$ & $\begin{array}{l}\text { Trimmer } \\
(100 \text { hp) }\end{array}$ & $\begin{array}{c}\text { Main } \\
\text { Saw + } \\
\text { Carriage } \\
\text { Feed } \\
(250 \text { hp })\end{array}$ & $\begin{array}{c}\text { Gang } \\
\text { Saw } \\
(\mathbf{1 0 0} \text { hp) }\end{array}$ & $\begin{array}{c}\text { Debarker } \\
(130 \text { hp) }\end{array}$ & $\begin{array}{l}\text { Chipper } \\
(300 \text { hp) }\end{array}$ & $\begin{array}{l}\text { Compressor } \\
\text { (300 hp) }\end{array}$ & $\begin{array}{c}\text { Log } \\
\text { Turner } \\
(20 \text { hp })\end{array}$ & $\begin{array}{c}\text { Log } \\
\text { Deck } \\
(20 \\
\text { hp) }\end{array}$ & $\begin{array}{c}\text { Line } \\
\text { Bar } \\
\text { Hdy. } \\
\text { (10 hp) }\end{array}$ & $\begin{array}{c}\text { Unlogged } \\
\text { Motors } \\
\text { (256 hp) }\end{array}$ \\
\hline 109 & 270 & 233 & 266 & 270 & 270 & 268 & 270 & 271 & 270 & 268 & 268 & 266 \\
\hline 110 & 343 & 345 & 361 & 310 & 343 & 314.5 & 349.5 & 390.5 & 343 & 314.5 & 314.5 & 342 \\
\hline 111 & 583 & 587 & 528 & 580 & 583 & 591 & 576.5 & 629.5 & 583 & 591 & 591 & 582 \\
\hline 112 & 121 & 142 & 140 & 123 & 121 & 127.5 & 124.5 & 131.5 & 121 & 127.5 & 127.5 & 130 \\
\hline 113 & 488 & 454 & 454 & 477 & 488 & 423 & 462 & 540.5 & 488 & 423 & 423 & 482 \\
\hline 114 & 571 & 612 & 605 & 588 & 571 & 529.5 & 631.5 & 630.5 & 571 & 529.5 & 529.5 & 598 \\
\hline 115 & 566 & 572 & 611 & 567 & 566 & 551 & 597 & 616 & 566 & 551 & 551 & 584 \\
\hline 116 & 661 & 641 & 639 & 633 & 661 & 614 & 666.5 & 690.5 & 661 & 614 & 614 & 647 \\
\hline 117 & 601 & 631 & 674 & 585 & 601 & 586 & 631 & 676 & 601 & 586 & 586 & 627 \\
\hline 118 & 614 & 610 & 605 & 563 & 614 & 599.5 & 635.5 & 630.5 & 614 & 599.5 & 599.5 & 604 \\
\hline 119 & 576 & 589 & 663 & 559 & 576 & 524.5 & 637.5 & 675.5 & 576 & 524.5 & 524.5 & 608 \\
\hline 120 & 595 & 580 & 599 & 551 & 595 & 598 & 627 & 629.5 & 595 & 598 & 598 & 592 \\
\hline 121 & 100 & 111 & 133 & 105.5 & 100 & 105.5 & 109.5 & 120.5 & 100 & 105.5 & 105.5 & 117 \\
\hline 122 & 424 & 391 & 421 & 430.5 & 424 & 425 & 441.5 & 450.5 & 424 & 425 & 425 & 427 \\
\hline 123 & 576 & 619.5 & 594 & 587 & 576 & 582.5 & 616 & 629.5 & 576 & 582.5 & 582.5 & 601 \\
\hline 124 & 603 & 625 & 654 & 596.5 & 603 & 552 & 635 & 675.5 & 603 & 552 & 552 & 611 \\
\hline 125 & 393 & 317 & 445 & 366 & 393 & 439.5 & 450.5 & 450.5 & 393 & 439.5 & 439.5 & 410 \\
\hline 126 & 583 & 625 & 668 & 602 & 583 & 592.5 & 625.5 & 675.5 & 583 & 592.5 & 592.5 & 625 \\
\hline 127 & 584 & 582 & 601 & 569 & 584 & 602.5 & 630.5 & 630.5 & 584 & 602.5 & 602.5 & 596 \\
\hline 128 & 581 & 614 & 573 & 576.5 & 581 & 597 & 634.5 & 675.5 & 581 & 597 & 597 & 614 \\
\hline 129 & 585 & 616 & 566 & 584.5 & 585 & 583 & 532 & 630.5 & 585 & 583 & 583 & 562 \\
\hline 130 & 492 & 462 & 542 & 496 & 492 & 457.5 & 572.5 & 585.5 & 492 & 457.5 & 457.5 & 523 \\
\hline 131 & 75 & 97 & 99 & 79 & 75 & 83 & 79 & 90.5 & 75 & 83 & 83 & 90 \\
\hline 132 & 541 & 532 & 566 & 526.5 & 541 & 477 & 557.5 & 585.5 & 541 & 477 & 477 & 534 \\
\hline 133 & 580 & 542 & 606 & 579 & 580 & 571 & 626 & 629.5 & 580 & 571 & 571 & 565 \\
\hline
\end{tabular}


Table A.16. Energy Consumption in kWh of Individual Motors in Sawmill 1

\begin{tabular}{|c|c|c|c|c|c|c|c|c|c|c|c|c|c|c|}
\hline $\begin{array}{l}\text { Shift } \\
\text { No. }\end{array}$ & $\begin{array}{c}\text { Head } \\
\text { Saw } \\
(200 \text { hp })\end{array}$ & $\begin{array}{l}\text { Resaw } \\
(60 \text { hp) }\end{array}$ & $\begin{array}{c}\text { Edger } \\
(50 \text { hp) }\end{array}$ & $\begin{array}{l}\text { Trimmer } \\
\text { (10 hp) }\end{array}$ & $\begin{array}{l}\text { Chipper } \\
\text { (150 hp) }\end{array}$ & $\begin{array}{l}\text { Debarker } \\
(\mathbf{5 0} \text { hp })\end{array}$ & $\begin{array}{c}\text { Compressor } \\
(60 \mathrm{hp})\end{array}$ & $\begin{array}{c}\text { Carriage } \\
\text { Feed } \\
\text { Motor } \\
(100 \text { hp) }\end{array}$ & $\begin{array}{c}\text { Top } \\
\text { Saw } \\
(40 \text { hp })\end{array}$ & $\begin{array}{c}\text { Log } \\
\text { Turner } \\
\text { (40 hp) }\end{array}$ & $\begin{array}{c}\text { Dust } \\
\text { Collector } \\
(15 \text { hp) }\end{array}$ & $\begin{array}{c}\text { Chip } \\
\text { blower } \\
\text { (30 hp) }\end{array}$ & $\begin{array}{c}\text { Unlogged } \\
\text { Motors } \\
\text { (163 hp) }\end{array}$ & $\begin{array}{c}\text { Total } \\
\text { kWh } \\
(968 \text { hp) }\end{array}$ \\
\hline 1 & 327.19 & 125.76 & 97.29 & 81.96 & 212.20 & 74.41 & 446.09 & 176.95 & 7.57 & 58.03 & 92.41 & 150.88 & 417.15 & $2,267.90$ \\
\hline 2 & 42.02 & 21.34 & 15.73 & 12.63 & 31.88 & 7.73 & 61.10 & 21.48 & 4.79 & 8.27 & 14.19 & 24.22 & 59.78 & 325.18 \\
\hline 3 & 369.47 & 156.96 & 120.38 & 93.54 & 276.48 & 80.28 & 546.62 & 188.64 & 40.17 & 65.93 & 116.64 & 158.48 & 500.27 & $2,713.86$ \\
\hline 4 & 388.26 & 160.19 & 117.73 & 93.54 & 279.31 & 225.52 & 550.62 & 200.66 & 34.38 & 64.84 & 122.64 & 125.26 & 523.36 & $2,886.31$ \\
\hline 5 & 152.38 & 61.41 & 45.80 & 36.45 & 109.60 & 26.57 & 209.31 & 78.85 & 9.54 & 26.02 & 49.27 & 61.20 & 194.34 & $1,060.73$ \\
\hline 6 & 243.60 & 100.16 & 74.18 & 59.21 & 162.64 & 55.05 & 283.27 & 124.65 & 3.25 & 39.73 & 74.50 & 86.47 & 293.41 & $1,600.11$ \\
\hline 7 & 154.61 & 68.64 & 47.53 & 38.67 & 110.83 & 30.96 & 216.13 & 81.43 & 8.74 & 26.76 & 51.62 & 60.15 & 201.62 & $1,097.69$ \\
\hline 8 & 230.01 & 95.04 & 72.04 & 59.98 & 146.31 & 47.65 & 314.01 & 114.36 & 13.14 & 38.94 & 70.96 & 92.58 & 291.76 & $1,586.78$ \\
\hline 9 & 76.89 & 31.81 & 27.40 & 21.12 & 67.76 & 14.59 & 129.03 & 43.12 & 8.68 & 15.68 & 30.33 & 31.78 & 113.50 & 611.69 \\
\hline 10 & 297.28 & 119.30 & 93.80 & 78.88 & 217.64 & 65.58 & 415.82 & 159.46 & 23.90 & 50.32 & 94.40 & 134.08 & 393.03 & $2,143.49$ \\
\hline 11 & 332.81 & 120.74 & 101.87 & 87.27 & 235.00 & 60.64 & 444.92 & 173.94 & 30.20 & 56.36 & 110.43 & 173.78 & 438.51 & $2,366.45$ \\
\hline 12 & 373.93 & 163.10 & 122.60 & 99.90 & 263.27 & 75.53 & 455.16 & 197.76 & 7.95 & 64.33 & 118.14 & 161.34 & 482.31 & $2,585.32$ \\
\hline 13 & 354.09 & 155.97 & 115.67 & 97.59 & 275.51 & 79.86 & 528.61 & 192.28 & 14.02 & 60.51 & 121.07 & 180.80 & 488.05 & $2,664.01$ \\
\hline 14 & 348.73 & 140.64 & 109.60 & 97.59 & 255.01 & 71.74 & 536.73 & 180.28 & 17.60 & 60.23 & 118.72 & 206.25 & 480.38 & $2,623.49$ \\
\hline 15 & 103.46 & 46.02 & 35.49 & 37.51 & 107.73 & 22.11 & 227.90 & 46.79 & 2.81 & 17.98 & 50.14 & 126.63 & 185.76 & $1,010.33$ \\
\hline 16 & 172.78 & 65.31 & 48.96 & 40.98 & 105.67 & 35.84 & 229.91 & 85.83 & 13.52 & 26.73 & 46.98 & 56.03 & 210.00 & $1,138.54$ \\
\hline 17 & 61.59 & 25.95 & 20.76 & 18.03 & 41.84 & 7.45 & 85.96 & 31.93 & 5.35 & 11.34 & 20.09 & 36.62 & 82.83 & 449.74 \\
\hline 18 & 385.20 & 133.38 & 116.93 & 97.68 & 239.28 & 57.25 & 536.13 & 211.31 & 32.34 & 62.57 & 117.68 & 177.48 & 495.29 & $2,662.51$ \\
\hline 19 & 109.74 & 54.66 & 38.67 & 33.27 & 92.79 & 18.89 & 185.68 & 63.75 & 11.44 & 21.13 & 41.99 & 66.35 & 168.04 & 906.38 \\
\hline 20 & 230.10 & 102.40 & 78.64 & 64.70 & 161.84 & 35.01 & 355.29 & 127.22 & 20.18 & 37.68 & 73.25 & 120.95 & 319.18 & $1,726.44$ \\
\hline 21 & 353.12 & 142.94 & 116.40 & 97.20 & 262.87 & 67.97 & 535.38 & 193.54 & 34.74 & 59.52 & 117.38 & 185.38 & 490.20 & $2,656.64$ \\
\hline 22 & 356.76 & 162.24 & 114.64 & 96.53 & 271.79 & 69.99 & 537.28 & 193.03 & 37.98 & 60.83 & 120.91 & 159.68 & 501.99 & $2,683.65$ \\
\hline
\end{tabular}


Table A.17. Energy Consumption in kWh of Individual Motors in Sawmill 2

\begin{tabular}{|c|c|c|c|c|c|c|c|c|c|c|c|c|}
\hline $\begin{array}{l}\text { Shift } \\
\text { No. }\end{array}$ & $\begin{array}{c}\text { Main } \\
\text { Saw } \\
(200 \text { hp })\end{array}$ & $\begin{array}{c}\text { Carriage } \\
\text { Motor } \\
(150 \text { hp })\end{array}$ & $\begin{array}{c}\text { Edger } \\
(50 \text { hp) }\end{array}$ & $\begin{array}{c}\text { Trimmer } \\
(25 \text { hp })\end{array}$ & $\begin{array}{c}\text { Compressor } \\
\text { (40 hp })\end{array}$ & $\begin{array}{l}\text { Chipper } \\
(187 \text { hp) }\end{array}$ & $\begin{array}{c}\text { Debarker } \\
(85 \text { hp })\end{array}$ & $\begin{array}{c}\text { Chip } \\
\text { Blower } \\
\text { (30 hp) }\end{array}$ & $\begin{array}{c}\text { Barn } \\
\text { Sweep } \\
(5 \text { hp) }\end{array}$ & $\begin{array}{c}\text { Conveyor } \\
\text { (15 hp) }\end{array}$ & $\begin{array}{c}\text { Unlogged } \\
\text { Motors } \\
(30 \text { hp) }\end{array}$ & $\begin{array}{c}\text { Total } \\
\text { kWh } \\
(817 \text { hp })\end{array}$ \\
\hline 23 & 228.07 & 94.79 & 33.03 & 33.38 & 121.18 & 133.98 & 191.22 & 13.2 & 5.29 & 11.92 & 37.77 & 903.83 \\
\hline 24 & 167.22 & 78.07 & 26.83 & 27.49 & 99.47 & 123.78 & 142.45 & 13.23 & 4.99 & 11.11 & 29.59 & 724.23 \\
\hline 25 & 367 & 172.86 & 58.35 & 60.88 & 235.01 & 251.96 & 267.34 & 24.65 & 10.49 & 23.23 & 63.37 & $1,535.14$ \\
\hline 26 & 386.43 & 172.86 & 55.99 & 60.88 & 229.43 & 258.14 & 289.45 & 33.18 & 9.82 & 22.12 & 65.14 & $1,583.44$ \\
\hline 27 & 155.89 & 66.91 & 21.8 & 23.56 & 94.32 & 91.48 & 97.67 & 8.78 & 3.24 & 7.46 & 24.88 & 595.99 \\
\hline 28 & 177.05 & 83.64 & 28.13 & 29.46 & 111.53 & 140.08 & 114.29 & 17.68 & 5.19 & 11.85 & 30.52 & 749.42 \\
\hline 29 & 110.59 & 44.61 & 16.47 & 15.71 & 64.28 & 68.52 & 64.46 & 6.59 & 2.32 & 5.15 & 17.27 & 415.97 \\
\hline 30 & 275.7 & 128.25 & 42.69 & 45.17 & 166.23 & 196.74 & 179.61 & 25.68 & 7.89 & 17.37 & 46.56 & $1,131.89$ \\
\hline 31 & 387.6 & 172.86 & 59.7 & 60.88 & 239.73 & 257.11 & 269.68 & 25.74 & 10.27 & 22.83 & 64.69 & $1,571.09$ \\
\hline 32 & 371.09 & 172.86 & 56.24 & 60.88 & 238.68 & 239.69 & 236.8 & 32.56 & 10.48 & 22.83 & 62.24 & $1,504.35$ \\
\hline 33 & 385.85 & 172.86 & 58.23 & 60.88 & 238.72 & 256.74 & 242.96 & 24.53 & 10.43 & 23.01 & 63.46 & $1,537.67$ \\
\hline 34 & 244.05 & 105.95 & 37.24 & 37.31 & 148.76 & 153.85 & 179.29 & 14.51 & 5.86 & 13.09 & 39.98 & 979.89 \\
\hline 35 & 84.11 & 44.61 & 14.16 & 15.71 & 66.38 & 80.24 & 94.26 & 7.69 & 3.19 & 6.84 & 17.98 & 435.17 \\
\hline 36 & 280.46 & 117.1 & 42.05 & 41.24 & 159.71 & 167.97 & 221.85 & 18.32 & 6.43 & 14.35 & 45.96 & $1,115.44$ \\
\hline 37 & 113.91 & 55.76 & 18.5 & 19.64 & 80.34 & 87.25 & 78.71 & 14.33 & 3.79 & 8.41 & 20.4 & 501.04 \\
\hline 38 & 380.8 & 172.86 & 59.92 & 60.88 & 239.18 & 275.95 & 282.51 & 32.41 & 10.61 & 23.72 & 65.93 & $1,604.77$ \\
\hline 39 & 386.42 & 172.86 & 60.05 & 60.88 & 239.46 & 253.15 & 236.8 & 25.32 & 10.23 & 22.67 & 63.22 & $1,531.06$ \\
\hline 40 & 364.79 & 161.71 & 55.88 & 56.95 & 223.15 & 233.56 & 244.59 & 26.99 & 9.72 & 21.43 & 59.55 & $1,458.32$ \\
\hline 41 & 21.64 & 11.15 & 3.47 & 3.93 & 15.01 & 17.96 & 20.17 & 1.62 & 0.79 & 1.72 & 4.13 & 101.59 \\
\hline 42 & 349.4 & 150.55 & 54.4 & 53.02 & 213.2 & 236.58 & 229.72 & 22.33 & 9.53 & 20.74 & 57.29 & $1,396.76$ \\
\hline 43 & 96.9 & 39.03 & 13.35 & 13.75 & 64.61 & 49.95 & 49.25 & 5.14 & 2.04 & 4.62 & 14.47 & 353.11 \\
\hline 44 & 280.85 & 133.83 & 48.82 & 47.13 & 175.22 & 206.25 & 209.5 & 31.16 & 8.04 & 17.88 & 49.36 & $1,208.04$ \\
\hline 45 & 332.25 & 150.55 & 53.57 & 53.02 & 206.74 & 249.25 & 259.58 & 31.13 & 8.73 & 19.56 & 58.24 & $1,422.62$ \\
\hline 46 & 37.65 & 22.3 & 7.66 & 7.85 & 24.94 & 32.16 & 26.18 & 4.54 & 1.24 & 2.71 & 7.1 & 174.33 \\
\hline 47 & 351.61 & 172.86 & 60.36 & 60.88 & 246.15 & 266.99 & 237.69 & 36.44 & 10.34 & 23.08 & 63.16 & $1,529.56$ \\
\hline 48 & 209.04 & 89.22 & 31.08 & 31.42 & 126.07 & 139.59 & 118.7 & 13.56 & 4.94 & 11.1 & 33.68 & 808.4 \\
\hline 49 & 179.35 & 83.64 & 28.9 & 29.46 & 102.1 & 127.28 & 105.25 & 17.78 & 5.27 & 11.69 & 29.96 & 720.68 \\
\hline 50 & 307.06 & 150.55 & 47.31 & 53.02 & 207.51 & 233.05 & 181.21 & 22.18 & 9.39 & 20.59 & 53.19 & $1,285.06$ \\
\hline 51 & 267.81 & 117.1 & 39.93 & 41.24 & 156.05 & 172 & 172.93 & 17.38 & 6.72 & 14.81 & 43.54 & $1,049.51$ \\
\hline 52 & 143.99 & 55.76 & 19.3 & 19.64 & 76.92 & 86.54 & 68.97 & 13.41 & 3.9 & 8.52 & 21.44 & 518.39 \\
\hline 53 & 359.69 & 172.86 & 60.57 & 60.88 & 234.63 & 262.24 & 253.18 & 26.5 & 10.38 & 22.91 & 63.07 & $1,526.91$ \\
\hline 54 & 48.84 & 16.73 & 6.15 & 5.89 & 35.72 & 21.11 & 25.83 & 2.11 & 0.9 & 2.01 & 7.13 & 172.42 \\
\hline 55 & 338.03 & 156.13 & 55.37 & 54.98 & 196.52 & 228.32 & 229.03 & 25.41 & 9.73 & 21.18 & 56.34 & $1,371.04$ \\
\hline 56 & 68.35 & 44.61 & 7.75 & 7.85 & 47.04 & 34.88 & 32.52 & 3.49 & 1.17 & 2.62 & 10.79 & 261.07 \\
\hline 57 & 320.29 & 150.55 & 54.53 & 53.02 & 195.24 & 221.47 & 272.39 & 21.99 & 9.09 & 19.95 & 57.01 & $1,375.53$ \\
\hline
\end{tabular}


Table A.18. Energy Consumption in kWh of Individual Motors in Sawmill 3

\begin{tabular}{|c|c|c|c|c|c|c|c|c|c|c|c|c|}
\hline $\begin{array}{l}\text { Shift } \\
\text { No. }\end{array}$ & $\begin{array}{c}7 \text { Feet Saw } \\
\text { (345 hp) }\end{array}$ & $\begin{array}{c}\text { Edger } \\
(200 \text { hp })\end{array}$ & $\begin{array}{l}\text { Trimmer } \\
(180 \text { hp) }\end{array}$ & $\begin{array}{c}6 \text { feet } \\
\text { Carriage } \\
\text { Feed } \\
(300 \mathrm{hp})\end{array}$ & $\begin{array}{c}\text { Gang } \\
\text { Saw } \\
(418 \text { hp })\end{array}$ & $\begin{array}{l}\text { Chipper } \\
(200 \text { hp) }\end{array}$ & $\begin{array}{c}\text { Debarker } \\
(210 \text { hp) }\end{array}$ & $\begin{array}{l}\text { Sorter } \\
\text { Chain } \\
\text { (50 hp) }\end{array}$ & $\begin{array}{c}\text { Compressor } \\
(150 \text { hp })\end{array}$ & $\begin{array}{c}\text { Hydraulic } \\
\text { Pump } \\
\text { (60 hp) }\end{array}$ & $\begin{array}{c}\text { Unlogged } \\
\text { Motors } \\
(\mathbf{5 1 7 . 5} \mathrm{hp})\end{array}$ & $\begin{array}{c}\text { Total } \\
\text { kWh } \\
(2,630.5) \mathrm{hp}\end{array}$ \\
\hline 58 & 967.33 & 273.79 & 559.78 & 953.53 & 864.35 & 673.82 & 567.53 & 52.11 & $1,284.08$ & 550.56 & $1,718.02$ & $8,464.90$ \\
\hline 59 & 282.7 & 82.88 & 179.37 & 225.39 & 210.82 & 183.55 & 181.38 & 14.82 & 280.99 & 161.81 & 460.87 & $2,264.58$ \\
\hline 60 & 747.45 & 230.73 & 508.95 & 722.88 & 657.87 & 569.8 & 426.74 & 36.61 & 913.21 & 406.22 & $1,330.60$ & $6,551.06$ \\
\hline 61 & 842.91 & 265.54 & 502.48 & 800.43 & 500.1 & 668.53 & 470.65 & 42.65 & 983.12 & 486.71 & $1,418.81$ & $6,981.93$ \\
\hline 62 & 196.17 & 55.36 & 103.35 & 175.67 & 183.6 & 140.37 & 100.07 & 8.05 & 210.34 & 95.6 & 322.95 & $1,591.53$ \\
\hline 63 & 279.17 & 85.21 & 188.81 & 250.89 & 225.08 & 187.03 & 147.96 & 17.68 & 280.66 & 182.13 & 470.87 & $2,315.49$ \\
\hline 64 & 678.35 & 231.08 & 463.32 & 760.98 & 639.2 & 578.24 & 417.21 & 41.47 & 913.43 & 401.27 & $1,305.60$ & $6,430.15$ \\
\hline 65 & 482.36 & 158.32 & 299.25 & 498.93 & 402.35 & 406.17 & 285.92 & 26.7 & 564.3 & 303.52 & 871.73 & $4,299.55$ \\
\hline 66 & 499.3 & 195.23 & 297.16 & 495.9 & 393.98 & 483.47 & 311.38 & 20.9 & 544.23 & 309.69 & 904.51 & $4,455.75$ \\
\hline 67 & 922.73 & 312.46 & 627.67 & 1012.56 & 819.36 & 789.33 & 568.81 & 43.78 & $1,189.02$ & 614.53 & $1,757.46$ & $8,657.71$ \\
\hline 68 & 961.92 & 333.54 & 630.6 & 998.31 & 891.73 & 732.41 & 571.12 & 42.87 & $1,220.70$ & 606.18 & $1,778.46$ & $8,767.84$ \\
\hline 69 & 808.58 & 233.58 & 547.31 & 817.43 & 785.64 & 611.7 & 439.21 & 48.32 & 996.25 & 514.84 & $1,478.30$ & $7,281.16$ \\
\hline 70 & 773.09 & 223.32 & 506.18 & 868.04 & 790.29 & 720.77 & 245.23 & 42.74 & 996.25 & 569.1 & $1,460.50$ & $7,195.51$ \\
\hline 71 & 692.94 & 230.85 & 487.34 & 811.51 & 725.49 & 452.73 & 420.32 & 49.04 & 996.25 & 475.89 & $1,359.40$ & $6,701.76$ \\
\hline 72 & 740.49 & 221.84 & 451.78 & 874.5 & 622.99 & 805.88 & 418.91 & 46.34 & 946.25 & 510.4 & $1,435.88$ & $7,075.26$ \\
\hline 73 & $1,011.96$ & 331.77 & 618.21 & 953.31 & 837.03 & 770.72 & 531.01 & 49.62 & $1,196.25$ & 604.1 & $1,760.46$ & $8,664.44$ \\
\hline 74 & 477.2 & 210.31 & 424.74 & 575.7 & 448.29 & 586.39 & 362.75 & 27.91 & 809.23 & 405.41 & $1,100.27$ & $5,428.20$ \\
\hline 75 & 293.17 & 108.12 & 194.3 & 328.43 & 280.28 & 271.5 & 195.33 & 15.81 & 387.02 & 201.17 & 579.19 & $2,854.32$ \\
\hline 76 & 597.11 & 208.49 & 420.92 & 605.26 & 503.1 & 482.92 & 341.25 & 30.69 & 774.04 & 385.01 & $1,109.16$ & $5,457.95$ \\
\hline 77 & 331.78 & 115.74 & 208.8 & 349.59 & 302.61 & 294.27 & 207.85 & 16.59 & 422.2 & 200.49 & 624.3 & $3,074.22$ \\
\hline 78 & 873.14 & 329.03 & 621.57 & 888.19 & 739.64 & 823.44 & 527.02 & 43.77 & $1,196.25$ & 578.71 & $1,683.46$ & $8,304.22$ \\
\hline 79 & 894.96 & 325.42 & 603.95 & 970.34 & 780.54 & 808.27 & 560.3 & 44.48 & $1,196.25$ & 596.46 & $1,727.46$ & $8,508.43$ \\
\hline 80 & 202.71 & 65.18 & 125.9 & 188.55 & 136.89 & 162.34 & 78.83 & 9.63 & 211.1 & 136.4 & 335.65 & $1,653.18$ \\
\hline 81 & 775.95 & 258.77 & 494.99 & 768.05 & 728.16 & 650.31 & 282.54 & 39.83 & 985.14 & 443.72 & $1,382.81$ & $6,810.27$ \\
\hline 82 & $1,038.26$ & 340.06 & 614.21 & 944.61 & 881.9 & 752.43 & 560.18 & 46.6 & $1,196.25$ & 611.19 & $1,778.46$ & $8,764.15$ \\
\hline
\end{tabular}


Table A.19. Energy Consumption in kWh of Individual Motors in Sawmill 4

\begin{tabular}{|c|c|c|c|c|c|c|c|c|c|c|}
\hline $\begin{array}{l}\text { Shift } \\
\text { No. }\end{array}$ & $\begin{array}{c}\text { Head } \\
\text { Saws } \\
(350 \text { hp })\end{array}$ & $\begin{array}{l}\text { Edger } \\
(175 \text { hp) }\end{array}$ & $\begin{array}{l}\text { Trimmer } \\
(57.5 \text { hp) }\end{array}$ & $\begin{array}{c}\text { Carriage } \\
\text { feeds } \\
(250 \mathrm{hp})\end{array}$ & $\begin{array}{l}\text { Chipper } \\
(200 \text { hp) }\end{array}$ & $\begin{array}{l}\text { Debarker } \\
(\mathbf{8 0} \text { hp })\end{array}$ & $\begin{array}{c}\text { Log } \\
\text { Turner } \\
(20 \text { hp) }\end{array}$ & $\begin{array}{l}\text { Compressor } \\
\text { (100 hp) }\end{array}$ & $\begin{array}{l}\text { Unlogged } \\
\text { Motors } \\
(301.5 \text { hp) }\end{array}$ & $\begin{array}{c}\text { Total } \\
\text { kWh } \\
(\mathbf{1 , 5 3 4} \text { hp })\end{array}$ \\
\hline 83 & 377.04 & 106.65 & 67.73 & 217.95 & 135.35 & 77.74 & 19.24 & 179.88 & 322.65 & $1,504.23$ \\
\hline 84 & 786.09 & 213.36 & 140.67 & 478.6 & 275.96 & 139.35 & 36.38 & 427.67 & 683.62 & $3,181.70$ \\
\hline 85 & $1,253.40$ & 332.51 & 208.41 & 734.04 & 438.12 & 209.85 & 52.9 & 646.25 & $1,059.77$ & $4,935.25$ \\
\hline 86 & $1,206.55$ & 340.87 & 208.41 & 701.81 & 430.11 & 183.69 & 52.74 & 605.14 & $1,017.77$ & $4,747.09$ \\
\hline 87 & $1,101.31$ & 308.71 & 192.78 & 651.52 & 393.57 & 177.64 & 48.16 & 552.39 & 935.81 & $4,361.89$ \\
\hline 88 & 83.97 & 25.88 & 15.63 & 39.33 & 40.66 & 15.52 & 3.19 & 47.07 & 74.16 & 345.41 \\
\hline 89 & 553.26 & 167.15 & 104.2 & 339.41 & 216.53 & 111.83 & 27.2 & 313.62 & 500.89 & $2,334.09$ \\
\hline 90 & 577.49 & 171.02 & 104.2 & 354.43 & 224.91 & 79.06 & 27.12 & 373.61 & 522.39 & $2,434.23$ \\
\hline 91 & $1,202.43$ & 350.23 & 208.41 & 694.75 & 436.59 & 180.68 & 53.33 & 618.45 & $1,024.77$ & $4,769.64$ \\
\hline 92 & 311.94 & 89.89 & 62.52 & 183.7 & 128.07 & 76.22 & 14.95 & 179.47 & 285.83 & $1,332.59$ \\
\hline 93 & 841.54 & 233.33 & 145.88 & 464.92 & 274.64 & 134.78 & 29.9 & 430.86 & 699.94 & $3,255.79$ \\
\hline 94 & 817.84 & 227.18 & 114.62 & 417.61 & 278.92 & 45.77 & 29.89 & 439.2 & 651.02 & $3,022.05$ \\
\hline 95 & 181.45 & 42.17 & 41.68 & 92.02 & 93.04 & 64.86 & 3.7 & 152.41 & 182.56 & 853.89 \\
\hline 96 & 906.9 & 273.95 & 161.51 & 544.49 & 348.7 & 162.16 & 42.19 & 521.74 & 806.9 & $3,768.55$ \\
\hline 97 & 626.88 & 185.79 & 114.62 & 368.61 & 230.83 & 122.07 & 28.38 & 321.91 & 541.02 & $2,540.12$ \\
\hline 98 & 540.17 & 151.94 & 93.78 & 329.18 & 202.72 & 69.79 & 25.26 & 349.41 & 481.75 & $2,244.00$ \\
\hline 99 & $1,248.22$ & 338.76 & 208.41 & 722.77 & 428.37 & 155.83 & 55.97 & 688.4 & $1,062.77$ & $4,909.50$ \\
\hline 100 & $1,049.10$ & 286.31 & 182.36 & 585.35 & 419.62 & 171.54 & 41.43 & 585.87 & 896.18 & $4,217.76$ \\
\hline 101 & 669.38 & 195.89 & 123.38 & 401.48 & 238.8 & 86.66 & 34.73 & 419.12 & 596.92 & $2,766.36$ \\
\hline 102 & $1,139.43$ & 328.5 & 208.41 & 701.39 & 427.23 & 128.61 & 56.02 & 699.75 & $1,012.77$ & $4,702.11$ \\
\hline 103 & 365.47 & 102.44 & 67.73 & 205.82 & 137.28 & 62.27 & 15.02 & 207.16 & 315.15 & $1,478.34$ \\
\hline 104 & 765.04 & 219.81 & 137.13 & 477.33 & 283.5 & 106.81 & 38.03 & 412.33 & 669.04 & $3,109.02$ \\
\hline 105 & $1,103.54$ & 312.52 & 208.41 & 579.51 & 410.16 & 210.99 & 40.18 & 630.66 & 962.77 & $4,458.74$ \\
\hline 106 & 704.82 & 184.84 & 114.62 & 351.81 & 229.03 & 92.16 & 27.04 & 347.56 & 561.02 & $2,612.90$ \\
\hline 107 & 562.59 & 156.05 & 93.78 & 342.18 & 202.33 & 71.38 & 23.73 & 291.73 & 474.75 & $2,218.52$ \\
\hline 108 & $1,230.53$ & 347.93 & 208.41 & 716.81 & 432.56 & 169.14 & 56.3 & 599.79 & $1,038.77$ & $4,800.24$ \\
\hline
\end{tabular}


Table A.20. Energy Consumption in kWh of Individual Motors in Sawmill 5

\begin{tabular}{|c|c|c|c|c|c|c|c|c|c|c|c|c|c|}
\hline $\begin{array}{l}\text { Shift } \\
\text { No. }\end{array}$ & $\begin{array}{c}\text { Resaw } \\
(150 \\
\text { hp) }\end{array}$ & $\begin{array}{c}\text { Edger } \\
(50 \text { hp })\end{array}$ & $\begin{array}{l}\text { Trimmer } \\
(100 \text { hp) }\end{array}$ & $\begin{array}{c}\text { Main } \\
\text { Saw + } \\
\text { Carriage } \\
\text { Feed } \\
(250 \text { hp })\end{array}$ & $\begin{array}{c}\text { Gang } \\
\text { Saw } \\
\text { (100 hp) }\end{array}$ & $\begin{array}{c}\text { Debarker } \\
(130 \text { hp) }\end{array}$ & $\begin{array}{l}\text { Chipper } \\
\text { (300 hp) }\end{array}$ & $\begin{array}{c}\text { Compressor } \\
\text { (300 hp) }\end{array}$ & $\begin{array}{c}\text { Log } \\
\text { Turner } \\
(20 \text { hp) }\end{array}$ & $\begin{array}{c}\text { Log } \\
\text { Deck } \\
(20 \text { hp })\end{array}$ & $\begin{array}{c}\text { Line } \\
\text { Bar } \\
\text { Hdy. } \\
\text { (10 hp) }\end{array}$ & $\begin{array}{l}\text { Unlogged } \\
\text { Motors } \\
(256 \text { hp) }\end{array}$ & $\begin{array}{c}\text { Total } \\
\text { kWh } \\
(1,686 \text { hp })\end{array}$ \\
\hline 109 & 266.68 & 87.57 & 111.24 & 477.78 & 303.62 & 95.32 & 262.02 & 244.03 & 38.55 & 65.77 & 9.18 & 363.39 & $2,325.14$ \\
\hline 110 & 339.09 & 128.20 & 191.30 & 545.60 & 367.88 & 110.21 & 338.22 & 350.96 & 42.44 & 73.99 & 12.11 & 463.60 & $2,963.61$ \\
\hline 111 & 562.24 & 217.25 & 249.48 & 962.84 & 597.87 & 207.00 & 559.34 & 583.80 & 85.33 & 138.03 & 19.97 & 763.33 & $4,946.48$ \\
\hline 112 & 118.43 & 53.16 & 61.85 & 211.62 & 171.41 & 45.05 & 119.95 & 119.50 & 14.64 & 25.37 & 5.29 & 176.12 & $1,122.39$ \\
\hline 113 & 465.75 & 169.75 & 209.99 & 825.05 & 523.28 & 155.91 & 444.43 & 485.57 & 63.96 & 115.81 & 17.10 & 639.08 & $4,115.69$ \\
\hline 114 & 550.47 & 228.60 & 275.55 & 1014.08 & 694.61 & 193.52 & 603.31 & 571.10 & 85.22 & 144.57 & 19.18 & 809.21 & $5,189.42$ \\
\hline 115 & 584.71 & 214.67 & 290.57 & 992.76 & 643.64 & 199.46 & 573.25 & 545.77 & 76.79 & 139.42 & 21.25 & 781.91 & $5,064.19$ \\
\hline 116 & 636.66 & 238.55 & 297.90 & 1110.42 & 734.73 & 215.06 & 641.41 & 629.59 & 88.96 & 148.90 & 21.67 & 868.99 & $5,632.85$ \\
\hline 117 & 660.73 & 237.00 & 297.04 & 1033.93 & 746.90 & 204.86 & 605.39 & 599.72 & 83.50 & 142.81 & 21.71 & 861.58 & $5,495.17$ \\
\hline 118 & 581.81 & 226.89 & 269.01 & 975.21 & 705.53 & 207.80 & 609.51 & 565.91 & 82.31 & 137.07 & 20.60 & 811.26 & $5,192.91$ \\
\hline 119 & 592.07 & 219.78 & 331.18 & 956.19 & 752.44 & 185.87 & 603.46 & 604.58 & 76.11 & 136.55 & 21.62 & 830.99 & $5,310.84$ \\
\hline 120 & 549.96 & 217.43 & 281.18 & 940.07 & 650.44 & 209.89 & 599.95 & 566.74 & 79.28 & 135.17 & 20.00 & 791.28 & $5,041.39$ \\
\hline 121 & 107.75 & 42.04 & 67.25 & 186.97 & 142.79 & 38.85 & 104.05 & 110.13 & 15.58 & 26.45 & 4.89 & 157.02 & $1,003.77$ \\
\hline 122 & 452.40 & 147.63 & 191.09 & 739.78 & 467.60 & 151.99 & 421.52 & 399.89 & 58.50 & 104.13 & 14.89 & 572.66 & $3,722.08$ \\
\hline 123 & 525.63 & 235.64 & 265.94 & 996.77 & 726.37 & 206.34 & 583.58 & 566.56 & 83.84 & 142.79 & 19.91 & 808.71 & $5,162.08$ \\
\hline 124 & 569.72 & 231.45 & 326.89 & 1033.32 & 663.94 & 190.20 & 603.16 & 603.56 & 78.22 & 143.99 & 21.26 & 830.49 & $5,296.20$ \\
\hline 125 & 356.15 & 116.21 & 232.85 & 610.46 & 505.48 & 151.68 & 427.50 & 414.92 & 50.58 & 85.75 & 12.99 & 552.48 & $3,517.06$ \\
\hline 126 & 570.96 & 232.38 & 320.85 & 1048.13 & 720.59 & 206.28 & 602.24 & 582.28 & 80.81 & 146.93 & 22.96 & 837.58 & $5,371.99$ \\
\hline 127 & 515.41 & 215.55 & 284.59 & 978.27 & 700.82 & 209.15 & 614.44 & 574.60 & 77.41 & 136.80 & 20.72 & 800.14 & $5,127.90$ \\
\hline 128 & 579.96 & 229.77 & 261.66 & 1006.33 & 736.17 & 208.52 & 619.38 & 604.64 & 76.38 & 140.05 & 21.75 & 827.22 & $5,311.83$ \\
\hline 129 & 505.04 & 229.97 & 319.13 & 950.68 & 422.74 & 204.78 & 528.21 & 583.06 & 69.75 & 120.84 & 20.71 & 735.22 & $4,690.13$ \\
\hline 130 & 496.86 & 171.81 & 253.07 & 872.85 & 658.43 & 163.39 & 558.51 & 528.58 & 68.75 & 122.32 & 18.99 & 728.87 & $4,642.43$ \\
\hline 131 & 70.24 & 35.44 & 48.60 & 140.12 & 124.39 & 30.38 & 74.49 & 82.49 & 12.04 & 19.72 & 3.89 & 119.38 & 761.18 \\
\hline 132 & 565.63 & 200.33 & 282.73 & 923.40 & 537.40 & 169.65 & 537.35 & 533.08 & 69.65 & 127.72 & 18.92 & 734.74 & $4,700.60$ \\
\hline 133 & 527.85 & 201.68 & 362.06 & 990.06 & 238.54 & 201.90 & 614.78 & 592.83 & 77.77 & 142.74 & 20.50 & 739.72 & $4,710.43$ \\
\hline
\end{tabular}


Table A.21: Electrical Parameters of Sawmill Motors

\begin{tabular}{|c|c|c|c|c|c|c|c|c|c|}
\hline \multirow[b]{2}{*}{ Motor } & \multicolumn{3}{|c|}{ Sawmill 1} & \multicolumn{3}{|c|}{ Sawmill 2} & \multicolumn{3}{|c|}{ Sawmill 5} \\
\hline & $h p$ & $P F^{*}$ & Voltage* & $h p$ & $P F^{*}$ & Voltage ${ }^{*}$ & $h p$ & $P F^{*}$ & Voltage* \\
\hline Head Saw & 200 & 0.60 & 470 & 200 & 0.41 & 487 & 150 & 0.60 & 483 \\
\hline Re-saw & 60 & 0.80 & 478 & - & - & - & 150 & 0.85 & 460 \\
\hline Top Saw & 40 & 0.28 & 470 & - & - & - & - & - & - \\
\hline Edger & 50 & 0.60 & 478 & 50 & 0.42 & 486 & 50 & 0.85 & 460 \\
\hline Trimmer & 10 & 0.90 & 477 & 25 & 0.37 & 488 & 100 & 0.94 & 480 \\
\hline Debarker & 50 & 0.60 & 473 & 85 & 0.70 & 487 & 130 & 0.40 & 480 \\
\hline Gang saw & - & - & - & - & - & - & 100 & 0.75 & 477 \\
\hline Carriage feed Motor & 100 & 0.38 & 478 & $150^{\#}$ & 0.41 & 487 & 100 & 0.60 & 483 \\
\hline Air Compressor & 60 & 0.86 & 474 & 40 & 0.64 & 485 & 300 & 0.60 & 467 \\
\hline Chipper & 150 & 0.40 & 494 & 150 & 0.42 & 487 & 300 & 0.35 & 478 \\
\hline Chip Blower & 30 & 0.62 & 474 & 30 & 0.48 & 487 & - & - & - \\
\hline Dust Collector & 15 & 0.81 & 475 & $37^{\#}$ & - & - & - & - & - \\
\hline Log turner & 40 & 0.47 & 474 & - & - & - & 20 & 0.44 & 483 \\
\hline Conveyor & - & - & - & 15 & 0.48 & 487 & - & - & - \\
\hline Barn Sweep & - & - & - & 5 & 0.48 & 487 & - & - & - \\
\hline Log Deck & - & - & - & - & - & - & 20 & 0.76 & 480 \\
\hline Line Bar Hydraulic & - & - & - & - & - & - & 10 & 0.46 & 460 \\
\hline Unlogged Motors & 163 & - & - & 30 & - & - & 256 & - & - \\
\hline Total & 968 & - & - & 817 & - & - & 1,686 & - & - \\
\hline
\end{tabular}

* Average values, hp - motor horsepower, PF - power factor, \#Chipper and Dust Collector were monitored together 
Table A.21: Electrical Parameters of Sawmill Motors

\begin{tabular}{|l|c|c|c|c|c|c|}
\hline & \multicolumn{3}{|c|}{ Sawmill 3 } & \multicolumn{3}{c|}{ Sawmill 4 } \\
\hline \multicolumn{1}{|c|}{ Motor } & $\boldsymbol{h p}$ & $\boldsymbol{P F}$ & Voltage $^{*}$ & $\boldsymbol{h p}$ & $\boldsymbol{P F}^{*}$ & Voltage $^{*}$ \\
\hline Head saw 1 & 172.5 & 0.77 & 476 & 200 & 0.71 & 468 \\
\hline Head saw 2 & 172.5 & 0.77 & 476 & 150 & 0.73 & 465 \\
\hline Carriage feed motor 1 & 150 & 0.71 & 468 & 150 & 0.67 & 465 \\
\hline Carriage feed motor 2 & 150 & 0.71 & 468 & 100 & 0.65 & 467 \\
\hline Chipper & 200 & 0.84 & 465 & 200 & 0.69 & 469 \\
\hline Debarker 1 & 210 & 0.76 & 474 & 40 & 0.81 & 463 \\
\hline Debarker 2 & - & - & - & 40 & 0.79 & 464 \\
\hline Edger 1 & 200 & 0.79 & 465 & 100 & 0.71 & 471 \\
\hline Edger 2 & - & - & - & 75 & 0.75 & 469 \\
\hline Air compressor & 150 & 0.99 & 479 & 100 & 0.85 & 472 \\
\hline Gang Saw & 418 & 0.88 & 470 & - & - & - \\
\hline Trimmer & 180 & 0.81 & 466 & 57.5 & 0.72 & 465 \\
\hline Sorter Chain & 50 & 0.63 & 470 & - & - & - \\
\hline Hydraulic Pump & 60 & 0.83 & 464 & - & - & - \\
\hline Log Turner & - & - & - & 20 & 0.65 & 462 \\
\hline Unlogged Motors & 517.5 & & & 301.5 & - & - \\
\hline \multicolumn{1}{|c|}{ Total } & $\mathbf{2 , 6 3 0 . 5}$ & - & - & $\mathbf{1 , 5 3 4}$ & - & - \\
\hline
\end{tabular}

* Average values, hp - motor horsepower, $\mathrm{PF}$ - power factor 
Table A.22: Stepwise Regression for Model 1

Alpha-to-Enter: 0.15 Alpha-to-Remove: 0.15

Response is $\mathrm{SEC}$ on 10 predictors, with $\mathrm{N}=108$

\begin{tabular}{|c|c|c|c|c|c|c|c|c|}
\hline Step & 1 & 2 & 3 & 4 & 5 & 6 & 7 & 8 \\
\hline Constant & 45.51 & -14.91 & -14.69 & -15.01 & -37.84 & -25.82 & -27.23 & -28.19 \\
\hline Motor hp & 0.0466 & 0.0545 & 0.0456 & 0.0533 & 0.0724 & 0.0744 & 0.0789 & 0.0818 \\
\hline T-Value & 9.20 & 12.58 & 10.45 & 9.01 & 12.96 & 14.82 & 14.73 & 20.60 \\
\hline P-Value & 0.000 & 0.000 & 0.000 & 0.000 & 0.000 & 0.000 & 0.000 & 0.000 \\
\hline Density & & 1.20 & 1.34 & 1.27 & 1.05 & 0.78 & 0.80 & 0.78 \\
\hline T-Value & & 7.08 & 8.56 & 7.92 & 7.75 & 5.86 & 6.10 & 6.05 \\
\hline P-Value & & 0.000 & 0.000 & 0.000 & 0.000 & 0.000 & 0.000 & 0.000 \\
\hline Double Line & & & 18.3 & 15.0 & 8.3 & 9.7 & 3.4 & \\
\hline T-Value & & & 4.76 & 3.59 & 2.33 & 3.01 & 0.80 & \\
\hline P-Value & & & 0.000 & 0.001 & 0.022 & 0.003 & 0.424 & \\
\hline 4 to 8 Qtr + Pallet & & & & -0.00027 & -0.00139 & -0.00172 & -0.00162 & -0.00163 \\
\hline T-Value & & & & -1.91 & -7.03 & -9.12 & -8.45 & -8.61 \\
\hline P-Value & & & & 0.059 & 0.000 & 0.000 & 0.000 & 0.000 \\
\hline $\operatorname{Min}$ & & & & & 0.078 & 0.105 & 0.106 & 0.107 \\
\hline T-Value & & & & & 7.03 & 9.32 & 9.51 & 9.75 \\
\hline P-Value & & & & & 0.000 & 0.000 & 0.000 & 0.000 \\
\hline Cant + Tim & & & & & & -0.00185 & -0.00223 & -0.00231 \\
\hline T-Value & & & & & & -5.11 & -5.62 & -6.01 \\
\hline P-Value & & & & & & 0.000 & 0.000 & 0.000 \\
\hline Resaw & & & & & & & -8.8 & -11.0 \\
\hline T-Value & & & & & & & -2.16 & -3.67 \\
\hline P-Value & & & & & & & 0.034 & 0.000 \\
\hline S & 19.7 & 16.2 & 14.8 & 14.6 & 12.0 & 10.8 & 10.6 & 10.6 \\
\hline $\mathrm{R}-\mathrm{Sq}$ & 44.38 & 62.36 & 69.10 & 70.15 & 79.89 & 84.02 & 84.73 & 84.63 \\
\hline$R-S q(a d j)$ & 43.86 & 61.64 & 68.21 & 68.99 & 78.90 & 83.07 & 83.66 & 83.72 \\
\hline PRESS & 42558.5 & 29414.0 & 24698.5 & 24263.4 & 16656.1 & 13809.7 & 13515.4 & 13304.6 \\
\hline R-Sq (pred) & 42.19 & 60.05 & 66.45 & 67.04 & 77.38 & 81.24 & 81.64 & 81.93 \\
\hline
\end{tabular}


Table A.23: Stepwise Regression for Model 2

Alpha-to-Enter: 0.15 Alpha-to-Remove: 0.15

Response is SEC on 9 predictors, with $\mathrm{N}=108$

\begin{tabular}{|c|c|c|c|c|c|c|c|c|c|}
\hline $\begin{array}{l}\text { Step } \\
\text { Constant }\end{array}$ & $\begin{array}{r}1 \\
156.15\end{array}$ & $\begin{array}{r}2 \\
116.15\end{array}$ & $\begin{array}{r}3 \\
79.07\end{array}$ & $\begin{array}{r}4 \\
71.23\end{array}$ & $\begin{array}{r}5 \\
80.29\end{array}$ & $\begin{array}{r}6 \\
79.89\end{array}$ & $\begin{array}{r}7 \\
66.39\end{array}$ & $\begin{array}{r}8 \\
76.15\end{array}$ & $\begin{array}{r}9 \\
93.31\end{array}$ \\
\hline $\begin{array}{l}\text { Maint } \\
\text { T-Value } \\
\text { P-Value }\end{array}$ & $\begin{array}{l}-19.7 \\
-7.44 \\
0.000\end{array}$ & $\begin{array}{r}-24.3 \\
-10.32 \\
0.000\end{array}$ & $\begin{array}{l}-20.3 \\
-8.85 \\
0.000\end{array}$ & $\begin{array}{l}-17.8 \\
-7.37 \\
0.000\end{array}$ & $\begin{array}{l}-18.8 \\
-8.42 \\
0.000\end{array}$ & $\begin{array}{l}-18.8 \\
-8.62 \\
0.000\end{array}$ & $\begin{array}{l}-16.0 \\
-6.37 \\
0.000\end{array}$ & $\begin{array}{l}-14.0 \\
-7.35 \\
0.000\end{array}$ & $\begin{array}{l}-13.2 \\
-8.26 \\
0.000\end{array}$ \\
\hline $\begin{array}{l}\text { Density } \\
\text { T-Value } \\
\text { P-Value }\end{array}$ & & $\begin{array}{r}1.24 \\
6.50 \\
0.000\end{array}$ & $\begin{array}{r}1.21 \\
6.97 \\
0.000\end{array}$ & $\begin{array}{r}1.30 \\
7.57 \\
0.000\end{array}$ & $\begin{array}{r}1.37 \\
8.63 \\
0.000\end{array}$ & $\begin{array}{r}1.37 \\
8.75 \\
0.000\end{array}$ & $\begin{array}{r}1.40 \\
9.06 \\
0.000\end{array}$ & $\begin{array}{r}0.89 \\
6.89 \\
0.000\end{array}$ & $\begin{array}{r}0.64 \\
5.53 \\
0.000\end{array}$ \\
\hline $\begin{array}{l}\text { Temp } \\
\text { T-Value } \\
\text { P-Value }\end{array}$ & & & $\begin{array}{r}0.52 \\
4.78 \\
0.000\end{array}$ & $\begin{array}{r}0.41 \\
3.62 \\
0.000\end{array}$ & $\begin{array}{l}-0.01 \\
-0.07 \\
0.942\end{array}$ & & & & \\
\hline $\begin{array}{l}\text { Double Line } \\
\text { T-Value } \\
\text { P-Value }\end{array}$ & & & & $\begin{array}{r}12.6 \\
2.75 \\
0.007\end{array}$ & $\begin{array}{r}30.5 \\
5.18 \\
0.000\end{array}$ & $\begin{array}{r}30.3 \\
6.85 \\
0.000\end{array}$ & $\begin{array}{r}28.6 \\
6.51 \\
0.000\end{array}$ & $\begin{array}{r}29.6 \\
8.91 \\
0.000\end{array}$ & $\begin{array}{r}24.6 \\
8.53 \\
0.000\end{array}$ \\
\hline $\begin{array}{l}\text { Resaw } \\
\text { T-Value } \\
\text { P-Value }\end{array}$ & & & & & $\begin{array}{r}19.6 \\
4.37 \\
0.000\end{array}$ & $\begin{array}{r}19.4 \\
5.91 \\
0.000\end{array}$ & $\begin{array}{r}14.4 \\
3.67 \\
0.000\end{array}$ & $\begin{array}{r}29.3 \\
8.58 \\
0.000\end{array}$ & $\begin{array}{r}19.5 \\
6.05 \\
0.000\end{array}$ \\
\hline $\begin{array}{l}\text { hp x Min } \\
\text { T-Value } \\
\text { P-Value }\end{array}$ & & & & & & & $\begin{array}{r}0.00001 \\
2.20 \\
0.030\end{array}$ & $\begin{array}{r}0.00009 \\
9.09 \\
0.000\end{array}$ & $\begin{array}{r}0.00011 \\
12.58 \\
0.000\end{array}$ \\
\hline $\begin{array}{l}4 \text { to } 8 \text { Qtr }+ \\
\text { T-Value } \\
\text { P-Value }\end{array}$ & Pallet & & & & & & & $\begin{array}{r}-0.00198 \\
-8.82 \\
0.000\end{array}$ & $\begin{array}{r}-0.00222 \\
-11.62 \\
0.000\end{array}$ \\
\hline $\begin{array}{l}\text { Cant + Tim } \\
\text { T-Value } \\
\text { P-Value }\end{array}$ & & & & & & & & & $\begin{array}{r}-0.00223 \\
-6.66 \\
0.000\end{array}$ \\
\hline $\begin{array}{l}S \\
R-S q \\
R-S q(\text { adj }) \\
\text { PRESS } \\
R-S q \text { (pred) }\end{array}$ & $\begin{array}{r}21.4 \\
34.31 \\
33.69 \\
50139.3 \\
31.89\end{array}$ & $\begin{array}{r}18.1 \\
53.14 \\
52.25 \\
36604.6 \\
50.28\end{array}$ & $\begin{array}{r}16.5 \\
61.58 \\
60.47 \\
30304.4 \\
58.84\end{array}$ & $\begin{array}{r}16.0 \\
64.20 \\
62.81 \\
28851.0 \\
60.81\end{array}$ & $\begin{array}{r}14.8 \\
69.85 \\
68.37 \\
24871.8 \\
66.22\end{array}$ & $\begin{array}{r}14.7 \\
69.85 \\
68.68 \\
24413.5 \\
66.84\end{array}$ & $\begin{array}{r}14.4 \\
71.21 \\
69.80 \\
23795.9 \\
67.68\end{array}$ & $\begin{array}{r}10.9 \\
83.74 \\
82.78 \\
13712.0 \\
81.37\end{array}$ & $\begin{array}{r}9.10 \\
88.74 \\
87.95 \\
10398.0 \\
85.88\end{array}$ \\
\hline
\end{tabular}


Table A.24: Stepwise Regression for Model 3

Alpha-to-Enter: 0.15 Alpha-to-Remove: 0.15

Response is SEC on 9 predictors, with $\mathrm{N}=108$

\begin{tabular}{|c|c|c|c|c|c|c|c|c|c|}
\hline $\begin{array}{l}\text { Step } \\
\text { Constant }\end{array}$ & $\begin{array}{r}1 \\
156.15\end{array}$ & $\begin{array}{r}2 \\
116.15\end{array}$ & $\begin{array}{r}3 \\
79.07\end{array}$ & $\begin{array}{r}4 \\
71.23\end{array}$ & $\begin{array}{r}5 \\
80.29\end{array}$ & $\begin{array}{r}6 \\
79.89\end{array}$ & $\begin{array}{r}7 \\
71.29\end{array}$ & $\begin{array}{r}8 \\
98.59\end{array}$ & $\begin{array}{r}9 \\
122.20\end{array}$ \\
\hline $\begin{array}{l}\text { Maint } \\
\text { T-Value } \\
\text { P-Value }\end{array}$ & $\begin{array}{l}-19.7 \\
-7.44 \\
0.000\end{array}$ & $\begin{array}{r}-24.3 \\
-10.32 \\
0.000\end{array}$ & $\begin{array}{l}-20.3 \\
-8.85 \\
0.000\end{array}$ & $\begin{array}{l}-17.8 \\
-7.37 \\
0.000\end{array}$ & $\begin{array}{l}-18.8 \\
-8.42 \\
0.000\end{array}$ & $\begin{array}{l}-18.8 \\
-8.62 \\
0.000\end{array}$ & $\begin{array}{l}-18.3 \\
-8.49 \\
0.000\end{array}$ & $\begin{array}{r}-25.7 \\
-12.08 \\
0.000\end{array}$ & $\begin{array}{r}-28.3 \\
-14.73 \\
0.000\end{array}$ \\
\hline $\begin{array}{l}\text { Density } \\
\text { T-Value } \\
\text { P-Value }\end{array}$ & & $\begin{array}{r}1.24 \\
6.50 \\
0.000\end{array}$ & $\begin{array}{r}1.21 \\
6.97 \\
0.000\end{array}$ & $\begin{array}{r}1.30 \\
7.57 \\
0.000\end{array}$ & $\begin{array}{r}1.37 \\
8.63 \\
0.000\end{array}$ & $\begin{array}{r}1.37 \\
8.75 \\
0.000\end{array}$ & $\begin{array}{r}1.40 \\
9.07 \\
0.000\end{array}$ & $\begin{array}{r}1.04 \\
7.38 \\
0.000\end{array}$ & $\begin{array}{r}0.80 \\
6.10 \\
0.000\end{array}$ \\
\hline $\begin{array}{l}\text { Temp } \\
\text { T-Value } \\
\text { P-Value }\end{array}$ & & & $\begin{array}{r}0.52 \\
4.78 \\
0.000\end{array}$ & $\begin{array}{r}0.41 \\
3.62 \\
0.000\end{array}$ & $\begin{array}{l}-0.01 \\
-0.07 \\
0.942\end{array}$ & & & & \\
\hline $\begin{array}{l}\text { Double Line } \\
\text { T-Value } \\
\text { P-Value }\end{array}$ & & & & $\begin{array}{r}12.6 \\
2.75 \\
0.007\end{array}$ & $\begin{array}{r}30.5 \\
5.18 \\
0.000\end{array}$ & $\begin{array}{r}30.3 \\
6.85 \\
0.000\end{array}$ & $\begin{array}{r}29.8 \\
6.88 \\
0.000\end{array}$ & $\begin{array}{r}35.1 \\
9.41 \\
0.000\end{array}$ & $\begin{array}{r}31.7 \\
9.54 \\
0.000\end{array}$ \\
\hline $\begin{array}{l}\text { Resaw } \\
\text { T-Value } \\
\text { P-Value }\end{array}$ & & & & & $\begin{array}{r}19.6 \\
4.37 \\
0.000\end{array}$ & $\begin{array}{r}19.4 \\
5.91 \\
0.000\end{array}$ & $\begin{array}{r}17.0 \\
5.03 \\
0.000\end{array}$ & $\begin{array}{r}38.0 \\
8.92 \\
0.000\end{array}$ & $\begin{array}{r}31.5 \\
8.04 \\
0.000\end{array}$ \\
\hline $\begin{array}{l}\text { Min } \\
\text { T-Value } \\
\text { P-Value }\end{array}$ & & & & & & & $\begin{array}{r}0.0177 \\
2.21 \\
0.029\end{array}$ & $\begin{array}{r}0.0793 \\
6.90 \\
0.000\end{array}$ & $\begin{array}{r}0.1055 \\
9.51 \\
0.000\end{array}$ \\
\hline $\begin{array}{l}4 \text { to } 8 \text { Qtr }+ \\
\text { T-Value } \\
\text { P-Value }\end{array}$ & Pallet & & & & & & & $\begin{array}{r}-0.00142 \\
-6.61 \\
0.000\end{array}$ & $\begin{array}{r}-0.00162 \\
-8.45 \\
0.000\end{array}$ \\
\hline $\begin{array}{l}\text { Cant + Tim } \\
\text { T-Value } \\
\text { P-Value }\end{array}$ & & & & & & & & & $\begin{array}{r}-0.00223 \\
-5.62 \\
0.000\end{array}$ \\
\hline $\begin{array}{l}\text { S } \\
\text { R-Sq } \\
\text { R-Sq (adj) } \\
\text { Mallows Cp } \\
\text { PRESS } \\
\text { R-Sq (pred) }\end{array}$ & $\begin{array}{r}21.4 \\
34.31 \\
33.69 \\
329.3 \\
50139.3 \\
31.89\end{array}$ & $\begin{array}{r}18.1 \\
53.14 \\
52.25 \\
207.1 \\
36604.6 \\
50.28\end{array}$ & $\begin{array}{r}16.5 \\
61.58 \\
60.47 \\
153.4 \\
30304.4 \\
58.84\end{array}$ & $\begin{array}{r}16.0 \\
64.20 \\
62.81 \\
138.1 \\
28851.0 \\
60.81\end{array}$ & $\begin{array}{r}14.8 \\
69.85 \\
68.37 \\
102.9 \\
24871.8 \\
66.22\end{array}$ & $\begin{array}{r}14.7 \\
69.85 \\
68.68 \\
100.9 \\
24413.5 \\
66.84\end{array}$ & $\begin{array}{r}14.4 \\
71.22 \\
69.81 \\
93.8 \\
23730.7 \\
67.77\end{array}$ & $\begin{array}{r}12.1 \\
79.91 \\
78.72 \\
38.5 \\
16910.0 \\
77.03\end{array}$ & $\begin{array}{r}10.6 \\
84.73 \\
83.66 \\
8.7 \\
13515.4 \\
81.64\end{array}$ \\
\hline
\end{tabular}


Table A.25: Stepwise Regression for Model 4

Alpha-to-Enter: 0.15 Alpha-to-Remove: 0.15

Response is Total kWh on 9 predictors, with $\mathrm{N}=108$

\begin{tabular}{|c|c|c|c|c|c|c|c|c|c|}
\hline $\begin{array}{l}\text { Step } \\
\text { Constant }\end{array}$ & $\begin{array}{r}1 \\
-287.3\end{array}$ & $\begin{array}{r}2 \\
374.4\end{array}$ & $\begin{array}{r}3 \\
547.0\end{array}$ & $\begin{array}{r}4 \\
383.1\end{array}$ & $\begin{array}{r}5 \\
394.8\end{array}$ & $\begin{array}{r}6 \\
553.4\end{array}$ & $\begin{array}{r}7 \\
563.0\end{array}$ & $\begin{array}{r}8 \\
393.0\end{array}$ & $\begin{array}{r}9 \\
345.2\end{array}$ \\
\hline hp x Min & 0.00534 & 0.00510 & 0.00513 & 0.00515 & 0.00491 & 0.00492 & 0.00470 & 0.00456 & 0.00449 \\
\hline T-Value & 73.94 & 75.54 & 85.18 & 88.92 & 70.47 & 73.05 & 40.17 & 36.68 & 38.66 \\
\hline P-Value & 0.000 & 0.000 & 0.000 & 0.000 & 0.000 & 0.000 & 0.000 & 0.000 & 0.000 \\
\hline Maint & & -197 & -225 & -180 & -211 & -219 & -221 & -234 & -236 \\
\hline T-Value & & -7.36 & -9.25 & -6.71 & -8.52 & -9.11 & -9.37 & -10.06 & -10.16 \\
\hline P-Value & & 0.000 & 0.000 & 0.000 & 0.000 & 0.000 & 0.000 & 0.000 & 0.000 \\
\hline Cant + Tim & & & -0.0258 & -0.0271 & -0.0128 & -0.0120 & -0.0117 & -0.0070 & \\
\hline T-Value & & & -5.39 & -5.90 & -2.58 & -2.50 & -2.48 & -1.44 & \\
\hline P-Value & & & 0.000 & 0.000 & 0.011 & 0.014 & 0.015 & 0.152 & \\
\hline Double Line & & & & 143 & 258 & 361 & 342 & 375 & 395 \\
\hline T-Value & & & & 3.33 & 5.81 & 6.49 & 6.19 & 6.87 & 7.45 \\
\hline P-Value & & & & 0.001 & 0.000 & 0.000 & 0.000 & 0.000 & 0.000 \\
\hline Resaw & & & & & 243 & 326 & 277 & 281 & 315 \\
\hline T-Value & & & & & 5.17 & 6.08 & 4.87 & 5.10 & 6.32 \\
\hline P-Value & & & & & 0.000 & 0.000 & 0.000 & 0.000 & 0.000 \\
\hline Temp & & & & & & -3.8 & -3.4 & -3.8 & -4.0 \\
\hline T-Value & & & & & & -2.90 & -2.60 & -3.00 & -3.13 \\
\hline P-Value & & & & & & 0.005 & 0.011 & 0.003 & 0.002 \\
\hline 4 to 8 Qtr + & Pallet & & & & & & 0.0056 & 0.0093 & 0.0100 \\
\hline T-Value & & & & & & & 2.22 & 3.35 & 3.65 \\
\hline P-Value & & & & & & & 0.029 & 0.001 & 0.000 \\
\hline Density & & & & & & & & 4.8 & 5.6 \\
\hline T-Value & & & & & & & & 2.86 & 3.55 \\
\hline P-Value & & & & & & & & 0.005 & 0.001 \\
\hline $\mathrm{S}$ & 231 & 189 & 168 & 160 & 143 & 138 & 136 & 131 & 132 \\
\hline $\mathrm{R}-\mathrm{Sq}$ & 98.10 & 98.75 & 99.02 & 99.11 & 99.30 & 99.35 & 99.38 & 99.43 & 99.42 \\
\hline$R-S q(a d j)$ & 98.08 & 98.72 & 98.99 & 99.08 & 99.26 & 99.31 & 99.34 & 99.38 & 99.38 \\
\hline PRESS & 5841286 & 3907799 & 3139170 & 2888926 & 2355002 & 2220127 & 2132237 & 2018104 & 2027969 \\
\hline R-Sq (pred) & 98.04 & 98.69 & 98.95 & 99.03 & 99.21 & 99.26 & 99.29 & 99.32 & 99.32 \\
\hline
\end{tabular}


Table A.26: Unlogged Motors in Sawmill 1 to 5

\begin{tabular}{|c|c|}
\hline \multicolumn{2}{|c|}{ Sawmill 1} \\
\hline Motor Name & Motor size (hp) \\
\hline Off bearer & 3 \\
\hline Carriage Setworks & 5 \\
\hline Infeed Cant deck & 9 \\
\hline Infeed /outfeed rollers & 3 \\
\hline cant cross over deck & 3 \\
\hline Jump Chains & 3 \\
\hline \begin{tabular}{|l|} 
Trim Saw 1 \\
\end{tabular} & 3 \\
\hline \begin{tabular}{|l} 
Trim Saw 2 \\
\end{tabular} & 3 \\
\hline Trim Saw 3 & 3 \\
\hline \begin{tabular}{|l|} 
Trim Saw 4 \\
\end{tabular} & 3 \\
\hline \begin{tabular}{|l} 
Trim Saw 5 \\
\end{tabular} & 3 \\
\hline Green Chain & 5 \\
\hline Transfer chain & 5 \\
\hline Oversize Belt & 10 \\
\hline Vibrating Conveyor & 5 \\
\hline Rotary Screen & 8 \\
\hline Infeed debarker Deck & 10 \\
\hline Debarker Hydraulic pump & 10 \\
\hline Debarker Drag Chain & 5 \\
\hline Small saw dust belt & 2 \\
\hline Desk conveyor 1 & 3 \\
\hline Desk conveyor 2 & 3 \\
\hline \begin{tabular}{|l|} 
Desk conveyor 3 \\
\end{tabular} & 3 \\
\hline Desk conveyor 4 & 3 \\
\hline Webster vibrating conveyor & 5 \\
\hline Knife Grinder & 5 \\
\hline Rip Saw & 40 \\
\hline Total & 163 \\
\hline \multicolumn{2}{|c|}{ Sawmill 3} \\
\hline Motor Name & Motor size (hp) \\
\hline Hydraulic Pump Carriage & 27.5 \\
\hline Hydraulic Log Turner & 30 \\
\hline Hydraulic Pump Carriage & 30 \\
\hline Hydraulic Log Turner & 30 \\
\hline Hydraulic Board descrambler & 20 \\
\hline Hydraulic Transfer Chains & 20 \\
\hline Center Line Chain & 25 \\
\hline Package Outfeed Chains 1 & 15 \\
\hline Package Outfeed Chains 2 & 20 \\
\hline Unscrambler pump & 20 \\
\hline Conveyor and Rolls pump & 30 \\
\hline Sorter Pump & 50 \\
\hline Haul out Chains & 20 \\
\hline Unscrambler pump & 20 \\
\hline Stacker and lift pump & 20 \\
\hline Out feed pump & 20 \\
\hline Trimmer block belt & 15 \\
\hline Vibrator & 15 \\
\hline Chip Transfer bin & 15 \\
\hline Air Compressor & 75 \\
\hline Total & $\mathbf{5 1 7 . 5}$ \\
\hline
\end{tabular}

\begin{tabular}{|c|c|}
\hline \multicolumn{2}{|c|}{ Sawmill 2} \\
\hline Motor Name & Motor size (hp) \\
\hline Hydraulic Board descrambler & 15 \\
\hline Vibrating Conveyor & 15 \\
\hline Total & 30 \\
\hline \multicolumn{2}{|c|}{ Sawmill 5} \\
\hline Motor Name & Motor size (hp) \\
\hline Hydraulic Log Turner & 30 \\
\hline Hydraulic Board descrambler & 20 \\
\hline Hydraulic Transfer Chains & 20 \\
\hline Center Line Chain & 15 \\
\hline Package Outfeed Chains 1 & 15 \\
\hline Package Outfeed Chains 2 & 20 \\
\hline Unscrambler pump & 20 \\
\hline Conveyor and Rolls pump & 20 \\
\hline Sorter Pump & 25 \\
\hline Vibrating Conveyor & 6 \\
\hline Hydraulic Pump Carriage & 20 \\
\hline Hydraulic Log Turner & 25 \\
\hline Hydraulic Pump Carriage & 10 \\
\hline Unscrambler & 5 \\
\hline Cross tie outfeed & 5 \\
\hline \begin{tabular}{|r|} 
Total \\
\end{tabular} & 256 \\
\hline \multicolumn{2}{|c|}{ Sawmill 4} \\
\hline Motor Name & Motor size (hp) \\
\hline Infeed Decks & 20 \\
\hline Hydraulic Power Units & 20 \\
\hline Inside Feed Decks & 30 \\
\hline Carriages & 10 \\
\hline Drop Belts & 20 \\
\hline Edger Feed Motor & 5 \\
\hline Roll Case Drive & 10 \\
\hline Collection Deck & 7.5 \\
\hline Unscrambler & 5 \\
\hline Cross tie outfeed & 5 \\
\hline Sawdust + Chip Belts & 6 \\
\hline Sawdust + Chip Augers & 20 \\
\hline Cross over Belts & 6 \\
\hline Sawdust Chain & 5 \\
\hline Log turners hydraulic power unit & 40 \\
\hline Dust Collector & 15 \\
\hline Sawdust Conveyor & 5 \\
\hline Hydraulic Power Unit Edger & 10 \\
\hline Main dust Conveyor & 15 \\
\hline Short dust Conveyors & 9 \\
\hline Chip Conveyor & 5 \\
\hline Shaker & 5 \\
\hline Grading Deck & 5 \\
\hline Green Chain & 15 \\
\hline Cooling Fans & 3 \\
\hline Total & 301.5 \\
\hline
\end{tabular}


Table A.27: Operation Cost Report of Sawmill 4 for Sawing Poplar during Data Logging Period

\begin{tabular}{|c|c|c|c|c|c|c|c|c|}
\hline \multirow[t]{2}{*}{ PO 5-16 } & \multicolumn{8}{|c|}{ Operation Report } \\
\hline & \begin{tabular}{|r|} 
Date $>$ \\
Species $>$ \\
\end{tabular} & $\begin{array}{c}\text { 5/16/11 } \\
\text { PO }\end{array}$ & $\begin{array}{c}5 / 17 / 11 \\
\text { PO }\end{array}$ & $\begin{array}{c}5 / 18 / 11 \\
\mathrm{PO}\end{array}$ & $\begin{array}{c}5 / 19 / 11 \\
\text { PO }\end{array}$ & $\begin{array}{c}\text { date } 5 \\
\text { PO }\end{array}$ & $\begin{array}{c}\text { date } 6 \\
\text { PO }\end{array}$ & $\begin{array}{r}\text { Run Total } \\
\text { PO }\end{array}$ \\
\hline ade & \$/MBF & BF & $\mathrm{BF}$ & $B F$ & BF & $\mathrm{BF}$ & $B F$ & $\mathrm{BF}$ \\
\hline$\overline{\overline{14} \mathrm{FAS}}$ & $\$ 525$ & 6633 & 133874 & (9216: & 9416 & & & 39139 \\
\hline $141 \mathrm{COM}$ & $\$ 350$ & 4527 & 6654 & 6628 & 6204 & & & 24003 \\
\hline \multirow[t]{3}{*}{$142 \mathrm{COM}$} & \$300 & 1965 & 3799 & 4659 & 3 & & & ‥13900 \\
\hline & ....... & & & & & & & \\
\hline & . . . . & ..... & (n).... & r & & & & \\
\hline \multirow{4}{*}{$\begin{array}{l}1 / 4 \mathrm{FAS} / 1 \mathrm{~F} \\
1 / 41 \mathrm{COM} \\
1 / 42 \mathrm{COM} \\
1 / 43 \mathrm{~A} \mathrm{COM}\end{array}$} & $\$ 575$ & 1282 & 1962 & 964 & 1068 & & & 5276 \\
\hline & $\$ 400^{\circ}$ & 2516 & 3546 & 3008 & 2238 & & & 11308 \\
\hline & $\$ 300$ & 8140 & 12192 & 14478 & 11656 & & & 46166 \\
\hline & $\$ 500$ & & 1008 & & & & & 10008 \\
\hline \multirow[t]{3}{*}{$x_{4}$} & $\cdots \$ 350$ & 4133 & 6370 & 71382 & 5548 & & & 232338 \\
\hline & & & & & & & & \\
\hline & $\$ 325$ & 1906 & 201 & 231 & 74 & & & 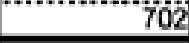 \\
\hline \multicolumn{2}{|c|}{ rotal BF Lbr sawn } & 29397 & 49526 & 46066 & 39761 & & & 164750 \\
\hline \multirow{2}{*}{\multicolumn{2}{|c|}{$\begin{array}{l}\text { COL \& BRT } \\
\text { COM }\end{array}$}} & $27 \%$ & $32 \%$ & $22 \%$ & $26 \%$ & & & $27 \%$ \\
\hline & & $24 \%$ & 2 & $21 \%$ & $21 \%$ & & & $21 \%$ \\
\hline \multicolumn{2}{|c|}{ COM \& LOWER } & $49 \%$ & $47 \%$ & $5 \%$ & $52 \%$ & & & $52 \%$ \\
\hline \multirow{2}{*}{\multicolumn{2}{|c|}{$\begin{array}{l}\text { umber value } \\
\text { umber Avg/MBF }\end{array}$}} & $\$ 11,35433$ & $\$ 19,731.43$ & $\$ 17,156,08$ & 515.15436 & & & $\$ 6339620$ \\
\hline & & $\$ 386$ & $\$ 398$ & $\$ 372$ & \$381 & & & $\$ 365$ \\
\hline \multirow{4}{*}{\multicolumn{2}{|c|}{$\begin{array}{l}\text { awing Time (hr) } \\
\text { 3awing Cost } \\
\text { sawing Cost /MBF Lbr }\end{array}$}} & $7 H R S$ & ioHR & 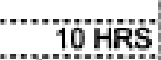 & 9.5 HRS & & & \\
\hline & & $-\$ 484740$ & $\$ 7,0000$ & $-\$ 70000$ & $\$ 6,562.95$ & & & $\$ 25.410 .35$ \\
\hline & & …........165 & ................ & ..........\$152 & ........ & & & $\$ 154$ \\
\hline & & & & & & & & \\
\hline \multirow{2}{*}{\multicolumn{2}{|c|}{$\begin{array}{l}\text { Debarker } 1 \mathrm{BF} \\
\text { Debarker } 2 \mathrm{BF}\end{array}$}} & …....97777 & 18756 & 16915 & 13351 & & & 58799 \\
\hline & & -.....11281 & 19205 & 16\%39 & 15164 & & & 6258 \\
\hline \multirow{2}{*}{\multicolumn{2}{|c|}{ otal BF }} & 21058 & 37961 & 33354 & 28535 & & & 121388 \\
\hline & & & & & & & & \\
\hline \multicolumn{2}{|c|}{ logs sawn 1} & & 166 & 175 & 133 & & & 566 \\
\hline \multicolumn{2}{|c|}{ logs sawn 2} & 105 & 143 & 191 & 136 & & & 575 \\
\hline \multirow{2}{*}{\multicolumn{2}{|c|}{ otal \# logs sawn }} & 198 & 308 & 366 & 2699 & & & 1141 \\
\hline & & & & & & & & \\
\hline \multirow{2}{*}{\multicolumn{2}{|c|}{ Dvernun }} & $40 \%$ & $30 \%$ & $36 \%$ & $39 \%$ & & & $36 \%$ \\
\hline & & -4/4"FAS & 441 сом & $4 / 42 \mathrm{COM}$ & BII FÄAS & $841 \mathrm{COOM}$ & $8 / 42 \mathrm{COM}^{\circ}$ & \\
\hline \multirow{2}{*}{\multicolumn{2}{|c|}{$\begin{array}{l}F \text { Lumber } S Y>K Y \\
\text { Lumber } S Y>K Y\end{array}$}} & 39139 & 2.4003 & (13900 & 5276 & 11308 & 4616 & 139802 \\
\hline & & 52054797 & $\$ 8,4045$ & s4.17\%ö0 & $\$ 3,033.70$ & $\$ 452320$ & $\$ 13,84980$ & 55452922 \\
\hline \multirow{3}{*}{\multicolumn{2}{|c|}{$\begin{array}{l}n \text {. Dust Apulled } \\
n \text {. Chips Pulled } \\
h \text { Bark Pulled }\end{array}$}} & & & & & & & \\
\hline & & & & & & & & \\
\hline & & & & & & & & \\
\hline \multirow{3}{*}{\multicolumn{2}{|c|}{$\begin{array}{l}\log \text { Cost } \\
\operatorname{og} \text { Avg Cost /MBF } \\
\operatorname{og} \text { Ave BF }\end{array}$}} & 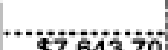 & 落13 & \% & 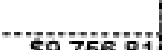 & & & \\
\hline & & 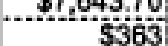 & 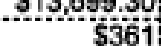 & $\begin{array}{l}\$ 1+1,049 \\
5344\end{array}$ & $\$ 9.756 .81$ & & & 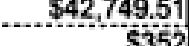 \\
\hline & & 106 & 123 & 92 & 106 & & & 106 \\
\hline \multirow{2}{*}{\multicolumn{2}{|c|}{ rofit $/ \mathrm{hr}$}} & & & & & & & \\
\hline & & 39 & šäo & $\$ 2$ & al & & & ...... \\
\hline \multirow{2}{*}{\multicolumn{2}{|c|}{$\begin{array}{l}\text { rofit /MBF lumb } \\
\text { rofit /MBF logs } \\
\text { otal Profit }\end{array}$}} & $\$ 54$ & $-\$ 25$ & $\$ 44$ & $-\$ 44$ & & & -\$39 \\
\hline & & $-\$ 1,136.77$ & $-\$ 967.87$ & $-\$ 1,493.62$ & $-\$ 1,165.41$ & & & $-\$ 4,763.66$ \\
\hline
\end{tabular}


Table A.28: Sample Format used for Collecting Saw Blade Material and Maintenance Data Filled by Sawmill 4

How many hours can these saws work between re-sharpening? (Blade life)

\begin{tabular}{|l|l|}
\hline Type of Saw & Blade Life \\
\hline Head Saw & $\mathbf{5}$ HDUr \\
\hline Resaw & \\
\hline Edger & WEEK \\
\hline Trimmer & WEWK \\
\hline
\end{tabular}

Time required for re-sharpening (also mention whether it is done in house or sent outside)

\begin{tabular}{|l|c|c|}
\hline Type of Saw & Re-sharpening Time & Place it is Done \\
\hline Head Saw & I HR 45 MiN & IN HOUSE \\
\hline Resaw & & \\
\hline Edger & N/A & OUT SIDE \\
\hline Trimmer & N/A & OUT SIOE \\
\hline
\end{tabular}

What is the material of the blade?

\begin{tabular}{|l|c|c|}
\hline Type of Saw & Blade Materlal & $\begin{array}{c}\text { Did the blade material } \\
\text { changed recently, then when }\end{array}$ \\
\hline Head Saw & SWEDISH Steel & NO \\
\hline Resaw & & \\
\hline Edger & NOT SURE & \\
\hline Trimmer & NOT SURE & \\
\hline
\end{tabular}

Time required to change saw and when will they do that (during production or break time or maintenance)?

\begin{tabular}{|l|c|l|}
\hline Type of Saw & Time required to change saw & Changed during \\
\hline Head Saw & $18 \mathrm{MIN}$ & LUNCH \\
\hline Resaw & & \\
\hline Edger & $30 \mathrm{MIN}$ & AFIER WOrK MR \\
\hline Trimmer & $20 \mathrm{MIN}$ & AFTER Work HR \\
\hline
\end{tabular}

Saw Parameters:

\begin{tabular}{|c|c|c|c|c|}
\hline Equipment & Head Saw & Resaw & Edger & Trimmer \\
\hline $\begin{array}{l}\text { Type of Saw } \\
\text { (Circular or Band) }\end{array}$ & BAND & & CIRCLE & CIRCLE \\
\hline Thickness of Saw & .078 & & $3 / 16^{2}$ & $3 / 16^{11}$ \\
\hline Length & $40^{\circ}$ & & $24^{\prime \prime}$ & $18^{4}$ \\
\hline Width & $10^{n}$ & & $10^{\prime \prime}$ & $10^{\circ}$ \\
\hline Diameter & $20^{\circ}$ LOOP & & $18.20 \%$ & $18-20=$ \\
\hline Number of teeth & 240 & & 25 & 60 \\
\hline Tooth Spacing & $2^{\prime \prime}$ & & $1 \sqrt{24}$ & $1 / 2^{n}$ \\
\hline Tooth width & .148 & & $1 / 4^{4}$ & $1 / 8^{*}$ \\
\hline \multicolumn{5}{|l|}{ Tooth Angle } \\
\hline Hook angle & 30 & & 30 & 30 \\
\hline switch width & & & & \\
\hline
\end{tabular}

